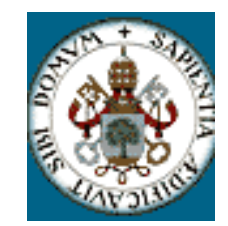

UNIVERSIDAD DE VALLADOLID

FACULTAD DE FILOSOFÍA Y LETRAS

DEPARTAMENTO DE FILOLOGÍA INGLESA

DOCTORADO EN TRADUCCIÓN E INTERPRETACIÓN

\title{
ANÁLISIS LINGÜÍSTICO DE LA TRADUCCIÓN NATURAL: DATOS DE PRODUCCIÓN DE DOS NIÑOS GEMELOS BILINGÜES INGLÉS/ESPAÑOL
}

Tesis doctoral

Esther Álvarez de la Fuente

Directoras

Dra. Raquel Fernández Fuertes (Universidad de Valladolid) Prof ${ }^{a}$. Dra. Juana M. Liceras (Universidad de Ottawa, Canadá)

Valladolid, 2007

CEsther Álvarez de la Fuente, 2007 


\section{AGRADECIMIENTOS}

En primer lugar, quiero expresar mi agradecimiento a mis directoras de tesis, la Dra. Raquel Fernández Fuertes y la Dra. Juana M. Liceras, por haber confiado desde el primer momento en mi capacidad para elaborar este trabajo. En concreto, a la Dra. Juana M. Liceras, por el apoyo y la disponibilidad con los que siempre he podido contar y, especialmente, a la Dra. Fernández Fuertes por el apoyo incondicional, la dedicación constante y la calidad profesional que como co-directora me ha brindado, así como por el cariño y la amistad que me ha demostrado a lo largo de todos estos años y que en muchas ocasiones me han animado a seguir con esta labor tan ardua.

Así mismo, quiero extender mi agradecimiento a mi amiga y compañera Susana Muñiz Fernández por sus constantes muestras de apoyo, su implicación personal en situaciones que a veces han sido difíciles de superar y por haber compartido con ella también muchas alegrías.

En segundo lugar, quisiera dar las gracias a Isabel Parrado Román, Ana Isabel Hernández Bartolomé, Marisol Velasco Sacristán, Elisa Rosado y Todd Spradlin que, a lo largo de esta odisea doctoral, me han dado muestras de afecto y se han ofrecido a ayudarme cuando lo he necesitado.

Agradezco también la generosidad de los padres de los niños protagonistas de este trabajo por permitirme conocer a Simon y Leo, quienes me abrieron las puertas de su mundo de juegos incondicionalmente.

Por último, me gustaría mencionar de forma especial a Goyo, una persona que forma parte de mí y con la que estoy en deuda, pues gran parte del tiempo dedicado a esta tesis no he podido compartirlo con él. Gracias por tu comprensión, tu paciencia y tu cariño. 
A mis padres y a Goyo 


\section{ÍNDICE DE CONTENIDOS}

\section{CAPÍTULO 1: BILINGÜISMO. ADQUISICIÓN BILINGÜE Y MEZCLA DE}

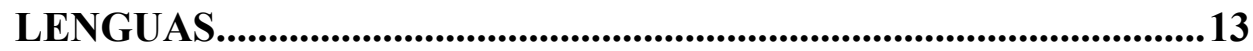

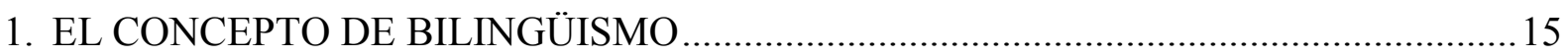

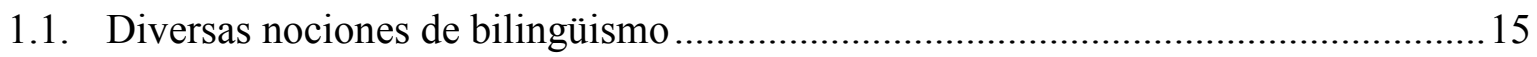

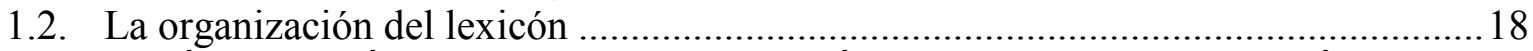

2. LA TEORÍA LINGÜÍSTICA Y LA ADQUISICIÓN BILINGÜE: LA GRAMÁTICA

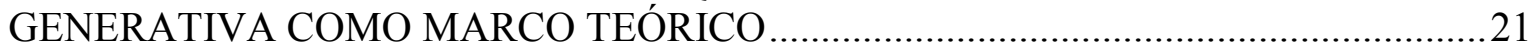

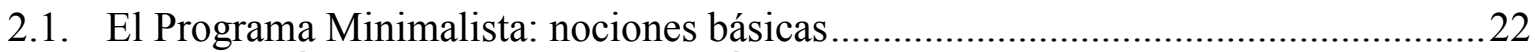

3. LA ADQUISICIÓN BILINGÜE SIMULTÁNEA: LAS ETAPAS DEL DESARROLLO

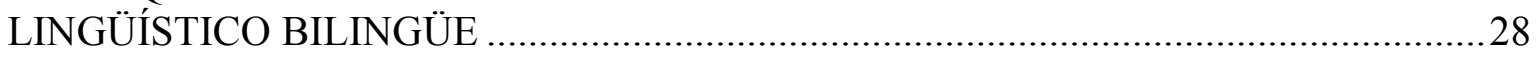

3.1. Las etapas del desarrollo lingüístico bilingüe .......................................................29

3.2. La primera etapa y los Equivalentes de Traducción (EET): el/los sistema/s

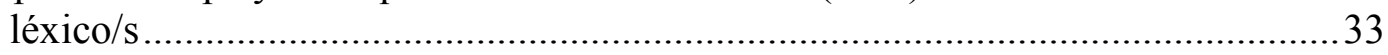

3.3. La primera etapa y la mezcla temprana de lenguas: ¿uno o dos sistemas

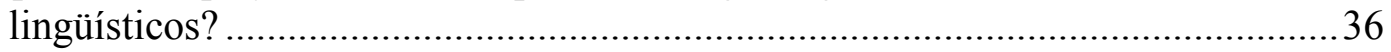

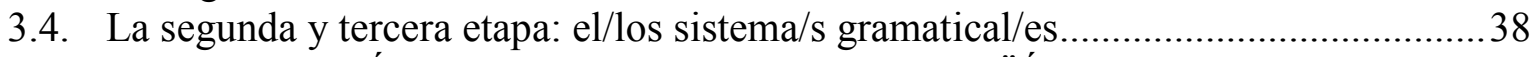

4. LA DIFERENCIACIÓN DE LOS DOS SISTEMAS LINGÜÍSTICOS ............................40

4.1. El debate de un único sistema lingüístico frente a dos sistemas lingüísticos.............41

4.2. La diferenciación de lenguas en diversos niveles lingüísticos .................................43

4.3. ¿A qué edad se produce la diferenciación de lenguas? .............................................. 44

4.4. La mezcla de lenguas a partir de la diferenciación de los sistemas

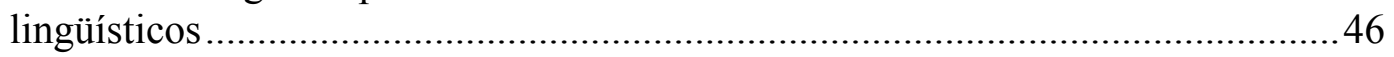

4.5. La diferenciación de los sistemas lingüísticos y los fenómenos característicos de la adquisición bilingüe simultánea: la alternancia de códigos y la traducción natural .................................................................... 48

5. LA MEZCLA DE LENGUAS: LA ALTERNANCIA DE CÓDIGOS EN LOS NIÑOS BILINGÜES

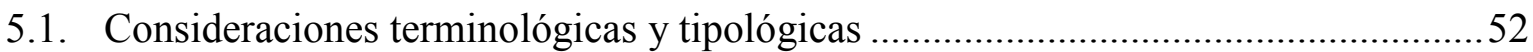

5.1.1. La mezcla de lenguas: terminologías y tipologías................................................53

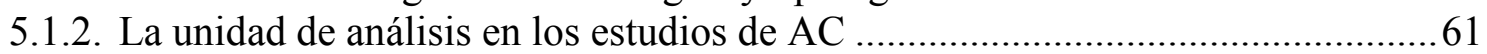

5.1.3. La MC y la AC: el niño bilingüe frente al adulto bilingüe...................................64

5.2. ¿Cómo dar cuenta de la mezcla de lenguas en el discurso infantil?...........................65

5.2.1. La AC: líneas generales de investigación en la explicación del fenómeno...........66

5.2.2. La AC: el enfoque gramatical y el enfoque pragmático ....................................69

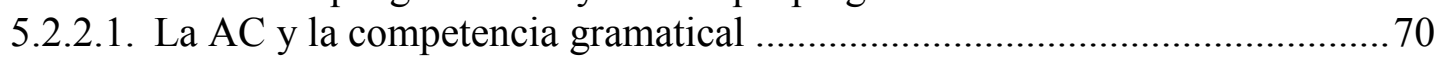

5.2.2.2. La AC y la competencia pragmática: los recursos comunicativos bilingües 


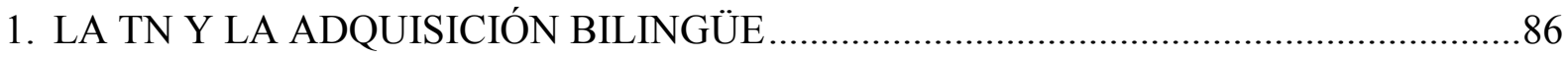

1.1. La traducción como método para inferir los modelos de memoria léxica bilingüe .86

1.2. Los equivalentes de traducción (EET) en el desarrollo bilingüe infantil y su importancia en la TN .

1.3. El papel de los niños bilingües como mediadores lingüísticos ("brokers") en distintos ámbitos sociales

2. LA TN COMO CARACTERÍSTICA INHERENTE AL BILINGÜISMO: LA

COMPETENCIA BILINGÜE Y LA COMPETENCIA TRADUCTORA .

2.1. La TN en los estudios de adquisición bilingüe: una habilidad metalingüística inherente al bilingüismo

2.2. Los modelos de desarrollo de la competencia traductora y su relación con la competencia bilingüe .

2.2.1. Harris (1980b) y Harris y Sherwood (1978): el paralelismo entre el desarrollo del bilingüismo y la competencia traductora.

2.2.2. Malakoff y Hakuta (1991): la importancia de la conciencia metalingüística

2.2.3. Toury (1986): la formación académica y la función social .................................124

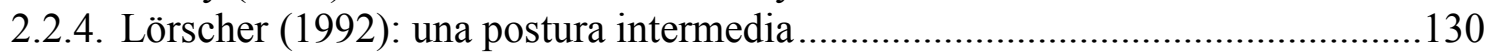

2.2.5. Nuestro planteamiento: nuevas consideraciones en el estudio de la TN ............132

3. LA TN Y LOS ESTUDIOS TEÓRICOS DE TRADUCCIÓN

3.1. Los traductores naturales frente a los traductores profesionales: diferencias y similitudes

3.2. Los niños bilingües como traductores naturales...

3.3. Las consecuencias de la importancia de la $\mathrm{TN}$ en los estudios de traducción: la ampliación del concepto de traducción y la necesidad de un enfoque descriptivo.

\section{CAPÍTULO 3: LOS PLANTEAMIENTOS TEÓRICO-METODOLÓGICOS DEL PRESENTE ESTUDIO LONGITUDINAL ....................................151}

1. ¿CÓMO ENCAJA LA TN EN LOS ESTUDIOS DE ADQUISICIÓN BILINGÜE SIMULTÁNEA Y EN LOS ESTUDIOS DE TRADUCCIÓN?

1.1. Una propuesta de clasificación de la mezcla de lenguas: el Cambio de Códigos frente a la Alternancia de Códigos

1.2. La TN como estrategia bilingüe: similitudes entre la TN y la AC .........................156

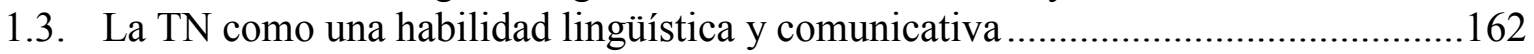

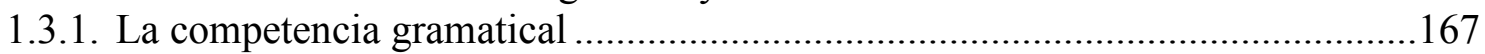

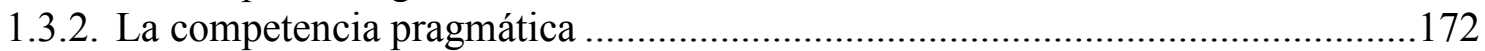

1.4. El reconocimiento de la TN realizada por niños bilingües...................................180

1.5. La TN en los estudios teóricos de traducción............................................................182

2. DE LO PRESCRIPTIVO A LO DESCRIPTIVO: ¿QUÉ NOS DICEN LOS DATOS? ...184

2.1. La necesidad de datos de producción lingüística para estudios teóricoprácticos en el campo del bilingüismo y de la traducción ....

2.2. El estudio longitudinal como punto de partida del análisis de la TN: de la competencia a la actuación ....

2.3. Algunos estudios longitudinales en el bilingüismo infantil.

2.3.1. La metodología de la recogida de datos longitudinales

2.3.2. El contexto lingüístico: la fórmula una persona-una lengua..... 


\section{CAPÍTULO 4: DESCRIPCIÓN DE LA METODOLOGÍA Y PRESENTACIÓN DE}

LOS DATOS DE PRODUCCIÓN BILINGÜE INGLÉS/ESPAÑOL 203

1. LOS SUJETOS Y EL INPUT LINGÜÍSTICO...............................................................204

2. LA RECOGIDA DE DATOS: LA METODOLOGÍA Y LOS TIPOS DE DATOS.........207

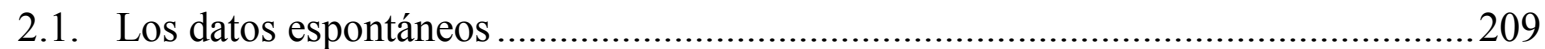

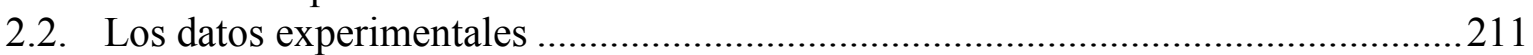

2.2.1. El diseño de las tres pruebas experimentales..................................................212

2.2.2. Los patrones seguidos en la organización de las pruebas experimentales .........217

2.2.3. La ejecución de las pruebas experimentales.......................................................2219

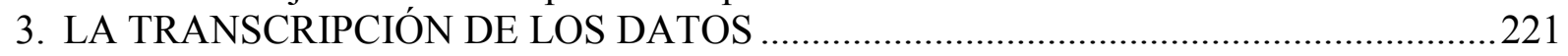

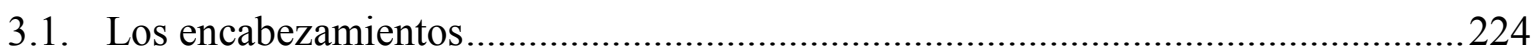

3.2. La línea principal y las líneas de producción ........................................................225

3.3. La línea dependiente.........................................................................................227

4. LA SELECCIÓN DE LOS DATOS PARA EL PRESENTE ESTUDIO: NUESTRO

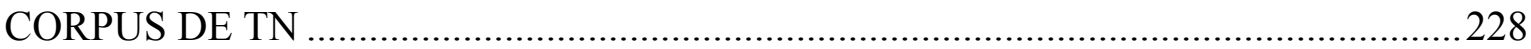

5. LA PRESENTACIÓN DE LOS CASOS DE TN PROCEDENTES DE NUESTRO

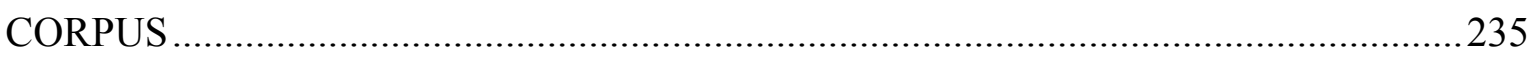

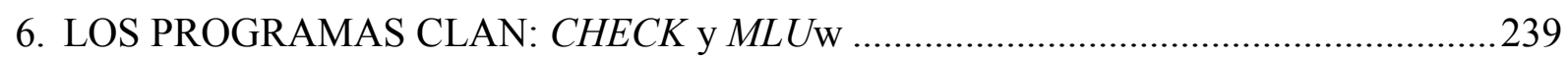

\section{CAPÍTULO 5: EL ANÁLISIS DE LOS DATOS Y LOS RESULTADOS DEL}

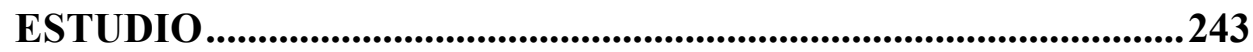

1. CUESTIONES PREVIAS AL ANÁLISIS .........................................................................245

1.1. Los problemas teórico-metodológicos que se plantean: la unidad de

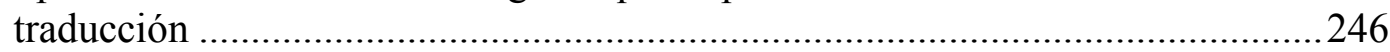

1.2. Los casos excluidos del corpus de datos ................................................................249

1.3. Las propiedades definitorias de la $\mathrm{TN}$ y la distinción entre la $\mathrm{TN}$ y la actividad nula de traducción ................................................................................253

1.3.1. La definición de TN: los aspectos lingüísticos y contextuales ............................254

1.3.1.1. Los aspectos lingüísticos inherentes a la TN .............................................254

1.3.1.2. Los aspectos más externos a la TN: el contexto situacional........................262

1.3.2. La distinción entre la TN y la actividad nula de traducción................................2265

2. LAS VARIABLES DE ANÁLISIS Y EL TRATAMIENTO ESTADÍSTICO .................267

2.1. Propuesta de variables de análisis ......................................................................267

2.1.1. Variable 1: el tipo de actividad traductora.........................................................226

2.1.2. Variable 2: la tipología semántico-conceptual .................................................22

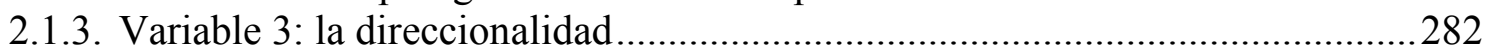

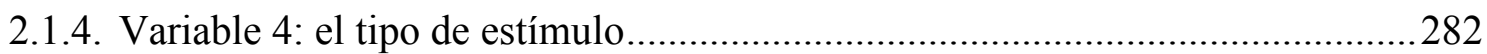

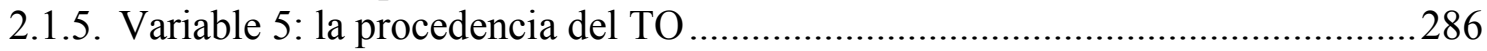

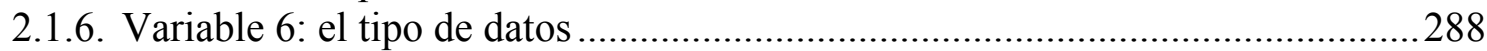

2.1.7. Un ejemplo de codificación y clasificación a partir de las variables de

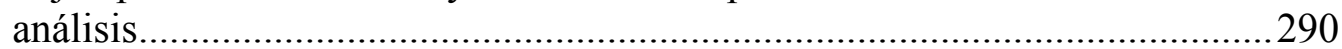

2.2. El tratamiento estadístico de los datos: el contraste de porcentajes ...........................292

3. EL ANÁLISIS DEL CORPUS DE DATOS: LAS CARACTERÍSTICAS

INTRÍNSECAS DE LAS TTNN DE SIMON Y LEO Y LA INFLUENCIA DE LOS

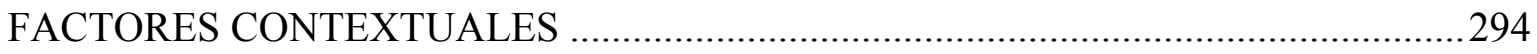

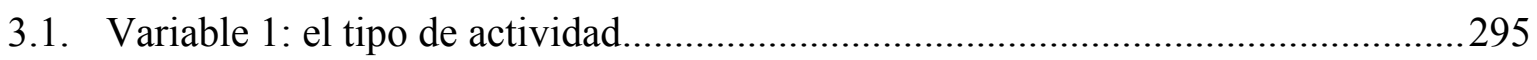

3.1.1. La producción de casos de TN según la variable 1 ..........................................296

3.1.2. Las diferencias de producción entre Simon y Leo según la variable 1 ...............298 
3.1.3. Las diferencias de producción entre Simon y Leo según la variable 1 por etapas.....

3.1.4. Conclusiones sobre la producción de TTNN de Simon y Leo según la variable 1

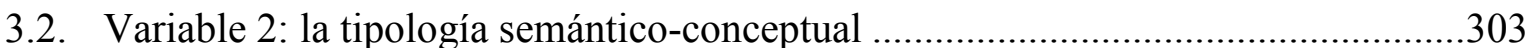

3.2.1. La producción de casos de $\mathrm{TN}$ según la variable 2 .

3.2.1.1. Las variables contextuales y la variable 2: la ausencia/presencia de estímulo

3.2.1.2. Las variables contextuales y la variable 2: la procedencia del TO

3.2.2. Las diferencias de producción entre Simon y Leo según la variable 2

3.2.2.1. Las variables contextuales y la variable 2: las diferencias de producción entre Simon y Leo según la presencia/ausencia de estímulo

3.2.2.2. Las variables contextuales y la variable 2: las diferencias de producción entre Simon y Leo según la procedencia del TO 320

3.2.3. Las diferencias de producción entre Simon y Leo según la variable 2 por etapas.

3.2.4. Conclusiones sobre la producción de TTNN de Simon y Leo según la variable 2

3.3. Variable 3: la direccionalidad

3.3.1. La producción de casos de TN según la variable 3 .

3.3.2. Las diferencias de producción entre Simon y Leo según la variable 3 .333

3.3.2.1. Las variables contextuales y la variable 3 : la ausencia/presencia de estímulo

3.3.2.2. Las variables contextuales según la variable 3: la procedencia del TO......337

3.3.3. Las diferencias de producción entre Simon y Leo según la variable 3 por etapas

3.3.4. Conclusiones sobre la producción de TTNN de Simon y Leo según la variable 3

4. LA ACTIVIDAD NULA DE TRADUCCIÓN: LA AUSENCIA DE TN

4.1. Las implicaciones de las variables de análisis en el estudio de la ausencia de TN

4.1.1. Las variables lingüísticas en la actividad nula de traducción ...........................346

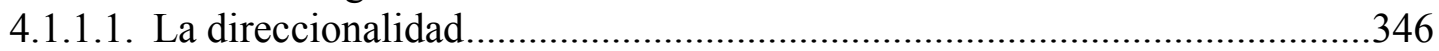

4.1.1.2. La longitud y la complejidad del TO ........................................................350

4.1.2. Las variables contextuales en la actividad nula de traducción ............................355

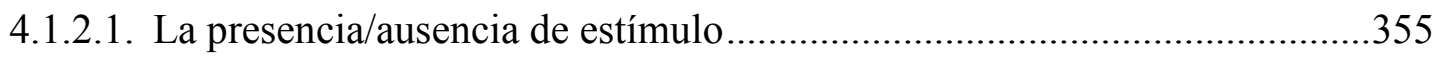

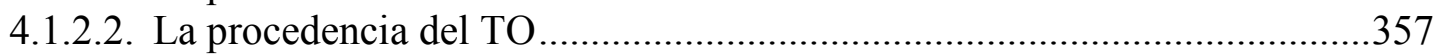

4.2. Conclusiones generales acerca de la actividad nula de traducción............................358

5. CONSECUENCIAS DE NUETROS RESULTADOS EN EL ACERCAMIENTO

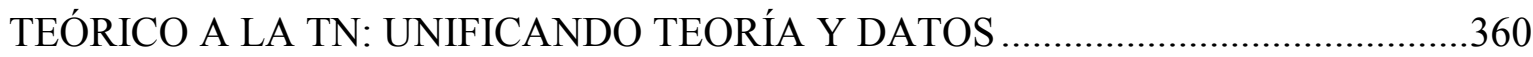

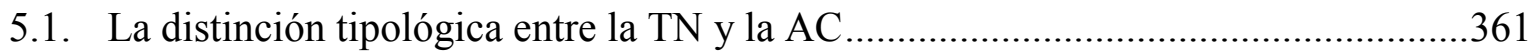

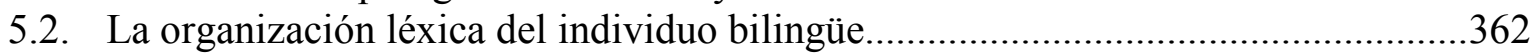

5.3. Las etapas del desarrollo lingüístico en el niño bilingüe y la influencia de los

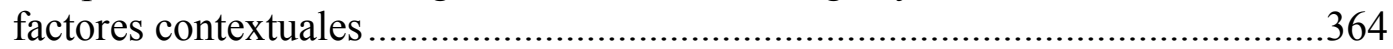

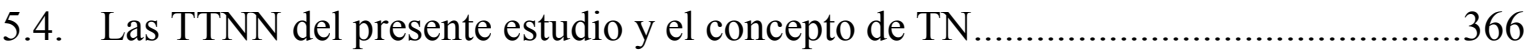

5.5. La comparación de la TN con la actividad nula de traducción..................................368 
APÉNDICES

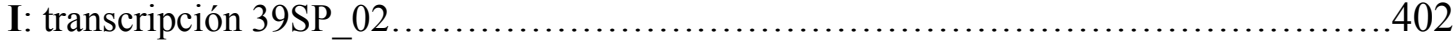

II: símbolos CHAT utilizados en los datos del presente estudio.......................4 414

III: las sesiones en español (SP) de la selección de datos...............................416

IV: las sesiones en inglés (EN) de la selección de datos............................418

V: etapas en el proceso de adquisición de Simon y Leo en nuestra selección de datos......420

VI: corpus de datos de TN del presente estudio y su clasificación........................421

ÍNDICE DE TABLAS, GRÁFICOS Y DIAGRAMAS

ÍNDICE DE ABREVIATURAS 


\section{INTRODUCCIÓN}

El presente trabajo de investigación se centra en el estudio de uno de los fenómenos de producción lingüística más característicos de la adquisición bilingüe simultánea que se denomina traducción natural (TN de aquí en adelante) y que se define como aquella que realizan los hablantes bilingües en circunstancias cotidianas y sin haber recibido una formación especializada en la materia (Harris 1977). En nuestro caso, analizamos la producción de TTNN de dos sujetos bilingües simultáneos inglés/español incluida en una selección de datos del estudio longitudinal de Fernández Fuertes et al. (2002-2005).

Con el fin de poder ubicar este fenómeno dentro de los estudios tanto de bilingüismo como de traducción, comenzaremos estableciendo, en el primer capítulo de este estudio, las bases teóricas de las que partimos y en las que incluimos distintas nociones de lo que se entiende por bilingüismo, así como los diversos criterios que se han utilizado para poder definirlo.

Desde un punto de vista general, dichos criterios se pueden agrupar fundamentalmente en tres: aquellos criterios que, partiendo de una perspectiva externa al hablante, consideran que el bilingüismo es el uso de dos (o más) lenguas por parte de un mismo individuo en función del contexto lingüístico en el que se encuentre (Mackey 1962; Grosjean 1982, 2001, etc.); aquellos que también tienen en cuenta el contexto lingüístico, pero en el que el hablante bilingüe ha adquirido las lenguas (coordinado y compuesto, fundamentalmente) (Weinreich 1968); y, finalmente, los criterios que, partiendo de una perspectiva más inherente al hablante bilingüe, clasifican el bilingüismo en diversos tipos según el nivel de competencia que tenga el hablante en cada una de las lenguas (equilibrado y dominante). 
Es precisamente esta perspectiva interna centrada en la organización de las lenguas en la mente del hablante bilingüe la que ha ido ganando cada vez más peso en los estudios de bilingüismo. Este tipo de estudios, sobre todo los relacionados con la Gramática Generativa y, concretamente, con el Programa Minimalista (Chomsky 1995, 1998, 2001) como los de MacSwan (2000, 2005), proponen una base teórica que da cuenta de la misma manera de la facultad del lenguaje del hablante monolingüe y del bilingüe, de tal forma que consideran que los principios que rigen el bilingüismo han de ser los mismos que los del monolingüismo. Específicamente, la propuesta de MacSwan (2000, 2005) se basa en que, a diferencia de los niños monolingües que tienen un único lexicón, los niños bilingües que se encuentran expuestos a dos lenguas desde el nacimiento tienen dos lexicones (en los que se recogen las variaciones paramétricas de esas lenguas) y un único sistema computacional, entendido este como el sistema de reglas con el que se organiza el lexicón y cuya función es derivar estructuras que converjan en la Forma Fonética (la que contiene los rasgos fonéticos) y la Forma Lógica (la que recoge los rasgos semánticos).

Este planteamiento relacionado con los mecanismos internos que funcionan en la mente de los hablantes bilingües será el que tratemos concretamente en el apartado 2 del primer capítulo y que nos servirá para poner de manifiesto el interés que ha despertado este tipo de cuestiones en múltiples estudios relacionados con la adquisición y el desarrollo lingüístico de dichos hablantes (Deuchar 1995; Deuchar y Quay 2000; Meisel 2001; Genesee 2003, etc.).

Para poder ahondar en los mencionados estudios, mostraremos en los apartados $3 \mathrm{y}$ 4 cómo la mayoría de los estudios que se centran en el bilingüismo infantil (simultáneo o secuencial) tratan las diferentes etapas en las que se puede dividir el desarrollo lingüístico del niño bilingüe, así como la importancia y la influencia que han tenido este tipo de planteamientos a la hora de estudiar un fenómeno característico de la adquisición bilingüe como es la mezcla de lenguas.

Ambos temas se pueden resumir en una sola cuestión: ¿puede el niño bilingüe simultáneo separar los dos sistemas lingüísticos desde etapas muy tempranas de su desarrollo bilingüe sin pasar por una etapa de fusión de lenguas que hace que las mezcle en su discurso? Las respuestas a esta pregunta han traído consigo un debate que gira en torno a dos hipótesis principales. La primera hipótesis, la del sistema lingüístico unitario (Volterra y Taeschner 1978; Redlinger y Park 1980; Taeschner 1983; Vihman 1985; Arnberg y Arnberg 1992, entre otros), parte de que el niño bilingüe cuenta con un único 
lexicón en las primeras etapas (constituido por elementos de las dos lenguas) y sólo de forma gradual irá diferenciando los dos sistemas, uno por cada lengua. Para demostrarlo, se basan en la presencia de enunciados con mezcla de lenguas en la producción lingüística de los niños bilingües durante las primeras etapas de su desarrollo lingüístico. En cambio, la segunda hipótesis, la del sistema lingüístico diferenciado (Lindholm y Padilla 1978a; De Houwer 1990; 1995; Lanza 1992, 1997; Paradis y Genesee 1996; Johnson y Lancaster 1998; Meisel 1989, 2001, entre otros), defiende que los niños bilingües diferencian los dos sistemas lingüísticos ya desde la primera etapa de su desarrollo y, además, utilizan dichos sistemas según las demandas contextuales. Para probar esta hipótesis, analizan los casos de mezcla de lenguas teniendo en cuenta determinados factores que afectan al input de los niños bilingües como, por ejemplo, las estrategias discursivas que utilizan los padres con sus hijos, así como las necesidades comunicativas de estos.

En el presente trabajo apoyaremos esta segunda hipótesis y plantearemos una serie de cuestiones que surgen a raíz del mencionado debate tales como si la diferenciación lingüística con la que cuentan los niños desde el principio se da en todos los niveles lingüísticos (fonológico, morfosintáctico y pragmático) o a qué edad se puede constatar que los niños bilingües cuentan con dos sistemas lingüísticos diferenciados.

Muy relacionado con esta última cuestión, están los casos de mezcla de lenguas que producen los niños bilingües, por lo que vamos a tratar también en este punto la importancia de la alternancia de códigos (AC) y de la TN en la adquisición bilingüe en general y en la diferenciación de lenguas en particular. Así, la AC, que se refiere al uso alternado de dos lenguas en una misma conversación (Milroy 1995) y que puede encontrarse tanto en las producciones lingüísticas de adultos bilingües como en las de niños bilingües, es uno de los tipos de mezcla de lenguas que más atención ha recibido por parte de los estudios de adquisición bilingüe, de ahí que constituya el tema central del apartado 5 del primer capítulo. Por este motivo, procederemos a tratar el tema de la mezcla de lenguas en general planteando las dificultades terminológicas y tipológicas que surgen alrededor de este tipo de fenómenos y que retomaremos en el capítulo 3 cuando realicemos nuestra propuesta de clasificación. Al mismo tiempo, aludiremos a las características de la AC tanto desde una perspectiva gramatical como pragmática, enfoques que nos servirán para poner de manifiesto que la $\mathrm{TN}$, como otro tipo de mezcla de lenguas, se puede analizar de la misma manera que la $\mathrm{AC}$ y que ambos fenómenos no son dos 
comportamientos lingüísticos arbitrarios sino que responden a una serie de principios tanto gramaticales como pragmáticos.

De esta manera, si se puede demostrar que los niños bilingües utilizan medios gramaticales diferentes para expresar las mismas o similares funciones semánticopragmáticas en ambas lenguas, esto constituiría una prueba de que están diferenciando los dos sistemas gramaticales (Meisel 1989).

Una vez que planteemos la importancia de la $\mathrm{AC}$ en la producción de niños bilingües, así como sus características gramaticales y pragmáticas, en el capítulo 2 aplicaremos estos enfoques de forma más concreta a lo que algunos autores denominan también "alternancia de códigos" pero que nosotros denominaremos "cambio de códigos", siendo este también uno de los tipos de producciones con mezcla de lenguas que utilizan los niños bilingües en la conversación y considerando la TN uno de los posibles casos que se pueden incluir en este tipo de producción bilingüe.

Con el fin de relacionar el capítulo 2 con el capítulo $1 \mathrm{y}$, al mismo tiempo, tratar la TN como una producción lingüística por si misma e independiente de la $\mathrm{AC}$, nos dedicaremos en el apartado 1 del capítulo 2 a resaltar el papel que ha tenido la TN en diversos tipos de estudios. Así, al principio del apartado 1 de este capítulo, nos centraremos en cómo se ha tratado lo que para nosotros es TN en los estudios de bilingüismo, en los que se ha utilizado la traducción como método de inferencia de modelos léxicos en la mente del hablante bilingüe en general (De Groot et al. 1994; Gollan y Kroll 2001; Heredia y Brown 2004; Pavlenko 2000, etc.). También en ese tipo de estudios se ha aludido a cómo en la traducción que realizan los niños bilingües se pone de manifiesto la separación formal de las dos lenguas, así como la puesta en práctica de la conciencia bilingüe (Lanza 1992), de ahí que consideremos la importancia del análisis de los casos de TN a lo largo del desarrollo lingüístico del niño bilingüe como evidencia de la diferenciación de lenguas desde las primeras etapas de dicho desarrollo. En este sentido, encontramos de gran interés para el presente trabajo algunos estudios clásicos de adquisición bilingüe y otros más recientes (Swain 1973; Harris 1980b; Redlinger y Park 1980; Vihman 1985; Lanza 1997; Nicoladis y Secco 1998; Paradis et al. 2000) en los que se hace referencia, aunque sea con una terminología diferente, a las producciones lingüísticas que implican un trasvase de información de una lengua a otra en un mismo 
contexto conversacional (equivalentes de traducción yuxtapuestos, emparejamientos de palabras, duplicaciones, auto-correcciones, etc.).

A continuación, si bien este enfoque de estudio relacionado con el desarrollo lingüístico bilingüe resulta más interesante para el planteamiento del presente trabajo de investigación, consideramos oportuno incluir también en el capítulo 2 el enfoque sociolingüístico, el cual se ha centrado en lo que se ha denominado "brokering". Este término puede basarse en cierta manera en el concepto de TN que aquí manejamos en el sentido de que hace referencia a una mediación lingüística (no profesional) en la que participan niños bilingües que se implican activa y personalmente en una transacción cultural con el fin de que sus familiares (normalmente refugiados o inmigrantes) tengan acceso a determinados ámbitos públicos y sociales (educativos, económicos, administrativos, etc.) (Shannon 1990a/b, 1996; Tse 1996; Hall y Sham 1998; Orellana et al. 2003a, etc.). Sin embargo, el carácter sociolingüístico de estos trabajos hace que se centren en las relaciones sociales o situacionales que motivan estas mediaciones lingüísticas y no en las traducciones presentes en el desarrollo bilingüe, que, en definitiva, son las que constituyen la base de estudio de este trabajo y las que tratamos en el apartado 2 del capítulo 2.

Específicamente, en dicho apartado nos ocuparemos de nuevo del enfoque lingüístico, intentando establecer una relación interdisciplinar entre los estudios de bilingüismo infantil y los estudios que tratan la relación entre la competencia bilingüe y la competencia traductora en los hablantes bilingües, en los que se aúnan investigadores tanto del campo del bilingüismo como del campo de la teoría de la traducción. Precisamente, las consecuencias de esta conexión entre el bilingüismo y la actividad traductora nos conducen a la constatación de la importancia del estudio de la TN no sólo dentro de los estudios de adquisición sino también de traducción. De esta manera, en los sucesivos subapartados, mostraremos las propuestas de varios estudios (Harris 1980b y Harris y Sherwood 1978; Malakoff y Hakuta 1991; Toury 1986; Lörscher 1992) acerca del desarrollo paralelo de la competencia traductora y la competencia bilingüe, diferenciándose dichas propuestas en función del concepto de competencia traductora del que partan. Así, encontraremos trabajos que se muestran a favor de la coexistencia de dicha competencia con el bilingüismo (Harris 1980b y Harris y Sherwood 1978; Srivastava y Gupta 1989; Malakoff y Hakuta 1991), mientras que otras parten de la no consideración de la TN como un tipo de traducción o de la diferencia que existe entre los traductores naturales y los profesionales 
(Toury 1986; Newmark 1991; Neubert y Shrieve 1992; Lörscher 1992, etc.). De estos últimos estudios nos ocupamos con más detalle en el apartado 3 dedicado al papel de la TN en los estudios teóricos de traducción.

A partir de cada uno de estos planteamientos, nuestra postura se basará en la necesidad de ampliar el concepto de traducción, adoptando un enfoque no prescriptivo sino descriptivo y explicativo, tanto en los estudios teóricos de traducción como en el análisis de la producción de traducciones a través de datos de producción lingüística de hablantes bilingües. El problema al que nos enfrentamos, en ese sentido, es que excepto Harris (1980a/b), que se apoya en la revisión de datos previos procedentes de estudios de bilingüismo infantil (Ronjat 1913; Leopold 1939-1949; Von Raffler-Engel 1970; Swain 1972a, 1973; Swain y Wesche 1975; Volterra y Taeschner 1978; etc.), siendo sólo algunos de ellos longitudinales (Swain 1972a; Swain y Wesche 1975) y recopilando algunos nuevos, ninguno de estos trabajos hace uso de datos longitudinales referidos a la TN. Por otro lado, existen estudios descriptivos con datos longitudinales de niños bilingües en los que se pueden localizar casos de TN producidos por estos niños. Sin embargo, si bien vamos a hacer referencia a dichos casos en varias ocasiones, lo cierto es que el interés de la investigación de ese tipo de estudios no es concretamente el de la TN (Ronjat 1913; Leopold 1939-1949; Swain 1972a/b; Swain y Wesche 1972; Swain et al. 1974; entre otros).

Así pues, la escasez de datos longitudinales relacionados con el estudio concreto de la TN en general y de los niños bilingües en particular, nos lleva a plantear nuestro propio análisis de TTNN tomando como punto de partida la base de datos de Fernández Fuertes et al. (2002-2005) sobre dos niños gemelos bilingües simultáneos con el par de lenguas inglés norteamericano y español peninsular. Consideramos, pues, que el trabajo que aquí presentamos constituye un estudio pionero tanto en el campo de la adquisición como en el campo de la traducción, ya que profundiza en el análisis lingüístico de las TTNN producidas por dos niños bilingües inglés/español a lo largo de un período de poco más de 4 años.

En el capítulo 3, correspondiente a las propuestas que presentamos en el presente estudio, tomaremos como centro de estudio la TN per se, de tal forma que, en el apartado 1 de dicho capítulo, integraremos la $\mathrm{TN}$ en los estudios de bilingüismo para, a continuación, 
plantear la relación que se puede establecer entre este fenómeno y otros fenómenos relacionados con la mezcla de lenguas como la AC. Siguiendo esta línea, expondremos las similitudes y las diferencias entre ambos fenómenos, llegando a la conclusión de que si bien ambas constituyen un tipo de mezcla de lenguas característico de la adquisición bilingüe, la AC supone una alternancia de lenguas sin trasvase de significado entre ambas, mientras que la $\mathrm{TN}$ es un tipo de cambio de códigos que implica un trasvase de significado de una lengua a otra. A su vez, esta comparación nos servirá para demostrar que la TN puede considerarse también una habilidad lingüística y comunicativa semejante a otras producciones típicas de la adquisición bilingüe como es la $\mathrm{AC}$ que, a diferencia de la $\mathrm{TN}$, ha recibido una gran atención por parte de los estudios de bilingüismo, a pesar de que este tipo de traducción nos puede ofrecer datos interesantes sobre la competencia gramatical y pragmática de los niños bilingües. Siguiendo esta línea de investigación, comprobaremos que los niños bilingües son capaces de traducir y que, de hecho, realizan traducciones a edades tempranas porque, a la hora de comunicar un mismo mensaje en dos lenguas, son conscientes de la existencia de dos sistemas lingüísticos así como de las diferencias entre estos sistemas, aunque en esta diferenciación también tendrá un papel decisivo el contexto lingüístico en el que se encuentren los niños.

En el apartado 2 del capítulo 3, proponemos que la TN sea parte integrante tanto de los estudios de bilingüismo infantil como de los estudios teóricos de traducción, ya que un análisis de los procedimientos que utilizan los niños bilingües para traducir contribuye a la descripción del funcionamiento tanto de la competencia bilingüe como de la competencia traductora innata. De este análisis se pueden beneficiar los traductores profesionales y la teoría de la traducción, ya que, tal y como había planteado Harris (1977; 1992), el estudio científico de la traducción debe partir del estudio de la TN, pues es una habilidad natural previa a la adquisición de un nivel de competencia profesional. Es decir, debemos partir del análisis de la traducción en estado natural, de la traducción que realizan los niños desde edades muy tempranas, pues es aquí donde se encuentra la base de la competencia traductora.

Con este fin y tal y como hemos mencionado anteriormente, contamos con los datos de producción lingüística de dos niños gemelos bilingües inglés/español, Simon y Leo (Fernández Fuertes et al. 2002-2005), de los que obtendremos los casos de TN que son el objeto de análisis de este trabajo de investigación. En los primeros apartados del capítulo 
4, describimos la selección de datos que abarca un período de poco más de 4 años, es decir, desde que los niños tienen 2;00 años hasta los 6;03.

También en el capítulo 4 damos una gran importancia al contexto lingüístico en el que se desenvuelven nuestros sujetos y el input que estos reciben, ya que, viven en Salamanca la mayor parte del año y sólo durante 2 ó 3 meses al año se trasladan a Estados Unidos. Aunque el padre es hablante nativo de español peninsular y la madre de inglés norteamericano, ambos son bilingües y practican con sus hijos la fórmula de una persona una lengua (es decir, se dirigen a sus hijos en sus respectivas lenguas maternas) (Ronjat 1913), una estrategia comunicativa que puede tener una gran influencia en los resultados del análisis de las traducciones recopiladas en nuestro corpus de datos.

También detallaremos la metodología de recogida y selección de datos para nuestro estudio en donde describiremos los dos tipos de datos de producción con los que contamos: los datos espontáneos, en los que los niños interactúan normalmente con los padres, y los datos experimentales, en los que han de actuar como intérpretes entre dos investigadores monolingües con el fin de que estos puedan comunicarse.

En el capítulo 5 del trabajo y con el fin de analizar los mecanismos lingüísticos utilizados por nuestros sujetos en la producción de TTNN, así como la influencia de los factores contextuales en dicha producción, presentamos el análisis lingüístico de los casos de TN recopilados para nuestro estudio y que conforman nuestro corpus de datos. Para ello, y de forma preliminar, distinguiremos aquellos casos de $\mathrm{TN}$ per se en los que el proceso se ha llevado a cabo total (TN completa y reformulación) o parcialmente (TN incompleta) de aquellos casos en los que la actividad de traducción ha resultado nula, a pesar de que la situación hubiese requerido tal traducción.

A continuación, en el apartado 2 del mencionado capítulo, estableceremos los pilares fundamentales en los que se apoya nuestro análisis y que son, por un lado, las variables de análisis que proponemos, las cuales giran en torno a los parámetros gramaticales y contextuales que siguen las TTNN (y los casos de actividad nula) recopiladas y que nos permitirán realizar una clasificación de este tipo de producciones; y, por otro lado, el tratamiento estadístico de las principales variables que vamos a tener en cuenta para el análisis, en el que pondremos de manifiesto las diferencias o similitudes que 
encontremos en el comportamiento traductor de nuestros dos sujetos a la hora de producir TTNN (o de no producirlas).

En cuanto a las variables de análisis que proponemos para la clasificación de las TTNN, presentaremos cada una de ellas con sus correspondientes definiciones y ejemplos, teniendo en cuenta lo planteado en los capítulos anteriores en los que hemos aludido a la importancia que tienen en el estudio de la TN tanto el aspecto formal como el aspecto situacional. En este sentido, consideramos que el objetivo de nuestro trabajo es doble ya que examinaremos, por un lado, la importancia en la TN de aquellas variables lingüísticas que son intrínsecas a la traducción (el tipo de actividad traductora; la tipología semánticoconceptual y la direccionalidad) y, por otro lado, la influencia en este tipo de variables de otros aspectos más externos a la TN que se asocian al contexto en el que se produce este tipo de producción lingüística (la presencia/ausencia de un estímulo que provoque la producción de TTNN y la procedencia del texto origen que los niños traducen).

A partir de este tipo de variables, procederemos a realizar en el apartado 3 el análisis de las características intrínsecas de las TTNN de Simon y Leo y la influencia de los factores contextuales en dichas características, así como el análisis de la actividad nula de traducción. Para ello, plantearemos para cada una de las variables intrínsecas tres cuestiones de análisis. En primer lugar, el número total de casos de TTNN que realizan ambos sujetos según la variable correspondiente; en segundo lugar, las preferencias de uno y otro niño a la hora de producir un tipo de traducción u otro, así como el grado de significatividad de las diferencias entre ambos; y, en tercer lugar, el estudio del desarrollo del comportamiento traductor en nuestros sujetos en función de la variable concreta de estudio a lo largo de las tres etapas planteadas.

Finalmente, una vez presentados los resultados del análisis, procederemos a exponer las implicaciones más importantes que nuestros resultados pueden tener en las principales cuestiones teóricas que hemos ido presentando a lo largo de los capítulos anteriores y que mencionamos a continuación: la distinción tipológica entre la TN y la AC; la presencia de TTNN durante el desarrollo lingüístico de los niños bilingües; la influencia de factores contextuales en la producción de estas traducciones; $y$, finalmente, la correspondencia o la falta de ella entre las TTNN manejadas en este estudio y el concepto de traducción del que partimos, así como la comparación entre las TTNN per se y la actividad nula de traducción. 
En la última parte del presente trabajo de investigación, se incluye un apartado dedicado a las conclusiones que planteamos a partir de los resultados del análisis lingüístico de la TN que aquí presentamos, así como a sus posibles aplicaciones a futuros trabajos de investigación. 


\section{CAPÍTULO 1: BILINGÜISMO. ADQUISICIÓN BILINGÜE Y MEZCLA DE LENGUAS}

En este capítulo nos proponemos establecer las bases teóricas del presente trabajo en las que se incluyen distintas nociones de lo que se entiende por bilingüismo, algunas de las cuales se tratarán en mayor profundidad en apartados posteriores. Con el fin de poder ubicar la traducción natural en el estudio del bilingüismo y, más concretamente, de la adquisición bilingüe, hemos partido de cuestiones muy generales presentando en el primer apartado de este trabajo de investigación el concepto de lo que se entiende por bilingüismo, así como el papel de la traducción realizada por los hablantes bilingües en el debate que se plantea en este campo de estudio acerca de la organización mental de las lenguas en este tipo de hablantes. De forma más específica, aludiremos a los diversos criterios que se han utilizado para definir el bilingüismo, así como la relación de este con determinados fenómenos lingüísticos en los que se incluyen la mezcla de lenguas en general y la traducción natural en particular.

Como veremos en este capítulo, el bilingüismo constituye una forma de comunicación de la que disponen los hablantes bilingües, los cuales se pueden clasificar en diversos grupos dependiendo del proceso de adquisición de las dos lenguas, de la etapa o del contexto en el que las han adquirido o de las implicaciones que tenga el uso de dichas lenguas desde una perspectiva social. Se trata, pues, de criterios tanto internos como externos al individuo bilingüe cuyo punto de referencia ha ido variando dentro de la literatura dedicada al bilingüismo. De hecho, si bien en un principio el punto de partida del estudio del bilingüe eran los criterios externos, sobre todo a partir de la segunda mitad del 
siglo XX y a medida que avanzamos en el estudio de este tema, tanto el concepto de bilingüismo como la perspectiva de su análisis van centrándose cada vez más en el hablante bilingüe y, concretamente, en la representación de las dos lenguas en la mente de dicho hablante.

Este tipo de acercamiento al hablante bilingüe es el que, por tanto, ha ido ganando más importancia y más peso en los estudios específicos de bilingüismo, sobre todo desde los orígenes de la Gramática Generativa, cuya perspectiva parte la organización de las lenguas en la mente del bilingüe al que, al mismo tiempo, consideran que es un hablante cuya facultad del lenguaje funciona de la misma manera que la de un hablante monolingüe. De este planteamiento, así como de este marco teórico en el que encuadramos nuestra investigación, trataremos en el segundo apartado de este capítulo.

Es esta perspectiva, es decir, aquella que tiene como punto de referencia los mecanismos internos que funcionan en la mente del individuo bilingüe, la que ha servido de punto de partida a múltiples estudios relacionados con la adquisición y el desarrollo lingüístico de los hablantes bilingües, sobre todo en lo que respecta al lexicón bilingüe y su papel en fenómenos típicos bilingües como la mezcla de lenguas, temas que trataremos a lo largo de los apartados 3 y 4.

Uno de los fenómenos que se produce en un contexto de mezcla de lenguas en hablantes bilingües es el que se conoce como alternancia de códigos, la cual ha sido documentada tanto en niños como en adultos bilingües, y de la que trataremos en la última parte de este capítulo, centrándonos concretamente en la aparición de este y de otro tipo de fenómenos lingüísticos en el discurso bilingüe infantil de gran interés para el presente estudio como es la traducción natural. 


\section{EL CONCEPTO DE BILINGÜISMO}

A continuación, presentaremos, de forma general, algunas de las nociones de bilingüismo que se han planteado en la literatura relacionada con este tema para, seguidamente, centrarnos en estudios en los que, partiendo de dichas nociones, han propuesto determinados modelos de almacenamiento y organización del lexicón en la mente del hablante bilingüe.

\subsection{Diversas nociones de bilingüismo}

Si consideramos que bilingüismo es la habilidad que tiene una persona para usar dos o más lenguas como una forma de comunicación en determinadas situaciones y de cambiar de una lengua a otra si fuera necesario (Oksaar 1983), una gran cantidad de factores pueden entrar en juego a la hora de definir lo que se conoce como bilingüismo. Dichos factores se pueden agrupar en torno a dos ideas básicas: el conocimiento de dos lenguas y la diversidad de situaciones que pueden incluirse en la definición de este fenómeno. Así, por un lado, habría que recurrir a un término más general como contacto de lenguas o lingüistica de contacto (Romaine 1989; Siguán 2001) para poder incluir todos aquellos fenómenos relacionados con el conocimiento de dos lenguas y no sólo con lo que se entiende por bilingüismo. Por otro lado, sin embargo, la definición de bilingüismo está lejos de tener un carácter preciso $\mathrm{y}$, de hecho, en la actualidad sigue siendo demasiado amplia, dada la gran variedad de criterios, situaciones, grados o niveles de competencia en las diferentes destrezas lingüísticas (la comprensión y la expresión tanto orales como escritas) en cada una de las lenguas. Teniendo en cuenta ambas ideas, los estudiosos del bilingüismo han tratado de buscar una definición más restringida y específica para cada uno de los casos de bilingüismo, lo cual, a su vez, ha supuesto aludir a diferentes tipos de parámetros con el fin de precisar este concepto.

En este sentido, dos son los criterios generales que se suelen tener en cuenta cuando se intenta definir el concepto de bilingüismo:

- el uso alternativo de dos (o más) lenguas por parte del mismo individuo, el cual es capaz de adaptar dicho uso a determinadas situaciones como, por ejemplo, la 
lengua utilizada por el interlocutor con el que está interactuando (Weinreich 1968; Mackey 1962; Grosjean 1982, 2001; Genesee 2003); y

- el grado de fluidez o el nivel de competencia lingüística que tenga una persona en dos (o más) lenguas (Haugen 1969; Baetens Beardsmore 1982; Kroll et al. 1998; Sánchez-Casas 1999). A diferencia del criterio anterior, esta definición toma como punto de partida no tanto los factores externos al hablante de los que depende el uso de dos lenguas, sino el conocimiento que este tiene de cada una de ellas. Según este segundo criterio, se puede hablar de dos tipos de bilingüismo: bilingüismo equilibrado (un nivel de competencia semejante en ambas lenguas) frente a bilingüismo dominante (el nivel de conocimiento de una lengua es superior al de la otra).

Sin embargo, otros autores se valen de criterios diferentes para poder plantear otro tipo de clasificaciones posibles. Así, Sánchez-Casas (1999), Wei (2000), Butler y Hakuta (2004), entre otros, ofrecen una compilación de la variedad tipológica del bilingüismo y hacen uso de criterios como los siguientes:

- las circunstancias en las que se adquieren las lenguas: propuesto por Weinreich (1968), este criterio es un clásico de los estudios de bilingüismo y en él se basa la distinción de tres tipos de bilingüismo:

- bilingüismo coordinado: el individuo adquiere las lenguas habladas por personas distintas y en contextos o entornos diferentes, de tal forma que puede adquirir una de las lenguas en el hogar familiar con los padres y la otra en la comunidad en la que vive, con los amigos o a través de los medios de comunicación, por ejemplo. Ervin y Osgood (1954) consideraban que en este tipo también se incluyen aquellas personas que aprenden la L2 en un ámbito académico o por inmersión cultural;

○ bilingüismo compuesto: el individuo aprende las dos lenguas en un mismo contexto donde las utiliza a la vez. Sería el caso, por ejemplo, del niño que adquiere dos lenguas en un hogar donde las personas hablan dichas lenguas de forma intercambiable y en las mismas situaciones; 
- bilingüismo subordinado: el individuo domina la lengua materna y está en proceso de aprender una L2;

- la edad: dependiendo de este factor, Butler y Hakuta (2004) distingue entre bilingüismo temprano (propio de la persona que ha adquirido dos lenguas durante la infancia) y bilingüismo tardio (el de la persona que ha adquirido una lengua segunda después de la infancia o en edad adulta);

- el orden de adquisición: Meisel (2001) y Butler y Hakuta (2004), entre otros, utilizan el término bilingüismo simultáneo para referirse a la adquisición de dos lenguas maternas $(\mathrm{L} 1+\mathrm{L} 1)$ desde el nacimiento, en un contexto natural y de manera simultánea, y el término bilingüismo secuencial para denominar a la adquisición de una lengua materna (L1) desde la infancia y la posterior adquisición de una lengua segunda (L2) que se aprende en un contexto institucional en la gran mayoría de los casos. En el caso del bilingüismo simultáneo, este ha recibido otros nombres distintos como bilingüismo como L1 (Swain 1972a; Lanza 1993; De Houwer 1990, 1995, 1998; Genesee 2001; Meisel 1989, 1994a/b/d, 2001), al igual que el bilingüismo secuencial, al que algunos estudios se refieren como bilingüismo consecutivo o sucesivo (McLaughlin 1978; Lindholm y Padilla 1978a);

- el estatus de las lenguas: algunos autores como Lambert (1979) o Wei (2000), entre otros, aluden, por un lado, al bilingüismo aditivo, en el que la adquisición de la L2 se produce sin una pérdida de la competencia en la L1, siendo ambas lenguas valoradas socialmente, y, por otro, al bilingüismo sustractivo, donde la L2, mayoritaria y valorada socialmente, es adquirida o aprendida a costa de la pérdida de la L1, la cual es hablada por una minoría de bajo estatus social;

- otros criterios: Baker (1993), por ejemplo, habla de la actitud del individuo hacia cada una de las lenguas que adquiere, así como del contexto comunicativo en el que se desarrollan o se utilizan las lenguas, distinguiendo, según este último criterio, entre bilingüismo individual (cuando es un individuo el que hace uso de las dos lenguas) y bilingüismo social (cuando es un grupo de individuos el que hace uso de las dos lenguas en un mismo espacio geográfico).

Una de las clasificaciones que más aceptación tuvo durante muchas décadas fue la de Weinreich (1968), punto de referencia de muchos de los estudiosos del bilingüismo, en 
la que el criterio fundamental se basaba en las circunstancias en las que el individuo bilingüe hubiese adquirido las dos lenguas. Sin embargo, a pesar de que esta clasificación sigue siendo de referencia obligada en los estudios de bilingüismo, lo cierto es que abarcaría casos que incluirían desde la adquisición natural y simultánea de dos L1, hasta el aprendizaje formal de una L2 (Schreuder y Weltens 1993). De esta manera, es posible que se den situaciones que puedan resultar difíciles de englobar en un solo tipo de bilingüismo y que hacen que esta clasificación sea demasiado general para resultar práctica. De hecho, el bilingüismo coordinado y el bilingüismo compuesto parecen el resultado de un proceso de adquisición lingüística, mientras que el subordinado recoge el desarrollo de dicho proceso. Quizás por este motivo, algunos autores como De Groot (1993) hablan sólo de bilingües coordinados y bilingües compuestos, considerándolos los dos extremos de una situación de carácter continuo, a lo largo de la cual el sistema de representación mental de cada una de las lenguas del bilingüe puede variar.

Así pues, aunque la clasificación de Weinreich (1968) es un tanto rígida desde el punto de vista práctico, son muchos los investigadores, como la propia De Groot (1993), que recurren a dicha clasificación para analizar las formas de organización del lexicón en el individuo bilingüe, tal y como veremos en el siguiente apartado.

\subsection{La organización del lexicón}

Tomando como punto de partida la clasificación de Weinreich (1968), los estudios de autores como De Groot (1993), Grosjean (1982), Romaine (1989) y Wourtensen et al. (1998), entre otros, han tenido una gran influencia en las diferentes hipótesis sobre la representación de los sistemas lingüísticos en el hablante bilingüe que veremos en apartados posteriores [ver 1.1. en el capítulo 2]. Con el fin de adelantar algunas cuestiones, hemos creído conveniente aludir a determinados planteamientos generales que ofrecen estos autores, los cuales parten de la idea de que existe una correlación entre la forma en la que el hablante adquiere las dos lenguas en cada uno de los tres tipos de bilingüismo nombrados por Weinreich (1968) (coordinado, compuesto y subordinado) y la organización mental del lexicón en cada tipo de hablante bilingüe. De esta manera, cada uno de los tres tipos de bilingües se diferenciarán no sólo por los factores que hayan influido en su proceso de adquisición sino también por el tipo de relación que exista entre 
la forma en la que se almacenan los lexicones en su mente bilingüe y la forma conceptual que dichos lexicones representen, tal y como se observa en los diagramas 1-3.

Diagramas 1-3. La organización del lexicón bilingüe

(Heredia y Brown 2004)

\section{Bilingües coordinados}
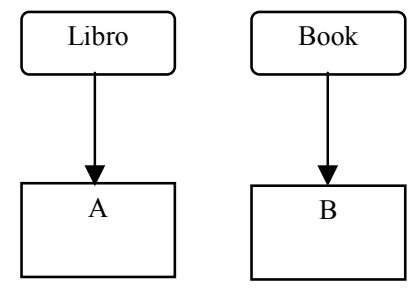

2. Bilingües compuestos

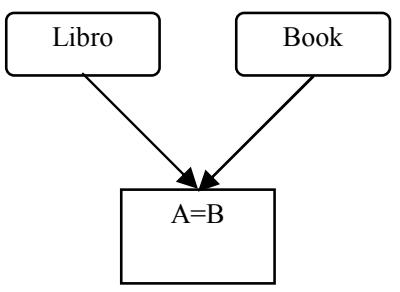

3. Bilingües subordinados

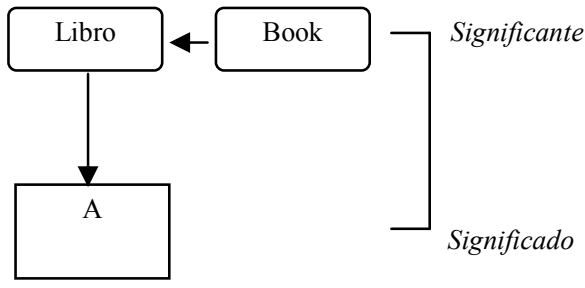

Atendiendo a esta diferenciación, por un lado, el bilingüe coordinado mantendrá las dos lenguas por separado, de tal manera que dispondrá de esas dos lenguas para expresarse y de dos sistemas o representaciones conceptuales (uno asociado a cada uno de los dos lexicones).

Por otro lado, el bilingüe compuesto dispondrá de dos formas de expresión, aunque tendrá un único sistema o representación conceptual, lo cual, según Romaine (1989), supone que, en este tipo de bilingües, las lenguas se encuentran fusionadas en la mente del bilingüe.

Finalmente, el bilingüe subordinado también tiene dos lexicones que comparten un único sistema conceptual, aunque, a diferencia del compuesto, accede a dicho sistema a través de la traducción de la palabra de la L1 y no accede directamente a su representación conceptual en la L2, como ocurre en los otros dos tipos.

Estas propuestas sobre la organización mental del lexicón en el hablante bilingüe influirán en las hipótesis y modelos que intentan describir el carácter de las relaciones que se establecen entre las dos lenguas en los diferentes tipos de bilingües, lo cual será de gran importancia a la hora de analizar, como veremos en posteriores apartados [ver 1.1. en el capítulo 2], qué relaciones léxicas o conceptuales se pueden dar entre las lenguas cuando un bilingüe traduce.

Estos criterios de clasificación han dado lugar, desde la década de 1960, a uno de los debates más interesantes y controvertidos relacionados con el estudio del bilingüismo: el que gira en torno a cómo se organizan las lenguas en el cerebro bilingüe o a la cuestión 
de si los bilingües tienen un único sistema lingüístico (independiente o compartido) o dos sistemas lingüísticos diferenciados (uno por cada lengua). Teniendo en cuenta la clasificación de los diagramas 1-3, se puede inferir que dicho debate parte de la importancia que tiene el lexicón en la mente del hablante por toda la información que en él se codifica para la representación gramatical y su correspondiente Forma Lógica (la que recoge los rasgos semánticos) y Forma Fonética (la que contiene los rasgos fonéticos), tal y como se plantea desde la Gramática Generativa [ver el apartado 2].

Para poder profundizar aún más en los posibles modelos de organización del lexicón en la mente del hablante bilingüe, determinados autores (De Bot et al. 1995; Verhoeven 1994) proponen las siguientes hipótesis, las cuales también ocuparán un lugar importante en los estudios de bilingüismo temprano y simultáneo, tal y como veremos en el apartado dedicado a los modelos de la memoria bilingüe [ver 1.1. en el capítulo 2]:

- la hipótesis de la independencia: se basa en que el bilingüe dispone de dos almacenes conceptuales, uno para cada lengua, tal y como aparece representado en el diagrama 1;

- la hipótesis de la interdependencia: el individuo bilingüe tiene un único almacén conceptual pero una etiquetación diferente para cada lengua, como en el diagrama 2. En el caso concreto de los bilingües subordinados, tal y como aparece en el diagrama 3, estos también disponen de un único almacén conceptual, pero una de las lenguas (la L2) depende de la otra (la L1) desde el momento en el que este tipo de hablantes tienen que traducir la palabra de la L2 a la L1 para acceder a la representación conceptual de dicha palabra.

Así pues, si tenemos en cuenta lo visto hasta ahora, lo que se observa es que, si bien en los primeros estudios relacionados con el bilingüismo el foco de atención se centraba en intentar definir el bilingüismo adoptando una perspectiva externa al individuo (teniendo en cuenta, por ejemplo, el tipo de la relación social que se establece entre las dos lenguas o los contextos en los que estas se adquieren), a medida que avanzamos en el estudio del bilingüismo observamos que se va ampliando la concepción del bilingüismo al considerar como punto de partida al hablante bilingüe $\mathrm{y}$, concretamente, el análisis conjunto $\mathrm{y}$ 
simultáneo de la L1 y la L2 y su almacenamiento y organización en la mente de dicho hablante.

Precisamente esta misma perspectiva es la que va a adoptar la Gramática Generativa en relación con la representación de las lenguas en la mente del hablante bilingüe y que constituirá el marco teórico del trabajo que presentamos y que trataremos a continuación.

\section{LA TEORÍA LINGÜÍSTICA Y LA ADQUISICIÓN BILINGÜE: LA GRAMÁTICA GENERATIVA COMO MARCO TEÓRICO}

Los temas del presente apartado van a girar en torno a cuestiones generales de teoría lingüística, concretamente, en torno a cuestiones relacionadas con diferentes propuestas de corte generativo que se basan fundamentalmente en la Teoría de Principios y Parámetros (PP) (Chomsky 1981, 1991). Esta Teoría se basa, concretamente, en la existencia de unos principios universales e invariables por el que se rigen todas las lenguas y que vienen determinados por la llamada Gramática Universal (GU). Por GU se entiende la dotación genética o la facultad innata que tiene el ser humano para adquirir el lenguaje. Al mismo tiempo, se propone que la GU cuenta también con una serie de opciones, denominadas parámetros, que han de ser fijados y que son los que dan cuenta de que las lenguas, a pesar de compartir principios universales, son diferentes.

Para poder explicar los mecanismos que subyacen a la facultad del lenguaje, entendida esta como el par constituido por el sistema articulatorio-perceptual (o sensorimotor) y el sistema conceptual-intencional, estos trabajos de corte generativo, entre ellos la versión más reciente, el denominado Programa Minimalista (PM) (Chomsky 1995, 1998, 2001), proponen que existen dos niveles de representación lingüística o interfaces en toda estructura gramatical: aquel que se corresponde con el componente fonético (o Forma Fonética) y aquel que se corresponde con el componente semántico (o Forma Lógica). Ambos niveles, que trataremos con más detalle en posteriores apartados [ver 2.1. y 2.2. en el presente capítulo], son, pues, los que caracterizan el lenguaje y los que nos servirán para interpretar las representaciones de toda expresión lingüística (Hornstein et al. 2005). 
Entre estos trabajos que parten del Programa Minimalista destacamos los de MacSwan $(2000,2005)$ quien, con el fin de unificar los principios que dan cuenta de la facultad del lenguaje, plantea que dicha facultad en un hablante bilingüe sigue los mismos principios que en un hablante monolingüe. De esta manera, se apoyaría la idea de que el bilingüismo se puede explicar, desde un punto de vista teórico, de la misma manera que la facultad del lenguaje monolingüe y que la adquisición bilingüe o el uso de dos lenguas no implican que haya que recurrir a principios específicos para dar cuenta de esa facultad bilingüe.

\subsection{EI Programa Minimalista: nociones básicas}

Los planteamientos de la lingüística teórica de corte generativo, en general, y de la adquisición de lenguas, en particular, sitúan al hablante como centro de estudio del funcionamiento del lenguaje (Chomsky 1968), lo cual lo convierte, en nuestro caso concreto, en un marco teórico muy adecuado para nuestro estudio cuyo eje central también es la capacidad lingüística del hablante bilingüe.

De esta manera y tal y como hemos apuntado anteriormente, dentro de los trabajos de corte generativo y en especial en el marco de PP (Chomsky 1981, 1991) y el PM (Chomsky 1995, 1998, 2001), se parte de unos principios universales que afectan a todas las lenguas por igual y que están determinados por la GU, la cual incluye también, como hemos dicho, una serie de opciones paramétricas que explicarían la variación entre las lenguas.

Afinando todas estas cuestiones teóricas, el PM plantea dos cuestiones básicas. En primer lugar, las lenguas se diferencian en los rasgos del lexicón que constituyen la base de esas opciones paramétricas, de tal forma que, por ejemplo, el rasgo [+ fuerte] de la flexión verbal en español y el rasgo [- fuerte] de la flexión verbal en inglés, que son las lenguas que nos ocupan en este trabajo, justifican la naturaleza implícita de los sujetos en español, frente a la naturaleza explícita de esos mismos elementos en inglés (Kato 1999, entre otros).

En segundo lugar, los principios que se incluyen en la GU han de cumplirse en la derivación de las estructuras pertenecientes a una determinada lengua, de tal forma que la 
derivación o representación de toda estructura ha de constar de los cuatro niveles que figuran en el diagrama $4^{1}$.

Diagrama 4. Los niveles de representación lingüística según el PM

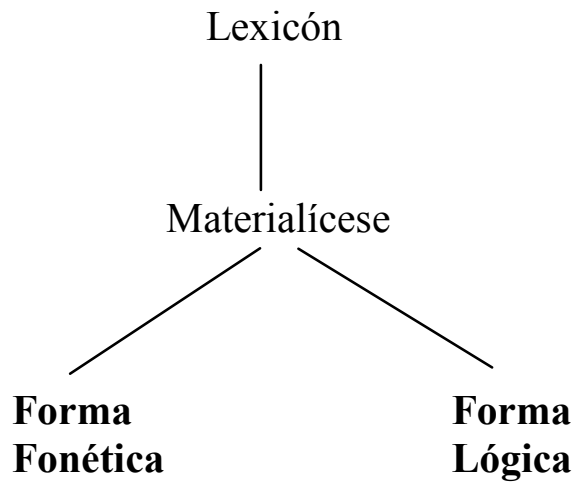

El primer nivel de representación es el Lexicón, el cual está constituido por ítems cuya naturaleza puede ser léxica (nombres, verbos, adjetivos, etc.) o funcional (flexión, tiempo, concordancia, etc.), y que es donde se localizan las variaciones paramétricas, más concretamente, en los rasgos que portan los ítems del lexicón; el segundo nivel es lo que se conoce como Materialícese, un nivel que se corresponde con el punto en el que la derivación de una representación gramatical se divide en dos componentes, el fonético y el lógico. Así, el siguiente nivel de representación se corresponde con la Forma Lógica (FL) o aquella que recoge los aspectos lingüísticos del significado de una oración y que están conectados con el sistema conceptual-intencional; y el cuarto y último nivel es el de la Forma Fonética (FF), que es la que contiene los rasgos fonéticos que determinan la pronunciación de las estructuras gramaticales y está conectada con el sistema articulatorioperceptual (o sensorimotor).

Así pues, para crear expresiones lingüísticas que se puedan interpretar desde el punto de vista de la FF y de la FL (es decir, para que se produzca la derivación de dichas expresiones), hay que seleccionar ítems que se encuentran almacenados en el Lexicón y, tras una serie de operaciones morfológicas, se llega al nivel del Materialícese, a partir del

\footnotetext{
${ }^{1}$ En realidad, el PM (Chomsky 1993), con el fin reducir la teoría gramatical a un mínimo, habla solamente de dos niveles de representación que son necesarios desde un punto de vista conceptual (la Forma Fonética y la Forma Lógica) y considera que el Lexicón y el Materialícese son más bien niveles formales en los que se aplican una serie de operaciones. Sin embargo, en el presente trabajo no aludiremos a dicha distinción ni entraremos a describir cada una de las operaciones que tienen lugar en la derivación, por lo que hablaremos de "niveles de representación" en general.
} 
cual la derivación ha de ser interpretada tanto desde el punto de vista fonético (en el nivel de la FF) como desde el punto de vista semántico-conceptual (en el nivel de la FL) para que dicha derivación converja y no fracase.

Si consideramos que en este marco de la gramática generativa se parte del carácter universal de la facultad del lenguaje, estos niveles de representación lingüística se podrán aplicar no sólo a la descripción de la facultad del lenguaje en los hablantes monolingües sino también en los bilingües. Precisamente, de la base de esta comparación entre ambos tipos de hablantes trataremos en el siguiente apartado.

\subsection{La teoría lingüística y la adquisición del lenguaje: el hablante bilingüe frente al hablante monolingüe}

Relacionando estas cuestiones lingüísticas de carácter teórico y abstracto con el proceso de adquisición de una lengua materna, se establece que, durante dicho proceso, el individuo ha de fijar los parámetros correspondientes a la lengua que está adquiriendo según el input al que esté siendo expuesto y, más concretamente, los rasgos que definen esos parámetros y que son los elementos portadores de la información lingüística que será necesaria para la producción de enunciados por parte de un hablante.

En el caso más específico de la adquisición bilingüe, los niños tienen que fijar los parámetros según los rasgos que capten del input al que están expuestos, lo cual no significa que el proceso de adquisición bilingüe sea diferente al proceso de adquisición monolingüe. Es más, como hemos apuntado anteriormente, dentro de la teoría generativa y en estudios como el de MacSwan (2000, 2005), se propone una base teórica que da cuenta de la misma manera de la facultad del lenguaje del hablante monolingüe y del bilingüe. De esta forma, los principios que rigen el bilingüismo han de ser los mismos que los del monolingüismo $^{2}$. Concretamente, la propuesta de MacSwan (2000, 2005) es que, a diferencia de los niños monolingües que tienen un único lexicón (como hemos visto representado en el diagrama 4), los niños bilingües que se encuentran expuestos a dos lenguas desde el nacimiento tienen dos lexicones. Estos dos lexicones (uno por cada

\footnotetext{
${ }^{2}$ Este autor sale al paso de las propuestas que, para explicar la producción bilingüe en usos como el de la alternancia de códigos, recurren a reglas o principios que no son propios de las gramáticas monolingües. 
lengua) están ligados a un único sistema computacional, entendido este como el sistema de reglas con el que se organiza el lexicón y cuya función es el derivar estructuras que converjan en la FF y la FL. De esta manera, MacSwan $(2000,2005)$ representa la diferencia entre un hablante monolingüe y uno bilingüe con los diagramas 5 y 6 que aparecen a continuación:

Diagrama 5. La facultad del lenguaje monolingüe

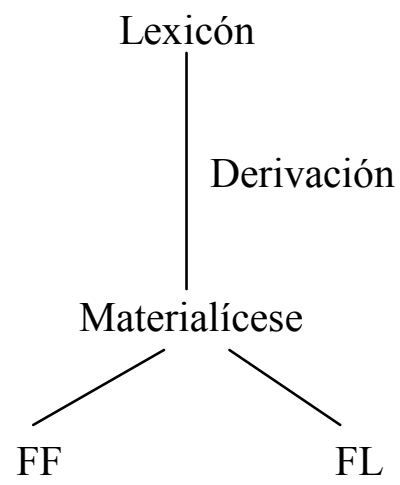

\author{
Diagrama 6. La facultad del lenguaje \\ bilingüe
}

[adaptado de MacSwan 2000: 54]

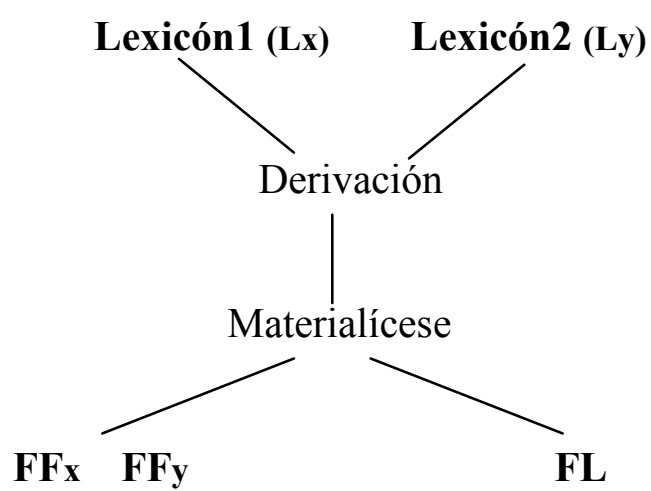

Tal y como lo representa MacSwan $(2000,2005)$ en el diagrama 6 , los hablantes bilingües disponen de una FF doble, correspondiendo una de las FF (FFx) a una de las lenguas (Lx) y la otra FF (FFy) a la otra lengua (Ly), y un solo sistema computacional ${ }^{3}$. De esta manera, ambas lenguas comparten una misma FL en la que tiene lugar la interpretación semántica, un planteamiento que resulta relevante para la propuesta que presentaremos en capítulos posteriores acerca del proceso que siguen los hablantes bilingües cuando traducen de una lengua a otra [ver el apartado 1.3.1. del capítulo 3].

Analizando la comparación entre la facultad del lenguaje monolingüe y la facultad del lenguaje bilingüe, es importante rechazar la idea de que, desde el punto de vista biológico, el ser humano está predispuesto a adquirir sólo una lengua, puesto que el adquirir más de una lengua es lo normal y habitual en nuestra sociedad actual. De esta

\footnotetext{
${ }^{3}$ Como veremos en el apartado 3 del presente trabajo, aunque MacSwan $(2000,2005)$ afirme que este sistema computacional es sólo uno y no dos para cada lengua, no hay que confundir este planteamiento con la hipótesis de que el niño bilingüe tenga en un principio un sistema lingüístico unitario. Además, hay que tener en cuenta que, según la propuesta de este autor, los rasgos se distribuyen de forma diferente en cada lexicón, de tal forma que el sistema computacional actúa de manera diferente en la materialización en cada una de las lenguas.
} 
manera, aunque en algunas referencias (Genesee 2001) aún se mencionan ciertos planteamientos de carácter neuro-cognitivo que mantienen que la facultad del lenguaje es fundamentalmente monolingüe durante las primeras etapas del desarrollo lingüístico, lo cierto es que gozan de una mayor aceptación otras perspectivas, como la de Chomsky (1981) o Meisel (2001), que se apoyan en la idea de el que un niño adquiera dos lenguas ha de verse como algo tan natural como cualquier otra capacidad innata del ser humano, es decir, como algo contingente a la facultad del lenguaje. En este sentido, la teoría lingüística debería poder dar cuenta de esta capacidad para adquirir y utilizar más de una lengua, algo que la investigación teórica y empírica se ha encargado de analizar en las últimas décadas. Este tipo de estudios se ha centrado en aspectos tales como el proceso de desarrollo de la adquisición bilingüe en niños desde su nacimiento; en el análisis de los mecanismos o los patrones de adquisición infantil que se manifiestan de forma específica en la adquisición de dos lenguas primeras (L1+L1); y en si ese proceso y esos mecanismos de adquisición son diferentes o semejantes a los característicos de los niños monolingües (Meisel 2004).

De esta manera, el planteamiento de semejanzas y diferencias entre la adquisición bilingüe y monolingüe serviría, por un lado, para reafirmar algo que se ha venido manteniendo desde los años 80 y es que un bilingüe no equivale a dos monolingües (Grosjean 1982; Romaine 1989; Hoffmann 1991; Patterson 1998) y, por otro lado, para rechazar la idea de que el bilingüismo supone una desviación de la norma que es el monolingüismo, ya que está probado que los hablantes bilingües constituyen una parte representativa de la población mundial (Cristal 1997; Tucker 1998; Genesee 2001; Genesee y Cenoz 2001; Bhatia y Ritchie 2004, entre otros).

Sin embargo, hasta hace poco no ha sido raro encontrar estudios que aludieran a los efectos negativos inherentes que suponían para un niño la adquisición y el uso de dos lenguas (como recogen, entre otros, Grosjean 1982; Malakoff 1991; Hoffmann 1991; Romaine 1999; Harmers y Blanc 2000; Baetens Beardsmore 2003): se hablaba de que podía afectar al desarrollo psicológico y cognitivo del niño, o de que podía causar un retraso, una confusión lingüística o un desarrollo incompleto de una de las dos lenguas (siempre en comparación con los monolingües que adquieren dichas lenguas). Pero lo cierto es que existen otros estudios que hablan precisamente de todo lo contrario, de las consecuencias positivas que puede traer consigo la adquisición bilingüe de primeras lenguas. Así, por ejemplo, entre otras capacidades, los bilingües toman conciencia antes que los monolingües de la naturaleza arbitraria del lenguaje (Grosjean 1982; Romaine 
1989), pueden alcanzar niveles más altos de conciencia metalingüística (Bialystok 1987, 2001) y tienen una mayor flexibilidad cognitiva (Malakoff 1991) y sociolingüística (De Houwer 1998; Harmers y Blanc 2000).

Son precisamente estos temas relacionados con los efectos psicolingüísticos y cognitivos los que ocupan la mayoría de los estudios de bilingüismo infantil, sobre todo durante los años 60 (Weinreich 1968; Mackey 1962; entre otros), aunque los pioneros en la investigación de adquisición de primeras lenguas se remontan a Ronjat (1913) y a Leopold (1939-1949). Sólo posteriormente (hacia finales de 1980), los estudios sobre bilingüismo van a prestar más atención al análisis no sólo teórico sino también empírico de cómo los niños bilingües adquieren de forma simultánea dos o más lenguas utilizando datos de producción lingüística tomados de situaciones tanto naturales como experimentales (Romaine 1989; De Houwer 1990; Meisel 1990, 1994d; Lanza 1997, 2001; Deuchar y Quay 2000, entre otros).

Es más, es a partir de ese momento cuando se toma conciencia de que, a pesar de sus características intrínsecas, si se realiza dicho análisis partiendo de pruebas de carácter experimental (Meisel 1994a) que, al mismo tiempo, tengan lugar en un contexto natural (como el familiar, por ejemplo) también puede contribuir en gran medida al estudio del desarrollo de la facultad humana del lenguaje. Concretamente, puede contribuir a la investigación de los universales en la adquisición del lenguaje (Nicoladis 2001; Genesee 2003) en los diversos niveles lingüísticos: el fonético (Paradis 1996); el léxico (Quay 1995); el sintáctico (De Houwer 1990; Meisel 1990, 1994d; Döpke 2000) y el pragmático (Genesee et al. 1995; Lanza 1997).

En el caso concreto de los aspectos relacionados con el nivel léxico y el sintáctico del proceso de adquisición, la mayoría de los estudios tienden a centrarse en el debate de si los sistemas lingüísticos están almacenados de forma conjunta o separada en la mente del niño bilingüe, así como en los efectos que este tipo de almacenamiento puede tener en la diferenciación de lenguas, tema que trataremos en el apartado que vamos a presentar a continuación. 


\section{LA ADQUISICIÓN BILINGÜE SIMULTÁNEA: LAS ETAPAS DEL DESARROLLO LINGÜÍSTICO BILINGÜE}

Al igual que sucede con la definición de bilingüismo, también existen dificultades de carácter terminológico y tipológico cuando se habla de bilingüismo infantil, aunque, en este caso, quizás las definiciones gocen de un carácter más preciso al restringirse las situaciones a casos de adquisición temprana de lenguas. De esta forma, los dos tipos de bilingüismo que se suelen asociar a la adquisición de dos lenguas por parte de niños son el bilingüismo simultáneo y el bilingüismo secuencial [ver el apartado 1.1. del presente capítulo]. Dependiendo de los autores, se establece que el bilingüismo simultáneo es aquel en el que el niño se ve expuesto regularmente a más de una lengua bien desde su nacimiento o hasta el primer mes de vida (De Houwer 1995), en el primer año (Lindholm y Padilla 1978a), al comienzo del habla (Deuchar y Quay 2000) o hasta los 3 años (McLaughlin 1978). El bilingüismo secuencial, en cambio, se daría cuando el niño adquiere una lengua segunda a partir de los 3 años (McLaughlin 1978) o desde el primer mes hasta los 2 años (De Houwer 1995). Es decir, aún no se tiene muy claro qué edad es la que marca el punto de inflexión a partir del cual podemos afirmar que estamos ante uno u otro caso de adquisición bilingüe.

En relación con el primer tipo de bilingüismo al que hemos aludido y tal y como encontramos en muchos estudios de bilingüismo (McLaughlin 1978; Fantini 1985; Grosjean 1982; Pearson y Fernández 1994; Meisel 2001; Genesee y Cenoz 2001; Comeau y Genesee 2001; Genesee 2003), adoptaremos el término adquisición bilingüe simultánea, pues es la denominación que mejor describe el tipo de adquisición en el que se centra nuestro trabajo. De esta manera, a la hora de enmarcar el presente estudio en el bilingüismo infantil y, más concretamente, en la adquisición bilingüe simultánea, tendremos en cuenta, por un lado, la competencia que tienen los niños en ambas lenguas tomando como referencia el uso que hacen de dichas lenguas en el caso concreto de las traducciones que realizan, y, por otro lado, el uso que hacen los niños de esas lenguas a lo largo de su desarrollo bilingüe y que, por tanto, estará vinculado a la edad de este tipo de hablantes.

Así pues, y con el fin de ir acotando progresivamente los temas centrales del presente estudio, pretendemos exponer a continuación una visión general de las cuestiones que muchos investigadores han planteado acerca de las diferentes etapas que se dan en el 
desarrollo lingüístico del niño bilingüe, así como la importancia e influencia que han tenido dichas cuestiones a la hora de tratar un fenómeno característico de la adquisición bilingüe como es la mezcla de lenguas.

\subsection{Las etapas del desarrollo lingüístico bilingüe}

En los estudios de adquisición bilingüe simultánea ha ocupado un lugar preponderante durante décadas la siguiente cuestión: ¿puede el niño que adquiere dos lenguas simultáneamente desde el nacimiento separar los dos sistemas lingüísticos desde el principio o desde muy temprano, sin pasar por una etapa de confusión y mezcla de las dos lenguas? Muchos han sido los autores que han argumentado sus hipótesis respecto a esta cuestión, partiendo todos en mayor o menor medida de la aportación de Volterra y Taeschner (1978) sobre las diferentes etapas dentro del desarrollo del bilingüismo y que algunos investigadores consideran que son demasiado generales (De Houwer 1995). Tomando como participantes de un estudio longitudinal a sus dos hijas bilingües alemán/italiano, (siendo el período estudiado en cada niña el que abarca la edad de 1;00 a 4;00 años), Volterra y Taeschner (1978) plantean un modelo basado en las tres etapas siguientes dentro del desarrollo lingüístico de un niño bilingüe ${ }^{4}$. Adaptaremos cada una de estas etapas a las propuestas de MacSwan (2000, 2005) sobre la facultad del lenguaje bilingüe expuesto en los diagramas 5 y 6 [ver el apartado 2.2. del presente capítulo] con el fin de observar las diferencias entre ambos modelos y de plantear posibles críticas al modelo de Volterra y Taeschner (1978).

1. Primera etapa: el niño $(1 ; 06-1 ; 11)$ tiene un único sistema léxico, sin diferenciar, en el que se incluyen palabras de ambas lenguas. En esta etapa los niños rechazan los Equivalentes de Traducción (EET) entre las lenguas. De esta manera, por ejemplo, si el niño conoce la palabra "casa", no tiene por qué utilizar el ET correspondiente en la otra lengua, "house" en este caso, para referirse a ese mismo concepto, porque, según Volterra y Taeschner (1978), el niño no parece considerar que una palabra en una lengua se corresponda de forma exacta al ET en la otra.

\footnotetext{
${ }^{4}$ Si bien Volterra y Taeschner (1978) aluden al carácter gradual de esta división en etapas sin realizar una separación estricta por edades, hemos incluido las edades aproximadas que abarcarían dichas etapas basándonos en los ejemplos que utilizan estas autoras, aunque, tal y como ya ha apuntado Meisel (1989), la división longitudinal resulta un tanto confusa, pues algunas características propias de la primera etapa aparecen en la segunda y lo mismo sucede entre la segunda y la tercera etapa.
} 
Según nuestra adaptación, si representamos lo que plantean Volterra y Taeschner (1978) siguiendo el modelo de MacSwan (2000, 2005), obtendremos el diagrama 7(a) correspondiente a esta primera etapa.

\section{Diagrama 7(a). $1^{a}$ etapa del desarrollo bilingüe}

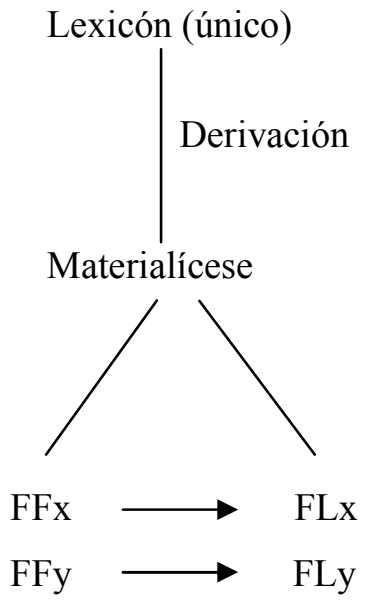

Atendiendo a este diagrama, podemos apuntar que, según Volterra y Taeschner (1978), durante la primera etapa de su desarrollo lingüístico en la que se parte de un único lexicón, el niño bilingüe, a pesar de tener un único lexicón, dispone de dos FF (una por cada lengua) y dos FL (una por cada lengua también), de ahí que no reconozca los EET como tales equivalentes conceptuales. De esta manera, si comparamos este diagrama con los mostrados en el apartado 1.2. de este capítulo acerca de la organización mental del lexicón en los hablantes bilingües, podemos establecer que en esta etapa de su desarrollo bilingüe el niño se asemeja a un bilingüe coordinado [ver el diagrama 1a de dicho apartado] en lo que respecta a las FL pero no en cuanto a las FF, ya que, a diferencia del hablante coordinado, el niño tendría los dos lexicones fusionados en uno solo.

2. Segunda etapa: el niño (2;05-3;01) distingue dos sistemas léxicos diferentes pero aplica las mismas reglas sintácticas para ambas lenguas, como le sucede a Lisa cuando produce oraciones en italiano como "grande pesciolino fa pipi" ["el grande pez hace pipí"], donde el adjetivo "grande" se encuentra delante del nombre tal y como se expresaría en alemán. Además, en esta etapa el niño bilingüe puede traducir de forma exacta de una lengua a otra, mezclar palabras de las dos lenguas en una sola oración y pasar de una lengua a otra en la misma interacción verbal. 
Si planteamos el mismo paralelismo con el modelo de MacSwan (2000, 2005), obtendremos el diagrama 7(b), en el que hemos distinguido ya dos lexicones (uno por cada lengua) pero seguimos teniendo dos FL, de tal forma que puede darse el caso de que la FF de una de las lenguas se mezcle con la FF de la otra, interpretándose cada una de ellas con su correspondiente FL y produciéndose, por tanto, una derivación con mezcla de lenguas.

\section{Diagrama 7(b). $2^{a}$ etapa del desarrollo bilingüe}

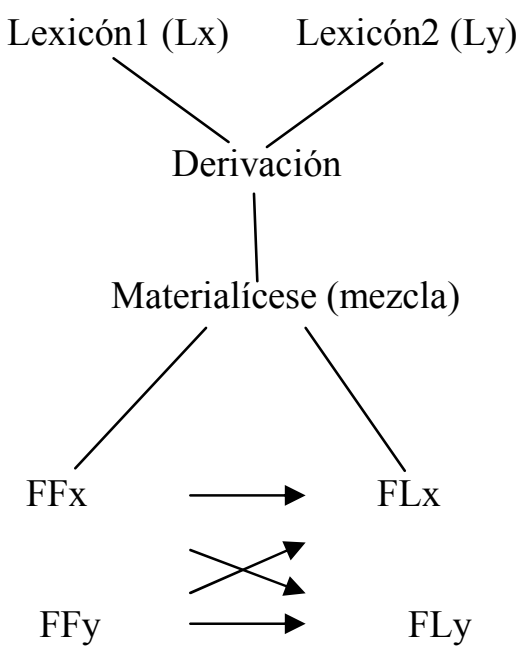

Así pues, el diagrama 7(b) se correspondería con una etapa de transición entre la fusión de los dos lexicones y la separación estricta de dichos lexicones, de tal forma que, si tenemos en cuenta la organización del lexicón expuesta en el apartado 1.2. de este capítulo, en esta segunda etapa de su desarrollo bilingüe el niño se comportaría como un bilingüe compuesto [ver el diagrama $1 \mathrm{~b}$ de dicho apartado].

3. Tercera etapa: el niño $(3 ; 01-3 ; 06)$ tiene dos sistemas lingüísticos que se diferencian tanto en el léxico como en la sintaxis. Es decir, en esta etapa es cuando se produce la diferenciación de lenguas, aunque esto no impide que durante un tiempo siga mostrando algunas interferencias entre ambas.

Según este planteamiento, la tercera etapa del desarrollo lingüístico del niño bilingüe se correspondería con una adaptación propia del modelo de MacSwan (2000, 2005) que mostramos en el diagrama 7(c). 
Diagrama 7(c). $3^{a}$ etapa del desarrollo bilingüe

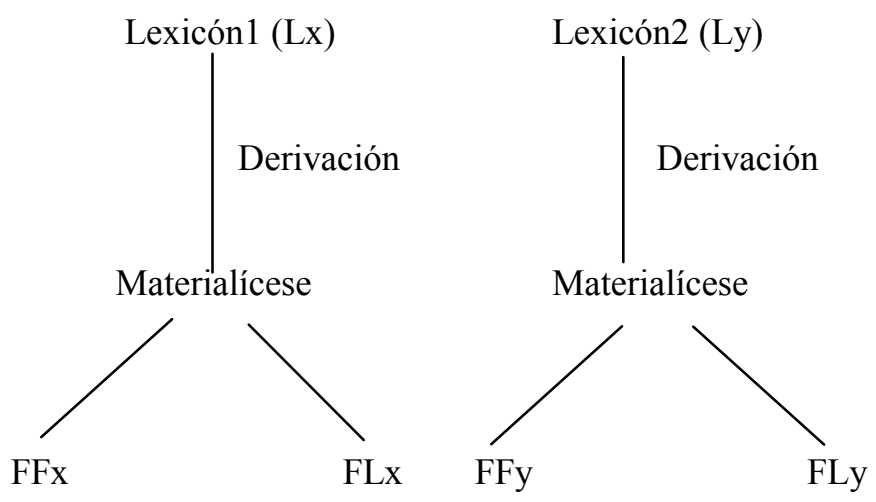

De esta manera, la tercera etapa se correspondería con la separación definitiva de los dos lexicones con sus respectivas representaciones conceptuales (similar a la situación en la que se encontrarían los bilingües coordinados en el diagrama 1a del apartado 1.2. de este capítulo), de tal forma que, según la propuesta de Volterra y Taeschner (1978), se supone que, llegados a este punto, los niños bilingües tienen la capacidad de separar los dos sistemas lingüísticos de forma estricta $y$, por tanto, de no producir casos de mezcla de lenguas. Esta situación se asemejaría, pues, a la comparación de un hablante bilingüe con la suma de dos hablantes monolingües, una concepción que iría en contra del propio modelo de MacSwan (2000, 2005) y de los argumentos de otros autores como Grosjean (1982) o Hoffmann (1991), tal y como hemos visto anteriormente en el apartado 2.2. del presente capítulo.

Mostrando el paralelismo entre la propuesta de Volterra y Taeschner (1978) y nuestra propia adaptación del modelo de la facultad bilingüe de MacSwan (2000, 2005), hemos pretendido poner de manifiesto que establecer un modelo distinto para cada una de estas etapas del desarrollo bilingüe no es adecuado ni desde el punto de vista conceptual ni desde el punto de vista metodológico. Además, tampoco consideramos adecuado plantear que los niños bilingües parten de un único lexicón y que, a medida que van desarrollando su competencia lingüística, su comportamiento es comparable al comportamiento de los bilingües compuestos y, en la etapa final, al de los bilingües coordinados. Retomaremos estas propuestas, así como nuestra postura a este respecto, en el capítulo 3 cuando expongamos las hipótesis que planteamos en el presente trabajo de investigación para, a partir de ahí, realizar en el capítulo 5 el análisis de los datos de los que disponemos, en el 
que nos dedicaremos a comprobar si los resultados de dicho análisis apoyan nuestras propuestas o, por el contrario, ratifican el planteamiento de Volterra y Taeschner (1978).

En esta línea, podemos afirmar que, a pesar de que el modelo de Volterra y Taeschner (1978) ha tenido una gran influencia en los estudios sobre bilingüismo, también ha recibido críticas, sobre todo a partir de los 90, no sólo por implicar connotaciones negativas en determinados efectos del bilingüismo (la confusión de los dos lexicones), sino también por razones metodológicas y conceptuales (Genesee 1989; Meisel 1989; De Houwer 1990; Quay 1995; Köppe 1997; MacSwan 2000). Concretamente, de estas tres etapas, la que ha recibido más críticas, análisis y argumentos a favor y en contra es la primera, sobre todo porque, si seguimos a Volterra y Taeschner (1978) y a Taeschner (1983), los niños bilingües sólo disponen de un único lexicón mezclado, es decir, pasan por una etapa de fusión de lexicones. Este tipo de planteamientos conduce a la propuesta de hipótesis como la hipótesis de la fusión de la que habla Meisel (2001) y a una serie de implicaciones relacionadas con otros fenómenos como el uso de los EET o la mezcla temprana de lenguas.

A continuación, pasaremos a analizar en mayor profundidad cada una de las etapas que plantean Volterra y Taeschner (1978), así como las diversas interpretaciones y críticas que han surgido a raíz de los argumentos expuestos para cada una de dichas etapas. Una vez hecho esto, relacionaremos estas cuestiones con el debate que gira en torno a la diferenciación de los sistemas lingüísticos y la presencia de fenómenos como la mezcla de lenguas en los niños bilingües.

\subsection{La primera etapa y los Equivalentes de Traducción (EET): el/los sistema/s léxico/s}

Según el modelo de Volterra y Taeschner (1978), en una primera etapa los niños bilingües no utilizan EET o los también denominados dobletes (palabras conocidas en ambas lenguas y que normalmente tienen el mismo significado referencial; e.g. "casa/house") porque para ellos esas palabras no se corresponden de forma exacta desde un punto de vista conceptual. Para reforzar esta idea, estas autoras recurren al trabajo de Clark (1987), quien propone el llamado principio de contraste, según el cual, en los 
primeros meses de adquisición léxica, los niños monolingües asumen que cada forma o palabra en una lengua tiene un significado distinto, de tal manera que no adquirirán palabras nuevas si su significado ya está presente en su vocabulario. En definitiva, lo que se puede desprender de la propuesta de Clark (1987) en relación al bilingüismo es que en los primeros meses del desarrollo bilingüe los EET no se encuentran disponibles.

Sin embargo, este planteamiento no ha estado exento de críticas. Así, Pearson et al. (1995) sugieren que Volterra y Taeschner (1978) parten de una prueba empírica, necesaria pero no suficiente, como es el rechazo de los EET por parte de los participantes de su estudio, para, a partir de ahí, adoptar una postura teórica, la de que los niños bilingües tienen un único sistema léxico y no dos sistemas léxicos independientes, tal y como lo hemos representado anteriormente en el diagrama 6.

Siguiendo el razonamiento de Pearson et al. (1995), también se han apuntado varias razones por las que los niños bilingües, a pesar de poseer EET, no los utilizan:

- los EET pueden resultar más difíciles desde el punto de vista fonológico, lo cual hace que el niño opte por evitar su uso. Así, por ejemplo, Celce-Murcia (1978) alude a la dificultad que tiene una niña bilingüe inglés/francés de 2;04 años para pronunciar el fonema /f/ y que hace que durante un largo período de tiempo utilice el término francés "pied" (pie) y no el término en inglés "foot”, a pesar de que los padres la corrigen repetidamente;

- el grado de conocimiento o dominio de una de las dos lenguas frente a la otra puede hacer que la producción lingüística del niño no sea equilibrada y utilice más una lengua que la otra (Pearson et al. 1995).

Por otro lado, si bien existen estudios como los de Volterra y Taeschner (1978), Taeschner (1983) o Klausen y Hayashi (1990), en los que se demuestra que los niños utilizan muy pocos EET, se dispone de estudios más actuales (Quay 1993a/b; 1995; Pearson et al. 1995; Pearson et al. 1997; Johnson y Lancaster 1998; Deuchar y Quay 2000) que utilizan una metodología diferente y que retan el planteamiento de partida de Volterra y Taeschner (1978), al demostrar que los niños de sus estudios en ningún momento rechazan los sinónimos bilingües en sus lexicones iniciales. Es más, tienen recursos léxicos desde el principio del desarrollo del lenguaje para elegir los términos en una lengua o en 
otra. Es decir, siguiendo con el ejemplo planteado anteriormente ("casa/house"), los niños bilingües conocen tanto "casa" como "house" y eligen una u otra según determinados factores de tipo pragmático (la lengua del interlocutor o de la situación comunicativa, por ejemplo) o de tipo lingüístico (un vacío léxico momentáneo, una de las palabras es la que recuerdan en un momento puntual, etc.), factores que trataremos en posteriores apartados dedicados a la competencia pragmática y gramatical de los niños bilingües [ver 5.2.2. en el presente capítulo y 1.3. en el capítulo 3].

Siguiendo con este planteamiento, Quay (1995) puntualiza que los sinónimos bilingües no tienen por qué ser sinónimos absolutos, sino palabras que tienen una referencia general y que pueden ocupar una el lugar de la otra en una amplia gama de contextos, pero no de una forma absoluta. Es decir, que el niño puede decir algo así como "la casa del rey" para referirse al castillo o al palacio del rey, de tal forma que, por ejemplo, podría utilizar como pares equivalentes "casa/palace" o "casa/castle" en lugar de "casa/house".

Por tanto, y siguiendo también el estudio de Nicoladis (1998) el uso de EET podría reflejar una diferenciación temprana en el nivel léxico en los niños bilingües. Sin embargo, otros autores como Pearson et al. (1995), aunque en un primer momento rechazan este principio de contraste de Clark (1987), posteriormente adoptan una postura intermedia sugiriendo que, si bien algunos niños parecen utilizar este principio como una estrategia y no como una restricción (como Manuela, en Deuchar y Quay 2000), otros niños, en cambio, simplemente parecen no utilizarlo (Nicoladis 1998). En lo que sí que están de acuerdo, junto con Johnson y Lancaster (1998) y Deuchar y Quay (2000), es en no considerar la presencia de dobletes como un apoyo claro a la hipótesis de una existencia temprana de un solo lexicón o dos lexicones diferenciados, puesto que, si bien la aparición de los EET es una condición necesaria, no es una condición suficiente para establecer una diferenciación léxica sino que, además, hay que demostrar que los niños saben utilizar estos EET en los contextos apropiados.

En el marco de este debate, desde la perspectiva adoptada en el presente trabajo, habría que recalcar que el que los niños bilingües utilicen EET o sinónimos no absolutos en determinados contextos supondría la existencia de un recurso del que disponen estos niños para realizar traducciones léxicas ya en una etapa temprana del desarrollo lingüístico, sin tener que esperar a etapas más tardías, tal y como se propone en el modelo de Volterra y Taeschner (1978), lo cual vendría a apoyar nuestra propuesta de que los niños bilingües 
pueden realizar, y de hecho realizan, traducciones desde etapas muy tempranas en el proceso de la adquisición bilingüe, algo que viene constatado por los datos de los dos niños bilingües de nuestro estudio (como veremos en el capítulo 4 dedicado a nuestras propuestas).

\subsection{La primera etapa y la mezcla temprana de lenguas: ¿uno o dos sistemas lingüísticos?}

También la interpretación de esta primera etapa ha sido objeto de muchas investigaciones y debates al dar por hecho que, como los niños sólo disponen de un único lexicón mezclado, es de esperar que en esta etapa del desarrollo bilingüe se dé un período inicial de mezcla de elementos de ambas lenguas (Vihman 1985), la cual irá disminuyendo según se vayan diferenciando dichas lenguas. Así, por ejemplo, el niño bilingüe estonio/inglés del estudio de Vihman (1985:303-304), en el período 1;07-2;00 años, produce enunciados con mezcla o lo que esta autora denomina "yuxtaposición de equivalentes de traducción" como los de (1).

Raivo: bilingüe estonio/inglés

(a) Raivo: see suur big.

[este grande $]_{\text {estonio }}$ grande inglés$_{\text {s }}$ ]

(b) (Raivo está buscando huevos cocidos en una sartén)

Raivo: ei ole, all gone.

[no haber $]_{\text {estonio, }}$ todo ido inglés $_{3}$

$\left(\right.$ Vihman 1985) ${ }^{5}$

Así, en una etapa inicial Raivo produce casos del tipo (1a) y (1b) en los que utiliza elementos procedentes del inglés y del estonio, los cuales, además, hacen referencia al mismo concepto y, por tanto, se trata de EET utilizados en un solo enunciado ( "suur" y "big" en (1a) y "ei ole" y "all gone" en (1b)). A medida que avanza en el desarrollo bilingüe, Raivo utilizará cada vez menos este tipo de producciones, lo cual se considerará una evidencia de que diferencia las dos lenguas.

\footnotetext{
${ }^{5}$ A partir de aquí, indicaremos la edad de los sujetos en el momento de la producción (leído como [años; meses.días]) y la fuente de cada uno de los ejemplos en la parte inferior derecha, excepto cuando los ejemplos formen parte del corpus de datos en los que se basa el presente estudio. Dicho corpus procede de los datos recopilados para un proyecto de investigación (Fernández Fuertes et al. 2002-2005).
} 
El razonamiento de Vihman (1985) llega a ser un tanto confuso pues no muestran claramente la correlación entre la proporción de enunciados con mezcla de lenguas y la separación de los sistemas lingüísticos. Así, por lo general, se dice que primero se da la mezcla de lenguas y posteriormente se produce la diferenciación lingüística (en el tercer año de vida normalmente), algo que Fantini (1985) se encarga de demostrar con su hijo Mario que deja de mezclar las lenguas hacia los 3 años, que es cuando es capaz de mantener los dos sistemas separados. Para Redlinger y Park (1980), en cambio, la disminución de enunciados mezclados se da debido a que el niño va diferenciando cada vez más las lenguas. De esta manera, no está claro cuál es la causa y cuál la consecuencia o qué sucede primero, la disminución de la mezcla de elementos de ambas lenguas o la diferenciación de dichas lenguas, algo que añade una mayor confusión a la forma en que interpretan los datos. Es algo similar a lo que apuntan Paradis y Genesee (1996) cuando sugieren que la relación que se establece entre la hipótesis de que el niño bilingüe dispone de un único sistema lingüístico y la presencia de mezcla de lenguas en su producción lingüística dependen de un razonamiento circular: una es evidencia de la otra y viceversa.

El tema de la mezcla de lenguas en este período del desarrollo bilingüe se complica aún más cuando algunos estudios (De Houwer 1990; Goodz 1994; Meisel 1990; Lanza 1992, entre otros) no han encontrado en la producción de sus sujetos evidencia de mezcla o, si la han encontrado, lo han hecho sólo en una pequeña proporción. A esto se le añaden dos cuestiones importantes cuando se profundiza en dicho tema: por un lado, la carencia de una definición y una terminología clara en lo referente a este fenómeno de mezcla en el desarrollo bilingüe, y, por otro, el hecho de que los niños siguen produciendo enunciados con mezclas y, por tanto, la aparición de este tipo de enunciados no se limita a la primera etapa, sino que también se puede dar en la segunda etapa y en la tercera (Köppe y Meisel 1995 aportan casos de mezcla funcional cuando los niños tienen sólo 3;00 años). Por este motivo, consideramos que hay que dar cuenta de la presencia de enunciados con mezcla de lenguas recurriendo a razones alternativas diferentes a la de la existencia de un único sistema (Genesee 1989; Quay 1995; Paradis y Genesee 1996; Romaine 1999; Vinagre Laranjeira 2005), tal y como plantearemos en el apartado 5 de este capítulo, dedicado al estudio de la alternancia de códigos en el bilingüismo infantil. 


\subsection{La segunda y tercera etapa: el/los sistema/s gramatical/es}

En lo que respecta a la segunda etapa, según Taeschner (1983), lo que más destaca es que en esta fase los niños ya reconocen que tratan con dos lenguas, de ahí que sólo durante este período comiencen a aprender los EET casi para cada palabra. Sin embargo, en esta etapa el problema está en que los niños bilingües, aunque sí separan los dos sistemas léxicos, no separan los dos sistemas gramaticales, de tal forma que, al igual que sucedía en la anterior etapa con los lexicones, ahora se da la fusión de los sistemas gramaticales. Como prueba de esta fusión, Volterra y Taeschner (1978) recurren a los casos de interferencia o transferencia, definida por Paradis y Genesee (1996) como la influencia de la gramática de una lengua en la gramática de la otra durante el proceso de adquisición lingüística. Según Paradis y Genesee, aunque no constatan la aparición de este tipo de producciones en los sujetos de su estudio, un supuesto caso de transferencia que podría aparecer en las producciones de un niño bilingüe inglés/francés sería el que vemos en (2), donde las propiedades gramaticales del francés en (2a) harían que el niño utilizara en inglés una forma de negación postverbal como en (2b).

(2) (a) Je ne joue ${ }_{\text {verbo }}$ pas $_{\text {negación... }}$

(b) I play not truck.

(Paradis y Genesee 1996)

De igual manera, los sujetos de nuestro estudio también producen algunos casos que podrían considerarse transferencias sintácticas como los de (3a) y (3b), donde se pone de manifiesto cómo Simon y Leo a la edad de 3;00 años utilizan determinadas propiedades de la gramática del inglés en las producciones en español, como son, en (3a) la premodificación de un nombre con genitivo sajón, y en (3b) la localización del adjetivo a la izquierda del nombre. 
(a) *SIM: $\quad+$, los tres cerditos cuento .

(b) *LEO: $\quad<\mathrm{y} y>[/]$ y vio un malo lobo que lo quiere comer $+\ldots$

Aparte de estas consideraciones sobre las transferencias, en las que no vamos a profundizar dentro de este estudio, habría que tener en cuenta que, aunque aún no se dispone de pruebas suficientes para constatar si en la producción lingüística temprana los niños cuentan un único sistema computacional o dos (Meisel 1989; Romaine 1989), existen otros estudios como los de Meisel $(1989,2001)$ en los que se ha demostrado que los niños bilingües son capaces de diferenciar los sistemas desde muy temprano, tan pronto como surgen ciertas propiedades morfosintácticas específicas de cada lengua. Es más, según Poulin-Dubois y Goodz (2001), los niños bilingües desarrollan dos conjuntos diferentes de sonidos desde muy temprano y pueden reconocerlos incluso desde la etapa del balbuceo.

Finalmente, existe un mayor consenso en lo que respecta a la tercera etapa puesto que a estas alturas del proceso se supone que el niño ya tiene un lexicón dual completo y un único sistema lingüístico, lo cual hace que evite la mezcla de lenguas y diferencie pragmáticamente las lenguas según el interlocutor, de tal forma que, con la separación definitiva de dichas lenguas y el aumento de fluidez en cada una de ellas, el niño se convertirá en un hablante con una competencia bilingüe completamente desarrollada en ambas lenguas. Sin embargo, tal y como plantearemos más adelante, no hay que olvidar que existe evidencia de que no sólo a partir de esta tercera etapa sino también en hablantes bilingües adultos se pueden dar casos de mezcla de lenguas, lo cual nos lleva a considerar que este comportamiento lingüístico puede seguir formando parte de la competencia bilingüe del hablante incluso cuando dicha competencia está plenamente desarrollada.

\footnotetext{
${ }^{6}$ Los ejemplos utilizados en este trabajo de investigación que proceden del estudio longitudinal de Fernández Fuertes et al. (2002-2005) se encuentran transcritos en CHAT, un formato de transcripción estándar que describimos en el apartado 3 del capítulo 4 .
} 


\section{LA DIFERENCIACIÓN DE LOS DOS SISTEMAS LINGÜÍSTICOS}

Atendiendo a la propuesta de Volterra y Taeschner (1978) expuesta en el anterior apartado, así como a los apoyos y a las críticas que esta ha recibido, nos encontramos con opiniones divididas en lo que respecta a la interpretación del desarrollo lingüístico del niño bilingüe simultáneo. La mayor parte de la investigación a este respecto se ha centrado en si el niño bilingüe tiene un único sistema lingüístico o dos ya desde la primera etapa de su desarrollo lingüístico. Como hemos visto previamente algunos autores (Volterra y Taeschner 1978; Taeschner 1983; entre otros) suponen que los niños bilingües pasan por una etapa en la que no pueden diferenciar sus dos lenguas, de ahí que las mezclen en determinados enunciados, lo cual se puede interpretar como una prueba de que estos niños tienen un único sistema lingüístico o un sistema lingüístico unitario. Sin embargo, también hemos aludido a autores (De Houwer 1995; Genesee 2001; entre otros) que apoyan la hipótesis contraria, argumentando que lo normal es que los niños bilingües desarrollen dos sistemas lingüísticos diferenciados desde el principio y que sean capaces de utilizar o alternar las lenguas en desarrollo con gran facilidad, atendiendo adecuadamente al contexto o a las características comunicativas de sus interlocutores.

Para analizar lo que defiende cada uno de estos dos grupos de investigadores, expondremos a continuación las dos hipótesis principales en las que basan sus argumentos, para pasar a analizar posteriormente y con mayor detalle algunas cuestiones que surgen tras el planteamiento de dichos argumentos, tales como en qué niveles lingüísticos y a qué edad se vería reflejada dicha diferenciación, y cuál es el papel que juega la mezcla de lenguas en la adquisición bilingüe ${ }^{7}$.

\footnotetext{
${ }^{7}$ Aunque estas son las dos posturas principales que se plantean con respecto a la diferenciación de los sistemas lingüísticos en los niños bilingües, podríamos aludir a un tercer planteamiento (Sankoff y Poplack 1981) que propone la existencia de una tercera gramática para los casos de mezcla de lenguas. Esta hipótesis no ha tenido mucha aceptación pues muchos autores (Woolford 1983, Toribio y Brown 1995, MacSwan 2000, 2005, entre otros) no son partidarios de crear una gramática especial, ya que lo que reflejan fenómenos como la mezcla de lenguas en los niños bilingües es el estado de desarrollo de los sistemas gramaticales que componen su bilingüismo y no una gramática diferente.
} 


\subsection{El debate de un único sistema lingüístico frente a dos sistemas lingüísticos}

En primer lugar, la llamada hipótesis del sistema lingüístico unitario (Ronjat 1913; Leopold 1939-1949; Swain 1972; Volterra y Taeschner 1978; Redlinger y Park 1980; Taeschner 1983; Vihman 1985; Saunders 1988; Arnberg y Arnberg 1992, etc.) parte de que en las primeras etapas el niño bilingüe comienza estableciendo un único sistema léxico, que estaría compuesto por elementos de las dos lenguas y que sólo posteriormente y de forma gradual (entre los 2;00 y los 3;00 años de edad) se separaría en dos sistemas, uno por cada lengua. Para probar esta hipótesis, sus defensores se basan, por un lado, en que los niños bilingües de sus estudios producen una alta proporción de mezcla de lenguas durante las primeras etapas de su desarrollo lingüístico, la cual va decreciendo paulatinamente hasta llegar a una separación de los dos sistemas; por otro lado, aluden también a que los niños, ya en la segunda etapa, utilizan EET entre las lenguas de forma indiscriminada porque perciben las palabras como sinónimos dentro de un único sistema.

Esta hipótesis, basada en los estudios de la mezcla de elementos de dos lenguas que realizan los niños bilingües, ha sido cuestionada por autores como Genesee $(1989,2001)$, Paradis y Genesee (1996) y Nicoladis y Genesee (1996), quienes consideran que dichos estudios ofrecen ejemplos anecdóticos de mezcla de lenguas, de tal forma que, al no tener en cuenta el entorno comunicativo, no consiguen demostrar si los niños mezclan las lenguas de forma indiscriminada o no en los diferentes contextos comunicativos.

En segundo lugar, la hipótesis del sistema lingüístico diferenciado (Lindholm y Padilla 1978a; Genesee 1989; Meisel 1989; De Houwer 1990; 1995; Lanza 1992, 1997; Quay 1995; Paradis y Genesee 1996; Johnson y Lancaster 1998; Wapole 2000; Sinka 2000; etc.), también llamada hipótesis de la diferenciación (Meisel 2001), parte de que los niños bilingües diferencian los dos sistemas lingüísticos en esa primera etapa y, además, utilizan dichos sistemas de acuerdo a las exigencias contextuales. Para probar esta hipótesis, consideran que es necesario analizar la mezcla de lenguas teniendo en cuenta diversos factores que pueden afectar al input del niño (por ejemplo, las estrategias discursivas de los padres cuando se comunican con sus hijos, como sugiere Lanza 1992), así como las necesidades contextuales y la sensibilidad del hablante al contexto de la interacción o a la elección de lenguas. 
Con el fin de encontrar evidencias que apoyen esta segunda hipótesis, investigadores como De Houwer (1990), Meisel (1989, 1994a/b/c/d) o Gavarró (1998; 2003) estudian esta diferenciación temprana de sistemas en el nivel gramatical, pues sus sujetos utilizan medios gramaticales diferentes para expresar lo mismo. Concretamente, Meisel (1994a), por ejemplo, recoge los trabajos de Ezeizabarrena (1994), Idiazabal (1994), Larrañaga (1994) y Mahlau (1994a/b), en los que se analizan una serie de aspectos estructurales distintos en las dos lenguas en cuestión (euskera/castellano), como la concordancia sujeto-verbo, el orden de elementos en la oración, el uso del género, etc. La conclusión a la que llegan estos estudios es que desde una edad muy temprana el niño bilingüe está desarrollando dos sistemas lingüísticos separados y que, por tanto, hay que rechazar la tesis de que los sistemas gramaticales se encuentren amalgamados o fusionados en las etapas tempranas del desarrollo bilingüe.

Una vez expuestos los planteamientos básicos de cada una de las hipótesis, consideramos necesario realizar una precisión: existen autores que no utilizan el término diferenciación en un sentido general, sino que pueden referirse a la diferenciación de las lenguas en distintos niveles como son el pragmático y el léxico. A este respecto, Nicoladis (1998) apunta que no hay que confundir la diferenciación pragmática con la diferenciación léxica (la producción de EET), que es lo que puede suceder en estudios longitudinales de niños bilingües (Lanza 1988; Genesee et al. 1995; Nicoladis y Genesee 1996; Köppe 1997; Deuchar y Quay 2000 y Quay 2001). En estos estudios se alude a la diferenciación léxica en estos niños en relación a las situaciones o a los interlocutores, evidenciando su capacidad para diferenciar las dos lenguas desde un punto de vista pragmático antes de los 2;00 años (y no sólo con sus padres sino con interlocutores que no les son familiares). Según Vihman (1985) esta sería otra capacidad de carácter psicológico o cognitivo, aunque su manifestación sea lingüística.

A pesar de estas críticas, Paradis y Genesee (1996) concluyen que, si bien la diferenciación pragmática no proporciona una evidencia directa a favor de la diferenciación léxica, resultaría difícil explicar cómo los niños bilingües pueden conseguir la separación pragmática de las lenguas en cuestión sin tener diferenciadas las representaciones de dichas lenguas. Precisamente parte de los argumentos de esta postura nos servirá en el presente trabajo para plantear que fenómenos relacionados con la mezcla de lenguas, como la alternancia de códigos (AC) o la traducción natural (TN), pueden 
verse regidos por la competencia pragmática o funcional (Genesee 2003), pero, al mismo tiempo, necesitan realizarse como competencia gramatical, cuestión que trataremos en sucesivos apartados de este y otros capítulos [ver el apartado 5 del presente capítulo; el 2 del capítulo 2 y el 1.3. del capítulo3], donde analizaremos con más detalle estos fenómenos característicos de la adquisición bilingüe simultánea.

\subsection{La diferenciación de lenguas en diversos niveles lingüísticos}

Una de las primeras cuestiones que nos surge cuando recurrimos a todas las fuentes hasta ahora mencionadas es que muchas de ellas se centran en la diferenciación en un nivel lingüístico determinado. Así, Pearson et al. (1995) o Quay (1995), entre otros, investigan la diferenciación léxica; Meisel (1989, 1994a/b/c/d), De Houwer (1990) o Paradis y Genesee $(1996,1997)$ se ocupan más del estudio de la diferenciación morfosintáctica, mientras que la diferenciación pragmática se analiza en estudios como los de Lanza (1992), Genesee et al. (1995), Nicoladis y Genesee (1996) o Genesee (2001). También sería conveniente nombrar trabajos como los de Celce-Murcia (1978), Schnitzer y Krasinski (1996), Paradis (1996), Johnson y Lancaster (1998), Gut (2000) o Bosch y Sebastián-Gallés (2001) que, aunque pocos en número en comparación con los dedicados a otros niveles de diferenciación, se han centrado en el estudio de la diferenciación fonológica.

Lo que plantean Deuchar y Quay (2000) a este respecto, y basándose en el estudio longitudinal de Manuela, una niña bilingüe inglés/español, es que la diferenciación de lenguas ocurre en momentos diferentes del desarrollo, según el aspecto lingüístico que se esté estudiando: en primer lugar, se da la diferenciación léxica (entre 1;07 y 1;08 años), a la que le sigue la morfosintáctica $(1 ; 11$ años) y sólo posteriormente (entre $1 ; 11$ y 2;03 años) aparecerá el contraste de sonidos diferentes. En este sentido, estas autoras consideran que la diferenciación se produce gradualmente, como manera de ofrecer otra alternativa a los dos sistemas iniciales que no sea la del sistema inicial unitario. Sin embargo, esta postura no queda muy clara ya que, desde el momento en el que estas autoras afirman que la diferenciación ocurre en diferentes fases del desarrollo lingüístico y que es gradual, dan por sentado que el punto de partida es un solo sistema lingüístico.

En esta misma línea se encuentran también los estudios de otros autores como el de Nicoladis (1998), quien plantea que la aparición de los EET es el primer paso para la 
diferenciación de lenguas, siendo posterior la diferenciación sintáctica. Meisel (1989, 1990), en cambio, considera que la diferenciación lingüística viene provocada por el desarrollo sintáctico, mientras que para Van der Linden (2000) la diferenciación no es simultánea en todos los ámbitos lingüísticos, de tal forma que la diferenciación pragmática y léxica es anterior a la sintáctica (hacia los 2;07 años en Anouk, la niña de su estudio). Otros autores, desde la perspectiva del PM como Gavarró (2003) y MacSwan (2000, 2005), plantean que la diferenciación de lenguas supone simplemente el dominio de sistemas fonológicos diferentes, así como el dominio de los elementos léxicos de las dos lenguas, sin aludir a la diferenciación sintáctica, lo cual va en concordancia con lo que planteábamos en el apartado 2.2.

\section{3. ¿A qué edad se produce la diferenciación de lenguas?}

Otra cuestión que nos surge tras el análisis de estas fuentes es que los defensores de la hipótesis del sistema lingüístico diferenciado hablan de una diferenciación de lenguas desde el comienzo de la producción del habla o al menos a partir de la etapa de una sola palabra, pero ¿qué sucede en la etapa anterior, cuando el niño tiene menos de dos años? Si se plantea que desde el comienzo de su desarrollo bilingüe el niño diferencia los dos sistemas lingüísticos, tendríamos que plantearnos entonces si esa diferenciación se da desde el comienzo de la producción del habla o desde la primera etapa de adquisición. En este sentido, las siguientes cuestiones que se plantearían serían qué es lo que sucede en una etapa anterior a la producción del habla y en qué momento se puede constatar dicha diferenciación desde el punto de vista de la producción lingüística.

A este respecto, Quay (1995) afirma que no se puede utilizar la elección de lenguas en las etapas más tempranas del desarrollo lingüístico (antes de los 2;00 años de edad o durante lo que ella denomina etapa pre-sintáctica de una palabra) como evidencia directa de la separación de lenguas porque es posible que el niño bilingüe carezca de recursos léxicos para realizar dicha elección. Sin embargo, según Genesee (2001), los niños que se ven expuestos a dos lenguas desde el nacimiento poseen la capacidad de diferenciar desde un punto de vista cognitivo-perceptivo los sistemas lingüísticos, algo que constituiría un requisito previo para establecer posteriores representaciones diferenciadas de dichos sistemas. 
Al hilo de lo planteado por Genesee (2001), habría que tener en cuenta si en esa diferenciación inicial tiene alguna influencia el que los niños se desarrollen en un contexto de una persona-una lengua (Ronjat 1913), en el que cada uno de los padres se dirige al niño en su lengua materna [ver el apartado 2.3.2. del capítulo 3]. De hecho, según apuntan Deuchar y Quay (2000), a pesar de que los padres sigan esta estrategia, es posible que exista un desequilibrio de lenguas en el input que reciben los niños y que dicha diferenciación no dependa de la asociación de una lengua a una persona.

Sobre este tema aún no existen muchos estudios experimentales que evidencien el dominio de lenguas en una etapa tan temprana como pueden ser los primeros meses de vida o que muestren el proceso de percepción de bebés expuestos a dos lenguas simultáneamente durante la etapa pre-lingüística (Bosch y Sebastián-Gallés 2001). Sin embargo, estudios sobre la percepción del habla durante la etapa de balbuceo de niños potencialmente bilingües, como los de Oller et al. (1997), Pearson (1998), Poulin-Dubois y Goodz (2001), entre otros, establecen como conclusión (aunque con mucha cautela) que, al igual que los niños monolingües parecen distinguir su lengua nativa de una lengua extranjera, los niños bilingües parecen diferenciar las dos lenguas nativas a las que se encuentran expuestos, atendiendo a determinadas características fonéticas y prosódicas de dichas lenguas. Esta conclusión, a su vez, sirve de apoyo a la hipótesis de que los niños bilingües desarrollan sistemas lingüísticos diferentes en una etapa anterior a la producción lingüística, frente a aquellos que argumentan que los niños bilingües son como los monolingües inicialmente y que el bilingüismo como tal no emerge hasta más tarde (hacia los 3;00 años), basando esta hipótesis en la mezcla de lenguas que utilizan los niños bilingües durante las primeras etapas de producción lingüística. Sin embargo, en el siguiente apartado y en otros posteriores [ver 5.2.] aludiremos a cómo los partidarios de la hipótesis contraria, la del sistema lingüístico diferenciado, recurren a otras planteamientos para explicar la aparición de la AC como un fenómeno característico de la producción lingüística de un niño bilingüe. 


\subsection{La mezcla de lenguas a partir de la diferenciación de los sistemas lingüísticos}

La última cuestión que nos interesa tratar tras los planteamientos presentados en los apartados previos es cómo la teoría lingüística puede explicar, una vez que el niño (y el adulto) bilingüe ha diferenciado los sistemas lingüísticos (según la hipótesis del sistema lingüístico unitario) o cuando tiene los dos sistemas diferenciados desde el principio (según la hipótesis del sistema lingüístico diferenciado), por qué sigue recurriendo a enunciados mezclados. Tal es el caso de los sujetos de nuestro estudio cuando producen ejemplos como los de (4), donde Leo introduce palabras del inglés (marcadas como @en) dentro de contextos cuya lengua matriz es el español.

\section{Leo: bilingüe inglés/español}

(a)*LEO: yo tengo comida en mi bottle@en, eh@i ?

(b)*LEO: yo quiero ver ogres@en a ver .

Existen varios tipos de explicaciones para este fenómeno en ese momento del desarrollo bilingüe. Así, si bien Volterra y Taeschner (1978) no hablan exactamente de la presencia de enunciados mezclados en la tercera etapa del desarrollo bilingüe sino de interferencias sintácticas, las justifican diciendo que, aunque el niño intenta mantener los sistemas lingüísticos separados tanto como sea posible, el proceso hasta llegar a una separación completa es difícil y a veces el niño se encuentra en situaciones de conflicto que pueden dar lugar a que surjan interferencias (como cuando ha de cambiar de lenguas rápidamente para comunicarse con personas que hablan lenguas diferentes, por ejemplo). En cambio, Genesee (1989) afirma que, aunque el niño bilingüe es capaz de diferenciar los sistemas lingüísticos desde el principio, hay que prestar atención al papel del input que reciben estos niños (aunque de esto no hay una evidencia sistemática), pues los padres pueden utilizar enunciados mezclados que constituyan una posible fuente de influencia en la mezcla que siguen produciendo los niños.

A este respecto, lo cierto es que en la actualidad la diferenciación temprana o la hipótesis de la diferenciación es la hipótesis que más aceptación tiene entre los estudios de bilingüismo (Gawlitzek-Maiwald y Tracy 1996; Paradis y Genesee 1996; Schelletter 2000; Döpke 1998, 2000; entre otros), los cuales argumentan, sin profundizar mucho más en el tema, que es de esperar que exista algún grado de contacto o interacción entre las lenguas 
que se desarrollan en los niños bilingües. De hecho, según Gawlitzek-Maiwald y Tracy (1996) es este grado de contacto entre las gramáticas participantes el que explica la presencia de enunciados mezclados en la producción lingüística del niño bilingüe, aunque, según Paradis y Genesee (1996), esta presencia tampoco implica necesariamente que exista una interacción sistemática entre las dos lenguas en el nivel de la competencia, ya que pueden influir otros factores como el input que reciban los niños o el predominio de una de las lenguas (Döpke 1998, 2000).

Al hilo de este razonamiento, se va a hablar de dos variantes dentro de la hipótesis de la diferenciación. En la primera de ellas, la llamada hipótesis del desarrollo interdependiente (Cummins 1979), se argumenta que una de las lenguas sirve de guía al desarrollo de la otra, de tal forma que se dará la influencia sistemática de la gramática de una lengua en la gramática de la otra durante el proceso de adquisición bilingüe. En este sentido, los patrones de desarrollo de la adquisición bilingüe son diferentes de los de la adquisición monolingüe. La segunda, denominada hipótesis del desarrollo autónomo (Paradis y Genesee 1996, 1997; Meisel 2001, entre otros), se basa en que los patrones de adquisición de cada lengua son los mismos que los que guían la adquisición de las mismas lenguas en los niños monolingües, de tal forma que ninguna de las dos lenguas influirá en la gramática de la otra durante el proceso de adquisición y los dos sistemas se diferenciarán tan pronto como los niños tengan acceso al sistema gramatical.

La primera hipótesis podría implicar, por un lado, que una de las lenguas es la lengua dominante (Petersen 1988) y, por otro, que el desarrollo lingüístico puede resultar más lento o más acelerado dependiendo de las propiedades estructurales de las lenguas implicadas, algo a lo que ya han aludido algunos estudios (Meisel 1989; De Houwer 1990; Paradis y Genesee 1996; Juan-Garau y Pérez-Vidal 2001). En cambio, la hipótesis del desarrollo autónomo en la diferenciación gramatical indicaría que el desarrollo bilingüe es semejante al desarrollo lingüístico monolingüe, una postura semejante a la que plantea MacSwan $(2000,2005)$ y que hemos expuesto en el apartado 2.2. del presente capítulo. Además, esta segunda hipótesis no excluye que se produzcan casos de enunciados mezclados, transferencias o incorporaciones sistemáticas de una propiedad lingüística de una lengua en la otra, en cuyo caso, se suele aludir a que determinados aspectos gramaticales, según la terminología chomskiana, son más vulnerables que otros. 
Tanto este tema de la diferenciación de los sistemas lingüísticos como la postura que vamos a adoptar en el marco teórico en el que incluimos el presente trabajo serán las cuestiones que presentemos el siguiente apartado. De esta forma, estas dos cuestiones constituyen la base teórica que nos lleva a explicar la mezcla de temprana de lenguas, la cual vamos a tratar en el apartado 5.2. cuando estudiemos en mayor profundidad la AC en el discurso bilingüe infantil.

\subsection{La diferenciación de los sistemas lingüísticos y los fenómenos característicos de la adquisición bilingüe simultánea: la alternancia de códigos y la traducción natural}

Una vez expuesta la mayor parte de los argumentos en los que se basan las dos hipótesis del desarrollo bilingüe (la del sistema unitario y la del sistema lingüístico diferenciado), así como algunas de las cuestiones que pueden surgir a partir de dichos argumentos, consideramos conveniente plantear la postura que vamos a adoptar a este respecto en el presente trabajo.

En primer lugar, pretendemos apoyar la hipótesis de la diferenciación con el análisis de los datos de los que disponemos, aunque no nos centraremos en el debate de un solo sistema unitario frente a dos sistemas separados, sino que partiendo del análisis de determinados fenómenos característicos de la adquisición bilingüe como son la AC y, sobre todo, la TN, observaremos la separación temprana de las lenguas en los niños bilingües del estudio longitudinal (Fernández Fuertes et al. 2002-2005) del que hemos seleccionado nuestros datos. De hecho, el carácter de fenómenos como el de la TN en niños bilingües nos permitirá reflejar la existencia de la diferenciación de lenguas, tanto en el nivel pragmático como en el nivel morfosintáctico.

Finalmente, nos gustaría precisar que, si bien los datos longitudinales del proyecto (Fernández Fuertes et al. 2002-2005), de donde procede la selección de los datos del presente estudio, comenzaron a recogerse cuando los niños tenían 1;01 años de edad, su producción lingüística es escasa hasta los 2;00 años aproximadamente, de ahí que no podamos abordar la cuestión de si los sistemas lingüísticos ya están diferenciados desde el primer año de vida. Sin embargo, lo que sí podemos plantear es que habría que proporcionar una explicación diferente a la de la falta de diferenciación de lenguas para justificar la presencia de casos de TN y de AC como los de (5) y de (6), respectivamente. 
*MEL:you want the water?

*LEO: uh@i .

*MEL: can you say water?

*MEL: [\% holding up the cup of water] what is this ?

*LEO: [\% reaching for the cup] ah@i !

*MEL:water?

*LEO: ah@i [\% getting frustrated] !

\%com: Melanie puts the cup on Leo's tray

*MEL:mommy's going to take this zucchini away, ok [\% taking the zucchini off Simon's tray] ?

*LEO: awa@sp [: agua] .

(6) Leo: bilingüe inglés/español

(a)*MEL: owie@i, he got an owie@i .

*LEO: owie@i allí@sp .

(b) *LEO: and what (i)s el@sp sea in Spanish ?

Así, habrá que encontrar motivos por los cuales, por un lado, el primer caso de TN recogido en nuestros datos aparezca a la edad de 1;02, subrayado en (5), donde Leo, ante la necesidad de beber agua, opta por utilizar el equivalente de traducción de "water" en español, "agua"; y, por otro lado, los motivos por los que el primer caso espontáneo de $\mathrm{AC}$ se produzca cuando tienen 1;11 y el último cuando tienen 6;03 años, casos que aparecen en $(6 a)$ y $(6 b)$ respectivamente, donde en un contexto inglés utilizan términos en españolmarcados como@sp 8 .

De esta manera, la interacción entre las lenguas podrá observarse tanto en fenómenos como la mezcla o la AC de (6), que es el punto de partida de diversos estudios sobre bilingüismo infantil (Lanza 1997, 2000; Genesee 2001; Grosjean 2001; Genesee 2003, entre otros), como en la TN de (5), que no ha recibido tanta atención por parte de los investigadores del bilingüismo como fenómeno con entidad propia (Grosjean 1982; Bialystok 1991; Comeau y Genesee 2001), pero que constituye el pilar temático del presente estudio y cuyo análisis contribuye a la caracterización del bilingüismo y al debate de un sistema frente a dos sistemas lingüísticos.

\footnotetext{
${ }^{8}$ Como veremos en el apartado 4 del capítulo 4, los ejemplos (5) y (6a) no se incluirán en los datos a analizar, ya que hemos establecido que la etapa inicial de desarrollo lingüístico de nuestros sujetos de la que hemos partido este estudio (2;00 años) es un poco más tardía que lo que se ha venido estableciendo en la bibliografía sobre el tema.
} 
Como conclusión general a lo planteado en este apartado, consideramos que lo que hacen los niños bilingües desde edades muy tempranas no es sólo mezclar las lenguas sino también separarlas, lo cual sirve de respaldo a la diferenciación temprana de los dos sistemas lingüísticos. De hecho, si prestamos atención a los últimos ejemplos utilizados en (5) y (6), se puede observar que los niños de nuestro estudio producen antes un caso de TN (concretamente a los 1;02 años) que de AC (a los 1;11 años).

Al mismo tiempo, esto nos lleva a plantear que uno de los objetivos principales de nuestra investigación es el de analizar cómo interactúan las lenguas a lo largo del proceso de adquisición y qué uso hace de ellas el niño bilingüe. Por este motivo, tanto el fenómeno de la AC como el de la TN, del que nos ocuparemos en detalle en posteriores apartados, hay que tenerlos en cuenta como fenómenos característicos del proceso de adquisición bilingüe simultánea. Para ello, en los apartados siguientes, trataremos, en un primer momento, de acercarnos al tema de la mezcla de lenguas en general planteando las dificultades terminológicas y de tipología que surgen alrededor de los fenómenos relacionados con la mezcla de lenguas (alternancia de códigos, mezcla de códigos, cambio de códigos, préstamos, etc.) para, finalmente, ubicar en los estudios de adquisición bilingüe simultánea la TN que realizan los niños bilingües. 


\section{LA MEZCLA DE LENGUAS: LA ALTERNANCIA DE CÓdIGOS EN LOS NIÑOS BILINGÜES}

Uno de los fenómenos característicos del comportamiento lingüístico de los niños bilingües es el uso de la mezcla de lenguas, siendo los ejemplos (7) y (8) dos de los varios casos posibles de AC procedentes del corpus de datos del estudio longitudinal del que partimos.

\section{Leo: bilingüe inglés/español}

*LEO: quiero@sp see Sesame Stweet [: Street] .

\section{Leo: bilingüe inglés/español}

*LEO: y entonses [: entonces] comió esto y esto y esto y [/] y metió dos patas aquí <y y> [/] y mhm@i < he knock on the door $>$ [@en] [\% golpea el libro como si llamara a la puerta].

$[3 ; 00.24]$

En estos ejemplos podemos observar cómo Leo tanto cuando utiliza el inglés en (7), donde el contexto en el que se incluye la grabación es inglés, como cuando utiliza el español en (8), donde el contexto de grabación es español, puede alternar los códigos en diferentes niveles lingüísticos introduciendo elementos procedentes de la otra lengua (el español y el inglés, respectivamente).

El primer problema al que nos enfrentamos a la hora de definir lo que se entiende por mezcla de lenguas es que se suele utilizar de forma intercambiable con el término alternancia de códigos, la cual, según Milroy y Muysken (1995: 7) se refiere al "alternative use by bilinguals of two or more languages in the same conversation", tal y como hemos visto reflejado en los casos de (7) y (8).

Al mismo tiempo, la dificultad aumenta cuando nos topamos con una gran cantidad de distinciones y denominaciones dentro de los estudios dedicados a este tema. Es más, es posible que debido a que se trata de un fenómeno más complejo de lo que se pudiera pensar en un primer acercamiento, no exista un consenso en lo que a una definición unitaria se refiere.

De este modo, los apartados siguientes dedicados a la mezcla de lenguas en general y a la AC en particular están organizados en torno a dos ideas fundamentales. En primer lugar, aludiremos a las cuestiones terminológicas y tipológicas que tan problemáticas 
pueden resultar cuando nos adentramos en la investigación de este fenómeno, poniendo de relieve la distinción entre la $\mathrm{AC}$ que realizan los niños bilingües y la que realizan los adultos bilingües, $y$, en segundo lugar, plantearemos los diferentes enfoques (el gramatical y el pragmático) que se pueden adoptar cuando se pretende analizar con mayor detalle la AC desde un punto de vista lingüístico.

\subsection{Consideraciones terminológicas y tipológicas}

Partiendo de la definición de Milroy y Muysken (1995), la AC puede referirse a la alternancia que realizan todo tipo de bilingües dentro de cualquier nivel lingüístico (fonológico, léxico, oracional, discursivo, pragmático, etc.) que forme parte de una conversación. En este sentido, podríamos encontrar tantas definiciones como tipos de bilingüismo en los que se hace uso de este fenómeno y, al mismo tiempo, tipos diferentes de alternancia dependiendo del nivel lingüístico que se analice y del enfoque desde el que queramos plantear dicho análisis.

Por este motivo, y en primer lugar, al igual que sucedía con el término bilingüismo [ver el apartado 1 del presente capítulo], cuando nos referimos concretamente al fenómeno de la $\mathrm{AC}$, encontramos definiciones que aluden, o bien al uso alternado de dos lenguas ya adquiridas (Mackey 1962; Haugen 1969; Grosjean 1982; De Houwer 1995; Milroy y Muysken 1995), o bien a una interacción entre dos lenguas resultante del proceso de adquisición de la competencia bilingüe (Genesee 1989; Romaine 1989; Meisel 1989), una interacción que, a su vez, consistiría en la combinación de elementos procedentes de dichas lenguas en un fragmento del discurso (un enunciado o una conversación).

En segundo lugar, los investigadores no se suelen poner de acuerdo en lo que respecta al término que hay que utilizar para referirse a este fenómeno de contacto de lenguas (Grosjean 1997, 2001). Así, algunos autores (Burling 1978; Haugen 1969; Grosjean 1982; Poplack 1980, 1981; Vihman 1985; Petersen 1988; Meisel 1989; Romaine 1989; De Houwer 1995; Genesee 2003) prefieren utilizar de forma intercambiable los términos alternancia de códigos y cambio de códigos (o alternancia de lenguas y cambio de lenguas) y otros (Celce-Murcia 1978; Redlinger y Park 1980; Sridhar y Sridhar 1980) optan por referirse a la mezcla de códigos o la mezcla de lenguas. 
A pesar de esta variedad de términos para referirse a veces a un mismo fenómeno, creemos que es conveniente apuntar que, si bien es corriente encontrar el uso intercambiable de los términos alternancia de códigos y mezcla de lenguas, muchos investigadores establecen una diferenciación entre ambos (Lindholm y Padilla 1978b; Lanza 1992, 1997; Meisel 1994a; Köppe y Meisel 1995). Por este motivo, a continuación, expondremos diversas definiciones y clasificaciones relacionadas con los fenómenos característicos de la mezcla de lenguas (especialmente en lo que respecta a su uso en los niños bilingües) y que serán las que tomemos como referencia a la hora de proponer nuestra propia clasificación en el apartado 1.1. del capítulo 3.

\subsubsection{La mezcla de lenguas: terminologías y tipologías}

Por lo general, el término mezcla de lenguas abarca cualquier comportamiento lingüístico que contiene enunciados con elementos de lenguas diferentes (Di Sciullo et al. 1986). Sin embargo, otros autores como Lindholm y Padilla (1978b) le dan a este término otra denominación y prefieren hablar de interacción o interferencia lingüistica para englobar todos esos tipos de enunciados. Así, como se puede observar en el diagrama 8, Lindholm y Padilla (1978b) consideran que este tipo de interacciones lingüísticas incluyen, a su vez, otros tres tipos.

Diagrama 8. La tipología y terminología de la mezcla de lenguas

(Lindholm y Padilla 1978b)

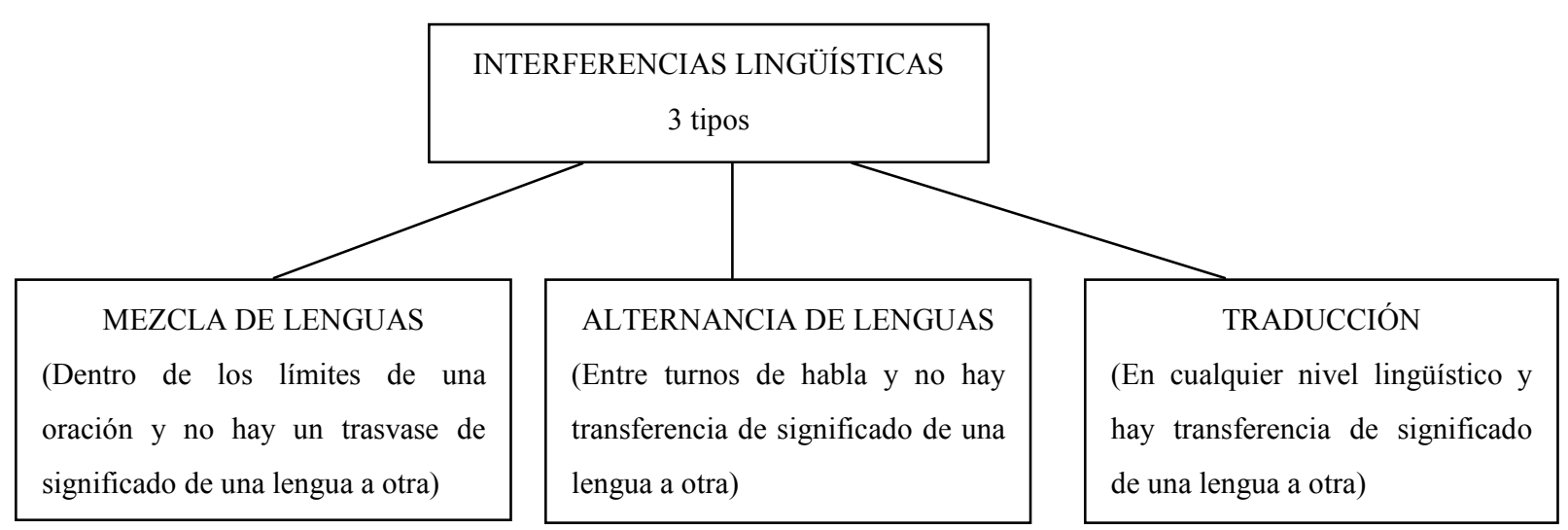

Según Lindholm y Padilla (1978b), la mezcla de lenguas tiene lugar dentro de los límites de una oración y cuando no existe un trasvase de significado de una lengua a otra, como en (9a), donde la mezcla de lenguas aparece en el nivel léxico (el determinante 
español va seguido de un nombre en inglés), o en (9b), donde la mezcla tiene lugar entre la cláusula principal y la subordinada.

(9) Niño bilingüe inglés/español

(a) Este es un fireman

(b) It was walking up pero salió, ¿verdad Mami?

(Lindholm y Padilla 1978b)

En el segundo tipo, la alternancia de lenguas, tampoco existe un trasvase de información de una lengua a otra y tiene lugar entre un turno de habla de un interlocutor que utiliza una lengua y el turno de habla siguiente en el que hay un cambio de lengua. Tal es el caso de (9c), donde la investigadora monolingüe de español le formula una pregunta al niño en español y este le responde en inglés y, por tanto, con una alternancia de lengua.

(9) (c) Investigador: ¿Qué son estos? Niño: Parrots.

(Lindholm y Padilla 1978b)

En el tercer tipo, o traducción, Lindholm y Padilla (1978b) avanzan aún más en la distinción de fenómenos relacionados con lo que consideran que son interferencias lingüísticas, definiendo lo que sucede en el ejemplo (9d) como aquella interacción en la que se produce una transferencia de significado de una lengua a otra y que puede tener lugar en cualquier nivel lingüístico ( $\sin$ necesidad, añadimos nosotros, de que sea necesario mezclar para traducir).

(d) Niño: un clown. Investigador: ¿Eh?

Niño: un payaso.

(Lindholm y Padilla 1978b)

En el caso de la propuesta de Lanza $(1992,1997)$, como podemos ver en el diagrama 9, esta considera que en la mezcla de lenguas se incluye cualquier tipo de interacción lingüística o de contacto de lenguas en el discurso bilingüe, de tal forma que la 
AC constituye un tipo de mezcla de lenguas en el que se incluirían dos subtipos según el nivel lingüístico en el que se localiza la $\mathrm{AC}^{9}$.

Diagrama 9. La tipología y la terminología de la mezcla de lenguas

(Lanza 1992, 1997)

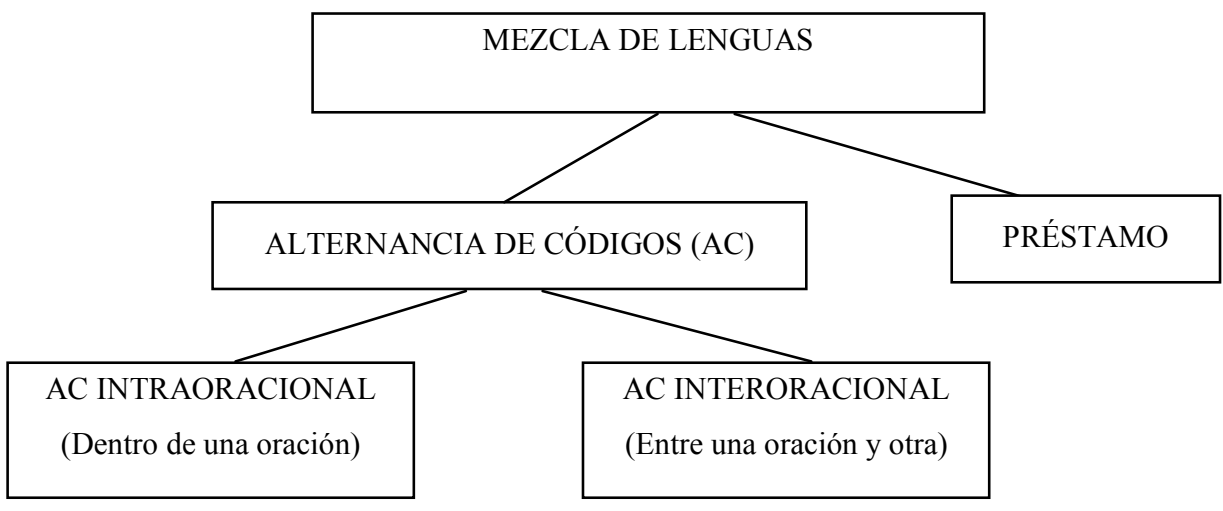

Concretamente, la AC puede ser interoracional (el uso de dos lenguas entre una oración y otra), como en el ejemplo (10a), o intra-oracional (el uso de dos lenguas en una sola oración), como en el ejemplo (10b), la cual también suele denominarse mezcla de códigos (MC de aquí en adelante) en muchos estudios de bilingüismo (Nicoladis y Genesee 1997, 1998; Nicoladis y Secco 1998; Paradis et al. 2000, entre otros ${ }^{10}$ ).

\section{Tomas y Siri: bilingües inglés/noruego}

(a) Tomas (buscando un juguete): borte. All gone?

[se ha ido] $]_{\text {noruego }}$

(b) Siri: Jeg full.

$[\text { yo }]_{\text {noruego }}$

(Lanza 1997)

También Meisel (1989, 1994a) y Köppe y Meisel (1995) incluyen bajo el epígrafe mezcla de lenguas a aquellos fenómenos relacionados con la yuxtaposición de las

\footnotetext{
${ }^{9}$ Aunque no sea este el tema que nos ocupa, aludiremos someramente a la distinción que muchos investigadores suelen hacer entre la AC y el préstamo (Pfaff 1979; Poplack 1980; Di Sciullo et al. 1986; Azuma 1993; Lanza 1993, 1997; Grosjean 1997; Köppe y Meisel 1995; Myers-Scotton 1997, entre otros). La diferencia fundamental entre ambos fenómenos lingüísticos es que mientras que el préstamo está integrado tanto morfológica como fonológicamente en la lengua que lo recibe o la lengua base, la AC no, aunque la distinción no siempre esté muy clara (Gardner-Chloros 1995).

${ }^{10}$ La propia Lanza (1997) alude a esta sinonimia que suele darse entre los términos mezcla de códigos y alternancia intraoracional, pero considera que el primero hace referencia a algo más específico [como veremos a continuación en Köppe y Meisel (1995), por ejemplo], mientras que el segundo tiene un significado más general.
} 
características gramaticales de las dos lenguas, ya sea en los límites de la cláusula o dentro de la misma. En el diagrama 10 se puede apreciar un resumen esquemático de la clasificación que proponen estos autores.

Diagrama 10. La tipología y la terminología de la mezcla de lenguas (Meisel 1989, 1994a y Köppe y Meisel 1995)

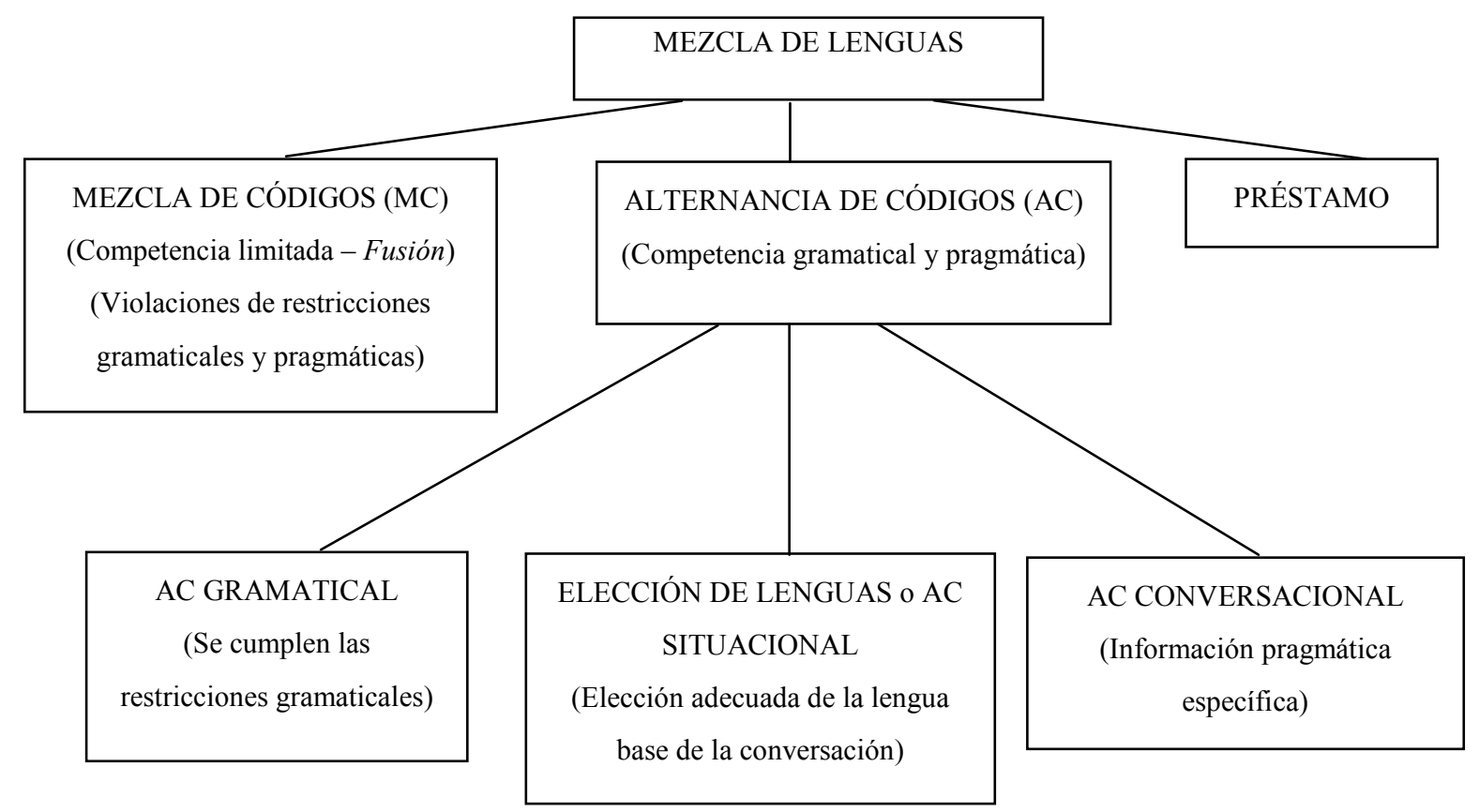

El primer fenómeno al que se refieren estos autores es lo que denominan fusión o mezcla de códigos (MC) (la integración de partes de la gramática de una de las lenguas en la otra), un tipo de mezcla de lenguas que asocian a la violación de las restricciones gramaticales y que suelen producir los niños en etapas tempranas de su desarrollo lingüístico. Este es el caso que se corresponde con el ejemplo (11), donde la forma lingüística del genitivo sajón propia del inglés se ha integrado en una estructura en francés (que carece de esta forma).

(11) Annika: bilingüe inglés/francés

Annika: ça c'est Daniel's $\underline{\text { s. }}$ [este es] francés de Daniel inglés $_{\text {] }}$

(Meisel 1994a)

Otro tipo de fenómeno lingüístico relacionado con la mezcla de lenguas que estos autores también tienen en cuenta es la $\mathrm{AC}$, la cual puede clasificarse tanto desde la 
perspectiva de la competencia gramatical como desde la de la competencia pragmática. De esta manera, y desde el primer punto de vista, Köppe y Meisel (1995) hablan de la existencia de la AC gramatical, donde, a diferencia de los casos de MC o de fusión, se respetan las restricciones gramaticales específicas. Tal es el caso del ejemplo (12), donde se respeta la llamada restricción de equivalencia (Poplack 1980), según la cual, la equivalencia de las dos lenguas que constituyen la alternancia (el francés y el alemán, en este caso) se mantiene mientras el orden de los elementos de la oración (el determinante y el nombre, en este ejemplo) no se excluya en la otra lengua ${ }^{11}$.

\section{Ivar: bilingüe alemán/francés}

Ivar: Moi je va à la küche. [yo va a la $]_{\text {francés }}$ cocina $a_{\text {alemán }}$ ]

(Köppe y Meisel 1995)

Desde el punto de vista de la competencia pragmática, la AC puede ser de dos tipos, situacional o conversacional, y se refieren al cambio de lenguas que se da según el interlocutor, el contexto situacional o el tema de la conversación, siempre y cuando no se violen restricciones gramaticales o pragmáticas concretas. Un caso de AC situacional lo mostramos en (13), donde Ivar está interactuando con un investigador alemán (A) y otro francés (F) y alterna del alemán al francés al mismo tiempo que traduce (indicado con el subrayado) con el fin de adecuarse a la lengua de cada uno de estos interlocutores.

\section{Ivar: bilingüe alemán/francés}

A: Frag sie doch mal "was ißt du denn gern?"

[¿por qué no le preguntas "qué quieres comer"?] alemán

Ivar (a F): eh, brot? Du pain? De pain?

F: Hein? Quoi?

$$
\text { [eh, ¿pan? alemán ¿pan? francés ¿pan? francés] }
$$

[¿mhm? ¿qué? $]_{\text {francés }}$

Ivar: nee n-no de pain? comme manger?

$$
\text { [¿no alemán no pan? francés } \left.¿ \text { para comer? }{ }_{\text {francés }}\right]
$$

(Köppe y Meisel 1995)

En el caso de la AC conversacional, la función pragmática que tiene la alternancia en el contexto comunicativo es distinta a la del ejemplo (13), pues el niño bilingüe la puede

\footnotetext{
${ }^{11}$ Esta y otras restricciones las comentaremos en apartados posteriores [ver 5.2.2.1. en el presente capítulo].
} 
utilizar para solicitar traducciones o para realizar comentarios metalingüísticos, como en el caso de (14), donde Annika, que suele hablar con su madre en francés, le pregunta a esta cómo se dice una palabra en alemán.

(14) Anika: bilingüe alemán/francés

Anika: mais maintenant comment ça s'appelle encore vorlesen? [pero ¿cómo se dice leer en alemán otra vez?] francés

Madre: qu'est-ce que tu veux savoir? [what do you want to know? $]_{\text {francés }}$

Anika: vorlesen.

$[\text { leer }]_{\text {alemán }}$

Madre: lire.

[leer $]_{\text {francés }}$

(Köppe y Meisel 1995)

En el caso de que se produzca una violación gramatical o pragmática estaríamos ante un caso de MC o fusión, aunque, como el propio Meisel (1989) reconoce, a veces es difícil establecer un límite claro entre este fenómeno (del que hemos mostrado un ejemplo en (11)) y lo que él denomina la AC propiamente dicha (que se corresponderían con los casos de (12)-(14)).

Por último, nos gustaría aludir a otra clasificación de la tipología de la AC que hemos incluido en el diagrama 11 y que se corresponde con la propuesta de McClure (1981). 
Diagrama 11. La terminología y la tipología de la AC

(McClure 1981)

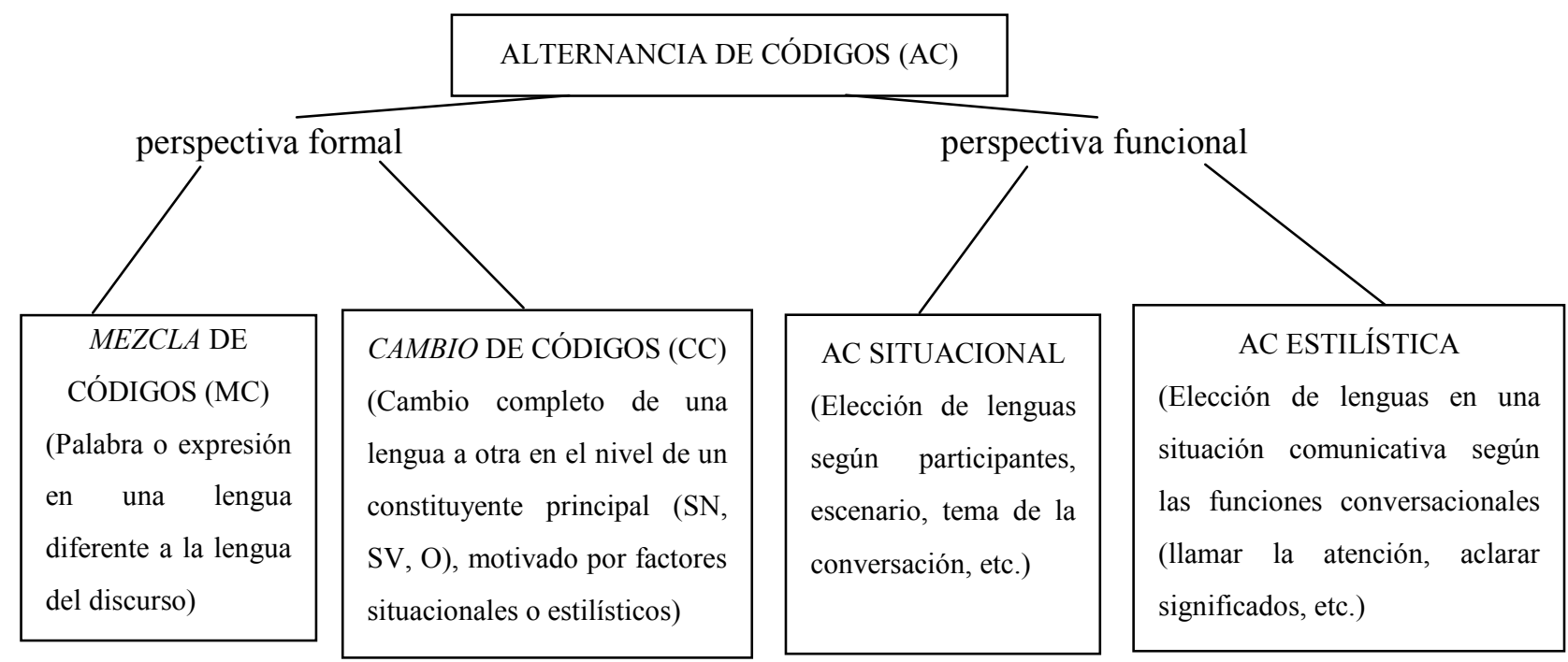

Esta autora considera que, desde un punto de vista formal, la AC puede suponer una mezcla de códigos o un cambio de códigos. La MC se corresponde con una palabra o expresión en una lengua diferente a la lengua del discurso y viene motivada por un vacío léxico o porque, en un momento dado, el hablante no puede acceder al término en la lengua para expresar lo que quiere decir, como en (15a), donde para el hablante la expresión idiomática "can't talk business" carece de un equivalente adecuado en español.

\section{(15) Adultos bilingües inglés/español}

(a) No van a aceptar una mujer que can't talk business. $\quad$ (McClure 1981)

El cambio de códigos, en cambio, supone una alternancia en el nivel de un constituyente principal (un sintagma nominal o una oración, por ejemplo), lo cual supone un cambio radical al sistema lingüístico de la otra lengua y viene motivado normalmente por factores situacionales y estilísticos. Un ejemplo sería el de (15b), en el que se ha producido un cambio de lengua en el nivel del sintagma preposicional.

(b) I put the forks en las mesas.

(McClure 1981)

Basándose en factores funcionales, McClure (1981) distingue, a su vez, entre la $A C$ situacional y la $A C$ estilística. La AC situacional es aquella elección de lenguas que se ve afectada por determinados factores situacionales como las características lingüísticas de los 
participantes, el tipo de relación que mantengan entre ellos (si son padres e hijos, por ejemplo), el escenario (dentro del hogar familiar o fuera de él), el tema de la conversación, etc. Un ejemplo de AC situacional sería el de (15c), en el que la niña (CS) cambia de código (del inglés al español) para poder formular al investigador español (Roli) la misma pregunta que le acaba de dirigir al investigador anglófono (E).

\section{Niños bilingües inglés/español}

(c) CS: I want to play checkers.

E: Ask Roli if you can.

CS: ¿Puedo jugar checkers?

(McClure 1981)

El segundo tipo, la AC estilística, es aquella que ocurre durante la misma situación comunicativa y sirve para llevar a cabo otras funciones dentro de una conversación, como enfatizar algo, especificar a qué interlocutor se dirige el hablante o aclarar un significado con una traducción, por ejemplo. Tales serían los casos de (15d), donde, con el fin de enfatizar la orden que ha dado, la niña $(\mathrm{P})$ la repite con una traducción, y de (15e), en el que el niño (R) repite en español el contenido de lo que acaba de decir en inglés, para aclararle al investigador (I) lo que le acaba de decir.

(d) Stay here Roli. ¡Te quedas aquí!

(e) I: ¿Dónde fuiste?

R: A school.

I: ¿Huh?

$\mathrm{R}: \underline{\text { A (la) escuela. }}$.

(McClure 1981)

Lo que podemos concluir de esta clasificación de McClure (1981) es que esta autora considera que la traducción que realizan los niños bilingües y la AC están relacionadas, ya que la primera se puede considerar un tipo de $\mathrm{AC}$ estilística que cumple una función comunicativa, un planteamiento que, como veremos más adelante en este capítulo y en otros posteriores, se acerca a una de las propuestas relacionadas con las características de la TN que sugerimos en este trabajo. 
Así pues, como hemos visto en distintos estudios (Lindholm y Padilla 1978b; Lanza 1992, 1997; Meisel 1989, 1994a; Köppe y Meisel 1995; McClure 1981), la AC ha sido el fenómeno más estudiado dentro de la investigación dedicada a la mezcla de lenguas. Precisamente es esta gran variedad de tipologías basadas en las diversas cuestiones relacionadas con este fenómeno lo que a veces induce a la confusión terminológica que trataremos en el capítulo dedicado a las propuestas de este estudio y que se basa en la distinción básica de tres tipos de producciones bilingües que se incluyen bajo el término general de mezcla de lenguas: el cambio de códigos (CC) (siendo un tipo la TN), la AC y otros fenómenos lingüísticos (como los préstamos, las interferencias, etc.) [ver el apartado 1.1. del capítulo 3].

Pero para poder entender mejor la propuesta terminológica que sugeriremos en posteriores capítulos, creemos conveniente prestar atención en el siguiente apartado a otro criterio de clasificación de la AC ya que, aparte de las tipologías sugeridas por distintos autores expuestas en los diagramas 8-11, también existen varios trabajos que ofrecen una tipología de la AC basándose en la unidad lingüística que constituya el enunciado en el que se incluya este fenómeno (De Houwer 1995), tal y como veremos a continuación.

\subsubsection{La unidad de análisis en los estudios de $A C$}

Una de las dificultades añadidas al investigar el tema de la $\mathrm{AC}$ es que, dependiendo de en qué unidad lingüística de análisis se localice esta producción bilingüe, podremos tener diversos tipos de AC. Sin embargo, tal y como hemos observado, los autores mencionados y los que se mencionan a continuación aluden a la aparición de este fenómeno en enunciados, conversaciones o discursos bilingües.

En este sentido, sólo Lanza (1992: 638) ofrece una definición de lo que entiende por enunciado, diciendo que "an utterance is a word or a group of words with a single intonation contour" y añadiendo que "a mixed utterance consists of a co-occurrence of both languages either within one word (...) or a group of words". Si bien esta definición resulta un poco amplia, lo cierto es que en el resto de trabajos no encontramos ninguna definición precisa de lo que entienden por enunciado o por la unidad de análisis con la que trabajan, de lo cual deducimos que dependiendo del tipo de estudio o de las unidades gramaticales que pretendan analizar, se referirán a un enunciado de una sola palabra, de varias o a enunciados dentro de toda una conversación. Así, por ejemplo, Genesee (2001) 
habla de los fragmentos de la conversación y Celce-Murcia (1978) y Genesee et al. (1995) de los enunciados de más de dos palabras.

Siguiendo estos planteamientos, pueden existir diversos análisis y tipologías de la AC atendiendo a la unidad lingüística concreta que se analice. Así, Celce-Murcia (1978) y Petersen (1988), por ejemplo, aluden a la alternancia que se da en el nivel interno de una sola palabra, como sucede en (16a) y (16b), donde mostramos algunas de las producciones de una niña bilingüe inglés/francés y de una danés/inglés incluidas en esos estudios.

(16) (a) Caroline: bilingüe inglés/francés

Caroline: piedball.

$$
\left[\text { pie }_{\text {francés }}+\text { pelota }_{\text {inglés }}=\text { fútbol }\right]
$$

(Celce-Murcia 1978)

(b) Thea: bilingüe danés/inglés

Thea: I'm laving pandekages.

$$
\text { [estoy } \text { inglés }_{\text {haci }} \text { danés }_{\text {endo }} \text { inglés } \text { crepes }_{\text {danés }} \text { ] }
$$

(Petersen 1988)

Swain y Wesche (1975), Redlinger y Park (1980), Vihman (1985) y Bhatia y Ritchie (1996a) hablan sólo de la combinación de elementos (palabras o sintagmas) de dos lenguas en una única oración, centrándose en la alternancia lingüística de carácter sintagmático, siendo dos de estos casos el de (17a), en el que Marcus, un niño bilingüe español/alemán, utiliza un sintagma preposicional en español dentro de una oración en alemán; y el de (17b), en el que aparece un caso de alternancia de verbos.

(a) Marcus: bilingüe español/alemán

Marcus: Putzen Zähne con jabón.

[se lava los dientes] $]_{\text {alemán }}$

(Redlinger y Park 1980)

(b) Adulto bilingüe inglés/hindú

merii patín saarii choose kar-egii.

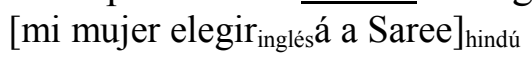

(Bhatia y Ritchie 1996a) 
Poplack (1980, 1981), Meisel (1989), Genesee et al. (1995) y Genesee (2001), entre otros, se interesan más por el análisis de este fenómeno desde el punto de vista de la longitud de la estructura lingüística en la que se incluye la AC. Así, estos autores analizan la $\mathrm{AC}$ dentro de una cláusula o entre cláusulas, como en (18a) y (18b), respectivamente.

\section{Adultos bilingües inglés/español}

(a) Vendré straight del trabajo pa'1 bloque.

(b) You didn't have to worry that somebody que te iba a tirar con cerveza o una botella o something like that.

(Poplack 1981)

Adoptando otra perspectiva, otros investigadores (Lanza, 1992, 1997; MyersScotton y Jake, 1995; Myers-Scotton, 1995; Toribio 2001; Genesee 2001; entre otros) incluyen en su estudio de la $\mathrm{AC}$ el análisis de los enunciados con mezcla que se dan dentro de una conversación, entre los que se incluirían casos de mezcla fonológica, morfosintáctica, léxica, sintáctica o discursiva ${ }^{12}$. Cada uno de estos tipos puede darse con mayor o menor frecuencia en las gramáticas en desarrollo de los niños bilingües, aunque no existe un consenso general en lo que respecta a la comparación de estos tipos de AC con la competencia bilingüe de los sujetos analizados (si son niños o adultos) (Romaine 1989).

\footnotetext{
${ }^{12}$ Una de las dificultades añadidas al investigar el tema de la $\mathrm{AC}$ es que, de todos los autores mencionados y los que se mencionan a continuación, sólo Lanza (1992) ofrece una definición de lo que entiende por enunciado [ver el principio de este apartado]. Si bien esta definición resulta un poco amplia, lo cierto es que en el resto de trabajos no encontramos ninguna definición precisa de lo que entienden por enunciado, de lo cual deducimos que dependiendo del tipo de estudio o de las unidades gramaticales que pretendan analizar, se referirán a un enunciado de una sola palabra, de varias o a enunciados dentro de toda una conversación. Así, por ejemplo, Genesee (2001) habla de los fragmentos de la conversación y Celce-Murcia (1978) y Genesee et al. (1995) hablan de las intervenciones de más de dos palabras.
} 


\subsubsection{La MC y la AC: el niño bilingüe frente al adulto bilingüe}

Dentro de la discusión sobre la terminología y la tipología relacionada con la AC, se puede aludir a otro aspecto que algunos estudios (Vihman 1985; Meisel 1994a) incluyen en la definición de este fenómeno, cuando plantean una diferenciación conceptual entre la alternancia que utilizan los niños bilingües y la que utilizan los adultos bilingües. Es decir, lo que utilizan los niños bilingües es lo que denominan mezcla de códigos, que es cualquier interacción que se produzca entre los sistemas lingüísticos en desarrollo del niño bilingüe (Genesee 1989) y que siga unos patrones diferentes a la $A C$ utilizada por los hablantes bilingües más mayores o adultos. Por tanto, según estos autores, la diferencia estribaría en el estado de la competencia bilingüe: si está en desarrollo (el niño bilingüe) o si ya está desarrollada (el adulto bilingüe). Es más, incluso en el caso de un hablante adulto bilingüe, tal y como señala Toribio (2001), el tipo de AC que realice dependerá del grado de conocimiento que este posea de las dos lenguas.

Para Meisel (1989, 1994a) y Köppe y Meisel (1995), tal y como aparece en el diagrama 10, se trataría más de una distinción formal, pues consideran que la mezcla temprana de códigos y la AC son dos fenómenos separados. Para llegar a esta conclusión se basan en que el niño en las primeras etapas del desarrollo lingüístico bilingüe tiene una competencia gramatical limitada (o fusión, según su terminología), de ahí que viole inconscientemente las restricciones gramaticales y pragmáticas que caracterizan el lenguaje adulto $\mathrm{y}$, como consecuencia, produzca inicialmente una proporción alta de mezclas que no pueden clasificarse como casos de $\mathrm{AC}^{13}$. Sólo cuando el niño aumente la competencia bilingüe, dejará de producir casos de MC (propia de los niños durante el desarrollo bilingüe) y llegará un momento en el que sólo producirá casos de AC (es decir, casos de mezcla propia de los adultos), ya que habrá adquirido un conocimiento lingüístico de ambas lenguas lo suficientemente elaborado como para respetar las reglas que rigen la AC. Sin embargo, en el presente trabajo adoptaremos el término alternancia de códigos para referirnos también a aquella que realizan los niños bilingües, pues diferimos de la postura que adoptan estos autores a este respecto al considerar que los niños bilingües no siempre violan determinadas normas lingüísticas y que, si hablamos de bilingüismo infantil, esa AC (ya sea fonológica, morfológica, léxica o sintáctica) forma parte del

\footnotetext{
${ }^{13}$ Curiosamente, Köppe y Meisel (1995) consideran que aquellos casos de AC que se realizan de forma involuntaria y que van seguidos de una autocorrección no se consideran un caso de MC, de lo que deducimos que es el carácter consciente/inconsciente o voluntario/involuntario de la producción lo que también marca una diferencia entre la $\mathrm{AC}$ y la MC. 
proceso normal del desarrollo bilingüe y de la adquisición de la competencia en más de una lengua (Romaine 1989; Liceras et al. 2005) ${ }^{14}$. Es más, si nos centramos en la distinción entre $\mathrm{AC}$ en niños frente a $\mathrm{AC}$ en adultos, en un principio, la $\mathrm{AC}$ en el bilingüismo infantil se consideraba un fenómeno de contacto de lenguas que se producía de forma indiscriminada y que reflejaba una incapacidad, por parte del niño, de desarrollar sistemas lingüísticos diferenciados. Sin embargo, existen estudios sobre la $\mathrm{AC}$ de niños bilingües (intraoracional en su gran mayoría) (Paradis et al. 2000; Lanza 1997; Vihman 1998; Genesee 2001) en los que se llega a la conclusión de que dicha alternancia, lejos de ser casual o aleatoria, se encuentra regida por una serie de operaciones o reglas gramaticales específicas y por los principios gramaticales de las lenguas participantes (Poplack 1980; Woolford 1983; Joshi 1985; Belazi et al. 1994; Myers-Scotton 1997; Meisel 2001; Genesee 2003; Liceras et al. 2003; Liceras y Fuertes 2005; Liceras et al. 2005; Fernández Fuertes, Álvarez de la Fuente y Liceras (en prensa), etc.), algo que trataremos en los apartados siguientes.

\section{2. ¿Cómo dar cuenta de la mezcla de lenguas en el discurso infantil?}

Dentro de este apartado presentaremos las líneas generales de investigación que se han seguido para intentar explicar el fenómeno de la mezcla de lenguas en la adquisición bilingüe, concretamente de la $\mathrm{AC}$, para lo cual, aludiremos a los dos enfoques principales en los que se ha centrado dicha investigación: el gramatical y el pragmático.

Con este fin, expondremos los distintos criterios que han adoptado cada uno de esos enfoques para analizar la $\mathrm{AC}$, así como las restricciones, tanto gramaticales como pragmáticas, por las que se rige este fenómeno y su importancia a la hora de evidenciar la separación de los sistemas lingüísticos en los niños bilingües de la que hemos tratado en el apartado 4 de este capítulo.

\footnotetext{
${ }^{14}$ Actualmente, aún existe un debate sobre si la gramática infantil es idéntica a la del adulto desde el principio o, en cambio, algunos aspectos de la adquisición del lenguaje necesitan madurar. La primera postura es defendida por la llamada hipótesis de la continuidad fuerte o adquisición instantánea (Chomsky 1986, 1993; Pollock 1989; Jakubowicz 1992) y la segunda por la hipótesis de la maduración o de la continuidad débil (Borer y Wexler 1987; Radford 1990).
} 


\subsubsection{La AC: líneas generales de investigación en la explicación del fenómeno}

Si tenemos en cuenta algunas referencias clásicas sobre el tema del bilingüismo, no es difícil observar la actitud negativa que ha existido hacia este fenómeno, tal y como demuestra lo que decía Goodenough (1926: 393) cuando afirmaba que "the use of a foreign language in the home is one of the chief factors in producing mental retardation". Igualmente, Haugen (1969), Mackey (1962) o Clyne (1987), entre otros, se referían a la $\mathrm{AC}$ en general (la producida por niños y la producida por adultos) como un caso de interferencia o transferencia en el que se utiliza, inadecuadamente, un elemento o rasgo de una lengua en la otra. Posteriormente, sobre todo hasta finales de la década de 1980, y atendiendo a los argumentos planteados en el apartado anterior con respecto al incumplimiento de normas lingüísticas por parte de niños bilingües (Meisel 1989, 1994a; Köppe y Meisel 1995), no es extraño que en determinados estudios (especialmente los que apoyan la hipótesis del sistema lingüístico unitario) a veces se adopte la perspectiva de que la AC producida por los niños bilingües es fruto de un error, de una falta de competencia en una de las dos lenguas, de una confusión de los sistemas lingüísticos, o de una desviación de la norma de uso de una de las lenguas. Esta postura en general la resumen Genesee et al. (2004: 108) cuando dicen que "a commonly held perception of codemixing is that it is a 'bastardized' (ungrammatical) form of language". Sin embargo, en la actualidad es más corriente encontrar estudios que aluden a la existencia de factores determinantes en el uso de la $\mathrm{AC}$ en niños y en adultos (una necesidad comunicativa, la dominancia de una de las lenguas, el papel del input, etc.) o de diversas razones alternativas a la ausencia de diferenciación lingüística que pueden explicar la presencia y los patrones de funcionamiento de este fenómeno en el habla tanto en uno como en otro tipo de hablantes bilingües. Así, existen diversos estudios que justifican la presencia de este fenómeno en ambos grupos de hablantes sin adoptar una perspectiva negativa de su uso, como Genesee et al. (2004: 133), quienes afirman que no es "a signal in and of itself that an L2 child is confused or impaired in any way", una actitud semejante a la que vamos a presentar a continuación.

El primer argumento que se suele esgrimir (Grosjean 1982; Soares y Grosjean 1984; Goodz 1994; De Houwer 1995; Quay 1995; Genesee et al 1995; Paradis y Genesee 1996; Nicoladis y Genesee 1996; Romaine 1999; Deuchar y Quay 2000; Genesee 1989, 2001) es el de que el hablante bilingüe, ante una necesidad lingüística o un vacío léxico 
momentáneo, realiza una búsqueda en su repertorio léxico. Es decir, aunque en un momento dado carece del término léxico o del ET en una lengua, sí dispone de dicho término en la otra, de tal forma que para expresar determinados significados en una lengua le puede resultar más difícil utilizar un recurso más complejo en dicha lengua (como la paráfrasis) que utilizar el equivalente en la otra (Toribio y Brown 1995).

Otros autores (Petersen 1988; Meisel 1989; Genesee et al. 1995; Döpke 1998; Nicoladis 2002; Paradis 2001) consideran que la AC, tanto en niños como en adultos, (sobre todo la de carácter léxico) se debe a que el hablante bilingüe tiene una lengua dominante, siendo su competencia en esa lengua mayor que en la otra, con lo cual, la $\mathrm{AC}$ suele ser unidireccional, de tal forma que los elementos de la lengua dominante serán los que, por lo general, sirvan para llenar los vacíos léxicos que se produzcan en la otra lengua y casi nunca a la inversa.

También Grosjean (1995) busca factores determinantes muy concretos, como las posibles relaciones fonológicas y ortográficas que pueden compartir las lenguas y que, como sucede en el caso de los homófonos entre dos lenguas ("knot" en inglés y "note" en francés, por ejemplo), pueden hacer que el hablante bilingüe active uno de los lexicones (el de inglés) a pesar de que la lengua del contexto se corresponda con el otro lexicón (el de francés), de tal forma que a los hablantes bilingües inglés/francés de su estudio les presenta oraciones del tipo de (19) para observar si este tipo de reacciones son frecuentes.

(19) Il faudrait qu'on knot les deux cordes.

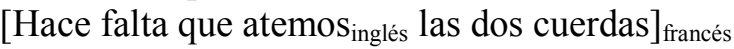

(Grosjean 1995)

Al mismo tiempo, además de la relación entre los lexicones de las dos lenguas con respecto al significado, hay autores que también se han ocupado de otras relaciones léxicas entre las dos lenguas (Romaine 1989; Genesee et al. 1995; De Houwer 1995; Lanza 1992, 1997, 2000; Van der Linden 2000) y quienes sugieren que la adquisición de un determinado término puede asociarse desde el principio con más fuerza o con una mayor frecuencia al contexto de una de las lenguas que al de la otra, como sucede en (20). 
\%context: the twins are explaining how the roots of a tree were tied by a rope

*IVO: cómo le agarra?

*IVO: con qué ?

*LEO: con una cosita .

*IVO: con una cosita, pero cómo se llama esa cosita?

*LEO: un rope@en .

*SIM: con la cuerda .

En este ejemplo, uno de los niños de nuestro estudio, Leo, asocia la palabra "rope" a lo que han hecho ese día con su madre (plantar árboles en el jardín), quien les habla exclusivamente en inglés, de ahí que cuando Ivo, su padre, al preguntarles en español acerca de lo que han hecho, pueda provocar que Leo utilice una AC y, a continuación, que Simon responda con el término equivalente en español (rope-cuerda) que es el contexto que marca Ivo (al seguir la estrategia de una persona-una lengua (Ronjat 1913).

De esta manera, no se ha prestado suficiente atención a los contextos en los que se adquiere el input bilingüe (las situaciones sociolingüísticas, las estrategias de corrección, lo estricto de la estrategia una persona-una lengua, etc.) y, en este sentido y en el caso concreto del bilingüismo infantil, también se han sugerido razones por las que se producen casos de AC relacionados con las estrategias discursivas de los padres o de los adultos, que pueden ser bilingües y alternar códigos, si bien este tipo de situaciones no explicarían todos los casos.

Siguiendo esta línea, Grosjean (1982) dirige su atención al hecho de que determinadas cuestiones pragmáticas pueden provocar la aparición de enunciados con mezcla: las intenciones o estrategias deliberadas por parte del hablante bilingüe (enfatizar o contrastar un mensaje; transmitir un enfado; repetir lo que ha dicho alguien; excluir a alguien de la conversación; mejorar la comunicación; etc.) o la capacidad lingüística del receptor (si es bilingüe o monolingüe).

Una vez esbozados diferentes enfoques para explicar tanto la $\mathrm{AC}$ en hablantes bilingües en general, como la $\mathrm{AC}$ en niños bilingües en particular, se puede llegar a la conclusión de que este tipo de producciones forman parte no sólo de un proceso de desarrollo bilingüe en el caso de los niños sino también de una capacidad o de un recurso 
lingüístico del que dispone el hablante bilingüe en general y, por tanto, se pueden considerar estrategias tanto de adquisición como de competencia bilingüe. Puesto que el objetivo de este capítulo es la caracterización de la $\mathrm{AC}$ en los niños bilingües, creemos necesario plantear el análisis de este fenómeno a partir de los diferentes enfoques que se pueden adoptar, de tal forma que hablaremos a continuación del tratamiento de la AC en ese tipo de hablantes desde dos puntos de vista, el de la competencia gramatical y el de la competencia pragmática.

\subsubsection{La AC: el enfoque gramatical y el enfoque pragmático}

Como ya hemos mencionado, tradicionalmente la $\mathrm{AC}$ se ha venido considerando una interferencia o interacción lingüística en la que se da una desviación de cualquiera de las dos lenguas o la influencia mutua de dos sistemas lingüísticos. Sin embargo, esta perspectiva que ve este fenómeno bilingüe como un error, una confusión, un fallo, etc. en la competencia gramatical o en la competencia pragmática (Schlyter 1987) se considera un análisis poco satisfactorio, ya que pueden existir factores condicionantes tanto de carácter lingüístico como de carácter contextual que hay que tener en cuenta.

De esta forma, se puede decir que la AC no es arbitraria (o accidental, como planteaba Leopold 1939-1949) sino que está sujeta a restricciones regidas por factores sociales o pragmáticos y lingüísticos o estructurales, así como por todos los mecanismos que entran en juego en una interacción verbal y que están relacionados con dichos factores.

Parece que entonces la pregunta clave ante todo lo expuesto en el apartado anterior sería qué criterios (gramaticales o pragmáticos) utilizar para dar cuenta de los casos de AC en el bilingüismo infantil. De hecho, para aclarar lo que se entiende por estos criterios, Meisel (1994a) y Köppe y Meisel (1995) definen, por un lado, la competencia gramatical como la habilidad del individuo bilingüe para respetar las restricciones gramaticales específicas de cada lengua y, por otro, la competencia pragmática como la habilidad del hablante bilingüe para seleccionar la lengua según determinados factores externos como el interlocutor, el contexto situacional, el tema de conversación, etc., y teniendo en cuenta las reglas sociolingüísticas. Así pues, en este tipo de interacciones lingüísticas, el bilingüe ha de atender tanto a los aspectos formales como a los funcionales del uso de la lengua (Lanza 1997), de ahí que, mientras que algunos investigadores se centran en la AC (en sentido 
general) como recurso comunicativo (Lanza 1992, 1997), otros optan por estudiar las reglas sintácticas por las que se rige este fenómeno (Poplack 1980, 1981; Sankoff y Poplack 1981; Belazi et al. 1994; MacSwan 2000, 2005, entre otros).

Finalmente, como precisión a esta introducción sobre el enfoque lingüístico y pragmático que se puede adoptar, habría que tener en cuenta que a veces estos enfoques son difíciles de distinguir por estar interrelacionados (tal y como veíamos en los diagramas 8 y 10 del apartado 5.1.1. sobre las diferentes tipologías de la mezcla de lenguas). En este sentido, en el presente trabajo de investigación vamos a tener en cuenta ambas perspectivas para poder explicar este comportamiento bilingüe (y más concretamente el de la TN) desde el punto de vista formal y comunicativo (Poplack 1981; Sankoff y Poplack 1981; Grosjean 1982; Romaine 1989), pues dicho comportamiento requiere ambas competencias, la gramatical y la pragmática, en las dos lenguas. Es esta distinción entre la competencia gramatical y la competencia pragmática en el caso concreto de la AC producida por los niños bilingües lo que ocupa el contenido de los apartados siguientes, así como los diferentes factores a los que se han aludido en diversos trabajos relacionados con el tema de la mezcla de lenguas infantil que están especialmente enfocados a formalizar las restricciones que rigen este fenómeno.

\subsubsection{La AC y la competencia gramatical}

Como ya mencionamos anteriormente, si atendemos al análisis desde el punto de vista gramatical, se suele hablar de que la AC se puede dar en el nivel fonológico, léxico (entre palabras o dentro de una palabra), sintagmático, sintáctico (intra o interoracional) y discursivo o conversacional. De la misma manera, en el caso concreto del bilingüismo infantil, la AC se ha estudiado en el nivel fonológico (Lindholm y Padilla 1978a), en el nivel léxico (Redlinger y Park 1980; Vihman 1985; Lanza 1997), en el nivel sintáctico (Swain y Wesche 1975; Volterra y Taeschner 1978; Taeschner 1983; Meisel 1989; Köppe y Meisel 1995) y en el nivel discursivo (Lanza 1992, 1997; Vinagre Laranjeira 2005).

Los que parten de esta perspectiva gramatical, como Poplack (1980), plantean que la AC (utilizando su propia terminología) no es arbitraria, sino que está regida por reglas. Concretamente, se centran en la naturaleza de las restricciones sintácticas en la AC tanto del bilingüe equilibrado adulto como de aquel que carece de fluidez en las dos lenguas, 
destacando la existencia de dos restricciones universales principales: la del morfema libre (Sankoff y Poplack 1981), según la cual la AC no puede darse entre un morfema ligado y una forma léxica, como sucede en (21a), y la de equivalencia, según la cual la equivalencia de las dos lenguas que constituyen la alternancia se mantiene cuando el orden de cualquiera de los dos elementos de la oración (uno antes y el otro después del punto en el que se produzca la alternancia) no se excluye en la otra lengua, como en (21b), donde la equivalencia (del inglés y del español) en el orden de los elementos que componen la alternancia se mantiene en "le told" pero no en "*told $l e$ ".

$$
\begin{aligned}
& \text { (a) *estoy eat-iendo } \\
& \text { (b) *told le, pero sí le told }
\end{aligned}
$$

Según estos autores, tanto en un tipo de bilingüe como en el otro, la AC requiere un nivel alto de competencia en ambas lenguas, pues este fenómeno no es el resultado de una competencia imperfecta, sino que supone un conocimiento suficiente de los dos sistemas gramaticales, más concretamente de aquellas reglas que comparten y en las que se diferencian.

Una vez hecho este planteamiento, la cuestión que surge es si podríamos aplicar estas mismas reglas al comportamiento bilingüe no sólo adulto sino también infantil. A este respecto, algunos investigadores (Poplack 1980; Meisel 1994a; Toribio y Brown 1995; Bhatia y Ritchie 1996b; Toribio 2001) han propuesto que los niños bilingües inicialmente no son sensibles a las normas de la AC. Es más, según estos autores, no puede probarse que la $\mathrm{AC}$ esté gobernada por reglas en el bilingüismo incipiente porque una condición previa importante para que emerja no se satisface: la de que las dos gramáticas estén lo suficientemente articuladas y diferenciadas.

A este respecto, McClure (1981) y Zentella (1997) argumentan que el tipo de alternancia se relaciona con el tipo de conocimiento que el niño tiene de las dos lenguas: los niños que no son bilingües equilibrados alternan códigos fundamentalmente en el nivel de la palabra (nombres en la mayoría de los casos), una correlación que se ha vuelto a apuntar recientemente (Bernardini y Schlyter 2004), y los que lo son eligen utilizar la alternancia en el nivel sintagmático dentro de la oración. 
En esta misma línea, Poplack (1980), en un análisis más profundo de los diferentes tipos de AC (según su terminología), llega a la conclusión de que las alternancias intraoracionales suponen un mayor grado de competencia en las dos gramáticas participantes que otras manifestaciones de contacto de lenguas, de ahí que considere que se puede utilizar la AC como indicador de la competencia bilingüe.

En este punto es donde vuelve a cobrar importancia la distinción ya planteada anteriormente [ver el apartado 5.1.3.] entre la AC en el lenguaje infantil temprano y la AC propia de los bilingües más mayores o adultos, entre las que se dan diferencias tanto desde el punto de vista gramatical como desde el punto de vista pragmático. En cuanto a las restricciones gramaticales, que son las que tratamos en este apartado, Woolford (1983) y Köppe y Meisel (1995) afirman que sólo cuando el niño bilingüe desarrolle las categorías funcionales, las mezclas que produce estarán guiadas por principios sintácticos.

Sin embargo, un paso siguiente en la investigación sobre este tema en concreto lo dan Paradis et al. (2000) cuando plantean que, si las reglas estructurales se encuentran sujetas a un cambio evolutivo, entonces habría que observar si los niños bilingües se aproximan al sistema de reglas de los bilingües adultos o si obedecen a esas reglas tan pronto como emerja la sintaxis en el habla. Por este motivo, sería necesario estudiar la competencia gramatical de este tipo de hablantes para comprobar las siguientes posibilidades: si existen reglas particulares que rigen la $\mathrm{AC}$ en niños bilingües frente a las reglas que rigen la $\mathrm{AC}$ en bilingües adultos y si la primera está restringida por los mismos principios sintácticos que la segunda.

Dentro de este tipo de planteamientos, consideramos de especial interés para el análisis de nuestros datos los trabajos de MacSwan (2000, 2005), al que ya aludimos al comienzo de este trabajo [ver el apartado 2.2.]. Según este autor, la AC intraoracional (siguiendo su propia terminología) es el resultado natural de mezclar dos lexicones durante la derivación, siempre y cuando se respeten las características intrínsecas y los principios de formación de cada lexicón, que se realicen las operaciones de derivación adecuadas y que se apliquen los principios universales pertinentes; si estas restricciones no se respetan, la AC fracasaría. Es decir, la alternancia ha de responder a una FL adecuada para que la estructura converja y algo similar sucedería con la $\mathrm{FF}$, pues cada lengua tiene su propio sistema fonológico y, adaptando el modelo de MacSwan $(2000,2005)$ a los hablantes bilingües, al tratarse de dos FF, también tendrán que respetarse determinadas reglas relativas a esta interfaz lingüística. 
En cuanto a los mecanismos de carácter gramatical que restringen la $\mathrm{AC}$, ya hemos mencionado las restricciones que proponen Poplack $(1980,1981)$ y Poplack y Sankoff (1981), pero existen propuestas alternativas, algunas de las cuales son las que vamos a presentar a continuación ${ }^{15}$.

Así, según la denominada "closed-class items constraint” (Joshi 1985), las palabras funcionales (entre las que Joshi incluye los determinantes, las preposiciones, los auxiliares, los cuantificadores, etc.) no pueden alternarse, como en (22), donde la preposición en marathi "war” no puede alternarse con la preposición en inglés "on”;

$$
\text { *some chairs- } \frac{\text { war }}{[\mathrm{en}]_{\text {marathi }}}
$$

(Joshi 1985)

Según la restricción denominada "functional head constraint" (Belazi et al. 1994), el rasgo del complemento que seleccione un núcleo funcional ha de concordar con el rasgo correspondiente de dicho núcleo funcional. Por ejemplo, en (23a) el cuantificador "pocos" concuerda con los rasgos de género y número del nombre al que acompaña, "estudiantes", pero no así en (23b) con el rasgo de género (aunque sí de número), por lo que esta AC no sería permitida.

(a) Pocos estudiantes finished the exam

(b) * Pocos students finished the exam

(Belazi et al. 1994)

Sin embargo, más recientemente, MacSwan (2005: 5) critica estas y otras restricciones de la $\mathrm{AC}$ que se han propuesto a lo largo de la bibliografía dedicada a este tema, pues, apoyado en un enfoque minimimalista, considera que "nothing constrains codeswitching apart from the requirements of the mixed grammars". De esta manera, el mecanismo que subyace en un caso de AC parte de que son los elementos léxicos extraídos de cualquiera de los dos lexicones los que introducen los rasgos en la derivación para, a continuación, proceder al cotejo de rasgos propio de cualquier derivación. Este

\footnotetext{
${ }^{15}$ Sobre otro tipo de restricciones sintácticas ver además Sankoff y Poplack (1981) y Belazi et al. (1994), entre otros.
} 
planteamiento hace que MacSwan concluya que la AC puede explicarse recurriendo a los principios de la GU y de las gramáticas específicas implicadas en un enunciado concreto en el que se produzca la alternancia, de ahí que considere que, aunque pueden existir estructuras con $\mathrm{AC}$ en las que los rasgos entre una y otra lengua no coincidan, no existen reglas propias de la $\mathrm{AC}$.

Con respecto a la concordancia de rasgos, existen diversos estudios, entre los cuales destacamos los de Liceras et al. (2003, 2005), Spradlin et al. (2003) y Liceras y Fernández Fuertes (2005), que proponen una matización al planteamiento de MacSwan (2000, 2005) en la llamada hipótesis de la materialización de los rasgos gramaticales ("Grammatical Features Spell-out Hypothesis") según la cual, si los hablantes bilingües tienen dos lexicones, entonces tendrán una doble realización de ese lexicón (aunque tengan un único sistema computacional) de tal forma que esa doble realización tendrá también sus consecuencias para el análisis de fenómenos característicos del comportamiento bilingüe como puede ser la AC. En este caso, según Spradlin et al. (2003) y Liceras y Fernández Fuertes (2005), ante casos de AC en el nivel del sintagma determinante, podemos encontrar que el hablante bilingüe produzca cuatro outputs diferentes como "la roca", "the rock", "la rock" o "the roca", proporcionados por un mismo sistema computacional y que tienen una misma FL. De todos estos sintagmas determinantes con mezcla, "el rock" o "la rock" son los que proporcionan una mayor información desde el punto de vista de los rasgos gramaticales (el de género y el de concordancia, si la hay, de género del determinante español) y, por ello, el tipo de output que tienden a utilizar de forma más natural los bilingües simultáneos, como sucede en los casos de (24a)-(24c).

(24) Simon y Leo: bilingües inglés/español

(a) *LEO: (1)e falta un t(r)ee@en .

(b) *LEO: $\quad$ cuando $<\operatorname{los} \operatorname{los}>[/]$ los hamicas [: hormigas] en la rock@en pone(n) la lengua aquí y luego se caen . [3;05.14]

(c) *SIM: $\quad$ otro@sp naus $[:$ nose $]$.

(25) Simon: bilingüe inglés/español

*MEL:

*SIM:

*MEL:

*SIM: where do you put socks?

[\% holding his foot] aquí@sp . aquísp what's that? foot.
$[2 ; 05 ; 27]$ 
En una reformulación de esta hipótesis, Liceras y Fernández Fuertes (2005) plantean que, dado que el niño bilingüe tiene dos lexicones, cuando produzca casos de AC preferirá aquellos en los que las categorías funcionales contengan más rasgos no interpretables (es decir, el determinante en español en "el rock" o "la rock").

Esta misma hipótesis, aunque aplicada a otro fenómeno típico del comportamiento bilingüe como es la TN en (25), nos llevaría a plantear (Fernández Fuertes, Álvarez de la Fuente y Liceras (en prensa)) que, en este caso, la FL recoge dos outputs, uno por cada lengua ("aqui/foot"), estableciendo una relación semántica entre el deíctico “aquil” y el nombre "foot" al que hace referencia dicho deíctico, como se puede apreciar en el comentario que se incluye en el contexto de la producción ("holding his foot"). Esa relación semántica puede ser de distinto tipo (de equivalencia o no equivalencia) pero será la que aporte una determinada información recogida en los rasgos del lexicón de la lengua a la que se traduce (al inglés, en el caso de (25)). Este tipo de análisis de la TN lo trataremos en los capítulos 2,3 y 5 del presente estudio.

Así pues, las restricciones gramaticales que rigen tanto la $\mathrm{AC}$ en hablantes adultos como la $\mathrm{AC}$ en niños bilingües sigue despertando un gran interés en los estudios de bilingüismo ya que, en definitiva, lo que vendría a demostrar el planteamiento de estas restricciones es que se trata, no de un comportamiento lingüístico arbitrario, sino de un fenómeno que responde a una serie de principios no sólo gramaticales sino también pragmáticos, siendo estos últimos los que vamos a tratar en el siguiente apartado.

\subsubsection{La AC y la competencia pragmática: los recursos comunicativos bilingües}

Además de las restricciones gramaticales hay estudios que se han ocupado de si la AC infantil puede ser sensible a determinadas restricciones pragmáticas. Esta línea de investigación también la han seguido Köppe y Meisel (1995), que se han centrado en analizar cómo y cuándo el niño bilingüe descubre que el uso de ambas lenguas en su entorno está gobernado por reglas sociales y pragmáticas. En este sentido, se puede hablar de que el análisis de la $\mathrm{AC}$ característica de la adquisición bilingüe infantil (o mezcla de códigos, según la terminología de Köppe y Meisel 1995) ha de incluir también factores pragmáticos (es decir, aquellos que se refieren al uso funcional de los recursos 
lingüísticos), entre los cuales, se podrían destacar los siguientes: si los niños respetan las reglas funcionales o contextuales del uso de las lenguas (como adaptarse a la lengua del interlocutor con el que esté interactuando, por ejemplo); cómo y cuándo los niños descubren que hay que utilizar las lenguas por separado o, por el contrario, que es apropiado utilizarlas simultáneamente en el discurso; si el receptor es bilingüe o monolingüe; si la lengua que utilizan en un momento dado responde a una situación o un contexto determinado (el familiar, el de la conversación, etc.), si son conscientes de cuál es su papel dentro de dicho contexto y de qué estrategias comunicativas pueden valerse; etc.

Si bien algunos partidarios de la hipótesis del sistema único (Redlinger y Park 1980) aluden a que todos estos factores sociolingüísticos podrían contribuir a la diferenciación gradual de lenguas, Genesee (1989) critica dichos estudios porque, a pesar de reconocer la importancia de esos factores, no han tenido en cuenta en sus análisis este tipo de consideraciones de carácter sociolingüístico o contextual.

En definitiva, y tal y como sugiere Lanza (1997), es necesario tener en cuenta no sólo la competencia gramatical que tienen estos niños a lo largo de las diversas etapas de su desarrollo, sino también otro tipo de conocimientos tales como los sociolingüísticos, los contextuales, así como una competencia pragmática que les permita utilizar una lengua adecuadamente en cada situación, según el contexto o los interlocutores. Es decir, hay que tener en cuenta en este tipo de estudios todos estos factores que se engloban en la competencia comunicativa (Hymes 1971) de este tipo de hablantes.

Siguiendo esta línea, y como ya observamos en el diagrama 10 [ver el apartado 5.1.1. de este capítulo], Köppe y Meisel (1995) hablan de dos tipos de AC desde el punto de vista pragmático ${ }^{16}$ : la $\mathrm{AC}$ situacional y la $\mathrm{AC}$ conversacional. El primer tipo, que se establece desde muy temprano (a partir los 2;00 años de edad), se refiere a la AC que se basa en la elección de lenguas según la lengua base de la conversación, del interlocutor, del tema de la conversación o del contexto situacional. Sería propia, por ejemplo, de aquella situación en la que los niños bilingües, utilizando una u otra lengua como medio lingüístico de comunicación, actúan de intérpretes entre dos hablantes monolingües para que ambos se integren en la conversación o en el juego. De esta forma, este tipo de alternancia, traducción (según la terminología de Lindholm y Padilla (1978b) en el diagrama 8) o cambio de códigos (según la terminología de McClure (1981) en el diagrama 11),

\footnotetext{
${ }^{16}$ Nótese que para Köppe y Meisel (1995), estos tipos que plantean son casos de AC y no de MC, ya que, aunque se refieren a casos producidos por niños, en ellos se respetan las restricciones pragmáticas. 
respondería a un intento de enfrentarse a una situación en la que se les exige interactuar simultáneamente en dos lenguas y, por tanto, al uso de una estrategia pragmática que suele ser característica del comportamiento bilingüe de estos niños. Precisamente, este tipo de situación la podemos encontrar en nuestro estudio, tanto en los datos experimentales, donde los niños actúan de intérpretes entre dos investigadores monolingües, como en los datos espontáneos, ya que los padres de los niños practican la fórmula de una persona-una lengua, y se dirigen a ellos en sus respectivas lenguas maternas, algo que puede provocar diversas situaciones en las que tienen que cambiar de códigos o, en definitiva, traducir de una lengua a otra. A estos dos tipos de datos nos referiremos con mayor detalle en el capítulo 4, dedicado a la descripción de la metodología seguida en la recogida de nuestros datos.

También contamos en nuestro estudio con datos en los que se incluyen casos del segundo tipo de AC de la que hablan Köppe y Meisel (1995), la alternancia conversacional (o estilística, según el diagrama 11 de McClure 1981), que es aquella que conlleva información específica de carácter social o pragmático (comentarios metalingüísticos como, por ejemplo, solicitar traducciones, repetir lo que ha dicho alguien en la lengua original, jugar con ambas lenguas, etc.) y en la que podemos encontrar algún caso de TN que venga inducida por causas diferentes a las planteadas para la alternancia situacional.

Al hilo de este último planteamiento, para algunos autores como Vihman (1985), el comienzo de la conciencia bilingüe (o cuando el niño bilingüe empieza a ser consciente de que maneja dos lenguas) es lo que constituye los cimientos de la diferenciación de lenguas.

Sin embargo, según Lanza (1997), el que se aluda a que el niño carece de conciencia bilingüe (el conocer cuándo utilizar una de las lenguas y cuándo es apropiado mezclar las dos), no es válido ya que, según esta y otros autores (De Houwer 1990; Döpke 1992; Genesee et al. 1995; Köppe y Meisel 1995; Nicoladis y Genesee 1996), la AC de los niños bilingües de 2;00 años demuestra que estos niños tienen ya una competencia pragmática que les permite mezclar lenguas o mantenerlas separadas según el contexto en el que se utilicen las lenguas (es decir, cambiar códigos como cuando traducen, por ejemplo), lo cual hace que se pueda describir la mezcla de lenguas también como un comportamiento bilingüe pragmático.

Por otro lado, según Lanza $(1992,1993)$ la ampliación del uso de la AC como recurso estilístico (es decir, el paso del uso de la AC situacional a la estilística) no aparece 
hasta que los niños tienen 5;00 o 6;00 años, de tal forma que la alternancia en niños de edades más tempranas a estas refleja un menor grado de conciencia bilingüe. Estos estudios se centran en la $\mathrm{AC}$ (a nivel léxico y discursivo) de una niña bilingüe inglés/noruego, Siri, que puede diferenciar las lenguas según las demandas situacionales: en el caso de las alternancias relacionadas con el nivel discursivo, Siri es capaz de mantener las lenguas separadas tanto en situaciones en las que su madre intenta imponer un contexto monolingüe, como en (26), como en situaciones en las que el padre le pide los EET de las dos lenguas asociados a hablantes determinados (a la madre o al padre), como en $(27)^{17}$. Es decir, con sus padres la niña mantiene un uso social diferente de las lenguas, lo cual forma parte de su competencia pragmática.

\section{Siri: bilingüe inglés/noruego}

Siri: Jeg mett, jeg mett. [estoy llena, estoy llena] $]_{\text {noruego }}$

Madre: You're mett? What does Mama say?

Siri: F:ull.

$$
\text { [¿estás }{ }_{\text {inglés }} 1 \text { lena }{ }_{\text {noruego }} \text { ?] }
$$

Madre: Full. That's a girl!

(27) Siri: bilingüe inglés/noruego

Padre: Hva sier Mama?

Siri: horse.

$$
\text { [¿qué dice mamá? }]_{\text {noruego }}
$$

Padre: Hva sier Papa? (...)

Siri: hest? [¿qué dice papá?] $]_{\text {noruego }}$ [¿caballo? $]_{\text {noruego }}$

Padre: Hest, ja. Flink jente! [caballo, sí. ¡Buena chica! ] noruego

Así pues, el uso de la AC situacional por parte del niño bilingüe no ha de verse como un caso de confusión, sino como un recurso que el niño utiliza para cumplir con determinadas demandas comunicativas ya a la edad de poco más de 2;00 años (Lanza

\footnotetext{
${ }^{17}$ Nótese que, si bien los casos de (26) y (27) se incluyen en los trabajos de Lanza (1992, 1997) como casos de mezcla de lenguas en el nivel discursivo (enunciados en otra lengua dentro del discurso), lo cierto es que se trata de casos con características propias que los situarían en una tipología más específica dentro de los fenómenos de la mezcla de lenguas: serían casos de cambio de códigos en los que se produce una traducción infantil, tal y como veremos en posteriores apartados [ver 1.1 .
} en el capítulo 3]. 
1997). En este sentido, se suele decir que el uso de la estrategia de una persona-una lengua (Ronjat 1913) juega un papel importante en la elección de lenguas según el interlocutor (Redlinger y Park 1980), ya que, atendiendo a esta estrategia, los padres, a pesar de ser bilingües, utilizan desde el principio su lengua materna cuando se comunican con los niños y por lo general sólo una de esas lenguas maternas (la de la madre o la del padre) es el principal medio de comunicación entre los padres y la lengua de la comunidad en la que viven [ver el apartado 2.3.2. del capítulo 3].

Sin embargo, incluso los niños que han adquirido dos lenguas siguiendo esta fórmula utilizan la AC (Toribio y Brown 1995), a pesar de ser una estrategia que favorece la estricta separación de las lenguas en el nivel pragmático explícitamente (y en todos los niveles en general). Por este motivo, habría que tener en cuenta otros factores que también pueden provocar la aparición de casos de AC como, por ejemplo, intentar adecuarse a la situación de habla o a la interacción con cada uno de los interlocutores (monolingües o bilingües) en una conversación que tenga lugar tanto dentro del contexto familiar como fuera de él.

Teniendo en cuenta lo anterior, también las habilidades de actuación son necesarias para que el niño pueda alternar códigos, es decir, el efecto de un entrenamiento natural en esta habilidad de mezclar lenguas o el papel del input lingüístico que recibe el niño ha de ser tan importante como su acceso al conocimiento gramatical de dichas lenguas (Meisel 1994e). Así, Ivar, el niño del estudio de Meisel (1994e), dirige enunciados en francés a su madre ("maman du thé" [mamá té]) o a otro interlocutor francófono aunque el contexto sea una situación en la que la lengua base sea el alemán debido a que su madre, siguiendo la fórmula de una persona-una lengua (Ronjat 1913), suele dirigirse a Ivar en francés y la interacción con el investigador ha de ser necesariamente en esta lengua también.

Igualmente, son importantes otros factores como el tema de conversación o la edad, pues, según Köppe y Meisel (1995), uno de sus sujetos, Ivar, a partir de los 1;04 años ya selecciona la lengua apropiada para cada interlocutor, sea este monolingüe de francés (F) o de alemán (A), como en (28). 
Ivar (a A): oh der kann nich fahr(en) der auto.

[oh este no puede mover el coche $]_{\text {alemán }}$

F: qu'est-ce qu'elle a fait l'auto la voiture?

[¿qué ha hecho el auto el coche?] francés

Ivar (a F): peut peut pas rouler.

[no puede moverse $]_{\text {francés }}$

(Köppe y Meisel 1995)

Según Meisel (1994e), los niños de 2;00 a 2;06 años utilizan la mezcla como una habilidad pragmática y sólo posteriormente (a los 5;00 años aproximadamente) pueden utilizar habilidades pragmáticas o sociolingüísticas más sutiles que no sólo impliquen un comentario breve a otro interlocutor, aunque, tal y como hemos visto anteriormente en los ejemplos (13) y (14), los niños pueden ser más sutiles en este sentido mucho antes, ya que pueden, por ejemplo, producir traducciones, como en la de (13), o comentarios metalingüísticos, como el de (14) a los 3;07 años.

Así pues, en general, tanto la adaptación al contexto situacional como el carácter social o pragmático de una conversación, puede dar lugar a la producción de $\mathrm{AC}$ en un niño bilingüe, aunque también pueden contribuir otros factores (Nicoladis y Genesee 1997, 1998; Lanza 1997) como el contexto de aprendizaje de determinadas palabras (como veíamos en el ejemplo (20) del apartado 5.2.1.), el input de otros hablantes en el entorno más cercano o las estrategias discursivas que sigan los padres en las conversaciones con los niños (si aceptan o rechazan el uso de la mezcla del niño; si el propio input de los padres es mezclado o no), por nombrar algunos más.

Este tipo de planteamientos son los que llevan a Köppe y Meisel (1995) a concluir que los aspectos pragmáticos de la mezcla de lenguas pueden contribuir a una separación temprana de lenguas, así como al desarrollo de estrategias específicas que ayudan a evitar la mezcla. En este sentido, nos gustaría apuntar que, si bien estamos de acuerdo con la primera sugerencia de estos autores, no lo estamos con la última, ya que consideramos que la mezcla de lenguas (tanto la $\mathrm{AC}$ como el CC) no es un comportamiento a evitar sino que es parte del proceso de adquisición bilingüe y parte de los recursos de los que dispone el niño bilingüe para comunicarse, tal y como ya apuntábamos en el apartado 5.1.3. del presente capítulo. 
Así pues, podríamos decir que la mezcla de lenguas en general ha sido estudiada por lingüistas, sociolingüistas y psicolingüistas que se han centrado en dos temas principales: dónde se da la mezcla, cuáles son los elementos lingüísticos que son más dados a alternarse (restricciones formales o sintácticas) y por qué ocurre (restricciones pragmáticas y cognitivas $)^{18}$. Por tanto, si bien muchos estudios relacionados con la mezcla tratan de las restricciones formales o estructurales, se puede decir que este fenómeno también está gobernado por restricciones pragmáticas. De esta forma, dependiendo del tipo de enfoque que se adopte, se pueden analizar las restricciones gramaticales o las restricciones pragmáticas que caracterizan la mezcla de lenguas infantil. Aunque la mayor parte de los estudios que tratan este tema adoptan un enfoque gramatical, en ellos también se tiende a tenerse en cuenta variables pragmáticas, pues ofrecen descripciones del input de los niños y del contexto en el que se producen los distintos fenómenos lingüísticos que implican una mezcla de lenguas. De hecho, se admite que las restricciones gramaticales y las pragmáticas, que tradicionalmente se han estudiado por separado, interactúan $\mathrm{y}$, precisamente, esta relación tan estrecha es la que constituirá la base del análisis de los casos de TN que presentamos en este trabajo.

Para finalizar, apuntaremos dos ideas claves en las que nos hemos basado para exponer los temas del apartado 5: por un lado, y siguiendo a Meisel (1989), si se puede demostrar que un niño bilingüe utiliza medios gramaticales diferentes para expresar las mismas o similares funciones semántico-pragmáticas en ambas lenguas, esto constituiría una prueba de que está diferenciando los dos sistemas gramaticales; y, por otro lado, una vez hecho este planteamiento, una investigación profunda de la AC nos llevaría a la conclusión de que esta, tanto en niños como en adultos bilingües, está regida por restricciones gramaticales y pragmáticas (Milroy y Muysken 1995; Grosjean 1997; Sinka 2000; Vinagre Laranjeira 2005, entre otros).

Aunque hasta ahora hemos centrado estos dos enfoques, el gramatical y el pragmático, en la mezcla de lenguas realizada por los niños bilingües, haciendo especial hincapié en los casos de AC que estos hablantes producen, a continuación nos proponemos aplicar estos criterios a otro tipo de mezcla de lenguas que nosotros denominaremos

\footnotetext{
18 Aunque no forma parte de nuestro estudio el análisis del procesamiento de la mezcla de lenguas, existen algunos trabajos que, partiendo de una perspectiva psicolingüística, investigan acerca del acceso al lexicón de los niños bilingües utilizando los casos de AC (Ruan 2003, entre otros).
} 
cambio de códigos (CC), siendo uno de los posibles tipos de CC la traducción realizada por los niños bilingües en una conversación. A este tipo de fenómeno bilingüe, denominado traducción natural, ya hemos aludido en el apartado 4.5. [ver el ejemplo (5)] y hemos visto varios ejemplos a lo largo del presente capítulo [ver (9d), (10a), (13) y (26)-(28)], aunque bajo una terminología diferente: para Lanza $(1992,1997)$ serían casos de mezcla de lenguas; para Köppe y Meisel (1995) casos de AC de carácter pragmático y para McClure (1981) situaciones en las que se produce un AC situacional o estilística. El término cambio de códigos, junto con la denominación de Lindholm y Padilla (1979b), que son los únicos que la denominan traducción, será, por tanto, el que adoptaremos en los siguientes capítulos del presente estudio. 


\section{CAPÍTULO 2: LA TRADUCCIÓN NATURAL (TN)}

Este capítulo se centra en el análisis de un fenómeno característico de la adquisición bilingüe que es la traducción natural y que constituye el centro del presente trabajo de investigación. La traducción natural (TN) se define como aquella que realizan los bilingües en circunstancias cotidianas y sin haber recibido una formación académica en la materia (Harris 1977) ${ }^{19}$. Los objetivos que perseguimos en los apartados que siguen son los que figuran a continuación y que hacen referencia, por un lado, al papel de la traducción realizada por hablantes bilingües en campos de investigación distintos como son la psicolingüística y la sociolingüística, $y$, por otro, a la relación que se puede establecer entre la competencia bilingüe y la competencia traductora en el campo de la adquisición bilingüe.

En primer lugar, en los apartados que siguen mostrar, por un lado, cómo la traducción se ha tenido en cuenta en los estudios de bilingüismo como método de inferencia de modelos léxicos en la mente del hablante bilingüe en general, así como la importancia que ha tenido lo que nosotros también denominaremos $\mathrm{TN}$ en los estudios de adquisición bilingüe simultánea, en particular. Por otro lado, y también dentro de los estudios de bilingüismo, aunque, en este caso, desde una perspectiva más sociolingüística, también aludiremos a la propuesta que han ofrecido algunos estudios sobre lo que denominan "brokering" o mediación lingüística en la que participan adultos, adolescentes y niños en diversas comunidades de inmigrantes, y la relación de este concepto con lo que nosotros entendemos por TN.

\footnotetext{
${ }^{19}$ Aunque, dada la etapa de desarrollo lingüístico a la que pertenecen los datos que utiliza Harris y los que utilizamos en el presente estudio, el término más adecuado para este fenómeno sería interpretación natural (Harris 2003), con el fin de evitar confusiones terminológicas hemos optado por el término traducción como un término general que abarca ambas actividades.
} 
En segundo lugar, y centrándonos más en el bilingüismo infantil, plantearemos la relación que se puede establecer entre la competencia bilingüe y la competencia traductora, haciendo especial hincapié en las diversas propuestas teóricas en relación a los modelos de desarrollo de la competencia traductora en los niños bilingües.

Finalmente, y dado que al estudiar la traducción realizada por sujetos bilingües no sólo estamos tratando con un fenómeno característico del bilingüismo sino también con una competencia y una actividad que tradicionalmente se ha venido relacionando con otros ámbitos de investigación como los estudios teóricos de traducción, dedicaremos el último apartado al papel que ha tenido la TN en dichos estudios, así como a las cuestiones que han surgido en torno a ella dentro de este campo.

\section{LA TN Y LA ADQUISICIÓN BILINGÜE}

En un primer acercamiento a la investigación, dentro de los estudios de bilingüismo (sobre todo dentro del campo de la psicolingüística) existe una gran cantidad de referencias sobre la traducción que realizan los hablantes bilingües (adultos en su mayoría), así como otros trabajos que, a diferencia de los anteriores, parten de una perspectiva sociolingüística. A continuación mostraremos a algunas de las conclusiones a las que llegan tanto un tipo de estudios como el otro, con el fin de tenerlas en cuenta cuando tratemos en mayor profundidad el tema de la importancia de las traducciones que realizan los niños bilingües durante el desarrollo de la competencia lingüística, que es lo que constituye una de las piezas clave sobre la que se sustenta el presente estudio longitudinal.

\subsection{La traducción como método para inferir los modelos de memoria léxica bilingüe}

En el campo de la psicolingüística, la traducción que realizan los hablantes bilingües en general y la que realizan los niños bilingües en particular ha constituido el centro de atención de varios estudios que parten de las evidencias que proporcionan diversas pruebas experimentales como la designación de imágenes y la categorización semántica, así como la traducción oral de la L2 a la L1 (directa) o de la L1 a la L2 (inversa) (De Bot 1992, Snodgrass 1993, Green 1993, Sánchez-Casas 1999, Forster y Jiang 
2001, De Groot 1993, Kroll 1993 y los estudios de estos dos últimos autores con diversos colaboradores como los de Kroll y Sholl 1992; De Groot et al. 1994; Kroll y Stewart 1994; Dufour y Kroll 1995; Sholl et al. 1995; Kroll et al. 1998; Van Hell y De Groot 1998; Kroll y Tokowic 2001; Gollan y Kroll 2001; etc.). Los autores citados utilizan el análisis del proceso de traducción en tareas experimentales como herramienta o método para, por un lado, inferir cómo se organiza el lexicón en la mente del hablante bilingüe y, por otro, para investigar, dependiendo del tipo de hablante bilingüe, la mayor o menor fuerza de las conexiones entre las dos lenguas de dicho hablante y si dichas conexiones pueden ser de carácter léxico o de carácter conceptual. Estas tareas experimentales consisten en que el sujeto bilingüe, por un lado, tiene que traducir, por ejemplo, house por la palabra española casa (prueba de producción) y, por otro lado, decidir si las dos palabras que muestran, house-casa, son equivalentes de traducción (prueba de reconocimiento). Otros estudios como el de Davidson et al. (1997) utilizan la traducción como método para analizar las restricciones, las ambigüedades y las correcciones léxicas en los niños bilingües, aunque, desafortunadamente, no ofrecen ningún ejemplo concreto de las traducciones de los niños.

Siguiendo esta línea, a partir de $\operatorname{los}$ años 80 , a diferencia de estudios anteriores en los que se trataba de determinar si el bilingüe tiene uno o dos sistemas de memoria, diversos psicolingüistas (Potter et al. 1984; Kroll y Sholl 1992; De Groot et al. 1994; Kroll y Stewart 1994; Kroll et al. 1998; Sánchez-Casas 1999; Gollan y Kroll 2001) tratan de analizar cómo y en qué medida esos dos niveles de representación independientes (el léxico y el conceptual) están conectados y qué tipo de restricciones determina el carácter específico de dichas representaciones. De esta manera, proponen dos modelos de memoria bilingüe en los que se intenta describir la naturaleza de las relaciones que se dan entre las dos lenguas de un hablante bilingüe en esos dos niveles de representación. En ambos modelos, el de asociación de palabras y el de mediación conceptual, se parte de que las palabras se encuentran almacenadas en sistemas de memoria léxica que, a su vez, se encuentran separados, mientras que los conceptos están almacenados en un sistema de memoria abstracto y común a ambas lenguas (Kroll y Stewart 1994).

Los postulados básicos de cada uno de estos modelos se exponen a continuación en los diagramas 11 y 12 y, aunque la mayoría de los estudios que tratan este tema tienen como sujetos a hablantes bilingües secuenciales $(\mathrm{L} 1+\mathrm{L} 2)$ o a aprendices adultos de una 
$\mathrm{L} 2^{20}$, sus propuestas se tendrán en cuenta cuando se analicen las traducciones realizadas por los niños bilingües simultáneos $(\mathrm{L} 1+\mathrm{L} 1)$ del presente estudio.

1. El Modelo de asociación de palabras: lo que se propone en este modelo es que la relación que se da entre la L1 y la L2 de un hablante bilingüe (con fluidez en ambas lenguas, pero no equilibrado, puesto que el lexicón de la L2 es más reducido que el de la L1) es de carácter léxico, de tal forma que el acceso a los conceptos o significados de las palabras de la L2 se produce a través de un proceso de traducción en el que se activan las palabras equivalentes en la L1, como en el diagrama 12(a);

Diagrama 12(a). Modelo de asociación de palabras

(De Groot et al. 1994)

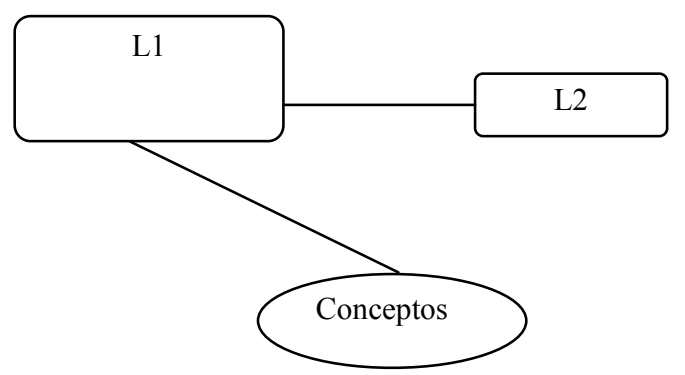

2. El Modelo de mediación conceptual: según este modelo, el léxico de la L1 y el de la L2 tienen acceso, de forma independiente, a una representación conceptual común, de tal forma que la traducción entre ambas lenguas se llevaría a cabo accediendo directamente al nivel conceptual de la palabra en la L2, como en el diagrama 12(b);

Diagrama 12(b). Modelo de mediación conceptual

(De Groot et al. 1994)

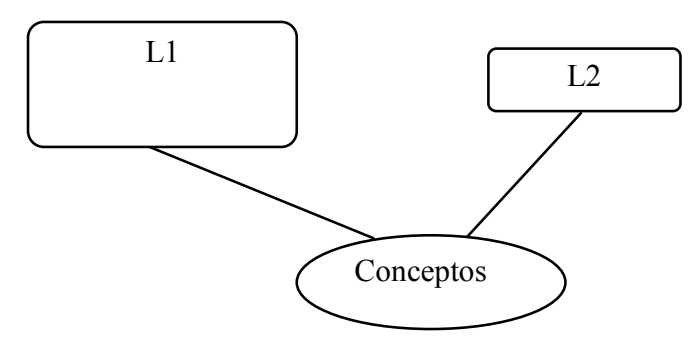

\footnotetext{
${ }^{20}$ El concepto de bilingüismo del que parten estos autores no se refiere exclusivamente al control nativo de dos lenguas (L1+L1) o bilingüismo equilibrado [ver el apartado 1.1. del capítulo 1], sino también a aquel concepto que incluya la posesión de determinadas habilidades comunicativas en una L2.
} 
Esta distinción recuerda a la organización del lexicón bilingüe propuesta por Heredia y Brown (2004) en los tipos diferentes de bilingües, tal y como presentamos en el capítulo 1 del presente trabajo, pues a los bilingües coordinados y a los subordinados [ver los diagramas 1 y 3 . del capítulo 1] se les relaciona con el primer modelo (traducen a través de la asociación de palabras), mientras que a los bilingües compuestos [ver el diagrama 2 del capítulo 1] se les asocia con el segundo (traducen a través de la mediación conceptual).

Según Gollan y Kroll (2001), las investigaciones posteriores a estos modelos plantean un reto a la conclusión general de que todos los bilingües, independientemente de su nivel de conocimiento de las lenguas, son capaces de acceder a los conceptos de las palabras de la L2. En esta línea, sugieren que los dos modelos son correctos, pero que describen fases diferentes en el desarrollo de la L2: es decir, en el proceso de aprendizaje de la L2, el hablante bilingüe ha de pasar por una etapa inicial en la que se accede al significado de las palabras de la L2 a través de la L1. Una vez que el hablante bilingüe supere esta etapa y vaya adquiriendo una mayor fluidez en la L2, la mediación conceptual entre ambas lenguas será mayor, aunque las conexiones léxicas seguirán permaneciendo activas.

Este paso de la mediación léxica a la mediación conceptual durante el proceso de adquisición de la L2, lo explican Kroll y Stewart (1994) proponiendo el llamado Modelo jerárquico revisado, tal y como se muestra en el diagrama 13, en el que las palabras de la L1 y las palabras de la L2 (menores en número, ya que, según estos autores, la mayoría de los bilingües conocen más palabras en la L1 que en la L2) se interrelacionan a través de dos tipos de conexiones, las léxicas y las conceptuales.

Diagrama 13. Modelo jerárquico revisado de la representación léxica y conceptual en la memoria bilingüe

(Kroll y Stewart 1994)

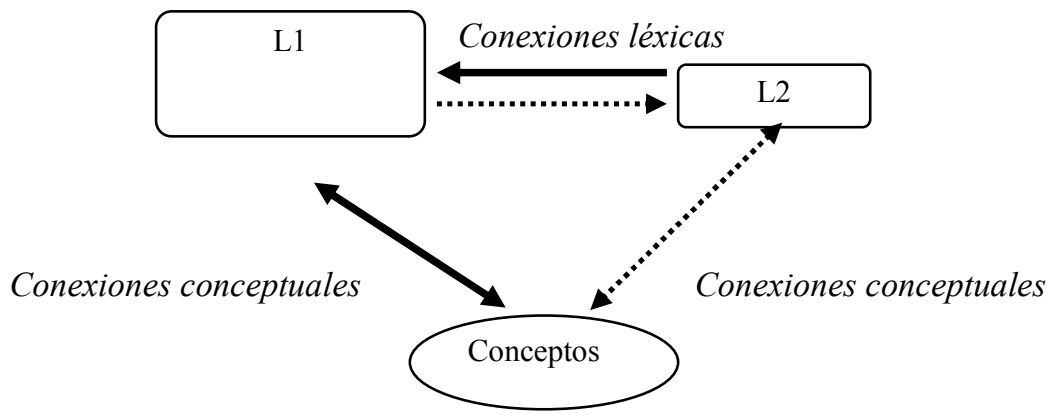


Este modelo asume que tanto las relaciones léxicas como las conceptuales son bidireccionales, de tal forma que, en el primer tipo de relaciones, las que se dan en el nivel léxico, la conexión es más estrecha si se traduce de la L2 a la L1 (indicado en el diagrama con una flecha lineal) pero menos estrecha si se traduce de la L1 a la L2 (indicado con una flecha punteada), lo cual se debe a que en un primer momento los aprendices de L2 asocian las palabras de la L2 a la L1.

En cuanto al segundo tipo de conexión, que tiene lugar en el nivel conceptual, existe una relación más estrecha entre la memoria léxica de la L1 y la memoria conceptual que entre la memoria léxica de la L2 y la memoria conceptual, de tal forma que la conexión entre las palabras y los conceptos es más estrecha si se traduce de la L1 a la L2 y menos estrecha si se traduce de la L2 a la L1. Sin embargo, dependiendo de la competencia en la L2 que tengan los hablantes, las conexiones entre las palabras en la L1 y la L2 varían, de tal forma que la fuerza de estas conexiones puede ir cambiando gradualmente a medida que aumenta la competencia en la L2: en un principio, el hablante bilingüe accede a los significados de las palabras de la L2 a través de la L1 (de ahí que las conexiones que van de la L2 a la L1 sean muy fuertes, pero no viceversa), pero a medida que dicho hablante aumenta su competencia en la L2, la conexiones conceptuales entre la L2 y los conceptos serán más fuertes o directas (de ahí que las conexiones puedan llegar a darse también a la inversa, como indican las fechas dobles), aunque las conexiones léxicas siguen permaneciendo activas.

Esta conclusión la basan en una serie de estudios empíricos ${ }^{21}$ en los que se demuestra que se tarda más o menos tiempo en realizar la traducción dependiendo de la direccionalidad que se siga en dicha traducción. Es decir, el procesamiento será diferente si el bilingüe realiza una traducción directa (de la L2 a la L1) o si realiza una traducción inversa (de la L1 a la L2). La primera se trataría de una traducción que depende de la asociación de palabras, de tal forma que las relaciones léxicas que se establecen en este tipo de traducción son más estrechas (y, por tanto, la traducción será más rápida). En cambio, la segunda estaría mediada conceptualmente, es decir, en la traducción L1-L2 la conexión conceptual con la L1 es más estrecha que con la L2, pero, al mismo tiempo, las

\footnotetext{
${ }^{21}$ De Groot (1993), Kroll y Stewart (1994), Kroll et al. (1998), Sánchez-Casas (1999) y Gollan y Kroll (2001) dedican parte de sus análisis al estudio de la traducción de cognados, así como a la traducción de palabras concretas y abstractas. En el caso del análisis de la traducción de las palabras concretas y abstractas, llegan a la conclusión de que las primeras son traducidas con más rapidez que las segundas, debido a que las palabras concretas tienen un mayor número de rasgos conceptuales comunes entre las lenguas que las palabras abstractas.
} 
relaciones léxicas son menos estrechas, de ahí que dicha traducción inversa (L1-L2) sea más lenta y menos precisa (sobre todo si el sujeto del estudio es un bilingüe tardío).

A pesar de que todos estos análisis pueden tener implicaciones importantes para los estudios de traducción y para el análisis del proceso de adquisición bilingüe (especialmente de lenguas segundas), autores como Pavlenko (2000) consideran que las tareas de traducción no constituyen una metodología lo suficientemente sensible como para diferenciar entre los diversos tipos de bilingües, puesto que la mayoría de los participantes de los estudios arriba mencionados suelen ser aprendices adultos con un mayor o menor dominio de la lengua segunda $(\mathrm{L} 1+\mathrm{L} 2)$ y no hablantes bilingües equilibrados $(\mathrm{L} 1+\mathrm{L} 1)$ en los que, según De Groot et al. (1994), ya no tendrá sentido hablar de traducción directa e inversa.

Atendiendo a este último planteamiento, en el análisis de datos que presentaremos en el capítulo 5, intentaremos tener en cuenta estas propuestas (que tienen como sujetos de estudio a bilingües secuenciales, L1+L2) para aplicarlas a niños bilingües simultáneos $(\mathrm{L} 1+\mathrm{L} 1)$, de tal forma que enfocaremos la direccionalidad de las traducciones no como directa/inversa, sino de qué lengua se parte (o lengua origen) y a qué lengua se traduce (o lengua meta).

Al mismo tiempo, como hemos observado en este apartado, la importancia que tiene en el proceso traductor la conexión existente entre el nivel de representación léxica y el nivel de representación conceptual (o, en términos utilizados por la gramática generativa, la relación entre los dos lexicones y la Forma Lógica, como veíamos en el apartado 2.2. del capítulo 1) nos llevará a plantear el papel que tiene la traducción en la adquisición bilingüe, así como la relación entre la competencia traductora y la competencia bilingüe. 


\subsection{Los equivalentes de traducción (EET) en el desarrollo bilingüe infantil y su importancia en la $\mathbf{T N}$}

Partiendo de lo que hemos visto en el anterior apartado y en otros previos [ver los apartados 2 y 3 en el capítulo 1], los resultados de este último tipo de estudios, que tienen como sujetos a adultos bilingües secuenciales $(\mathrm{L} 1+\mathrm{L} 2)$, pueden tenerse en cuenta para analizar la naturaleza de las relaciones (tanto léxicas como conceptuales) que existen entre las dos lenguas en la mente de ese tipo de bilingües, uno de los temas de interés para el presente estudio de investigación. Sin embargo, dado que este estudio tiene como sujetos a dos niños bilingües simultáneos (L1+L1), nos vamos a centrar en el papel de la traducción en el campo de la adquisición bilingüe, concretamente, en el debate de la organización de las lenguas en la mente del niño bilingüe a lo largo de su desarrollo lingüístico, que ha dado lugar al debate entre la hipótesis del sistema unitario y la hipótesis del sistema diferenciado.

En relación a este debate, algunos de los investigadores defensores de la primera hipótesis (Vihman 1985) se han referido al comienzo de la conciencia bilingüe o metalingüística como un impulso para el proceso de diferenciación de lenguas ${ }^{22}$. Según Lanza (1992), en estos estudios se encuentra implícita la idea de que la conciencia bilingüe subyacente se manifiesta en la separación formal de las dos lenguas durante los primeros años del niño, ya que la traducción implica una conciencia bilingüe que el niño pone en práctica. Precisamente aquí es donde radicaría la importancia del análisis de los casos de TN en las primeras etapas del desarrollo lingüístico del niño bilingüe, pues dicho análisis podría ayudarnos a plantear en qué etapa podemos encontrar evidencias de la existencia de la conciencia bilingüe en el niño. Sobre esta cuestión, Volterra y Taeschner (1978) y Toribio y Brown (1995) afirman que sólo una vez que se haya logrado la transición de la etapa de un lexicón fusionado a la etapa de dos lexicones diferenciados, el niño será capaz de traducir de una lengua a otra. También Leopold (1939-1949), aunque de una forma más sutil, habla de que los primeros signos de esa diferenciación son evidentes cuando Hildegard tiene 2;02 años y traduce de una lengua a otra habitualmente.

Sin embargo, habría que investigar si el niño puede realizar traducciones antes de este período de transición y así comprobar si, efectivamente, parte de un solo lexicón que

\footnotetext{
22 El término "conciencia bilingüe" procede de la traducción literal de los términos "bilingual consciousness" o "bilingual awareness" que utilizan estos y otros autores (Imedadze 1960, McLaughlin 1984, Malakoff y Hakuta 1991, entre otros). 
unifica las dos lenguas o si, en cambio, ya tiene dos lexicones diferenciados desde la primera etapa.

Obviamente, para plantear que el niño puede traducir inicialmente habría que tener en cuenta que en esas primeras etapas la competencia lingüística aún no está desarrollada por completo, lo cual influirá tanto en la cantidad como en el tipo de traducciones que nos podamos encontrar. Por este motivo, en esas etapas tempranas sólo podríamos centrarnos en las unidades léxicas y, más concretamente, en aquellos casos en los que los niños utilizan una palabra de cada lengua para referirse a la misma cosa o a la misma clase de cosa (Nicoladis y Secco 1998). Dentro de estos pares de términos o EET, los que más nos interesan son aquellos que se utilizan en un mismo enunciado o aparecen cercanos en el discurso. Así, Swain (1973) habla sobre un tipo de mezcla léxica que utiliza Michael, dos de cuyos ejemplos se pueden observar en (29a) y (29b).

Michael: bilingüe francés/inglés

(a) Michael: Un autre Johnnie. Another one.

[otro Johnnie] $]_{\text {francés }}$

(b) Investigador: What are they called?

Michael: Des bonbons. A candy.

$[\text { los caramelos }]_{\text {francés }}$

(Swain 1973)

Estos casos, según esta autora, son traducciones que suelen tener forma de "reinforcing lexical items in one language with a translation equivalent in the other, much as one might give a synonym to make sure the listener got the point" (Swain 1973: 9). Aunque en el caso de (29a) carecemos de un mayor contexto en el que ubicar el ejemplo, en el caso de (29b), Michael ofrece la traducción léxica ("bonbons-candy") porque el interlocutor al que tiene que proporcionar la información solicitada es anglófono.

Este mismo tipo de traducción ha ido recibiendo nombres diferentes a lo largo de la bibliografía dedicada al bilingüismo, en lo cual se puede observar una cierta reticencia generalizada a denominar traducción a casos como los de (29) o los que veremos a continuación. 
Harris (1980b) la denomina emparejamiento de palabras y se daría en casos como el de (30) entre el inglés y el francés, en el que un investigador anglófono le indica a Michael la equivalencia de dos palabras ("comb" y "peigne") que el niño expresa utilizándolas de forma conjunta en un solo enunciado.

\section{Michael: bilingüe francés/inglés}

A: In French it's a peigne... and in English it's called a comb... comb, peigne. [peine $]_{\text {francés }}$

Michael: Comb, peigne, Peigne et comb.

[peine $y]_{\text {francés }}$ peine inglés $_{\text {s }}$.

(Swain 1972a, recopilado por Harris 1980b)

El término que Redlinger y Park (1980) utilizan para referirse a este tipo de casos es duplicación (por ser enunciados que primero se dicen en una lengua y luego en otra, aunque sin pausas internas) y sería una forma de marcar énfasis, como en (31a)-(31c), donde los niños, Danny y Henrik, dicen lo mismo utilizando ambas lenguas en un solo enunciado.

Danny: bilingüe inglés/alemán

(a) Danny: Look, guck!

$$
\text { [imira! }]_{\text {alemán }}
$$

(b) Danny: She is painting malen da.

[pintando ahí] alemán

Henrik: bilingüe francés/alemán

(c) Henrik: Oui, ja.

$$
\text { [sí } \left.i_{\text {francés, }}, i_{\text {alemán }}\right]
$$

(Redlinger y Park 1980)

Vihman (1985) y Paradis et al. (2000) se refieren a los EET yuxtapuestos, como en (32), pero inciden en que no se trata de un caso de confusión de lenguas, sino que los consideran un tipo de alternancia en el que el enunciado contiene una combinación de sinónimos que le sirve al niño para mantener la interacción con sus padres, lo cual implicaría la repetición del mismo mensaje en cada una de las lenguas de sus progenitores. 
Niño: sleeping dodo.

Finalmente, Lanza (1997), basándose en un análisis conversacional, habla de autoreparación o auto-corrección, un recurso que responde a una demanda comunicativa en un momento dado y que se puede ver claramente ejemplificado en (33).

Siri: bilingüe inglés/noruego

Madre: The cow! What's the cow doing right there?

Siri: spis. [comer $]_{\text {noruego }}$

Madre: Hm?

Siri: eat.

En este caso Siri, que recibe input en inglés por parte de la madre e input en noruego por parte del padre, utiliza en un primer momento una palabra en noruego cuando está con su madre para, a continuación y tras la reacción de esta, expresar ese mismo concepto en inglés, según Lanza, como una manera de reparar la interrupción en la comunicación con su madre.

Curiosamente, para demostrar la falta de diferenciación de lenguas, los estudios defensores del sistema unitario sostienen que el niño bilingüe carece del ET de una lengua, de tal forma que rellena ese vacío léxico con un elemento de la otra lengua. Sin embargo, como hemos visto en el capítulo 1 [ver los apartados 3.2. y 4 del mencionado capítulo] y en otros estudios, sobre todo a partir de los años 90 (Pearson et al. 1993; Genesee et al. 1995; Quay 1995; Deuchar y Quay 2000), el hecho de que durante la etapa de una sola palabra los niños bilingües utilicen EET dependiendo del interlocutor con el que estén interactuando puede suponer una evidencia a favor de la diferenciación temprana de lenguas. De la misma manera, en otros estudios como el de Burling (1978), se ha aludido a la capacidad o habilidad de traducción por parte de los niños bilingües como una prueba de que estos niños tratan las dos lenguas como sistemas lingüísticos separados. Sin embargo, 
Burling (1978: 69), cuyos ejemplos aparecen en (34), sólo puede asegurar que este reconocimiento o toma de conciencia no se produce en el niño bilingüe de su estudio hasta los 2;01-2;03 años, a pesar de encontrar un caso de lo que, según sus palabras, "seemed to me like a translation" cuando el niño tiene 1;06 años, y de admitir que el niño reconoce que determinados términos en lenguas diferentes son equivalentes.

\section{Stephen: bilingüe garo/inglés}

(a) Anotación:

si se le pregunta a Stephen en inglés que si quiere leche, responde afirmativamente y sin dudar con el equivalente garo " $d u t$ " [leche].

(b) Anotación:

cuando se le pregunta a Stephen por el significado de la palabra "table", (los garos usan un préstamo del inglés fonéticamente similar a la original) hace una pausa breve y después proporciona la traducción "dining room table".

(Burling 1978)

Del mismo modo, Vihman (1985) considera que hacia los 2;01 años, Raivo, el niño bilingüe objeto de su estudio, es consciente de la diferenciación de lenguas y como prueba recurre a una referencia metalingüística explícita del niño cuando ofrece traducciones o pide que le traduzcan enunciados a cualquiera de las dos lenguas, dejando patente su concienciación de la situación bilingüe y de la elección de lenguas. Como hemos indicado arriba, este autor no incluye ningún ejemplo de estos casos, por lo que nos resulta difícil saber de qué tipo de traducciones está hablando y no podemos compararlas con las que realizan otros niños de otros estudios o los de nuestro estudio.

En trabajos anteriores como los de Leopold (1939-1949) y Ronjat (1913) también se establece una asociación causal entre la diferenciación de lenguas y la competencia traductora al considerar que los niños de sus estudios, cuando tienen 2;00 años, tratan conscientemente las dos lenguas como dos sistemas lingüísticos por separado y son capaces de traducir, como lo demuestran en (35a) y (35b). 
Louis: bilingüe francés/alemán

(a) Anotación:

Padre: Non, ne reste pas ici, il fait trop froid, va voir Deda. $[\text { no, no te quedes aquí, hace mucho frío, ve a ver a Deda }]_{\text {francés }}$ Louis (a Deda): Papas Zimmer ist zu kalt.

Hildegard: bilingüe inglés/alemán

(Ronjat 1913)

(b) Padre (a la madre): Der Balg kann wohl noch etwas aufbleiben.

[la diablilla puede quedarse levantada un poco más $]_{\text {alemán }}$ Hildegard (a la madre): Mama, Papa says you can keep me up. [2;11]

(Leopold 1939-1949)

Es más, algunos estudios como el de Slobin (1973) hablan de la capacidad que tienen los niños bilingües para expresar nociones bastante similares en sus dos lenguas, lo cual, en definitiva, pone de manifiesto su habilidad para traducir y constituye una evidencia a tener en cuenta en el debate de un solo sistema frente a dos sistemas lingüísticos diferenciados, puesto que al hablar de traducción en los niños bilingües se reconoce explícitamente la existencia de dos sistemas lingüísticos diferenciados.

Como punto final a estos planteamientos, aludiremos a autores como Quay (1995) que, basándose en el análisis de los EET producidos por una niña bilingüe inglés/español desde su nacimiento hasta los 1;10 años, proporcionan evidencias de que la niña puede tener EET ya desde el principio del habla, lo cual supondría un hecho importante a tener en cuenta en nuestro estudio, pues si esos EET se utilizan dentro de un mismo enunciado, podemos encontrarnos ante los primeros casos de TN en la niña bilingüe. Nuestra selección de datos no incluye edades tan tempranas, ya que comienza cuando los niños tienen 2;00 años (dos meses más que el sujeto de Quay 1995), de tal forma que, aunque no se incluye en dicha selección el primer caso de TN que se localiza en el estudio longitudinal cuando uno de los sujetos tiene 1;01 años [ver el ejemplo (5) en el capítulo 1], observaremos si producen EET desde el comienzo del estudio, siendo de especial interés para nuestra investigación este tipo de elementos léxicos cuando se localizan en un mismo enunciado. 
Tanto de este caso como de otros diferentes trataremos en el capítulo 5 dedicado al análisis de datos del presente estudio longitudinal.

En este apartado nos hemos centrado en la concepción de la TN en relación al desarrollo lingüístico bilingüe. Si bien este es el enfoque que resulta más interesante desde el punto de vista de la base del análisis del presente trabajo, hemos creído oportuno incluir en este capítulo un apartado en el que, aunque se parte de un concepto de traducción similar al de la TN, la perspectiva de estudio es diferente, ya que no se centra en la importancia de la TN a lo largo del desarrollo de la adquisición bilingüe, sino en el papel de este tipo de traducción desde el punto de vista sociolingüístico. Concretamente, dicha perspectiva se ha dedicado recientemente, como hemos indicado anteriormente, al estudio de lo que se ha denominado "brokering”, que vendría a ser una mediación lingüística en la que participan niños bilingües y que resulta necesaria en determinadas situaciones comunicativas, como expondremos a continuación.

\subsection{El papel de los niños bilingües como mediadores lingüísticos ("brokers") en distintos ámbitos sociales}

Un tema de interés reciente en el que se están llevando a cabo diversos análisis (Hall y Sham 1998; Hall 2004; Hall 2003-2005) es el denominado "brokering” o mediación lingüística, en la que se incluyen aquellas situaciones dentro del ámbito familiar en las que hablantes bilingües (normalmente refugiados o grupos de inmigrantes) tienen que traducir o interpretar para otras personas que carecen del mismo nivel de competencia en la lengua de la comunidad en la que viven. Así, aunque este papel de mediador lingüístico (o intérprete no profesional, según las fuentes) a menudo recae sobre personas adultas (Knapp-Potthoff y Knapp 1986, 1987; Müller 1989; Wadensjö 1998) no es raro documentar situaciones en las que son niños o adolescentes bilingües (en mayor o menor grado) los encargados de traducir o interpretar para sus familiares en diversos ámbitos sociales (Shannon 1990a; Bullock y Harris 1997; Hall y Sham 1998; Walichowski 2001; Orellana et al. 2003a/b; Valdés 2003).

A este respecto, lo que plantean Hall y Sham (1998) es que el niño bilingüe mediador (o "language broker", siguiendo su terminología) no se limita simplemente a transmitir una información entre dos interlocutores, sino que en esa mediación, además, el 
niño se implica activamente en una transacción cultural con el fin de que esas dos partes, lingüística y culturalmente diferentes, se comuniquen. Es más, según Orellana et al. (2003a), los niños que traducen para sus familiares permiten que estos tengan acceso a información en muchos ámbitos públicos y sociales (educativos, económicos, administrativos, culturales, etc.) que, de otra manera, sería muy difícil que obtuvieran. De esta manera, dado el carácter personal de estas interacciones, el niño no es un intermediario objetivo sino que se implica emocionalmente en ellas y a veces ha de tomar ciertas decisiones que hacen que adquiera una posición de responsabilidad dentro de la familia (Tse 1996) que incluso puede sobrepasar su madurez precisamente por ser aún un niño.

También existen trabajos dentro de una perspectiva similar (Olmedo 2003) que aluden a que los niños bilingües también pueden actuar de mediadores lingüísticos en un contexto académico como puede ser el aula de un colegio, donde ayudan a aquellos compañeros que tienen una competencia menor en una de las lenguas para que puedan entender lo que les dice el profesor. Para ello, estos niños utilizan diversas estrategias comunicativas entre las que se encuentra la traducción, como se demuestra en (36), donde Norberto, viendo que hay compañeros que no han levantado la mano tras lo que dice el profesor, decide traducir lo que este ha dicho al resto de la clase.

\section{Norberto: bilingüe inglés/español}

Profesor: ¿Quién va a respetar las reglas hoy? Levanta la mano si vas a respetar las reglas hoy.

Norberto: Raise your hand if you want to respect the rules. $\quad[5 ; 00-6 ; 00]$

(Olmedo 2003)

Sin embargo, muy pocos trabajos centrados en la mediación lingüística de niños bilingües han conseguido recopilar datos de carácter empírico en los que se pueda observar la actuación de estos niños como traductores. De hecho, muchos de ellos se basan en entrevistas a adultos que de niños tuvieron experiencias como mediadores o a niños directamente, pero sin recoger ninguna interacción propiamente dicha ${ }^{23}$. De los pocos estudios empíricos con niños como mediadores que han recopilado datos de este tipo

\footnotetext{
${ }^{23}$ Hay que tener en cuenta que, dado que en este tipo de interacciones la mayor parte de las veces los participantes son inmigrantes que tienen que tratar temas muy personales (económicos, financieros, administrativos, médicos, etc.), no suele considerarse ético el grabar o recoger de alguna manera este tipo de datos (Hall y Sham 1998).
} 
destacan el de Shannon (1990a) y los de Orellana et al. (2003a/b). En el estudio de Shannon (1990a) se incluye la única transcripción realizada hasta ahora de niños actuando de intermediarios o mediadores lingüísticos para sus familiares en distintos tipos de situaciones, como sucede en (37).

\section{Lisa: bilingüe inglés/español}

Sra. Pérez: Dile que ahora el niño está más liso y más vivo y que lo notamos más activo.

Lisa: She says that the baby is more active and he's more strong he can lift up.

Padre: These days around our house he's been- what I think we're gonna do is buy a little walker for this house too because he has a walker at our house and he just cruises around in- like, I don't know if you've seen that commercial where the little kid. That's the way he is now. He runs from one room to the next as fast as he can.

Lisa: Mami, ¿sabe este comercial que enseñan en la televisión de este niño?

Sra. Pérez: Sí.

Lisa: Y luego se pone así la mamá y luego lo mira y sale corriendo que casi así es el bebé en la casa que van, que tienen que comprar uno para aquí también porque se mantienen no más y corriendo en la casa.

Sra. Pérez: Oh. Qué bueno. Dile que si ya le dijo Silvia que ya empezó comer comida, comida ya de grandes?

Lisa: My mom wants to know if he already told you that he's been eating.

Padre: Eating a lot?

Lisa: The food we eat, most of the food we eat.

Padre: Oh, really? Like what kind of food?

Lisa: ¿Como qué clase de comida?

Sra. Pérez: Ah. Como caldito de frijoles, poquito.

Lisa: Yah.

Sra. Pérez: Sí.

Lisa: Just the juice of it.

(Shannon 1990a)

En (37), podemos observar un fragmento en el que Lisa actúa de intérprete entre su madre (la Sra. Pérez) y el hombre que ha contratado a esta para cuidar de su hijo [ver otro fragmento posteriormente en el ejemplo (45) en el apartado 3.1.].

En cuanto a los estudios de Orellana et al. (2003a/b), a pesar de que reúne un número elevado de transcripciones en las que adolescentes bilingües español/inglés realizan traducciones orales de textos escritos y además recoge entrevistas sobre las experiencias de estos jóvenes con la actividad traductora, lo cierto es que se centran en el 
análisis de aquellos ámbitos especializados en los que estos adolescentes traducen para su familia.

Así pues, atendiendo a lo que plantean estos estudios, lo que se enfatiza con el término "brokering" que aquí hemos presentado, es la importancia que tiene este tipo de situaciones desde el punto de vista sociológico, ya que, si bien parten de que los niños bilingües realizan traducciones, no analizan las traducciones desde un punto de vista lingüístico sino que plantean su importancia con respecto a una serie de aspectos que se derivan de esta interacción social entre el mediador lingüístico y sus interlocutores. Entre estos aspectos que destacan se encuentran los siguientes: la implicación que esta actividad mediadora tiene en la responsabilidad del niño con respecto a su familia; qué tipo de situaciones especializadas demandan este tipo de actividad; las exigencias cognitivas que conlleva esta actividad para el mediador (Hall y Sham 1998), ya que a veces traducir le produce estrés o tensión (la familia depende de él para realizar ciertos intercambios verbales de carácter social); etc.

Como conclusión a este apartado es conveniente señalar que, si bien estos estudios parten del concepto de TN planteado por Harris y Sherwood (1978) en cuanto que se centran en una traducción de carácter no profesional, a diferencia de estos autores pioneros que tratan las traducciones espontáneas y cotidianas de niños en hogares bilingües, los estudios sobre los niños mediadores tratan más bien de las relaciones sociales o las situaciones que motivan dichas mediaciones, sobre todo en comunidades de inmigrantes, así como del impacto que estas mediaciones tienen en el desarrollo del niño en general y no de forma concreta en su desarrollo lingüístico.

Nuestro enfoque, en cambio, es bastante diferente y va más en la línea de Harris (1980a/b) y Harris y Sherwood (1978), por lo que, si bien aludiremos a este tipo de estudios en posteriores apartados por la relación que puede establecerse entre la mediación lingüística y la TN, nuestro análisis no se basará en esta propuesta. 


\section{LA TN COMO CARACTERÍSTICA INHERENTE AL BILINGÜISMO: LA COMPETENCIA BILINGÜE Y LA COMPETENCIA TRADUCTORA}

Partiendo de nuevo de un enfoque no sociolingüístico sino lingüístico, pretendemos establecer una conexión interdisciplinar entre, por un lado, los estudios de bilingüismo infantil que han mostrado un mayor o menor interés en las TTNN como fenómenos característicos del proceso de adquisición bilingüe y, por otro, los estudios que tratan la relación entre la competencia bilingüe y la competencia traductora en los hablantes bilingües. En el primer caso, la bibliografía sobre adquisición bilingüe nos ayuda a encontrar un lugar para la TN como una habilidad metalingüística y comunicativa, aunque la mayor parte de los análisis se realizan desde un punto de vista más pragmático que lingüístico ${ }^{24}$. En cambio, en el segundo tipo de estudios, el interés central de la investigación es establecer un modelo de desarrollo de la competencia traductora y su relación con la competencia bilingüe, para lo cual se aúnan investigadores tanto del campo del bilingüismo como del campo de la teoría de la traducción. Sería conveniente precisar que, si bien la actitud que tienen los investigadores centrados en el bilingüismo infantil hacia la TN realizada por niños bilingües es positiva en general, la de los teóricos de la traducción ha sido la contraria: rechazan el tener en cuenta la $\mathrm{TN}$ como un tipo de traducción, ya que, al definirla siempre en relación con la traducción profesional, no entra dentro del concepto de lo que entienden por traducción, como veremos sobre todo a partir del apartado 3 del presente capítulo.

\subsection{La TN en los estudios de adquisición bilingüe: una habilidad metalingüística inherente al bilingüismo}

Uno de los temas de interés para la psicolingüística dentro de los estudios de bilingüismo ha sido la relación entre el grado de competencia bilingüe y las habilidades de traducción de los hablantes bilingües (Grosjean 1982). Sin embargo, a pesar de que suele ser una creencia generalizada que los bilingües son traductores natos, lo cierto es que con respecto a esta opinión se suelen dar actitudes diversas (como veremos en el apartado siguiente). Así, el uso de la habilidad de traducción puede verse como una habilidad

\footnotetext{
${ }^{24}$ Aunque estos estudios distinguen entre los aspectos pragmáticos y los lingüísticos, desde la perspectiva chomskiana la pragmática es una interfaz del modelo lingüístico. 
metalingüística y una habilidad comunicativa, si entendemos por habilidad metalingüística aquella que tiene el mismo origen que la habilidad de utilizar dos lenguas en una conversación pero que, además, permite al hablante (en este caso al bilingüe) representar explícita y controladamente los aspectos abstractos de la estructura lingüística de las lenguas que conocen (Bialystok 2001) ${ }^{25}$. En este sentido, se podría decir que habrá bilingües que resulten ser traductores muy competentes y que, por tanto, analicen las estructuras lingüísticas abstractas adecuadamente y controlen aquellos aspectos específicos especialmente problemáticos, mientras que otros demuestren una habilidad bastante pobre $\mathrm{y}$, por tanto, presten una menor atención a las situaciones confusas y analicen en menor medida la representación de las estructuras lingüísticas.

Este contraste traductor competente / traductor pobre nos puede llevar a considerar que la habilidad de traducción es un tanto compleja y difícil de llevar a cabo, que puede desarrollarse pero que requiere de algo más que una competencia en ambas lenguas, de ahí que incluso un bilingüe equilibrado pueda encontrar dificultades para traducir de una lengua a otra (Paradis 1980). Los argumentos de este tipo parten de que la habilidad para traducir es independiente de otras habilidades lingüísticas como hablar, comprender o leer en dos lenguas y, por tanto, poco tiene que ver con la fluidez que tenga el hablante bilingüe en las respectivas lenguas (Grosjean 1982).

Sin embargo, habilidades como la de traducción dotan al fenómeno del bilingüismo de ventajas o características positivas desde el punto de vista intelectual, ya que este tipo de habilidad se puede considerar una habilidad metalingüística que ayuda a desarrollar otras habilidades lingüísticas como las anteriormente mencionadas. De hecho, está documentado cómo muchos niños acuden a esta habilidad de forma natural y habitual para actuar como intérpretes para sus familiares o para su entorno más cercano, siendo algunos de ellos bastante experimentados en esta tarea (Harris y Sherwood 1978; Buchanan 1993; Philips 1993; Lozès-Lawani 1994; Shannon 1996; Bullock y Harris 1997; Valdés 2003; Orellana 2003; etc.). Sin embargo, estas traducciones realizadas por niños intérpretes o traductores, por lo general, no han recibido un gran interés por parte de los estudios de

\footnotetext{
${ }^{25}$ A este respecto, podemos encontrar posturas a veces un poco contradictorias en algunos autores. Así, por ejemplo, a raíz de los resultados de algunos de sus estudios, Malakoff $(1991,1992)$ concluye que no puede afirmar categóricamente que la habilidad traductora sea una habilidad metalingüística per se, puesto que es posible que el conocimiento metalingüístico esté incluido en un grado de competencia lingüística más general, aunque admite que esto requeriría más investigación. Al parecer, una investigación más profunda es la que le lleva a afirmar en otro estudio (Malakoff y Hakuta 1991) que la traducción es una habilidad metalingüística que se ve reflejada en los traductores naturales cuando estos evalúan tanto la equivalencia de significado de un texto en la lengua origen y en la lengua meta, como la estructura oracional más adecuada para transmitir dicho significado.
} 
bilingüismo. Así, algunos de ellos aluden a unos pocos ejemplos de traducciones realizadas por niños bilingües pero no con el fin de analizarlos como traducciones en sí, sino para evidenciar otras cuestiones como la diferenciación de lenguas o la conciencia bilingüe (Bergman 1976; Burling 1978; Volterra y Taeschner 1978; Hoffmann 1991; Fantini 1985; Pettito et al. 2001). Estos estudios a veces ni siquiera se refieren a los ejemplos de TN con el término traducción (como ya pusimos de manifiesto en el apartado 1.2. del presente capítulo), pues suelen utilizarlos para tratar otros aspectos como la adquisición bilingüe de determinadas construcciones sintácticas, la competencia comunicativa en los niños bilingües o las estrategias comunicativas de sus padres, o para tenerlos en cuenta en relación a otro fenómeno bilingüe como es la alternancia de códigos (AC) (para el primer aspecto ver Gawlitzek-Mailwald 2000; para el segundo, Grosjean 1982; Lanza 1997, 2001; Comeau y Genesee 2001; Juan-Garau y Pérez-Vidal 2001; y para el tercero, McClure 1977; Petersen 1988; Romaine 1989; Lanza 1988, 1992; Köppe y Meisel 1995; Toribio y Brown 1995; Nicoladis 1998; Quay 2001). Algunos de estos trabajos (Grosjean 1982; Köppe y Meisel 1995) tratan la traducción realizada por los niños bilingües pero aludiendo a un par de casos o anécdotas y sin detenerse en el tema con más detalle, y otros aluden a que los niños bilingües de sus estudios traducen libremente pero sin ofrecer ningún ejemplo (Petersen 1988).

A pesar de esta carencia de estudios interesados en la traducción como habilidad inherente al bilingüismo (y no como herramienta de investigación con otros fines, como hemos visto en el apartado 1.1. de este capítulo), es corriente encontrar tanto en estudios pioneros como en estudios más recientes sobre bilingüismo infantil (Ronjat 1913; Leopold 1939-1949; Fantini 1985; Vihman 1985; Saunders 1988; Lanza 1988; Döpke 1992; Köppe y Meisel 1995; Comeau y Genesee 2001; Albrecht 2004; Fernández Fuertes, Álvarez de la Fuente y Liceras (en prensa)) cómo los niños traducen enunciados espontáneamente o a petición de sus interlocutores, normalmente sus padres, como en el caso de (38a), en el que Louis (un niño bilingüe francés/alemán) traduce una palabra que él mismo ha producido en alemán con el fin de responder a la demanda que le plantea su padre (cuya L1 es el francés y que se dirige al niño sólo en esta lengua). 
(a) Madre: Was hat Papa im Mund?

[¿qué tiene papá en la boca? ] alemán

Louis: Pfeife .

[pipa $]_{\text {alemán }}$

Padre: Qu'est-ce que c'est que ça?

[¿qué es eso?] francés

Louis: Pipe.

$$
[\text { pipa }]_{\text {francés }}
$$

(Ronjat 1913, recogido por Harris y Sherwood 1978)

\section{Anika: bilingüe alemán/francés}

(b) Anika: mais maintenant comment ça s'appelle encore vorlesen?

[pero ahora ¿cómo se dice otra vez] francés leer ${ }_{\text {alemán}}$ ?]

Madre: qu'est-ce que tu veux savoir?

[¿qué es lo que quieres saber?] francés

Anika: vorlesen.

$[\text { leer }]_{\text {alemán }}$

Madre: lire.

$[\text { leer }]_{\text {francés }}$

(Köppe y Meisel 1995)

También es habitual encontrar casos en los que los niños solicitan traducciones a otros interlocutores, sobre todo a los padres, como el que vimos en el ejemplo (14) en el anterior capítulo [ver el apartado 5.1.1.], ahora repetido como (38b), donde Anika se dirige a su madre en francés para preguntarle cómo se dice una palabra alemana ("vorlesen") en francés y así poder comunicar más directamente su demanda a la madre.

Se han aludido a varias razones por las que los niños recurren a esta habilidad. Así, Fantini (1985), como se puede ver en (38c), considera que su hijo Mario solicita traducciones a su madre, hablante de español, para aumentar sus conocimientos lingüísticos.

Mario: bilingüe inglés/español

(c) Anotación:

Mario: ¿Cómo se dice play en español?

Mario: ¿Qué es study? 
Sin embargo, otros autores como Grosjean (1982), De Houwer (1990), Lanza (1988) o Comeau y Genesee (2001) consideran que los niños utilizan la habilidad de traducción (o el solicitar una traducción) como una estrategia comunicativa para satisfacer sus propias necesidades comunicativas o las de sus interlocutores y que así no haya una ruptura en la comunicación, como se demuestra en los ejemplos que mostramos a continuación en (39a) y (39b).

Siri: bilingüe inglés/noruego

(a) Siri (que acaba de dar palmas): Klappe hand.

Madre: Hm?

$$
\left[\text { dar }_{\text {noruego }} \text { palmadas }\right]_{\text {inglés }}
$$

Siri: $\underline{\text { Clap hand. }}$

Madre: Did you clap your hands?

Siri: $\mathrm{mm}$.

(Lanza 1988)

Alx: bilingüe francés/inglés

(b) Alx: There's water right there.

Investigador: Quoi?

Alx: Water!

$$
\text { [¿qué?] }]_{\text {rrancés }}
$$

Investigador: Je comprends pas.

Alx: De l'eau!

$$
\text { [no te entiendo }]_{\text {francés }}
$$

$[i e l \text { agua! }]_{\text {francés }}$

(Comeau y Genesee 2001)

En ambos casos, tanto Siri como Alx reaccionan a una interrupción en la comunicación con sus interlocutores (la madre y el investigador, respectivamente) traduciendo lo que acaban de decir a la otra lengua (la asociada a cada interlocutor), recuperando así esa comunicación.

Con respecto a esta diversidad de planteamientos, nos gustaría apuntar que las razones que dan tanto unos como otros autores pueden ser igualmente válidas, ya que hay que tener en cuenta que los niños de los casos (38) y (39) tienen edades distintas, por lo que la motivación o las motivaciones por las que viene dada una traducción (o la petición 
de una traducción) pueden responder a distintas etapas del desarrollo lingüístico del niño o a situaciones comunicativas diferentes.

Como conclusión, por tanto, dentro de los estudios de adquisición bilingüe se ha dado poca importancia al análisis lingüístico de la $\mathrm{TN}$ en los niños bilingües en comparación con el metalingüístico y comunicativo. Por este motivo creemos conveniente que, si bien hay que tener en cuenta ineludiblemente el aspecto eminentemente pragmático y comunicativo de la $\mathrm{TN}$ a la hora de analizar este fenómeno dentro del proceso de adquisición, también habría que incluir en dicho análisis el aspecto lingüístico-formal, tal y como se ha planteado en relación a otros fenómenos característicos de la adquisición bilingüe como la AC. De ambas cuestiones trataremos en el capítulo 4 dedicado a las propuestas que se plantean en el presente estudio.

Sin alejarnos del campo del bilingüismo pero haciendo referencia al mismo tiempo a otro campo de estudio como es la teoría de la traducción, expondremos a continuación diferentes propuestas que se han sugerido para establecer la relación entre la competencia bilingüe y la competencia traductora.

\subsection{Los modelos de desarrollo de la competencia traductora y su relación con la competencia bilingüe}

A partir de que Harris (1977) afirmara que todos los bilingües son capaces de traducir de una forma natural, han surgido varios estudios que se han encargado de analizar una serie de cuestiones básicas relacionadas con dicha afirmación ${ }^{26}$. Así, en los siguientes apartados veremos varios estudios que plantean un desarrollo paralelo de la competencia traductora y la competencia bilingüe y otros cuyo planteamiento es diferente, dependiendo de lo que cada uno de ellos entienda por competencia traductora. En este sentido, encontraremos posturas que se muestran a favor de la coexistencia de dicha competencia con el bilingüismo, mientras que otras partirán de la diferencia que existe entre aquellos que se dedican profesionalmente a la traducción (traductores profesionales) y aquellos que realizan traducciones en la vida cotidiana sin haber recibido una preparación especializada en la materia (traductores naturales).

\footnotetext{
${ }^{26}$ El propio Harris (1977) alude a Ljudskanov (1969), quien, intentando resaltar la importancia del proceso de traducción, ya había hecho referencia a esta idea al afirmar que todo sujeto bilingüe traduce de un modo u otro gracias a una cierta intuición y a un cierto hábito, aunque no profundiza más en el tema.
} 
De esta manera, algunos estudios (Harris y Sherwood 1978; Harris 1980a/b; Srivastava y Gupta 1989; Malakoff y Hakuta 1991) defienden el desarrollo paralelo de la competencia bilingüe y la competencia traductora, centrándose ambos tipos de estudios en la figura del traductor natural (aunque con algunas diferencias, tal y como veremos a continuación), mientras que otros estudios partirán de que ambas competencias no se desarrollan de forma paralela, aunque en este caso unos se centran en la figura del traductor profesional (Toury 1986) y otros en las diferencias entre el traductor profesional y el traductor natural (Lörscher 1992).

A partir de los razonamientos que ofrecen cada una de esas posturas, plantearemos la necesidad de ampliación del concepto de traducción, adoptando un enfoque no tanto prescriptivo, sino más bien descriptivo, tanto en los estudios teóricos de traducción como en el análisis del proceso de traducción a través de datos de producción lingüística de hablantes bilingües.

Finalmente, la escasez de datos relacionados con el estudio concreto de la TN en hablantes bilingües en general y en niños bilingües en particular, nos llevará a plantear nuestro propio análisis de TTNN en dos sujetos (gemelos) bilingües inglés/español cuya producción lingüística se recoge en el estudio longitudinal que constituye la base del presente trabajo de investigación.

\subsubsection{Harris (1980b) y Harris y Sherwood (1978): el paralelismo entre el desarrollo del bilingüismo y la competencia traductora}

En este apartado trataremos diversas cuestiones que surgen a raíz de la relación que se puede establecer entre el desarrollo del bilingüismo y la competencia traductora. Así, en un primer momento presentaremos el planteamiento de Harris y Sherwood (1978) acerca de la correlación que se da entre la competencia bilingüe y la competencia traductora que les lleva a afirmar que todos los hablantes bilingües son capaces de traducir. Seguidamente, y al hilo de este mismo planteamiento, aludiremos a las distintas etapas que estos autores han establecido en el desarrollo de la competencia traductora en los niños bilingües, así como el tipo de traducciones que implican dicho desarrollo, tanto desde el punto de vista de las estrategias lingüísticas utilizadas como desde el punto de vista de factores contextuales como la procedencia del texto origen a traducir. Finalmente, 
tendremos en cuenta el debate que se plantea con respecto a la naturaleza consciente o inconsciente de la TN que lleva a algunos investigadores como Darwish (2000) a plantear que los niños bilingües realizan TTNN de forma inconsciente y, por lo tanto, no se pueden considerar traducciones como tales.

Para poder entender el planteamiento de Harris y Sherwood (1978), es necesario explicar lo que estos autores entienden por competencia traductora. Así, la TN, como producto lingüístico, es el resultado de la actuación de la competencia en cada una de las dos lenguas del bilingüe junto con una tercera competencia (la competencia traductora) que identifican con una competencia verbal innata, la cual, como sus calificativos indican, se trataría de una capacidad que no se aprende, que es anterior a cualquier enseñanza o aprendizaje formal de la misma y que, por tanto, se desarrolla de forma natural y paralela a la competencia lingüística de ambas lenguas. En el caso de las TTNN realizadas por niños bilingües, Harris y Sherwood (1978) parten de la terminología chomskiana para denominar a esta capacidad competencia, aunque consideran que se trata de una competencia verbal y no de una competencia traductora tal cual, puesto que es una competencia que aún está por desarrollarse. Sin embargo, al mismo tiempo se alejan de dicha terminología cuando afirman que es una competencia innata no porque forme parte del bagaje genético de la GU sino por tratarse más bien de una predisposición para traducir con la que nace el ser humano, sin profundizar más en esta cuestión.

En lo que respecta al paralelismo entre el bilingüismo y la competencia traductora, Harris (1977) defiende que la evolución de ambos es concomitante, de tal forma que todos los hablantes bilingües son capaces de traducir. Podemos encontrarnos desde posturas radicalmente opuestas a la de este autor hasta reconsideraciones o puntualizaciones a este argumento. Así, entre las posturas opuestas podemos encontrar la de muchos teóricos de los estudios de traducción (Delisle 1984; Toury 1986; Newmark 1988, 1991; Presas 2000; Hurtado Albir 2001, entre otros) que afirman todo lo contrario, que no todos los bilingües son capaces de traducir, y que esa habilidad rudimentaria de pasar de una lengua a otra de la que hablan Harris (1977) y Harris y Sherwood (1978), aunque es una de las bases de la competencia traductora, no constituye por sí sola la competencia traductora, sino que es necesario el desarrollo de otras subcompetencias (competencia profesional, estratégica, etc.), algo que trataremos en los siguientes apartados. 
Entre las puntualizaciones que se sugieren a esta argumentación de Harris (1977) encontramos la de Srivastava y Gupta (1989), quienes afirman que los bilingües $\operatorname{compuestos}^{27}$ son los únicos capaces de realizar traducciones de forma natural. En este tipo de bilingües, las dos lenguas se encuentran separadas pero, desde el punto de vista cognitivo, las procesan como una sola, lo cual es, precisamente, lo que les permite traducir. En definitiva, esto mismo es lo que vamos a plantear sólo que desde otro marco teórico y lingüístico de estudio, ya que propondremos una posible forma de poner el modelo bilingüe de MacSwan $(2000,2005)$ al servicio de la TN [ver el apartado 2.2. en el capítulo 2].

Esta relación que se establece entre la capacidad traductora y el bilingüismo no sólo viene dada porque ambos fenómenos implican un contacto entre lenguas, sino porque, al mismo tiempo, tal y como postulan Harris (1980b) y Harris y Sherwood (1978), no se aprende a traducir sino que su adquisición coincide con la aparición del bilingüismo. Es decir, no sólo existe una correlación entre el bilingüismo y la capacidad para traducir, sino que además existe una reciprocidad entre ambos fenómenos: todos los traductores tienen que ser bilingües (a uno u otro nivel) y todos los bilingües pueden traducir (también a uno u otro nivel). El resultado, pues, es que la habilidad traductora coexiste con el bilingüismo, de tal forma que la evolución del bilingüismo en un individuo será paralela a su evolución como traductor (entendida esta figura del traductor, evidentemente, no como un traductor profesional).

Si tenemos en cuenta que algunos bilingües comienzan a serlo desde su infancia o desde su nacimiento (es decir, los bilingües equilibrados), los casos de TN de niños bilingües que aparecen en estudios pioneros sobre bilingüismo infantil (Ronjat 1913; Leopold 1939-1945; Raffler-Engel 1970; Swain 1972a, entre otros), así como otros casos que él mismo compila (Harris 1980a/b), conducen a este autor a la conclusión de que los niños (incluso a edades muy tempranas) pueden traducir y de que lo que realizan estos niños bilingües (y todos los bilingües en general) en circunstancias cotidianas y sin que hayan recibido una formación especial en traducción es lo que se denomina traducción natural (Harris 1973, 1977).

Para poder demostrar que existe un paralelismo en la evolución del bilingüismo y de la competencia traductora, Harris y Sherwood (1978) ofrecen una muestra de casos de

\footnotetext{
${ }^{27}$ Recordemos que los bilingües compuestos son aquellos que tienen dos códigos lingüísticos almacenados en una sola unidad de significado (Butler y Hakuta 2004) [ver el apartado 1 del capítulo 1]. 
TN en niños bilingües procedentes de diversos estudios y, posteriormente, y basándose en esa compilación de casos, Harris (1980b) plantea que el niño bilingüe pasa por unas determinadas etapas en el desarrollo de su capacidad traductora, las cuales le servirán para potenciar su bilingüismo y su diferenciación temprana de lenguas.

Las cinco etapas que distingue Harris (1980b) son las siguientes:

1. Pre-traducción: en esta etapa, que puede comenzar cuando el niño tiene 1;02 años, este produce pares de palabras bilingües que tienen el mismo significado, pero esto no se considera TN per se, ya que lo que hace el niño es ir construyéndose un léxico bilingüe de manera natural, "un diccionario bilingüe interiorizado", en palabras de Harris (1980b:620), que le servirá como herramienta rudimentaria para empezar a practicar su futura labor como traductor. Para ilustrar este estadio de pre-traducción o, lo que él denomina “word-twinning”, Harris ofrece el ejemplo de (30), repetido aquí como (40a), en el que Michael repite lo que acaba de decir el investigador anglófono pero no con el fin de que lo reciba un interlocutor concreto, por lo que carece de intención comunicativa.

(40a) Michael: bilingüe francés/ingles

A: In French it's a peigne... and in English it's called a comb...comb,peigne... [peine] $]_{\text {francés }}$

Michael: Comb, peigne, Peigne et comb. [peine y $]_{\text {francés }}$ peine inglés $_{\text {s }}$

(Swain 1972a, recopilado por Harris 1980b)

2a . Autotraducción intrapersonal: en esta segunda etapa el niño (con unos 1;08 años) traduce para sí mismo enunciados (normalmente de una sola palabra) que él mismo ha producido, por lo que su finalidad no es tampoco transmitir información a otro interlocutor. Harris (1980b) no ofrece ningún ejemplo de esta segunda etapa, aunque sí lo hace en Harris y Sherwood (1978), que es el que mostramos en (40b).

\section{(40b) Louis: bilingüe francés/alemán}

Anotación:

Louis ve un barco por el río y se dice a sí mismo: Schiff bateau.

[barco alemán $_{\text {barco }}$ francés $][1 ; 08]$

(Ronjat 1913, recopilado por Harris y Sherwood 1978) 
En este ejemplo Louis emite un par de equivalentes léxicos en las dos lenguas de forma seguida y en un mismo enunciado, lo cual recuerda a los pares de palabras bilingües de la anterior etapa, pero Harris se limita a decir que esta segunda etapa puede solaparse con el final de la etapa de pre-traducción, sin profundizar más en la distinción.

3a . Autotraducción interpersonal: el niño, a partir de los 1;09 años, traduce lo que él mismo ha dicho al receptor de la lengua meta. Se trataría de casos en los que el niño empieza a hablar en una lengua diferente a la del receptor y tiene que autotraducirse para que este le entienda, como en el ejemplo de (40c) que ofrece Harris.

(40a) Michael: bilingüe francés/inglés

M: I told you it's Marcel's.

If: C'est ton ours, oui. [es tu oso, sí] francés

M: Non, c'est à Marcel.

$[\text { no, es de Marcel }]_{\text {francés }}$

(Swain 1972a, recopilado por Harris 1980b)

4a Transducción: el niño realiza lo que se entiende normalmente por traducción, ya que en esta situación de traducción, están presentes el niño, que es el que traduce, y los respectivos interlocutores monolingües (el de la lengua origen y el de la lengua meta), de tal forma que este tipo de traducción es funcional y se observa a partir de los 2;02 años de edad. El ejemplo que Harris nos proporciona lo mostramos en (40d), donde Michael traduce al investigador francófono (F) lo que le ha dicho el investigador anglófono (A), a petición de este.

(40d) Michael: bilingüe francés/inglés

A: Ask her if she has any eggs.

$\mathrm{M}$ [a F]: T'as-tu des oeufs?

[¿tienes huevos? $]_{\text {francés }}$

(Swain 1972a, recopilado por Harris 1980b) 
5 . Traducción consciente: a medida que el niño toma conciencia de que maneja dos lenguas, el niño-traductor también se muestra consciente del carácter lingüístico de la actividad de traducir y de su papel como intermediario entre otros interlocutores (hacia el final de los 3;00 años). De esta manera, comunica información en una lengua o en otra al actuar como intermediario entre dos personas, por lo que tendría una función social y, al mismo tiempo, sería consciente del concepto de traducción. Tal es el caso de (40e) (que no aparece en Harris 1980b), donde, tal y como propone Harris, al utilizar el estilo indirecto ("Elle a dit..."), el niño reconoce que es el equivalente de traducción de otro texto que ya existe y no simplemente otra manera de expresar lo mismo.

\section{(40e) Michael: bilingüe francés/inglés}

A: Tell her that the wolf knocked on the door.

$\mathrm{M}[\mathrm{a} \mathrm{F}]$ : Elle a dit a fait ça, pis après y a entrè.

[ella ha dicho que ha hecho esto y después de eso ha entrado] $]_{\text {francés }}$

(Swain 1972a)

La diferencia entre la tercera y la cuarta etapa se basa, por tanto, en el carácter consciente de la situación de traducción, ya que en la anterior etapa el niño aún no es consciente de lo que es traducción.

Por otro lado, Harris (1980a) afirma que en cada una de estas etapas, entre las que no se da una separación estricta, el niño seguirá una serie de tácticas o estrategias de traducción, las cuales se pueden clasificar en dos tipos dependiendo de la clase de procesos que impliquen. Harris (1980a) toma estas estrategias de Seleskovitch (1976) y son las siguientes: la transcodificación, o la traducción de las estructuras lingüísticas, y la interpretación, o el proceso de captación y traducción del mensaje o sentido, siendo esta última estrategia o modalidad de traducción la que más encajaría en los postulados básicos de la TN (Forlemu 1985), tal y como veremos más adelante en el apartado 3.3. del presente capítulo.

Analizando esta clasificación en cinco etapas y la correspondiente subclasificación según el tipo de proceso, consideramos que se pueden destacar tres cuestiones dentro de la 
propuesta de Harris (1980a/b) y de Harris y Sherwood (1978). La primera tiene que ver con el carácter longitudinal de esta división en etapas, que genera una serie de dudas y confusiones; la segunda se relaciona con el hecho de que en esta clasificación también se ha tenido en cuenta la procedencia del enunciado a traducir (si el texto origen lo ha producido el sujeto u otro interlocutor presente en la interacción); y la tercera cuestión surge debido a que, en su clasificación, Harris (1980b) alude a que sólo en algunas etapas los niños son conscientes de estar traduciendo, ya que sólo cuando toman conciencia de que son bilingües pueden ser conscientes de lo que significa traducir.

En cuanto a la primera cuestión, a pesar de que Harris (1980b) considera que la separación entre dichas etapas no es estricta, si atendemos a las edades que este autor menciona, observamos que, por un lado, se pueden dar casos de uno u otro tipo de traducción en etapas diferentes. Sin embargo, en ningún momento deja claro si, una vez que el niño-traductor pasa de una etapa a otra, deja de producir los tipos de traducción correspondientes a etapas previas. De hecho, existen ejemplos procedentes de otros estudios, y que hemos utilizado previamente en este trabajo [ver los ejemplos (33) y (39) en los apartados 1.2. y 2.1.], que bien podrían incluirse en la segunda etapa como ejemplos de autotraducción intrapersonal, aunque los sujetos que producen dichos ejemplos tengan más de 2;00 y de 3;00 años. Además, si bien Harris habla de que la autotraducción interpersonal puede darse a partir de que el niño bilingüe tiene 1;09 años, en el ejemplo que muestra en (40c) el niño tiene más de 3;00 años ${ }^{28}$.

Por otro lado, es evidente que también en este caso cobra importancia el uso temprano de los EET [ver el apartado 3.2. en el capítulo 1], pues es importante interpretar tanto las producciones de la primera etapa como las de la segunda como una puesta en práctica de esos pares léxicos y, al mismo tiempo, como una práctica que hay que tener en cuenta en el proceso de desarrollo bilingüe y de la competencia traductora.

Sin embargo, Harris no explica claramente la diferencia entre los casos de pretraducción y los de traducción intrapersonal, de ahí que induzca a la confusión. Desde nuestro punto de vista, consideramos que en ambos casos estamos ante el uso, por parte del niño bilingüe, de EET en un mismo enunciado o conversación, tal y como ya habíamos

\footnotetext{
${ }^{28}$ Dado que Harris no indica la edad a la que corresponde el ejemplo (40c), hemos añadido la edad correspondiente teniendo como referencia directa el estudio de Swain (1972a) del que Harris extrae la mayoría de sus ejemplos. 
visto en otros ejemplos anteriores [ver el ejemplo (10a) del apartado 5.1.1. del capítulo 1 y los ejemplos (30)-(32) del apartado 1.2. de este capítulo] $]^{29}$.

En cuanto a la cuestión relacionada con el origen del enunciado que se traduce, también consideramos importante la aportación que a este respecto realizó Swain (1972a), en cuyos datos de Michael, un niño bilingüe francés/inglés, se basó Harris en un principio para realizar esta clasificación. Swain distingue entre dos tipos de traducción según la procedencia del texto origen, de tal forma que si el enunciado a traducir es proporcionado por el niño, la traducción es espontánea (o auto-traducción interpersonal, según Harris), que sería diferente a aquella traducción común en la que el enunciado que el niño traduce se lo proporciona el interlocutor (que para Harris es transducción y se correspondería con la cuarta etapa). Para ejemplificar ambos casos, Swain (1972a: 91) hace uso de los ejemplos de (41a), en el que aparecen, según esta autora, los dos tipos de traducción en la misma conversación, y de (41b), en el que sólo aparece un caso de traducción espontánea.

\section{Michael: bilingüe francés/inglés}

(a) Investigador anglófono: Ask her if she wants to go to the store today. Michael: You want to go to the store? (TRADUCCIÓN COMÚN) Investigador francófono: Pardon?

$$
[\text { ¿cómo? }]_{\text {francés }}
$$

Michael: Tu veux aller au magasin? (TRADUCCIÓN ESPONTÁNEA) [¿quieres ir al kiosko?] francés

(b) Michael: Do you see the glasses?

Investigador francófono: Pardon?

$$
\text { [¿cómo? }]_{\text {francés }}
$$

Michael: Tu vois ti les lunettes? (TRADUCCIÓN ESPONTÁNEA)

[¿ves tú las gafas? $]_{\text {francés }}$

Lo curioso de la tipología que establece Swain (1972a) es que, fijándonos en el caso de traducción normal de (41a), llama la atención que esta autora considere ese caso como una traducción cuando, a nuestro entender, se trataría de una repetición o una paráfrasis, puesto que, en vez de realizar un cambio de códigos (CC) para cumplir con la

\footnotetext{
29 También consideramos conveniente apuntar que, en el caso de estos ejemplos, carecemos del contexto suficiente para saber si se encuentran con uno o dos interlocutores monolingües presentes, de ahí que pudieran clasificarse como otro tipo de traducción, según la clasificación de Harris (1980b).
} 
demanda del investigador, el niño repite el mensaje en la misma lengua que el investigador anglófono. La razón es que Swain asume que el bilingüismo y el monolingüismo son manifestaciones del mismo proceso psicolingüístico, de tal forma que considera que la traducción es un tipo de paráfrasis, un planteamiento que, por un lado, nos sirve para establecer también un paralelismo entre el proceso de adquisición bilingüe y el monolingüe (tal y como veíamos en el apartado 2.2. del capítulo 1), pero que, por otro, podría inducir a una confusión terminológica, ya que, desde nuestro punto de vista, para que se produzca una traducción es necesario que exista un $\mathrm{CC}$, algo que no sucede en el primer caso que aparece en (41a).

Al mismo tiempo, atendiendo a la procedencia del enunciado que traduce el niño, si analizamos con detalle el argumento de Swain, nos percatamos de que no tenemos el contexto suficiente en los ejemplos para poder constatar que el enunciado procede del investigador o del propio niño (es decir, si se trata de una traducción espontánea, según la terminología de esta autora, o se trata más bien de una autotraducción, siguiendo la de Harris).

En esta línea, Harris y Sherwood (1978), teniendo también en cuenta el origen del enunciado que el niño traduce, intentan precisar la terminología utilizada por Swain atendiendo a la función de la traducción dentro del contexto situacional (si es redundante como (40a) y (40b) o cumple una función en el contexto del momento, como en (40c)(40d)). Es más, Harris (1980b) alude a la posibilidad de que el niño no reciba ningún estímulo externo (verbal o no verbal) de ningún hablante presente en la interacción o de que no reciba peticiones directas para que traduzca, en cuyo caso, podríamos considerarlos casos de traducción espontánea por la reacción del niño, mientras que en los casos de traducciones inducidas los investigadores instan al niño a traducir constantemente.

Finalmente, la tercera cuestión que puede traer consigo cierta confusión en los planteamientos de Harris (1980a/b) y de Harris y Sherwood (1978) es la cuestión de si los niños son conscientes o no de estar traduciendo. A este respecto, Harris (1977) y Harris y Sherwood (1978) aluden a una situación anterior a la etapa de pre-traducción que denominan respuesta bilingüe (ya comentada por Ronjat 1913 y Leopold 1939-1949), en la que el estímulo en una lengua puede dar lugar a una respuesta en la otra, pero sin que se pretenda realizar una traducción (de hecho, no necesariamente tiene que parecer una traducción), siendo (42) un ejemplo. 
Padre: Dis merci.

[di gracias $]_{\text {francés }}$

Louis: Danke.

[gracias $]_{\text {alemán }}$

En este caso, un estímulo en una lengua provoca una reacción del niño en la otra, es decir, según la terminología del diagrama 9 expuesta anteriormente en este trabajo y por lo que deducimos del mismo ejemplo, se trataría de un CC temprano en el turno de habla en el que se da un trasvase de información de una lengua a otra. Sin embargo, no la consideran una actividad de traducción como tal, porque, según estos autores, se trata de una reacción de carácter inconsciente.

Curiosamente, el hecho de considerar que una actividad de traducción no es tal debido a que el niño lo hace de forma inconsciente o involuntaria no parece encajar mucho con las etapas que distingue Harris (1980a) en la labor de traducción, puesto que alude a las que él denomina traducciones conscientes sólo en la última etapa del desarrollo traductor del niño. Sin embargo, desde nuestro punto de vista, consideramos que Harris se refiere concretamente a aquellas traducciones que el niño realiza sabiendo ya lo que significa el concepto de traducción (una especie de conocimiento metalingüístico). De hecho, en otro de sus estudios (Harris y Sherwood 1978) afirma que un niño de 5;00 años ya es plenamente consciente de la traducción e, incluso, puede tener una teoría rudimentaria para explicarlo, tal y como podemos constatar también en los sujetos de nuestro estudio cuando tienen poco más de 4;00 años en el siguiente ejemplo.

Simon y Leo: bilingües inglés/español

*LEO: [\% whispering to Esther] está repitiendo .

*EST: está repitiendo ?

*EST: pero lo está repitiendo bien o mal ?

*SIM: [\% to Leo and Esther] loros loros !

*RAQ: loros !

*LEO: [\% to Simon and Raquel] vosotros más loros vosotros más loros !

*RAQ: no porque nosotros tenemos que repetirlo porque tenemos que decírselo a ellos en inglés .

*RAQ: no somos unos loros a que no S ?

*SIM: sí pero ellos se lo han dicho a ella que nosotros hemos dicho a ellos así que son unos loros a que sí ?

*RAQ: eso eso .

*LEO: quién dice loro es más loro . 
Este aspecto consciente o inconsciente de la traducción infantil es algo que ya planteaba Ronjat (1913) cuando hablaba de que las traducciones que realmente son traducciones son aquellas que el niño realiza de forma consciente y que no tienen una función redundante, y que el resto no guardan ninguna relación con la traducción. Esta postura sería semejante a la de Leopold (1939-1949) cuando prefiere calificar estos casos en los que existe una traducción no consciente como una mera transposición.

Sin embargo, el paralelismo entre el desarrollo de la habilidad traductora y el del bilingüismo, así como la correlación entre ambos fenómenos, da lugar a que, por un lado, Harris (1978) plantee que sólo cuando el bilingüe sea consciente de la diferenciación de lenguas podrá ser consciente de lo que es traducir, y, por otro, Swain (1972b) afirme que las traducciones hacen que los bilingües sean conscientes de su bilingüismo.

A este tipo de debate que surge a raíz de la relación entre la toma de conciencia del bilingüismo y la traducción realizada por los niños bilingües aludiremos en apartados posteriores [ver el apartado 2.2.5.], pero adelantaremos aquí que tiene su origen, según McLaughlin (1984), en los diferentes criterios que utilizan los investigadores cuando hablan de conciencia bilingüe. Así, Ronjat (1913) sostenía que Louis es consciente de su bilingüismo cuando utiliza pares de sinónimos procedentes de las dos lenguas; Imedadze (1960), en cambio, argumentaba que esto no indica necesariamente una conciencia de bilingüismo, sino que indica simplemente que el sujeto utiliza los medios que tiene a su alcance para comunicarse y que en realidad es la práctica de traducción (es decir, según esta autora, el uso de equivalentes en las dos lenguas cuando el niño interactúa con hablantes monolingües de cada una de dichas lenguas) la que, hacia el final de los 2;00 años supone el comienzo de la toma de conciencia bilingüe. Según Imedadze (1960) esta toma de conciencia culmina cuando el sujeto tiene 2;04 años que es cuando deja de recurrir a palabras en la otra lengua y solicita el equivalente correspondiente en dicha lengua; Swain (1972a/b), Swain y Wesche (1975), Bergman (1976) y Lindholm y Padilla (1978b) también utilizaron la traducción como evidencia de que el niño es consciente de la diferenciación de lenguas.

Sin embargo, ni el trabajo de Ronjat (1913) ni el de Imedadze (1960) tenían como objeto de estudio el proceso latente de la traducción de sujetos bilingües y, en el caso de los trabajos de Swain (1972a/b), lo que pretendía esta autora era utilizar este tipo de traducciones como método para analizar la competencia lingüística. A pesar de ello, este tipo de planteamientos han sido retomados recientemente por investigadores como 
Darwish (2000), entre otros, que considera que tanto el bilingüe como el traductor han de ser conscientes de su intención de traducir para que se pueda hablar de competencia traductora. Para argumentarlo, Darwish (2000) distingue entre, por un lado, el carácter innato, natural e inconsciente de la habilidad que tienen los niños bilingües para traducir y que no se considera traducción per se, y, por otro, el carácter innato y consciente pero no natural (sino artificial) de lo que realizan los adultos, que sí se considera traducción. Es decir, para este autor la clave está en la naturaleza consciente frente a inconsciente de la traducción y en afirmar que la traducción no es natural sino que requiere de una formación especializada en la materia, de tal forma que lo que realizan los niños de forma natural, espontánea e inconsciente no se puede considerar traducción como tal. Según nuestro punto de vista, lo que Darwish plantea es una contradicción pues es como afirmar que el balbuceo o las palabras que los niños producen en la primera etapa de su desarrollo lingüístico no se considera lenguaje per se. Además, es difícil que se pueda demostrar que el niño realiza traducciones de forma involuntaria o inconsciente y no como una forma de practicar la disponibilidad de dos lexicones.

Así pues, el planteamiento de Darwish (2000) nos ofrece un punto de inflexión en lo planteado hasta ahora en este apartado. De hecho, el panorama investigador observado hasta aquí refleja fundamentalmente dos posturas extremas ya que, por un lado, para Swain (1972a) una traducción sería todo lo que suponga un trasvase de significado de un enunciado a otro enunciado diferente, independientemente de que ello suponga un cambio de códigos o no, mientras que, por otro, para Darwish (2000) sólo la traducción profesional, que requiere una formación y una voluntad consciente, es la que puede considerarse traducción como tal y no aquella que se realiza de forma natural e involuntaria. Ante estas perspectivas, podríamos decir que la clasificación que proponen Harris y Sherwood (1978) implica en cierta forma una postura intermedia pues en dicha clasificación atienden, por un lado, tanto a la procedencia del enunciado origen como al hecho de que ha de darse un trasvase de información de una lengua a otra (es decir, un CC) $\mathrm{y}$, por otro, a que, aunque las traducciones previas a la última etapa las realizan sin ser conscientes del concepto de traducción, no dejan de ser traducciones. Al mismo tiempo, al igual que Darwish (2000), Harris y Sherwood (1978) defienden la idea de que los niños bilingües tienen la habilidad innata, natural y espontánea para traducir, aunque difieren de este autor al considerar que lo que los niños realizan es traducción aunque no hayan recibido una formación especializada en la materia. 
De algunas de estas cuestiones seguiremos tratando en el siguiente apartado dedicado a la propuesta de Malakoff y Hakuta (1991), la cual parte de muchos de los planteamientos de Harris y Sherwood (1978) expuestos en este apartado, aunque dando más importancia al aspecto cognitivo de la competencia bilingüe.

\subsubsection{Malakoff y Hakuta (1991): la importancia de la conciencia metalingüística}

Malakoff y Hakuta (1991) perfilan más la concepción básica de la competencia traductora que tienen Harris y Sherwood (1978), argumentando que para ser capaz de traducir de forma natural (y, por qué no, de traducir bien) no sólo es necesario poseer una competencia en las dos lenguas y esa predisposición innata para traducir, sino que los traductores naturales han de saber evaluar equivalencias de significado y saber cuál es la estructura oracional más adecuada para transmitir dichas equivalencias. Es decir, los traductores naturales han de estar dotados de una conciencia metalingüística que interactúe con la competencia traductora. Al mismo tiempo, estas autoras se alejan del planteamiento de Harris y Sherwood (1978) al afirmar que, al igual que sucede con otras destrezas lingüísticas (la expresión oral, la lectura, la escritura, etc.), para mejorar la competencia traductora es necesario un input que se base en tareas o estudios de traducción (es decir, un input formal, no natural), así como una relación directa con la situación en la que tenga lugar la interacción (la importancia del factor socio-cultural), algo que ayudará también a mejorar el conocimiento metalingüístico en determinados contextos en los que se pongan de manifiesto las habilidades no sólo de carácter comunicativo sino también académico.

Lo que habría que matizar de la postura de Malakoff y Hakuta (1991) es que, por un lado, no contempla, como otros estudios (Shannon 1990a/b, 1996; Walichowski 2001; Orellana 2003; Valdés 2003; etc.), el caso de la competencia traductora en contextos que no sean académicos (como los naturales o familiares) y, por otro, que cuando llega el momento de referirse a los niños bilingües de su estudio (bilingües secuenciales (L1+L2) de entre 9;00 y 12;00 años), hablan de habilidad traductora y no de competencia traductora, al considerar que estos niños no tienen un conocimiento consciente de las diferencias específicas entre los sistemas lingüísticos (es decir, no reciben una formación escolar en lingüística contrastiva), de tal forma que, aunque son capaces de comunicar un significado, suelen hacerlo a través de estructuras oracionales pobres (algo a lo que ya habían aludido otros autores como Swain (1972b) y Swain et al. 1974). Por tanto, para Malakoff y Hakuta 
(1991) la habilidad traductora en los niños bilingües equivale a la suma de dos elementos: el primero, la conciencia metalingüística, entendida como la conciencia de la naturaleza lingüística que subyace al uso del lenguaje y que permite al individuo recuperar la comprensión y la producción de un enunciado, y que, en el caso de los niños bilingües aún está poco desarrollada; y, el segundo elemento, la habilidad de comunicarse en dos lenguas que viene dada por la competencia bilingüe que tienen estos niños. Sin embargo, según nuestro punto de vista, el hecho de que puedan transmitir un significado a través de dos formas de expresión pertenecientes a dos lenguas diferentes (que, no lo olvidemos, en el caso de nuestros sujetos son dos L1) implica que han de tener un conocimiento lingüístico, pero no un conocimiento explícito a un nivel formal o propio de un lingüista (Srivastava y Gupta 1989), sino un conocimiento implícito o intuitivo de esas dos lenguas que les permite traducir (es decir, tienen la GU o el conocimiento del sistema de reglas y principios que constituye la competencia lingüística de un individuo, según la definición de Chomsky 1965).

El que estas autoras propongan que la conciencia metalingüística forma parte de la competencia traductora en los niños bilingües vendría a reafirmar la idea de que dicha competencia no equivale a la suma de la competencia de dos lenguas (Pym 2002), sino que es necesario además que entre en juego la conciencia metalingüística que ayuda a los niños bilingües a controlar mejor sus procesos mentales en la realización de actividades académicas o no académicas (un argumento que iría claramente en contra de aquellos que aluden a los efectos negativos del bilingüismo en niños, tal y como comentamos en el apartado 2.2. de capítulo 1).

Al mismo tiempo, y teniendo en cuenta la actuación de los niños de su estudio en la realización de esas actividades académicas, Malakoff y Hakuta (1991) defienden que es posible que, a pesar de que sus sujetos utilizan diversas estrategias de traducción como la perífrasis, la reformulación o los circunloquios, las traducciones que realizan sean poco adecuadas o erróneas, algo que achacan al grado de fluidez en la competencia lingüística de los niños y al hecho de que el contexto en el que se producen es escrito y, por tanto, según ellas, se trata de una modalidad más exigente que la oral. Sin embargo, todas estas afirmaciones también habría que matizarlas ya que, en primer lugar y según nuestro punto de vista, estas autoras están ofreciendo un enfoque demasiado prescriptivo al calificar las traducciones que realizan sus sujetos de erróneas, tomando además como punto de referencia y de comparación las traducciones realizadas por los adultos. Es decir, adoptan 
la posición de alguien que está valorando las traducciones de hablantes adultos y no de niños que están en proceso de adquirir una L2 y, como tales, son traducciones que forman parte de este proceso de adquisición y que han de ser interpretadas, por tanto, en ese contexto y no como algo erróneo con respecto al lenguaje adulto. En segundo lugar, los sujetos de su estudio son bilingües secuenciales inglés/español (L1+L2) que tienen el inglés como lengua dominante, algo que puede afectar a la direccionalidad de sus traducciones y que no nos permite comparar en igualdad de condiciones la frecuencia de ambas direcciones (de inglés a español y de español a inglés). Finalmente, el que aseguren que en traducción la modalidad escrita requiere un mayor esfuerzo que la oral es un argumento que puede resultar dudoso, puesto que en la modalidad oral se pueden enfrentar al problema de memorizar el enunciado que hay que traducir y de no poder corregir inmediatamente lo que se acaba de expresar, es decir, tienen el problema de la inmediatez que supone la comunicación oral frente a la posibilidad de reflexión en la comunicación escrita.

Además, como se puede observar en (44a) y en (44b), ya cuando los niños de nuestro estudio (bilingües simultáneos $(\mathrm{L} 1+\mathrm{L} 1)$ ) tienen unos dos años y medio encontramos casos de traducción complejos en los que entran en juego mecanismos que van más allá del emparejamiento léxico y en los que utilizan otras estrategias de traducción igual de complejas que las que pueden utilizar los adultos (que, no olvidemos, poseen un conocimiento lingüístico más desarrollado aunque no tengan una formación académica en traducción).

(44) Simon y Leo: bilingües inglés/español

(a) \%com: Simon intenta encender un juguete

*SIM: no@sp puedo@spno@sp puedo@sp.

*MEL: how do you say no@sp puedo@sp in English ?

*SIM: $\quad$ (h)elp .

(b) *MEL: how do you say ahora@sp yo@sp in English [\% speaking from behind camera]?

*LEO: $\quad$ ahora@sp yo@sp.

*LEO: $\quad$ my turn .

Así, en (44a) nos encontramos ante una auto-traducción en la que no se produce un emparejamiento léxico sino una ampliación del mensaje del enunciado origen (" $n o$ puedo”) con una gran carga pragmática puesto que con el mensaje del enunciado meta no 
sólo transmite su incapacidad para encender el juguete sino también que necesita ayuda de Melanie, su madre, para hacerlo; y en (44b), Melanie incita expresamente a Leo para que traduzca del español al inglés, produciendo en este caso una traducción que contiene la misma información que el enunciado origen y que no supone una transposición literal (o transcodificación) de unidades de palabras, sino que atiende a una forma de expresión lingüística más propia de la lengua meta para transmitir un significado conceptual equivalente. De estas y otras traducciones que realizan nuestros sujetos y de las estrategias que pueden llegar a utilizar trataremos en mayor profundidad en los apartados dedicados al análisis de los mismos en el capítulo 5.

Las cuestiones que se pueden plantear a partir de aquí, y tomando como ejes el estudio de Malakoff y Hakuta (1991) y el que aquí presentamos, son las siguientes: si seguimos el estudio de estas autoras, lo primero que nos planteamos es hasta qué punto el contexto oral en el que aparecen las traducciones de los sujetos de nuestro estudio y el hecho de que se incluyan en un contexto natural o familiar y no académico puede afectar a lo adecuado o no de la traducción como resultado. Y, en segundo lugar, si Malakoff (1991) afirma que los bilingües equilibrados son los que tienen un mayor control cognitivo sobre la actividad de traducción dentro del ámbito académico porque son los que suelen tener una mayor experiencia en esta labor (sobre todo a nivel familiar), esto podría implicar que sin dicha experiencia (académica o familiar) o input a nivel formal, nuestros sujetos, bilingües simultáneos y equilibrados de menor edad, carecerían de ese control y, por tanto, cometerían más errores en sus TTNN, algo que trataremos de refutar en el capítulo 5 dedicado al análisis de los datos.

Hasta aquí, no encontramos que lo que Harris y Sherwood (1978), por un lado, y Malakoff y Hakuta (1991), por otro, entienden por competencia traductora se contradiga o que haya grandes diferencias entre sus argumentos. El debate y la divergencia vendrán dados fundamentalmente por Toury (1986), un autor de gran influencia en los estudios teóricos de traducción y cuyos postulados expondremos a continuación. 


\subsubsection{Toury (1986): la formación académica y la función social}

La relación entre la competencia bilingüe y la competencia traductora también es un tema de interés para Toury (1986), quien considera que, si bien el ser humano tiene una habilidad innata para traducir y que esta coexiste con el bilingüismo (lo mismo que afirmaban Harris y Sherwood 1978), ambos fenómenos no se desarrollan de forma paralela, sino que la competencia bilingüe ha de ser condición previa y necesaria, aunque no suficiente, para el desarrollo de la competencia traductora (algo que ya habían planteado Delisle (1984) y Newmark (1988), quienes afirman que el ser bilingüe no equivale a ser capaz de traducir). Es necesario, al mismo tiempo, una formación académica en la materia para que esa competencia traductora tenga una función social.

Por tanto, coincide con Harris y Sherwood (1978) y con Darwish (2000) al reconocer que la capacidad humana para traducir es universal, pero difiere de Harris y Sherwood (1978) a la hora de identificar lo que es necesario o suficiente para considerar que un individuo es traductor. De esta manera, efectivamente, el bilingüismo constituye el punto de partida de la competencia traductora, pero Toury considera necesario distinguir entre la predisposición innata para traducir y la competencia traductora tal cual (propia de los traductores profesionales), que sería más bien una competencia adicional que no tiene por qué aparecer de forma paralela al desarrollo del bilingüismo, ni derivarse necesariamente del mismo.

La diferencia de perspectivas entre Harris y Toury se basa en lo que cada uno de ellos entiende por competencia traductora, puesto que, según Toury, lo que Harris hace al afirmar que la traducción en sí misma coexiste con el bilingüismo es reducir la TN (al menos en el caso de los niños) a una mera competencia de lenguas, cuando se trata de una competencia adicional. Es decir, el conocimiento de unas determinadas lenguas, por sí solo, no hace a un individuo competente para traducir, de tal forma que habría un vacío entre esa predisposición innata para traducir y el desarrollo de la traducción como habilidad humana. Por este motivo, Toury (1984) alude a que es necesaria una competencia adicional que denomina competencia de transferencia (semejante a la supercompetencia de Wilss 1976), con la cual el bilingüe, a través de un mecanismo mental interlingüe o de transferencia, es capaz de activar la habilidad traductora y de aplicarla a enunciados verbales de una u otra lengua. Además, esta competencia requiere de una preparación, una formación académica o institucional que permitirá al bilingüe 
avanzar en el desarrollo de esta competencia, que es la que realmente coexiste con el bilingüismo.

Este planteamiento nos lleva a abordar otra cuestión problemática para algunos autores con respecto a la TN y que se relaciona con el contexto en el que tiene lugar dicha traducción. Al parecer, uno de los argumentos a los que se alude para no considerar la TN como un tipo de traducción (o, directamente, como traducción per se) es que se desarrolla normalmente en un contexto natural o familiar y no en un contexto académico o profesional, que es lo que defiende Toury (1986). De hecho, es una cuestión que sigue despertando interés en la actualidad (Shreve 1997; Darwish 2000; Wei 2000, entre otros), pues podemos encontrar definiciones de lo que se entiende por bilingüe natural como la siguiente, en la que se pone de manifiesto la actitud generalizada hacia la relación entre el bilingüismo y la traducción:

"natural bilingual: someone who has not undergone any specific training and who is often not in a position to translate or interpret with facility between two languages" (Wei 2000: 6-7).

En esta definición se da por hecho que, al no haber recibido una formación específica en traducción, no sólo el individuo bilingüe no está en condiciones de traducir sino que además le resultará difícil hacerlo. Sin embargo, consideramos que cuando se habla de formación en traducción siempre está ligada a lo institucional y nunca a la práctica diaria de uso de las dos lenguas y de traducción entre ambas que el bilingüe va adquiriendo a medida que se va desarrollando lingüísticamente, aunque no reciba clases de gramática o de traducción. Es decir, la práctica es ya en sí misma una formación o entrenamiento en el manejo de las dos lenguas y en la traducción, aunque no sea de tipo académico. De esta cuestión volveremos a tratar cuando presentemos las propuestas del presente trabajo de investigación [ver el apartado 1.3. del capítulo 3].

En definitiva, lo que subyace a la postura de Toury (1986) y de Wei (2000) es que la competencia traductora es aquella que poseen los traductores profesionales, mientras que la competencia verbal innata que, según Toury (1986), apenas se puede medir, es una predisposición que no tiene por qué desarrollarse. Sin embargo, en esta hipótesis hay que precisar que Toury (1984) tiene como objetivo de su estudio la enseñanza de la traducción 
en un ámbito institucional y, como tal, considera la traducción como un objeto lingüístico (sobre todo en su modalidad escrita) limitado casi exclusivamente a determinadas características textuales en niveles lingüísticos diferentes (el sintáctico, el semántico y el pragmático).

A pesar de que nuestro trabajo parte de TTNN orales que realizan niños bilingües en un contexto familiar y, por tanto, se alejan tanto del tipo de traducciones (profesionales $\mathrm{y}$ escritas, en un contexto institucional) como del tipo de traductores (adultos y con formación académica) que analiza Toury (1984, 1986), podemos encontrar puntos en común con el planteamiento de este autor. Así, sugerimos que la TN tiene ciertos paralelismos con la concepción de traducción que tiene Toury, puesto que, si bien las características de las TTNN desde un punto de vista lingüístico pueden ser diferentes en un nivel sintáctico (no hay que olvidar que la competencia lingüística de los niños se encuentra en desarrollo), no lo son tanto a nivel semántico, ya que los trasvases de contenido que podemos observar en las TTNN de nuestros sujetos no tienen por qué ser ni elementales (Lörscher 1988, 1992) ni meras transcodificaciones (Harris 1980a). Es más, desde el punto de vista pragmático, son traducciones que se adaptan a las circunstancias, contextos e interlocutores que participan en la interacción comunicativa, cumpliendo una función social aunque no en un contexto institucional o profesional sino familiar, tal y como hemos observado en los casos de (44a) y (44b) por ejemplo.

Volviendo al trabajo de Toury (1986), creemos interesante hacer referencia a la figura de lo que él denomina traductor nativo, que, a pesar de tener ciertas similitudes con el término traductor natural, tienen marcos de aplicación y un carácter evolutivo diferentes, siendo dos las diferencias fundamentales entre ambos conceptos: el objetivo que persiguen los autores con cada uno de esos conceptos y la función social que desempeña cada tipo de traductor.

Así, por un lado, mientras que Harris (1973) pretende llevar a cabo un estudio científico de la traducción, o traductología, que tenga como base las TTNN (sobre todo las realizadas por los niños bilingües de corta edad) y que sea reconocida por la comunidad de los estudios teóricos de traducción, Toury (1984, 1986), en cambio, tiene en mente la elaboración de una hipótesis sobre las características definitorias del desarrollo de la competencia traductora en el bilingüe, pero desde un punto de vista diferente, el de la 
pedagogía de la traducción. Obviamente esta diferencia hará que el papel que ocupa la TN en ambos estudios sea muy distinto: para Harris la TN debería estar en el centro de los estudios de traducción mientras que para Toury el epicentro de estos estudios está en la formación académica en traducción y, por tanto, en la traducción profesional.

Por otro lado, según el modelo evolutivo de la competencia traductora de Harris (1980b) que hemos visto en el apartado 2.2.1. de este capítulo, hasta la tercera etapa, las traducciones infantiles pueden resultar redundantes desde el punto de vista de su función social: la comunicación. Sin embargo, siguen siendo traducciones para Harris (1980b) y Harris y Sherwood, aunque Toury (1986) no las considera como tales precisamente porque carecen de esa función social o comunicativa. De esta manera, Toury $(1984,1986)$ hace que el desarrollo de la habilidad de traducción (a partir de la competencia innata) dependa de las circunstancias socio-culturales en las que se producen las traducciones. Es decir, para que el traductor nativo se desarrolle, es necesario que se tenga en cuenta tanto la predisposición innata para traducir como los factores sociales que el traductor nativo va acumulando a través de las enseñanzas, el aprendizaje o la formación adquirida, así como sus experiencias traductoras (de carácter profesional, se entiende). Partiendo de una competencia innata, llegará a adquirir en las fases más avanzadas de su desarrollo la habilidad de comunicar enunciados traducidos de forma aceptable y no se reducirá simplemente a ser un bilingüe con una predisposición innata (Toury 1986). Este argumento es semejante al que se plantea cuando se habla de la adquisición de una lengua en la formación de futuros lingüistas frente a la adquisición de lenguas por parte de hablantes bilingües. Es decir, Toury habla siempre del bilingüe como un traductor profesional potencial que, a través de un input formal y especializado, llegará a convertirse en un traductor profesional, de tal forma que, según este autor, la competencia en unas lenguas determinadas, por sí sola, no hace que un individuo sea capaz de traducir.

Esta postura de Toury nos podría llevar a pensar que este autor podría aceptar la transducción y la traducción consciente de Harris (1980b) como tales traducciones, pues en este caso sería más evidente la función comunicativa que los niños llevan a cabo: actuar de puente de comunicación entre dos interlocutores monolingües. Sin embargo, lo que Toury critica en realidad de la hipótesis de Harris es que este no tiene en cuenta las funciones sociales al clasificar las diferentes TTNN de los sujetos que son objeto de su análisis. Es decir, lo que Toury entiende por función social en la traducción no es una comunicación interpersonal que se puede dar entre los niños y sus interlocutores, sino que se refiere a 
aquella traducción que viene a cumplir unas normas socio-culturales o a cubrir unas necesidades determinadas dentro la sociedad en general ${ }^{30}$. De esta manera, Toury hace que el desarrollo de la habilidad de traducción (a partir de la competencia innata) dependa de las circunstancias socio-culturales en las que se producen las traducciones, de tal forma que, para que el traductor nativo se desarrolle, es necesario que se tenga en cuenta, por un lado, su disposición innata para traducir ("nature”) y, por otro, los factores sociales que el traductor nativo va acumulando a través de las enseñanzas recibidas (el aprendizaje adquirido o "nurture") $)^{31}$. Todo ello, junto con sus experiencias traductoras o situaciones, le proporcionará una serie de normas de traducción que, a su vez, le harán mejorar su habilidad traductora para que esta sea socialmente aceptable. Siguiendo este proceso, podrá llegar a convertirse, según Toury (1986), en un traductor cada vez más profesional.

Desde nuestro punto de vista, la crítica que se podría hacer a la postura de Toury (1986) es que este autor basa la traducción en cuestiones externas a la traducción en sí misma que además son tremendamente rígidas. Está claro que toda traducción implica un contexto en el que realizar el trasvase de información de una lengua a otra con alguna finalidad pero, por un lado, esa finalidad no tiene por qué estar limitada al ámbito exclusivamente profesional $\mathrm{y}$, por otro, existen además características intrínsecas a toda traducción que también hay que tener en cuenta.

Esta importancia que se da al componente funcional lleva a Bullock y Harris (1997) y a otros investigadores (Knapp-Potthoff y Knapp 1987; Shannon 1990a/b, 1996; Tse 1996; Walichowski 2001; Orellana 2003) a considerar que en los estudios sobre la TN y la llamada mediación lingüística [ver el apartado 1.3. del presente capítulo] no sólo hay que tener en cuenta la edad de los sujetos (como había hecho el propio Harris en sus artículos anteriores), sino también los factores extralingüísticos que influyen en estas situaciones, tales como los factores sociales y culturales ${ }^{32}$, los sociolingüísticos (el estatus de las dos lenguas implicadas en el bilingüismo) o la formación y la experiencia que les ayude a mejorar su competencia traductora (que no tiene por qué ser una formación

\footnotetext{
${ }^{30}$ Esta función social de la que habla Toury (1986) no implica tampoco que el "brokering" [ver el apartado 1.3.] se considere un tipo de traducción porque responda a unas determinadas necesidades sociales, ya que, en este caso, tampoco estos niños reciben enseñanzas normativas que tienen que aplicar a la actividad de traducción para que esta resulte adecuada en la forma, es decir, resulte adecuada desde el punto de vista profesional.

${ }^{31}$ Esta es la terminología que aúna y separa a los estudiosos de la adquisición del lenguaje en lo que se refiere a qué es innato (la GU) y qué proporciona el medio, de tal forma que se encuentra en la base de los debates entre los innatistas (Chomsky 1957, 1965; Erreich y Valian 1980; etc.), por un lado, y los conexionistas (Elman et al. 1996, entre otros), por otro.

${ }^{32}$ Sería el caso, por ejemplo, de aquellas comunidades de inmigrantes donde niños de todas las edades actúan como traductores e intérpretes dentro de contextos reales, una situación que se denomina "brokering", tal y como vimos en el apartado 1.3. del presente capítulo [ver, además, la nota a pie de página anterior].
} 
institucional o académica). Es más, para autores como Tse (1996) este tipo de factores son fundamentales no tanto para mejorar sino para adquirir la competencia traductora, postura que viene apoyada por Shreve (1997) cuando afirma que esta acumulación de factores y de experiencias, o de aprendizaje consciente, es lo que va a llevar al traductor profesional a diferenciarse del traductor natural, pues el conocimiento de cómo aplicar las equivalencias comunicativas le llevará a adquirir la competencia traductora (en definitiva, la competencia de transferencia de la que hablaba Toury 1986). Sin embargo, aunque es evidente que, al igual que sucede con la adquisición de una lengua, si el bilingüe no traduce, no podrá desarrollar su competencia traductora, tampoco es menos evidente que no todo niño bilingüe ha de llegar a convertirse en un traductor profesional, de ahí que consideremos que el comparar la TN con la traducción profesional sería como comparar la adquisición monolingüe y los recursos de los niños monolingües con aquellos de un filólogo, por ejemplo. Esta comparación sería semejante a la que plantean Srivastava y Gupta (1989) cuando dicen que existe un paralelismo entre las siguientes relaciones:

$$
\begin{aligned}
& \text { relación (1): hablante monolingüe - lingüista } \\
& \text { relación (2): hablante bilingüe - experto en traductología }
\end{aligned}
$$

Es decir, estaríamos hablando de dos esferas distintas con un punto clave común que es el lenguaje pero cuya valoración no debe jerarquizarse ni tampoco reducirse a la cuestión de quién habla mejor (el niño o el filólogo) o traduce mejor (el traductor natural o el traductor profesional), puesto que el medio (el lenguaje y la traducción) es el mismo, comunicarse, aunque sea en dos esferas distintas.

Los planteamientos mostrados dentro de este apartado llevan a una serie de autores a ver la TN no como una actividad individual sino como una función social, como un servicio a la sociedad, que incluso puede darse en ámbitos especializados como el de la administración, el jurídico o el médico, por ejemplo, como es el caso de los "brokers" o mediadores lingüísticos (Shannon 1990a; 1996; Bullock y Harris 1997; Orellana 2003; Valdés 2003; etc.), que ya tratamos en un apartado anterior [ver el apartado 1.3.]. 
Así pues, a diferencia de Toury (1986) y según estos autores, los factores extralingüísticos, sobre todo los sociales y culturales, son esenciales en un modelo evolutivo de la competencia traductora, algo que ha dado lugar a que se reconsidere la TN dentro de los estudios de traducción y a que se propongan, a su vez, distintos tipos de traducción partiendo de dichos factores. Precisamente, estas distinciones tipológicas constituyen la base del estudio de Lörscher (1992), que es el último trabajo que vamos a presentar dentro del apartado 2.2.

\subsubsection{Lörscher (1992): una postura intermedia}

Este debate en torno a lo que se entiende por competencia traductora y su desarrollo lo justifica Lörscher $(1988,1992)$ a través de un modelo funcional en el que, además de la naturaleza intrínseca de las traducciones, tiene en cuenta los contextos sociales y comunicativos, lo cual le sirve para adoptar una postura intermedia entre la hipótesis de Harris (1980b) y la de Toury (1986), vistas en los apartados anteriores.

Según Lörscher (1992), la habilidad de traducción es una habilidad primitiva que se deriva de forma natural del bilingüismo pero no tiene por qué desarrollarse obligatoriamente hacia un tipo de habilidad más elaborada. En el caso de que esa habilidad primitiva se desarrollase a través de un aprendizaje y una formación especializada, se obtendrían formas de traducción diferentes a las rudimentarias del inicio, hasta alcanzar, como punto final, una habilidad de carácter profesional.

Lörscher $(1988,1992)$ plantea de esta manera una solución a esta controversia que se reduce a una simple cuestión de formas y funciones de la habilidad traductora en general. Es decir, no sólo no existe una única forma de traducción, sino que, dependiendo de los contextos sociales y comunicativos (de nuevo la importancia de los factores extralingüísticos), según este autor, se pueden tener formas diferentes de traducción entre las que distingue las tres siguientes: 
- la traducción o mediación rudimentaria (los traductores naturales)

- la traducción de los aprendices de lenguas extranjeras (los estudiantes de traducción) $)^{33}$

- la traducción profesional (los expertos profesionales en la materia)

Este planteamiento ha servido a estudios más actuales (Sayols Lara 2002) para justificar el hecho de que en el estudio de la adquisición de la competencia traductora la $\mathrm{TN}$ es un tipo de traducción, la que realizan los bilingües de forma más o menos espontánea en circunstancias de la vida cotidiana. Sin embargo, para poder aprender a traducir, no es necesario que previamente se haya sido un traductor natural, puesto que existen individuos bilingües que se presentan a las pruebas de acceso de las escuelas de traducción sin haber tenido tampoco una formación especial en la materia. Partiendo de esto, su conclusión es que no es imprescindible ser bilingüe para aprender a traducir y, por tanto, las tres formas de traducción que acabamos de mencionar no tienen por qué ser un continuum. Sin embargo, en este punto volvemos a entrar de nuevo en la cuestión de qué es lo que se considera un individuo bilingüe: el que Sayols Lara (2002: 13) considere que una persona no es bilingüe porque "el seu domini de la llengua materna és molt més exhaustiu que no pas el de la segona llengua", puede que nos lleve a pensar que no son bilingües equilibrados o simultáneos $(\mathrm{L} 1+\mathrm{L} 1)$ pero no a concluir categóricamente que no son bilingües, ya que podemos encontrar bilingües secuenciales (L1+L2) que tienen un nivel de competencia en la L2 inferior al que tienen en la L1 y sin la cual nunca podrían traducir.

Aunque hemos ido apuntando en los apartados anteriores algunas apreciaciones a cada una de las ideas y los debates más importantes sobre el desarrollo de la competencia traductora, procederemos a continuación a presentar el punto de vista del que partimos en este trabajo.

\footnotetext{
33 Aunque no es el tema que nos ocupa en el presente trabajo, nos gustaría aludir a otro tipo de traducciones que no se contemplan como tales dentro de los estudios de traducción y que son aquellas que se utilizan como herramienta pedagógica para mejorar la competencia lingüística de los aprendices de lenguas extranjeras o de lenguas segundas (Shannon 1990a; Malakoff y Hakuta 1991; entre otros). En este sentido, Lörscher (1992) también considera que son traductores no profesionales los estudiantes de lenguas extranjeras que, en la fase inicial de aprendizaje, suelen traducir textos de la lengua meta, actividad que compara con lo que Harris y Sherwood (1978) denominan auto-traducción en los traductores naturales (aunque en un contexto, el aula, más artificial que natural). Se trataría de bilingües secuenciales (L1+L2) cuya competencia parcial en la lengua que están aprendiendo es lo que les permite traducir, pero de una forma superficial y literal, donde lo que prima son las equivalencias formales y no el aspecto comunicativo del texto. Este tipo de traducciones ha tenido una finalidad didáctica, la de evaluar la competencia lingüística en la lengua segunda o la lengua extranjera, pero podría ser también de interés para el análisis del desarrollo de la competencia traductora como tal.
} 


\subsubsection{Nuestro planteamiento: nuevas consideraciones en el estudio de la TN}

Como conclusión a todas estas posturas teóricas arriba presentadas, aludiremos a los diferentes modelos que describen la relación entre la competencia bilingüe y la competencia traductora, así como a determinadas puntualizaciones que hemos considerado oportuno realizar a raíz de los planteamientos de dichos modelos y que mostramos en la tabla 1 (indicadas como A, B, C y D).

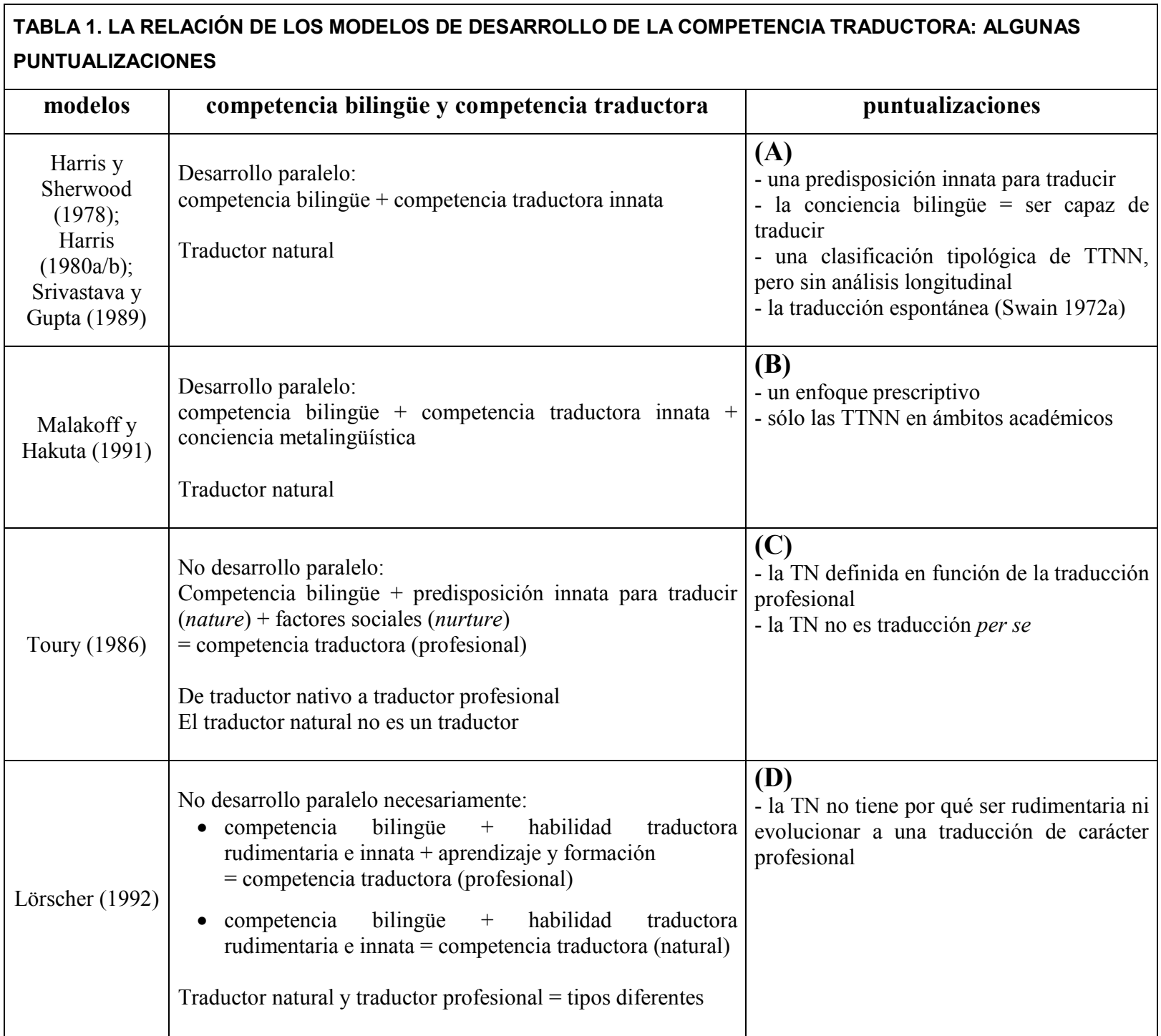

(A) En primer lugar, partiendo de lo presentado en la tabla 1 y retomando algunas de las cuestiones argumentadas en los apartados anteriores, una de las críticas generales que puede hacerse a los planteamientos de Harris y Sherwood (1978) y Harris (1978) es 
que, por un lado, apenas profundizan en el carácter innato de lo que ellos denominan la predisposición para traducir y, por otro, el hecho de que Harris (1980b) no establezca etapas basadas en la edad de un mismo sujeto o en la Longitud Media del Enunciado $(\mathrm{LME})^{34}$, algo que evidencia tanto la falta de una delimitación de edades más precisa en las etapas como la carencia de este tipo de información para tener una perspectiva longitudinal de la clasificación de TTNN que plantea este autor y que ya describimos en el apartado 2.2.1. Al mismo tiempo, el que afirmen que sólo cuando el niño bilingüe sea consciente de la diferenciación de lenguas será capaz de traducir para después considerar que la traducción consciente es la que realiza sólo en la última etapa, nos recuerda al debate planteado en el apartado 1.2. del presente capítulo sobre cuándo podemos hablar de evidencia de conciencia bilingüe en el niño. Precisamente este tipo de debate es lo que nos haría entrar de nuevo en un argumento circular: el hecho de que los niños traduzcan ¿constituiría una evidencia de que tienen una conciencia bilingüe? o sólo cuando el niño sea consciente de su bilingüismo ¿será capaz de traducir?

En este sentido, consideramos que no se puede plantear este argumento circular sino que el hecho de que, tal y como hemos dicho anteriormente, el niño bilingüe esté expuesto a dos lenguas implica que utilicen, inevitablemente, los recursos de ambas como parte del dispositivo de adquisición de la competencia bilingüe, de la misma manera que el niño monolingüe utiliza recursos como la paráfrasis [ver el apartado 2.2.1. de este capítulo], tal y como se representa en el modelo que propone MacSwan $(2000,2005)$ al que, con una serie de adaptaciones, nos acogemos [ver el apartado 2.2. del capítulo 1].

Ahora bien, la forma concreta en que se desarrollan los casos de TN y en cómo esta evoluciona y se plasma en el uso es algo que vamos a constatar dejando hablar a los datos. De esta manera, será la división longitudinal de los casos de TN en etapas (basada en la LMEp de los niños en cada etapa) y el análisis de los primeros casos de TN que producen nuestros sujetos lo que nos sirva para plantear en qué etapa de su desarrollo bilingüe y traductor podemos hablar de la existencia evidente de dos lexicones diferenciados y, por tanto, de la existencia temprana de la competencia y el uso bilingüe en los niños.

\footnotetext{
${ }^{34}$ Tal y como veremos en el capítulo 4 dedicado a los datos, la LMEp (Longitud Media del Enunciado por palabras) es el valor resultante de dividir el número de palabras que produce un sujeto a lo largo de una grabación determinada por el número de enunciados que dicho sujeto produce en dicha grabación. Se trata de una medida que, junto con la versión similar que mide los morfemas o LMEm (Longitud Media del Enunciado por morfemas), se utiliza sistemáticamente en los estudios de adquisición de la L1 (Aguado 1988; Malakoff et al. 1999).
} 
A partir de aquí y, siguiendo con el planteamiento de Harris (1977), habría algunas cuestiones que pueden inducir a la confusión cuando estudiamos con mayor detenimiento parte de los modelos presentados en la tabla 1.

Una de estas cuestiones es que consideramos que la terminología utilizada por Harris (1977) (traducción espontánea frente a traducción inducida) y Swain (1972a) (traducción espontánea frente a traducción común) [ver el apartado 2.2.1.] con respecto al tipo de estímulo que da lugar o no a las traducciones infantiles puede resultar un tanto confusa, pues la variedad de situaciones o contextos en los que pueden darse dichas traducciones puede ser muy amplia, así como la combinación de factores que entran en juego (si aparecen en situaciones naturales o forman parte de una prueba experimental; la naturaleza de lo que se puede considerar un estímulo para que el niño traduzca; si el interlocutor es bilingüe o monolingüe y de quién parte la petición de traducción; cuál es la situación en la que aparecen los casos de $\mathrm{TN}$; etc.). Por este motivo y tal y como plantearemos en el capítulo dedicado a la clasificación de variables para el análisis de los datos [ver el apartado 2 del capítulo 5], consideramos que hay que distinguir, al igual que ya plantearon Lindholm y Padilla (1978b), aquellas traducciones que en este trabajo denominamos inducidas (aquellas en las que el interlocutor le pide al niño directa y expresamente que traduzca o diga algo en la otra lengua), de las traducciones que el niño realiza por iniciativa propia (aquellas que parten del propio niño, sin que ningún interlocutor le induzca expresamente a traducir a otra lengua). De esta forma, también evitamos la confusión que pudiera surgir en lo que respecta a la naturaleza de los datos de producción lingüística y cuyo papel puede tener una mayor o menor relevancia en el tipo de reacción del niño ante un contexto lingüístico determinado. Nos estamos refiriendo con esto al tipo de técnica utilizado para la obtención de datos y que tendría, como resultados, dos tipos de datos: los datos espontáneos (que se producen en un contexto natural, habitual y familiar para los niños) y los datos experimentales (procedentes de pruebas experimentales en las que se insta al niño expresamente a que traduzca o actúe como intérprete entre investigadores monolingües $)^{35}$.

\footnotetext{
${ }^{35}$ Como veremos en el capítulo 5 dedicado al análisis de los datos, el hecho de que la mayoría de los casos de TN que se incluyen en los datos de carácter experimental sean inducidos, no significa necesariamente que en ese tipo de datos no existan casos en los que el niño traduce por iniciativa propia. Lo mismo podemos argumentar con los datos espontáneos, en los que, como veremos más adelante, podremos encontrar casos de TN inducidos expresamente por los interlocutores, de ahí que hayamos creído conveniente separar estas dos cuestiones en la clasificación de las TTNN de nuestro estudio. 
(B) En segundo lugar, y también como una cuestión confusa, es que el término natural puede hacer referencia tanto al contexto en el que dicha traducción se produce (un contexto familiar y no académico), como a las habilidades cognitivas y lingüísticas que participan en ella (Sherwood 2000) y que no se han aprendido a través de medios formales. En este sentido, esta confusión, esta vez de carácter conceptual, puede venir dada también por lo que se entienda por natural y consciente en relación a la actividad traductora ${ }^{36}$. El hecho de que, tal y como plantea Darwish (2000) [ver el apartado 2.2.1.], una traducción sea natural por el mero hecho de ser un acto inconsciente, no tendría razón de ser en el caso de los ejemplos recopilados para el presente estudio (los datos experimentales incluidos), puesto que en todos ellos los sujetos muestran una clara intención de hacerse entender, de comunicarse, de adaptarse al contexto y de responder a las expectativas del interlocutor, ya sea este un miembro de su familia o un investigador monolingüe. Por este motivo, consideramos más adecuado el planteamiento de Harris (1977) y no tanto el de Malakoff y Hakuta (1991) pues, aparte de que en nuestro estudio no vamos a adoptar un enfoque prescriptivo sino descriptivo, tampoco nos centraremos en la TN realizada por niños dentro de un ámbito académico sino en aquella traducción que es natural no sólo por el contexto en el que se produce (el hogar familiar) sino porque es innata en el ser humano, desde el planteamiento teórico que hemos presentado. De hecho, como ya apuntábamos anteriormente [ver el apartado 2.2. del capítulo 1], el proceso y los mecanismos de adquisición bilingüe son semejantes a los característicos de la adquisición monolingüe, de tal manera que podremos observar que tanto los niños bilingües como los monolingües pueden tener en definitiva el mismo recurso para comunicarse (Swain 1972a; Darwish 2000): a este paralelismo se refieren tanto Swain (1972a), cuando afirma que la traducción es un tipo de paráfrasis que pueden realizar sólo los bilingües, como Bialystok (2001), cuando considera que la paráfrasis es una habilidad lingüística utilizada tanto por los monolingües, que disponen sólo de un lexicón, como por los bilingües, los cuales además, al disponer de dos lexicones, pueden utilizar la traducción como recurso comunicativo.

\footnotetext{
${ }^{36}$ El propio Harris (comunicación personal) también se ha planteado la cuestión de si el término natural sería el más adecuado para referirse a este tipo de traducción, pero por un motivo diferente: este término puede confundirse con otro tipo de traducción del mismo nombre que se incluye en los estudios teóricos de traducción y que es aquella que se basa en una versión fiel del texto original (As-Safi y Ash-Sharifi 1997). De hecho, Harris (1992) ya se había planteado denominarlas traducciones naive o ingenuas, pero consideramos que estos calificativos le dan un matiz peyorativo y restan importancia a las traducciones que realizan los niños bilingües.
} 
(C) En tercer lugar, aunque ya hemos comentado nuestro punto de vista en el apartado 2.2.3. dedicado a Toury (1986), conviene retomar la idea de este autor de que las traducciones y los traductores (siempre en un contexto profesional) han de tener una función social. En este sentido, hay que tener en cuenta que los sujetos del presente estudio, niños bilingües simultáneos y equilibrados, parte de cuyos datos presentamos en este estudio, son traductores naturales que no cumplen una función social del tipo planteado por Toury, pero aún así las TTNN que realizan (los datos experimentales incluidos) satisfacen las demandas comunicativas de las circunstancias en las que aparecen, como plantea Lörscher $(1988,1992)$. Por tanto, son traducciones que tienen una función comunicativa (aunque Toury (1986) difiera al respecto) y que se dan en un contexto social igual de real, aunque quizás más restringido o aislado, puesto que se limitan al hogar familiar bilingüe (al menos los espontáneos) y no pertenecen al contexto de una comunidad bilingüe en sí misma (como las que producen los “brokers" o mediadores lingüísticos a los que nos referimos en el apartado 1.3.).

(D) Siguiendo con este último planteamiento, nuestra postura puede inclinarse más hacia la de Lörscher (1992), aunque con algunas matizaciones: la TN es una forma de traducción diferente a la profesional, pero no se la puede considerar rudimentaria o una simple mediación, pues, aunque en determinados ejemplos los enunciados pueden ser simples, esto no quiere decir que los mecanismos que se utilicen para realizar traducciones sean simples o poco complicados. Es más, hay ocasiones en las que las traducciones producidas son muy complejas, más que los propios enunciados originales. En todo caso, no se trata únicamente de lo simples o rudimentarias que sean las TTNN o de una cuestión de que las TTNN tengan que evolucionar a un tipo de traducciones de carácter profesional, como apuntamos en el apartado 2.2.4., sino que es una cuestión de tratarlas de la misma manera que algunos autores (Liceras et al. 2005, entre otros) tratan la AC [ver el apartado 5.1.3. del capítulo 1] en los niños bilingües simultáneos: como parte del proceso de adquisición del bilingüismo como primera lengua.

Para finalizar, consideramos que el que las TTNN se realicen a pesar de que los hablantes bilingües no hayan recibido una formación académica en la materia, no es óbice para seguir considerándolas un tipo de traducción, aunque sea diferente a la traducción profesional. El hecho de que se aluda a la dificultad que puedan tener los bilingües para realizar TTNN (Von Raffler-Engel 1970; Kirstein 1972; Steiner 1975; Wei 2000, entre 
otros) no ha sido avalado por ningún estudio empírico dedicado al análisis de este tema. Es más, hay ciertos puntos en los que no se ponen de acuerdo, pues, según algunos de estos autores, los bilingües simultáneos tienen menos facilidad para traducir que los bilingües que han adquirido una formación o una experiencia en la materia, mientras que otros estudios (Srivastava y Gupta 1989; Lörscher 1992) consideran que son los niños bilingües simultáneos los que son capaces de hacerlo sin dificultad.

Como conclusión general a este apartado, podemos afirmar que muchas son las cuestiones a debate que giran en torno a lo que se entiende por TN y su relación paralela con el bilingüismo. Quizás todas las posturas diferentes a las que hemos hecho referencia en este apartado tengan como origen lo que se entiende por traducción y traductor, de ahí que dediquemos el apartado siguiente a ubicar la TN en los estudios de traducción y ver lo que estos pueden aportar al estudio de la TN en la que se centra el presente estudio.

\section{LA TN Y LOS ESTUDIOS TEÓRICOS DE TRADUCCIÓN}

Como hemos visto en uno de los apartados anteriores de este capítulo [ver el apartado 2.2.], la mayoría de los estudios teóricos de traducción se han dedicado a aludir a los traductores naturales teniendo como referencia a los traductores profesionales. Así, la TN siempre se ha definido por aquellas características que la diferencian de las traducciones profesionales, de ahí que muchas veces se refieran a ella, sobre todo a la TN realizada por niños, por lo que no es o por lo que no cumple más que por sus características intrínsecas y como otro tipo de traducción. El motivo por el cual se ha venido produciendo esta situación durante tanto tiempo es porque, desde los estudios teóricos de traducción, se ha considerado que la TN no entra dentro del concepto de traducción tan restringido que dichos estudios manejan. De estas y otras cuestiones trataremos a continuación. 


\subsection{Los traductores naturales frente a los traductores profesionales: diferencias $y$ similitudes}

Como un tipo de traducción subordinada a la traducción profesional (TP) dentro de los estudios teóricos de traducción, Lörscher (1992), entre otros, analiza las diferencias y las semejanzas entre los tipos de producciones en la actividad traductora que nos ayuden a establecer una conexión entre la TN y la TP.

La traducción llevada a cabo por los traductores profesionales es una actividad muy valorada dentro de los estudios de traducción, pues es el resultado de un trabajo elaborado y de una formación extensa que estos han adquirido en ámbitos institucionales, de tal forma que tienen que someterse a unas normas de traducción (lo que Ljudskanov (1969: 50) denominaba “certains critères acceptés a priori”); los traductores naturales, aunque no han recibido ninguna formación académica o profesional en la materia, pueden recurrir a las habilidades lingüísticas y cognitivas que les proporciona el hecho de ser bilingües, pero no a los criterios normativos y académicos que proporciona el conocimiento lingüístico explícito (Srivastava y Gupta 1989).

Precisamente por esto último, la finalidad de los traductores naturales es la de comunicar el mensaje de forma aceptable y comprensible y no la de preocuparse por seguir los estándares de traducción. En este sentido, gozan de una mayor libertad a la hora de expresarse que los traductores profesionales, quienes, al estar limitados por reglas y principios establecidos por los estudios de traducción, muchas veces se esfuerzan por proporcionar en el texto meta un equivalente perfecto y lo más cercano posible al texto origen (Harris 1992). Al mismo tiempo, también habría que tener en cuenta las restricciones propias de la TP como profesión, en la que la labor de traducción se ve supeditada a los requerimientos del contexto o del cliente que haya solicitado esa traducción.

Otro criterio que se establece para la distinción entre los traductores profesionales y los naturales es la calidad del producto final. Suele achacarse una baja calidad a las TTNN en lo que respecta al nivel de la estructura lingüística, pero no en lo referente al nivel semántico. Sin embargo, hay que tener en cuenta que este criterio de valorar la calidad de las traducciones parte de un punto de vista prescriptivo, en el que se comparan las TTNN realizadas por niños bilingües con las que realiza un adulto, tal y como apuntábamos en el 
apartado 2.2.3. de este capítulo. De todas formas, también se echaría en falta que esta comparación de la calidad se viera refrendada o rechazada por estudios de carácter más práctico o empírico ${ }^{37}$.

Al mismo tiempo, los traductores naturales se diferencian de los profesionales en que actúan en contextos familiares o comunitarios, es decir, en situaciones menos formales o no institucionales. Este sería el caso, por ejemplo, de los intérpretes no profesionales (Knapp-Potthoff y Knapp 1987) o de aquellos bilingües que actúan de mediadores interpersonales pero no de manera profesional (Müller 1989).

Ante estas diferencias generales, parecería raro encontrar características comunes entre ambos tipos de traductores. Sin embargo, es precisamente en el punto anterior en el que pueden coincidir: los traductores naturales y los profesionales se pueden encontrar ante las mismas situaciones comunicativas que, en ocasiones, pertenecen a ámbitos bastante especializados como traducir una película, documentos administrativos, jurídicos o bancarios, informes médicos (Harris 1978; Harris y Sherwood 1978; Buchanan 1993; Shannon 1990a, 1996; Orellana 2003; Valdés 2003, entre otros) e incluso textos literarios (Philips 1993; Aubin 1994). Así, mostraremos un ejemplo que da Shannon (1990a), reproducido en (45), en el que Leti, una niña de 11 años que vive en EEUU y que es bilingüe inglés/español, ha de hacer de intérprete entre el médico y su madre que apenas entiende el inglés.

\section{Leti: bilingüe inglés/español}

Doctor: How do you feel about returning to work on the first of September?

Leti: First of September? That's when we're going to school?

Doctor: No. I want your mom to respond. How does she feel about returning to work?

Leti: Oh... ¿que cómo se sentiría si va a trabajar el primero de septiembre?

Mother: Dile que yo no me siento bien pero si él quiere mandarme que...

Leti: She doesn't feel well, but if you want to send her it's ok with her.

Doctor: Well, we don't want to send her if she's not going to be able to work.

Mother: ¿Qué dice, Leti?

Leti: Que no la quiere mandar si no puede trabajar.

(Shannon 1990a)

\footnotetext{
${ }^{37}$ En cuanto a los estudios empíricos de traducción, el de Christoffells et al. (2003) se centra en el análisis de la memoria léxica dentro del proceso de la interpretación simultánea de un grupo de 24 estudiantes (adultos) que tienen el holandés como L1 y el inglés como L2 y que carecen de experiencia previa en la interpretación. En la prueba experimental se les pide traducir un texto presentado oralmente a la lengua meta y una de las conclusiones a la que llegan estos autores es que la habilidad para traducir de forma simultánea que tienen los bilingües sin preparación en la materia es algo que debería tenerse en cuenta en las teorías actuales sobre el procesamiento del lenguaje y, añadimos nosotros, sobre los estudios de traducción, ya que se accede a esta habilidad sin la "contaminación" de las estrategias idiosincrásicas que estos intérpretes pueden haber desarrollado (Shlesinger 1994).
} 
Tal y como veíamos en el ejemplo (37) de un apartado anterior dedicado a la mediación lingüística de niños bilingües, también llamado "brokering" [ver el apartado 1.3.], en (45) se observa que una niña es capaz de realizar traducciones o interpretaciones dentro de un ámbito distinto al familiar pero igual de cotidiano que es el de la consulta de un médico, algo que ya está documentado cuando se alude a que los niños y adolescentes pertenecientes a familias de inmigrantes tienen que hacer de intérpretes sobre todo para algunos parientes en diferentes ámbitos sociales.

Asimismo, los traductores naturales y los traductores profesionales pueden utilizar las mismas técnicas o estrategias de traducción, aunque los traductores naturales son los que, por lo general, tienen más problemas de transferencia estructural o de transcodificación que de interpretación (Harris 1980a), lo cual puede deberse a que, como aludíamos anteriormente, la finalidad de la TN es la de captar y transmitir el mensaje, pasando un poco más por alto la expresión formal, algo con lo que los traductores profesionales no se muestran tolerantes.

Otro punto de conexión entre ambos es que los traductores naturales suelen ser intérpretes naturales (un término que se adecua más a los niños bilingües de menor edad), puesto que normalmente las producciones de este tipo están asociadas al medio oral y no tanto al medio escrito, lo cual no es nuevo, puesto que dentro del ámbito de la traducción profesional, también se distingue entre la interpretación y la traducción ${ }^{38}$.

Por último, habría que destacar que, al igual que los traductores profesionales, los traductores naturales se convierten en canales de comunicación en una doble dirección (sobre todo si se trata de bilingües equilibrados), aunque lo más común dentro de la práctica profesional es que los traductores suelan traducir a la L1 y que necesiten la revisión de un hablante nativo en sus traducciones a la L2.

Según lo expuesto en este apartado, lo primero que llama la atención es que siempre se realizan análisis comparativos entre la TN y la TP (como veíamos en Lörscher (1992), apartado 2.2.4.) teniendo como punto de referencia la TP, de modo que la TN casi siempre se define con respecto a la profesional. Esto es lo que puede haber contribuido a subordinar el estudio de este tipo de traducción y a veces a denostarlo. Sin embargo, quizás

\footnotetext{
38 Siguiendo el razonamiento de Harris (1977; 1978), obviamente, si se tienen en cuenta las traducciones realizadas por niños de la edad que tienen los sujetos del presente estudio $(2 ; 00-6 ; 03)$ no merece la pena hacer la distinción teórica que existe entre traducción e interpretación, puesto que en el presente trabajo sólo estudiamos el lenguaje oral y no el escrito. [ver la nota 19].
} 
la cuestión clave no sea comparar la TN con la TP, sino aceptar que las TTNN, incluidas las realizadas por niños, son traducciones per se, que son manifestaciones lingüísticas de naturaleza diferente e independiente de la TP y, en definitiva, que tienen entidad propia y, por tanto, se pueden estudiar por sí mismas sin caer en una eterna comparación con la TP o, incluso, con la TN realizada por bilingües adultos. En este sentido, esta traducción, por ser una actividad y un elemento fundamental del hablante bilingüe, ha de tener su propio y destacado lugar en los estudios de adquisición y la que nos va a servir como punto de partida de este trabajo de investigación, tal y como planteamos en el siguiente apartado.

\subsection{Los niños bilingües como traductores naturales}

A raíz de lo expuesto en el anterior apartado, consideramos pertinente tener que volver a aludir a la cuestión relacionada tanto con el tipo de hablante (niño y adulto) como con el tipo de bilingüe del que hablamos (simultáneo o secuencial) y con su grado de competencia (equilibrado o dominante) en cada una de las lenguas participantes en la actividad traductora.

En este sentido, es importante recalcar que este estudio se va a centrar, a su vez, en un tipo de traductor natural: el niño bilingüe simultáneo con una competencia semejante en ambas lenguas. En estos casos, la cuestión que se plantea es a qué edad se manifiesta esa habilidad innata para traducir: en algunos estudios se argumenta que ya está constatada a la edad de 5;00 años (Harris 1973, 1977, 1980a; Harris y Sherwood 1978) y en otros que en los niños esta habilidad está poco desarrollada (Lörscher 1992). Atendiendo a estos planteamientos, la postura de Lörscher (1992) se encuentra más cercana a la de Toury (1986), que, como ya hemos visto en los apartados 2.2.3. y 2.2.4., considera que dicha habilidad no se puede desarrollar hasta que el individuo no alcance el nivel de competencia bilingüe necesario para poder producir traducciones adecuadas desde el punto de vista de la función comunicativa, el estilo o el tipo textual.

Sin embargo, aparte de estas disquisiciones evolutivas, lo que se ha venido documentando en los últimos 20 años es que para muchos niños el traducir es una actividad que forma parte de su vida cotidiana como bilingües (Grosjean 1982; Shannon 1990a, 1996; Sayols Lara 2002; Valdés 2003; etc.). Desgraciadamente, a diferencia de la $\mathrm{TP}$, existen pocos estudios que analicen la habilidad de TN de estos niños: algunos de estos 
estudios (Shannon 1996a/b; Tse 1996; Hall y Sham 1998; Walichowski 2001; Valdés 2003; Orellana et al. 2003a/b; Hall 2004; etc.) plantean este tema como algo anecdótico o desde un punto de vista exclusivamente sociolingüístico y otros (Kroll y Stewart 1994; Kroll et al. 1998; Sánchez-Casas 1999; Gollan y Kroll 2001; Davidson et al. 1997; etc.) la utilizan como herramienta para analizar la competencia lingüística, pero son muchos los autores que le restan la importancia que merece dentro de los estudios teóricos de traducción (Delisle 1984; Krings 1986; Keith 1989; Newmark 1988, 1991; Neubert y Shrieve 1992, entre otros).

Así pues, para poder ir aplicando a nuestro propio estudio las diferentes aportaciones mostradas en este capítulo dedicado a la TN, aludiremos a que los sujetos participantes en el presente estudio comienzan a traducir de forma natural y constatada antes de los 5;00 años de edad, dando lugar a producciones lingüísticas que incluso, aunque en un contexto social más reducido como es el familiar, encajarían en la propuesta de lo que para Toury (1986) es una traducción adecuada, algo que trataremos en el capítulo 3 dedicado a las propuestas que planteamos en el presente trabajo de investigación.

Una vez que se recojan las traducciones realizadas por los niños bilingües, es necesario analizar los procedimientos que estos utilizan, así como el proceso que siguen cuando traducen, para describir cómo funciona la competencia traductora innata, cuáles son sus características y cómo evoluciona, lo cual nos puede llevar a profundizar aún más en el proceso de traducción. De este análisis se beneficiarían los traductores profesionales y la teoría de la traducción, lo cual es, precisamente, lo que había planteado Harris (1977; 1992) cuando afirmó que no debería subestimarse la TN y que, de hecho, el estudio científico de la traducción debiera partir del análisis de este tipo de traducción, pues es una habilidad natural previa a la adquisición de un nivel de competencia profesional. Es decir, debemos partir del análisis de la traducción en estado natural, de la traducción que realizan los niños desde edades muy tempranas, pues es aquí donde se encuentra la base de la competencia traductora.

Evidentemente, la valoración que se pueda llevar a cabo sobre las traducciones que realizan los niños bilingües puede variar dependiendo, no sólo de la edad de estos sujetos, sino también de la competencia que tengan en cada una de las lenguas, pero esto es algo que también puede darse en otro tipo de traducciones como las profesionales. En todo caso, si bien los niños pueden no tener todavía un alto dominio de las estructuras sintácticas de las lenguas que manejan y esto puede afectar al resultado de la traducción en cualquiera de 
las lenguas (como parte del proceso de adquisición de las dos lenguas y del desarrollo de su competencia traductora), sus traducciones suelen destacar por la calidad de carácter semántico (Harris 1980a; Malakoff y Hakuta 1991; Malakoff 1992), teniendo en cuenta que no siempre lo que traducen son unidades lingüísticas mínimas, tal y como mostraremos en los datos de producción lingüística de los sujetos del presente estudio.

Así pues, y ante lo planteado hasta ahora sobre la TN realizada por niños bilingües, dada la escasez de estudios empíricos sobre este fenómeno y sobre el desarrollo de la competencia traductora, los datos de producción que presentamos en este trabajo de investigación nos aportarán información sobre cuestiones como cuándo se puede afirmar que la habilidad de traducción en estos niños está constatada, qué tipo de traducciones realizan (no tanto si son traducciones pobres o más elaboradas sino a qué mecanismos lingüísticos responden), cómo funciona esa competencia traductora en los niños bilingües de nuestro estudio o, en definitiva, qué nos dicen de la forma en que está representado el lenguaje (y sus unidades) en la mente del bilingüe (de estas y otras cuestiones trataremos en mayor profundidad en el capítulo 4, dedicado a las propuestas del presente estudio).

Obviamente, por todo lo que hemos visto hasta ahora en este capítulo, el investigar este tipo de cuestiones implica un cambio de perspectiva en los estudios teóricos de traducción, el cual constituirá el tema principal del siguiente apartado.

\subsection{Las consecuencias de la importancia de la TN en los estudios de traducción: la ampliación del concepto de traducción y la necesidad de un enfoque descriptivo}

Debido a que la TN no viene amparada por una formación académica o institucional, no recibe el reconocimiento de los estudios teóricos de traducción (centrados en la TP de textos científico-técnicos y literarios) por considerar que la labor que realizan los traductores naturales no debería estar a la misma altura que la que realizan los traductores profesionales, pues carece de rigor científico. Sin embargo, lo que se está enfatizando con este enfoque es una destreza especializada cuya finalidad es proporcionar en la lengua meta un texto que sea equivalente desde el punto de vista semántico, funcional, textual, etc. al texto origen, de tal forma que, al adoptar dicho enfoque, las 
producciones de los traductores naturales no encajan con los criterios teóricos ideales y, por tanto, no pueden entrar dentro de esa definición.

Por este motivo, y para poder incluir el concepto y el término de traducción natural en los estudios teóricos de traducción, Harris (1980b) propone dar un nuevo enfoque a la definición de traducción, para lo cual se centrará en las tres consideraciones fundamentales que presentamos a continuación y que nos servirán, a su vez, para presentar con mayor detalle algunas de las cuestiones principales que plantea dicho enfoque.

La primera de las características de la $\mathrm{TN}$ es que en este tipo de traducción se da una mayor importancia a la equivalencia semántica frente a la equivalencia formal. Es decir, la TN es una traducción basada no tanto en el aspecto formal, sino, y sobre todo, en una equivalencia de significado o una relación semántico-conceptual entre el texto origen y el texto meta en el nivel de la FL, remitiéndonos al modelo propuesto por MacSwan (2000, 2005) [ver el apartado 2.2. del capítulo 1].

La segunda consideración importante hace referencia al tipo de producciones bilingües que tratamos, ya que muchas de las producciones lingüísticas que han recibido distintos nombres en diversos estudios sobre adquisición bilingüe (yuxtaposición de EET, duplicaciones, emparejamientos, auto-correcciones, etc.) [ver el apartado 1.2. del presente capítulo] se corresponden con lo que nosotros consideramos que es TN, pues en ellas se produce un trasvase de significado de una lengua a otra dentro de la misma situación comunicativa.

Finalmente, la tercera consideración se centra en otro parámetro que hay que tener en cuenta como característica fundamental de la TN y es el tipo de traductor, pues dicha traducción puede ser realizada por personas que a un nivel u otro son bilingües y que tienen o no una formación previa en la materia.

Partiendo de estas características, consideramos, en primer lugar, que es importante insistir en que el que se defina traducción como una equivalencia de significado es algo que se ha venido haciendo tradicionalmente en los estudios de traducción. Sin embargo, en la literatura relacionada con el aspecto teórico de la traducción se ha evolucionado en lo que al concepto de equivalencia se refiere. Así, desde un punto de vista tradicional (Delisle 1984, Toury 1984, entre otros), la traducción ha de responder a una relación de identidad entre dos textos, en la que el TM sea equivalente tanto desde el punto semántico, como desde el punto de vista pragmático y estilístico, al TO. Esta interpretación del concepto de 
equivalencia en traducción ha dado lugar a un enfoque prescriptivo en el que se parte de una serie de criterios a priori por los cuales el traductor ha de regirse con el fin de interpretar el sentido del TO "correctamente". En cambio, otros investigadores del campo de la traducción (Nida 1964, 1976; Seleskovitch 1976; Rabadán Álvarez 1991, entre otros) adoptan un enfoque distinto con respecto a este concepto, dotándole de un carácter más dinámico o comunicativo, de tal forma que consideran que no es tanto el componente formal sino el aspecto semántico-pragmático, o la reproducción del mensaje a los interlocutores meta, lo que ha de primar en el concepto de equivalencia. Precisamente, tendremos en cuenta las implicaciones de esta definición en lo que hemos denominado la estructura semántico-conceptual o Forma Lógica (FL) cuando tratemos con detalle la descripción de las variables de clasificación de las TTNN realizadas por nuestros sujetos y recopiladas en nuestro corpus de datos, así como el análisis de las mismas [ver los apartados 2 y 3 del capítulo 5 , respectivamente].

Sin embargo, a pesar del enfoque comunicativo, los trabajos teóricos a los que hemos hecho referencia siguen partiendo de los criterios de equivalencia que el traductor profesional ha de respetar, por lo que sus planteamientos o bien no tienen en cuenta la TN como un tipo de traducción o bien, si la tienen en cuenta (Toury 1984; Hurtado Albir 2001), consideran que constituye la base de la competencia traductora pero que no está a la misma altura que la traducción profesional.

Al mismo tiempo, hay que tener en cuenta que, a pesar de que se podrían incluir diversos parámetros a la hora de definir lo que se entiende por traducción como producto (Wadensjó 1998; Halverson 1998), tradicionalmente los estudios teóricos de traducción se han centrado en un enfoque textual y no empírico (Harris 1992), de tal forma que es corriente encontrar posturas entre los teóricos de traducción, como la de Neubert y Shrieve (1992), que defienden que el texto ha de ser el primer objeto de estudio de la traducción y no los casos concretos de la $\mathrm{TN}$, cuya existencia no reconocen.

En segundo lugar, una de las consecuencias que traería consigo esta propuesta de ampliar el concepto de traducción sería la de incluir dentro del término traducción no sólo las traducciones del ámbito profesional, sino también diferentes tipos de TN o de producciones a las que aluden diversos autores (aunque no todos las consideren traducciones per se, tal y como indican los adjetivos con los que las califican). Este tipo de producciones resultan también interesantes desde el punto de vista teórico $\mathrm{y}$, de hecho, 
deberían ser prioritarias dentro del estudio científico de la traducción del que habla Harris (1973).

Al hilo de lo que acabamos de plantear, la variedad terminológica aplicada a producciones de diverso tipo que comparten la característica de base que es la transmisión de un mensaje o información de una lengua a otra, puede que haya dificultado la tarea de dirigir los estudios sobre TN a una investigación que parta de un origen común. Por ello, hemos considerado oportuno presentar, a continuación, una relación de términos que podemos encontrar a lo largo de la bibliografía dedicada a este tipo de producciones, tanto en el ámbito de la adquisición bilingüe como en el de la traducción, así como las características fundamentales (formales o funcionales) que dan los autores que las mencionan con el fin de comprobar que suelen utilizar un nombre distinto para designar el mismo fenómeno.

- las traducciones naturales, en las que lo más importante es el contenido o la transmisión de información frente a la expresión lingüística (Harris 1977);

- las mediaciones o traducciones rudimentarias, aquellas que producen los bilingües en situaciones comunicativas reales y en las que se da más importancia al sentido que a la forma (Lörscher 1988; 1992);

- las traducciones limitadas o aquellas que producen los niños cuando da comienzo su bilingüismo (Toury 1984);

- las auto-traducciones, aquellas que surgen por iniciativa propia del sujeto o por venir provocadas por otro interlocutor, independientemente de que resulten redundantes o no desde el punto de vista funcional (Harris 1980b);

- los casos de duplicación o enunciados que primero se dicen en una lengua y luego en otra sin pausas internas (Redlinger y Park 1980);

- los EET yuxtapuestos que se refieren a aquella combinación de sinónimos en un mismo enunciado (Vihman 1985; Paradis et al. 2000);

- las auto-reparaciones o auto-correcciones en las que, con el fin de que no se interrumpa la comunicación con su interlocutor, el bilingüe expresa un mismo concepto en ambas lenguas durante una conversación (Lanza 1997); 
- las traducciones pedagógicas o escolares, que, en el caso de los bilingües secuenciales, niños o adultos, sirven para mejorar la competencia tanto de la L1 como de la L2 (Malakoff 1991; Lörscher 1992);

- las mediaciones lingüísticas (o “brokering”), que son las que facilitan la comunicación entre dos partes lingüística y culturalmente diferentes (Tse 1996; Hall 2004).

El estudio de este tipo de traducciones o producciones lingüísticas relacionadas de una u otra manera con la traducción (como la reformulación, la repetición de mensajes en la otra lengua, enunciados en la otra lengua que sirven para retomar una comunicación interrumpida, etc.) plantearía nuevos retos para el estudio de la traducción en general y de la traducción profesional en particular.

En tercer lugar, y en lo que respecta a la característica relacionada con el tipo de traductor, si tenemos en cuenta la terminología que acabamos de exponer, podríamos generalizar más en lo que respecta a las personas que pueden llevar a cabo una traducción $\mathrm{y}$, por tanto, podemos encontrar una variedad terminológica semejante a la anterior cuando hablamos del concepto de traductor. De esta manera, podemos aludir a los siguientes términos que se han venido incluyendo en varios estudios relacionados con este fenómeno, siendo la mayoría de ellos trabajos de carácter sociolingüístico.

- los traductores naturales (Harris 1973-2003; Harris y Sherwood 1978; LozèsLawani 1994; Bullock y Harris 1997; Sherwood 2000);

- los traductores rudimentarios (Lörscher 1992);

- los mediadores lingüísticos o “brokers” (Knapp-Potthoff y Knapp 1986, 1987; Tse 1996; Walichowski 2001; Orellana et al. 2003a/b; Hall 2004);

- los intermediarios de lenguas (Shannon 1990a, 1996);

- los intérpretes no profesionales (Knapp-Potthoff y Knapp 1987; Bullock y Harris 1997);

- los traductores/intérpretes novatos (Valdés 2003). 
La mayoría de estos autores citados consideran que un análisis de este tipo de traductores podría servir para profundizar no sólo en el análisis de la TN, sino también para establecer diferencias y similitudes entre los diferentes papeles que dichos individuos pueden desempeñar en una interacción lingüística en la que entre en juego la traducción.

Hasta aquí hemos presentado lo que supone este nuevo concepto más amplio de traducción, de tal forma que en el presente trabajo definiremos la TN como un fenómeno con entidad propia cuya característica fundamental es la transmisión del mensaje de un enunciado a otra lengua. Al mismo tiempo, se trata de un tipo de producción lingüística muy relacionada con el proceso de adquisición bilingüe $\mathrm{y}$, como tal producción, tiene propiedades tanto de carácter lingüístico (más inherentes al fenómeno) como de carácter contextual (más externos al fenómeno en sí), de tal forma que, al estudiar la TN, consideramos que hay que tener en cuenta las diversas cuestiones que puedan surgir de ambos tipos de propiedades, tal y como plantearemos en el capítulo 3. Finalmente, y por este motivo, partimos de la idea de que el estudio de la TN ha de enmarcarse en un enfoque descriptivo y explicativo del bilingüismo y de la traducción más que en el clásico enfoque que ha constituido la base de la teoría de la traducción hasta este momento.

Centrándonos más concretamente en cómo la TN puede encajar dentro de ese nuevo concepto, el adoptar un acercamiento descriptivo y explicativo no es una tarea fácil desde el momento en que la mayoría de los autores, incluso aquellos estudiosos que lo proponen, no pueden evitar la inclinación prescriptiva en algunos de sus razonamientos y caer en ciertas contradicciones como la aparente necesidad de evaluar las TTNN como si de traducciones profesionales se tratasen. Así, por ejemplo, como hemos visto a lo largo del capítulo, Swain (1972b), Swain et al. (1974) y Malakoff y Hakuta (1991) aluden a la calidad de las TTNN cuando hablan de traductores buenos y traductores pobres; Lörscher (1988, 1992) las denomina traducciones rudimentarias o primitivas; y Harris (1978: 424) alude a "the pathology of natural translation", es decir, a los errores leves propios de los traductores naturales (como los "false friends" u otras interferencias, que son consideradas errores leves en traductores naturales pero graves en el caso de los traductores profesionales), dejando entrever prejuicios normativos. De hecho, sería preferible no tanto aplicar a este tipo de traducciones un criterio de evaluación de la calidad diferente al que se aplica a las traducciones profesionales o a las traducciones de los estudiantes de las escuelas de traducción, sino saber dar cuenta de los casos de TN, es decir, por qué ocurren, qué es lo que subyace a su aparición o su uso (comunicación personal, Harris 2003), qué 
nos dicen de la estructura y funcionamiento del lenguaje, etc., que es lo que pretendemos hacer en el presente trabajo de investigación.

Por tanto, consideramos que el tipo de criterio o criterios que hay que tener en cuenta con respecto al análisis de las TTNN ha de ser distinto al que se aplique no sólo al bilingüe adulto sino también al traductor profesional, ya que necesariamente las condiciones internas (la madurez cognitiva y lingüística de los sujetos, por ejemplo) y las externas (las necesidades comunicativas o la función social de las traducciones que realizan) en las que se producen estas traducciones son diferentes. Es decir, no se trata de evaluar la calidad de las traducciones, sino de tratar de analizar los mecanismos internos que las rigen y explicar así cómo se va desarrollando la competencia traductora partiendo de ese conocimiento innato de la competencia en ambas lenguas. 


\title{
CAPÍTULO 3: LOS PLANTEAMIENTOS TEÓRICO- METODOLÓGICOS DEL PRESENTE ESTUDIO
}

\author{
LONGITUDINAL
}

Dentro de este capítulo nos proponemos establecer la base teórica y práctica para nuestro análisis a partir de las propuestas presentadas en capítulos anteriores. Es decir, tomaremos como centro de nuestro estudio la TN per se en lugar de la adquisición, los estudios de traducción o la teoría lingüística general. Desde la perspectiva que adoptamos, y tomando como base la definición de Harris (1977), la TN será aquella que realizan los niños bilingües en su vida cotidiana sin haber recibido una instrucción formal en la materia.

De esta manera, las cuestiones que trataremos en la primera parte de este capítulo serán las siguientes. En primer lugar, cómo integrar la TN en los estudios de bilingüismo para, a continuación, plantear la relación que se puede establecer entre este fenómeno y otros fenómenos relacionados con la mezcla de lenguas como es la alternancia de códigos (AC). Siguiendo esta línea, mostraremos cómo la TN puede considerarse también una habilidad lingüística y comunicativa semejante a otros fenómenos característicos de la adquisición bilingüe como es la $\mathrm{AC}$, que, a diferencia de la $\mathrm{TN}$, ha recibido una gran atención por parte de los estudios de bilingüismo. En segundo lugar, nuestra intención, además de estudiar la $\mathrm{TN}$ en relación a otros fenómenos bilingües, es fundamentalmente demostrar que la $\mathrm{TN}$ ha de ser parte integrante tanto de los estudios de bilingüismo infantil como de los estudios teóricos de traducción. En tercer lugar, pretendemos analizar la TN, 
concretamente la realizada por niños bilingües, como un fenómeno con entidad propia, para lo cual hemos considerado indispensable contar con datos de carácter longitudinal y que provengan de niños bilingües.

Precisamente en la segunda parte de este capítulo, presentaremos la importancia de estos datos, ya que, aunque partamos de la teoría lingüística para analizarlos, avalar o rechazar determinadas hipótesis (planteadas tanto en el campo del bilingüismo como en el de la traducción), tenemos que remitirnos constantemente a la información que nos ofrece la producción lingüística de nuestros sujetos, como veremos en el capítulo dedicado al análisis de los datos.

Finalmente, en la tercera parte, dado que en este trabajo partimos de una selección de datos procedente de un estudio longitudinal (Fernández Fuertes et al. 2002-2005), aludiremos a ciertos aspectos de la metodología de recogida de datos lingüísticos que han seguido algunos estudios longitudinales de bilingüismo infantil, así como la importancia en la mayoría de dichos estudios, y en el nuestro, de la estrategia comunicativa que siguen los padres y que se conoce con el nombre de una persona-una lengua (Ronjat 1913).

\section{1. ¿CÓMO ENCAJA LA TN EN LOS ESTUDIOS DE ADQUISICIÓN BILINGÜE SIMULTÁNEA Y EN LOS ESTUDIOS DE TRADUCCIÓN?}

Con el fin de estudiar la TN dentro de los estudios de bilingüismo y, concretamente, su relación con otros fenómenos característicos de la adquisición bilingüe simultánea como la AC, podríamos partir de lo planteado por Muysken (1995) cuando afirma que, en muchas situaciones donde se produce un contacto de lenguas, confluyen una serie de fenómenos interrelacionados: la mezcla de lenguas, la alternancia de códigos, el préstamo, la interferencia, etc. Entre estos fenómenos podríamos incluir también el de la traducción que realizan los niños bilingües en situaciones determinadas. Ahora bien, ¿qué lugar ocuparía esta TN dentro de las diversas clasificaciones a las que hemos hecho referencia anteriormente en nuestro estudio [ver el apartado 5.1.1. del capítulo 1]? Para responder a esta pregunta, en primer lugar, vamos a proponer una clasificación de los diferentes fenómenos asociados al contacto de lenguas en la que ubicar la TN como fenómeno relacionado con la mezcla de lenguas y, concretamente, como un tipo de cambio 
de códigos (CC) que se puede dar en el discurso bilingüe. A partir de esta propuesta, intentaremos aclarar fundamentalmente las diferencias que existen entre lo que nosotros denominamos AC y la TN con el fin de dotar a este fenómeno de entidad propia y con características especificas en el desarrollo de la adquisición bilingüe.

En segundo lugar, dedicaremos un apartado a las aportaciones que supondría el análisis de la TN desde el punto de vista de los estudios teóricos de traducción para, finalmente, reconocer que tanto dentro de este tipo de estudios como dentro de los estudios de adquisición bilingüe, necesitamos partir de los datos de producción lingüística de niños bilingües para poder analizar los mecanismos que operan en la realización de TTNN por parte de este tipo de sujetos.

\subsection{Una propuesta de clasificación de la mezcla de lenguas: el Cambio de Códigos frente a la Alternancia de Códigos}

Basándonos en las clasificaciones de otros autores (Pfaff 1979; Lanza 1992, 1997; Meisel 1989; Köppe y Meisel 1995 y McClure 1981) [ver el apartado 5.1.1. del capítulo 1], presentamos a continuación nuestra propia propuesta de clasificación que integra la TN con otros fenómenos típicos de situaciones en las que se produce mezcla de lenguas. Así, el siguiente diagrama 14 constituye una combinación de las clasificaciones y los diferentes aspectos relacionados con la mezcla de lenguas que tratamos en anteriores apartados y que representa nuestra propia propuesta de clasificación, tal y como aparece a continuación.

Diagrama 14. La mezcla de lenguas y la TN: propuesta de clasificación

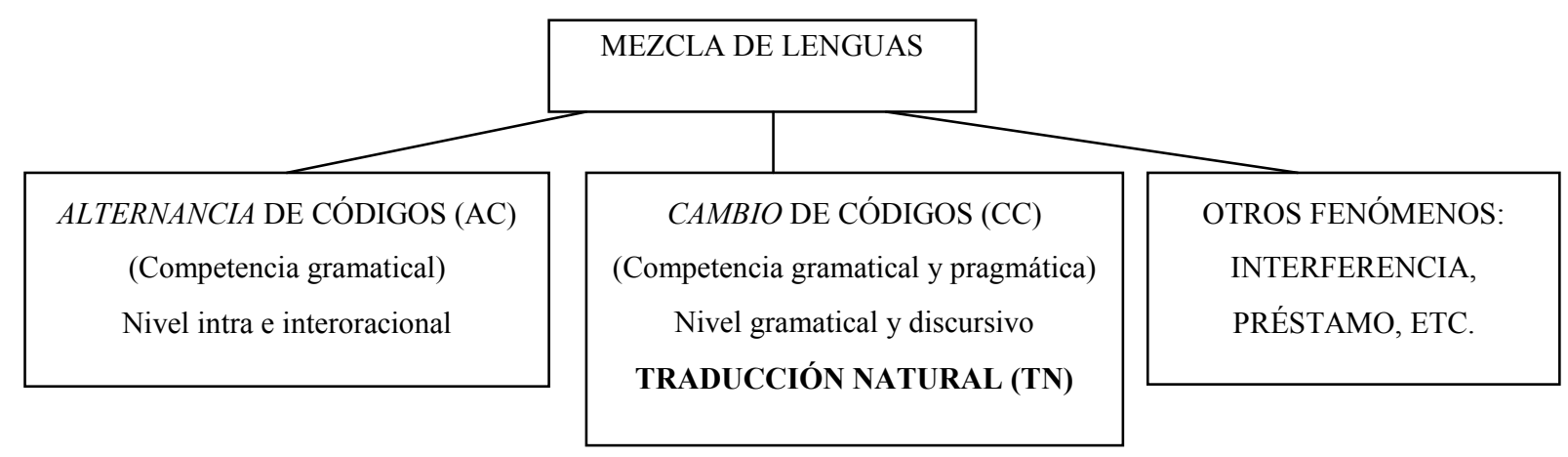


Para poder justificar esta clasificación del diagrama 14, hemos de tener en cuenta las siguientes cuestiones. Por un lado, tal y como apunta Toribio (2001), el término código (“code" en inglés) se ha venido utilizando en los estudios más recientes de bilingüismo como sinónimo de lengua o variedad de habla. Quizás por este motivo, haya surgido una confusión terminológica en relación a varios fenómenos (mezcla de lenguas o de códigos, alternancia de lenguas o de códigos, cambio de lenguas o de códigos), cuando es posible que la distinción formal radique en el nombre que se le dé al primer término de estas nomenclaturas (alternancia, mezcla o cambio) que, a su vez, se refiere a diferentes tipos de fenómenos típicos del comportamiento bilingüe.

Por otro lado, como ya habíamos mencionado en el capítulo 1 del presente estudio, en la investigación sobre este tema los términos mezcla de lenguas y alternancia de códigos a veces se utilizan de forma intercambiable, pero en el presente estudio, tal y como indicamos en el diagrama 14, consideramos que el primero es un término más general y más amplio en el que se incluye cualquier tipo de interacción lingüística en el discurso bilingüe que implique el uso de dos lenguas. De esta manera, planteamos que uno de los tipos de mezcla de lenguas que se puede dar en la producción bilingüe es la $\mathrm{AC}$, distinto del CC. Otros autores como Meisel (1989) y Köppe y Meisel (1995) [ver el diagrama 10 y los apartados 5.1.1. y 5.1.3. del capítulo 1] argumentan una diferenciación entre la AC, regida por reglas y propia de los bilingües adultos, y la mezcla de lenguas (MC), en la que no se respetan las restricciones lingüísticas de la $\mathrm{AC}$ de los adultos y es propia de los niños bilingües en la etapa pre-funcional. Sin embargo, como ya apuntábamos anteriormente, por cuestiones metodológicas más que conceptuales, hemos creído conveniente hablar de AC para referirnos tanto a aquella alternancia que producen los adultos como a aquella que producen los niños bilingües y que necesariamente ha de tener propiedades diferentes como las tendrían las gramáticas adultas frente a las gramáticas infantiles en desarrollo. Al mismo tiempo, hemos incluido consideraciones relacionadas con la competencia lingüística bilingüe (Meisel 1989; Köppe y Meisel 1995) y con los niveles lingüísticos en los puede darse la AC (Lanza 1992, 1997) y que veíamos en el apartado 5.1.1. del capítulo 1. De esta manera y como se ve en el diagrama 14, intentamos realizar una diferenciación entre los diversos fenómenos de mezcla de lenguas que pueden darse y que nos permita incluir entre ellos la TN como fenómeno también característico del bilingüismo. 
Para ello, a continuación partiremos en ese diagrama, para describir, como un primer acercamiento, los niveles más importantes de clasificación con el fin de distinguir el $\mathrm{CC}$ de la $\mathrm{AC}$.

Partimos de que la diferencia básica entre el $\mathrm{CC}$ y la $\mathrm{AC}$ es que la estructura lingüística en la que se localiza la $\mathrm{AC}$ es una oración o dos (nivel intraoracional, como en el ejemplo (46b) o interoracional), mientras que, desde el punto de vista de nuestra clasificación ,el CC se incluye en unidades lingüísticas que, a su vez, pueden constituir toda una conversación y suele implicar un cambio en el turno de habla, como sucede en el ejemplo (46b), procedente de nuestros datos.

a) Leo: bilingüe inglés/español

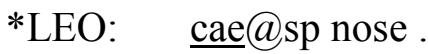

b) Simon: bilingüe inglés/español

*SIM: it's a tool toy .

*MEL: it's a tool toy yeah .

*MEL: $\quad$ now < what do you $>$ [///] how do you use that one ?

*SIM: pues@sp es@sp muy@sp sencillo@sp .

Lo que observamos en el ejemplo (46b) es un CC producido en el turno de habla (o una alternancia de lenguas según el diagrama 8 de Lindholm y Padilla (1978b) en el capítulo 1) puesto que nos encontramos ante una situación en la que Simon está hablando en inglés con Melanie, que siempre se dirige a los niños en inglés, y en el siguiente turno de habla se dirige a ella en español (marcado con@sp en el ejemplo), lo cual puede deberse a diversas causas como puede ser el hecho de no querer excluir del juego a una de las investigadoras presentes en la conversación que es monolingüe español.

El caso de (46c), sin embargo, no se corresponde con un CC sino con una AC en el nivel intraoracional, pues Leo, en la conversación de donde está extraído este enunciado, está hablando con Melanie e introduce un elemento en español ("cae”) dentro de una oración en inglés.

Por tanto, según la clasificación propuesta en el diagrama 14, el ejemplo (46a) es un caso de $\mathrm{CC}$, diferente al de la $\mathrm{AC}$, pero en el que, además, no se ha producido un trasvase de significado entre un código y otro. Por este motivo, consideramos que el ejemplo (46b) 
es un tipo de CC pero distinto a otros tipos de CC como los de $\mathrm{TN}$, en los que ha de producirse necesariamente dicho trasvase, como sucede en el ejemplo (46c).

(46c) Leo: bilingüe inglés/español

*MEL: what's that?

*LEO: $\quad$ cabeza@sp !

*MEL: cabeza@sp, how do you say that in English ?

*LEO: head!

En este sentido, proponemos que la TN es un tipo CC en el que se da la presencia de dos enunciados expresados en dos lenguas diferentes: el texto origen ("cabeza", en el caso del ejemplo (46c)) y el texto meta ("head", en ese mismo ejemplo), existiendo entre ambos una relación de carácter semántico-conceptual que no se da en los casos de AC.

De esta y de otras diferencias que podemos encontrar entre la $\mathrm{TN}$ y otros fenómenos relacionados con la mezcla de lenguas, sobre todo la $\mathrm{AC}$, trataremos en el siguiente apartado.

\subsection{La TN como estrategia bilingüe: similitudes entre la $T N$ y la AC}

Teniendo en cuenta lo expuesto en el anterior apartado, la TN y la AC suelen considerarse fenómenos relacionados con el bilingüismo y, aunque a veces se estudian de forma conjunta y se relacionan tipológicamente, lo cierto es que no se ha mostrado el mismo interés por la traducción en los niños bilingües que por la $\mathrm{AC}$, llegando a considerarse la traducción una forma de jugar con las lenguas (Grosjean 1982) y, por tanto, un fenómeno de menor entidad como estrategia comunicativa que la $\mathrm{AC}$.

Sin embargo, está claro que a pesar de las dificultades terminológicas, a las que aludimos en el apartado previo y en otros anteriores [ver el 5.1.1. en el capítulo 1], ambos fenómenos pueden agruparse bajo el mismo epígrafe, el de la mezcla de lenguas, si atendemos a nuestra propuesta de clasificación en el diagrama 14. Por este motivo, es imprescindible acudir a las referencias sobre la AC para poder investigar acerca de la traducción como un caso de mezcla de lenguas, aunque la mayor parte de las veces la segunda se defina en función de la primera. De hecho, en determinados estudios 
interesados en la AC más que en la traducción en sí (Genesee 1989; Romaine 1999), se ha aludido a que la traducción realizada por los hablantes bilingües es una función comunicativa de la alternancia de lenguas que esos mismos hablantes producen. En cambio, otras investigaciones más recientes y de carácter más psicolingüístico (Price et al. 1999) van más allá y plantean que la traducción puede considerarse un caso especial de $\mathrm{AC}$, pues, en definitiva, implica necesariamente un cambio de lenguas, aunque también con un control adicional en el proceso mental para evitar las interferencias lingüísticas.

En este sentido, si entendemos por interferencia (Paradis y Navarro 2003) la influencia estructural de una lengua en otra a lo largo del desarrollo bilingüe y en diversos niveles lingüísticos, lo es cierto que podemos encontrar este tipo de casos en los niños de nuestro estudio, como en (47) (o como los ejemplos de (3a) y (3b) del apartado 3.4. del capítulo 1), en el que Sol (nombre utilizado cuando se desconoce cuál de los dos niños lo dice, Simon o Leo) contesta al teléfono utilizando una traducción literal del inglés "who is it?"'.

\section{Simon o Leo: bilingües inglés/español}

*RAQ: y así suena el teléfono, eh@i ?

*SOL: quién está allí ?

*RAQ: uy@i cuidado .

*SOL: quién (e)stá ?

*RAQ: que es lo que tienes que decir cuando coges el teléfono ? [3;05.14]

Sin embargo, en nuestro estudio no tendremos en cuenta casos como los de (47) como ejemplos de TN puesto que, según nuestro punto de vista, este tipo de interferencias lingüísticas no están ligadas a la traducción como tal sino a toda una producción bilingüe desde el momento en que los niños tienen acceso al lexicón de cada una de las lenguas. Es más, tal y como han planteado recientemente Genesee et al. (2004), la influencia entre las lenguas (adoptando un término más positivo para este fenómeno lingüístico) no es prolífica en el habla de los niños bilingües y, lejos de ser un signo de confusión entre dos lenguas o de error como se había planteado anteriormente (Arnberg 1987, entre otros), constituye un fenómeno que forma parte del desarrollo bilingüe y una estrategia práctica que los niños bilingües utilizan cuando no han adquirido una determinada estructura en alguna de las dos lenguas o, si la han adquirido, quieren dar más información con este tipo de estructuras, tal 
y como mantienen Liceras et al. (2003, 2005), Spradlin et al. (2003) y Liceras y Fernández Fuertes (2005) en la hipótesis de la materialización de los rasgos gramaticales ("Grammatical Features Spell-out Hypothesis") [ver el apartado 5.2.2.1 del capítulo 1].

Lo que sí tendremos en cuenta en el presente estudio son las semejanzas y las diferencias que se pueden establecer entre la TN y la AC, parte de las cuales ya hemos ido adelantando en el apartado anterior. Concretamente y a diferencia de la AC (identificada con el nivel intra e interoracional), la TN supone el cambio de un código a otro en el transcurso de una conversación que, como característica exclusiva, implica, además, un trasvase de significado entre ambas lenguas, lo cual no se da en el caso de la AC.

A partir de aquí, creemos conveniente realizar una serie de aclaraciones. Por un lado, y desde el punto de vista de una clasificación formal, es posible que la AC pueda darse en el mismo enunciado que una $\mathrm{TN}$, como cuando dentro de lo que es la traducción de un enunciado en una lengua, el niño introduce elementos léxicos de la otra lengua en dicho enunciado (indicado con@sp o @en, dependiendo de la lengua de la que procedan dichos elementos), como en los ejemplos (48a) y (48b).

\section{Simon: bilingüe inglés/español}

(a) *SUS: what's that ?

*SIM: una pistola.

*EST: $\quad$ pero no sabe español .

*SIM: [\% a Susana] eh@fp es@sp un@sp rifle [\% pho /'raifl/].

(b) *SUS: $\quad$ tell her to [/] to write the month $\mathrm{xxx}[\%$ susurrando a Simon] here .

*SIM: $\quad$ tienes que mascar [: marcar] el month@en .

Concretamente, en (48a) Simon, en su intento por traducirle a Susana (hablante monolingüe de inglés) lo que le acaba de decir en español, opta por producir una AC intraoracional en la que el término con mayor carga semántica, el nombre "rifle”, lo dice en la lengua adecuada a su interlocutor, en inglés. En el ejemplo de (48b), en el que Simon tiene que traducir a un investigador monolingüe de español lo que Susana le pide, también observamos un caso de TN en el que, a su vez, se localiza un caso de AC en el nivel del sintagma nominal que supone la presencia de una palabra en inglés, "month", dentro de un contexto oracional en español. 
Por tanto, la diferencia fundamental entre uno y otro fenómeno es que mientras que en la TN comparamos un enunciado (origen) con otro (meta), en el caso de la AC también existe una mezcla de palabras procedentes de dos lenguas (en este caso intraoracional) pero no las comparamos porque no existe una relación semántico-conceptual entre ellas.

Varios casos de AC y de TN que aparecen simultáneamente en el discurso se han documentado también en otros estudios, como en las traducciones de Hildegard en Leopold (1939-1949), de las que mostramos un ejemplo en (49).

\section{Hildegard: bilingüe inglés/alemán}

Hildegard: Put this shoe on.

Padre: Sag's auf deutsch!

[dilo en alemán] alemán

Hildegard: Bitte, put this.

Padre: what?

[por favor alemán pon esto] $]_{\text {inglés }}$

Hildegard: $\underline{\text { Schuh on }}$

$$
\text { [zapato] alemán }
$$

(Leopold 1939-1949)

En este ejemplo, Hildegard, ante la petición expresa de su padre de que traduzca al alemán, produce una $\mathrm{AC}$ dentro de un mismo enunciado y, ante la incomprensión del padre, vuelve a intentar traducir produciendo de nuevo una traducción incompleta, es decir, una traducción con presencia de AC, pues sólo ha traducido "shoe" por "schuh" y ha dejado "on" en su lengua original, sin cambiar el código en esa parte del enunciado.

Sin embargo, el hecho de que ambos fenómenos puedan aparecer simultáneamente en el discurso no significa que sean lo mismo (Swain y Wesche 1975; Lindholm y Padilla 1978b), puesto que, en la TN lo que se da es un trasvase de significado o de información de una lengua a otra (o de un código a otro), lo cual puede suponer que el sujeto, u otro participante de la conversación, emita un enunciado en una lengua (texto origen) y, a continuación (normalmente en el siguiente turno de habla, pero no necesariamente) emita un enunciado en la otra lengua (o texto meta) en el que exprese lo mismo que en el enunciado origen; en el caso de la $\mathrm{AC}$, en cambio, estamos ante una mezcla de lenguas dentro de un mismo enunciado que se puede dar en diversos niveles lingüísticos (entre oraciones o dentro de oraciones, en el nivel del sintagma o en el interior de una palabra), 
como el caso de $\mathrm{AC}$ en el nivel del sintagma determinante que se produce en (48a) o en $(50)$.

\section{Michael: bilingüe francés/inglés}

(Michael está intentando que su muñeco coma una zanahoria) Investigador: Put it in his mouth. That's where he eats from. Michael (al investigador francófono): Moi vais mettre dans sa mouth.

La cuestión es que en esta relación que planteamos entre la $\mathrm{AC}$ y la $\mathrm{TN}$, una no siempre tiene por qué implicar la otra, puesto que si tomáramos de forma aislada (es decir, sin el contexto que nos proporciona el discurso o la conversación) los enunciados de los casos de (48)-(50) en los que se ha producido la $\mathrm{AC}$, no podríamos asegurar que se ha producido también una TN. Sin embargo, si contamos con el contexto previo suficiente para poder observar un trasvase de significado de una lengua a otra (que será posible en el caso de nuestro estudio pero no siempre lo será en el caso de ejemplos mostrados en otros estudios en los que a menudo no se aporta el contexto), estaremos ante un caso de TN en el que se ha producido una $\mathrm{AC} \mathrm{y}$, por tanto, ante un caso de TN que resulta incompleta por no haber habido un CC completo.

Siguiendo esta misma línea y como vimos en el diagrama 8 [ver el apartado 5.1.1. del capítulo 1], Lindholm y Padilla (1978b) tratan lo que ellos denominan la mezcla de lenguas (que, según nuestra propuesta en el diagrama 14, se corresponde con una AC), la alternancia de lenguas (o CC sin traducción) y la traducción (o CC con trasvase de significado) como tres fenómenos distintos, lo cual vendría a justificar también el tipo de clasificación que estamos presentando.

Así pues, nuestro planteamiento es que puede haber casos en los que ambos fenómenos se den a la vez, en los que el niño elige la AC cuando desconoce los equivalentes de traducción de determinados términos o le resultan difíciles de traducir (como puede haber sucedido en (48)), o cuando los lexemas de una lengua le aportan una mayor información que los de la otra, como en (50), donde el uso del pronombre posesivo en francés (con dos rasgos no interpretables, el de género y el de número) "sa” aporta una 
información mucho más rica y transparente desde un punto de vista morfológico que el artículo en inglés "the”, que sólo tiene un rasgo no interpretable, el de número (en la línea de Liceras y Fernández Fuertes 2005 y de Spradlin et al. 2003, como ya vimos en el apartado 5.2.2.1. del capítulo 1), enfatizándose en este caso y al mismo tiempo, el carácter esencialmente comunicativo de la $\mathrm{TN}$ en la que se incluyen (concretamente en el texto meta) los elementos léxicos más relevantes desde el punto de vista semántico-conceptual.

Por otro lado, si atendemos a la distinción entre la AC y la mezcla de códigos (MC) que realizan Meisel (1989) y Köppe y Meisel (1995) [ver el diagrama 10 en el capítulo 1], en el supuesto de que hablásemos de casos de TN en niños bilingües, la clasificación sería un tanto confusa, puesto que, según estos autores, si nos encontramos ante una TN en la que no se respeten las restricciones sintácticas o pragmáticas de cada una de las lenguas, se trataría de una $\mathrm{MC}$, mientras que, si se respetan dichas restricciones, se consideraría un caso de AC situacional o conversacional. Para evitar este tipo de confusiones, partiremos de lo que apunta Lanza (1992) con respecto a los enunciados con AC y que nosotros aplicamos concretamente a la $\mathrm{TN}$ : este tipo de traducciones que realizan los niños no tienen por qué ser semejantes a las que realizan los bilingües adultos (profesionales de la traducción o no), ya que la competencia bilingüe y el nivel de conocimiento lingüístico y metalingüístico de este tipo de hablantes difieren desde el momento en que los adultos ya han alcanzado un nivel de competencia que los niños están aún desarrollando.

Por tanto, en el análisis de las TTNN infantiles, y tal y como sucede con la AC en los niños bilingües, habrá de tenerse en cuenta la competencia gramatical que tienen estos niños en el momento en el que las realizan pero, al mismo tiempo, la competencia pragmática, pues también es un aspecto importante dentro de esta clasificación. De hecho, McClure (1981) [ver el diagrama 11 en el capítulo 1] alude a dos tipos de AC: la situacional y la estilística (o conversacional, según Meisel 1989). Sin embargo, si bien McClure considera que la AC temprana de los niños bilingües es de carácter situacional, mientras que la AC estilística es una habilidad que requiere un mayor grado de conciencia metalingüística (Lanza 1997), nosotros consideramos que las TTNN que realizan los niños bilingües pueden ser de ambos tipos, puesto que estos niños pueden elegir la lengua dependiendo del participante (por ejemplo, cuando sus interlocutores son dos hablantes monolingües y tienen que actuar como intérpretes entre ellos) y también son capaces de aclarar significados a través de traducciones que ponen de manifiesto un conocimiento metalingüístico al que a veces no se le concede la importancia adecuada. De esta manera, y 
siguiendo el diagrama propuesto en 14, el CC englobaría desde lo que Lanza (1997) denomina la alternancia situacional temprana hasta la alternancia conversacional y pragmática más sofisticada, de ahí que el estudio longitudinal en el que basamos el presente trabajo constituya una fuente idónea para poder investigar interacciones lingüísticas como las TTNN y su evolución a lo largo de un determinado período de la vida de nuestros sujetos.

Por todo lo dicho hasta ahora, la TN no tiene por qué ser un fenómeno cuyo estudio haya de estar supeditado al de la $\mathrm{AC}$, sino que, como fenómeno con entidad propia y también característico del comportamiento lingüístico de los hablantes bilingües, merece un análisis por sí solo, aunque para ello tengamos que recurrir a las referencias dedicadas a la AC dentro del campo del bilingüismo (mucho más numerosas que las dedicadas a la traducción) y no podamos evitar en ciertos momentos la comparación o el estudio conjunto de ambos fenómenos.

Una vez que hemos definido la $\mathrm{TN}$ en función de determinadas características (sobre todo formales) con el fin de enmarcarla dentro de una situación en la que se produce una mezcla de lenguas (distinta de otras situaciones como la de la AC) y de ubicarla en una clasificación y en una tipología de fenómenos típicos bilingües, procederemos a continuación a presentar con detalle las características principales de la $\mathrm{TN}$ en el contexto de la adquisición bilingüe, tanto desde el punto de vista gramatical como pragmático.

\subsection{La TN como una habilidad lingüística y comunicativa}

Los estudios de adquisición bilingüe de primeras lenguas suelen apoyar la relación directa entre el grado de competencia en las dos lenguas y el tipo de interacción entre lenguas que el niño refleja en su producción (De Houwer 1995; Babbe 1995). En este sentido, Valdés (1981) y Lipski (1985) sostienen que la competencia en ambas lenguas es una condición previa pero insuficiente para la $\mathrm{AC}$, puesto que, por ejemplo, el pertenecer a una comunidad en la que se practica dicha alternancia también puede determinar la producción de este tipo de fenómenos. Si adaptamos esto mismo al fenómeno de la TN, esta postura es semejante a la de Toury (1986) cuando plantea que para poder traducir no sólo es necesaria una competencia en ambas lenguas sino además una competencia 
adicional con una función social, es decir, una competencia traductora ${ }^{39}$. Sin embargo, a diferencia de estos planteamientos, nosotros consideramos que, si bien es evidente que la competencia lingüística es algo necesario para poder traducir, la competencia traductora es una competencia innata que tienen los niños bilingües, tal y como han defendido otros autores (Harris 1980a/b; Harris y Sherwood 1978; Sherwood 2000), que responde a una necesidad comunicativa, en este caso en un contexto familiar (no profesional).

Siguiendo con este razonamiento, al igual que a los niños bilingües no se les enseña a alternar las lenguas (Toribio 2001), tampoco se les enseña a traducir, de ahí que se podría decir que tienen un conocimiento intuitivo de qué mecanismos han de utilizar en las operaciones de traducción y que forman parte de la GU, es decir, de su dotación genética relativa al lenguaje. Sin embargo, al mismo tiempo, habría que tener en cuenta que, al igual que los niños reciben un input para poder desarrollar el conocimiento gramatical de ambas lenguas, estos niños también pueden recibir un input en el que se incluyan traducciones. Evidentemente, no se trataría de una instrucción formal (que es la que propone Toury (1986) para el desarrollo de esta habilidad), sino un input metalingüístico procedente sobre todo de los padres que suelen proporcionar traducciones a sus hijos (denominadas por Harris (1980a) traducciones pasivas) o actuar de intérpretes para ellos en determinadas interacciones (Leopold 1939-1949; Fantini 1985; Saunders 1983, 1988; Lanza 1988, 1992, 1997, 2001; entre otros), siendo este un comportamiento lingüístico que no ha de pasarles desapercibido a los niños. Como ejemplos, podemos observar los casos de (51) y (52).

Mario: bilingüe inglés/español

(a) Mario: ¿Sabes?, mi school bus no tiene un stop sign. Lo rompieron. Padre: Ah... ¿quién rompió la señal del autobús?

Mario: Unos nenes malos.

(Fantini 1985)

Thomas: bilingüe inglés/alemán

(b) Thomas: It might be a Geschwür.

$$
\text { [úlcera }]_{\text {alemán }}
$$

Madre: Oh, you mean an ulcer, do you?

Thomas: Yeah, that's the word.

(Saunders 1988)

\footnotetext{
${ }^{39}$ Sankoff y Poplack (1981) afirman algo semejante con respecto a la AC al considerar que esta, como recurso comunicativo, representa un desarrollo que requiere la competencia en los dos códigos que la componen, así como una habilidad adicional para manipularlas.
} 


\section{Mat: bilingüe inglés/francés}

(c) Mat (sosteniendo una pieza de un puzzle en el aire): Plane! Padre: avion!

$$
\text { [avión] }]_{\text {francés }}
$$

(Lanza 2001)

En (51), donde aparecen casos procedentes de estudios en los que se analizan casos de AC, observamos que el padre o la madre son los que suelen corregir los casos de $\mathrm{AC}$ que producen sus hijos proporcionándoles el equivalente adecuado en la lengua base de la comunicación en ese momento, la cual suele venir determinada por la lengua que utiliza cada uno de los progenitores en las interacciones con sus hijos, sobre todo si siguen la estrategia de una persona-una lengua (Ronjat 1913) [ver el apartado 2.3.2. del presente capítulo], en la que los padres se comunican con sus hijos utilizando sus respectivas lenguas primeras.

\section{Simon: bilingüe inglés/español}

(a) *MEL: what's this ? *SIM: gana@sp [: rana] .

*MEL: oh@i a froggy yeah .

(b) *SIM: what is a tape in Spanish ?

*MEL: cinta@sp.

En (52), procedentes en este caso de nuestro estudio longitudinal, observamos el mismo comportamiento sobre todo en el caso de Melanie, la madre, que en (52a) proporciona el término equivalente en inglés para que la interacción siga teniendo como lengua base esta lengua y no el español, pero que en (52b) cambia de código para proporcionar el equivalente español ante la demanda explícita del niño para que traduzca.

También algunas estrategias discursivas de los padres, como podemos apreciar en los diversos ejemplos de (53), pueden influir en las proporciones de AC y de TN que realicen los niños, algo a lo que ya se ha aludido en otros estudios (Genesee et al. 1995; Nicoladis y Genesee 1996, 1998). 
Mario: bilingüe inglés/español

(a) Mario (a su madre): ¿Dónde está mi kite? Madre: ¿Qué? ¿Cómo se dice en español? Mario: Ah, mi volador.

Tomas: bilingüe noruego/inglés

(b) Madre: What is that?

Tomas: $\mathrm{Ku}$ !

[ivaca! $]_{\text {noruego }}$

Madre: A ku. What's it called in English?

[una inglés vaca $_{\text {noruego }}$ ]

Tomas: $\underline{\text { cow. }}$.

Leo: bilingüe inglés/español

(c) *MEL: look, what's that ?

*LEO: $\quad$ (ov)eja@sp .

*MEL: how do you say oveja@sp in English ?

*MEL: how does mommy say oveja@sp ?

*LEO: $\quad$ s(h)eep .

Así, en estos tres casos son los padres los que solicitan a los niños una traducción en la otra lengua, bien para que la interacción entre ellos tenga como lengua base la L1 de la madre (en este caso) o bien para que los niños pongan en práctica ambos lexicones a lo largo de su desarrollo lingüístico.

Sin embargo, no siempre encontramos casos de TN vinculados a demandas explícitas por parte de los padres. De esto dan muestra casos como el de Ronjat (1913) en (54a), y el de uno de los sujetos de nuestro estudio en (54b).

\section{Louis: bilingüe francés/alemán}

(a) Louis (a la asistenta): Maria, apporte-moi mon fusil.

[Maria tráeme mi fusil $]_{\text {francés }}$

Louis (a su madre): Maria, bring mir mein Gewehr, hab ich gesagt.

[Maria, trae mi rifle, he dicho $]_{\text {alemán }}$

(Ronjat 1913, recopilado por Harris y Sherwood 1978) 


\section{Simon: bilingüe inglés/español}

(b) \%com: Simon continues trying to make his toy make noise

*SIM: $\quad$ está@sp loto@sp [: roto].(...)

*SIM: [\% Melanie reaches over to touch his toy] ah@i !

*MEL: [\% laughing] ah@i I'm not allowed to touch it ?

*SIM: $\quad$ b(r)eak b(r)eak.

*MEL: $\quad$ how about $+/$.

*SIM: $\quad$ b(r)eak mommy b(r)eak.

En el caso de (54a), observamos cómo Louis traduce al alemán (la L1 de la madre) lo que le acaba de decir a la asistenta (hablante monolingüe de francés) sin que el niño haya recibido ningún estímulo expreso del tipo “¿cómo se dice en alemán?”. Es decir, que ha realizado una TN por iniciativa propia, lo mismo que Simon en (54b) sólo que, en este caso, en un intento por llamar la atención de Melanie sobre el hecho de que su juguete no funciona, el niño traduce al inglés lo que acaba de decir en español y que, de esta forma, el mensaje llegue más directamente a Melanie que, aunque es bilingüe, tiene el inglés como L1 y se comunica con los niños en inglés.

Siguiendo con la comparación de la TN con la AC, por un lado, y a diferencia de lo que sostenían algunos estudios sobre la $\mathrm{AC}$, no se puede plantear que la TN surja de un control insuficiente de una de las lenguas, sino que es una habilidad que requiere un nivel de competencia en ambas lenguas y que puede alcanzar en su desarrollo un alto grado de sofisticación (sin necesidad de que esta esté vinculada a una instrucción formal).

Por otro lado, si consideramos que la TN es un tipo de mezcla de lenguas (como proponemos en el diagrama 14), podríamos sostener que, al igual que la $\mathrm{AC}$, es un fenómeno que puede estar sujeto a restricciones tanto de carácter gramatical como de carácter pragmático, de ahí que haya que analizar tanto los aspectos formales (el trasvase de unas categorías a otras o de un nivel lingüístico a otro, si hay estructuras más complicadas que otras para traducir, si son traducciones de enunciados propios o de otros interlocutores, el tipo de estrategias traductoras, si el desarrollo de la competencia traductora es paralelo a la competencia lingüística, etc.), como los contextuales (a qué tipo de reglas pragmáticas atienden los niños cuando traducen, si el receptor de la traducción es bilingüe o monolingüe, si traducen por iniciativa propia o vienen provocadas por un interlocutor o una situación comunicativa determinada, etc.). 
En esta doble perspectiva de análisis nos hemos basado para diseñar nuestra propuesta de clasificación del diagrama 14 y seguiremos teniéndola en cuenta para la propuesta de variables en torno a las cuales realizaremos el análisis más detallado de nuestro corpus de ejemplos en el capítulo 5.

\subsubsection{La competencia gramatical}

En cuanto a los aspectos gramaticales, pocos son los estudios (Harris 1980a; Malakoff y Hakuta 1991; Sherwood 2000) que, partiendo de este enfoque, se hayan dedicado a analizar las TTNN de hablantes bilingües en general y de niños bilingües en particular. Sin embargo, se podría plantear que la TN puede ser un indicador del grado de competencia bilingüe, de tal forma que, dependiendo de cuál sea este grado dentro del desarrollo del lenguaje, podremos tener un tipo de traducción u otra (emparejamiento de palabras, traducciones léxicas, traducciones a nivel fonológico, traducciones donde entran en juego determinadas operaciones sintácticas, etc.) que variará a medida que el niño bilingüe vaya adquiriendo una mayor competencia en ambas lenguas. En este sentido, también puede resultar interesante la direccionalidad en la que realizan las traducciones (de inglés a español, o de español a inglés, aludiendo al par de lenguas que aparecen en nuestro corpus de datos), y la frecuencia de una de las direcciones con respecto a la otra, por ejemplo.

Siguiendo un tipo de análisis similar, el trabajo de Harris (1980a) es el único que ofrece una clasificación de cada caso de TN realizado por un niño bilingüe desde un punto de vista lingüístico. Así, tal y como aludíamos en el apartado 2.2.1. del capítulo 2, este autor considera que los casos de TN que él mismo recopila (del sujeto de Swain (1972a), concretamente) se pueden analizar como transcodificaciones (o traducciones de estructuras lingüísticas) o como interpretaciones (o traducciones del mensaje), aunque su estudio se centra en las primeras. Dentro de esas transcodificaciones habla de que las TTNN pueden incluir emparejamientos de palabras, traducciones de carácter léxico, transformaciones sintácticas, traducciones sintéticas, paráfrasis sintácticas, adaptaciones pragmáticas (de estilo directo a estilo indirecto, o a la inversa), etc., pero no realiza un análisis similar sobre lo que este autor considera interpretaciones (simplemente alude al hecho de que algunos casos de transcodificación incluyen también interpretaciones pero sin especificar cuáles). 
A pesar de no existir otros trabajos con un planteamiento similar al de Harris (1980a), en el análisis de los casos de TN del presente estudio tendremos en cuenta dos cuestiones importantes: por un lado, que la $\mathrm{TN}$ responde a restricciones gramaticales específicas, de tal forma que habrá que tener en cuenta si en las traducciones que el niño bilingüe realiza utiliza recursos gramaticales diferentes para expresar lo mismo en ambas lenguas (un orden de palabras determinado, definiciones, paráfrasis, el uso de sinónimos, etc.), algo que constituiría una evidencia de que puede diferenciar los dos sistemas gramaticales; por otro lado, también habrá que tener en cuenta si los recursos gramaticales que utiliza el niño bilingüe coinciden con el significado de lo que se quería expresar originalmente, es decir, si respeta las equivalencias semánticas en el trasvase de una lengua a otra y si estas equivalencias son totales o si el niño ha economizado o ampliado el contenido original en su traducción final. En definitiva, ver la correspondencia entre ese doble lexicón del que habla MacSwan $(2000,2005)$ [ver el diagrama 6 del apartado 2.2. en el capítulo 1] y su representación semántico-conceptual (FL), con respecto al proceso de traducción.

En este sentido, consideramos oportuno apuntar que, en el presente estudio, adoptaremos un concepto amplio de lo que se entiende por competencia gramatical, ya que nuestro enfoque se centrará en el plano lingüístico semántico-conceptual y no en el plano de la morfología o de la sintaxis, tal y como se veremos a continuación.

En un intento por adaptar la propuesta de MacSwan (2000, 2005) a este planteamiento en relación al proceso de la traducción que presentamos en este trabajo, Fernández Fuertes, Álvarez de la Fuente y Liceras (en prensa), proponen lo siguiente recogido en el diagrama 15 . 
Diagrama 15. El PM y la facultad del lenguaje bilingüe: la TN

(Fernández Fuertes, Álvarez de la Fuente y Liceras (en prensa))

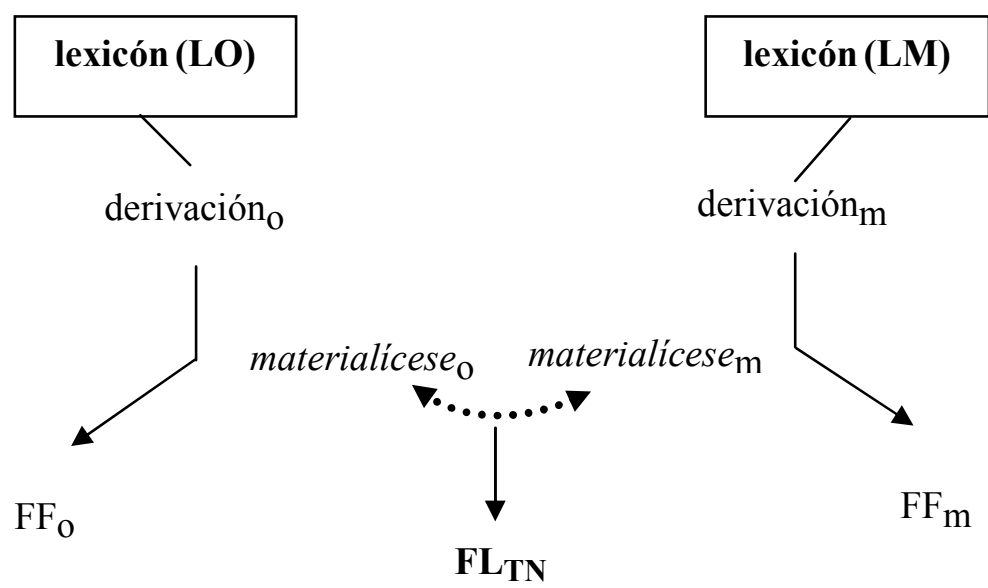

(binomio TO/TM)

$$
\begin{aligned}
& \mathrm{LO}=\text { lengua origen } \\
& \mathrm{LM}=\text { lengua meta } \\
& \mathrm{FF}=\text { forma fonética } \\
& \mathrm{FL}=\text { forma lógica } \\
& \mathrm{TO}=\text { texto origen } \\
& \mathrm{TM}=\text { texto meta } \\
& \mathrm{O}=\text { origen } \\
& \mathrm{m}=\text { meta }
\end{aligned}
$$

Los procesos que se describen en el diagrama 15 representan la producción de los casos de TN que hemos ido viendo a lo largo de este trabajo. Así, partiendo de lo expuesto en dicho diagrama, procederemos a describir paso a paso estos procesos que incluimos en nuestra propuesta.

En primer lugar, si tenemos en cuenta los niveles de representación lingüística según el Programa Minimalista [ver los apartados 2.1. y 2.2. del capítulo1], nuestra propuesta se basa en el hecho de que los niños bilingües hacen uso de las opciones que les proporcionan los dos lexicones (uno por cada lengua), que, en el caso de la producción de casos de TN, se corresponderían con el lexicón de la lengua origen (LO) y con el lexicón de la lengua meta (LM). Si nos centramos en la producción del enunciado o texto origen (TO), sombreado en el diagrama 15(a), observamos que el hablante bilingüe empareja los ítems del lexicón de la LO, de tal forma que, seguidamente, la derivación del TO ha de ser interpretada tanto desde el punto de vista fonético (concretamente en el nivel de una de las 
formas fonéticas, la del texto origen o $\mathrm{FF}_{\mathrm{o}}$ ) como desde el punto de vista semánticoconceptual (es decir, ha de corresponderse con una FL).

Diagrama 15(a). Primer paso: la derivación del TO

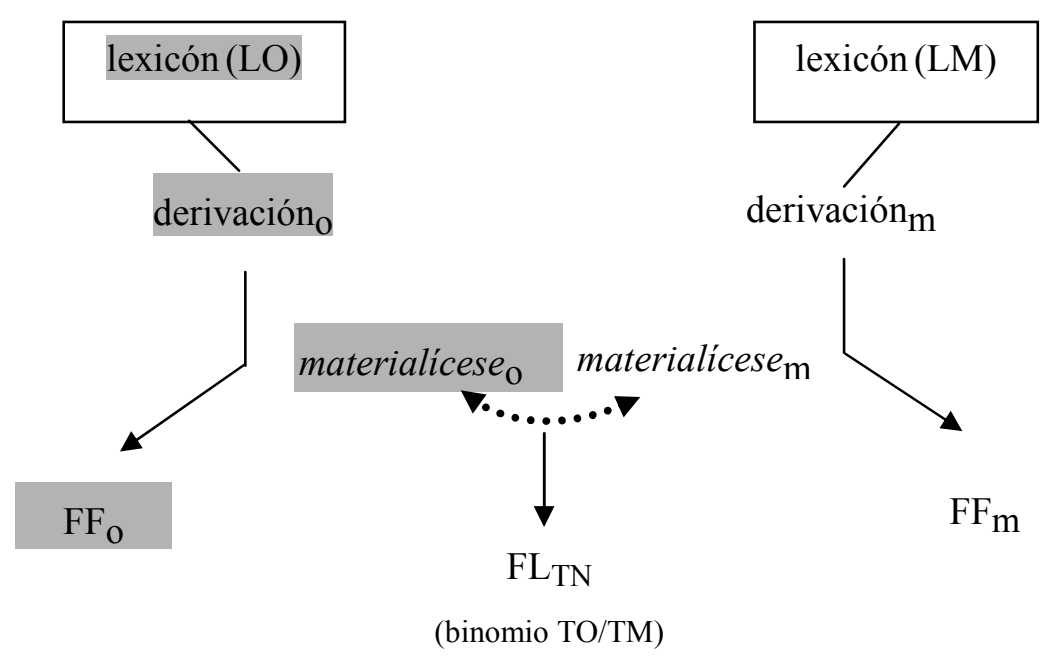

Una vez producido el $\mathrm{TO}$, el segundo paso sería paralelo al primero con la diferencia de que en este caso, tal y como mostramos en el sombreado del diagrama 15(b), la producción que ha de generarse es el enunciado o texto meta (TM).

Diagrama 15(b). Segundo paso: la derivación del TM

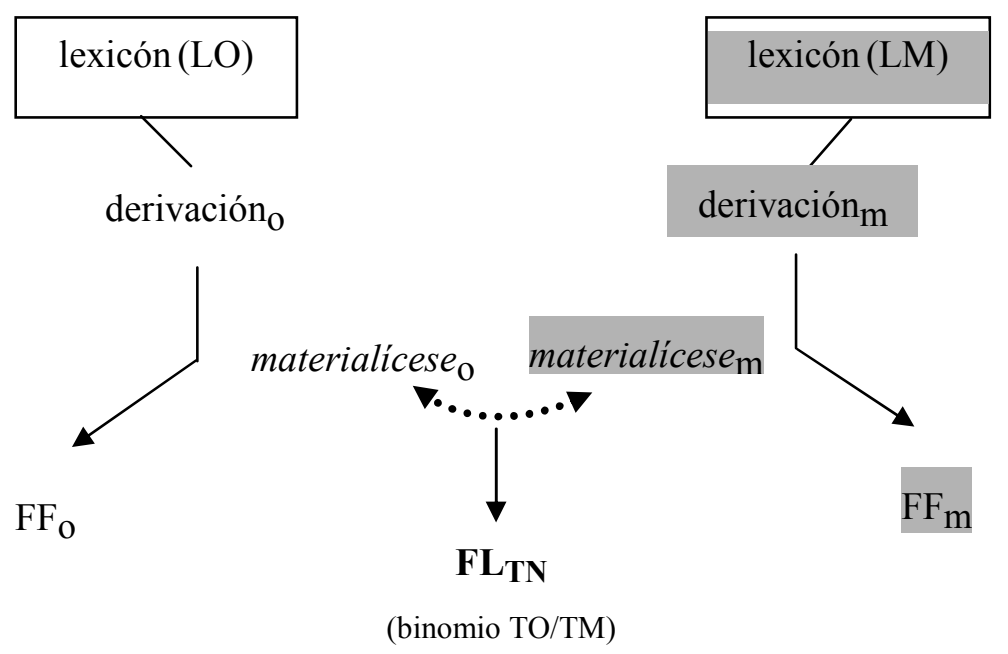


En este caso, también la derivación del TM ha de ser interpretada desde el punto de vista fonético en el nivel de la FF, concretamente, en la FF correspondiente a la lengua en la que está expresado el TM (es decir, $\mathrm{FF}_{\mathrm{m}}$ ), mientras que desde el punto de vista semántico-conceptual, la derivación del TM viene determinada por la misma FL que la del TO y no por una específica de la LM como tal.

De esta manera, tal y como destacamos en el diagrama 15(c), es precisamente en el tercer y último paso de la producción de casos de TN, es decir, en el nivel de la FL en el que se encuentra la relación conceptual común del binomio TO/TM.

Diagrama 15(c). Tercer paso: la FL del binomio TO/TM

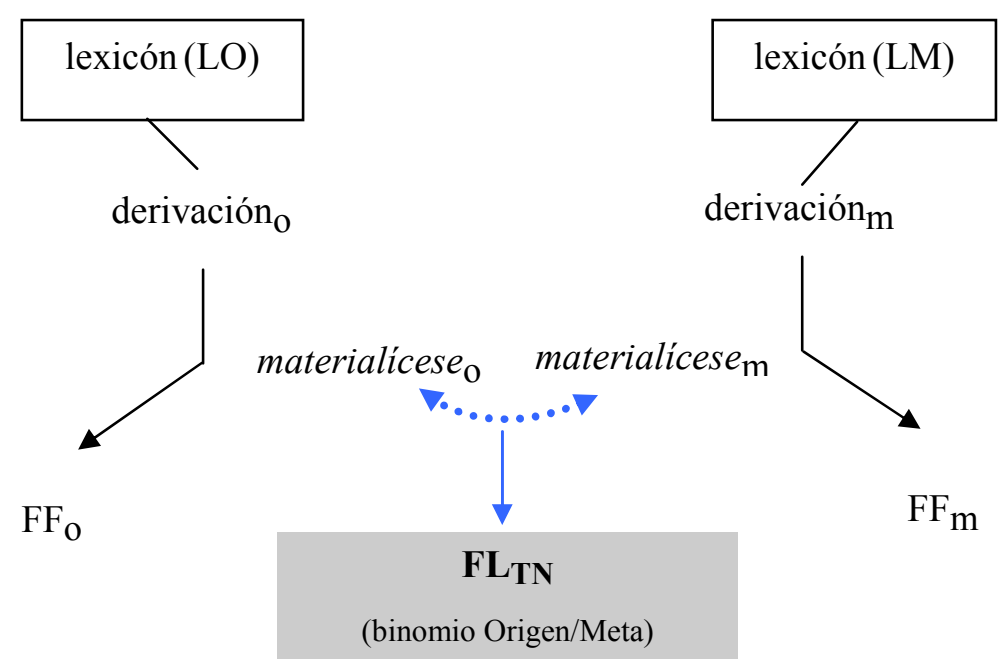

Así pues, en la TN la FL viene definida por el binomio enunciado origen/enunciado meta para que así funcionen ambas derivaciones en un contexto comunicativo concreto.

Llegados a este punto, consideramos conveniente puntualizar que el hecho de que estemos ante una única FL y no dos (una por cada lengua) tiene dos implicaciones: por un lado, el hablar de la existencia de una sola FL tiene su razón de ser, ya que la traducción es un proceso que parte del TO y llega al TM, de tal forma que el vínculo entre ambos textos es esa FL común. Es decir, es la FL del TO la que marca y constituye el punto de arranque del TM y sobre ella el TM se legitimará según se adecúe o no a la FL del TO. Por otro lado, el que exista una sola FL no significa que exista necesariamente una superposición absoluta entre el TO y el TM, ya que, adaptando el concepto de FL al caso de la 
traducción, la relación conceptual en este binomio puede ser de diverso tipo, desde una equivalencia semántica total (en el caso de los emparejamientos léxicos, por ejemplo) hasta una equivalencia parcial (en el caso de las traducciones económicas o expansivas).

Estas y otras cuestiones son las que pretendemos plantear en el análisis de las TTNN que componen nuestro corpus de ejemplos (y algunos de los ejemplos procedentes de otros estudios) siguiendo el enfoque teórico de carácter generativista que expusimos al principio de este trabajo [ver el apartado 2 del capítulo 1], de tal forma que vamos a realizar un análisis que tenga en cuenta sobre todo el nivel semántico-conceptual en el proceso de traducción y, a partir de ahí, qué tipo de relaciones se establecen entre la Forma Lógica del TO y de la traducción como producto o TM (es decir, si son traducciones equivalentes al TO o no lo son, en cuyo caso, hablaremos de traducciones de carácter expansivo o de carácter económico). Este tipo de clasificación y análisis lo trataremos en mayor profundidad en los capítulos 5 y 6 , dedicados, respectivamente, a la presentación y al análisis de los datos.

Relacionado con lo que acabamos de plantear, está el tema del siguiente apartado, puesto que, siguiendo a Crystal (2003), hay que tener en cuenta que la interpretación semántica (o FL) es necesaria para determinar cuestiones como la deducción pragmática y el uso apropiado de una lengua en situaciones determinadas.

\subsubsection{La competencia pragmática}

Existe un gran número de trabajos que se ha dedicado al análisis de la $\mathrm{AC}$ en los niños bilingües desde el punto de vista pragmático que, en mayor o menor medida, aluden a la traducción que realizan este grupo de hablantes, puesto que la TN se puede considerar una habilidad de carácter pragmático o una estrategia comunicativa que forma parte del desarrollo lingüístico de los individuos bilingües. En este sentido, algunos autores (De Houwer 1990; Genesee et al. 1995; Comeau y Genesee 2001), planteando una analogía con los individuos monolingües, se han encargado de analizar si este tipo de estrategias son comunes a las estrategias comunicativas utilizadas por los hablantes monolingües o son habilidades específicas e inherentes de los bilingües. A este respecto, Malakoff y Hakuta (1991) han profundizado más en esta comparación y plantean que, puesto que la traducción 
y la paráfrasis son tareas metalingüísticas que dependen de la habilidad de extraer el significado de un enunciado y captar el significado equivalente en otro enunciado, el niño que realice bien una traducción también realizará bien una paráfrasis, recursos comunicativos que están muy relacionados como veremos en los datos que presentamos en apartados posteriores. De hecho, siguiendo con esta comparación de paráfrasis-traducción, Swain (1972a) considera que este es un punto en común entre el hablante monolingüe y el bilingüe [ver los apartados 2.2. del capítulo 1 y los apartados 2.2.1. y 2.2.5. del capítulo 2], pues el primero utiliza paráfrasis o sinónimos cuando el segundo traduce o utiliza equivalentes de traducción. Esta idea ha sido retomada en la actualidad por Darwish (2000), quien equipara la habilidad de expresar un mismo mensaje utilizando la misma lengua (la paráfrasis en el caso de los hablantes monolingües y los bilingües) con la habilidad de traducir un mismo mensaje entre dos lenguas (la TN en los hablantes bilingües).

Así pues, las estrategias lingüísticas y comunicativas que utilizan un hablante monolingüe y uno bilingüe serían semejantes, sólo que, en el caso de los bilingües, estos juegan con los recursos adicionales que les proporciona el disponer de otra lengua para expresarse. De hecho, no es extraño que algunos investigadores como Leopold (19391949) o Bialystok (2001), entre otros, consideren que, en este sentido, los bilingües tienen una conciencia metalingüística más desarrollada que la de los monolingües, aunque también hay autores que no encuentran pruebas para constatar esta ventaja (Verhallen y Schoonen 1993).

A este respecto, suele aludirse al carácter sofisticado de las estrategias o habilidades metalingüísticas propias de los niños bilingües que estos desarrollan para resolver dificultades lingüísticas, aunque, de nuevo, la mayor parte de los estudios específicos de bilingüismo se dedican al análisis de la $\mathrm{AC}$ y no tanto al de la traducción que realizan este tipo de sujetos.

Lo mismo sucede con aquellos estudios (Döpke 1992; De Houwer 1995; Lanza 1988, 1997, 2001; Kasuya 1998; Quay 2001) que se centran en mayor o menor medida en las estrategias discursivas de los padres de los niños bilingües, ya que el tipo de input que estos reciben de sus padres puede jugar un papel muy importante en el uso que hacen los niños de estrategias comunicativas en el nivel discursivo. Así, se considera un factor pragmático que afecta a la producción de la TN la estrategia discursiva que utilizan los padres u otros interlocutores cuando les piden a los niños que traduzcan un determinado 
enunciado. Lanza $(1992,1997)$ y Van der Linden (2000) ofrecen algunos ejemplos como los de (55a) y (55b), similares a los que ya hemos visto previamente [ver los ejemplos de (52) en el apartado 1.3.], en los que los niños reciben una demanda explícita de sus padres para que traduzcan.

Siri: bilingüe noruego/inglés

(a) Siri: Smekke.

$$
\text { [babero] }{ }_{\text {noruego }}
$$

Padre: Smekke. Skall du- . [babero. La piel-] $]_{\text {noruego }}$

Madre: What does Mama call it?

Siri: bib.

(Lanza 1997)

Anouk: bilingüe francés/holandés

(b) Padre: Park, en wat hebben we nog meer? Wat is dit? [un parque, y ¿qué más? ¿qué es esto?]holandés

Anouk: Boot. $[\text { barco }]_{\text {holandés }}$

Padre: En wat zegt mama hiervoor? Wat zegt mama? [y ¿cómo dice eso mamá? ¿qué dice mamá? $]_{\text {holandés }}$

Anouk: Bateau. $[\text { barco }]_{\text {francés }}$

(Van der Linden 2000)

Sin embargo, como hemos dicho anteriormente, los niños bilingües no sólo traducen a petición de los padres, sino que también saben cuándo necesitan actuar de intérpretes o de puente de comunicación entre dos interlocutores monolingües, por ejemplo. En estos casos, los niños se ven envueltos en una interacción simultánea en dos lenguas en la que pueden llegar a traducir sin ningún esfuerzo y dificultad, aunque a veces se produzcan casos que se denominan alternancia bloqueada (Saunders 1988) que, tal y como apuntan Köppe y Meisel (1995), también se pueden dar en las situaciones de traducción. La alternancia bloqueada se produce cuando el niño se dispone a traducir a la lengua apropiada para su interlocutor pero sigue utilizando la lengua origen en vez de traducir. Siguiendo nuestra terminología en el diagrama 14, se trataría de un intento de 
traducción en el que no se ha producido el Cambio de Códigos correspondiente y el proceso o la actividad de traducción ha resultado nula, ya que el proceso como tal se ha iniciado (existe un TO) y una voluntad de traducir la FL correspondiente, pero sin llegar al estadio final de la producción del TM. Un caso de este tipo sería el de (56a), semejante a alguno encontrado en los datos de nuestro estudio como se puede observar en (56b).

Ivar: bilingüe alemán/francés

(a) I: ja frag sie doch mal ob sie mit ins uni-restaurant mitkommt.

[sí, pregúntale si quiere venir con nosotros al restaurante de la universidad $]_{\text {alemán }}$ Ivar: willst du mit, uni im restaurant kommen?

[¿quieres venir con nosotros al restaurante de la universidad?] alemán

F: Hein? $[¿ \text { ¿Hum? }]_{\text {francés }}$

G: Marie-France versteht dich doch so nicho.

[Mari-France no te entiende así] alemán

Ivar: nö.

$[\text { no }]_{\text {alemán }}$

Ivar (a F): willst du mit im uni res-.(se interrumpe y se empieza a reír)

[¿quieres venir al resta- $]_{\text {alemán }}$

Ivar (a G): wie heiBt das französisch ein uni-restaurant?

[¿cómo se dice restaurante universitario en francés?] alemán

(Köppe y Meisel 1995)

Simon: bilingüe inglés/español

(b) *SUS: [\% a Simon] but do you know how to write them ? (..)

*SUS: not yet, but you're gonna learn right ?

*SIM: yeah .

*SUS: yeah okey so .

*EST: $\quad$ qué qué> [/] qué está diciendo que no me entero ?

*SUS: [\% a Esther] okey, you have to learn .

*SUS: poor Esther right?

*EST: qué ha dicho ?

*SUS: $\quad$ you have $<$ to to $>$ [/] to help her .

*SIM: [\% a Esther] that [/] that if you don't know the numbers yet

but we know how to count them to me.

$[4 ; 10.20]$

En el caso de (56a), el investigador germano-parlante insta a Ivar expresamente a que traduzca al francés un determinado mensaje, pero en su intento el niño no cambia de 
código, es decir, sigue utilizando el alemán en vez del francés, por lo que se produce una alternancia bloqueada y realiza, de nuevo, una actividad de traducción que podremos considerar nula. Algo semejante sucede en (56b) con Simon cuando, al tratar de explicar a Esther (la investigadora monolingüe de español) lo que les está diciendo Susana (la investigadora monolingüe de inglés), en vez de utilizar el español se dirige a Esther en inglés, teniendo de nuevo como resultado una TN nula semejante al ejemplo anterior.

Entre este tipo de estrategias encontramos que los padres pueden recurrir también a la mezcla de enunciados (o a su desaprobación), así como a la reformulación o repetición de sus enunciados en la otra lengua (es decir, actuando de traductores para sus hijos). Dependiendo de la negociación del contexto (bilingüe o monolingüe) que pretendan plantear los padres con respecto a la comunicación con sus hijos y de lo estrictamente que sigan el principio de una persona-una lengua [ver el apartado 2.3.2. del presente capítulo], provocarán en los niños la producción de casos de AC (desde un enfoque discursivo) o de traducciones con mayor o menor frecuencia. Al mismo tiempo, cuando los padres u otros interlocutores proporcionan al niño la misma información en ambas lenguas (es decir, realizan traducciones pasivas), este tiene la capacidad metalingüística de juzgar si las traducciones que han realizado dichos interlocutores son correctas o no, para lo cual, según Harris (1980a), necesitan disponer de la habilidad de juzgar si los dos enunciados en lenguas diferentes tienen el mismo significado o, dicho de otro modo, cotejar los dos outputs (el texto origen y el texto meta) y ver si están relacionados y de qué manera. Esta habilidad es lo que Harris y Sherwood (1978) denominan COMAL (Conservation of Meaning Across Languages), que, desde nuestro punto de vista, supone para los niños bilingües un entrenamiento metalingüístico que les sirve para considerar que, en determinadas situaciones (es decir, en las de traducción), dos enunciados no son semánticamente independientes sino que comparten una relación semántico-conceptual o una misma FL (tal y como planteamos en el apartado anterior). Un ejemplo de esta habilidad la tenemos en (57), donde se pone de manifiesto que Simon es capaz de juzgar si la traducción que ha realizado su hermano Leo (repetida en el ejemplo por Esther) es adecuada a lo que él mismo ha dicho, llegando al punto de ofrecer él mismo una autotraducción para evitar confusiones o malos entendidos en la comunicación. 
*SIM: you never know who: wins . (...)

*EST: qué ha dicho ?

\%com:Leo whispers to Esther

*EST: que ellos van a ganar?

*SIM: no, hamos [: hemos] dicho que nunca sabes quién gana .

Atendiendo a lo planteado anteriormente y haciendo una pequeña recopilación de los estudios que tratan este tema (Vihman 1985; Lanza 1988, 2001; Romaine 1989; Poulisse 1993; Quay 1995; Deuchar y Quay 2000; Genesee 2001), se puede decir que dentro de los recursos que utilizan tanto los hablantes monolingües como los bilingües, nos encontramos con ciertas estrategias pragmáticas o comunicativas en las que dichos hablantes recurren a medios de expresión similares para comunicar un mensaje. En el caso de los hablantes monolingües, al disponer de un solo lexicón, pueden utilizar la paráfrasis como estrategia comunicativa, mientras que en el caso de los hablantes bilingües, algunas de estas estrategias, como la $\mathrm{AC}$ y la $\mathrm{TN}$, constituyen medios lingüísticos proporcionados por la competencia bilingüe (es decir, por los dos lexicones) cuyo uso por parte de los niños bilingües, como hemos visto en anteriores apartados [ver el 4.3. en el capítulo 1 y el 1.2. en el capítulo 2], ha servido como evidencia de que existe la separación temprana de lenguas ${ }^{40}$.

Independientemente de lo que demuestren este tipo de producciones en el habla de los niños bilingües, está constatado que estas habilidades metalingüísticas les ayudan a desarrollar su competencia comunicativa, puesto que desarrollan su habilidad para elegir el medio disponible más eficaz para expresar lo que quieren transmitir. De esta forma, se observa cómo Siri, la niña del estudio de Lanza (1988), utiliza como estrategia comunicativa la traducción, bien sustituyendo una palabra noruega por su equivalente en inglés, como en (58a), o bien repitiendo un enunciado en la otra lengua para evitar así una ruptura de la comunicación con sus interlocutores, como en el ejemplo (39a) del capítulo anterior, repetido aquí como (58b).

\footnotetext{
${ }^{40}$ Como ya hemos visto también en apartados anteriores [ver el apartado 4 en el capítulo 2], para algunos autores (Genesee et al. 1995; Nicoladis y Genesee 1996; Köppe 1997; Deuchar y Quay 2000; Quay 2001; Genesee 2001) la habilidad pragmática que supone que el niño bilingüe alterne las lenguas implica una diferenciación de lenguas subyacente, lo cual, desde nuestro punto de vista, vendría a plantear la importancia que juega también el papel de la TN en la adquisición bilingüe y en esa diferenciación lingüística.
} 
(a) Siri (acaba de terminarse la leche): Empty.

Madre: Empty.

Siri: Daddy, daddy.

Madre: Daddy says...

Siri: Tom.

[vacío] $]_{\text {noruego }}$

(b) Siri (que acaba de dar palmas): Klappe hand.

Madre: Hm?

[dar palmadas] $]_{\text {noruego }}$

Siri: Clap hand.

Madre: Did you clap your hands?

Siri: $\mathrm{mm}$.

(Lanza 1988)

Lo que se deduce de todas estas referencias, es que los niños bilingües utilizan, efectivamente, una estrategia tan sofisticada como la TN no de forma arbitraria, sino que, al igual que sucede con la $\mathrm{AC}$, hacen un uso controlado de ella, respondiendo a las demandas de sus interlocutores o del contexto en el que se encuentren. Sin embargo, no existe consenso en lo que respecta al tipo de uso de estos fenómenos, de ahí que algunas fuentes (Arnberg 1987, entre otros), teniendo como referente las normas monolingües, aludan a que el cambio o la alternancia de códigos no son fenómenos que se realicen de forma consciente ni voluntaria y consideren que se debe a una confusión de lenguas o a una competencia imperfecta en una de las lenguas. En cambio, otras fuentes (Fantini 1985; Grosjean 1982; Meisel 1989; Romaine 1989; Price et al. 1999; Lanza 2000; Gollan y Kroll 2001; Genesee 2001; Comeau y Genesee 2001; Genesee et al. 2004), defienden que estos fenómenos constituyen una serie de recursos de los que no dispone el niño monolingüe y sí el bilingüe.

Siguiendo la línea de argumentación del segundo planteamiento, nosotros mantenemos que, como aspectos inherentes al bilingüismo, la $\mathrm{AC}$ y la $\mathrm{TN}$ pueden verse como medios o recursos lingüísticos de los que dispone el niño bilingüe que, al analizarlos de forma conjunta, tienen una serie de finalidades o causas generales que no sólo tienen que ver sistemáticamente con la falta de competencia en una de las lenguas. Como estrategias que se utilizan con la intención deliberada de mejorar la comunicación (Grosjean 1982), responden a la necesidad por parte del niño bilingüe de adaptarse al interlocutor y a la situación en la que se encuentra en un determinado momento. Tal es el 
caso, por ejemplo, de aquellas situaciones en las que el niño interactúa con dos hablantes monolingües de cada una de las dos lenguas y, al tener que hacer de intérprete entre ambos, cambia de código y traduce de una a otra. Este tipo de situación puede formar parte de su vida cotidiana aunque, en ocasiones, puede ser provocada como parte experimental de un estudio (Swain 1972a; Swain y Wesche 1975; Lindholm y Padilla 1978b; Poulisse 1993, y en este mismo trabajo, como veremos). Al mismo tiempo, a pesar de que es una finalidad que se suele asociar más a la $\mathrm{AC}$ en hablantes adultos, el niño también suele recurrir a la traducción con el fin de clarificar o enfatizar un mensaje, pues es un recurso metalingüístico del que el niño bilingüe también dispone (Romaine 1989). De hecho, el trabajo de Malakoff y Hakuta (1991), junto con el de Srivastava y Gupta (1989) y Fernández Fuertes, Álvarez de la Fuente y Liceras (en prensa), es de los pocos estudios que intentan estudiar ambos fenómenos, la $\mathrm{AC}$ y la $\mathrm{TN}$, de manera conjunta, pues para estas autoras ambas deberían considerarse habilidades lingüísticas bilingües (semejantes a las monolingües que consisten en paráfrasis, como ya hemos planteado), aunque se diferencian fundamentalmente en una cuestión: la TN se utiliza para mejorar la comunicación reproduciendo tanto como sea posible en la lengua meta el significado de un texto (o enunciado) en la lengua origen, mientras que en la $\mathrm{AC}$ no se reproduce lo que se ha dicho antes, sino que se utilizan palabras de la otra lengua jugando con las diferencias sutiles de significado entre los términos de los dos lexicones, de tal forma que, mientras que la traducción se aprovecha de las similitudes entre ambas lenguas (a nivel de la FL), la alternancia se aprovecha de las diferencias.

Para finalizar este apartado, podemos concluir que la $\mathrm{TN}$, al igual que la $\mathrm{AC}$, también constituye tanto un principio de adquisición bilingüe al ser de carácter innato como una estrategia bilingüe al tratarse de un uso consciente de este principio por razones fundamentalmente comunicativas. De esta manera, la TN forma parte del desarrollo lingüístico de los hablantes bilingües y, concretamente, tal y como afirma Lanza (1997) con respecto a los niños bilingües, demuestra la sensibilidad de estos hacia los aspectos formales y comunicativos del uso de las dos lenguas. Todas las situaciones mencionadas en las que el niño bilingüe traduce se verán reflejadas en los datos de TN recopilados para el presente estudio, pero antes consideramos oportuno argumentar por qué las TTNN son traducciones y por qué su estudio por sí mismas debería merecer un lugar destacado dentro 
de los estudios tanto de bilingüismo como de traducción, como venimos mencionando a lo largo de este trabajo.

\subsection{El reconocimiento de la $T N$ realizada por niños bilingües}

Independientemente del enfoque que se quiera adoptar, está claro que la TN y la AC, como fenómenos que coexisten en la adquisición bilingüe simultánea (Müller y Hulk 2001), a veces son difíciles de separar, puesto que no es raro encontrar referencias en las que se alude a que se da mezcla de enunciados dentro de las traducciones o a que hay traducciones dentro del enunciado mezclado. Está claro que la traducción implica un CC pero el CC o la AC no implica necesariamente una traducción. Sin embargo, esto no debería dar pie a relegar la traducción a un segundo plano con respecto a la AC, pues los niños bilingües pueden utilizarla con finalidades semejantes y no tienen por qué responder necesariamente a una confusión de lenguas, como hemos visto anteriormente. De esta manera, la traducción también puede ser un medio lingüístico (y metalingüístico) del que los niños bilingües disponen para expresar o transmitir información (tanto desde el punto de vista lingüístico como desde el punto de vista pragmático) o para mejorar la comunicación con sus interlocutores.

A pesar de ello, en algunos estudios mencionados en el presente trabajo (Lanza 1988, 1992; Köppe y Meisel 1995; Toribio y Brown 1995; Nicoladis 1998; Quay 2001), se suele dar una mayor importancia al análisis de la $\mathrm{AC}$ y no a la traducción como un fenómeno diferenciado, al que se suelen referir eludiendo el término traducción (reformulación, repetición del contenido de un enunciado en la otra lengua, uso de equivalentes o sinónimos en la otra lengua, sustitución de palabras en la otra lengua, etc.), cuando, en realidad, implican una labor y un proceso de traducción que realizan los niños bilingües de forma natural y habitual. Por este motivo, en el presente estudio, consideramos que muchos de los ejemplos que aparecen en dichos trabajos se considerarían casos de traducción infantil, tal y como se ha podido observar hasta ahora en los casos mostrados en el presente trabajo.

Al mismo tiempo, al igual que la $\mathrm{AC}$ ha servido como medio para evidenciar el desarrollo independiente de las lenguas en los niños bilingües, a nuestro juicio, las traducciones que realizan estos niños en general pueden resultar de gran interés para el 
análisis de fenómenos relacionados con la mezcla de lenguas. Esto sería posible si la perspectiva que se adoptara hacia las traducciones realizadas por los niños bilingües (al igual que sucede en algunos ámbitos con la $\mathrm{AC}$ ) no fuera tan negativa, algo que en ocasiones viene potenciado porque, según algunos autores (Grosjean 1982), la traducción (sobre todo la literal y la realizada por aquellos niños considerados malos traductores) suele implicar interferencias lingüísticas. Sin embargo, consideramos que las interferencias o influencias entre las lenguas no han de estigmatizarse, puesto que, como ya hemos visto, forman parte del desarrollo lingüístico bilingüe y, además, no siempre están presentes en las traducciones que realizan los niños bilingües (como hemos observado en algunos casos mostrados en anteriores apartados) y, si lo están, no son evidencia necesariamente de una falta de competencia en ninguna de las dos lenguas.

Así pues, desde nuestro punto de vista, sería posible adoptar una perspectiva diferente tanto en la actitud hacia la TN como en el análisis de la TN. Es más, creemos que también se puede tener a la TN como punto de referencia para el estudio general de la mezcla de lenguas, pues se podría observar cómo el niño bilingüe, al enfrentarse a un problema de carácter lingüístico o comunicativo a veces opta por traducir su mensaje a la otra lengua, como en (59a), o, en el caso de no encontrar la traducción adecuada o carecer del ET opta por recurrir a la AC, como en (59b), o, incluso opta por evitar la traducción si el contexto así lo permite, como en (59c), cuando el padre también entiende inglés y la repetición es suficiente.

Simon: bilingüe inglés/español

(a) *MEL: you wanna make something with the blocks ?

*SIM: sísp.

*MEL: what would you like to make?

*SIM: douse [: house] .

*MEL: a house?

*SIM: douse [: house] !

*MEL: two ?

*SIM: $\quad$ casa@sp !

*MEL: a house?

*SIM: sí@sp . 
(b) *SUS: tell her to [/] to write the month $x x x$ [\% susurrando a Simon] here.

*SIM: tienes que mascar [: marcar] el month@en .

*EST: $\quad$ tengo que $<$ mas $>$ [//] marcar el month@en ?

*EST: y el qué ?

*SIM: elmonth@en .

*EST: el month@en ?

*RAQ: cómo se dice eso en español ?

*SIM: no sé .

Frank: bilingüe alemán/inglés

(c) Padre: Frag mal Mutti, wieviel Uhr es ist.

[pregunta a mamá qué hora es] alemán

Frank: What's the time, Mum?

Madre: A quarter to three.

Frank: Mutti hat, 'It's a quarter to three', gesagt.

[mamá ha dicho.... $]_{\text {alemán }}$

(Saunders 1983)

En definitiva, lo que pretendemos plantear en este sentido, es que, a pesar de que la literatura sobre bilingüismo infantil no se ha ocupado con detenimiento del estudio de los casos de TN o aluden de forma anecdótica a ellos como uno de los posibles casos de AC o de mezcla de lenguas, la base de nuestro trabajo es el análisis de la TN que realizan los niños bilingües cuyas aportaciones pueden ser igual de interesantes que las de los estudios sobre AC en niños bilingües, tanto para la teoría lingüística en general como para el bilingüismo y los estudios de traducción en particular. Dado que ya hemos tratado el interés que puede suscitar el análisis de la TN de los niños bilingües en los estudios de adquisición bilingüe, a continuación, nos centraremos en la importancia que, a nuestro parecer, dicho análisis puede tener en el campo de la traducción.

\subsection{La TN en los estudios teóricos de traducción}

Hemos visto en apartados anteriores cómo en los estudios de bilingüismo infantil se refieren a la TN como una posible razón o factor por el que se da la AC. En el caso de los estudios teóricos de traducción, salvo raras excepciones (Harris 1973, 1980a/b, 2003; Harris y Sherwood 1978; Srivastava y Gupta 1989; Shannon 1996; Bullock y Harris 1997 y Sherwood 2000), consideran que las TTNN no son traducciones per se. En nuestro análisis, en cambio, definimos la TN como un fenómeno con entidad propia basado en la 182 
transmisión de un mensaje o del contenido de un enunciado en otra lengua y caracterizado por determinados rasgos gramaticales y también pragmáticos, no muy diferentes de los de la traducción profesional. Es más, cuando a los niños bilingües se les incita a realizar traducciones, interpretan estas, según Lanza (1997: 269), como “requests for information" por parte de sus interlocutores y están, por tanto, cumpliendo una función social determinada y real en la que interactúan dos lenguas.

Por lo tanto, lo que nuestro estudio pretende es que se incluya la TN como capacidad innata del ser humano y vinculada, por tanto, a la adquisición del lenguaje, concretamente y en este caso, a la adquisición bilingüe simultánea. Esta es la línea que Harris (1973) seguía al pretender llevar a cabo un estudio científico de la traducción que tuviese como base las TTNN, pero, aparte de la escasez de estudios empíricos sobre este fenómeno, la teoría de la traducción se ha centrado en el análisis de la calidad de las traducciones y de la competencia de los traductores profesionales (con un objetivo pedagógico en su mayoría), y no tanto en el análisis del proceso de traducción per se, que no afecta únicamente a los traductores profesionales sino que los mecanismos que rigen este proceso aparecen de manera más reveladora en el caso de los niños que traducen o de los traductores naturales en general. Es más, en el caso de los niños bilingües, al encontrarse en proceso de adquisición de dos lenguas, los datos de producción de estos sujetos como traductores naturales pueden reflejar aspectos intrínsecos de la capacidad traductora (sin una influencia académica de ningún tipo) que no se pueden observar en el caso de los traductores naturales adultos y de los traductores profesionales, algo semejante a lo que sucede con las cuestiones que surgen al comparar los datos de adquisición de una lengua por niños con los datos de los adultos hablantes de dicha lengua. De hecho, es precisamente el análisis de las implicaciones que puede traer consigo la conexión entre el bilingüismo y la actividad traductora lo que nos puede llevar a la necesidad del estudio de la TN y a su importancia no sólo dentro de los estudios de adquisición sino también dentro de los estudios de traducción. 


\section{DE LO PRESCRIPTIVO A LO DESCRIPTIVO: ¿QUÉ NOS DICEN LOS DATOS?}

Dentro de este apartado pretendemos mostrar la importancia que tiene la recopilación y el análisis de datos de producción lingüística para poder precisar y perfilar muchas de las cuestiones expuestas hasta el momento en este trabajo sobre la TN y, al mismo tiempo, para poder constatar si las siguientes propuestas tienen una base empírica y no solamente teórica.

Aunque en los apartados 2.1. y 2.2. trataremos con más detalle las propuestas presentadas en el presente trabajo y el tipo de estudio utilizado para demostrarlas, en líneas generales podríamos decir que planteamos que la $\mathrm{TN}$ es una producción bilingüe, concretamente un tipo de Cambio de Códigos (tal y como propusimos en el diagrama 14 del apartado 1.1. del presente capítulo), que puede considerarse también una habilidad lingüística y comunicativa con características similares y diferentes a otros fenómenos típicos de la adquisición bilingüe como la AC.

Si comprobamos que los niños bilingües son capaces de traducir, es decir, de comunicar un mismo mensaje en dos lenguas dentro de un mismo contexto comunicativo, entonces podremos afirmar que son conscientes de la existencia de dos sistemas lingüísticos así como de las diferencias entre estos dichos sistemas, aunque en esta diferenciación también habrá que tener en cuenta el papel del contexto lingüístico en el que se encuentran los niños.

Al mismo tiempo, y dado el interés que puede despertar este tipo de estudio, hemos propuesto que la TN sea parte integrante tanto de los estudios de bilingüismo infantil como de los estudios teóricos de traducción, ya que un análisis de los procedimientos que utilizan los niños para traducir contribuiría a la descripción de cómo funcionan la competencia bilingüe y la competencia traductora innata.

Con este fin, hemos situado en la base del presente trabajo de investigación los datos lingüísticos de un estudio longitudinal (Fernández Fuertes et al. 2002-2005) como marco empírico idóneo para poder observar el comportamiento traductor de dos niños gemelos bilingües inglés/español, Simon y Leo. Las propuestas presentadas en este trabajo de investigación sobre la TN son pioneras tanto en el campo de la adquisición bilingüe como en el campo de la traducción. Al mismo tiempo, el mencionado estudio del que 
partimos constituye, a su vez, el primer estudio longitudinal de dos niños gemelos bilingües inglés/español en el que la variedad de español es la peninsular y que abarca un período en la vida de los dos niños que va desde los 13 meses hasta los 6;11 años de $\operatorname{edad}^{41}$.

En el siguiente apartado trataremos del valor que tienen los datos de producción lingüística para poder llevar a cabo un estudio de carácter longitudinal de niños bilingües. Para ello, aludiremos a la importancia de este tipo de estudios en diversos ámbitos de la investigación lingüística, entre ellos el del bilingüismo y el de la traducción, que son los que más nos interesan para el presente trabajo. De esta manera, plantearemos de qué forma podemos aprovechar estos datos para llevar a cabo el análisis de las TTNN en este tipo de sujetos, adelantando algunas cuestiones relativas al análisis de esos datos que ofreceremos más adelante.

\subsection{La necesidad de datos de producción lingüística para estudios teórico-prácticos en el campo del bilingüismo y de la traducción}

Desde nuestro punto de vista, lo importante no es analizar cómo se debe traducir sino cómo se traduce. Es decir, hay que adoptar un enfoque empírico (y no sólo teórico) con la observación de las interacciones orales, que son las que, en nuestro caso concreto, más nos interesan. Por este motivo, a continuación justificaremos la importancia que tienen los estudios longitudinales para este tipo de investigación, ya que, por un lado, nos permitirán obtener los datos que nos interesan, en este caso de $\mathrm{TN} \mathrm{y}$, por otro, nos ayudarán a analizar cuestiones relacionadas con el conocimiento lingüístico del hablante bilingüe y la relación que se establece entre ambas lenguas en este tipo de sujetos a lo largo de un período concreto de su desarrollo lingüístico como bilingües.

En primer lugar, ante la carencia de estudios empíricos dentro de los estudios de traducción, es necesario tomar como punto de partida la descripción del comportamiento lingüístico de los niños bilingües en el campo de la adquisición del lenguaje. En este

\footnotetext{
${ }^{41}$ Existen otros tres estudios longitudinales de niños bilingües inglés/español (Lindholm y Padilla 1978a/b, Fantini 1985 y Deuchar y Quay 2000), pero en ninguno de ellos la variedad de español es el peninsular y, además, todos ellos abarcan un período de tiempo inferior al planteado en el estudio longitudinal del que partimos [ver la tabla 2 en el apartado 2.3 . al final de este capítulo, en la que ofrecemos una información más amplia acerca de estos trabajos].
} 
sentido, los estudios longitudinales constituyen una fuente idónea para analizar los mecanismos mentales que actúan en el proceso de traducción y los factores implicados en la competencia traductora (Toury 1986) ya que están basados en el análisis de la producción lingüística de uno o varios hablantes a lo largo de un determinado período de su vida (de 1;01 a 6;11 años, en el caso del estudio longitudinal del que partimos). La cuestión es que, cuantos más estudios longitudinales se realicen, mayor será el volumen de datos disponibles y, así, mayor será la base para rechazar o apoyar diversas hipótesis.

A este respecto, si bien los primeros estudios longitudinales de este tipo [ver el apartado 2.3.2. del presente capítulo] se basaban fundamentalmente en diarios y grabaciones de audio realizadas por los propios padres de los niños bilingües sujetos del estudio (Ronjat 1913; Leopold 1939-1949; Fantini 1985; Saunders 1983, 1988; Lanza 1988; entre otros), en la actualidad existe un gran interés por este tipo de datos, lo cual ha hecho que los estudios más recientes (Van der Linden 2000; Deuchar y Quay 2000; Comeau y Genesee 2001; Juan-Garau y Pérez Vidal 2001; Bel 2001; Albrecht 2004; Fernández Fuertes et al. 2002-2005, entre otros) realicen grabaciones periódicas de los sujetos en vídeo y en contextos naturales. Esta técnica metodológica, que es la utilizada en nuestra base de datos, garantiza una mayor fiabilidad en la interpretación de la producción de los niños y resulta una fuente muy directa para aquel investigador que no se encuentre presente en el proceso de obtención de datos. Al mismo tiempo, estos últimos estudios citados no sólo han recopilado datos sino que también han procedido a su transcripción, lo cual permite el uso de los datos para posteriores trabajos o para compararlos con los de otros estudios (de carácter longitudinal o no).

Por tanto, este tipo de investigación es quizás uno de los mejores métodos para observar realmente lo que es difícil observar: cómo se adquiere el lenguaje, cómo se lleva a cabo este proceso, cuáles son los mecanismos que lo rigen; y, junto con todo esto y de forma más particular, cómo dentro de este proceso de adquisición se incluye el fenómeno de la TN. Sin embargo, no es corriente que la TN constituya objeto de análisis ni por sí misma ni en relación con la adquisición bilingüe simultánea, a pesar de que muchos autores, desde perspectivas diferentes, han demostrado con un mayor o menor volumen de datos que la actividad traductora está muy extendida entre los hablantes bilingües, incluidos los niños (Harris 1977, 1978, 1980a/b; Harris y Sherwood 1978; Shannon 1990a/b; Malakoff y Hakuta 1991; Malakoff 1991, 1992; Lozès-Lawani 1994; Bullock y Harris 1997; Sherwood 2000; Walichowski 2001; Orellana 2003; etc.). En el caso de 
nuestro estudio, al contar con una cantidad mucho mayor, no sólo de datos globales, sino también de casos de $\mathrm{TN}$, esperamos demostrar que nuestros sujetos traducen de forma habitual aunque también existan situaciones en las que deciden no traducir por una $u$ otra razón, como veremos posteriormente.

En segundo lugar, el carácter empírico del análisis de TTNN que pretendemos presentar en este estudio sería una excelente materia prima para analizar el proceso evolutivo que se sigue en este tipo de producción: cuándo surgen los primeros casos, cómo evoluciona la competencia traductora, qué factores influyen en este desarrollo, qué relación se puede establecer entre esta competencia y la competencia bilingüe, así como la relación de la TN con otros fenómenos de mezcla de lenguas como la AC o los préstamos (si evidencian o no la ausencia de control y diferenciación lingüística, por ejemplo) o el conocimiento metalingüístico de las lenguas participantes (si influye o no y de qué forma una competencia diferente en las dos lenguas del hablante).

En definitiva, un estudio de investigación basado en cómo los niños bilingües realizan traducciones y no en cómo deberían realizarlas, nos llevaría a poder apoyar o rechazar algunas cuestiones que se han planteado a este respecto. Así, una de estas cuestiones es si la $\mathrm{TN}$, al igual que la $\mathrm{AC}$, está gobernada por reglas, pues esto demostraría que algunos de los casos no son evidencia de interferencia lingüística, sino más bien de un conocimiento lingüístico y metalingüístico sofisticado de las diferencias y similitudes entre las lenguas. Algunos estudios de niños bilingües (Hakuta 1990; Malakoff 1991; 1992; Fernández Fuertes, Álvarez de la Fuente y Liceras (en prensa)) vienen a apoyar esta última postura, al demostrar que las pocas intrusiones léxicas o estructurales que constatan en sus sujetos no son consecuencia de la confusión de lenguas o de algún tipo de error (como los calificarían los prescriptivistas como Weinreich (1968) o Arnberg (1987), entre otros), sino que los niños mezclan los códigos cada vez que la situación lo requiere y los separan en la labor de traducción.

Sin embargo, como ya hemos comentado anteriormente, pocos estudios han tratado estos dos fenómenos de la TN y la AC conjuntamente (Srivastava y Gupta 1989; Malakoff y Hakuta 1991; Fernández Fuertes, Álvarez de la Fuente y Liceras (en prensa)), lo cual nos lleva a retomar la cuestión de la relación que se establece entre ambas [ver el apartado 4.5. del capítulo 1 y los apartados 1.2. y 2.1. del capítulo 2]. Según Srivastava y Gupta (1989), la $\mathrm{TN}$ y la $\mathrm{AC}$ son dos fenómenos que coexisten en la mente del bilingüe (concretamente y según estas autoras, del bilingüe compuesto o simultáneo), algo que le lleva no sólo a 
utilizar las lenguas de forma separada, sino también a mezclarlas de forma natural y espontánea. De hecho, consideran que los casos de AC y CC constituyen una evidencia de la gran cantidad de traducción que pueden realizar los bilingües. Suponiendo que estas autoras se refieran a aquellos casos en los que se da un trasvase de contenido de una lengua a otra en una misma conversación (no lo aclaran), nosotros propondremos que, efectivamente, parte de esos casos de CC que realizan los sujetos de nuestro estudio constituirán TTNN, entre las que podremos encontrar casos de $\mathrm{AC}$, pero no necesariamente, ya que, aunque se puedan dar simultáneamente en el discurso, son dos fenómenos distintos [ver nuestra propuesta en el diagrama 14 del apartado 1.1. del presente capítulo].

Finalmente, en cuanto a la cuestión que se plantea entre la diferenciación de lenguas y la realización de traducciones, ya la habían planteado Swain et al. (1974), quienes concluían su artículo comentando que lo que hay que hacer es comprobar si las TTNN son traducciones competentes a edades tempranas y si los ejemplos de TN constituyen una evidencia de la diferenciación de lenguas. Es decir, para Swain et al. (1974) y para otros autores como Lindholm y Padilla (1978b), si los niños traducen es porque son conscientes de la existencia de dos sistemas lingüísticos para comunicar un mismo mensaje, lo cual dependerá del contexto lingüístico-social en el que los sujetos bilingües se encuentran.

Según nuestro punto de vista y atendiendo a las TTNN que producen los niños del presente estudio, podremos observar que dichas TTNN demuestran que los niños ya son conscientes desde edades muy tempranas de que tratan con dos sistemas lingüísticos y de que existen diferencias entre esos dos sistemas lingüísticos.

Por este motivo, y otros que expondremos en el siguiente capítulo, consideramos que es muy útil partir de un estudio longitudinal para poder observar y analizar fenómenos característicos de la adquisición bilingüe como la $\mathrm{TN}$, así como la necesidad de que existan trabajos de carácter descriptivo para la elaboración de futuros estudios y su comparación con otros similares. 


\subsection{El estudio longitudinal como punto de partida del análisis de la TN: de la competencia a la actuación}

Aunque hace ya casi 30 años que Harris (1978) se plantease el análisis de la TN como base para el estudio científico de la traducción en general y afirmase que todavía era un territorio apenas sin explorar, lo cierto es que en la actualidad aún se necesita una metodología para el estudio de este tipo de traducción desde un punto de vista lingüístico y más datos para ahondar en el proceso que caracteriza la actividad de traducción de los niños bilingües.

El problema al que nos enfrentamos, en ese sentido, es que excepto Harris $(1980 \mathrm{a} / \mathrm{b})$, que se apoya en la revisión de datos previos procedentes de estudios de bilingüismo infantil (Ronjat 1913; Leopold 1939-1949; Von Raffler-Engel 1970; Swain 1972a, 1973; Swain y Wesche 1975; Volterra y Taeschner 1978; etc.), siendo sólo algunos de ellos longitudinales (Swain 1972a; Swain y Wesche 1975) y recopilando algunos nuevos, ninguno de estos trabajos hace uso de datos espontáneos y longitudinales referidos a la TN. Por otro lado, es cierto que existen estudios descriptivos con datos longitudinales de niños bilingües, aunque su objeto de estudio no es concretamente la TN (Ronjat 1913; Leopold 1939-1949; Swain 1972a/b; Swain y Wesche 1975; Swain et al. 1974; entre otros). Sólo Harris (1980a/b) y Harris y Sherwood (1978) se encargaron de revisar los datos de estos estudios, llevando a cabo una descripción longitudinal de las características de los niños bilingües como traductores con el fin de profundizar en el análisis de la TN [ver el apartado 2.2.1. del capítulo 2].

De esta forma, ni los estudios longitudinales dentro del campo de la adquisición bilingüe (Fantini 1985; Deuchar y Quay 2000; entre otros) se han ocupado del fenómeno de la TN, ni los estudios sobre TN dentro del campo de los estudios de traducción (Srivastava y Gupta 1989; Shannon 1996; Bullock y Harris 1997; Sherwood 2000; etc.) se han basado en datos longitudinales.

Si bien en la actualidad existen algunos estudios dedicados a las traducciones que realizan los niños bilingües (Walichowski 2001; Orellana 2003; Valdés 2003), lo cierto es que son estudios que adoptan un enfoque sociolingüístico y no tanto lingüístico, pues se ocupan de las mediaciones lingüísticas (o “brokering”) que realizan los niños bilingües, 
pero centrándose en cuestiones derivadas de la interacción social que suponen este tipo de actuaciones, como ya vimos en el apartado 1.3. del capítulo anterior.

Ante esta situación, en el presente estudio nos proponemos presentar, tanto desde un punto de vista lingüístico como desde un punto de vista pragmático, el desarrollo de este tipo de producciones, lo cual nos ofrece la oportunidad de estudiar los patrones que pueden marcar las TTNN en hablantes bilingües simultáneos. Concretamente, consideramos que lo interesante sería investigar la evolución que se sigue en este tipo de fenómeno de contacto de lenguas, al igual que se ha hecho en los estudios sobre la AC en los niños bilingües, analizando cuestiones como las siguientes: cuándo y en qué contexto aparecen los primeros casos de $\mathrm{TN}$; si, como la $\mathrm{AC}$, en las primeras etapas lo que predomina es la traducción de carácter léxico; si a medida que el niño va adquiriendo un mayor grado de competencia lingüística las traducciones se vuelven más complejas o sofisticadas; qué aspectos gramaticales y también pragmáticos definen estas TTNN; qué características tienen en común las traducciones realizadas por niños de diversos estudios de bilingüismo con las de los niños que son objeto de nuestro estudio, etc. A su vez, todas estas cuestiones podrían resultar de interés para profundizar, desde diferentes enfoques, en el estudio de temas relacionados con el bilingüismo infantil, tales como la representación léxica en la mente del niño bilingüe, la conciencia metalingüística, el dominio de lenguas o, en general, el contacto de lenguas a lo largo del desarrollo de la adquisición bilingüe.

Para ello, consideramos que los estudios longitudinales constituyen la fuente idónea para analizar los mecanismos mentales que actúan en el proceso de traducción y los factores implicados en el desarrollo de la competencia traductora. Sin embargo, para alcanzar este objetivo la carencia de estudios empíricos tanto dentro de los estudios de bilingüismo como dentro de los de traducción supone uno de los problemas al que nos tenemos que enfrentar.

En nuestro caso, el corpus de datos incluye pruebas experimentales que van dirigidas a la obtención de datos específicos de TN y que consisten en ubicar a nuestros sujetos en un contexto en el que un interlocutor monolingüe anglófono y uno monolingüe de habla española tratan de comunicarse, de tal forma que la situación les induce a ver su labor traductora como el único medio para que dichos interlocutores interactúen. Este tipo de situación provocada también ha sido utilizada por diversos estudios sobre bilingüismo, aunque en algunos no se ofrecen ejemplos concretos y no en todos ellos el interés del estudio se centra en casos de TN (Harris 1973; Swain 1972a; Swain et al. 1974; Swain y 190 
Wesche 1975; Lindholm y Padilla 1978a/b; Petersen 1988; Arnberg y Arnberg 1992). Es más, hay estudios como el de Köppe y Meisel (1995) que, refiriéndose a los niños de Saunders (1988) y de Fantini (1985), aluden al hecho de que repiten sus propios enunciados en ambas lenguas para atraer la atención de los padres o asegurarse de que les han entendido, evitando utilizar el término traducción para estos casos concretos (quizás por su carácter espontáneo) y utilizándolo cuando uno de los niños de su estudio actúa de mediador entre dos investigadores monolingües (y considerándolo como una función pragmática de la AC pero sin ir más allá). En el caso de Lanza (1997), opta por hablar de casos de alternancia para aclarar un mensaje o de alternancia de repetición, que, en realidad, son traducciones que realiza la niña de su estudio (de las cuales hemos ido ofreciendo casos en diversos apartados, como en los ejemplos de (55) y (58)), a las que da importancia como una habilidad pragmática pero sin analizar los mecanismos lingüísticos que la niña ha utilizado a la hora de traducir.

También los datos de carácter espontáneo tendrán su lugar en el presente estudio, puesto que en el concepto de TN incluimos no sólo las traducciones realizadas por los niños durante las pruebas experimentales a las que hemos aludido, sino también las que producen en situaciones cotidianas en las que los interlocutores (los padres y, en ocasiones, también los investigadores) les solicitan traducciones, así como aquellas que realizan por iniciativa propia y que están lejos de ser meros accidentes tal y como aseguraba Leopold (1939-1949).

En cuanto a la metodología que se ha seguido en el estudio longitudinal del que partimos, las grabaciones periódicas en vídeo de los niños objeto de estudio, así como las transcripciones de todas las sesiones grabadas que vamos a manejar (y no sólo de los fragmentos en los que aparecen casos de $\mathrm{TN}$ ), suponen una gran ventaja con respecto a los casos de TN encontrados en estudios longitudinales anteriores de los que muchas veces carecemos del suficiente contexto para observar qué factores rodean a las traducciones realizadas por los niños bilingües de dichos estudios.

También la recopilación de casos de TN a lo largo de este estudio longitudinal nos permitirá refutar los calificativos que la mayoría de los autores a los que hemos aludido aplican a los casos de TN al considerar que son traducciones son imperfectas, simples o rudimentarias [ver el apartado 2.2. del capítulo 2]. Teniendo en cuenta que estos sujetos están en un proceso de desarrollo lingüístico (en este caso, el de una competencia simultánea de dos L1), los casos que presentamos en el este estudio están muy lejos de ser 
incorrectos o poco adecuados. De hecho, destacan por ser traducciones no tanto literales sino funcionales, que responden, por tanto, a una necesidad comunicativa en la que dan una mayor importancia al significado que a la equivalencia léxica o sintáctica más literal.

Finalmente y teniendo en cuenta el diagrama 15 propuesto en el apartado 1.1., si adaptamos el análisis de las TTNN recogidas en nuestro estudio al modelo bilingüe que ha planteado MacSwan (2000, 2005) [ver el diagrama 6 en el apartado 2.2. del capítulo 1] y las matizaciones de Spradlin et al. (2003) y de Fernández Fuertes, Álvarez de la Fuente y Liceras (en prensa) sobre la existencia de dos realizaciones diferentes del sistema computacional en el hablante bilingüe, todas las TTNN que los niños realizan respetan la Forma Lógica del enunciado origen, ofreciendo una serie de posibilidades como las siguientes: unas veces, como en (60a), el niño ofrece una Forma Lógica equivalente en la otra lengua con una Forma Fonética en inglés o en español, dependiendo de la direccionalidad de la traducción y de la adecuación al contexto situacional y lingüístico; y otras veces opta por una Forma Lógica no equivalente, puesto que o bien recoge en la traducción más rasgos semánticos que los que había en el enunciado origen (traducción expansiva), como sucede en (60b), o bien recoge menos rasgos que el enunciado origen (traducción económica), como en (60c), tal y como veremos más adelante en el siguiente capítulo.

(60) Simon y Leo: bilingües inglés/español

(a) *MEL: what's that?

*SIM: pavo@sp .

*MEL: what's that honey?

*LEO: tu(r)key.

(b)*SIM: no@sp puedo@sp no@sp puedo@sp.

*MEL: how do you sayno@sp puedo@sp in English ?

*SIM: (h)elp.

(c) *SUS: [\% a Simon] oh@i ask her tell her you wanted to mark this perhaps she wants to mark this as well .

*LEO: [\% a Esther] quieres marcar esto ?

Sean las traducciones del tipo que sean, estaremos ante un proceso traductor en el que el niño es capaz de seleccionar, no sólo el output más apropiado y la FF más adecuada, 
sino también los rasgos incluidos en la FL que considere más óptimos para cada situación de traducción.

Este tipo de análisis, a su vez, nos permitirá, por un lado, establecer frecuencias, variaciones y comparaciones de tipologías a lo largo de los poco más de cuatro años en los que se engloba la selección de datos realizada para el presente estudio y, por otro, adoptar un concepto más amplio y más flexible de lo que entendemos por traducción, así como una orientación en los estudios de traducción más empírica que teórica, puesto que de lo que se trata es de analizar no cómo deberían ser las TTNN como productos sino cómo son y de tener un punto de partida para explorar qué mecanismos, estrategias o técnicas entran en juego en la mente del niño bilingüe cuando traduce.

A continuación, compararemos brevemente el estudio longitudinal del que partimos con otros estudios longitudinales dedicados a la adquisición bilingüe de distintos pares de lenguas y en niños de diversas edades. Seguidamente, dedicaremos un apartado a la estrategia de una persona-una lengua (Ronjat 1913), que hemos ido mencionando a lo largo de este capítulo, pues consideramos que es una cuestión a tener en cuenta en el análisis de las TTNN que realizan los niños bilingües de nuestro trabajo de investigación.

\subsection{Algunos estudios longitudinales en el bilingüismo infantil}

Para que el análisis de la mezcla de lenguas en general y de la TN en particular dentro del marco de la adquisición simultánea de lenguas no se quede en datos anecdóticos, la mayoría de los estudios de bilingüismo infantil que aparecen en la tabla 2 suelen ser estudios longitudinales en los que se examina la evolución que siguen los niños cuando adquieren las dos lenguas de forma simultánea y desde el nacimiento ${ }^{42}$. En esta tabla, que aparece en la página siguiente, reflejamos una muestra de algunos de estos

\footnotetext{
42 Otros estudios longitudinales (Burling 1979; McLaughlin 1984; De Houwer 1990, entre otros) se centran también en la adquisición temprana pero de lenguas segundas, de ahí que no los hayamos incluido en la tabla 2. Tampoco hemos incluido el estudio de Pena Díaz (2006) por no centrarse en el bilingüismo infantil, aunque incluye en sus datos las producciones trilingües español/inglés/gallego de un grupo de hablantes que reside en Londres. Al mismo tiempo, señalaremos que esta tabla-resumen está basada en nuestra propia investigación y en el resumen que hace De Houwer (1998) sobre las metodologías que siguen los estudios sobre adquisición bilingüe de primeras lenguas. En ella también hacemos referencia a CHILDES (http://childes.psy.cmu.edu/), que es una base de datos de producción lingüística (tanto de niños como de adultos) principalmente monolingüe. Existe también una base similar de datos bilingües que es LIDES "Language Interaction Data Exchange System" (http://www.ling.lancs.ac.uk/staff/ruthanna/lipps/lipps.htm), donde aparecen las transcripciones correspondientes a algunos de los estudios mencionados en la tabla 2.
} 
estudios, así como el período de tiempo que abarcan y la metodología seguida para poder comparar unos con otros.

\begin{tabular}{|c|c|c|c|}
\hline Estudio & Sujetos y edad & Lenguas & Metodología \\
\hline Ronjat 1913 & 1 niño $(0 ; 01-3 ; 06)$ & alemán/francés & anotaciones \\
\hline Leopold 1939-1949 & 2 niñas $(0 ; 09-15 ; 07$ y $2 ; 06-8 ; 00)$ & inglés/alemán & anotaciones \\
\hline Von Raffler-Engel 1970 & 1 niño $(1 ; 06-6 ; 09)$ & inglés-italiano & anotaciones \\
\hline Swain $1972^{\mathrm{a}}$ & 4 niños $(2 ; 10-4 ; 00)$ & inglés/francés & grabaciones de audio \\
\hline $\begin{array}{l}\text { Volterra y Taeschner } 1978 \\
\text { Taeschner } 1983\end{array}$ & 2 niñas $(1 ; 05-3 ; 06$ y $1 ; 02-2 ; 06)$ & alemán/italiano & $\begin{array}{l}\text { grabaciones de audio } \\
\text { +anotaciones }\end{array}$ \\
\hline Lindholm y Padilla 1978a/b & 5 niños $(2 ; 10-6 ; 02)$ & inglés/español & grabaciones de audio \\
\hline Redlinger y Park 1980 & 4 niños $(2 ; 00-3 ; 01)$ & $\begin{array}{l}\text { español/alemán } \\
\text { inglés/alemán } \\
\text { francés/alemán }\end{array}$ & $\begin{array}{l}\text { grabaciones de audio } \\
\text { +anotaciones }\end{array}$ \\
\hline Saunders 1983, 1988 & 3 niños $(0 ; 01-10 ; 00)$ & inglés/alemán & anotaciones \\
\hline Fantini 1985 & 1 niño $(0 ; 11-5 ; 08)$ & inglés/español & $\begin{array}{l}\text { grabaciones de audio } \\
\text { +anotaciones }\end{array}$ \\
\hline Petersen 1988 & 3 niños $(3 ; 00)$ & danés/inglés & grabaciones de audio \\
\hline Lanza 1988-2001 & 1 niña $(1 ; 11-2 ; 07)$ & noruego/inglés & $\begin{array}{l}\text { grabaciones de audio } \\
\text { +anotaciones }\end{array}$ \\
\hline $\begin{array}{l}\text { Meisel 1994a/b; } \\
\text { Köppe y Meisel } 1995\end{array}$ & $\begin{array}{l}13 \text { niños }(1 ; 04-3 ; 00) \\
2 \text { niños }(1 ; 04-5 ; 01)\end{array}$ & francés/alemán & grabaciones audiovisuales \\
\hline Ezeizabarrena 1995 & 2 niños $(1 ; 08-4 ; 00)$ & vasco/español & grabaciones audiovisuales \\
\hline Nicoladis y Genesee 1998 & 7 niños $(2 ; 00-3 ; 06)$ & francés/inglés & $\begin{array}{l}\text { grabaciones audiovisuales } \\
+ \text { transcripción (CHAT) }\end{array}$ \\
\hline Döpke 1992, 1998 & 3 niños $(2 ; 00-2 ; 02)$ & alemán/inglés & grabaciones audiovisuales \\
\hline Nicoladis y Secco 1998 & 1 niño $(1 ; 00-1 ; 06)$ & portugués/inglés & $\begin{array}{l}\text { grabaciones audiovisuales } \\
\text { +transcripción (CHAT) }\end{array}$ \\
\hline Paradis et al. 2000 & 15 niños $(2 ; 00-3 ; 06)$ & francés/inglés & $\begin{array}{l}\text { grabaciones audiovisuales } \\
+ \text { transcripción (CHAT) }\end{array}$ \\
\hline Döpke 2000 & 4 niños $(2 ; 00-2 ; 07$ y $3 ; 05-5 ; 00)$ & alemán/inglés & grabaciones audiovisuales \\
\hline $\begin{array}{l}\text { Deuchar y Quay 2000 } \\
\text { Deuchar (CHILDES 2007) }\end{array}$ & 1 niña $(0 ; 10-2 ; 03)$ & inglés/español & $\begin{array}{l}\text { grabaciones audiovisuales } \\
\text { +transcripción (CHAT) }\end{array}$ \\
\hline Sinka 2000 & 2 niños $(1 ; 06-2 ; 05$ y $1 ; 3-2 ; 02)$ & letón/inglés & grabaciones de audio \\
\hline Comeau y Genesee 2001 & 18 niños $(3 ; 00$ y $5 ; 00)$ & francés/inglés & grabaciones audiovisuales \\
\hline Müller y Hulk 2001 & 3 niños $(1 ; 01-5 ; 06)$ & $\begin{array}{l}\text { holandés/francés } \\
\text { alemán/francés } \\
\text { alemán/italiano }\end{array}$ & grabaciones audiovisuales \\
\hline Juan-Garau y Pérez Vidal 2001 & 1 niño $(1 ; 03-4 ; 02)$ & catalán/inglés & $\begin{array}{l}\text { grabaciones audiovisuales } \\
\text { +anotaciones }\end{array}$ \\
\hline $\begin{array}{l}\text { Fernández Fuertes et al. 2002- } \\
2005\end{array}$ & 2 niños $(1 ; 01-6 ; 11)$ & inglés/español & $\begin{array}{l}\text { grabaciones audiovisuales } \\
\text { +transcripción (CHAT) }\end{array}$ \\
\hline $\begin{array}{l}\text { De Houwer, A. (CHILDES } \\
\text { 2007) }\end{array}$ & 1 niña $(2 ; 07-3 ; 03)$ & holandés/inglés & $\begin{array}{l}\text { grabaciones audiovisuales } \\
\text { +transcripción (CHAT) }\end{array}$ \\
\hline Serra, M. (CHILDES 2007) & 3 niños $(1 ; 01-4 ; 03)$ & catalán/español & $\begin{array}{l}\text { grabaciones audiovisuales } \\
+ \text { transcripción (CHAT) }\end{array}$ \\
\hline
\end{tabular}


El presente estudio se diferencia de la mayoría de los estudios que aparecen en la tabla 2 no sólo en el hecho de que los protagonistas son dos hermanos gemelos, sino también en la frecuencia y la metodología de trabajo utilizada. Sin embargo, consideramos muy importante que se recurra a varios estudios de este tipo para poder tener una visión más global del tema y ver si existe algún comportamiento lingüístico o patrón común entre esos niños bilingües y nuestros sujetos. De hecho, siguiendo lo planteado en algunos estudios sobre adquisición de lenguas tanto monolingüe (López Ornat 1994) como bilingüe (De Houwer 1998), nuestro trabajo se divide en una serie de etapas basadas en las edades de los niños, lo cual nos permitirá un contraste de hipótesis a lo largo de estos períodos.

Así pues, lo que se refleja en la tabla 2 es que podemos encontrar estudios que analizan el comportamiento de niños bilingües de diferentes edades, que hablan pares de lenguas diferentes y en los que se utilizan diferentes metodologías de obtención y grabación de datos, tal y como veremos en el siguiente apartado.

\subsubsection{La metodología de la recogida de datos longitudinales}

La metodología que se ha seguido en este tipo de trabajos ha ido evolucionando a lo largo del tiempo en lo que a cuestiones técnicas se refiere, aunque en esencia el procedimiento en sí no ha variado mucho. Si bien en los primeros estudios, las producciones lingüísticas de los niños se recogían en anotaciones o en grabaciones de audio (Ronjat 1913; Swain 1972a; Lindholm y Padilla 1978a; Fantini 1985; Lanza 19882001; etc.), en los últimos años lo más corriente es que las grabaciones se realicen en vídeo para no perder información de la interacción natural de estos sujetos con otros interlocutores. Así, en el ejemplo (61), tomado de las transcripciones de Deuchar en CHILDES (2007) en las que se basa el trabajo de Deuchar y Quay (2000), se incluyen diversas líneas, aparte de las de producción lingüística, en las que se nos ofrece otro tipo de información, como puede ser la situacional (\%sit) o la extralingüística (\%act), importante para tener en cuenta en este tipo de estudios. 
*FAT: M M ese quién es ?

\%eng: M M who's that?

*FAT: ese quién es ?

\%eng: who's that?

\%sit: FAT shows M a picture of himself

*CHI: papá .

\%pht: p a

\%eng: daddy

\%act: stretching forward to touch the picture with her finger

(Deuchar, CHILDES 2007)

Las grabaciones de estos estudios (en formato de audio, de vídeo o de ambos, y de una duración determinada) se realizan de forma periódica y en ellas aparecen los niños que son objeto de estudio interactuando libremente con sus padres o con los investigadores y realizando actividades o juegos en un entorno natural y familiar. Normalmente se intenta mantener las lenguas en contextos separados, de tal forma que es el adulto el que define el contexto lingüístico. Una vez obtenidos los datos de producción lingüística, el siguiente paso es proceder a su transcripción, para lo cual algunos de los estudios más actuales (Nicoladis y Genesee 1998; Nicoladis y Secco 1998; Paradis et al. 2000; Deuchar y Quay 2000; entre otros) utilizan, al igual que nosotros, el sistema de transcripción CHAT (McWhinney 2000) que describiremos en el apartado dedicado a la metodología de nuestro estudio dentro del capítulo 4.

Llegados a este punto, creemos conveniente realizar una serie de puntualizaciones acerca de los estudios que aparecen en la tabla 2 del apartado anterior y de nuestro estudio longitudinal. En primer lugar, en esta relación de estudios de la tabla 2, donde la mayoría de ellos son longitudinales, hay que tener en cuenta diferentes variables que a veces hacen difícil establecer puntos en común entre esos estudios no sólo en lo que a sujetos, metodología o etapas se refiere, sino también en lo que respecta a enfoques o perspectivas diferentes en los que se basan. De hecho, muchos de ellos tratan de la mezcla de lenguas en la conversación o mezcla de lenguas discursiva (siguiendo la terminología de Lanza 1992, 1997) y otros de aspectos gramaticales como la flexión verbal o la negación (Döpke 1998; Paradis et al. 2000; Meisel 1994a/b; entre otros). Además, algunos de estos estudios siguen una metodología determinada que no permite contextualizar adecuadamente los datos, como las anotaciones, por ejemplo, de tal forma que consideramos que las transcripciones realizadas a partir de las grabaciones en vídeo siempre serán más aprovechables desde este punto de vista. 
En segundo lugar, a pesar de que existen estudios de gran relevancia dentro del campo del bilingüismo infantil que se centran en el par de lenguas inglés/español (Lindholm y Padilla 1978a/b; Fantini 1985; Deuchar y Quay 2000), lo cierto es que en ninguno de ellos el objeto de investigación es la adquisición bilingüe del inglés y del español en su variante peninsular como la de nuestros propios sujetos. Por este motivo, también creemos necesario destacar la importancia que merece nuestro estudio.

Además, el volumen de datos que vamos a manejar es mayor que los incluidos en los estudios de bilingüismo infantil mencionados en la tabla 2, puesto que, exceptuando los estudios de Leopold (1939-1949) y de Saunders $(1983 ; 1988)$ que, no olvidemos, se basan en anotaciones, el resto incluye datos que abarcan una media de dos a tres años en la vida de los sujetos, mientras que nuestro estudio abarca un período de poco más de 6 años en la vida de los niños.

Finalmente, y dadas las diferencias tanto de carácter metodológico como de carácter longitudinal apuntadas hasta ahora entre unos estudios y otros en la tabla 2, creemos conveniente señalar que, si bien estos estudios centrados en el bilingüismo inglés/español son de referencia obligada para el presente trabajo de investigación, no perseguimos una comparación entre los datos de estos estudios y los nuestros, pero sí los tendremos en cuenta de forma puntual para extrapolar a otros datos algunos de los planteamientos que presentaremos en el capítulo dedicado al análisis de nuestros propios datos.

Una vez que hemos aludido a algunas de las características metodológicas de nuestro estudio, presentaremos a continuación aquellas que se relacionan más con el contexto lingüístico en el que se desenvuelven los sujetos, un tema que será de obligada referencia al analizar los casos de $\mathrm{TN}$ que incluimos en nuestro corpus de datos. 


\subsubsection{El contexto lingüístico: la fórmula una persona-una lengua}

Dado que, al igual que en muchos de los estudios del apartado anterior, en nuestro estudio la estrategia comunicativa que siguen los padres con los hijos es la de una personauna lengua (Ronjat 1913), creemos conveniente dedicar un apartado específico a este tema que, a su vez, consideramos que es clave para analizar algunos aspectos del fenómeno de la TN en el bilingüismo simultáneo ${ }^{43}$.

La fórmula de una persona-una lengua es una estrategia comunicativa que utilizan los padres con sus hijos y que consiste básicamente en que cada uno de estos, aunque sean bilingües, utiliza su L1 cuando se comunica con los niños desde el nacimiento. Normalmente, sólo una de esas L1 (la de la madre o la del padre) es el principal medio de comunicación entre los padres y suele ser la lengua de la comunidad en la que viven habitualmente. De esta manera, los padres proporcionan de forma regular y sistemática un input a sus hijos en cada una de las dos lenguas, manteniendo, al mismo tiempo, una relación emocional más natural con sus hijos a través de sus respectivas L1 (BarronHauwaert 2004).

Muchos son los autores que han tenido como objeto de su estudio a niños bilingües simultáneos cuyos padres (a veces esos mismos autores) han aplicado este principio con ellos, independientemente del tipo de enfoque de sus análisis. De hecho, los trabajos en los que esta estrategia ha tenido un gran papel van desde los primeros estudios sobre bilingüismo infantil hasta la mayoría de los más recientes: Ronjat (1913), Leopold (19391949), Volterra y Taeschner (1978), Redlinger y Park (1980), Fantini (1985), Saunders (1983, 1988), Döpke (1992, 1998), Meisel (1994a), Köppe y Meisel (1995), Genesee et al. (1995), Paradis y Genesee (1996), Deuchar y Quay (2000), Van der Linden (2000), Schelletter (2000), Gawlitzek-Maiwald (2000), Bosch y Sebastián-Gallés (2001), Lanza (1988-2001), Quay (2001), etc.

La razón por la que los padres suelen elegir este tipo de fórmula se debe a las ventajas que se le atribuyen como método para asegurar el desarrollo bilingüe del niño (Hoffmann 1991; De Houwer 1995) y que han sido descritas por diversos autores (Grosjean 1982; Fantini 1985; Genesee 1989; Döpke 1992; Malhau 1994; Baker 2000;

\footnotetext{
${ }^{43}$ En realidad, esta estrategia de “one person, one language” fue así denominada por Grammont (1902), ya que Ronjat (1913) la adaptó posteriormente con el nombre de "one parent, one language". Sin embargo, en este trabajo utilizaremos la referencia de Ronjat aunque la traducción al español se relacione más directamente con la denominación de Grammont. 
Bosch y Sebastián-Gallés 2001; entre otros), los cuales consideran que cuanto mayor sea esta separación de lenguas que los padres aplican de forma espontánea, más fácil y más rápido será el proceso de diferenciación de las lenguas por parte del niño y mejor será la comunicación de los niños con sus interlocutores. Al mismo tiempo, esto evitará la mezcla bilingüe en los niños al no utilizarse las lenguas de forma intercambiable por los mismos interlocutores. Sin embargo, estas consideraciones implican que los niños pueden confundir las dos lenguas en un primer momento y que dicha mezcla de lenguas es algo negativo, aunque ya hemos visto en apartados anteriores, [ver el apartado 4 del capítulo 1], que esta es una de las posibles posturas que se pueden adoptar con respecto a la diferenciación de lenguas pero con la que no estamos de acuerdo.

Una perspectiva que no sería tan negativa como la anterior sería la afirmación de que el uso de dos sistemas lingüísticos en un contexto lingüístico y familiar de este tipo favorece el conocimiento metalingüístico del niño, así como el desarrollo de su capacidad traductora (Redlinger y Park 1980; Fantini 1985; Clyne 1987; De Houwer 1995). De hecho, dos de las ventajas que se le puede atribuir a esta fórmula son, por un lado, que los niños reciben un input más "natural", ya que comunicarse con ellos en una lengua que no es la dominante o que no se ha utilizado durante la niñez puede resultar más forzado. Por otro lado, asegura el bilingüismo en el caso de que la lengua que no se habla en el país o comunidad en que crecen (como en España, en nuestro caso).

Sin embargo, justo sería aludir también a las desventajas que algunos autores encuentran en la aplicación de esta estrategia, pues los padres suelen diferir en lo que entienden por este principio de una persona-una lengua. De hecho, Deuchar y Quay (2000) apuntan que puede dar lugar a un desequilibrio dentro del hogar, pues es probable que los padres utilicen una de las dos lenguas para hablar entre ellos. Además, según estas autoras, es posible que la diferenciación de lenguas en el niño no dependa de la asociación de una lengua a una persona, sino de que el niño pueda mantener esa diferenciación recurriendo a niveles como el fonológico, el léxico o el morfosintáctico. En este sentido, coincidirían con Bosch y Sebastián-Gallés (2001) en que esta estrategia no debería considerarse el mecanismo primordial para facilitar la distinción de las lenguas. Es más, a pesar de que los niños crezcan en un ambiente de este tipo, pueden aprender patrones muy sutiles de alternancia de códigos (AC) (MacWhinney 2000), lo cual nos lleva a plantearnos dos cuestiones: por un lado y como vimos en el apartado 5.2. del capítulo 1, si pueden existir otros factores de los que depende la presencia de casos de AC o de cambio de 
códigos (CC) que sean independientes de la estrategia comunicativa que sigan los padres; y, por otro lado, en el caso concreto de la adquisición bilingüe simultánea, si habría que plantearse qué es lo que se atribuye al bilingüismo y al papel del input que reciben los niños y qué es lo que forma parte de la evolución natural de la predisposición innata para adquirir un sistema lingüístico (evolución en la que se incluyen fenómenos de mezcla de lenguas como la TN y la AC). De este tipo de cuestiones nos ocuparemos en el capítulo 5 dedicado al análisis de los datos, en el que intentaremos observar si, efectivamente, hay que tener en cuenta otros factores, aparte del input que reciben los niños, que afecten a la producción del CC (una necesidad lingüística; un vacío léxico; etc.), y más concretamente a la realización de TTNN por parte de los niños de nuestro estudio, y si existe una evolución en la capacidad traductora de estos niños desde los primeros casos de TN recogidos a los últimos.

Como conclusión a este capítulo, y a raíz de todo lo expuesto hasta ahora, consideramos que los datos de producción lingüística de los que vamos a partir para el análisis de la TN nos servirán para realizar las siguientes aportaciones:

(1) contribuir a arrojar luz sobre la naturaleza y el desarrollo de la competencia lingüística en general y de la traductora en particular;

(2) proporcionar un vínculo entre los diferentes fenómenos de lenguas de contacto entre los que están la $\mathrm{TN}$ y la $\mathrm{AC}$ como característicos de la adquisición bilingüe; y

(3) vincular e incluir el fenómeno de la TN tanto en los estudios de adquisición bilingüe como en los de traducción, sirviendo además como puente entre ambos campos de investigación. 


\section{CAPÍTULO 4: DESCRIPCIÓN DE LA METODOLOGÍA Y PRESENTACIÓN DE LOS DATOS DE PRODUCCIÓN BILINGÜE INGLÉS/ESPAÑOL}

Una vez expuestas las cuestiones teóricas y las propuestas que presentamos en este estudio sobre el fenómeno de la TN, este capítulo se centra en la descripción de la metodología de la recogida y clasificación de datos de producción lingüística procedentes de dos niños gemelos bilingües inglés/español, de la que ya hemos adelantado alguna información en la última parte del capítulo anterior [ver el apartado 2.3. del mencionado capítulo]. Como ya mencionamos en la introducción del presente trabajo, dado que la selección de datos que aquí presentamos procede, a su vez, de un estudio longitudinal más amplio sobre adquisición bilingüe inglés/español en gemelos (Fernández Fuertes et al. 2002-2005), parte de esa metodología incluye el seguimiento longitudinal de estos niños. En este sentido, y tal y como se ha planteado en algunos estudios sobre adquisición de lenguas tanto monolingüe (López Ornat 1994) como bilingüe (De Houwer 1998), la división de estos datos en etapas basadas en las edades de los sujetos nos permitirá el contraste de hipótesis a lo largo de estos períodos. Este planteamiento longitudinal consiste en el seguimiento y posterior análisis del proceso de adquisición de dos lenguas (inglés/español) por parte de dos niños gemelos a través de su producción lingüística y a lo largo de un período de tiempo de más de 6 años, aunque nuestra selección de datos englobe sólo un período de poco más de 4 años (2;00-6;03). Este tipo de estudio nos permitirá 
observar el fenómeno de la TN en el proceso de adquisición bilingüe a lo largo de una serie de etapas del desarrollo lingüístico y ver cómo la teoría lingüística puede contribuir a explicar dicho fenómeno.

En lo que respecta a los contenidos concretos del presente capítulo, este se estructura de la siguiente manera: como marco metodológico del trabajo de investigación que aquí presentamos, procederemos, en primer lugar, a describir las características de los sujetos del estudio longitudinal, así como las diversas situaciones comunicativas a las que estos niños pueden estar expuestos. Es decir, consideramos importante no sólo cuál o cuáles son las lenguas que manejan los padres en el contexto social en general y en el contexto familiar en particular, sino también cómo se comunican los padres entre sí y en qué lengua o lenguas se dirigen a sus hijos cada uno de ellos.

En segundo lugar, expondremos la metodología que se ha seguido en el estudio longitudinal para la recogida de los datos donde detallaremos las características técnicas y situacionales de las grabaciones, así como de los tipos de datos que se incluyen, haciendo especial hincapié en las pruebas de TN que se incluyen en los datos experimentales y que han sido diseñadas específicamente para su análisis en el presente estudio.

Finalmente, procederemos a presentar diversas cuestiones relacionadas con el tratamiento de la selección de datos que será esencial para su uso posterior en el correspondiente análisis [ver el capítulo 5].

\section{LOS SUJETOS Y EL INPUT LINGÜÍSTICO}

Los sujetos de nuestro estudio, a los que llamaremos Simon y Leo, han adquirido simultáneamente el inglés y el español desde la infancia y en un contexto natural. Simon y Leo nacieron en Salamanca el 27 de diciembre de 1998 de tal forma que al finalizar el presente trabajo de investigación cuentan con unos 8;00 años de edad.

La familia pertenece a la clase media, tanto el padre como la madre poseen un nivel educativo alto y trabajan en un ambiente universitario. Los niños han seguido un desarrollo físico y psíquico normal, no han padecido enfermedades infantiles anormales para su edad, ni han experimentado cambios radicales en su entorno familiar. 
Como una de las características personales de los niños de nuestro trabajo es conveniente incidir en el hecho de que se trate de niños gemelos puesto que, hasta el momento, no existe un estudio de este tipo que tenga como sujetos a niños que sean gemelos. También conviene puntualizar que está documentado (Dale et al. 1998; Viding et al. 2004) que desde el punto de vista del desarrollo lingüístico estos niños sufren un retraso en el inicio del habla con respecto a niños que no son gemelos (de unos 3 meses y medio, según Dale et al. 1998), de ahí que en las primeras grabaciones de los sujetos apenas se recojan producciones lingüísticas. Sin embargo, pronto se recuperan de este retraso alcanzando el mismo nivel de desarrollo lingüístico que los niños no gemelos, por lo que para Simon y Leo el ser gemelos no supone una desventaja con respecto al desarrollo lingüístico observado en niños en los que no existe esta relación biológica. Al mismo tiempo, el hecho de que sean gemelos nos permite el análisis de las producciones lingüísticas de dos sujetos de la misma edad que reciben el mismo input familiar dentro del mismo contexto social y situacional, garantizándose así una homogeneidad de datos que resultaría más difícil de conseguir entre niños de otros estudios o de edades diferentes.

En cuanto al contexto lingüístico planteado a nivel familiar, consideramos que este garantiza que ambas lenguas formen parte del input de los niños desde su nacimiento. Así, la madre, Melanie, procedente de Pensilvania (Estados Unidos), tiene como L1 el inglés norteamericano y el padre, Ivo, nacido en Madrid (España), es hablante nativo de español peninsular. Los padres tienen, en mayor o menor medida, un grado de competencia alto en la otra lengua, de tal forma que el bilingüismo está garantizado en el núcleo familiar.

Entre ellos, la madre y el padre hablan en español, la lengua del contexto lingüístico en el que viven (Salamanca), salvo cuando el contexto sociolingüístico lo requiere por estar presente un hablante monolingüe de inglés. De esta manera, el ambiente lingüístico en el que se mueven Simon y Leo les hace comunicarse en español con su padre y con los hablantes de esta comunidad, mientras que recurren al inglés cuando se comunican con su madre, en los viajes anuales a los Estados Unidos o cuando se encuentran presentes familiares o amigos que son hablantes monolingües de inglés, plasmando con esta situación, por tanto, lo postulado por la fórmula una persona-una lengua (Ronjat 1913) descrita anteriormente en el apartado 2.4. del capítulo anterior.

De esta manera, por un lado, el input del español de los niños se ve garantizado por el padre y los familiares paternos, que sólo les hablan en español, así como por otras variables sociolingüísticas fuera del hogar familiar, ya que viven en un entorno 
monolingüe de español (por lo general, sus amigos y compañeros de colegio son hablantes monolingües de español) y asisten a un colegio local monolingüe en Salamanca. Por otro lado, el input que reciben los niños en inglés se ve garantizado en este caso por la madre y los familiares maternos o los amigos anglófonos de la familia, que les hablan sólo en inglés, por las películas que ven en el televisor y que son casi exclusivamente en habla inglesa, así como por sus estancias anuales de tres meses en EEUU.

En lo que respecta al papel del input de los investigadores, con el fin de garantizar la homogeneidad y una situación comunicativa fluida, estos visitan a los niños en su casa de Salamanca los domingos cuando los padres están presentes y suelen ser los mismos en cada sesión. Así, en las sesiones de español, Raquel (presente desde la primera grabación) y Esther (autora de este trabajo y presente desde que los niños tenían 4;00 años aproximadamente) son las investigadoras que se dirigen a ellos en español, mientras que en las sesiones de inglés, suele ser Todd, el investigador anglófono (presente desde el inicio de las grabaciones hasta que los niños tenían casi 3;00 años), y Susana, otra investigadora anglófona (presente en la mayoría de las pruebas experimentales de traducción), los que se dirigen a los niños (y a los padres) solamente en inglés. Estos cuatro investigadores son los que interactúan con los niños durante las grabaciones, de tal forma que la familiaridad con ellos está garantizada, ya que a lo largo de esos 6 años los niños ven en estos investigadores a personas que forman parte de su ámbito más inmediato.

En este punto, sería conveniente aclarar que, aunque hablemos de investigadores anglófonos o de habla española, todos los investigadores que aparecen son bilingües pero se hacen pasar por hablantes monolingües con el fin de poder separar los contextos y de poder realizar determinadas pruebas experimentales, como veremos más adelante. Además, a pesar de este conglomerado lingüístico de interlocutores, en las grabaciones Melanie o los investigadores anglófonos (Todd o Susana) sólo se dirigen a los niños en inglés; la investigadora que se hace pasar por monolingüe de español, Esther, sólo en español; y Raquel, la investigadora bilingüe, utiliza como lengua habitual el español para comunicarse con ellos y sólo cambia al inglés en contadas ocasiones o cuando se trata de pruebas experimentales de traducción.

Así pues, al igual que se plantea en Deuchar y Quay (2000), por un lado, es el input lingüístico de los adultos lo que va a determinar el contexto lingüístico en el que se han de desenvolver los niños y, por otro, los padres, con su comportamiento lingüístico bilingüe, establecen un modelo a seguir por los niños, en el que no existe ningún prejuicio o rechazo 
ante el hecho de hablar dos lenguas o de traducir entre ellas. De hecho, los padres no suelen utilizar la AC como parte de sus recursos comunicativos con los niños, lo cual puede verse constatado en las grabaciones en las que aparecen interactuando con Simon y Leo. En el caso de las traducciones no podemos afirmar lo mismo ya que, en el input que los niños reciben de sus padres, es frecuente encontrar que estos proporcionan traducciones a sus hijos, tal y como hemos visto en el apartado 1.3. del capítulo 3 dedicado a nuestras propuestas.

Presentadas hasta aquí las características personales de nuestros sujetos y el contexto lingüístico en el que se desarrollan, expondremos en el siguiente apartado las pautas metodológicas básicas de las que hemos partido para la recopilación de datos de producción lingüística y la obtención, en condiciones controladas, de datos experimentales encaminados al análisis de las TTNN por parte de Simon y Leo y que incluiremos en el capítulo 5 del presente trabajo de investigación.

\section{LA RECOGIDA DE DATOS: LA METODOLOGÍA Y LOS TIPOS DE DATOS}

La base empírica de nuestro estudio es la recogida de datos, dentro de los cuales se distingue entre datos espontáneos y datos experimentales. Si bien en el caso de las grabaciones y las correspondientes transcripciones incluidas en los datos espontáneos se hace referencia a los distintos contextos lingüísticos (español frente a inglés) en los que se han realizado dichas grabaciones, en el caso de los datos experimentales no se realiza tal distinción, pues estos se caracterizan, precisamente, por incluir situaciones en las que se utilizan las dos lenguas simultáneamente. En relación a esta diferenciación de contextos, consideramos oportuno resaltar que la recogida de datos ha sido llevada a cabo por el equipo de investigación de la Universidad de Valladolid, UVA-Language Acquisition Lab, al que pertenece la autora del presente trabajo, el cual se dedica a la grabación de todas las sesiones (excepto las que graban los padres) y a la transcripción de las sesiones realizadas en contexto español, mientras que el equipo del Language Acquisition Lab de la Universidad de Ottawa (Canadá), Ottawa-LAL, se encarga de la transcripción de las sesiones en contexto inglés ${ }^{44}$.

\footnotetext{
${ }^{44}$ Me gustaría expresar mi más sincero agradecimiento tanto a los miembros del UVA-LAL (Raquel Fernández Fuertes, Susana Muñiz Fernández, Isabel Parrado Román y Montserrat Bermúdez Bausela), así como a los miembros del Ottawa-LAL (Juana M. Liceras, K. Todd Spradlin, Elisa Rosado, Rocío Pérez-Tattam, Shauna Flynn, Tamara Vardo, Melissa Grimas y Marco Llamazares Muñoz) por las labores de recogida y transcripción de datos que han realizado con tanta constancia y minuciosidad.
} 
Pasando a una descripción más detallada de la metodología en la recogida de datos del estudio longitudinal, esta se basa en la grabación de la producción lingüística de los niños en situaciones cotidianas con una cámara de vídeo. Dichas grabaciones se han digitalizado posteriormente en formato DVD para facilitar su manejo y posterior transcripción. A diferencia de otro tipo de estudios longitudinales basados únicamente en grabaciones de audio (como veíamos en la tabla 2 del apartado 2.3. del capítulo anterior), este tipo de grabaciones nos va a proporcionar información del contexto no verbal, de gran importancia en la comprensión y el análisis de los datos tanto espontáneos como experimentales, lo cual nos ayudará a deshacer ambigüedades o a prestar atención a otros aspectos como el lenguaje gestual, por ejemplo. A este respecto, la producción lingüística de Simon y Leo se recoge en contextos naturales y cotidianos (comiendo, jugando, etc.) en los que los niños se encuentran inmersos y que forman parte de su rutina diaria.

Igualmente, tanto en la grabación de datos espontáneos como en la de datos experimentales, los investigadores forman parte de ese ambiente natural y del ámbito más inmediato de los niños, ya que interactúan con ellos cada 2 ó 3 semanas (durante los tres primeros años) o una vez al mes o cada dos meses (en los últimos años de grabación). De esta manera, todos estos intercambios lingüísticos grabados recogen la interacción entre los niños y los adultos, bien sean los padres o los investigadores, o ambos.

Finalmente, en cuanto al papel de los investigadores en las grabaciones, creemos conveniente resaltar que estos investigadores se han integrado perfectamente en el ámbito familiar, una circunstancia bastante importante a la que ya hemos aludido, pues ayuda a conseguir naturalidad en las grabaciones y a evitar que los niños no hablen por considerarlos unos extraños. Además, los niños están acostumbrados a la presencia de la cámara de vídeo que, lejos de ser un elemento de distorsión como puede suceder con los adultos, a veces la consideran un juguete más, sin interferir en la espontaneidad de su comportamiento lingüístico.

A continuación, procederemos a la descripción de la metodología seguida en la recogida de los dos tipos de datos de los que disponemos, los espontáneos y los experimentales, incluyendo cuestiones tales como el contexto y la periodicidad con los que se graban, así como el recuento de las grabaciones que se incluyen en el estudio longitudinal de Fernández Fuertes et al. (2002-2005), de las cuales vamos a extraer las grabaciones correspondientes a nuestra selección de datos. 


\subsection{Los datos espontáneos}

Tal y como hemos comentado en la introducción anterior, en el caso de los datos espontáneos, las situaciones que recogen las grabaciones consisten fundamentalmente en conversaciones entre los niños y los padres o los investigadores dentro del hogar familiar. Actividades como comentar cuentos o participar en juegos, por ejemplo, son situaciones comunicativas reales que nos permiten analizar la producción lingüística de estos niños a lo largo de más de seis años.

De manera similar a lo que figura en la bibliografía especializada en estudios de adquisición monolingüe y bilingüe (Slobin 1985; De Houwer 1990; entre otros), las grabaciones periódicas de los datos espontáneos del estudio longitudinal comenzaron en febrero de 2000 cuando los niños tenían 13 meses y continúan en la actualidad cuando tienen poco más de 7 años. Dichas grabaciones fueron realizadas periódicamente por investigadores dos o tres veces al mes hasta que los niños cumplieron 3 años, tal y como figura en la tabla 3.

TABLA 3. PERIODICIDAD DE LAS GRABACIONES EN EL ESTUDIO LONGITUDINAL DE FERNÁNDEZ FUERTES ET AL. (2002-2005)

\begin{tabular}{|c|c|}
\hline Edad de los sujetos & $\mathbf{N}^{\mathbf{0}}$ de grabaciones \\
\hline $1 ; 01-2 ; 11$ & 2 ó 3 grabaciones al mes \\
\hline $3 ; 00-6 ; 00$ & 1 ó 2 grabaciones al mes \\
\hline $6 ; 00-7 ; 00$ & 1 grabación cada 3 ó 4 meses \\
\hline
\end{tabular}

A partir de que los niños cumplieron 3 años, las grabaciones se fueron espaciando, de tal manera que hasta que cumplieron 6 años se realizaban una media de dos grabaciones por mes y, finalmente, en el último año, una grabación cada tres o cuatro meses.

Con el fin de garantizar la continuidad en la obtención de datos longitudinales, los padres retoman las grabaciones cuando viaja a Estados Unidos, donde permanecen dos o tres meses en verano, de tal forma que esta periodicidad en las grabaciones garantiza una observación más detallada de los pasos en la evolución del desarrollo bilingüe de los niños (y de su competencia traductora, que es uno de los temas de interés del presente trabajo). 
En cuanto al número de grabaciones que se incluyen en el estudio longitudinal, a fecha de diciembre de 2006 se han grabado un total de 176 sesiones (115 en inglés y 58 en español), correspondiéndose cada una de ellas a una fecha de grabación.

Esta cantidad dispar entre las sesiones en inglés y las sesiones en español se debe al hecho de que la duración de las grabaciones en uno u otro contexto varía. Así, la duración media para las grabaciones en inglés es de unos 30 minutos, mientras que para las de español es de 50 ó 60 minutos, de ahí que, a pesar de que el número de sesiones es mayor en inglés que en español, el tiempo grabado para uno y otro contexto es más o menos similar.

También contribuye a esa disparidad de sesiones en español y en inglés, la diferencia en la frecuencia de grabación, ya que a veces las fechas entre una y otra sesión suponen una diferencia de pocos días, lo cual sucede sobre todo hasta que los niños cumplen 3;00. A partir de aquí, aunque las grabaciones se van espaciando en el tiempo (como hemos señalado en la tabla 3), es importante añadir que, en lo que respecta a las grabaciones realizadas por los padres, estos suelen realizar grabaciones cortas en varios días diferentes, sobre todo en un contexto inglés (especialmente durante los tres meses que pasan en Estados Unidos), de ahí que exista un mayor número de sesiones en inglés que en español.

Finalmente, para concluir este apartado, conviene a aludir a la organización de las sesiones, y sus correspondientes transcripciones, según el contexto lingüístico en el que fueron grabadas, ya que en las sesiones grabadas en un contexto español (marcadas como SP) los niños aparecen interactuando con el padre o los investigadores españoles, mientras que en las sesiones en un contexto inglés (marcadas como EN) interactúan con la madre o con un investigador anglófono. En el caso de las grabaciones en las que se incluyen las pruebas experimentales de traducción (marcadas como TR) y, por tanto, en las que los niños interactúan constantemente en las dos lenguas, en función de qué equipo las haya transcrito (el UVA-LAL o el Ottawa-LAL) se incluirán en un grupo de sesiones o en otro (en SP o en EN, respectivamente). 


\subsection{Los datos experimentales}

Como ya hemos mencionado, en las grabaciones no sólo se recogen datos espontáneos, sino también experimentales. Este tipo de datos son primordiales a la hora de suplir determinadas limitaciones intrínsecas a la producción de datos espontáneos. En nuestro caso, hemos localizado distintos casos de TN realizados por Simon y Leo en los datos de carácter espontáneo (interactuando con sus padres la mayoría de las veces), pero es posible que en las interacciones familiares no surjan determinadas estructuras lingüísticas de aparición menos frecuente, de ahí que los datos experimentales permitan ampliar las posibilidades de observación y constituyan así una fuente importante de datos. Aunque en el estudio longitudinal del que partimos se incluyen pruebas experimentales de $\mathrm{AC}$, en el presente estudio nos interesan otras pruebas que se incluyen en dicho estudio y que se relacionan con la TN, concretamente, aquellas que van dirigidas a la obtención de datos específicos de TN y que consisten en ubicar a los niños en un contexto en el que un interlocutor monolingüe anglófono y uno monolingüe de habla española tratan de comunicarse, de tal forma que se les hace creer a los niños que su labor traductora (o interpretativa) es el único medio para que dichos interlocutores se comuniquen. Actúan como lo que Swain et al. (1974) denominan enlace comunicativo y Harris (1973) canal comunicativo. Por tanto, traducen del inglés al español para que el hablante monolingüe los entienda (independientemente de quién parta el enunciado origen que hay que traducir) y del español al inglés para que el interlocutor anglófono los entienda de tal forma que todos puedan participar en la actividad lúdica correspondiente.

Creemos conveniente puntualizar que quizás las pruebas experimentales de traducción se puedan ver como un método artificial, puesto que los niños llevan a cabo el proceso de traducción en un contexto experimental y se encuentran en una situación comunicativa no real o poco natural, pero esto no quiere decir que ellos la perciban como tal o que traduzcan de forma menos natural, puesto que durante las pruebas experimentales, si bien la mayoría de las veces traducen inducidos por un interlocutor (un investigador o un familiar presente en la grabación), también hay casos en los que traducen de forma espontánea, sin que nadie les haya inducido a ello expresamente. Al mismo tiempo, tampoco debemos olvidar que también en los datos espontáneos podemos encontrar casos en los que un familiar (Melanie, normalmente) les induce a traducir, sin 
que esta circunstancia nos lleve a pensar que los niños traducen de forma más real o natural que en el caso de las pruebas experimentales.

En el estudio longitudinal se han llevado a cabo concretamente tres pruebas experimentales de traducción y tanto del tipo de actividad que se incluye en cada prueba como de los distintos participantes que en ella intervienen trataremos con más detalle en los apartados que siguen a continuación y que se centran en el diseño, la organización y la puesta en marcha de estas tres pruebas experimentales. Para ello, describiremos la técnica que se ha seguido en estas pruebas, en la que se han aplicado los patrones relacionados con la obtención de datos de producción lingüística de niños a través de pruebas experimentales que aparecen en Swain (1972a) o en Thornton (1996), entre otros.

\subsubsection{El diseño de las tres pruebas experimentales}

Para poder entender la mecánica de las tres pruebas de traducción diseñadas específicamente para el presente trabajo de investigación, procederemos a describir cada una de ellas.

En la primera prueba, se hace ver a los niños que Esther, una investigadora a la que consideran hablante monolingüe de español, ha de comunicarse con Susana, hablante monolingüe de inglés y a la que acaban de conocer. Esta investigadora anglófona es la única que sabe qué hacer con dos pósters interactivos en inglés que ella misma les ha regalado. En el primer póster hay que dibujar las manecillas de un reloj dependiendo de la hora que decidan poner, aunque pueden cambiar la hora en cualquier momento, ya que pueden borrar las manecillas que han dibujado con un pañuelo de papel. En la parte de arriba del segundo póster hay diferentes casillas para poner los días de la semana en inglés y en la parte de abajo aparecen doce viñetas, de las cuales ocho representan distintos paisajes y estados meteorológicos (por ejemplo, en una viñeta aparece un paisaje en el que el cielo está nublado, en otra hay árboles inclinados por el viento, etc.), y en las otras cuatro aparece un niño con un vestuario acorde al estado meteorológico del tiempo que haga (por ejemplo, en una de las viñetas aparece un niño que lleva un abrigo, en otra lleva unos pantalones cortos, etc.). A partir de la observación de estas viñetas, los niños tienen que decir a Susana qué tiempo hace en cada una de las viñetas para que ella lo marque o lo escriba en inglés (por ejemplo, “it's warm”, “it's raining”, etc.) y también traducírselo a 
Esther al español para que ella lo entienda. Con el fin de poder ilustrar en qué consiste la prueba, ofrecemos en (62a) un fragmento de la transcripción resultante de esta primera prueba de traducción.

(a) *SUS: yeah mark one the one you think is the weather today this ?

*SUS: this?

*SUS: put a cross here .

*SUS: $\quad$ [\% a Leo] or ask Esther to do it .

*SUS: $\quad$ explain what you've got to do but you've got to tell her what she's got to do .

*LEO: [\% a Esther] you do it .

*EST: qué ?

*LEO: marcarlo tienes que marcarlo .

*EST: ah@i marcar eh@fp el qué ?

*SIM: tienes que mascar [: marcar] +/.

*SUS: $\quad$ but $<$ she's got $>$ [/] she's got to mark the ones you want .

*LEO: marcar este .

*EST: cuál tengo que marcar?

*LEO: $\quad<$ este $>[>]$ !

*SIM: $\quad<$ este $>[<]$ !

*EST: este ?

*EST: por qué este?

*LEO: $\quad<$ po(r)que $>$ [>] .

*SIM: $\quad<$ po(r)que $>[<]$ no sabemos si hay sol o si hay viento .

*EST: $\quad$ ah@i vale este vale $<$ le dices $>$ [//] le puedes decir a Susana que qué más tengo qué hacer?

*SIM: [\% quitándole el rotulador a Esther para marcar uno él] mhm@fp a ver.

*EST: [\% a Leo] pregúntale a Susana qué más tengo qué hacer por favor.

*LEO: what do you need to do now ?

Atendiendo a este tipo de actividad se establece desde el principio que, para que todos, incluida Esther, puedan jugar y comunicarse, es necesario hacer entender a Esther qué es lo que hay que dibujar o escribir en los pósters para así poder integrarla también en la dinámica del juego. En este tipo de prueba no sólo se pretende poner de manifiesto que son capaces de estar traduciendo constantemente para que el juego no se ralentice o se interrumpa, sino también el carácter solidario de los niños, ya que gracias a sus traducciones pueden hacer que Esther y Susana se comuniquen y, sobre todo, que Esther, que es la que recibe la información de qué es lo que hay que hacer con los pósters a través de los niños, no se sitúe al margen del juego. 
En el caso de la segunda prueba, la situación es muy semejante, puesto que en la interacción se encuentran presentes dos investigadores monolingües de inglés, Susana (a quien ya conocen de la primera prueba de traducción) y Todd (al que ya conocen pero hace unos años que no ven), Esther, la investigadora que de nuevo se hace pasar por hablante monolingüe de español, y Raquel, a la que los niños reconocen como bilingüe, aunque se dirige a ellos la mayor parte de las veces en español. En esta ocasión, hay seis participantes en un juego de cartas, los cuatro adultos y los dos niños, de tal forma que se decide formar tres equipos: Simon con Raquel, Leo con Esther y Susana con Todd.

El juego de cartas, llamado "Go fish" en inglés, consiste en repartir cinco cartas a cada jugador, dejando el resto de las cartas boca abajo sobre la mesa. En su turno correspondiente, cada jugador ha de intentar formar parejas de animales (que son, en este caso, los dibujos que aparecen en las cartas), para lo cual el primer jugador tiene que pedir la carta que le falta a otro jugador diciendo algo así como “¿tienes un caballo?/Do you have a horse?". Si el otro jugador la tiene, ha de entregársela al primero pero si no la tiene, ha de decirle "vete a pescar/go fish". Si esto último sucede, el primer jugador ha de coger una carta del montón, pasando el turno al siguiente jugador. Gana aquel que consiga hacer más parejas de cartas (o de animales, en este caso).

Dadas las características lingüísticas de cada uno de los participantes en el juego, se provoca una situación completamente bilingüe que hace que los niños, de nuevo, tengan que traducir entre los hablantes monolingües de inglés y la hablante monolingüe de español con el fin de no dar al traste con el juego y la competición, tal y como se puede comprobar en (62b), donde mostramos un fragmento de la transcripción resultante de esta prueba para que la descripción de esta resulte más clara. 
(b) *RAQ: a ver qué [///] vamos a explicarle a Todd $<$ y a $>$ [/] y a Susana lo que hemos hecho .

*RAQ: se lo explicas en inglés que hablas mejor que yo ?

*LEO: $\quad[\%$ whispering] $\mathrm{xxx}$.

*RAQ: [\% whispering] que yo me equivoco siempre venga.

*EST: $\quad[\%$ to Leo] espera que les va a explicar S .

*RAQ: <que hemos cogido> [//] les dices que hemos cogido del montón ésta y que como teníamos otra en la mano hemos hecho pareja.

*RAQ: [\% whispering] tienes que decírselo en inglés .

*SIM: $\quad$ we got a lion and $\sin (\mathrm{ce})$ we get a li:on and we don't want to $\mathrm{u}(\mathrm{se})$ and we didn't have it and we had to go fis(h) and we get a beao [: bear] .

*TOD: oh@i you got a bear .

*SUS: ok you fished a bear .

*TOD: $\quad$ you fished a bear out of the pile oh@i ok allright . [5;05.29]

Finalmente, en la tercera prueba de traducción, hay una circunstancia nueva: la hablante monolingüe de español, Esther, está aprendiendo inglés, de tal forma que la prueba se divide en dos partes. En la primera parte, Esther lee un cuento en inglés para que los niños comprueben si, efectivamente, está aprendiendo inglés. Esto se aprovechará para preguntar a los niños el significado de algunos enunciados que aparecen en el cuento, pues se les hace ver que la competencia en inglés de la investigadora aún no es lo suficientemente buena como para entender todo lo que lee.

En la segunda parte, Melanie, Esther, Simon y Leo juegan a un juego de mesa, al que Melanie y los niños ya han jugado en otras ocasiones en inglés, llamado "Totally gross", que consiste en hacer pruebas un tanto peculiares y divertidas, y en realizar preguntas relacionadas con ámbitos de carácter científico, como la biología. Los participantes han de acertar la respuesta correcta entre las opciones que se ofrecen y pasar las pruebas para poder ir avanzando con su ficha por el tablero. La mecánica de este juego puede quedar más clara recurriendo al fragmento que aparece en $(62 \mathrm{c})$ y que se obtuvo durante la puesta en práctica de la prueba. 
(62) (c) *MEL: L, L, maybe we should explain to Esther about the question .

*MEL: how long [//] if you [/] if you eat something, how long does it hang around in your large intestine, down here, before you poop it out?

*MEL: two minutes ?

*MEL: $\quad$ two hours or two days [\% asking Simon for confirmation] ?

*SIM: yeah .

*MEL: $\quad$ [\% back to Leo] are you going to tell her ?

*SIM: no .

*SIM: well yes .

*SIM: but you do it this time .

*EST: bueno me lo dice mamá esta vez, vale ?

*SIM: sí .

*MEL: $\quad[\%$ to Esther $]$ vale ok .

*MEL: si comes algo, cuánto tiempo se queda en el intestino grande antes [/] antes de convertirse en caca?

*MEL: dos minutos, dos horas, o dos días ?

*MEL: ahora es mi pregunta me toca a mi .

*MEL: um@fp, I would say, two +...

*MEL: $\quad[\%$ thinking $]$ two..+

\%com: everyone laughs

*MEL: minutes ?

*RAQ: $\quad[\%$ from behind camera $]$ no .

*RAQ: no minutos no .

*MEL: hours or days ?

*MEL: two \# hours?

*RAQ: days .

*SIM: no, days .

*MEL: two days !

*LEO: I do n(o)t believe that !

Tal y como se puede observar en este ejemplo de ilustración, en esta tercera prueba Esther, aunque es capaz de leer en inglés con cierta dificultad, aún no tiene un grado de competencia suficiente en dicha lengua como para entender todas las preguntas y respuestas que se plantean en el juego, por lo que será necesario que alguien las traduzca para que ella pueda participar. En esta ocasión, Melanie ayuda en la labor de traducción a los niños, ya que son enunciados pertenecientes a un ámbito un tanto especializado y, por tanto, más complicados de traducir. De hecho, es la situación en la que los niños se muestran menos dispuestos a realizar dicha labor, quizás porque el juego se ralentiza demasiado a causa de la traducción.

Una vez diseñadas las pruebas, el siguiente paso es organizarlas y ver qué patrones generales han de seguirse en todas ellas para ponerlas posteriormente en funcionamiento. De la descripción de estos patrones generales nos ocuparemos en el siguiente apartado. 


\subsubsection{Los patrones seguidos en la organización de las pruebas experimentales}

En cuanto a los patrones comunes de organización y preparación de las 3 pruebas experimentales vamos a destacar los siguientes, que son los que exponemos a continuación de (A) a (D).

(A) En las tres pruebas aparecen Raquel y Esther, las investigadoras que hablan español y a las que Simon y Leo conocen desde hace tiempo y con las que ya están familiarizados. En el caso concreto de la primera prueba y de la segunda, aparecen, además, otros investigadores que se hacen pasar por monolingües de inglés, Todd y Susana (a la que no conocen), aunque antes de comenzar la grabación y la puesta en práctica de la prueba, hay un tiempo de contacto y acomodación tanto a los nuevos interlocutores como a la dinámica de producción que implica la prueba; en el caso de la tercera prueba, es Melanie, la madre, la que en un primer momento le explica la dinámica del juego a Esther y la que pide expresamente a los niños que traduzcan a esta investigadora las preguntas del juego correspondiente.

Es importante resaltar en este apartado que, con el fin de llevar a cabo todas estas pruebas, si bien los niños saben que Raquel es bilingüe a pesar de que les hable casi siempre en español, tanto Esther como Susana y Todd son en realidad investigadores bilingües (aunque se hagan pasar por monolingües), lo cual les permitirá controlar las diversas situaciones que puedan darse a raíz del carácter de este tipo de pruebas, evitando o solventando las dificultades que puedan surgir durante su puesta en marcha, como pedir repeticiones o aclaraciones de las traducciones que realicen los niños en un determinado momento, o evitando que un adulto, o ellos mismos, traduzcan por ellos, pues en eso consiste la labor de los niños y lo que se espera que produzcan.

Sin embargo, dado que los interlocutores instan casi constantemente a los niños a que traduzcan, es inevitable que el investigador "dirija" o "modele" en cierta manera el mensaje que hay que traducir a través de enunciados del tipo “¿qué ha dicho?”, “¿para qué es eso?”, “¿cómo se hace?", ¿por qué?”, "no entiendo”, "no sé lo que dice”, etc. para el español y "explain Esther how to do it", "what do I have to do?”, "what?”, "what are you saying?", etc. para el inglés.

Además, y en relación con lo que acabamos de apuntar, una de esas dificultades que puede surgir es, por ejemplo, que los niños se muestren reticentes a traducir y haya que 
animarles a hacerlo provocando, por ejemplo, un malentendido o una falta de coordinación en el juego. Aunque este tipo de intentos para resolver algunas situaciones puede suponer un cambio en el diseño original o en la puesta en marcha de la prueba, esto no significa que la investigación quede comprometida, pues con ese cambio de estrategia lo que se pretende es que los niños sigan realizando TTNN.

(B) Con el fin de que los niños no sean meros observadores de una situación, se plantean actividad lúdicas y amenas que consisten normalmente en un juego de mesa o de cartas que los niños ya conocen o al que han jugado en otras ocasiones en inglés, como el juego de cartas Go Fish, de la segunda prueba, o el juego de mesa Totally Gross, de la tercera, a los que ya hemos hecho referencia. Al mismo tiempo, los juegos han de permitir la participación de varios jugadores, ya que, de esa manera, se hace ver a los niños que si no actúan de puentes de comunicación entre los investigadores, el juego no puede continuar o, si continua, uno de esos investigadores puede quedarse sin jugar.

(C) La duración de las pruebas oscila entre 25 y 30 minutos aproximadamente, ya que, al cabo de este tiempo, los niños pierden la concentración y el interés y se cansan de traducir. Además, a diferencia de la primera prueba, en la que se encuentran por primera vez en la situación de tener que actuar de intérpretes entre dos interlocutores monolingües, en las otras dos esta labor ya no constituye una novedad y se convierte en una especie de carga, pues ralentiza cualquier juego.

D) Para que la recogida de datos y la transcripción de los mismos sea lo más fidedigna posible, hemos contado con un equipo de grabación compuesto por una cámara de vídeo digital apoyada sobre un trípode, de tal forma que ningún investigador tiene que estar pendiente de sostener la cámara o de cambiar de plano, pues son juegos en los que hay que permanecer sentado la mayor parte del tiempo. Además, uno de los investigadores es el encargado de hacer la grabación.

Finalmente, una vez diseñadas las pruebas y organizada su puesta en marcha, el último paso consiste en ejecutarlas, para lo cual también hay que seguir una serie de pautas que vamos a detallar a continuación. 


\subsubsection{La ejecución de las pruebas experimentales}

Para llevar a cabo las pruebas experimentales, hemos tenido en cuenta una serie de pautas tomadas de diversos estudios sobre la recogida de datos experimentales en niños (McDaniel et al. 1996; Thornton 1996; Crain y Thornton 1998), de tal manera que podemos resumir los pasos de la siguiente forma.

A) Sesiones de contacto: los niños conocen ya a Raquel y a Esther, que son las investigadoras que suelen ir a visitarles, pero, como ya hemos mencionado, en la primera prueba aparece una investigadora nueva, Susana, de tal forma que, antes de empezar a poner en práctica la prueba en sí, los niños charlan con ella para que así la conversación que surja durante la prueba sea más distendida. En el caso de la segunda prueba, como investigadores anglófonos aparecen Susana (a la que ya conocen de la prueba anterior) y Todd, al que conocieron unos dos años antes pero para el que consideramos necesario una toma de contacto con los niños antes de poner en práctica dicha prueba, tal y como hicimos con Susana. En la tercera prueba, como los interlocutores de los niños que iban a estar presentes eran Raquel, Esther y Melanie, obviamos esta sesión de contacto.

B) Sesión de calentamiento: con el fin de que los niños se sientan cómodos con sus interlocutores, es necesario dejar pasar unos minutos previos a la grabación de la prueba para que los niños se habitúen progresivamente a la dinámica de los juegos. Esta sesión es necesaria desde el momento en que la colaboración de los niños en este sentido es imprescindible, pues sin ella, no se pueden recabar los datos que nos interesan, en este caso, las TTNN.

C) Duración de las pruebas: tal y como apunta Thornton (1996), la duración de las pruebas no debe exceder los 30 minutos, de ahí que la primera prueba experimental de nuestro estudio dure 33 minutos, la segunda 27 y la tercera 26 (9 minutos la primera parte y 17 la segunda).

Una vez seguidas estas pautas y realizadas las tres pruebas experimentales de traducción, podemos recoger la información principal relativa a dichas pruebas en la tabla 4 , donde hemos incluido aspectos tanto técnicos como de duración y contextuales. 
TABLA 4. LAS PRUEBAS EXPERIMENTALES DE TRADUCCIÓN

\begin{tabular}{|c|c|c|c|c|l|}
\hline & Sesión & Duración & Edad & Actividad & \multicolumn{1}{c|}{ Participantes } \\
\hline $\begin{array}{c}\mathbf{1}^{\mathbf{a}} \\
\text { PRUEBA }\end{array}$ & $56 \mathrm{~B}(\mathrm{TR})$ & $00: 33: 54$ & $4 ; 10.19$ & $\begin{array}{c}\text { Pósters interactivos } \\
\text { (clock; calendar) }\end{array}$ & $\begin{array}{l}\text { - Simon y Leo } \\
\text { - Esther (ES) y Susana (IN) }\end{array}$ \\
\hline $\begin{array}{c}\mathbf{2}^{\mathbf{a}} \\
\text { PRUEBA }\end{array}$ & $61 \mathrm{~B}(\mathrm{TR})$ & $00: 27: 28$ & $5 ; 05.29$ & $\begin{array}{c}\text { Juego de cartas } \\
\text { (Go fish) }\end{array}$ & $\begin{array}{l}\text { - Simon y Leo } \\
\text { - Esther (ES), Raquel (ES/IN), } \\
\text { Susana (IN) y Todd (IN) }\end{array}$ \\
\hline $\begin{array}{c}\mathbf{3}^{\text {a }} \\
\text { PRUEBA }\end{array}$ & $74(\mathrm{TR})$ & $00: 42: 03$ & $6 ; 03.22$ & $\begin{array}{c}\text { Juego de mesa } \\
\text { (Totally Gross) }\end{array}$ & $\begin{array}{l}\text { - Simon y Leo } \\
\text { - Melanie (IN/ES) y Esther (ES) }\end{array}$ \\
\hline
\end{tabular}

Así pues, tal y como se muestra en la tabla 4, en el presente estudio hemos llevado a cabo tres pruebas de traducción correspondientes a tres sesiones $(56 \mathrm{~B}(\mathrm{TR}), 61 \mathrm{~B}(\mathrm{TR}) \mathrm{y}$ 74(TR)) que suponen casi dos horas de grabación.

En cuanto a las edades de los sujetos en cada una de estas pruebas, siguiendo a Thornton (1996), que es la que plantea que las pruebas experimentales de producción funcionan bien con niños de unos 3 años o más mayores, la primera prueba se realizó cuando los niños tenían 4;10 años. Si bien no existen datos experimentales específícos de TN antes de esta edad, esto no quiere decir que no podamos encontrar en los datos espontáneos situaciones en las que los niños traducen ante la petición de la madre con el fin de negociar un contexto anglófono con ella, lo cual nos proporciona un tipo de traducciones que podremos contrastar con las que se producen en el contexto de las pruebas experimentales.

En el caso de la segunda prueba, los niños tenían 5;05 años y en ella participaron los mismos investigadores que en la prueba anterior (los dos monolingües de inglés (IN) y de español (ES)), aunque se incorporaron otros dos investigadores (uno monolingüe de inglés (IN) y el otro bilingüe (ES/IN)), mientras que, en la tercera, , cuando tenían 6;03 años, aparecen con su madre (IN/ES) y la investigadora presente en las otras dos pruebas (ES). De esta manera, establecemos una separación temporal lo suficientemente larga entre una prueba y otra para poder observar algún cambio en la evolución de la capacidad traductora de los niños.

Una vez decrita la metodología seguida para la recogida de datos del estudio longitudinal, a continuación, dedicaremos el siguiente apartado a la descripción del sistema de transcripción de las sesiones grabadas. 


\section{LA TRANSCRIPCIÓN DE LOS DATOS}

Para facilitar el manejo de los datos y hacerlos aptos para el análisis lingüístico, se han seguido los siguientes pasos: el primero consiste en la transcripción ortográfica, así como en el uso de una serie de herramientas informáticas diseñadas para garantizar la fiabilidad de los datos transcritos y automatizar el proceso del análisis, para todo lo cual ha sido necesaria la labor conjunta del equipo de la Universidad de Valladolid, UVA-LAL, y el equipo de la Universidad de Ottawa (Canadá), Ottawa-LAL, enmarcados ambos en el estudio de Fernández Fuertes et al. (2002-2005). El segundo paso, es decir, la codificación de los datos partiendo de esas transcripciones es lo que constituye una de las principales aportaciones del presente trabajo de investigación y que trataremos con mayor detalle en el próximo capítulo.

Para poder lograr estos fines y, al mismo tiempo, tener la posibilidad de aprovechar los mismos datos para futuros estudios, la transcripción de los datos de Fernández Fuertes et al. (2002-2005) se ha llevado a cabo utilizando el sistema de transcripción y codificación CHAT (MacWhinney 2000), un sistema que nos permite hacer uso no sólo de los programas informáticos que se incluyen en la base de datos CHILDES ("Child Language Data Exchange System”), que en la actualidad constituye la base de datos más amplia sobre la adquisición de lenguas o pares de lenguas aportados por determinados estudios, sino que también permite disponer de esos datos para posteriores análisis desde muy diversas perspectivas.

El sistema CHAT ("Codes for the Human Analysis of Transcripts") es un formato estándar que se basa en el uso de una serie de convenciones y reglas para la realización de la transcripción ortográfica e informática de los datos de producción lingüística. Así pues, las transcripciones de los datos que se están llevando a cabo por parte de los equipos de investigación UVA-LAL y Ottawa-LAL se realizan en formato CHAT, que, como vimos en la relación de otros estudios de bilingüismo infantil en la tabla 2 [ver el apartado 2.3. del capítulo 3] y en muchos otros estudios, es el formato que utiliza en la actualidad la mayoría de los estudios que se basan en la recolección y transcripción de datos. Como muestra, adjuntaremos en el apéndice I la transcripción en formato CHAT de una sesión completa, en la que aparece sombreada la parte en la que hemos localizado un caso de TN. Igualmente, los ejemplos de TN que se utilizan en el presente trabajo, al ser partes o fragmentos conversacionales de estas transcripciones en las que los niños han producido 
TTNN, también aparecerán en dicho formato, por lo que hemos considerado oportuno hacer un repaso al sistema de transcripción CHAT en este trabajo.

Aludiendo a la labor de equipo mencionada anteriormente, creemos necesario poner de manifiesto que el trabajo de transcripción de datos es una tarea más compleja de lo que pudiera parecer en un primer momento, ya que, en primer lugar, hay tener en cuenta una serie de aspectos inherentes a este proceso como son las convenciones de transcripción de este sistema, la toma de decisiones acerca de los problemas que puedan surgir durante dicho proceso y, finalmente, la puesta en común de todos estos aspectos relativos a las transcripciones a través del intercambio de documentos entre los dos grupos de investigación dedicados a la transcripción de datos, el UVA-LAL y el Ottawa-LAL. Al mismo tiempo, el hecho de que se trate de grabaciones audiovisuales nos permite que aquellos enunciados que hayan sido difíciles de entender para los transcriptores en un momento determinado o en los casos de interpretación ambigua que sean relevantes para un análisis específico, el investigador siempre tiene la posibilidad de revisar la grabación en la que se incluyen esos casos $\mathrm{y}$, si es pertinente, discutir posibles interpretaciones divergentes con los otros investigadores.

En segundo lugar, este trabajo de transcripción ortográfica (que no comenzó hasta finales del año 2003) es una tarea laboriosa que exige una gran dedicación de tiempo si queremos disponer de una cantidad de datos representativa. De hecho, es un proceso que resulta muy arduo y lento, de tal forma que para llevar a cabo la transcripción de las grabaciones se necesita una hora por cada tres minutos de grabación aproximadamente, de ahí que la totalidad de los datos que componen el estudio longitudinal no se encuentren aún transcritos en CHAT.

De esta manera, resumimos en la tabla 5, que aparece a continuación, la información relativa a los datos transcritos del estudio longitudinal, de los cuales, y tal y como veremos en el apartado que sigue a este, seleccionaremos los datos que utilizamos en el presente trabajo de investigación. 
TABLA 5. LOS DATOS DISPONIBLES EN EL ESTUDIO LONGITUDINAL DE FERNÁNDEZ FUERTES ET AL.(2002-2005)

\begin{tabular}{|c|c|c|c|c|}
\hline & SP & EN & TR & Total general \\
\hline $\mathbf{N}^{\mathbf{0}}$ de sesiones grabadas & 58 & 115 & 3 & $\mathbf{1 7 6}$ \\
\hline $\mathbf{N}^{\mathbf{0}}$ de sesiones transcritas & 29 & 115 & 3 & $\mathbf{1 4 7}$ \\
\hline $\mathbf{( \mathbf { N } ^ { \mathbf { 0 } } \text { de archivos CHAT) }}$ & $(68)$ & $(185)$ & $(5)$ & $\mathbf{( 2 5 8 )}$ \\
\hline $\begin{array}{c}\text { Duración de las } \\
\text { grabaciones ya transcritas }\end{array}$ & $\begin{array}{c}19 \text { horas } \\
\text { (aprox.) }\end{array}$ & $\begin{array}{c}43 \text { horas } \\
\text { (aprox.) }\end{array}$ & $1 \mathrm{~h} 45^{\prime}$ & $\mathbf{6 4}$ horas (aprox.) \\
\hline
\end{tabular}

Tal y como se aprecia en la tabla 5, a fecha de diciembre de 2006, el estudio longitudinal cuenta con un total de 176 sesiones grabadas, de las cuales 58 se han grabado en un contexto español, 115 en un contexto en inglés y 3 se corresponden con las pruebas experimentales de traducción que ya describimos en el apartado 2.2. Esta diferencia numérica entre un contexto y otro, tal y como apuntamos en el apartado 4, se debe a que cada una de las sesiones se corresponden a fechas diferentes de grabación, de tal manera que, sobre todo cuando son los padres los encargados de grabar (especialmente cuando se encuentran en EEUU), estos realizan varias grabaciones cortas en días diferentes, de ahí que existan más sesiones en contexto EN que en contexto SP; por otro lado, la duración de las sesiones en EN y en SP también varía, de ahí que, a pesar de la disparidad numérica, el tiempo grabado en uno y en otro contexto es más o menos equilibrado.

Del total de las 176 sesiones grabadas, todas las sesiones en contexto EN y las sesiones TR están transcritas, mientras que sólo una parte de las sesiones en contexto SP, 29 concretamente, es la que se encuentra transcrita, de ahí que se disponga de menos horas transcritas de las sesiones SP que de las EN (19 y 43 horas, respectivamente).

Así pues, el estudio longitudinal dispone por el momento de un total de 147 sesiones transcritas que incluyen, a su vez, 258 archivos CHAT. El hecho de que haya más transcripciones que sesiones se debe a que cada una de las sesiones puede constar de uno o varios fragmentos, bien porque hay un cambio de escenario en la interacción o bien porque a veces las transcripciones son tan largas que es necesario dividirlas en varios archivos para facilitar el manejo (el programa informático recomienda que sólo se incluyan 1000 líneas aproximadamente de transcripción en cada archivo).

A partir de las sesiones transcritas, realizaremos la selección de datos para el presente trabajo de investigación, de la cual hablaremos en el apartado siguiente, ya que, anteriormente, consideramos necesario hacer una descripción del sistema CHAT 
(MacWhinney 2000) en el que se encuentran transcritos todos estos datos. Para ello, utilizaremos como ejemplo un fragmento de la sesión 56B(TR) mostrado en (63a-63c) que nos servirá, en primer lugar, para explicar los componentes principales de dicho sistema de transcripción (los encabezamientos, la línea principal y la línea dependiente) y, en segundo lugar, para agrupar algunos de los símbolos que aparecen en las transcripciones utilizadas en el presente trabajo de investigación.

\subsection{Los encabezamientos}

Un encabezamiento es una línea de texto que da información sobre los participantes, el contexto de la interacción y los datos técnicos, y que, a excepción de la línea de encabezamiento @End, aparece siempre al inicio del documento de transcripción CHAT.

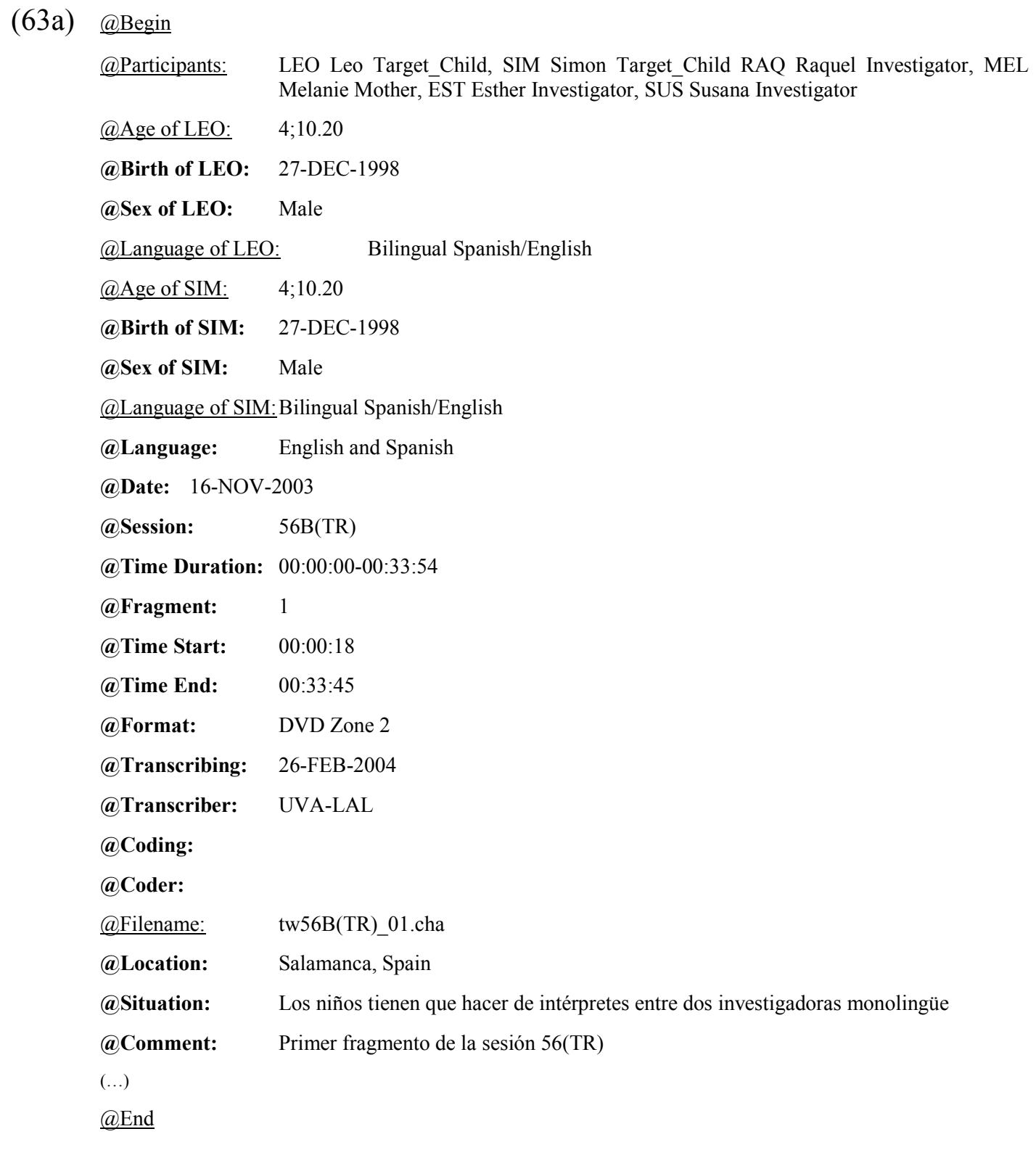


Como se puede observar en (63a), todos los encabezamientos han de ir precedidos por el símbolo@y en ellos se incluye la información necesaria relativa a diversos aspectos. Algunos de ellos son obligatorios (@Begin; @Participants; @Age; @Language; @Filename; y@End), indicados con subrayado en (63a), y otros son constantes (@Sex; @Transcribing; @Transcriber; @Time duration; @Comment; etc.), indicados en negrilla. En el caso de los encabezamientos constantes, se pueden añadir tantos como se quiera, de tal forma que en todos los archivos de cada una de nuestras transcripciones, aparte de los obligatorios, aparecerán todos los encabezamientos constantes que aparecen en (63a). Estos contienen información de carácter general sobre los sujetos (edad, fecha de nacimiento, lenguas que componen su bilingüismo, sexo) y la sesión (participantes, lengua predominante, localización y datos técnicos sobre la grabación como la fecha, la duración y el nombre del archivo, así como la fecha de transcripción y el equipo que la ha llevado a cabo).

\subsection{La línea principal y las líneas de producción}

Con la línea principal se empieza la transcripción de la conversación grabada y se localiza justo después de la información contenida en (63a). Las líneas principales constituyen la producción lingüística propiamente dicha.

(63b)

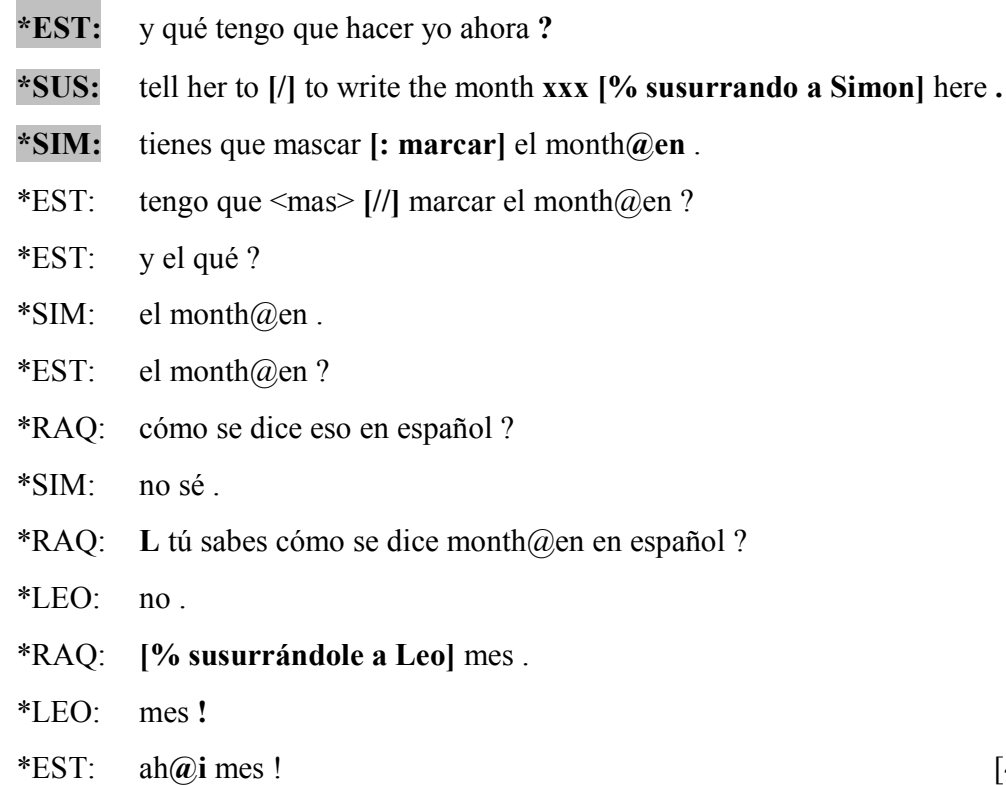

[4;10.19] / 56B(TR)_01 
Así, como se puede observar en el primer fragmento transcrito de la sesión 56B(TR), mostrado aquí como (63b), cada línea principal comienza con las tres iniciales del participante en la conversación escritas en mayúsculas (SIM para Simon y EST para Esther, por ejemplo), precedidas por un asterisco “*” y seguidas por dos puntos y una tabulación, como indica el sombreado. A continuación, se incluirá la línea de producción del participante que corresponda. En el caso de los nombres propios que aparecen dentro de las líneas de producción, sólo los nombres de los investigadores se transcriben completamente, mientras que los nombres de los niños y de los padres aparecerán con iniciales $(\mathrm{L}=\mathrm{Leo}, \mathrm{S}=$ Simon, $\mathrm{M}=$ Melanie e $\mathrm{Iv}=\mathrm{Ivo}$, como indica la parte en negrita de (63b)). En el caso de que, por cuestiones técnicas, no se sepa quién de los dos niños es el que habla (por estar fuera de plano o de espaldas a la cámara, por ejemplo), se utilizarán las siglas SOL (Simon o Leo) para indicar la imposibilidad de poder identificarlos.

Las líneas de producción han de terminar siempre con lo que se denomina "símbolo final”, que puede ser un punto (.), un signo más seguido de puntos suspensivos (+..), un símbolo de interrogación (?) o uno de exclamación (!). Estos símbolos finales tendrán que estar separados de la última palabra de la línea de producción por un espacio. En el caso de que la producción de cualquiera de los participantes no se entienda porque haya ruido de fondo o por cualquier otra circunstancia se utilizará el símbolo "xxx" para indicar que no se ha podido oír o entender lo que ha dicho el participante correspondiente.

Otras normas que hay que tener en cuenta y que se pueden observar en (63b) son las que aparecen marcadas en negrilla. Así, por ejemplo, hay que utilizar una serie de símbolos para poder indicar si hay una pausa (\#), una repetición ([/]), una reformulación $([/ / /])$, una corrección ([//]), la forma ortográfica correcta ([:]), un comentario acerca del contexto o información extralingüística que nos ayude a interpretar la producción [\%], etc.

También se utilizan símbolos de codificación dentro de las líneas de producción para dar información de determinadas palabras, como@i, que se utiliza para indicar que se trata de una interjección; @sp ("Spanish") o @en ("English”), para marcar que una determinada palabra se encuentra en un contexto diferente al que viene dictado por la oración, el contexto lingüístico o el interlocutor. En el caso de (63b) @en indicaría que en un contexto oracional que es el español (puesto que se está dirigiendo a Esther, que es hablante monolingüe de español), Simon ha utilizado una palabra en inglés. En el caso de que la situación hubiese sido la inversa, es decir, que hubiese utilizado una palabra o todo 
un enunciado en español para dirigirse a un anglófono, dicha palabra o enunciado se marcaría con@sp.

Este tipo de codificación que se realiza durante la transcripción es bastante útil, puesto que, por ejemplo, @i nos permitirá no considerar estas palabras para un determinado análisis o la marcación@en/@sp nos permitirá localizar rápidamente los casos de AC, por ejemplo, o los casos en los que los niños traducen por iniciativa propia, sin que nadie les inste a cambiar de código.

Con el fin de poder leer e interpretar mejor las transcripciones, así como su función principal dentro de las producciones, hemos incluido en el apéndice II una lista de los símbolos CHAT más utilizados en nuestro corpus de transcripciones y, más concretamente, en los fragmentos en los que aparecen casos de TN, cuya marcación trataremos con mayor detalle en el apartado 5.

\subsection{La línea dependiente}

Intercaladas entre las líneas de producción aparecen las líneas dependientes, que son aquellas en las que se incluye información de diverso tipo (fonológica, contextual, extralingüística, gestual, etc.) y que han de ir precedidas del símbolo "\%” y debajo de una línea principal, como se puede observar en (63c), donde aparece otra parte del primer fragmento de la sesión 56B(TR).

(c)

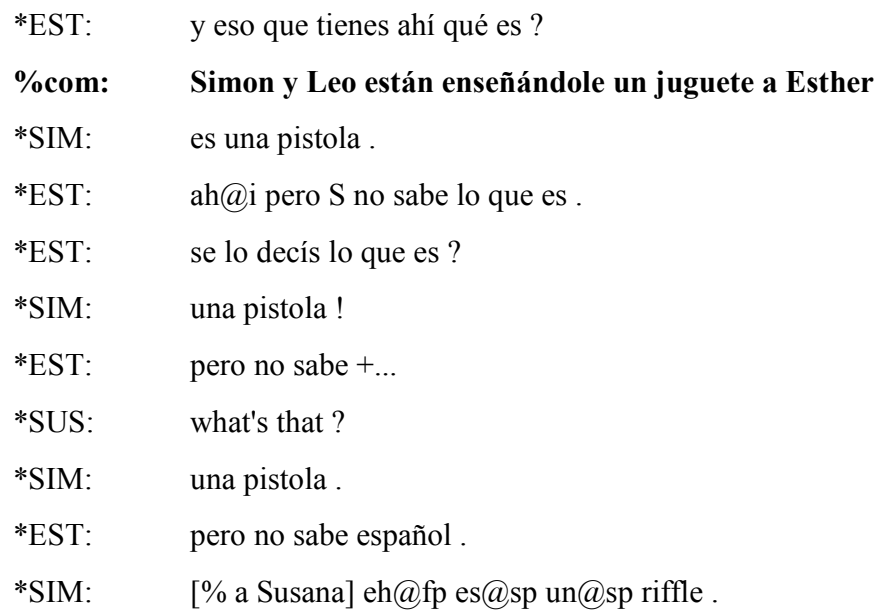


Así, en (63c) se ha incluido una línea dependiente (marcada en negrita) en la que aparece una información extralingüística que muchas veces resulta imprescindible para la mejor comprensión y seguimiento de la escena en la que se desarrolla la conversación, sobre todo por parte de aquellos que sólo hayan leído la transcripción y no hayan visto la grabación.

Seguidamente, describiremos cómo se ha procedido a realizar la selección de datos que constituye el corpus con el que vamos a trabajar en el presente estudio, de tal forma que aludiremos a los distintos criterios que hemos tenido en cuenta para elegir, de entre todos los datos disponibles (es decir, transcritos), las grabaciones que se incluyen en dicha selección.

\section{LA SELECCIÓN DE LOS DATOS PARA EL PRESENTE ESTUDIO: NUESTRO CORPUS DE TN}

Dado que, por un lado, tal y como vimos en el apartado 2 de este capítulo, la clasificación de las grabaciones y sus correspondientes transcripciones según el contexto lingüístico ( $\mathrm{SP}$ o EN) es más bien metodológica, y, por otro, dada la naturaleza del fenómeno de la TN (un CC en una situación dada o con unos interlocutores determinados), en el presente trabajo de investigación, aunque hablemos de con cuántas sesiones SP y EN contamos, tendremos en cuenta ambos contextos globalmente cuando analicemos las TTNN recopiladas. De esta forma, el contexto lingüístico en el que se produzcan los casos de TN vendrá marcado no tanto por el contexto de la grabación sino por la lengua de interacción que utilice el interlocutor cuando se dirija a los niños, algo que ya habían planteado Deuchar y Quay (2000) al tener en cuenta la lengua que habla el interlocutor adulto con los niños para definir el contexto lingüístico de cada grabación e incluso los diferentes contextos lingüísticos que pueden aparecer en una sola grabación ${ }^{45}$.

Este razonamiento se verá reflejado en el apartado correspondiente al análisis de datos, pues tendremos en cuenta en dicho análisis tanto la direccionalidad de las TTNN

\footnotetext{
${ }^{45}$ Tal es el caso, por ejemplo, de algunas grabaciones cuyo contexto es español pero en el que puede aparecer Melanie para dar de comer o de merendar a los niños interactuando con ellos en inglés. 
(español-inglés; inglés-español) como el interlocutor (anglófono o hispanófono) que interactúa con los niños en los casos correspondientes.

Teniendo en cuenta esta aclaración previa y contando con la información relativa a la totalidad de los datos que ya hemos mostrado en la tabla 5 del anterior apartado, pasaremos a ocuparnos específicamente de los datos que utilizamos.

Tal y como aparece resumido en la tabla 6, para el presente estudio hemos seleccionado 22 sesiones en español (SP) y 36 sesiones en inglés (EN) (todas ellas correspondientes a datos espontáneos), así como las 3 sesiones de traducción (TR) que constituyen los datos experimentales, procurando que la duración total en uno y en otro contexto fuese semejante (unas 15 horas y media en cada uno aproximadamente).

\begin{tabular}{|c|c|c|c|c|}
\hline \multicolumn{7}{|c|}{ TABLA 6. LA SELECCIÓN DE DATOS DEL PRESENTE ESTUDIO } \\
\hline TIPO DE DATOS & \multicolumn{2}{|c|}{ ESPONTÁNEOS } & EXPERIMENTALES & \multirow{2}{*}{ Total general } \\
\hline CONTEXTO LINGÜÍSTICO & SP & EN & TR & $\mathbf{6 3}$ \\
\hline $\mathbf{N}^{\mathbf{0}}$ de sesiones & 22 & 38 & 3 & $\mathbf{1 1 0}$ \\
\hline $\mathbf{N}^{\mathbf{0}}$ de archivos CHAT & 41 & 64 & 5 & $\begin{array}{c}\mathbf{3 3} \text { horas } \\
\text { (aprox.) }\end{array}$ \\
\hline Duración total & $15 \mathrm{~h}, 30^{\prime}$ & $15 \mathrm{~h}, 30^{\prime}$ & $1 \mathrm{~h} 45^{\prime}$ & \\
\hline
\end{tabular}

A este respecto, nos remitimos a los apéndices III y IV, en los que aparece de forma detallada la selección de sesiones que hemos realizado en uno y otro contexto, la información correspondiente a cada una de ellas en lo que respecta a la edad de los sujetos en ese momento, la Longitud Media del Enunciado por palabras (LMEp) y el número de enunciados producidos por cada uno de los niños en cada sesión, así como los datos técnicos relativos a la sesión correspondiente (la fecha y la duración de la grabación). Así, la información concreta que se puede obtener a partir del apéndice I, por ejemplo, es que la sesión 23 correspondiente al contexto español (SP) dura poco más de 40 minutos, se grabó el 9 de junio de 2001, es decir, cuando los niños tenían 2;05 años, y en dicha sesión la LMEp de Simon, por ejemplo, es de 1,653 palabras por enunciado, teniendo en cuenta que ha producido 72 enunciados a lo largo de la sesión.

A su vez, volviendo a la información que aparece en la tabla 6, cada una de estas sesiones consta de uno o varios fragmentos de transcripción que están en formato CHAT, 
de tal forma que en total contaremos con 41 archivos CHAT para el contexto español, 64 para el contexto en inglés y 5 para las pruebas experimentales de traducción, lo cual hace que contemos con unas 33 horas de grabación aproximadamente, repartidas en 63 sesiones y 110 fragmentos CHAT en total, un material que es lo que constituirá el corpus de datos que vamos a manejar en el presente trabajo de investigación.

Los criterios que hemos seguido para proceder a la selección de las sesiones que se indican en la tabla 6 y en los apéndices de III y IV, así como el recuento total del número de sesiones y la duración de las grabaciones en cada contexto que indicamos en la tabla 6 son los siguientes.

En primer lugar, dado que la labor de transcripción es ardua y se necesita mucho tiempo para llevarla a cabo (una hora por cada tres minutos de grabación) y que disponemos de menos sesiones transcritas en contexto español que en contexto inglés, hemos considerado como uno de los criterios partir de las sesiones transcritas en español y, a continuación, elegir aquellas sesiones en contexto inglés que se encuentren cerca en el tiempo de las sesiones SP transcritas. De este modo, en la medida de lo posible y como se puede observar en los apéndices III y IV, hemos procurado que las sesiones EN escogidas sean aquellas que se corresponden con la fecha de grabación de las sesiones SP, así como aquellas que sean anteriores o posteriores a estas, aunque siempre considerando que la diferencia de tiempo transcurrido entre la sesión SP de referencia y estas sesiones EN (anteriores o posteriores) escogidas a partir de dicha sesión no abarque un período superior a 4 meses (por ejemplo, tras la sesión 24ASP hemos escogido las sesiones EN (24B, 24C y 24H) correspondientes a los 3 meses posteriores a la fecha de grabación de dicha sesión).

En segundo lugar, con el fin de poder establecer una comparación adecuada entre el material del que disponemos en español y del que disponemos en inglés, también hemos tenido en cuenta la duración total de los datos espontáneos en uno y en otro contexto, de tal manera que hemos elegido las sesiones en contexto inglés prestando atención no sólo al período de tiempo existente entre las sesiones SP y las sesiones EN, sino también a la duración de las grabaciones. De esta manera, como ya hemos mencionado a lo largo de este capítulo y como se puede observar en la tabla 5, aunque las sesiones EN son más numerosas que las sesiones SP, conviene recordar que las sesiones EN suelen ser más cortas de duración, por lo cual hemos procurado que en el cómputo total exista un equilibrio en la duración de las sesiones en uno y en otro contexto (15 horas y media en cada lengua) para que los resultados sean comparables. 
Finalmente, hay que tener en cuenta que, dado que nuestro corpus constituye una selección de datos, nos gustaría aclarar dos cuestiones relacionadas con el aspecto longitudinal de este estudio. La primera cuestión es que a pesar de que el estudio dispone de transcripciones desde que los sujetos tienen 1;01 años, para nuestra investigación hemos tenido en cuenta los datos disponibles a partir de que los sujetos tienen 2;00 años, ya que, como ya argumentamos anteriormente en este trabajo [ver el apartado 4.5. del capítulo 1], en ese período inicial del estudio longitudinal sólo existe un caso de TN que es el que corresponde al ejemplo (5), repetido aquí como (64), y que vendría a demostrar que esa edad tan temprana los niños pueden traducir.

*MEL:you want the water?

*LEO: uh@i .

*MEL: can you say water?

*MEL: [\% holding up the cup of water] what is this ?

*LEO: [\% reaching for the cup] ah@i !

*MEL:water?

*LEO: ah@i [\% getting frustrated] !

\%com: Melanie puts the cup on Leo's tray

*MEL:mommy's going to take this zucchini away, ok [\% taking the zucchini off Simon's tray] ?

*LEO: awa@sp [: agua] .

Sin embargo, dado que, desde el punto de vista estadístico, la presencia de un solo caso de $\mathrm{TN}$ no resulta lo suficientemente significativo, no hemos incluido las sesiones correspondientes al período de edad comprendido entre los $1 ; 01$ y 1;11 años, considerando que la actividad de traducción comienza a ser significativa a partir de los 2;00 años ${ }^{46}$.

La segunda cuestión es que hemos tenido en cuenta los datos relativos no sólo a la edad de los niños en cada sesión sino también los respectivos valores de la LMEp y el número de enunciados producido por cada niño, pues este tipo de información puede resultar útil para establecer una división en etapas de un determinado período longitudinal y, al mismo tiempo, nos ofrece un valor de referencia para comprobar el output grabado de cada uno de los niños en las dos lenguas.

\footnotetext{
${ }^{46}$ Al mismo tiempo, hay que tener en cuenta de nuevo que, tal y como ya planteamos en el apartado 1 del presente capítulo, los niños gemelos en general presentan un desarrollo lingüístico inicial más tardío que los niños que no son gemelos (Dale et al. 1998, Viding et al. 2004, entre otros), por lo que no consideramos anómalo partir de la edad de 2;00 años para estudiar el desarrollo traductor de los sujetos del presente estudio.
} 
En el caso de los valores relativos al número de enunciados, los tendremos en cuenta no tanto para la división en etapas del estudio que aquí nos ocupa sino para tener una referencia de las intervenciones de cada uno de los niños en las distintas sesiones, ya que, sobre todo en las pruebas experimentales de traducción, uno de los niños (Leo, concretamente) interviene en la conversación en menos ocasiones que el otro, una circunstancia que, tal y como veremos en el capítulo de análisis tiene su influencia a la hora de realizar el cómputo total de TTNN realizadas por los sujetos.

En lo que respecta a los datos de la LMEp, entendemos por esta aquel valor resultante de dividir el número de palabras que produce cada niño en una sesión por el número de enunciados que ese mismo niño produce en dicha sesión. Está documentado (Klee et al. 1989; Rondal et al. 1987) que existe una correlación entre la LME y la edad de los niños, de tal forma que, según Brown (1973), se puede hablar de diferentes etapas en el desarrollo lingüístico de los niños en función del valor de la LME que suele estar entre los valores 1,75 y 4,5. A pesar de que Brown (1973) también considera que la LME debe calcularse en función del número de morfemas (LMEm) y no tanto del número de palabras (LMEp), en la actualidad se prefiere trabajar con la LMEp ya que, tanto en inglés (Malakoff et al. 1999) como en español (Aguado 1988), los valores son muy semejantes en un tipo de cálculo u otro.

Atendiendo a estas cuestiones, lo que mostramos en la tabla 7 es una relación entre las diferentes etapas en las que hemos dividido la producción lingüística de los sujetos y la LMEp de cada niño y en cada lengua correspondiente a cada una de dichas etapas ${ }^{47}$.

\begin{tabular}{|c|cc|cc|cc|}
\hline \multicolumn{1}{|c|}{ TABLA 7. LA LMEp EN LAS SESIONES DE ESPAÑOL, DE INGLÉS Y DE TRADUCCIÓN EN CADA ETAPA } \\
\hline & \multicolumn{2}{|c|}{ Inicial $\mathbf{( 2 ; 0 0 - 3 ; 0 0 )}$} & \multicolumn{2}{|c|}{ Intermedia $\mathbf{( 3 ; 0 5 - 4 ; 0 5 )}$} & \multicolumn{2}{c|}{ Final (4;09-6;03) } \\
\cline { 2 - 7 } & LEO & SIM & LEO & SIM & LEO & SIM \\
\hline Español & 2,288 & 2,326 & 3,309 & 3,824 & 3,494 & 3,555 \\
Inglés & 1,658 & 1,520 & 4,177 & 3,904 & 4,224 & 4,158 \\
Traducción & & & & & 3,148 & 4,422 \\
\hline Total por etapas & 1,887 & 1,813 & 3,839 & 3,873 & 3,894 & 3,982 \\
\hline
\end{tabular}

\footnotetext{
${ }^{47}$ En la tabla 7 hemos indicado aparte los valores de la LMEp resultantes de las tres pruebas de traducción por considerar que en dichas sesiones el intercambio de lenguas es constante y no podemos incluirla de forma estricta en ninguna lengua en concreto. 
El hecho de que, tal y como aparece en la tabla 7, la proporción de la LMEp tanto en un niño como en otro no sea similar en español y en inglés no ha de ser achacable a que haya un desequilibrio en el output de una lengua con respecto a la otra, sino que, como hemos visto previamente [ver la tabla 6 y los apéndices III y IV], aunque en tiempo la duración total en uno y otro contexto es similar, la variación de la duración de cada una de las sesiones individualmente (sobre todo en las sesiones en español correspondientes a la primera etapa) hace que el cálculo del promedio de LMEp en una y otra lengua sea tan diferente.

Por ello, hemos calculado la media por etapas atendiendo al valor medio de la LMEp, en inglés y en español conjuntamente, y por sujetos, lo cual aparece en el gráfico 1.

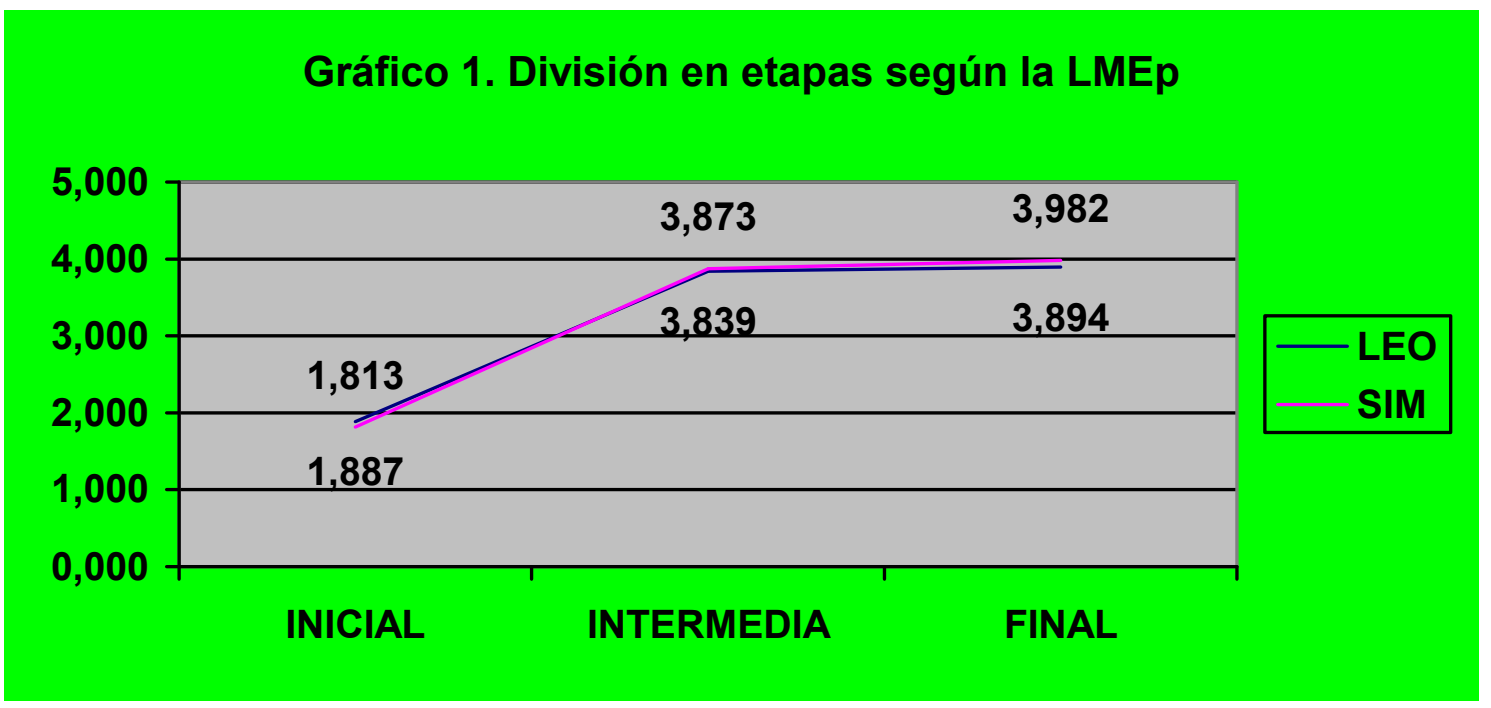

El gráfico 1 muestra el promedio de la LMEp en ambos niños a lo largo del total de sesiones que hemos seleccionado para nuestra investigación, un promedio que es prácticamente paralelo en ambos niños. Si atendemos a lo que en él figura, podemos apreciar que en la LMEp de Simon y de Leo durante la etapa inicial existe una clara tendencia ascendente y paralela en los valores de este cómputo (de 1,8 a 3,8 en ambos niños). En cambio, la diferencia entre la etapa intermedia y la etapa final no resulta significativa (de 3,8 a 3,9 en Simon y la misma en Leo), de ahí que consideremos que, si bien hay que tener en cuenta los valores de la LMEp en este tipo de estudios longitudinales $\mathrm{y}$, en nuestro caso, hemos podido tenerlo como referencia para la división entre la etapa inicial y la intermedia, no podemos tener un criterio claro para la división entre las dos últimas etapas que pretendemos plantear. 
Como consecuencia, hemos tenido en cuenta otros criterios que aparecen resumidos en la tabla 8 para la división en etapas, en la que hemos intentado que la duración entre unas y otras sesiones se mantuviera equilibrada a lo largo de las etapas en las que hemos dividido el presente estudio.

\begin{tabular}{|c|c|c|c|c|c|c|c|c|c|}
\hline TABLA 8. SELECCIÓN DE DATOS: SESIONES Y DURACIÓN DE LAS GRABACIONES EN CADA ETAPA \\
\hline Etapas & \multirow{2}{*}{ Edad } & \multicolumn{5}{|c|}{ Sesiones } & \multicolumn{5}{c|}{ Duración (aprox.) } \\
\cline { 3 - 10 } & & ES & IN & TR & Total & ES & IN & TR & Total \\
\hline Inicial & $\mathbf{2 ; 0 0 - 3 ; 0 0}$ & 8 & 14 & & $\mathbf{2 2}$ & $6 \mathrm{~h} 10^{\prime}$ & $6 \mathrm{~h}$ & & $\mathbf{1 2}$ horas \\
\hline Intermedi & $\mathbf{3 ; 0 5 - 4 ; 0 5}$ & 7 & 11 & & $\mathbf{1 8}$ & $5 \mathrm{~h} 35^{\prime}$ & $5 \mathrm{~h} 33^{\prime}$ & & $\mathbf{1 1}$ horas \\
\hline Final & $\mathbf{4 ; 0 9 - 6 ; 0 3}$ & 7 & 13 & 3 & $\mathbf{2 3}$ & $4 \mathrm{~h} 00^{\prime}$ & $4 \mathrm{~h} 00^{\prime}$ & $1 \mathrm{~h} 45^{\prime}$ & $\mathbf{9 h ~ 4 5 ^ { \prime }}$ \\
\hline
\end{tabular}

En esta tabla aparece la división en etapas por sesiones y por duración [ver el apéndice $\mathrm{V}$ para una información más detallada] y se observa que nuestro estudio comienza cuando los niños tienen 2;00 años y termina cuando tienen $6 ; 03$, lo cual supone que vamos estudiar los casos de TN que producen estos niños a lo largo de un período de poco más de 4 años.

Así pues, con el fin de que la división en etapas se establezca de la forma más equilibrada posible con respecto a la selección de datos que hemos realizado, tendremos en cuenta criterios que incluyen el período de tiempo que abarca cada etapa, el número de sesiones por cada una de dichas etapas y que la duración total de cada una de ellas sea lo más equilibrada posible.

A partir de la información reflejada en la tabla 8, para la etapa inicial en la que dividimos el estudio contamos con un total de 22 sesiones (8 en español y 14 en inglés), siendo la duración en uno y otro contexto semejante y que supone un total de 12 horas de grabación a lo largo de un año en la vida de los sujetos (de los 2;00 a los 3;00 años); para la etapa intermedia (que también abarca un período de un año), el número de sesiones incluidas es menor (7 en español y 11 en inglés) debido a que se producen de forma más espaciada en el tiempo, pero hemos procurado que la duración total sea lo más semejante posible a la de la etapa inicial (11 horas frente a 12); en el caso de la etapa final (que abarcaría un período más largo, es decir, un año y medio), aparte de las sesiones pertenecientes a los datos espontáneos también hemos incluido las correspondientes a las pruebas experimentales de traducción. El hecho de que en esta última etapa la duración 234 
total sea menor a pesar de que abarque un período más largo de la vida de los sujetos se debe a que en este período las grabaciones son mucho más espaciadas aún que en las de etapas anteriores $\mathrm{y}$, al mismo tiempo, la duración de estas grabaciones es mucho menor [ver el apartado 2].

Con esta división longitudinal, hemos procurado que exista un equilibrio en cada una de las etapas tanto en el número de sesiones utilizadas en uno y en otro contexto, como en la duración de las grabaciones, con el fin de poder comparar de forma adecuada los resultados que obtengamos a lo largo del estudio y, de esta manera, llevar a cabo un análisis coherente.

Establecidos ya los criterios de selección de datos, así como de los criterios en los que hemos basado la división de nuestro estudio en diferentes etapas, a continuación vamos a explicar la forma de presentación de los casos de TN que vamos a manejar en el nuestro corpus de datos con el fin de que resulte más fácil la lectura e interpretación de cada uno de dichos casos.

\section{LA PRESENTACIÓN DE LOS CASOS DE TN PROCEDENTES DE NUESTRO CORPUS}

Para explicar la forma de presentación de los casos concretos de TN que realizan Simon y Leo a lo largo del corpus de transcripciones en el que se basa el presente trabajo de investigación, utilizaremos como ejemplo los casos de (65a)-(65d), procedentes de distintas sesiones, en los que aparecen una serie de indicaciones relacionadas con la marcación del texto origen y del texto meta en los diversos casos de traducción. Dado que la mayoría de las veces se trata de conversaciones en las que participan los dos niños, es posible que dentro de un mismo fragmento aparezcan varios casos de $\mathrm{TN}$. Cuando esto ocurra, indicaremos con números ((1), (2), (3), etc.) cada uno de estos casos. El texto meta (TM) se subraya precedido de un número y el texto origen (TO) correspondiente irá precedido por el mismo número y se marcará también con un subrayado, tal y como aparece en $(65 a)$. 
(65a) *MEL: Raquel watch out!

*MEL: (1)there's a really fierce dragon behind you .

*MEL: (2)it's gonna chop your head off.

\%com: everyone giggles

*MEL: well I guess she doesn't .

*MEL: otherwise she would've jumped a mile huh?

*RAQ: de que os reís ?

*MEL: nada, nada, de nada .

*MEL: [\% to the boys] you guys gonna tell her?

*RAQ: de que os reís?

*RAQ: que os ha contado mamá, os ha contado un chiste mamá .

*SIM: [\% laughing] (1)mamá te ha dicho que había un dragón eh@fp detrás de tu espalda .

*RAQ: no me digas no $+/$.

*LEO: (2)te iba a cortar tu [= la] cabeza ! [5;03.21] / 59EN_01

En (65a), que se localiza en el primer fragmento de la sesión 59EN cuando los niños tienen 5 años, 3 meses y 21 días (información que se indicará siempre en la parte inferior derecha), tenemos dos casos de traducción: el primero (1) tiene como TO "there's a really fierce dragon behind you", cuyo TM, precedido también por (1), es "mamá te ha dicho que había un dragón eh@fp detrás de tu espalda”; en el segundo caso (2), Melanie dice "it's gonna chop your head off”, que Leo traduce como “ite iba a cortar tu cabeza!”.

En el caso de que un mismo enunciado (o parte de él) sea al mismo tiempo un TM de una primera traducción y un TO de una segunda traducción, habrá un subrayado más marcado en la parte correspondiente al enunciado que cumpla esas dos funciones, como se puede observar en $(65 b)$.

(65b)*MEL: ay@i don't step on the camera no .

*LEO: (1)o@sp quiero@sp sí@sp.

*MEL: can you say that in English ?

*LEO: (1) (2)10@sp quiero@sp hold it that .

*MEL: can you say that in English?

*LEO: (2)I want hold it that .

*MEL: you want to hold that?

Como se puede observar en el caso de (65b), Melanie le pide a Leo que traduzca al inglés lo que él acaba de decir en español (es decir, "lo quiero sí", que es el TO de la traducción (1)). Sin embargo, parte del TM correspondiente a la traducción (1) que 
produce Leo ("lo quiero hold it that") constituye, al mismo tiempo, el TO de la segunda traducción ("lo quiero", marcado con un doble subrayado), cuyo TM sería "I want”.

En el caso de que aparezca el TO subrayado y no exista otra parte del texto subrayada, se tratará de una TN nula, como la de (65c), en la que Leo no traduce lo que su madre le ha pedido expresamente que traduzca ( "yo no"), por lo que no señalamos ningún TM en el ejemplo.

(65c) *MEL: do you ever break things L ?

*LEO: yo@spno@sp.

*MEL: you no?

*MEL: how do you say yo@sp no@sp in English?

*LEO: yo@spno@sp.

*MEL: do you remember how we say it in English ?

*LEO: yo@sp no@sp .

En cambio, si nos encontramos ante una traducción de carácter situacional, en la que el TO no es una oración concreta sino toda una conversación, como en (65d), entonces no se subraya ningún enunciado como TO pero sí el correspondiente al TM, en el que se recoge la información de toda la situación precedente.

(65d) *SIM: [\% to Todd] I knew you had it .

*TOD: you did?

*TOD: how did you know?

*SIM: because I saw it .

*TOD: you saw it?

*TOD: are you gonna $+/$.

*SUS: S !

*SUS: [\% to Todd] careful with S .

*RAQ: [\% to Todd] no, it's your fault .

*SUS: careful with S .

*TOD: Susana <we gotta be careful $>$ [/] we gotta be careful of him lookin $(\mathrm{g})$ at our cards .

*RAQ: [\% to Simon] it's their fault .

*LEO: [\% to Esther] ha dicho que eran unos tramposos .

[5;05.29] / 61B(TR)_01

Llegados a este punto, consideramos importante apuntar que el sistema CHAT no establece cuáles han de ser la unidades lingüísticas que compongan las líneas de 
producción de cada interlocutor, pues estas pueden depender de las pausas, las reformulaciones, la tonalidad del enunciado, etc., algo que a veces se respeta utilizando determinados símbolos. Por este motivo, en todas las transcripciones de las que disponemos para el presente estudio, no se ha seguido una regla específica de lo que debe constituir el enunciado que se incluya en una sola intervención o línea de producción. Esta cuestión, unida al hecho de que, como comentábamos previamente en el apartado 2.2.2., en muchos casos el TM que producen los niños puede responder a la solicitud de una información concreta por parte del interlocutor (“¿para qué es eso?; “¿por qué?”; what do I have to do?; etc.), hacen que a la hora de localizar y analizar los casos de $\mathrm{TN}$ consideremos que no todo lo que aparece en una línea de producción de un hablante hay por qué considerarlo necesariamente el TO o el TM de la traducción, sino que, dependiendo del caso, sólo una parte del enunciado se considera como tal (la que se corresponda con la parte traducida o con la información que solicita el interlocutor, respectivamente). Esto es lo que sucede en el caso de (66a), donde el TO no se correspondería con la totalidad del enunciado de Simon (" $x$ for fox"), sino sólo con una parte ( $f o x ")$, que es la información que realmente le está exigiendo Esther.

(66a) \%com: Simon shows the card to Esther *SIM: $\mathrm{x}$ for fox .

*EST: qué es esto ?

*SIM: oh@i pues es un sorro [: zorro] . $[4 ; 10.19] / 56$ AEN_01

Este caso sería semejante a lo que sucede en (65b), visto anteriormente, en el que sólo se considera como TM una parte del enunciado ("I want") y no todo el enunciado entero ("I want peanuts please"). En cambio, también puede darse el caso en el que tanto el TO como el TM constituyan cada uno de ellos un enunciado por sí solo, como en (66b), donde el enunciado completo de Susana es el TO y el enunciado completo de Leo se corresponde con el TM.

(66b) *SUS: no there's something wrong here !

*EST: qué pasa?

*EST: qué ha pasado ?

*LEO: que hamos [= hemos] confundido . [4;10.19] / 56B(TR)_01 
Así pues, existe una gran variedad de situaciones de traducción que hemos intentado indicar de diferentes maneras, con el fin de ofrecer una presentación coherente de los casos de TN localizados en el corpus de transcripciones que vamos a manejar en el presente trabajo de investigación y que hemos incluido en el apéndice VI.

Finalmente, incluiremos en el siguiente apartado una pequeña descripción de los programas CLAN utilizados para ciertos tipos de análisis de las transcripciones, ya que nos ayudarán a obtener información, por ejemplo, acerca de la longitud media que tienen de los enunciados que producen los niños, así como el número de enunciados que estos producen en una sesión o en un fragmento concretos.

\section{LOS PROGRAMAS CLAN: $C H E C K$ Y MLU $U_{W}$}

El programa CHILDES dispone también de un paquete de programas CLAN ("Computerized Language Analysis") que sirven para analizar de forma automática los datos transcritos, de tal forma que permiten hacer un recuento de frecuencias, calcular la Longitud Media del Enunciado por palabras (LMEp) [ver el apartado 6], realizar análisis estadísticos, etc. A partir de la labor de equipo llevada a cabo por el proyecto (Fernández Fuertes et al. 2002-2005), hasta ahora se han utilizado dos programas de CLAN: el programa CHECK ("Verifying Data Accuracy") para que las transcripciones se ajusten al formato adecuado para el aprovechamiento de los programas CLAN (para aquellos investigadores que quieran disponer de las transcripciones para otro tipo de estudios) y el programa MLUw ("Mean Length of Utterance in words") para el cálculo de la LMEp, empleada por estudios clásicos y más actuales de adquisición (Brown 1973; Bel 2001, entre otros), y que es necesaria para poder tener una referencia del output de los niños en cada una de las sesiones y ver su desarrollo lingüístico de forma gradual, tal y como lo hemos mostrado en el apartado $4 \mathrm{y}$, concretamente, en el gráfico 1 de dicho apartado.

En cuanto al uso de otros programas para la explotación de los datos transcritos en formato CHAT, hemos encontrado que dada la naturaleza de las TTNN (que incluyen no sólo palabras u oraciones sino conversaciones y situaciones de longitud muy variable), hemos organizado la codificación y la clasificación de los ejemplos que reflejan el 
comportamiento traductor de Simon y Leo utilizando hojas de cálculo del programa EXCEL, el cual nos permitirá realizar también un análisis de frecuencias y tendencias en dicho comportamiento a través de las variables que más nos interesan en el presente estudio.

Finalizada la presentación sobre la recogida, la transcripción y la selección de los datos para nuestro trabajo de investigación, procederemos en el siguiente capítulo a la descripción del análisis de dichos datos. 


\section{CAPÍTULO 5: EL ANÁLISIS DE LOS DATOS Y LOS RESULTADOS DEL ESTUDIO}

Una vez mostrada en el capítulo anterior la descripción de la metodología para la recogida de datos seguida por el estudio longitudinal del que partimos, así como los criterios en los que nos hemos basado para la selección y el tratamiento de los datos que utilizamos en este trabajo de investigación, en este capítulo presentaremos el análisis gramatical (desde un punto de vista semántico-conceptual) y contextual de las TTNN recopiladas para dicho trabajo que proceden de la selección de datos que conforma nuestro corpus [ver el capítulo 4]. Para ello, consideraremos que los tres vértices principales en los que se apoya el presente capítulo son los siguientes: en primer lugar, las características definitorias de la TN y cómo estas también caracterizan las TTNN recogidas en este trabajo de investigación; las variables de análisis que hemos propuesto, las cuales giran en torno a las propiedades gramaticales y contextuales en las que se enmarcan los casos de TN recopilados y que nos permitirán realizar una clasificación objetiva de dichos casos; y el análisis estadístico de las principales variables en las que se apoya nuestro estudio, en el que pondremos de manifiesto las diferencias o similitudes que hemos encontrado en la evolución del comportamiento traductor de los niños bilingües que han producido esas TTNN.

De esta manera, en la primera parte de este capítulo hemos apuntado una serie de cuestiones preliminares que nos servirán para presentar de forma más clara la organización del análisis que hemos planteado en este trabajo. En las dos primeras cuestiones, hemos tenido en cuenta una serie de criterios antes de proceder a la definición de las variables. 
Entre estos criterios se encuentran, por ejemplo, lo que entendemos por texto origen (TO) y texto meta (TM) en los casos de TN con los que nos hemos encontrado, y aquellos criterios en los que nos hemos basado para excluir del análisis de nuestros datos aquellos casos que no consideramos TTNN. La tercera cuestión fundamental para entender nuestro análisis es la presentación de las características principales de lo que nosotros entendemos por TN y mostrar, de esta manera, que los casos encontrados en nuestro corpus de datos responden a dichas características. Al mismo tiempo, esta cuestión nos dará pie a plantear la diferencia que hemos establecido entre las producciones que constituyen un proceso de traducción per se, y que son el centro de nuestro estudio, y aquellas producciones en las que el proceso no llega a su fin y que, por tanto, son producciones que resultan nulas y que trataremos en el penúltimo apartado de este capítulo.

En la segunda parte, propondremos las variables de análisis de las que hemos partido para la clasificación de las diferentes producciones de traducción procedentes de dicha selección de datos, así como el tratamiento estadístico que hemos realizado para el análisis de los casos de TN incluidos en nuestro corpus. Con este fin, presentaremos cada una de esas variables con sus correspondientes definiciones y ejemplos, teniendo en cuenta lo planteado ya en los capítulos anteriores del presente trabajo en los que aludíamos a la importancia que tienen en el estudio de la TN tanto el aspecto formal como el situacional. Una vez realizada esta presentación, ofreceremos una clasificación de los datos utilizando dichas variables con objeto de ver cómo se puede catalogar la producción de TTNN, tanto desde el punto de vista gramatical como desde el punto de vista contextual. Por ello, consideramos que el objetivo de nuestro trabajo, que se presenta en la tercera parte de este capítulo, es doble ya que, por un lado, examinaremos la importancia en la $\mathrm{TN}$ de aquellas variables lingüísticas que son intrínsecas a la traducción (el tipo de actividad traductora, la tipología semántico-conceptual y la direccionalidad de las TTNN) y, por otro, observaremos la influencia que en estas variables pueden tener otras variables más externas a la TN y que se asocian más al contexto en el que se produce este tipo de producción lingüística (la presencia o la ausencia de un estímulo que provoque la producción de TTNN y la procedencia del TO que los niños traducen). De esta manera, pretendemos establecer una serie de patrones en el comportamiento traductor de nuestros sujetos, así como en la evolución de su capacidad para traducir a lo largo de las etapas en las que hemos dividido este trabajo. 
En apartado 4 de este capítulo, procederemos a realizar un análisis paralelo de lo que hemos denominado la actividad nula de traducción con el fin de poder comparar posteriormente estos resultados con los obtenidos en el apartado anterior relativos a las TTNN en las que el proceso traductor se ha llevado a cabo parcial o totalmente.

Finalmente, en el apartado 5, aludiremos a las principales implicaciones de nuestros resultados desde el punto de vista de los planteamientos teóricos tanto de los estudios de adquisición como de los de TN a los que hemos hecho referencia en los anteriores capítulos del presente trabajo de investigación con el fin de establecer si los resultados de nuestros datos se ajustan a dichos planteamientos.

Como punto de partida de este capítulo, en el apartado siguiente recogemos una serie de cuestiones preliminares que hemos tenido en cuenta para realizar la posterior clasificación y análisis de los casos de TN procedentes de nuestro corpus de datos.

\section{CUESTIONES PREVIAS AL ANÁLISIS}

Como paso previo a la clasificación de TTNN recopiladas para el presente estudio, hemos considerado necesario plantear una serie de cuestiones previas que nos permitirán exponer con mayor claridad el análisis de dichas traducciones. De esta manera, una cuestión importante en el proceso de recopilación de los casos de TN de nuestra base de datos es aquella que incluya lo que entendemos por unidad de traducción y qué es lo que conforma el binomio TO/TM del que ya hemos hablado en el capítulo 3 [ver el apartado 1.3.1. del mencionado capítulo]. La siguiente cuestión está relacionada con aquellas producciones lingüísticas que hemos descartado como casos de TN por una serie de motivos que explicaremos en el segundo apartado; y, finalmente, la tercera cuestión previa al análisis es la que se refiere a la distinción que hemos establecido, tanto en las variables como en el análisis de resultados, entre lo que son los casos de TN per se y los casos en los que la actividad de traducción ha resultado nula. Tanto el primer tipo de casos como el segundo se incluyen en el análisis de datos del presente trabajo de investigación, aunque nos centraremos sobre todo en el primer tipo. 


\subsection{Los problemas teórico-metodológicos que se plantean: la unidad de traducción}

El trabajo que aquí presentamos parte del planteamiento general de que se trata de un estudio de carácter descriptivo y explicativo, de tal forma que pretendemos establecer criterios objetivos que nos permitan clasificar un caso de TN no como una traducción correcta o incorrecta desde el punto de vista teórico de los estudios de traducción, sino como un fenómeno característico de la adquisición bilingüe en la que entran en juego una serie de mecanismos lingüísticos que son los que pretendemos analizar. Sin embargo, a veces para poder partir de estos criterios objetivos que nos ayuden a clasificar los casos de TN recopilados y su posterior análisis, existen problemas teórico-metodológicos, que son los que tratamos a continuación.

Como punto de partida, creemos conveniente aclarar lo que hemos considerado Texto Origen (TO) de la TN y su relación con el Texto Meta (TM). En este sentido, y con el fin de realizar el análisis que hemos llevado a cabo en el presente capítulo, nos hemos planteado la necesidad de elegir una unidad de traducción que dote a nuestro trabajo de cierta coherencia y que, de esta forma, los resultados sean lo más precisos posible. Basándonos en las propuestas de Llácer Llorca (1997; 2004), entendemos que la unidad de traducción es aquella que incluye el binomio mínimo TO/TM que expresa el mismo mensaje y que puede ir desde una palabra hasta un texto completo, pasando por todos los estadios intermedios. Siguiendo este razonamiento, en nuestro análisis de datos el TO puede ser una sola palabra, un sintagma, una oración o incluso toda una situación (es decir, varios enunciados procedentes del propio niño o de otros interlocutores). Consecuentemente, dentro de las intervenciones de los niños hemos seleccionado como TO y TM diversas estructuras lingüísticas, dependiendo del tipo de TN al que nos enfrentemos.

De esta manera, hemos analizado los casos de TN localizados siguiendo la propuesta que realizamos en los diagramas 15(a)-15(c) del capítulo 3, en los que planteábamos los pasos que se podían establecer a la hora de explicar el proceso que se sigue cuando un hablante bilingüe realiza TTNN: en primer lugar, la producción del TO con una FF determinada (en inglés o en español, en nuestro caso) y una sola FL y, a continuación, la producción de un TM que se corresponda con una FF distinta a la del TO y que, al mismo tiempo, se adecúe a la FL del TO, que es la que constituye el punto de partida de la producción de ese TM. De esta manera, ambos textos tendrán una FL común 
que es la que permite que se establezca una relación semántico-conceptual entre ambos textos.

En este sentido, podremos encontrar que esa relación semántico-conceptual entre el TO y el TM en una TN puede ser de dos tipos:

1. en el binomio TO/TM la unidad de traducción es equivalente en ambos textos, como veíamos en el ejemplo (66b) del capítulo 4, repetido aquí como (67a), donde Leo traduce una oración en inglés, "no there's something wrong here", por otra en español, "que hamos confundido";

(67a) *SUS: no there's something wrong here !

*EST: qué pasa?

*EST: qué ha pasado ?

*LEO: que hamos [= hemos] confundido .

2. en el binomio TO/TM la unidad de traducción no es equivalente en ambos textos, de tal forma que la unidad del TO puede ser mayor que la del TM, como en (65d), repetido aquí como (67b), donde todo un fragmento de una conversación se traduce en una sola oración, "ha dicho que eran unos tramposos", o menor, como en (66a), repetido como (67c), donde una sola palabra, "fox" se traduce por una oración, "es un zorro".

(b) *SIM: [\% to Todd] I knew you had it .

*TOD: you did?

*TOD: how did you know ?

*SIM: because I saw it .

*TOD: you saw it?

*TOD: are you gonna $+/$.

*SUS: $\quad$ S !

*SUS: $\quad[\%$ to Todd $]$ careful with $\mathrm{S}$.

*RAQ: $\quad[\%$ to Todd] no, it's your fault .

*SUS: $\quad$ careful with S .

*TOD: $\quad$ Susana <we gotta be careful $>$ [/] we gotta be careful of him lookin $(\mathrm{g})$ at our cards .

*RAQ: $\quad[\%$ to Simon] it's their fault .

*LEO: $\quad[\%$ to Esther] ha dicho que eran unos tramposos . 
(c) \%com: Simon shows the card to Esther

*SIM: $\quad \mathrm{x}$ for fox .

*EST: qué es esto ?

*SIM: $\quad$ oh@i pues es un sorro [: zorro] . [4;10.19] / 56AEN_01

Teniendo en cuenta esta diferenciación, y dado que estamos en un contexto oral en el que, en muchos casos, los interlocutores dirigen con sus estímulos verbales la traducción resultante o TM, indicaremos cuál es el fragmento o la parte del TO que los niños han traducido respondiendo a estas demandas comunicativas y que se corresponde con la definición que planteábamos en el apartado dedicado a las propuestas del presente estudio [ver el capítulo 4], donde considerábamos que el componente semántico o comunicativo, y no tanto el componente formal, es el que prima en la TN. Así, hemos planteado, por ejemplo, que lo que encontramos en (68) responde a lo que entendemos por TN, ya que en este caso Leo transmite parte del mensaje del enunciado que dirige a su madre en español ("yo si") al inglés ("I do") ante la petición de esta, aunque este TM no incluya toda la oración del enunciado ni se corresponda con la forma lingüística adecuada desde el punto de vista de una gramática adulta, que precisamente es lo que provoca la corrección de Melanie.

*MEL: we have to wait for $\mathrm{S}$.

*LEO: yo@sp sí@sp finished.

*MEL:how do you say yo@sp si@sp finished in English ?

*LEO: $\underline{I \text { do }}$.

*MEL:no, I am finished .

*LEO: I am finished.

De esta manera, el que en determinados casos, hayamos restringido la unidad de traducción a fragmentos mínimos y no a todo el enunciado no responde a algo arbitrario sino a una flexibilización de las unidades susceptibles de ser traducidas para cada situación de traducción, lo cual puede contribuir, al mismo tiempo, a la simplificación de criterios de clasificación de TTNN donde hemos tratado de mostrar una clasificación y un análisis rigurosos de cada uno de los casos en los que Simon y Leo han traducido.

Finalmente, y siguiendo con este planteamiento de los criterios de clasificación de la $\mathrm{TN}$, consideramos importante destacar que la única referencia de la que disponemos a este respecto es la de Harris (1980a) que distingue entre las TTNN que responden a una 
transcodificación y las que responden a una interpretación [ver el apartado 2.1.1. del capítulo 2]. Nosotros pretendemos dar un paso más allá y optar por un análisis morfosintáctico desde el punto de vista minimalista en el que se tenga en cuenta tanto el componente gramatical como la interface semántica o lógica. De esta manera, seguimos los dos enfoques, el gramatical y el pragmático, que encontramos en los estudios de bilingüismo sobre la mezcla de lenguas en general y de la AC y la TN en particular que ya hemos tratado en capítulos anteriores [ver los apartados 5.2.2. del capítulo 1 y 1.3. del capítulo 3]. Estos dos tipos de enfoques se verán reflejados en las variables de clasificación de los casos de TN del presente estudio, así como en la dinámica de análisis que presentaremos en los apartados 2-5 que se incluyen en este capítulo.

Con el fin de seguir ofreciendo la máxima objetividad en el análisis que vamos a presentar, también hemos considerado importante recoger aquellos casos procedentes de nuestro corpus que no hemos incluido en dicho análisis por una serie de razones, que son las que exponemos en el apartado siguiente.

\subsection{Los casos excluidos del corpus de datos}

En total, el número de casos excluidos del cómputo general de nuestro corpus de datos es de 20, siendo las razones de esta exclusión las que enumeramos a continuación de 1 a 6.

1. No se entiende lo que dice alguno de los niños o el interlocutor adulto debido a ruidos ambientales o cortes momentáneos en las grabaciones. En total, los casos excluidos por este motivo son dos, concretamente el del ejemplo (69a), donde las xxx indican que lo que dice Leo en sus dos intervenciones es ininteligible, con lo que desconocemos tanto el TO como el TM de una posible TN; y el del ejemplo (69b), donde conocemos el TO por la petición expresa de Ivo, el padre, para que Leo traduzca, pero no se ha entendido lo que ha respondido el niño. 
(69) (a) *MEL: what do you like to eat besides yoghourt?

*LEO: $\quad \mathbf{x x x}$.

*MEL: can you say that to me in English ?

*LEO: $\quad \mathbf{x x x}$ cheese no .

*MEL: you don't like cheese?

(b) *IVO: cómo se dice en inglés ele ?

*LEO: $\quad \mathbf{x x x}$.

*IVO: no,el@en .

2. Existe una ambigüedad en el enunciado, de tal forma que una de las posibles interpretaciones no supondría una traducción. En nuestros datos, existen dos casos de este tipo y son los siguientes.

(a) *RAQ: es que ése es el problema porque las casas son muy:

débiles, no ?

*SIM: $\quad$ mira to $[?$ two $]+\ldots$

*RAQ: no es como la casa de ladrillo .

*SIM: $\quad<$ mira to $>[/ /]$ mira hay dos .

\%com: Simon coge las dos espadas

(b) *LEO: un ta:r $+\ldots$

*RAQ: qué es eso ?

*LEO: eh@fp un pastel .

En (70a) no está claro si la palabra "to" que dice Simon se corresponde con la preposición en inglés, con el número "two" (en cuyo caso Simon lo estaría traduciendo por “dos") o con un fragmento fonológico en español (de ahí que, ante esta ambigüedad, la palabra no esté marcada ni con@en ni con@sp); en el caso de (70b) la ambigüedad viene dada porque no existe la certeza de que Leo quisiera decir "tart" en inglés ${ }^{48}$ (en cuyo caso estaríamos ante la TN tart-pastel) o “tarta” en español.

3. Se han excluido también los casos de interferencias o influencias estructurales de una lengua en otra (con un total de 13 casos en nuestros datos), como los distintos ejemplos de (71), en los que entran en juego otros mecanismos que están fuera del tema del presente estudio, puesto que, por un lado, y siguiendo los criterios expuestos hasta ahora en este apartado, consideramos que no hay un TO expreso en

\footnotetext{
${ }^{48}$ Aunque "tart" es una palabra con un uso más propio de la variante del inglés británico más que del norteamericano, es posible que los niños la pudieran utilizar, puesto que aparece en muchos cuentos que su madre les ha leído. 
el discurso y, por otro, las interferencias lingüísticas no están ligadas a la traducción como tal sino que se trata de fenómenos diferentes que también podemos encontrar en las producciones lingüísticas a lo largo del proceso de adquisición bilingüe como, por ejemplo, el orden de palabras en (70a), el calco estructural en (70b-70d), etc.

(a) *LEO: +, quiero comer a tú ! (...)

*LEO: $\quad<\mathrm{y} \mathrm{y}>[/]$ y vio un malo lobo que lo quiere comer $+\ldots$

(b) *RAQ: y así suena el teléfono, eh@i ?

$[3 ; 00.23] / 28 \mathrm{SP} \_02$

*SOL: quién está allí ?

*RAQ: uy@i cuidado .

*SOL: quién (e)stá ?

*RAQ: que es lo que tienes que decir cuando coges el teléfono ?

(c) *LEO: let me [\% del español "déjame"]. [3;11.26] / 42CEN_01

(d) *LEO: [\% fuera de plano] todavía no estoy acabado .

*RAQ: todavía no [/] no has acabado ? [4;09.08] / 54SP_01

4. Cuando se trata de una secuencia de elementos (meses, días de la semana, etc.), no tienen por qué considerarse una traducción sino una secuencia aprendida y memorizada en una u otra lengua, como ya argumentó Von Raffler-Engel (1970), de ahí que, a pesar de que unos momentos antes de este fragmento citaron los meses en inglés, no hayamos considerado el ejemplo de (72) como un caso de traducción.

(72) *EST: sabéis cuál es el mes en español ?

*EST: cómo son los meses ?

*EST: enero...+

*SIM: enero .

*SIM: sebrero [: febrero] .

*EST: febrero .

*SIM: mayo .

*EST: marzo .

*SIM: marso [: marzo] .

*SIM: octobre [: octubre] .

*EST: aha@i ven [\% a Leo].

*LEO: y se(p)tiembre .

*SIM: y octubre ! 
5. Existen nombres propios de personajes que en ocasiones pueden tener nombres diferentes en inglés y en español. Sin embargo, al aprenderlos directamente en una de las dos lenguas, los utilizan de igual forma en las dos y es muy corriente encontrar que los niños digan, por ejemplo, "Cookie Monster" en un contexto español o con un hablante de español, y no "Monstruo de las galletas". Sólo consideraremos que habrá traducción en lo que respecta a los nombres propios cuando se ponga de manifiesto en una misma situación conversacional la separación de códigos y la relación semántica entre ambos nombres, como en (73), donde Simon traduce el nombre del personaje Paco Pico en español por el correspondiente nombre en inglés, Big Bird, puesto que, dependiendo del contexto lingüístico, pueden usar uno u otro nombre.

\section{*SIM: mira Paco Pico !}

*RAQ: Paco Pico ?

*SIM: sí .

*RAQ: así se llama ese ?

*IVO: y en inglés cómo se llama Paco Pico ?

*SIM: Big@en Bird@en .

$[2 ; 10.21] / 25 \mathrm{SP} \_02$

6. Es posible que, dada la naturaleza de este tipo de grabaciones en las que los niños interactúan libremente con sus interlocutores, sin preocuparse de si la cámara les está grabando o no, los dos niños hablen encontrándose fuera de plano en un momento dado. Cuando esto sucede, no se puede saber a ciencia cierta quién está hablando, de ahí que no podamos atribuir a Simon o a Leo específicamente una producción determinada y utilicemos el nombre de SOL (Simon o Leo) cuando esto sucede. Así, podemos encontrar un caso de TN, mostrado en (74), que ha resultado descartado de nuestro cómputo de datos, al no poder determinar que, efectivamente, se trataría de un caso de autotraducción (si *SOL se corresponde con el mismo niño), un caso de reformulación (de nuevo, si *SOL se tratase del mismo niño) o un caso de traducción en el que uno de los niños traduce al otro (en cuyo caso, una de las intervenciones de ${ }^{*}$ SOL se correspondería con Simon y la otra con Leo, pero desconoceríamos quién dice qué). 
(74) \%com: los niños están fuera de plano

*RAQ: [\% riendo] ya no hay más, mira, aquí hay uno .

*SOL: where?

*SOL: dónde?

Para finalizar el apartado de las cuestiones preliminares, también hemos tenido en cuenta lo que consideramos que son las características definitorias de lo que entendemos por TN, de tal forma que, una vez expuestas dichas características, estableceremos la distinción entre la presencia de TN per se y la ausencia de TN en contextos en los que se solicita a los niños una traducción o ellos mismos lo perciben así, siendo la TN per se el tipo de fenómeno en el que nos vamos a centrar en el análisis, aunque sin perder de vista la actividad nula de traducción.

\subsection{Las propiedades definitorias de la $T N$ y la distinción entre la $T N$ y la actividad nula de traducción}

Lo que pretendemos, a continuación, es demostrar que los casos de traducción recopilados en el corpus de datos del presente estudio son, efectivamente, traducciones que responden al concepto de lo que se entiende por TN. Para ello, retomaremos las características principales que hemos ido apuntando a lo largo de los capítulos anteriores acerca de lo que se entiende por TN, según otros autores y según las propuestas planteadas en este trabajo. De esta manera, comprobaremos en los últimos apartados de este capítulo si, clasificando los casos de TN recopilados según las variables que vamos a proponer, se constatan las siguientes características en estas producciones lingüísticas específicas de los niños bilingües de nuestro estudio.

Una vez planteadas estas características de la $\mathrm{TN}$, procederemos a establecer la diferenciación entre la TN y lo que hemos denominado la actividad nula de traducción, ya que, aunque nuestro análisis se va a centrar en la TN per se, también tendremos en cuenta el análisis de aquellos casos en los que la actividad ha resultado nula para observar si existen características comunes que la relacionen con la TN per se. 


\subsubsection{La definición de TN: los aspectos lingüísticos y contextuales}

Con el fin de establecer las propiedades definitorias de lo que entendemos por TN, retomaremos tanto las cuestiones lingüísticas inherentes a la TN (la TN como un tipo de CC y diferente a la AC; la TN como trasvase semántico y comunicación del sentido del TO; y la doble direccionalidad), como los aspectos de carácter contextual (la influencia del tipo de estímulo y la procedencia del TO) que se han ido apuntando a lo largo de los capítulos anteriores de este trabajo de investigación.

\subsubsection{Los aspectos lingüisticos inherentes a la TN}

Si consideramos que la TN no es un fenómeno puntual sino un proceso en el que una producción lingüística está marcada por un acto de habla complejo, entonces la TN incluye un TO, un TM y un trasvase de información de un código a otro, o de un TO en una lengua a un TM en la otra. Así, si analizamos todo este proceso, hay que definir claramente qué entendemos por un caso de TN: si la $\mathrm{TN}$ va a estar marcada por ese proceso nada más iniciarse (cuando exista un TO) o si sólo se va a considerar TN cuando tengamos un TM, es decir, cuando el proceso de haya completado.

Siguiendo este último planteamiento, la clasificación que proponemos girará en torno a los tres parámetros siguientes.

- la presencia del TO;

- la presencia o la ausencia del TM; y

- $\quad$ el tipo de cambio de código.

Atendiendo a estos tres parámetros, podemos encontrarnos con cuatro tipos de casos en los que se dispone de un TO como punto de partida del proceso de traducción, independientemente de que este proceso se complete (total o parcialmente) o no. Así, es posible encontrar casos como el del ejemplo (75a), en el que existe un TO ("cómo se hace”) y su correspondiente TM ("how do you do it?"), conformando ambos un binomio 
basado en una relación semántico-conceptual, tal y como explicamos en el apartado 1.3.1. del capítulo 3.

(75a) *EST: pregúntale a Susana cómo se hace por favor . *SIM: [\% como si estuviese pensando]mhm@fp .

*EST: pregúntale cómo se hace anda .

*SIM: how do you do it?

En el caso del ejemplo (75a), el proceso de traducción se ha completado, puesto que el cambio de códigos se ha producido en su totalidad (de español a inglés, en este caso) y tenemos un TM en la lengua correspondiente ("how do you do it?").

El segundo caso con el que nos podemos encontrar es aquel en el que el TM está ausente de la producción por diversos motivos, que ya explicaremos en el apartado dedicado a la descripción de las variables. Tal sería el caso de (75b), en el que Leo no traduce el TO (la palabra “nariz”), a pesar de la petición explícita de Raquel, puesto que no realiza el cambio de códigos correspondiente (de español a inglés) sino que repite el TO sin reproducir el significado de este en la lengua meta.

(75b) *RAQ: cómo se dice nariz en inglés?

*LEO: nariz !

En el caso de producciones como la de (75b), consideramos que la actividad de traducción ha resultado nula, ya que no se ha producido un cambio de códigos y se da una ausencia del TM (de ahí que no aparezca subrayado ningún texto en el ejemplo).

En el caso de que el proceso de traducción no se anule sino que continúe, tendremos en cuenta, además, otros casos como el de (75c), en el que se ha producido un cambio de códigos completo (de inglés a español, en este caso), a pesar de que el TO forme parte de una estructura lingüística incompleta.

(75c) *SIM: y luego hay <una bee@en> [//] una abeja allí . [3;10.27] / 41SP_01 
De esta manera, consideramos que el ejemplo (75c) es también un caso de TN en el que el niño, Simon, interrumpe su propio enunciado cuando se da cuenta de que el código que está utilizando con su interlocutor ha de ser el español (“abeja”) y no el inglés ("bee”), de ahí que, con el fin de adaptarse a la lengua de dicho interlocutor, reformule en la otra lengua lo que acaba de decir y, por tanto, se autotraduzca o se corrija a si mismo. Este tipo de casos, tal y como propusimos en el apartado 1.4. del capítulo 3, lo hemos incluido como un posible caso de $\mathrm{TN}$ aunque otros autores utilicen una terminología diferente para referirse a este tipo de producciones como, por ejemplo, "auto-corrección" (Lanza 1997) [ver el apartado 1.2. del capítulo 2].

Finalmente, el último caso que incluiremos como un posible caso de TN será el que se observa en el ejemplo (75d), en el que el cambio de códigos entre el TO, expresado en español ("no puedo"), y el TM se ha llevado a cabo sólo parcialmente ("can't" está en inglés pero “yo” no), por lo que el proceso de traducción no se realizado por completo.

(75d)*LEO: no peyo@sp [: puedo] .

*MEL: how do you say no@sp puedo@sp in English ? (...)

*LEO: yo@sp can't . $[2 ; 05.12] / 23 \mathrm{EN} 01$

Estos casos de traducción parcial o incompleta en los que el TM está compuesto por elementos procedentes de dos lenguas se pueden considerar, al mismo tiempo, casos de AC intraoracional, aunque, dado que nos centramos en el estudio de la TN, desde el punto de vista de nuestra clasificación se trataría de un TM en el que una parte del TO se ha traducido pero la otra no, de ahí que se produzca la AC [ver el apartado 5 del capítulo 1 sobre este tipo de fenómenos en el discurso bilingüe infantil y el diagrama 14 del apartado 1.1. del capítulo 3 para entender la diferencia entre la TN y la AC que hemos propuesto].

De esta manera, al igual que planteamos en el capítulo 3, también la TN puede considerarse un tipo de fenómeno relacionado con la mezcla de lenguas pero diferente de otros tipos de mezcla de lenguas como la AC. La diferenciación entre estos dos fenómenos viene establecida por la naturaleza de ese proceso de traducción desde el momento en el que los niños pueden realizar traducciones en las que el $\mathrm{CC}$ ha sido completo (como en (75a) y (75c)) y traducciones en las que el CC no ha sido completo (como en (75d)) y, por tanto, el niño ha recurrido a la AC. 
Así pues, hemos considerado importante que exista esta distinción dentro de los fenómenos de la mezcla de lenguas entre la $\mathrm{TN}$ y la $\mathrm{AC}$, ya que en el corpus hemos localizado casos de $\mathrm{TN}$ en los que se incluyen casos de AC, como en el ejemplo (75d), pero también casos de $\mathrm{AC}$ no asociados a la $\mathrm{TN}^{49}$.

Al mismo tiempo, esta diferenciación nos lleva a retomar uno de los temas presentados en el apartado 4.5. del capítulo 1 acerca de la relación entre la diferenciación de los sistemas lingüísticos y los casos de mezcla de lenguas, ya que podríamos plantear que la cantidad de TTNN que realizan los sujetos de nuestro estudio constituye una evidencia de que Simon y Leo pueden separar las dos lenguas cuando las circunstancias así lo requieren y, por tanto, son conscientes de que disponen de dos lenguas para comunicarse según las necesidades del contexto. El hecho de que aparezcan casos de AC en las traducciones incompletas puede venir provocado por motivos diferentes al de la confusión o la fusión de los sistemas lingüísticos ${ }^{50}$. En este sentido, tanto la TN como la AC son dos de los fenómenos lingüísticos que forman parte del proceso de adquisición bilingüe en el que estos niños se encuentran inmersos y de la disponibilidad de dos lenguas. Trataremos en mayor profundidad las características de estos tipos diferentes de producciones cuando, en el apartado 2.1., definamos las distintas variables aludiendo a casos como los de (75a)(75d) procedentes de nuestro corpus de datos.

En todo caso, independientemente de que en la $\mathrm{TN}$ el $\mathrm{CC}$ se produzca de forma completa o incompleta, este tipo de traducción ha de constituir necesariamente un trasvase de significado de una lengua (o código) a otra, siendo esta condición otro de los aspectos lingüísticos inherentes a la TN. De esta manera, en los ejemplos de TN procedentes de nuestro corpus podemos encontrar casos en los que la equivalencia semántica entre el TO y el TM responde a una transcodificación o a una interpretación (según la terminología de Harris (1980a), mencionada en el apartado 2.2.1. del capítulo 2). Así, el primer caso se correspondería con el ejemplo (76a), donde Simon realiza una traducción de las estructuras

\footnotetext{
${ }^{49}$ Uno de estos casos en los que se produce una AC no asociada a una traducción es el que mostramos en el siguiente ejemplo de (i), en el que Simon produce una AC en el nivel intraoracional, pues el sujeto ("cat") es expresado en inglés y el verbo ("cae") en español, sin que se produzca ningún trasvase de significado entre ambos códigos.

(i) *MEL: oh@i no, and everything fell, look .

*MEL: $\quad$ the ball fell, the $+/$.

*SIM: ca(t) $\underline{\text { cae } @ s p ~ . ~}$

[16EN_03 / 2;01.01]

En este estudio no trataremos estos casos de AC, sino sólo aquellos asociados a la TN, ya que es esta la que constituye nuestro foco de análisis.

${ }^{50}$ Recordemos que, tal y como plantean Spradlin et al. (2003) y Liceras y Fernández (2005) para el caso de la AC, y Fernández et al. (en prensa), para el caso también de la $\mathrm{TN}$ [ver el apartado 5.2.2.1. del capítulo 1 y los apartados 1.1. y 1.3.1. del capítulo 3], en ambos fenómenos el hablante bilingüe, al disponer de dos lexicones, elige la fórmula que aporte mayor información tanto al sistema computacional (en el caso de los rasgos) como a las interfaces.
} 
lingüísticas ("yo solo" por "by myself") o, lo que nosotros consideramos un emparejamiento de ítems (no sólo estructural sino también semántico) en el que se expresa el mismo mensaje.

(76a)*SIM: no@sp, yo@sp solo@sp .

*MEL:how do you say yo@sp solo@sp in English?

*SIM: by myself.

La interpretación, en cambio, se correspondería tanto con el ejemplo (76b) como con el (76c). En el caso de (76b), Leo ha aplicado una estrategia de traducción que consiste en transmitir la información más importante del TO (“¿quieres marcar esto?”), dejando sin traducir la información que considera que es prescindible ("you wanted to mark this", además de “as well”).

(b) *SUS: [\% a Simon] oh@i ask her tell her you wanted to mark this, perhaps she wants to mark this as well.

*LEO: $\quad[\%$ a Esther] quieres marcar esto ?

$$
[4 ; 10.19] / 56 \mathrm{~B}(\mathrm{TR})+01
$$

(c) *SIM: $[\%$ to Todd $]$ vamos a pedirte esto .

*TOD: what?

*TOD: what do you want?

*SIM: $\quad$ alagayto [: alligator]

$[5 ; 05.29] / 61 B(T R) \_01$

En el caso de (76c), aunque la estrategia de traducción es similar puesto que se basa en la transmisión de la información más importante ("esto"), en este caso lo que hace el niño es utilizar el sustantivo al que se refiere el pronombre demostrativo ("alagayto"), dando, de esta manera, una mayor información al interlocutor sobre lo que quiere.

En la propuesta de clasificación que propondremos en el apartado 2.1. dedicado a las variables, tendremos en cuenta todos estos tipos de traducción basados en la relación de equivalencia semántica que se establece entre el TO y el TM. Sin embargo, a diferencia de la clasificación de Harris (1980b) y tal y como planteamos en el apartado 1.5. del capítulo 3, en el presente trabajo propondremos que la TN es una producción lingüística basada fundamentalmente en la transmisión de un mensaje de un enunciado producido en una 
lengua (o TO) a otro enunciado producido en la otra lengua (TM), una definición a la que responden los casos de TN que hemos recopilado en el presente estudio.

De una forma más específica y desde la perspectiva minimalista adoptada en el presente trabajo [ver el apartado 2 del capítulo 1 y 1.3.1. del capítulo 3], hemos partido de la premisa de que en la TN se establece una relación semántico-conceptual adecuada entre un TO y un TM que la FL recoge en una relación equivalente, como en (76a), o en una relación no equivalente, como en (76b) o (76c), un aspecto fundamental de la TN que trataremos con más detalle en el apartado 2.1. dedicado a la definición de las variables de análisis.

A raíz de estos ejemplos, podemos plantear que otra de las características lingüísticas inherentes a la TN es que responden a una finalidad básica que es la de comunicar un mensaje (Harris 1977, 1980b), de tal forma que se presta atención sobre todo a una relación semántica entre el TO y el TM. Sólo hemos encontrado un único caso, el de (77), en el que la relación semántica entre el TO y el TM es totalmente distinta y en donde la relación que establece la FL no se puede explicar desde la semántica.

(77) *RAQ: qué te pregunta Todd ?

*SIM: una oveja .

*RAQ: cómo se dice ? (...)

*LEO: bee@en . $[5 ; 05.29] / 61$ ASP_01

En este ejemplo, Leo traduce la palabra “oveja” por la palabra "bee”. Sin embargo, este caso puede venir provocado por las similitudes fonéticas que existen en español entre las palabras "oveja” /o'ßexa/ y "abeja” /a'ßexa/. Además, el hecho de que no se trate de una autotraducción puede reforzar el que se trate de una confusión en la interpretación del TO, cuya FL es la que constituye la base de la traducción resultante, de ahí que esta fracase.

La existencia de este ejemplo nos lleva a considerar, de nuevo, que el componente más importante de la TN es la equivalencia semántico-conceptual en el binomio TO/TM más que la equivalencia formal debido a su carácter esencialmente comunicativo, tal y como hemos visto en los ejemplos (75d), (76b) y (76c). Sin embargo, esto no quiere decir que en la $\mathrm{TN}$ el componente formal no se tenga en cuenta ya que podemos encontrar casos 
como el de (76a) o el que incluimos a continuación en (78) en los que la equivalencia no es sólo semántica sino también formal.

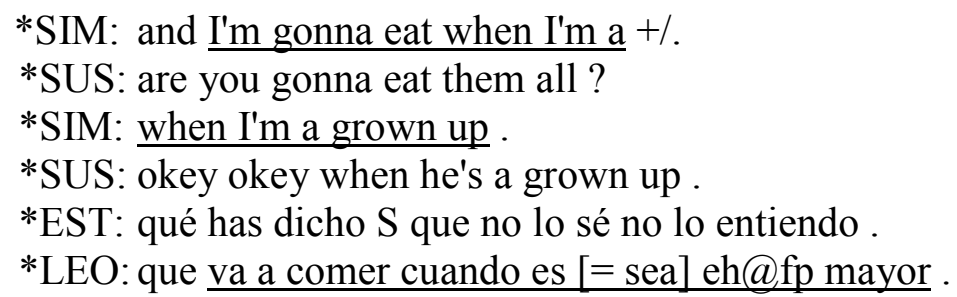

$[4 ; 10.19] / 56 \mathrm{~B}(\mathrm{TR}) \_01$

En este ejemplo Leo traduce al español (es decir, en el TM) todos los ítems del lexicón incluidos en el TO, estableciendo no sólo una equivalencia en el nivel semánticoconceptual sino también en el nivel formal.

Esto es lo que nos lleva a poner de manifiesto que, a diferencia de lo que han afirmado otros autores (Lörscher 1988, 1992) [ver el apartado 2.2.4. del capítulo 2], en las TTNN que han realizado los niños de nuestro estudio se presta atención no sólo al componente semántico o al sentido, sino también a la forma, aunque teniendo siempre en perspectiva que, aunque hablemos de un campo de actuación común (la traducción), estamos ante producciones lingüísticas de un niño, en el que la competencia traductora está en desarrollo, y no de un hablante adulto o de un traductor profesional, en el que la competencia traductora está ya desarrollada, tal y como ya apuntamos en otros capítulos del presente trabajo de investigación [ver los apartados 5.1.3. y 2.2. de los capítulos 1 y 2 , respectivamente $]^{51}$.

Al mismo tiempo, consideramos que el hecho de que la competencia traductora de nuestros sujetos se encuentre en un proceso de desarrollo no implica que esta se reduzca a una mera competencia lingüística, tal y como plantea Toury (1986) [ver el apartado 2.2.3. del capítulo 2], ya que no todas las traducciones que realizan dichos sujetos constituyen equivalencias formales. De hecho, los niños son capaces de poner en juego otros mecanismos lingüísticos complejos que vendrían a formar parte de los recursos de esa

\footnotetext{
${ }^{51}$ Evidentemente, dada la edad de los sujetos de nuestro estudio, hay que tener en cuenta el grado de desarrollo lingüístico que tienen dichos sujetos, ya que habrá formas lingüísticas en una u otra lengua (en español, en el caso de (78)) que aún no dominen (como puede ser la forma del verbo ser en el modo subjuntivo). Este mismo argumento nos ayuda, al mismo tiempo, a demostrar que no sólo el desarrollo traductor de este tipo de hablantes sino también el lingüístico es diferente al que tienen los adultos, lo cual nos lleva a afirmar, de nuevo, que no se pueden comparar las traducciones que hacen uno y otro tipo de sujetos en términos de cuáles son las que tienen una mayor o menor calidad.
} 
competencia traductora, como hemos podido observar en el ejemplo anterior de (76b) o en el que incluimos en (79).

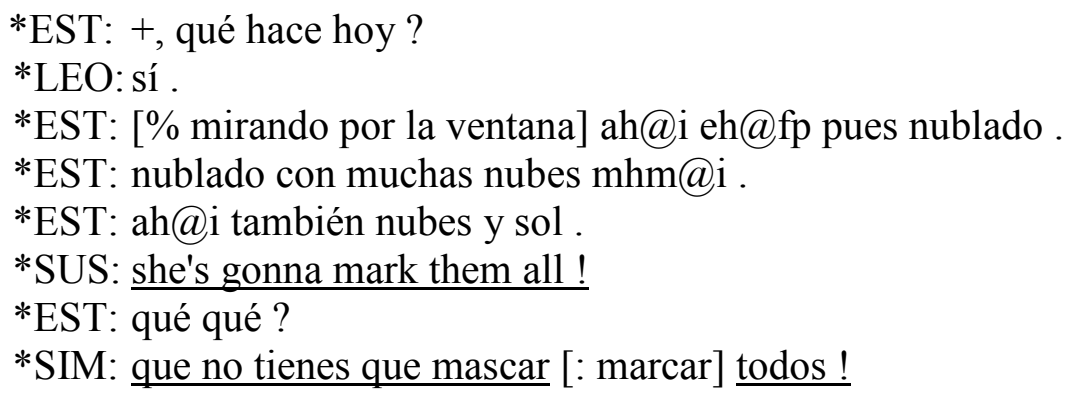

Tanto en los anteriores casos de (76b) y (76c) como en el caso de (79) nos encontramos con que los niños no han recurrido a una equivalencia formal y en la traducción han optado, en cambio, no por ofrecer una relación semántico-conceptual de absoluta equivalencia entre el TO y el TM, sino por una relación semántica entre ambos en la que parte de la información del TO no se transmite en el TM o una relación en la que la información que se transmite en el TO resulta ampliada en el TM. Lo primero es lo que sucede en (76b), donde Leo omite la primera parte de la información que Susana le pide que traduzca, y lo segundo en (76c) o en (79), donde Simon, cambiando el punto de vista expresado en el TO, indica en el TM lo que ha dicho Susana en inglés, así como la intención que esta perseguía con su enunciado: avisar de que no se puede marcar todas las casillas.

Finalmente, como parte de la competencia traductora y de los aspectos lingüísticos inherentes a la TN, podemos incluir la direccionalidad en la que esta se produce, que, en el caso de los sujetos de nuestro estudio, puede ser de dos tipos: de español a inglés, como el caso de (80a), o de inglés a español, como el caso de (80b).

(a) *LEO: [\% to Todd] eh@fp tienes un zorro ?

*TOD: what?

*LEO: $\quad$ do you have a fox ? [5;05.29] / 61B(TR)_01

(b) *EST: qué significa eso +"\%

*EST: +" but that's awful ?

*SIM: $\quad$ es terrible.

$[6 ; 03.22] / 74$ (TR)_01 
La compilación de casos clasificados desde este punto de vista puede ofrecernos resultados interesantes con respecto a los recursos lingüísticos y comunicativos que se encuentran a disposición de estos niños bilingües, de ahí que consideremos que también hay que tener en cuenta este factor tanto en la definición de TN que manejamos en el presente trabajo como en la propuesta de clasificación de las TTNN que presentaremos en el apartado 2.

Dado que en la TN no sólo es importante el aspecto lingüístico que hemos tratado hasta el momento, sino también las situaciones comunicativas en las que tiene lugar, también hemos considerado imprescindible aludir a los factores externos a la TN, es decir, a los aspectos contextuales que pueden afectar a la producción de casos de TN producidos por Simon y Leo. Desde esta perspectiva, expondremos a continuación los aspectos contextuales que, a nuestro parecer, resultan de gran importancia para realizar la presentación de las variables de análisis y de clasificación de TTNN que propondremos posteriormente.

\subsubsection{Los aspectos más externos a la TN: el contexto situacional}

En este apartado, partiremos de lo que Harris (1977: 6) entiende por TN, que es "the translation done by bilinguals in everyday circumstances without special training for $i t$ ". Siguiendo esta definición, las traducciones que realizan los sujetos bilingües simultáneos de nuestro estudio se enmarcan en un contexto familiar que forma parte de su vida diaria, en el que interactúan con los padres o los investigadores a través de actividades

y juegos, tal y como hemos descrito en el capítulo 4. Al mismo tiempo, a lo largo del período longitudinal que incluimos en el presente trabajo, los niños no han recibido una instrucción académica en la actividad de traducción, aunque sí han recibido un input metalingüístico procedente de los padres en el que se incluyen traducciones pasivas que forman parte también de ese contexto familiar y cotidiano [ver el apartado 1.3. del capítulo $3]$.

Este tipo de contexto no sólo se va a observar en los datos de carácter espontáneo, sino también en los datos de carácter experimental, en donde, al controlar la situación en la que se produce la interacción lingüística, los niños se encuentran inmersos en un contexto 
que favorece la producción de traducciones. En este tipo de situaciones los investigadores también forman parte del ambiente más inmediato de los niños al interactuar con ellos de forma periódica [ver el apartado 2 del capítulo 4].

Otro tipo de factores contextuales que, desde nuestro punto de vista, afecta a la producción de las TTNN en nuestros sujetos son los relacionados con el tipo de estímulo que reciben para traducir y con el origen del enunciado que se va a traducir. De esta manera, en primer lugar, aunque hemos visto en estudios mostrados en anteriores capítulos [ver el apartado 1.3. del capítulo 2] que existen niños bilingües que actúan de mediadores lingüísticos entre sus familiares y el entorno lingüístico en el que viven y, por tanto, tienen una función social (Hall y Sham 1998, Walischowski 2001, Orellana 2003a/b, Valdés 2003, entre otros), en nuestro caso, las TTNN que realizan los niños bilingües de nuestro estudio también responden a una función social, aunque el contexto en el que los niños las producen es mucho menos amplio, pues se reduce al ámbito familiar o del hogar bilingüe. Así, si tenemos en cuenta las situaciones que llevan a nuestros sujetos a realizar TTNN, podemos encontrarnos casos donde los niños reciben un estímulo verbal y explícito por parte de otros interlocutores para que traduzcan (en negrita), como el de (81a), aunque también podemos encontrarnos con TTNN que realizan por iniciativa propia, sin haber recibido una petición expresa de que traduzcan a la otra lengua, como el de $(81 b)^{52}$.
(a)*EST: eh@fp dile a Susana que qué es esto .
*LEO: [\% a Esther] a bear .
*SIM: $\quad[\%$ a Esther $]$ a bear
*EST: se lo podéis preguntar por favor?
*SIM: $\quad[\%$ a Susana $]$ this is a bear right ?

$[4 ; 10.19] / 56 \mathrm{~B}(\mathrm{TR}) \_01$

(b) *SIM: mirad que voy a contar una histo(ria) [\% se va hacia la cocina mientras se dirige a su madre] mummy@en I'm@en gonna@entell@en you@en a@en story@en xxx[\% sale de la habitación]. $[4 ; 04.28] / 51 \mathrm{SP} 01$

En segundo lugar, consideramos que los casos que presentamos son TTNN independientemente de la procedencia del enunciado que los niños traduzcan, de tal forma que, atendiendo al número de interlocutores que participen de la situación de traducción

\footnotetext{
52 Según la terminología de algunos autores como Harris (1977, 1980b) y Swain (1972a), entre otros [ver los apartados 2.2.1. y 2.2.5. del capítulo 2], este tipo de traducción es una traducción "espontánea". En el presente trabajo utilizamos el término "espontáneo" para diferenciar los datos según el tipo de técnica de recogida de datos espontáneos frente a datos experimentales) [ver los apartados 2.2.1. del capítulo 4].
} 
(uno, dos o varios interlocutores), podemos encontrarnos con tres casos diferentes de $\mathrm{TN}$ : el primer caso se produce cuando los niños actúan de mediadores entre dos interlocutores y, por tanto, son TTNN con una función contextual, como se refleja en el caso anterior de (81a); en el segundo caso, aunque algunos autores consideren que son traducciones redundantes desde un punto de vista funcional (Harris y Sherwood 1978; Harris 1980b), los niños traducen lo que ellos mismos han dicho (o se autotraducen) con el fin de respetar la fórmula de una persona-una lengua y, de esta manera, dirigirse a su interlocutor en la lengua en la que este se comunique con ellos, como en (81b); y el tercer caso se corresponde con aquella TN que recoge la información más importante de toda una situación o conversación en un solo enunciado (que es el que constituye el TM), como en (81c).

(81c) *SIM: [\% to Todd] I knew you had it .

*TOD: you did?

*TOD: how did you know?

*SIM: because I saw it .

*TOD: you saw it?

*TOD: are you gonna $+/$.

*SUS: S !

*SUS: [\% to Todd] careful with $\mathrm{S}$.

*RAQ: [\% to Todd] no, it's your fault .

*SUS: careful with S .

*TOD: Susana <we gotta be careful $>$ [/] we gotta be careful of him lookin $(\mathrm{g})$ at our cards .

*RAQ: [\% to Simon] it's their fault .

*LEO: [\% to Esther] ha dicho que eran unos tramposos .

$[5 ; 05.29] /$ 61B(TR)_01

Como conclusión general, tal y como hemos intentado demostrar a lo largo de este apartado, las traducciones recopiladas para el presente estudio responden a la definición y características de la TN y, como tales, las hemos presentado. De esta manera, hemos procurado dar importancia sobre todo a una serie de rasgos tanto de carácter lingüístico o formal en torno a los cuales también giran rasgos de carácter contextual propios de esta producción bilingüe, tal y como hemos venido planteando a lo largo del presente trabajo de investigación [ver el apartado 5.2. del capítulo 1 y el 1.3. del capítulo 3], y es lo que también vamos a intentar reflejar en la clasificación de variables de análisis que propondremos en el apartado 2.1. 


\subsubsection{La distinción entre la TN y la actividad nula de traducción}

Al principio del apartado 1.3.1.1. hemos distinguido cuatro tipos de producciones lingüísticas diferentes que giran en torno a lo que entendemos por TN. Si bien hemos intentado definir lo que entendemos por $\mathrm{TN}$ en los apartados anteriores, también creemos conveniente diferenciar este tipo de producción, en el que el proceso de traducción ha finalizado total (como en los casos anteriores de (75a) y (75c)) o parcialmente (como en el de (75d)), del tipo de producción en el que este proceso no llega a su fin (ni total ni parcialmente, como en (75b)) y, por tanto, resulta nulo desde el punto de vista de la actividad traductora. Así, en los primeros casos estaremos ante casos de traducción per se, mientras que en el último tipo estaremos ante una actividad de traducción que ha resultado nula, puesto que no se ha producido un CC y, por tanto, carecemos del TM correspondiente. Como consecuencia, denominaremos TN per se o simplemente TN a aquellos casos en los que exista el binomio TO/TM y actividad nula de traducción a aquellos casos en los que el proceso ha comenzado (puesto que existe un TO) pero no se ha completado ni parcial ni totalmente.

El hecho de que no podamos hablar de la presencia de este binomio en la actividad nula de traducción tiene como consecuencia no poder estudiar este tipo de producción desde el punto de vista semántico-conceptual, puesto que disponemos de un TO pero carecemos de un TM con el que establecer relaciones de este tipo. Sin embargo, esto no implica que no podamos hablar de otros factores aplicables a la TN per se que también podemos relacionar con esta actividad nula, ya que, a partir del ejemplo (82) que mostramos a continuación, podemos establecer también una serie de características tanto de carácter formal como contextual en relación a la actividad de traducción que ha resultado nula.

(82) *SIM: [\% pointing at Leo and Esther] theow [: their] turn .

*EST: qué ?

*EST: el qué ?

*SIM: it's still your turn . [5;05.29] / 61B(TR)_01

Así, en el ejemplo (82) podemos decir que en esta actividad nula de traducción, en primer lugar, la traducción debería haberse producido de inglés a español, con el fin de adaptarse a la lengua del interlocutor que le está preguntando; en segundo lugar, que, a 
pesar de la petición implícita de la investigadora para que traduzca, Simon no lo hace, pues no realiza un $\mathrm{CC}$ y, por tanto, simplemente reformula lo que acaba de decir pero en la misma lengua; y, en tercer lugar, lo que se le está solicitando es que traduzca lo que él mismo ha dicho y no que traduzca lo que ha dicho otro interlocutor, de ahí que estemos ante un caso en el que la actividad de autotraducción ha resultado nula.

Lo que pretendemos con esta división estructural entre la TN y la actividad nula de traducción es que, una vez realizado el análisis de los aspectos más destacables de la TN, procederemos a realizar el mismo tipo de análisis de la actividad nula de traducción teniendo en cuenta tanto aspectos formales (la direccionalidad en la que se debía haber realizado la traducción) como aspectos contextuales (la presencia o la ausencia de un estímulo, y la procedencia del TO que no se ha traducido) que nos ayuden a dar cuenta de esta ausencia de TN.

De esta manera, cuando en el apartado 3 del presente capítulo planteemos los resultados del análisis de nuestro estudio, nos vamos a centrar en el análisis de las TTNN per se o TTNN, partiendo de las variables propuestas y mostrando los resultados más significativos de dicho análisis. Solamente en un apartado posterior a este, es decir, en el apartado 4, procederemos a tratar la actividad nula de traducción con el fin de observar si existen semejanzas o diferencias con respecto al proceso de traducción per se y si existe algún rasgo específico que pueda explicar esta ausencia de traducción.

Antes de proceder al análisis estadístico de estos casos, presentaremos a continuación la definición y descripción de las distintas variables que nos servirán de base para la clasificación de cada uno de los casos de TN y de actividad nula de traducción encontrados en el corpus del presente trabajo de investigación. 


\section{LAS VARIABLES DE ANÁLISIS Y EL TRATAMIENTO ESTADÍSTICO}

En este apartado pretendemos presentar las variables en torno a las cuales gira el análisis de las TTNN encontradas en nuestro corpus. Para ello, en el primer apartado definiremos cada una de dichas variables y las correspondientes categorías y subcategorías que nos han servido para llevar a cabo la clasificación de las TTNN. Posteriormente, en el segundo apartado, describiremos brevemente el tipo de tratamiento estadístico que hemos aplicado a nuestros datos con el fin de facilitar la comprensión del análisis que presentamos en el apartado 3 y 4.

\subsection{Propuesta de variables de análisis}

Tal y como hemos venido planteando a lo largo de este trabajo de investigación, dos son las perspectivas básicas desde las cuales se pueden estudiar los casos de TN: la lingüística o formal y la contextual o situacional. Por este motivo, a continuación presentaremos cada una de las variables que proponemos para clasificar los casos de TN del presente estudio, teniendo en cuenta que habrá variables que se relacionen más con el texto y que, por tanto, serán inherentes al binomio TO/TM como la actividad de traducción, la direccionalidad y la tipología semántico-conceptual entre uno y otro texto, y variables que se relacionen, en cambio, con cuestiones más externas a la actividad de traducción y que vengan definidas por el contexto que rodea a dicha actividad: si es una traducción que los niños realizan por iniciativa propia o inducidos por algún interlocutor, que suele ser el padre, la madre o uno de los investigadores; la procedencia del TO, es decir, si el TO a traducir lo ha producido el mismo sujeto, otro interlocutor o procede de toda una conversación; o si la traducción se ha producido en aquellos datos de carácter espontáneo o en los de carácter experimental, en cuyo caso, se les induce a actuar constantemente de canal comunicativo entre interlocutores monolingües.

De esta manera, podremos tener en cuenta en nuestro análisis si un tipo u otro de variables (las formales o las contextuales) afecta más a la producción de casos de TN en los sujetos de nuestro estudio, o si un tipo de aspecto tiene más peso que otro a la hora de clasificar este tipo de traducciones. 
Un resumen de esta clasificación que veremos seguidamente con detalle aparece en la tabla 9, en la que mostramos las diversas categorías y subcategorías que hemos incluido en dichas variables, con sus correspondientes abreviaturas.

\begin{tabular}{|c|c|c|}
\hline VARIABLES & CATEGORÍAS & SUBCATEGORÍAS \\
\hline \multirow{4}{*}{ ACTIVIDAD } & Traducción completa (COMPL) & \\
\hline & Traducción incompleta (INCOMPL) & \\
\hline & Reformulación (REFORM) & \\
\hline & Traducción nula (NULA) & $\begin{array}{l}\text { Longitud del TO (LONG) } \\
\text { Complejidad del TO (COMPLEJ) }\end{array}$ \\
\hline \multirow[t]{2}{*}{ TIPOLOGÍA } & Forma lógica equivalente (FL EQ) & $\begin{array}{l}\text { Emparejamiento sin necesidad } \\
\text { comunicativa (EMP (no NC)) } \\
\text { Emparejamiento por necesidad } \\
\text { comunicativa (EMP (NC)) }\end{array}$ \\
\hline & Forma lógica no equivalente (FL NO EQ) & $\begin{array}{l}\text { Expansiva (EXP) } \\
\text { Económica }(\mathrm{ECO})\end{array}$ \\
\hline DIRECCIONALIDAD & $\begin{array}{l}\text { Español-inglés (ES-IN) } \\
\text { Inglés-español (IN-ES) }\end{array}$ & \\
\hline \multirow[t]{2}{*}{ ESTÍMULO } & Inducida (INDUC) & $\begin{array}{c}\text { Investigador (INV) } \\
\text { Padres (PAD) }\end{array}$ \\
\hline & Por iniciativa propia (IP) & \\
\hline \multirow{3}{*}{$\begin{array}{l}\text { PROCEDENCIA DEL } \\
\text { TO }\end{array}$} & Autotraducción (AUTOTRAD) & \\
\hline & Otros interlocutores (OTROS) & $\begin{array}{l}\text { Adulto (ADULT) } \\
\text { Hermano (HERM) }\end{array}$ \\
\hline & Situación (SITUA) & \\
\hline DATOS & $\begin{array}{c}\text { Espontáneos (ESPONT) } \\
\text { Experimentales (EXPERIM) }\end{array}$ & \\
\hline
\end{tabular}

Seguidamente, pasaremos a definir cada una de las variables y sus correspondientes categorías, utilizando ejemplos tomados de nuestro corpus de datos que ayudarán a ilustrar nuestros planteamientos. 


\subsubsection{Variable 1: el tipo de actividad traductora}

La primera variable que aparece en la tabla 9, a la que hemos denominado "actividad", se refiere a la descripción del producto final de la actividad traductora o del proceso de traducción, es decir, la traducción propiamente dicha o el texto meta (TM).

Dentro de esta primera variable hemos incluido 4 categorías diferentes a las que ya hemos hecho referencia en el apartado 1.3. y que son la traducción completa, la traducción incompleta, la traducción nula y la reformulación.

En la traducción completa (COMPL), todos o parte de los elementos lingüísticos que se incluyen en la traducción de un texto en la lengua origen (TO) se encuentran expresados en un texto en la lengua meta (TM), con lo que la actividad traductora o el proceso de traducción se considera completo, así como el cambio de códigos (CC), de modo que en este proceso se ha pasado del inglés al español o del español al inglés, dependiendo de la direccionalidad de la traducción o del CC.

En el caso del ejemplo de (83), Simon repite un enunciado en español ("está roto") dos veces y, ante la falta de atención de Melanie, realiza un CC al inglés ("break mommy break”), que conlleva una traducción completa a esta lengua.

\%com: Simon continues trying to make his toy make noise

*SIM: está@sp loto@sp [: roto].

*MEL:mi@sp schoolbus .

*SIM: está@sp loto@sp [: roto] .(...)

*SIM: b(r)eak b(r)eak .

*MEL: how about $+/$.

*SIM: b(r)eak mommy b(r)eak .

En la traducción incompleta (INCOMPL), en cambio, uno o más elementos lingüísticos que se incluyen en la traducción de un TO pertenecen a la lengua origen, de tal forma que el elemento o elementos lingüísticos en cuestión permanecen sin traducir produciéndose una alternancia de códigos $(\mathrm{AC})$ dentro de la traducción o un $\mathrm{CC}$ no completo o parcial. Esto es lo que sucede en el caso de (47a) que veíamos en el capítulo 3, repetido aquí como (84), en el que Simon, a la hora de traducir un enunciado en español 
("una pistola") al inglés para que Susana le entienda, produce un enunciado con AC ("es $u n^{\prime}{ }_{\text {español }}+$ rifle $\left._{\text {inglés }}\right)$, por lo que en el TM no se produce un CC completo ${ }^{53}$.

*SUS: what's that?

*SIM: una pistola .

*EST: pero no sabe español .

*SIM: [\% a Susana] eh@fp es@sp un@sp rifle [\% pho /'raifl/].

Otra de las categorías que hemos incluido en la variable asociada al tipo de actividad es la reformulación (REFORM), en la que el niño comienza el enunciado en una lengua pero, por diversas cuestiones (como la adaptación al interlocutor, por ejemplo), reformula seguidamente lo que acaba de decir en la otra lengua, un tipo de producción lingüística que Lindholm y Padilla (1978b) también habían considerado un tipo de traducción [ver el apartado 5.1.1. del capítulo 1]. Un ejemplo de reformulación lo podemos ver en (85), donde precisamente el símbolo CHAT [///] indicaría que Leo ha repetido lo que acaba de decir en español ("hay") reformulándolo en inglés ("there's").

$$
\text { *LEO: } \underline{\text { hay } @ s p ~[/ / /] ~ t h e r e ' s ~ a ~ p e a ~ i n ~ t o o ~ . ~}
$$

Prestando atención al ejemplo de (85), la diferencia entre la reformulación y una traducción completa o incompleta es que la reformulación se produce dentro del mismo enunciado y el TO constituye una estructura lingüística incompleta ("hay”) que se recoge desde un principio en la producción que constituye el TM en la otra lengua. De esta manera, Leo hace una pausa muy pequeña antes de terminar el enunciado (que es lo que indicaría también el símbolo [///]) para, seguidamente, cambiar de código (al inglés, en este

\footnotetext{
${ }^{53}$ Consideramos conveniente aclarar en este punto que sólo hablaremos de TN incompleta cuando el TM contenga una AC y no en casos como el de (ii), en el que el TO forma parte de un enunciado mezclado ("lo quiero hold it that") pero el TM en realidad se corresponde sólo con una parte de dicho enunciado ("lo quiero") y, por tanto, el proceso de traducción que se ha producido en este ejemplo ha resultado completo ("lo quiero" por "I want") y no incompleto.
}

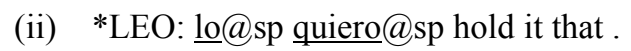

*MEL: can you say that in English ?

*LEO: I want hold it that .

*MEL: you want to hold that? 
caso) traduciendo esa estructura lingüística a dicho código ("there's") e incluyéndola en una oración completa ("there's a pea in too").

Finalmente, la traducción nula (NULA) se refiere a la ausencia de traducción, la cual puede venir provocada por diversas razones: los niños no realizan un $\mathrm{CC}$, por lo que repiten o parafrasean lo que han dicho pero utilizando la lengua origen, como en (86a), donde, ante la petición de Susana, Leo intenta traducirle a Esther al español lo que acaba de decir Susana, pero al seguir utilizando el inglés, no realiza un CC y la traducción resulta nula porque Esther sigue sin entenderle.

(86a) *SUS: yeah mark one the one you think is the weather today this?

*SUS: this ?

*SUS: put a cross here .

*SUS: [\% a Leo] or ask Esther to do it .

*SUS: explain what you've got to do but you've got to tell her what she's got to do .

*LEO: $[\%$ a Esther] you do it . [ [4;10.19] / 56B(TR)_01

En otras ocasiones la traducción nula se debe a que los niños se encuentran cansados, no les apetece o no quieren traducir, como se puede observar en (86b), cuando Simon se niega a traducirle a Esther la pregunta correspondiente porque ya llevan jugando un rato y el tener que traducir todas las preguntas le resta dinamismo y emoción al juego.

(86b) *MEL:how long [//] if you [/] if you eat something, how long does it hang around in your large intestine, down here, before you poop it out?

*MEL: two minutes?

*MEL: two hours or two days [\% asking Simon for confirmation]?

*SIM: yeah .

*MEL:[\% back to Leo] are you going to tell her ?

*SIM: no .

Sin embargo, tal y como sucede en otras situaciones, la razón por la que Simon no quiere traducir en (86b) se puede deber a que algunos de los términos que aparecen ("large intestine”, por ejemplo) pertenecen a un vocabulario específico, o incluso especializado, que pueden no conocer en la otra lengua, por lo que tendrían un problema de lexicón y no 
de traducción. De hecho, pueden existir otras razones de carácter lingüístico por las que no traduzcan algo: no recuerdan el TO (por lo que no pueden producir un TM) o no activan una palabra en una de las lenguas en ese momento, como en (86c), donde Simon no recuerda cómo se dice "month" en español a pesar de que unos minutos antes Esther había utilizado la palabra “mes” durante el juego.

(86c)*EST: el month@en ?

*RAQ: cómo se dice eso en español ?

*SIM: no sé .

$[4 ; 10.19] / 56 \mathrm{~B}(\mathrm{TR}) \_01$

[NULA]

También hemos considerado traducciones nulas aquellas en las que, en vez de producirse un trasvase lingüístico de una lengua a otra, el TM no es de carácter lingüístico sino gestual, como en (86d), en el que Leo reacciona de forma no verbal para transmitirle a Esther lo que ha dicho Melanie.

(86d) *EST: bueno y el premio para el ganador?

*LEO: pues no hay premios .

*EST: no hay premios?

*MEL: you could give her a hug and a kiss or something .

*EST: qué ?

\%com: Leo kisses Esther

$[6 ; 03.22] / 74(\mathrm{TR})[02$

[NULA]

Al mismo tiempo, los casos de (86e) se corresponden con traducciones nulas, según nuestro análisis, pues, en este caso, el niño transmite el mensaje mediante elementos deícticos.

(86e)*EST: (1) (2)the@en icing@en qué es eso ?

*LEO: (1)esto es icing@en .

*EST: pero qué es ?

*SIM: (2)se lo preguntas a M .

[6;03.22] / 74(TR)_01

[NULA] 
En este ejemplo, Leo, que probablemente tiene un vacío léxico en ese momento o carece del equivalente en español, señala en el cuento un dibujo para decirle a Esther lo que es “icing” y, aunque Esther insiste, Simon también decide evitar la traducción, por lo que, en este ejemplo, se consideraría que hay dos casos de traducción nula: (1), en el que el TM se corresponde con el uso de un deíctico, y (2), similar al caso de (86b), pues es posible que la ausencia de traducción responda a un vacío léxico.

Aunque podamos deducir en la mayoría de los casos que los niños no traducen por cuestiones extralingüísticas como el que estén cansados o simplemente no quieran hacerlo, con el fin de analizar si existe alguna razón por la cual los niños de nuestro estudio no traduzcan y que tenga que ver con aspectos de carácter lingüístico, plantearemos dos subcategorías dentro de la actividad nula de traducción en base a los siguientes criterios.

Por un lado, tendremos en cuenta la longitud del TO en la actividad nula (LONG) según el número de palabras del que conste dicho texto. De esta manera, distinguiremos tres grupos diferentes: en el primer grupo, se incluyen aquellos casos de actividad nula en la que el TO consta de entre 1 y 4 palabras, como vemos en (87a), donde el TO está formado por una palabra.

(87a)*LEO: ot(r)o@sp otro@sp .

*MEL:uh@fp what [///] how do you say otro@sp in English ?

*LEO: ot(ro) $+/ /$.

En el segundo grupo se incluirían aquellos casos en los que la actividad haya resultado nula y el TO conste de entre 7 y 14 palabras, como en (87b), y en el tercer grupo aquellos casos en los que el TO esté formado por más de 14 palabras, como en (87c), donde Leo no traduce este TO sino que le hace a Esther un comentario que, aunque está relacionado con la pregunta, no constituye una traducción.

(b) *SUS: you can mark one two three four.

*EST: qué hago ?

*SUS: $\quad$ ask her don't look at me L .

*EST: qué hago L qué hago ?

*LEO: mark this one. 
(c) *SIM: $\quad$ how long does your large intestine@sp let food hang around before you [/] you poop it out?

*SIM: two minutes, two hours, or two days ?

*LEO: [\% whispering to Esther] sabes qué pasa si comes mucho espárrago ?

*LEO: sabes qué pasa?

*MEL: how long...+

*MEL: $\quad[\%$ to Leo] ok, you tell Esther, you tell Esther .

*LEO: sabes qué pasa?

*EST: $\quad$ sabes qué pasa qué cuándo \&co ?

*LEO: $\quad$ si comes mucho espárrago ?

*EST: ah@i qué pasa?

*LEO: que, bueno tu caca se vuelve <un ve> [//] un poco verde .

*EST: $\quad$ la $[/ / /]$ mi caca se vuelve un poco verde ?

*LEO: como el espárrago . [6;03.22]/74(TR)_01

[NULA / LONG $(+\overline{1} 4)]$

Por otro lado, tendremos en cuenta como subcategoría dentro de la actividad nula de traducción la complejidad sintáctica del enunciado (COMPLEJ), para lo cual, no realizaremos una distinción sintáctica de cada una de las estructuras van a traducir, sino que polarizaremos esta clasificación en dos estructuras fundamentalmente: el sintagma (simple, constituido por ítems del lexicón entre los que no se establece relaciones de subordinación o coordinación, o complejo, constituido por una coordinación de sintagmas) y la oración (simple, constituida por un solo SV, o compleja, constituida por dos o más SSVV). Así, los casos de (87a) y (87d) se clasificarán como casos de actividad de traducción nula, en la que el TO es un sintagma, simple (SS) en el caso de (87a) y complejo (SC) en el caso de (87d).

(87d) \%com: fuera de plano Raquel y los niños escogen un juego diferente al del fragmento anterior y regresan a la mesa

*SIM: no sé cómo se llama en español pero sí sé como se llama en inglés .

*LEO: voy a recoger .

*EST: ah@i !

*RAQ:y cómo se llama en inglés ?

*SIM: Chutes@en and@en Ladders@en .

*EST:ah@i .

*RAQ:eh@i y eso [///] y cómo [/] < cómo se dicen> [//]< cómo se dice $>[/ /]$ y cómo se dicen esas dos palabras en español ?

*SIM: no sé .

[4;05.25] / 53SP_02

[NULA / COMPLEJ $(\overline{\mathrm{S} C})]$ 
En el caso de aquella actividad de traducción que resulte nula, podremos tener casos como el de (87b), en el que el TO está constituido por una oración simple (OS), o casos como el de (87c) en el que TO es una oración compleja (OC).

Una vez establecida esta subclasificación de la actividad nula de traducción, podremos aplicar también a esta variable otras que tendremos en cuenta para la TN per se (la direccionalidad, el tipo de estímulo y la procedencia del TO), excepto aquellas relacionadas con la relación semántico-conceptual entre el TO y el TM, ya que en este tipo de actividad nula disponemos del TO pero no del TM.

\subsubsection{Variable 2: la tipología semántico-conceptual}

En cuanto a la segunda variable, esta se basa en las características de las TTNN en el nivel semántico-conceptual o pragmático, donde se tendrá en cuenta la importancia de la relación que se establece entre la Forma Lógica (FL) del TO y la del TM, como propusimos en el diagrama 15 del capítulo 3. Tal y como aparece en dicho diagrama, esto no quiere decir que la FL del TO y la FL del TM sean diferentes, sino que existe, por así decirlo, una FL que se corresponde inicialmente con la del TO y de la que parte el TM resultante de proceso de traducción. De esta manera, según nuestra propuesta, sólo existe una FL en la que se refleja la relación semántico-conceptual que se establece en el binomio TO/TM y que puede ser de diferente tipo. De hecho, en nuestra clasificación hemos distinguido dos categorías dentro de esta variable referida a la tipología de las TTNN: aquella TN en la que la FL es equivalente (FL EQ) en el TO y en el TM y aquella en la que la FL de este binomio no es equivalente (FL NO EQ) ${ }^{54}$.

Por este motivo, para llevar a cabo la clasificación de TTNN recopiladas para el presente trabajo de investigación y partiendo de un enfoque descriptivo [planteado anteriormente en los apartados 3.3. y 2.2. de los capítulos 2 y 3, respectivamente], adoptaremos un concepto de equivalencia del binomio TO/TM en el que, si bien el componente formal tiene su lugar, daremos una mayor importancia al trasvase de un

\footnotetext{
54 Aunque desde una perspectiva diferente, también Lindholm y Padilla (1978b) establecieron dos tipos de traducción semejantes a las aquí planteadas: la traducción directa (el uso de palabras equivalentes en la lengua apropiada), que se correspondería con lo que en este trabajo denominamos emparejamiento por necesidad comunicativa, y la traducción conceptual (definir palabras o conceptos con otras palabras que no sean equivalentes), que es uno de los tipos de traducción que para nosotros se englobaría en lo que hemos denominado Forma Lógica no equivalente.
} 
mensaje entre el TO y el TM, es decir, al aspecto semántico-conceptual de las TTNN, con el fin de establecer diferencias entre un tipo de TN y otro.

De esta manera, y atendiendo al caso de que la FL de ese binomio TO/TM sea equivalente, proponemos, a su vez, dos subcategorías en las que, al mismo tiempo, daremos importancia el contexto lingüístico en el que se producen los casos de TN, entendiendo por este contexto aquel que viene marcado por el interlocutor (la fórmula una persona-una lengua, que ya tratamos en el apartado 1.2. del capítulo 4) y no por un contexto o situación sociolingüísticos determinados. Es decir, dentro de los casos de TN en los que se obtiene una FL equivalente, podremos encontrarnos con casos en los que se produce un emparejamiento de ítems sin una necesidad comunicativa y casos en los que el emparejamiento en la traducción responde a dicha necesidad.

El emparejamiento (EMP) de ítems del lexicón se corresponde con aquella traducción en la que se ha producido una relación de equivalencia tanto formal como semántico-conceptual entre dos unidades lingüísticas procedentes cada una de ellas de una lengua diferente y que, al mismo tiempo, no responde a una necesidad comunicativa por parte del niño. Este tipo de casos de traducción basado en el emparejamiento léxico podrían considerarse también equivalentes de traducción (EET), sobre todo si aparecen en la primera etapa del desarrollo lingüístico de los niños [ver el apartado 3.2. del capítulo 1], siempre y cuando las unidades lingüísticas que constituyen dichos equivalentes se encuentren cercanas en el discurso ya que, en caso contrario, seguirían considerándose EET pero no un tipo de TN. Es decir, el hecho de que un niño bilingüe disponga de EET en su repertorio léxico no significa que los tenga que utilizar necesariamente en situaciones de traducción, de tal forma que sólo hablaremos de TN con respecto a los EET cuando los niños los utilicen dentro de una misma conversación, como sucede en el ejemplo (88a).

(88a) *RAQ: qué de estrellitas verdad?

*SIM: mira hay $+/ /$.

*LEO: there@en [\% señalando la página de un libro] .

*LEO: aquí .

$[3 ; 09.30] / 39$ SP_01

[FL EQ / EMP (no NC)]

En este tipo de TN, Leo realiza una traducción en la que el tipo de relación semántico-conceptual que se establece entre un TO ("there”) y un TM ("aquí) es de 
carácter equivalente (FL EQ) y, al mismo tiempo, un emparejamiento de ítems que no responde a una necesidad comunicativa (EMP (no NC)) puesto que saben que Raquel es bilingüe y ha entendido lo que Leo ha dicho en inglés. Si bien en este caso la intención de Leo al traducir "there" al español puede ser la de utilizar la lengua habitual de comunicación con Raquel, otras veces esta intención no está tan clara, como en el emparejamiento léxico que se da en (88b).

(88b) *LEO: [\% slapping the water] bad bad malo@sp bad .

[3;02.12] / 31AEN_01

[FL EQ / EMP (no NC)]

Algunos autores (Harris 1980b) intentan dar un explicación de este tipo de casos planteando que es una forma de poner en práctica el léxico bilingüe y, añadimos nosotros, de mostrar una misma relación semántico-conceptual entre los términos de ambas lenguas.

La segunda subcategoría dentro de la TN con una FL equivalente en el binomio $\mathrm{TO} / \mathrm{TM}$ es aquella que se corresponde con un emparejamiento que responde a una necesidad comunicativa (NC). En este caso, el contexto lingüístico (es decir, el del interlocutor o el que plantean los interlocutores) juega un papel importante, pues este tipo de producción respondería claramente a la necesidad por parte de los niños de comunicarse con un interlocutor monolingüe, como en (89a), o con un interlocutor bilingüe, como Melanie en ejemplos que ya hemos visto anteriormente [ver el ejemplo (59a) del capítulo 3 o los de (87) en este mismo apartado] o en (89b), en los que el adulto no ha entendido u oído lo que han dicho los niños y estos utilizan la traducción para hacerse entender.

(a) *SIM: and I'm gonna eat when I'm a $+/$.

*SUS: are you gonna eat them all ?

*SIM: when I'm a grown up.

*SUS: $\quad$ okey okey when he's a grown up .

*EST: qué has dicho $\mathbf{S}$ que no lo sé no lo entiendo .

*LEO: que va a comer cuando es $[=\mathrm{sea}] \mathrm{eh} @$ fp mayor

[4;10.19]/ 56B(TR)_01

[FL EQ / EMP (NC)] 
(b) *MEL: maybe they're getting off the seesaw .

*MEL: where do you think they are ?

*LEO: there [\% pointing at the book] .

*MEL: Tigger ?

*LEO: no .

*MEL: tail ?

*LEO: aquí, E(r)nie Be(r)t aquí .

*MEL: they're there, uhhuh@i . [2;07.02] / 24BEN_02

Así, tanto en (89a) como en (89b), los dos enunciados origen mantienen una relación de equivalencia en lo que respecta a la FL con sus respectivos enunciados meta, aunque la necesidad comunicativa en (89a) responde al hecho de que Esther no entiende inglés $y$, por tanto, Leo ha de traducir al español lo que ha dicho su hermano, mientras que en (89b), responde al hecho de que Melanie no entiende lo que Leo le está diciendo ("Tigger"o "tail" en vez de "there") y este recurre al español ("aqui") para comunicarle lo mismo y que así ella le entienda, algo que es lo que finalmente sucede ("they're there, uhhuh").

Sin embargo, no consideraríamos que el caso de (89c) responda a una necesidad comunicativa, puesto que, como hemos comprobado, los niños son conscientes de que su madre es bilingüe y que, aunque le digan algo a Melanie en español, ella les va a entender. Así, en este ejemplo Leo responde a la pregunta que le plantea su madre en español ("vaca") y Simon lo traduce por el equivalente en inglés ("cow”), pero no porque su madre no haya entendido a Leo (de hecho, se ríe ante la respuesta), por lo que se trataría más bien de una traducción en la que la relación que se establece entre el TO y el TM con respecto a la FL es equivalente pero, en este caso, basada en un emparejamiento de ítems sin una necesidad comunicativa.

(89c) *MEL:[\% picking up the cow] and what is this one ?

*LEO: vaca@sp . \%com: Melanie laughs

*SIM: cow.

Siguiendo el orden establecido en la tabla 9, la segunda categoría que hemos incluido dentro de la variable "tipología" es aquella TN en la que la FL del binomio 
TO/TM no es equivalente. Así, tal y como ya hemos dicho anteriormente, esto no quiere decir que existan dos formas lógicas diferentes, una por cada texto, sino que la relación de equivalencia en el nivel de la FL entre el TO y el TM puede ser de distinto tipo: puede tratarse de una equivalencia total, como los emparejamientos de ítems que hemos visto anteriormente, o puede tratarse de una equivalencia parcial o no total, bien porque en la traducción el contenido es mayor que en el TO o bien porque dicho contenido es menor. En este sentido, se puede hablar de dos tipos de TN en la que la FL de este binomio no es equivalente.

El primer tipo de TN con una FL no equivalente es la que hemos denominado TN expansiva (EXP), que es aquella que resulta de una falta relativa de equivalencia semántico-conceptual en la que la información o el mensaje que se transmite en la lengua origen puede resultar ampliado, más detallado, más analítico, más explícito, etc. en la lengua meta por causas como una falta de contexto o de información previa, que es lo que se observa en (90a).

(90a) *RAQ: <que hemos cogido> [//] les dices que hemos cogido del montón esta y que como teníamos otra en la mano hemos hecho pareja.

*RAQ: $\quad[\%$ whispering] tienes que decírselo en inglés .

*SIM: $\quad$ we got a lion and sin(ce) we get a li:on and we don't want to u(se) and we didn't have it and we had to go fis(h) and we get a beao [: bear] .

En este ejemplo de TN expansiva, Simon traduce al inglés lo que ha dicho Raquel de tal manera que parte de la información que aparece en el TO se amplía en el TM, pues el niño informa de la situación previa ("we got a lion and since we get a lion and we don't want to use and we didn't have it") que les ha llevado a tener que coger una carta del montón ("we had to go fish") y, además, nos da de nuevo más información acerca de la carta que Raquel ha cogido ( "esta") y que forma pareja con la "otra”, indicando de qué carta están hablando concretamente ("bear”).

Este tipo de TN, en el que lo que resulta ampliado es el componente semánticoconceptual del TO, no tiene por qué implicar necesariamente una expansión léxica, como sucede en (90a), puesto que también se puede dar una mayor información con una sola 
unidad léxica en vez de con varias, que es lo que sucede precisamente en el caso de (60b) que vimos en el capítulo 3, repetido aquí como (90b), donde Simon amplía el mensaje del TO consistente en dos unidades léxicas ("no puedo") aportándole una gran carga pragmática, puesto que en el TM ("help") indica, con una sola palabra, tanto la incapacidad para encender el juguete como la necesidad de que su madre le ayude a hacerlo.

(90b)*SIM: no@sp puedo@sp no@sp puedo@sp .

*MEL:how do you say no@sp puedo@sp in English ?

*SIM: (h)elp .

$[2 ; 05 ; 27] / 24 A E N \_02$

[FL NO EQ / EXP]

El segundo tipo de TN con una FL no equivalente es la TN económica, que es aquella que resulta de una falta relativa de equivalencia semántico-conceptual en la que la información o el mensaje que se transmite en la lengua origen puede resultar más reducido, más sintético, más preciso, etc. en la lengua meta por causas como que el resto de la información puede considerarse secundaria, menos importante o implícita en el contexto. Uno de los ejemplos de TN económica que nos podemos encontrar de este tipo es el de (91a), donde Leo, en su papel de intérprete, traduce a Esther lo que Susana ha dicho que hay que hacer, pero omitiendo información ("the time; "here and here") que el niño ha considerado que es menos importante que Esther reciba.

(91a) *SUS: that's the clock but it doesn't have any xxx right?

*SUS: we're gonna mark the time here $+\ldots$

*EST: qué hay que hacer?

*SUS: + , and here .

*EST: qué hay que hacer?

*EST: qué hay que hacer chicos?

*SUS: finish it because it's not finished .

*SUS: we can't know the time with this clock right?

*SUS: now we can .

*LEO: tenemos que mascarlo $[:$ marcarlo] . [4;10.19] / 56B(TR)_01

[FL NO EQ / ECO]

Este tipo de TN supondría necesariamente una reducción del léxico con respecto al TO, ya que, al haberse omitido parte del componente semántico-conceptual del TO ("the time; "here and here”), habrá un número determinado de unidades léxicas en las que se 
expresaba dicha parte que no aparecerán en el TM. Esto mismo también sucede en aquellas TTNN económicas en las que los enunciados origen constituyen una gran parte de una conversación (es decir, es toda una situación más que un enunciado en sí mismo) y el niño decide, en este caso, transmitir el mensaje principal de esa parte del diálogo en un único enunciado meta. Este caso podemos verlo ejemplificado en (91b), donde, ante la petición insistente de Esther, Simon le traduce en un solo enunciado la conversación que está teniendo con Susana y con Leo acerca de qué tiempo hay que marcar para ese día ${ }^{55}$.

(91b) *SUS: which one do we mark today?

*SIM: eh@i .

*SUS: how is $[/ / /]$ what's the weather today?

*SUS: which one?

\%com: Simon y Leo miran por la ventana

*SIM: eh@fp sunny .

*LEO: cold .

*SUS: you sure?

*SUS: okey sunny and cold both of them?

*SUS: doesn't look very sunny right?

*SUS: looks very sunny?

*SIM:mhm@i .

*EST: de qué estáis hablando ahora ?

*SUS: it's like this right?

*SUS: you've got the sun but there's [/] there's some clouds as well right?

*SUS: I can't see clouds can you yeah?

*SUS: can we mark one then ?

*LEO: yeah .

*SIM: yeah .

*SUS: L which one ?

*SIM: [\% señalando uno de los dibujos] this one !

*SUS: okey one each .

*EST: de qué estáis hablando ahora ?

*EST: de qué estáis hablando ahora?

*EST: por favor me lo decís ?

*SIM: pues es:tamos hablando de mascarlo [: marcarlo] po(r)que $[/]$ po(r)que no sabemos si es $[/ / /]$ si sale el sol $<0$ si o si o si $>/ / /$ o si no sabemos si hay sol o si es viento.

*EST: ah@i vale vale vale .

\footnotetext{
${ }^{55}$ Tal y como ya indicamos en el apartado 5 del capítulo 4, cuando en ejemplos como el de (91b) el TO constituye toda una conversación, no subrayamos ninguna línea de producción, sino solamente el TM resultante.
} 


\subsubsection{Variable 3: la direccionalidad}

La tercera variable que proponemos en este trabajo depende de la lengua en la que está expresado el TO y en la que está expresado el TM, de tal forma que se puede hablar de una doble dirección en la actividad traductora. Es decir, las categorías que podríamos incluir en esta variable que hemos denominado "direccionalidad" serían dos: del español al inglés (ES-IN), cuando la traducción se realiza de un TO en español a un TM en inglés, como en el ejemplo (92a), o del inglés al español (IN-ES), cuando la traducción se realiza de un TO en inglés a un TM en español, como en (92b).

$$
\begin{aligned}
& \text { (a) *MEL: what's that ? } \\
& \text { *SIM: pavo@sp. } \\
& \text { *MEL: what's that honey? } \\
& \text { *LEO: } \quad \text { tu(r)key . [2;02.21] / 19EN_02 } \\
& \text { (b) *LEO: taklit [: chocolate] . } \\
& \text { *MEL: where ? } \\
& \text { *LEO: taklit [: chocolate] . } \\
& \text { *MEL: } \quad \text { where's that ? (...) } \\
& \text { *SIM: chocolate@sp . } \\
& \text { *MEL: chocolate! }
\end{aligned}
$$$$
[\mathrm{ES}-\overline{\mathrm{IN}}]
$$$$
\text { [2;08.04]/24HEN_02 }
$$

$[\mathrm{IN}-\overline{\mathrm{ES}}]$

\subsubsection{Variable 4: el tipo de estímulo}

$\mathrm{Si}$, hasta ahora, lo que pretendemos con estas variables y estas categorías es analizar las características de las TTNN relacionadas con el nivel semántico-conceptual o semántico-pragmático (actividad, tipología y direccionalidad), consideramos que también hay que tener en cuenta la naturaleza de la reacción de los sujetos ante un contexto lingüístico determinado, de ahí que hayamos incluido como cuarta variable en el análisis de las TTNN de nuestro estudio la relacionada con el tipo de estímulo que recibe el niño a la hora de producir una traducción.

Como ya hemos propuesto anteriormente en este trabajo [ver el apartado 1.2. del capítulo 4], el contexto lingüístico en el que se desenvuelven los sujetos viene marcado por la lengua que utiliza el interlocutor o los interlocutores que interactúan con ellos. En este sentido, la traducción que realizan los niños puede ser inducida (INDUC) bien por los padres (PAD) o bien por los investigadores (INV), de tal forma que, si cualquiera de estos 
interlocutores les piden expresamente a los sujetos que traduzcan o digan algo en la otra lengua ("how do you say X in English?"; "how does mummy say...?”; "ask Raquel”; “¿cómo se dice en español?”; por ejemplo), estaremos ante una TN de carácter inducido, como es el caso de (93a) y $(93 b)^{56}$.

(a) *MEL: look, what's that?

*LEO: $\quad$ (ov)eja@sp .

*MEL: uhhuh@i how do you say that in English do you know?

*MEL: how do you say oveja@sp in English ?

*MEL: how does mommy say oveja@sp ?

*MEL: do you know?

*LEO: $\quad$ s(h)eep .

(b) *SUS: $\underline{\text { one }}+\ldots$

*SIM: $\quad<$ two three four five six $>[>]$.

*LEO: $\quad<$ two three four five $\operatorname{six}>[<]$.

*SUS: $\quad$ six one is a bit smaller but six .

*EST: $\quad<y$ en $>$ [/] y en español ?

*EST: qué es eso en español ?

*SIM: $\quad$ uno dos tres cuatro sinco [: cinco] seis !

$[4 ; 10.19] / 56 \mathrm{~B}(\mathrm{TR})[01$

[INDUC-INV]

El estímulo que provoca que Leo traduzca en (93a) procede de la madre, Melanie, quien le pregunta expresamente cómo se dice "oveja" en inglés ("how do you say that in English"; "how does momy say...", etc.), mientras que en (93b) el estímulo que recibe Simon para traducir procede de uno de los investigadores, Esther, que también le comunica expresamente ( “y ¿en español?; ¿qué es eso en español?”) el deseo de que le traduzca lo que él y su hermano han dicho ${ }^{57}$.

En cuanto al segundo tipo de TN que podemos encontrar en nuestros datos según el tipo de estímulo que provoque la producción de la traducción, hemos incluido la que los niños realizan por iniciativa propia (IP), que es aquella que parte del propio sujeto, sin que ningún hablante le induzca ni directa ni expresamente a traducir o a decir algo en la otra lengua (a diferencia de lo que ocurre en la TN inducida). Un ejemplo de este tipo de TN lo

\footnotetext{
${ }^{56}$ Puesto que solamente en uno de los casos encontrados de TN el inductor es Safta, la abuela de los niños, hemos incluido a este familiar como dentro de la categoría (PAD).

${ }^{57}$ A pesar de que en el apartado 1.2. [párrafo 4] del presente capítulo sobre los criterios de exclusión de los casos de TN de este estudio consideramos que no incluíamos aquellos casos en los que hubiese una secuencia aprendida o memorizada en una u otra lengua, en este caso lo hemos interpretado como un caso de traducción porque el niño no se limita simplemente a decir una secuencia de números en español sino a traducir exactamente los números que él (con la ayuda de Susana) acaba de recitar.
} 
tenemos en (93c), donde los niños están con Melanie e Ivo y lo que le dice Simon a su madre en inglés se lo repite a su padre en español por decisión propia, sin que nadie le haya inducido expresamente a ello.

(93c) *SIM: mommy I wan(t) my lollipop I want to suck my lollipop .

*MEL: after breakfast

*LEO: my lollipo...+

\%com: the boys go off camera with their father

*IVO: nunca desayunan bien y los sábados no desayunan xxx porque desayunan muy tarde. (...)

*MEL: after breakfast you can eat it .

*IVO: qué memoria tienes !

*SIM: yo quiero mi chupa chuns [: chups] . [3;09.26] / 38EEN 01

Es importante precisar de nuevo dentro de este tipo de TN que, si bien el hecho de que el niño a veces interprete la reacción verbal o gestual del adulto ("what?”, "mhm?", "¿qué?”, etc.) como un estímulo indirecto que le induce a traducir (en cuyo caso se podría considerar una TN inducida), según nuestro punto de vista, este tipo de reacciones puede responder a otro tipo de motivos como, por ejemplo, que el interlocutor en ese momento no le ha oído bien o no ha entendido lo que ha dicho (como sucedía con (89b), (92a) y (92b), por ejemplo), sin que sepamos a ciencia cierta si la intención de dicho interlocutor es que el niño traduzca, cambie de código o simplemente que le repita lo que le acaba de decir. Por esta razón, aunque en estos casos concretos la TN que realizan los niños pudiera parecer menos espontánea (lo que les dice el interlocutor puede actuar como un estímulo implícito para que traduzcan), nosotros consideramos que, al no tratarse de un tipo de estímulo verbal por el que clara y expresamente se les induzca a traducir, son casos en los que los niños traducen por inicia propia, como sucede en (93d).

(93d)*SIM: quiero@sp atrás@sp the(re). *MEL: what sweetie?

*SIM: back the(re) .

En este ejemplo, la reacción verbal de Melanie ("what sweetie?”) puede haber sido estímulo suficiente para que Simon tradujera la parte de español de su enunciado ("quiero atrás") por la correspondiente en inglés ( "back”), pero este tipo de casos los consideramos TTNN que el niño realiza por iniciativa propia y no tanto inducidos, puesto que en la 
producción verbal de Melanie no se indica ni directa ni expresamente que eso sea lo que se demanda del niño ${ }^{58}$.

Sin embargo, cuando nos centramos exclusivamente en los casos pertenecientes a las pruebas experimentales, nos hemos topado con la dificultad de casos que podrían estar sujetos a más de una interpretación pues, en ese tipo de datos, aunque los interlocutores adultos (investigadores, la mayor parte de las veces) no dirijan expresamente a los sujetos y de forma constante estímulos verbales del tipo "dime lo que ha dicho", "no lo he entendido", “Tell Esther...”, etc., la situación que plantean desde el principio (los niños como único vínculo de comunicación de los adultos) hace pensar que todos los ejemplos de TN que aparezcan en los datos experimentales serán de carácter inducido. Pero esto no siempre es así, ya que, en el caso de (93e), Esther no le ha dicho a Leo expresamente que le traduzca al español lo que está diciendo el resto de interlocutores, ni siquiera ha intervenido o ha hecho un gesto indicándoselo $\mathrm{y}$, sin embargo, el niño se lo traduce igualmente, de ahí que consideremos que este tipo de casos son TTNN realizadas por iniciativa propia a pesar del contexto experimental en el que se encuentran.

(93e) *SIM: [\% to Todd] I knew you had it .

*TOD: you did?

*TOD: how did you know?

*SIM: because I saw it .

*TOD: you saw it?

*TOD: are you gonna $+/$.

*SUS: S !

*SUS: [\% to Todd] careful with S .

*RAQ: [\% to Todd] no, it's your fault .

*SUS: careful with S.

*TOD: Susana < we gotta be careful $>$ [/] we gotta be careful of him lookin $(\mathrm{g})$ at our cards .

*RAQ:[\% to Simon] it's their fault .

*LEO: [\% to Esther] ha dicho que eran unos tramposos .

$[5 ; 05.29] / 61 \mathrm{~B}(\mathrm{TR})[01$

[IP]

Esto vendría a explicar, por tanto, que lo que nos interesa para el análisis es refinar la distinción entre esta variable asociada al tipo de estímulo (inducida / por iniciativa

\footnotetext{
${ }^{58}$ Lindholm y Padilla (1978b), a diferencia de nuestro planteamiento, consideran que este tipo de casos serían también traducciones inducidas en las que el niño responde a una pregunta sutil por parte del investigador en la que no se le pide directamente que traduzca. Sin embargo, en el caso de dicho estudio todos los datos proceden de interacciones de los niños con investigadores, quienes pretenden provocar (aunque sea indirectamente) que los niños traduzcan, y no situaciones cotidianas en la vida de los niños.
} 
propia) y la relacionada con el tipo de datos (espontáneos / experimentales) que veremos más adelante, y observar el contexto específico de cada caso concreto y no el de una metodología a priori como puede ser "sesión SP" o "sesión EN", que veíamos en el capítulo anterior dedicado a la presentación de los datos.

\subsubsection{Variable 5: la procedencia del TO}

Dentro de este apartado, procederemos a explicar lo relativo a la procedencia del texto o enunciado origen del que se parte a la hora de realizar una traducción, es decir, para analizar las TTNN recopiladas para este estudio consideramos que también es importante tener en cuenta quién es el responsable del TO y relacionarlo con otro tipo de variables.

Para ello, proponemos que dentro de esta variable han de incluirse tres categorías diferentes: cuando el enunciado procede del propio sujeto que traduce, cuando el sujeto traduce lo que ha dicho otro interlocutor y cuando el sujeto se limita a traducir en un solo enunciado lo que se recoge en una conversación en la que participa más de un interlocutor.

En cuanto a la primera categoría, la autotraducción (AUTOTRAD), es aquella en la que el sujeto traduce un enunciado que él mismo acaba de emitir o que está cerca en el discurso, como sucede en (94a), donde Simon le traduce a Raquel lo que ha dicho en inglés previamente en el discurso.

(94a) *SIM: look how many I have it (i)s one two an(d) tree [: three] . $\%$ com: Melanie makes an incredulous face and shows three fingers *SIM: [\% showing three fingers] I meant these ones .

*MEL:you meant that many?

*SIM: [\% to Raquel] mira lo que me queda . [ [3;09.30] / 39EN_01

[AUTOTRAD]

En este tipo de casos, señalaremos que, aunque un adulto repita lo que el niño ha dicho, se considerará una autotraducción y no una traducción de lo que han dicho otros interlocutores, puesto que el enunciado parte originalmente y en un principio del niño, como sucede en (94b), donde el enunciado o texto origen "yo si" lo dice originalmente Leo, aunque luego la madre inste explícitamente a traducir al inglés lo que acaba de decir. 
(94b) *MEL: $\quad$ who wants milk ?

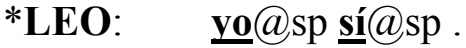

*MEL: how do you say yo@sp sí@sp in English ?

*LEO: $\quad$ I \# do .

Los sujetos también pueden traducir un TO que proceda de otros interlocutores (OTROS), bien de un adulto (ADULT), como un investigador o uno de los progenitores, como Todd en (94c), o bien del hermano (HERM), como en (94d), donde Simon traduce al inglés lo que ha dicho Leo, quien desconoce el equivalente en inglés.

(c)*TOD: uh@i do you have a bear ?

*LEO: hmm@fp yeah.

*EST: ok espera espera.

*LEO: [\% squealing] eeee@i !

*EST: pero qué ha dicho qué ha dicho que no me he enterado que no sé jugar .

*EST: qué ha dicho?

*LEO: ha dicho que tiene unos ositos . [5;05.29] / 61B(TR)_01

[OTROS / ADULT]

(d) *LEO: [\% pointing to the illustration] these ones named [= are named] corjos@sp [: cuernos] .

*MEL: yes you know what they're called?

*LEO: no .

*SIM: horns .

Finalmente, y como ya hemos comentado en (91b), en casos en los que existen varios enunciados (tanto del propio sujeto como de otros interlocutores) que componen el TO, los niños pueden optar por traducir en un solo enunciado toda la situación en la que se incluyen dichos enunciados, que es lo que sucede en casos como el de (91b), visto anteriormente, o en (94e), donde Simon quiere poner la cinta dentro de la cámara ("I have to put something in the camera") pero Melanie piensa que ya está dentro ("I think it's in there though"), por lo que, con el fin de asegurarse, Simon no le traduce lo que ha dicho su madre o él mismo, sino que le comunica a Raquel toda la situación planteada en un único TM donde resume toda la información que necesita saber ( ¿está la cinta adentro?”). 
(94e) *SIM: I have to put something in the camera .

*MEL: in the camera .

*MEL: the tape ?

*SIM: umhm@i .

*SIM: de [: the] tape .

*LEO: [\% pronouncing it for Melanie] no the tape the tape .

*MEL:I think it's in there though .

*SIM: no .

*MEL:ask Raquel .

*SIM: what is a tape in Spanish ?

*MEL: what?

*MEL:cinta@sp .

*SIM: [\% to Raquel off camera] has ponida [= puesto] [///] está la cinta adentro?

\subsubsection{Variable 6: el tipo de datos}

Para finalizar con la definición y descripción de las variables con las que vamos a trabajar, en la variable relativa al tipo de datos, vamos a distinguir entre las dos técnicas de recogida de datos con las que hemos trabajado en el presente estudio: los datos espontáneos y los datos experimentales, siendo los primeros los que tienen como contexto una situación cotidiana y habitual para los sujetos y los segundos aquellos que responden a un contexto preparado para que los niños actúen de intérpretes entre dos interlocutores monolingües.

Concretamente, en los datos espontáneos (ESPONT), como ya vimos en el apartado 2.1. del capítulo 4, se recogen situaciones de la vida familiar en el hogar de los sujetos en las que aparecen jugando, leyendo cuentos, etc., que nos pueden permitir saber en qué medida la labor de traducción forma parte de un comportamiento lingüístico habitual y cotidiano, como podemos observar en (95a).

(95a) *MEL: let's see maybe we could look at these pictures and we could $+/$. *SIM: cai@sp [: cae] .

*MEL:they're gone?

*MEL:S S how does mommy say cae@sp?

*LEO: fall. 
En este ejemplo los niños están viendo un cuento con Melanie y, como Simon ha utilizado una palabra en español, la madre le insta a que lo diga en inglés traduciéndolo, siendo esto un estímulo que actúa de inductor a Leo, que es el que responde a la petición.

Al mismo tiempo, las TTNN recopiladas para este estudio también se han obtenido a través de pruebas experimentales, que se corresponden concretamente con tres sesiones: 56B(TR), 61B(TR) y 74B(TR). Todas ellas se incluyen en lo que hemos denominado datos experimentales (EXPERIM) y en el apartado 2.2. del capítulo 4 aparecen descritas detalladamente. En este tipo de datos se recogen aquellas TTNN en las que se les insta a los sujetos a actuar de intérpretes entre dos investigadores monolingües, como en (95b), o como traductores para Esther, la investigadora monolingüe de español, en la tercera prueba, como se observa en (95c).

(b) *SIM: $(1)+$, tienes que rebis $[:$ recibir] \# $\underline{\text { sinco }}[$ : cinco] para ganar uno *RAQ: si . nuevo +1 .

*SIM: $(2)+$, pon estas otras aquí y di que si parejas .(...)

*RAQ: vale vamos a explicárselo a Susana $<\mathrm{y}$ a $>$ [/] y a Todd ?

*TOD: what do I have to do ?

*RAQ: vale \# S ?

*RAQ: ok so \# we have five cards yeah ?

*SIM: (1)you [/] you have to deal five howds [//] cowds [: cards] to everybody (2)and den [: then] you have to put other ones there $+\ldots$

(c) *SIM: +" see how many times you can blink in twenty seconds .(...)

*EST: qué tengo que hacer?

*SIM: what (i)s blink?

*MEL: parpadear o pestañear, pestañear .

*SIM: <a ver> [/] a ver qué eh@i + i...

*SIM: cuántas veces puedes pestañear en veinte segundos? 


\subsubsection{Un ejemplo de codificación y clasificación a partir de las variables de análisis}

Una vez descritas las variables a partir de las cuales vamos a plantear nuestro análisis, a continuación, mostraremos un caso de TN en (96) (utilizado en el capítulo 3 como (59a)) procedente de nuestro corpus de datos que nos servirá para ejemplificar los pasos que hemos seguido para la clasificación y codificación (indicadas en la tabla 10), así como su posterior introducción en nuestra base de datos.

(96) *MEL:you wanna make something with the blocks ?

*SIM: sí@sp .

*MEL: what would you like to make?

*SIM: douse [: house] .

*MEL: a house?

*SIM: douse [: house] !

*MEL: two ?

*SIM: \# casa@sp !

*MEL: a house?

*SIM: sí@sp .

[COMPL / IN-ES / FL EQ / EMP (NC) / IP / AUTOTRAD / ESPONT]

\begin{tabular}{|l|l|}
\hline \multicolumn{1}{|c|}{ TABLA 10. EJEMPLO DE CLASIFICACIÓN DE UN CASO TN EN FUNCIÓN DE LAS VARIABLES PROPUESTAS } \\
\hline \multicolumn{1}{|c|}{ VARIABLES } & \multicolumn{1}{c|}{ CLASIFICACIÓN (ABREVIATURA) } \\
\hline actividad traductora & Completa (COMPL) \\
tipología semántico-conceptual & $\begin{array}{l}\text { forma lógica equivalente (FL EQ) } \\
\text { (necesidad comunicativa) (EMP (NC)) }\end{array}$ \\
direccionalidad & inglés-español (IN-ES) \\
presencia/ausencia de estímulo & por iniciativa propia (IP) \\
procedencia del TO & Autotraducción (AUTOTRAD) \\
datos & espontáneos (ESPONT)
\end{tabular}

En el proceso de clasificación del ejemplo (96), también tenemos en cuenta, tal y como expusimos en el apartado 5 del capítulo 4, la información relativa al sujeto que produce la traducción, la edad en la que se produce el caso ( 2 años, 1 mes y 28 días), así como los datos relativos al archivo donde se incluye el caso (sesión 17, en contexto inglés, fragmento 1). 
Una vez clasificado el ejemplo, el paso siguiente es incluir, por un lado, la información relativa a la sesión en la que se localiza el caso de $\mathrm{TN}$, el sujeto que lo ha producido, así como la edad y el valor de la LMEp en dicha sesión. A continuación, se incluye la información correspondiente a cada variable que hemos expuesto anteriormente, elaborando así nuestra base de datos, tal y como se indica en la tabla 11 para el caso concreto de (96).

TABLA 11. EJEMPLO DE ELABORACIÓN DE NUESTRA BASE DE DATOS EN FUNCIÓN DE LAS VARIABLES
PROPUESTAS
\begin{tabular}{|c|c|c|c||c|c|c|c|c|c|}
\hline Sesión & Sujeto & Edad & $\begin{array}{c}\text { LME } \\
\mathbf{p}\end{array}$ & Actividad & $\begin{array}{c}\text { Tipología } \\
\text { (subtipología) }\end{array}$ & Direccionalidad & Estímulo & $\begin{array}{c}\text { Procedencia } \\
\text { del TO }\end{array}$ & Datos \\
\hline 17 EN_01 & SIM & $2 ; 01.28$ & 1,375 & COMPL & $\begin{array}{c}\text { FL EQ } \\
\text { EMP (NC) }\end{array}$ & IN-ES & IP & AUTOTRAD & ESPONT \\
\hline & & & & & & & & & \\
\hline
\end{tabular}

Así pues, y fijándonos en (96), hemos clasificado este caso de TN "house/casa" como una traducción completa, puesto que traduce todo el enunciado ("house" por “casa”), del inglés al español; se correspondería con una TN en la que la FL del binomio TO/TM es equivalente y respondería a una necesidad comunicativa por parte del niño para hacerse entender por Melanie, su madre. Por tanto, se trataría de una TN que Simon realiza por iniciativa propia, puesto que Melanie no le incita expresamente a traducir al español. Finalmente, en cuanto a la procedencia del enunciado origen que traduce Simon, se trataría de una autotraducción (aunque Melanie lo repita una línea más adelante) pues traduce algo que él mismo ha dicho anteriormente en el discurso, y es un caso que se incluye en los datos espontáneos.

Como resumen del apartado 2.1., hemos tratado de exponer con la mayor claridad y objetividad posible las pautas que hemos seguido en la clasificación de los datos de TN de los que disponemos para obtener los resultados que nos permitan realizar un análisis adecuado.

Para dicho análisis, tal y como aparece en la tabla 12 y como veremos en el apartado 3, hemos localizado en nuestro corpus de datos un total de 172 casos de TN o TN per se (completa, incompleta y reformulación), sin incluir los 20 casos que hemos descartado por las razones ya expuestas en el apartado 1.2. 
TABLA 12. LA PRODUCCIÓN DE LA ACTIVIDAD DE TRADUCCIÓN DE SIMON Y LEO

\begin{tabular}{|l|c|c|c|c|c|}
\hline & Completa & Incompleta & Reformulación & Nula & Total general \\
\hline Total por tipo de actividad & 154 & 9 & 9 & 55 & 227 \\
\hline
\end{tabular}

Aparte de estos casos, también hemos localizado 55 casos en los que la actividad de traducción ha resultado nula, los cuales, al igual que los 172 de $\mathrm{TN}$, han sido clasificados uno a uno siguiendo esta misma dinámica que hemos indicado arriba y tal y como aparece en el nuestro corpus de datos en el apéndice VI, por lo que contamos con un volumen de casos que nos permitirá plantear un análisis riguroso de todos los casos.

Una vez realizada la clasificación de todos estos tipos de producciones, describiremos en el apartado siguiente el tipo de tratamiento estadístico del que hemos partido para explotar estos datos, lo cual nos permitirá observar si existen diferencias significativas en los resultados obtenidos y mostrarlos en los apartados posteriores.

\subsection{El tratamiento estadístico de los datos: el contraste de porcentajes}

De las seis variables que hemos propuesto en el apartado anterior, nuestro análisis estadístico se va a centrar en las tres variables principales que son las relacionadas con el carácter lingüístico de la TN (el tipo de actividad, la direccionalidad y la relación semántico-conceptual del binomio TO/TM) y, al mismo tiempo, tendremos en cuenta dos variables de carácter contextual (la presencia/ausencia de estímulo y la procedencia del TO) para poder explicar determinados resultados obtenidos a partir de esas variables lingüísticas. En el caso de la variable 6, relacionada con el tipo de datos (espontáneos frente a experimentales), aludiremos a ella a lo largo del análisis para interpretar algunos de dichos resultados.

Para poder realizar el análisis que pretendemos llevar a cabo, hemos considerado oportuno realizar una breve descripción del tipo de tratamiento estadístico que hemos utilizado.

Con el fin de comprobar la representatividad de la muestra de datos que aquí presentamos, en primer lugar, hemos elaborado una serie de tablas para presentar los resultados de la aplicación de herramientas estadísticas que nos proporciona el programa 292 
informático EXCEL en el que hemos creado nuestra base de datos. El uso de estas herramientas nos permite aportar los porcentajes de frecuencia de las variables concretas (con sus respectivas categorías y subcategorías) que pretendemos estudiar.

En segundo lugar, una vez realizados estos análisis descriptivos de esas variables principales y dado que los sujetos de nuestro estudio son dos niños bilingües, consideramos necesario aplicar una prueba de decisión estadística que nos permita no sólo conocer si existen diferencias significativas entre Simon y Leo en lo que respecta a las categorías de las variables principales en las que nos vamos a centrar sino también contrastar dos variables en un solo niño. Para ello, puesto que lo que manejamos en nuestro análisis son caracteres cualitativos medidos a escala nominal (es decir, cada uno de los casos de TN se define fundamentalmente a partir de una serie de variables nominales, no numéricas), en nuestro estudio aplicaremos lo que se denomina un contraste de proporciones o contraste de porcentajes, a través del cual podremos establecer una comparación de dos proporciones en dos poblaciones (en este caso, en dos individuos o sujetos).

Este tipo de tratamiento estadístico nos permite comprobar, en el caso de que crucemos las variables en los dos sujetos de nuestro estudio o a lo largo de las distintas etapas en las que está dividido nuestro corpus de datos, si las diferencias de proporciones entre las variables relacionadas son estadísticamente significativas y no el producto de variaciones en el muestreo debidas al azar. De esta manera, en cada relación o contraste de proporciones se formulan dos hipótesis: la hipótesis nula, que se refiere a la igualdad de proporciones de las variables contrastadas en los dos sujetos (es decir, que las proporciones de uno y otro sujeto son iguales) y la hipótesis alternativa, que se refiere a la existencia de diferencias significativas entre los dos sujetos en lo que respecta a la variable contrastada (es decir, si la proporción de uno de los sujetos es mayor que la del otro, entonces se constata que dicha proporción es significativamente mayor que la proporción del otro sujeto).

Para poder aceptar o rechazar una u otra hipótesis, se calcula en cada relación o contraste de proporciones un valor determinado que nos permita obtener el nivel de significación. En el caso del presente estudio, se ha considerado que la significación estadística o el llamado p-valor se sitúa en 0,05. Es decir, si en un determinado contraste de proporciones el $p$-valor que obtenemos es igual o inferior a $0,05(\mathrm{p} \leq 0,05)$, entonces la hipótesis nula se rechaza con un riesgo del $0,05 \mathrm{y}$, por tanto, la diferencia encontrada entre las dos proporciones es significativa. 
A continuación, procederemos a realizar un análisis más detallado de las variables de carácter lingüístico asociadas a las características intrínsecas de la TN (el tipo de actividad, la tipología semántico-conceptual y la direccionalidad), teniendo en cuenta la influencia que en los resultados de dicho análisis pueden tener las variables relacionadas con aspectos más externos a la TN (el origen del enunciado y su emisor, la presencia o ausencia de un estímulo para que traduzcan y de quién parte dicho estímulo, así como el tipo de datos que manejamos en este estudio). Con este fin, nos centraremos, en un primer momento, en el análisis de resultados de frecuencia y ocurrencia de dichas variables, para, a partir de aquí, realizar un cruce de variables en cada uno de los niños por separado y desde una perspectiva longitudinal (por etapas).

\section{EL ANÁLISIS DEL CORPUS DE DATOS: LAS CARACTERÍSTICAS INTRÍNSECAS DE LAS TTNN DE SIMON Y LEO Y LA INFLUENCIA DE LOS FACTORES CONTEXTUALES}

A lo largo de este apartado el eje del análisis residirá en aquellas variables que hemos considerado más formales o lingüísticas e intrínsecas a la TN y que son las siguientes: el tipo de actividad, la tipología semántico-conceptual y la direccionalidad. Dado que, al mismo tiempo, la TN es un fenómeno lingüístico que se enmarca dentro de una situación comunicativa bilingüe o de contacto de lenguas, analizaremos las demás variables, de carácter contextual o más externo al proceso de traducción, en función de su papel con respecto a las otras tres variables principales. Concretamente, analizaremos las variables asociadas a la presencia o la ausencia de un estímulo explícito para que los niños traduzcan, así como a la procedencia del TO, y su influencia en la producción de las TTNN de nuestro estudio. También aludiremos a la distinción de la tipología de los datos, si son espontáneos o experimentales, cuando lo consideremos necesario para la interpretación de determinados resultados.

Una vez presentadas las variables principales, plantearemos en cada una de ellas tres cuestiones de análisis: a) el número total de casos de TTNN que realizan ambos sujetos según la variable correspondiente; b) las preferencias de uno y otro niño y la significación de las diferencias entre ambos, y c) el estudio del desarrollo del 
comportamiento traductor en nuestros sujetos y en función de la variable concreta de estudio a lo largo de las etapas planteadas previamente en el capítulo 4.

De esta manera, este apartado 3 se divide en tres partes, uno por cada variable principal, y en cada uno de ellos mostraremos, en primer lugar, los resultados obtenidos a partir de un análisis de frecuencias. En segundo lugar, a través de un contraste de proporciones o porcentajes, estudiaremos la actuación de cada uno de nuestros sujetos en conjunto (observando los patrones comunes del comportamiento traductor de los dos niños) e individualmente (observando la existencia de diferencias significativas entre Simon y Leo, en el caso de que existiesen), así como también la posible influencia de determinados factores contextuales en los resultados obtenidos. Seguidamente, analizaremos estos resultados correspondientes a cada variable desde un punto de vista longitudinal, es decir, los resultados del comportamiento traductor de estos dos niños bilingües a lo largo de las tres etapas que hemos planteado en el presente estudio.

\subsection{Variable 1: el tipo de actividad}

Partiendo de las variables de análisis propuestas en el presente trabajo, a continuación nos vamos a centrar en la primera de ellas, es decir, en los casos de TN como actividad o proceso de traducción. Así, atendiendo a esta primera variable, podemos encontrar tres tipos diferentes de TN. El primer tipo, la TN completa, como la del ejemplo (97a), se corresponde con aquella en la que el enunciado origen en inglés ("you did do it well") es traducido por el enunciado meta en español ("que sí lo has hecho bien ha dicho”) a través de un cambio de códigos (CC) completo.

(97a) *SIM: [\% a Esther] sí@sp you did do it well.

*EST: perdona?

*SIM: que sí lo has hecho bien ha dicho ! [4;10.19] / 56B(TR) 01

[COMPL]

El segundo tipo de actividad es la que hemos denominado TN incompleta, en la que se produce un CC parcial, como en el caso de (97b), en el que Simon traduce al español una parte del enunciado origen ("little mice"), dejando sin traducir el resto de elementos léxicos que conforman dicho enunciado y produciendo, por tanto, un TM en el que se incluye una $\mathrm{AC}$ intraoracional. 
(97b) *MEL:ok well I'll do it in English and then you say it in Spanish ok ?

*MEL: three little mice sat $+/ .(\ldots)$

*MEL:ok tres@sp that's the first word.

*SIM: tres@sp \&raton [//] ratoncitos@sp+... (...)

*SIM: [\% mumbling] tres@sp ratoncitos@sp sat down to spin .

Finalmente, el tercer tipo de actividad traductora es la reformulación, en la que el niño repite en una lengua lo que acaba de decir en la otra, como sucede en (97c), donde Leo reformula en inglés lo que acaba de decir en español para que sus interlocutores anglófonos le entiendan.

(97c) *LEO: nosotros vamos a [///] we are going to win you are going to lose.

$[5 ; 05.29] /$ 61B(TR)_01

[REFORM]

Resumida de esta forma la terminología, presentaremos a continuación en diversos apartados las principales cuestiones de análisis que hemos planteado en la introducción del apartado 3 .

\subsubsection{La producción de casos de TN según la variable 1}

Con el fin de analizar la cuestión relativa a la ocurrencia de casos de TN según el tipo de actividad traductora, mostramos a continuación la tabla 13, en la que figura un recuento total de los casos de $\mathrm{TN}$ existentes en nuestro corpus atendiendo a dicha tipología.

\begin{tabular}{|c|c|}
\hline \multicolumn{2}{|c|}{ TABLA 13. LA PRODUCCIÓN TOTAL DE TTNN SEGÚN LA VARIABLE 1 } \\
\hline Completa & $154(89,6 \%)$ \\
Incompleta & $9(5,2 \%)$ \\
Reformulación & $9(5,2 \%)$ \\
\hline Total general & $172(100 \%)$ \\
\hline
\end{tabular}


Lo que se observa en la tabla 13 es que, de los 172 casos totales de TTNN que han realizado nuestros sujetos a lo largo del período observado, casi el $90 \%$ de los casos se corresponden con TTNN completas, siendo el porcentaje de producción de los otros dos tipos de traducción bastante inferior (5,2\% en cada uno de los casos). El contraste de porcentajes entre las traducciones completas y las incompletas nos da como resultado un pvalor equivalente a 0 , el mismo resultado que si realizamos el contraste entre las traducciones completas y las reformulaciones. Es decir, la diferencia de porcentajes entre las traducciones completas y los otros dos tipos de traducciones es altamente significativa debido a que los p-valores resultantes del contraste de dichos porcentajes son inferiores a 0,05 .

De esta forma, los casos de traducción que realizan los niños más frecuentemente son los que hemos denominado TN completa, la cual puede corresponderse tanto con la traducción de una sola unidad léxica, como en (98a), como con la traducción de una o varias estructuras lingüísticas más complejas, como en (98b).

(a) *MEL: where ?

*MEL: where are you going?

*SIM: down .

*MEL: down ?

*SIM: $\quad$ ahí@sp .

(b) *MEL: Raquel watch out! [COMPL]

*MEL: (1)there's a really fierce dragon behind you .

*MEL: (2)it's gonna chop your head off.

\%com: everyone giggles (...)

*RAQ: os ha contado un chiste mamá ?

*SIM: [\% laughing] (1)mamá te ha dicho que había un dragón $\underline{\text { eh@ffp }}$

*RAQ: $\quad$ no me digas no $+/$.

*LEO: (2)te iba a cortar tu [= la] cabeza ! [5;03.21] / 59EN_01

Así, en (98a) el enunciado origen en inglés, “down”, constituye una sola palabra que es traducida al español por la palabra "ahi”, habiéndose producido un CC completo ${ }^{59}$.

\footnotetext{
${ }^{59}$ En el caso del ejemplo (98a), si bien el niño traduce una palabra de una lengua a otra, esto no implica necesariamente que se trate de un emparejamiento léxico en el que la FL sea equivalente, sino que se trata de una traducción en la que la FL no es equivalente, puesto que con la palabra en español ( "ahi") se expresa menos información que la que se expresa con la palabra en inglés ("down”), más específica desde el punto de vista semántico.
} 
En el caso de (98b), y ya en edades más avanzadas y, por tanto, con un mayor desarrollo de la competencia lingüística, los niños traducen unidades lingüísticas de mayor complejidad de forma completa y con el correspondiente CC, de tal forma que Simon traduce la primera oración expresada por Melanie, indicada con el subíndice (1), y Leo la segunda, indicada con el subíndice (2).

\subsubsection{Las diferencias de producción entre Simon y Leo según la variable 1}

Para poder observar si existen diferencias entre Simon y Leo con respecto a sus preferencias por un determinado tipo de traducción u otro, recurriremos a la tabla 14.

\begin{tabular}{|c|cc|c|}
\hline \multicolumn{4}{|l|}{ TABLA 14. LA PRODUCCIÓN DE TTNN EN SIMON Y LEO SEGÚN LA VARIABLE 1 } \\
\hline & Simon & Leo & Total por tipo de actividad \\
\hline Completa & $91(88,4 \%)$ & $63(91,4 \%)$ & $154(89,6 \%)$ \\
Incompleta & $6(5,8 \%)$ & $3(4,3 \%)$ & $9(5,2 \%)$ \\
Reformulación & $6(5,8 \%)$ & $3(4,3 \%)$ & $9(5,2 \%)$ \\
\hline Total por niño & $103(100 \%)$ & $69(100 \%)$ & $172(100 \%)$ \\
\hline
\end{tabular}

En el caso de Simon, de las 103 TTNN que realiza, poco más del $88 \%$ se corresponde con traducciones completas, mientras que el resto de porcentajes se reparten de manera igualitaria entre los otros dos tipos de traducción (5,8\% tanto de traducciones incompletas como de reformulaciones). En el caso de Leo, de las 69 TTNN que realiza, también el porcentaje más alto $(91,4 \%)$ se corresponde con traducciones completas, aunque el número de casos de los tres tipos de traducciones es inferior al de Simon. Sin embargo, un contraste de porcentajes entre los resultados de uno y otro niño nos indica que no existen diferencias significativas entre ellos $(\mathrm{p}=0,63 ; \mathrm{p}>0,05)$, siendo, por tanto, un comportamiento común en ambos su preferencia por las traducciones completas. 


\subsubsection{Las diferencias de producción entre Simon y Leo según la variable 1 por etapas}

Consideramos que otro aspecto importante dentro de este análisis es el factor longitudinal, a través del cual podemos mostrar el comportamiento traductor de los dos niños, así como las posibles diferencias que puedan observarse entre ellos, a lo largo de las tres etapas (inicial, intermedia y final) en las que hemos dividido este estudio. Para ello, comenzaremos mostrando en los gráficos 2 y 3 las variables relacionadas con la actividad de traducción en Simon y Leo, respectivamente, y cómo se reparte esa producción en las tres etapas.

Gráfico 2. La producción de TTNN de Simon según la variable 1 por etapas

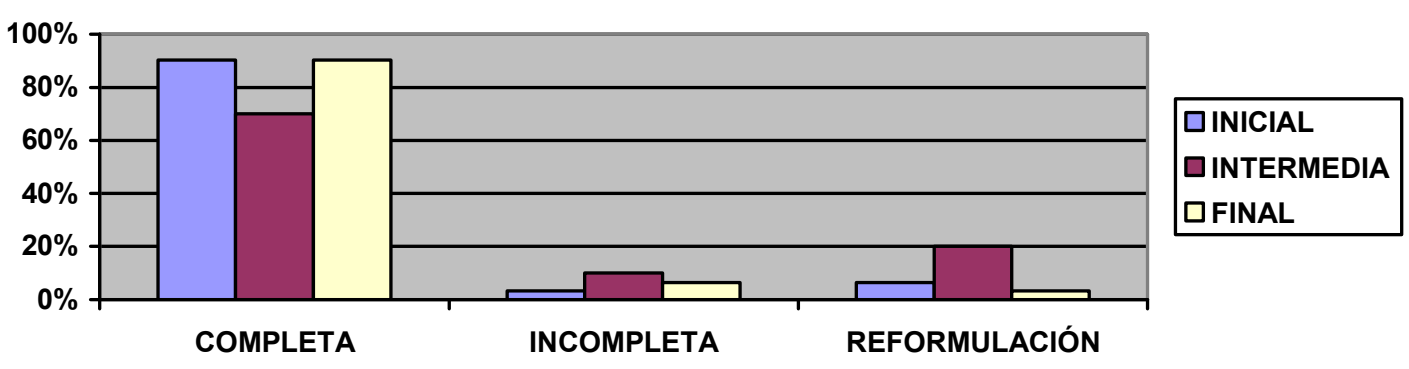

Gráfico 3. La producción de TTNN de Leo según la variable 1 por etapas

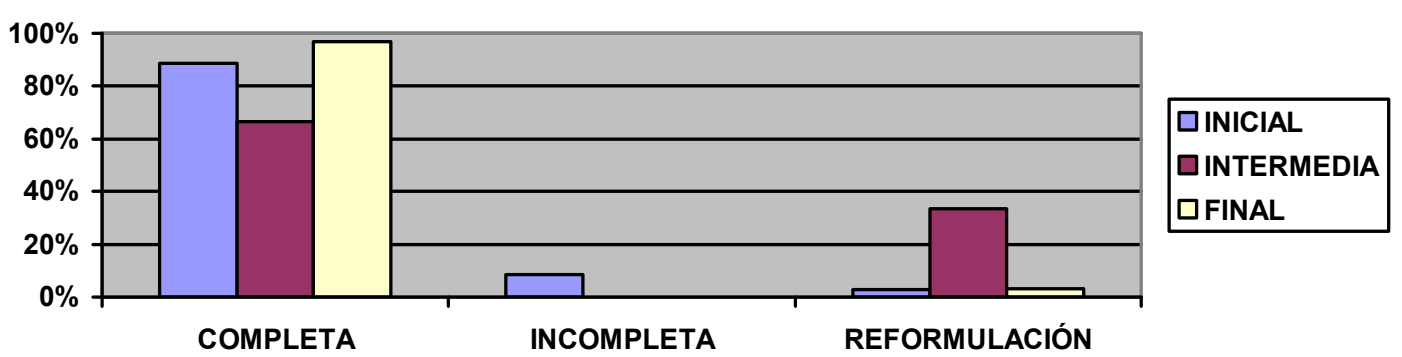

En los gráficos 2 y 3 se refleja claramente una preferencia significativa tanto de un niño como de otro por la traducción completa, un comportamiento traductor que parece la tónica general a lo largo de las tres etapas, siendo evidente que los niños producen traducciones incompletas y reformulaciones en una menor proporción a lo largo del período estudiado, llegando incluso a no producir ninguna traducción de este tipo. Tal es el 
caso, concretamente, de Leo y las traducciones incompletas durante las etapas intermedia y final, como se puede apreciar en el gráfico 3.

Para comprobar si este comportamiento es similar a lo largo de las tres etapas y si hay diferencias significativas entre Simon y Leo en lo que respecta a su actividad de traducción, hemos realizado los siguientes análisis cruzados partiendo de los resultados obtenidos y mostrados en la tabla 15.

\begin{tabular}{|c|cc|}
\hline \multicolumn{4}{|l|}{ TABLA 15. LA PRODUCCIÓN TOTAL DE TTNN DE SIMON Y LEO POR ETAPAS } \\
\hline & Simon & Leo \\
\hline Inicial (2,00-3;00) & $31(30,1 \%)$ & $35(50,7 \%)$ \\
Intermedia (3;05-4;05) & $10(9,7 \%)$ & $3(4,3 \%)$ \\
Final (4;09-6;03) & $62(60,2 \%)$ & $31(45 \%)$ \\
\hline Total por sujeto & $103(100 \%)$ & $69(100 \%)$ \\
\hline
\end{tabular}

En la etapa inicial Simon y Leo se comportan de forma similar en cuanto al número de casos de TN (31 y 35, respectivamente), pero no así en lo que respecta a la diferencia de los porcentajes de ambos, puesto que Leo produce significativamente $(p=0,003)$ más TTNN que Simon (35 casos frente a 31). En la etapa intermedia, en cambio, el comportamiento que siguen es muy similar a pesar de la disminución drástica del número de TTNN producidas por ambos niños (10 casos de Simon y 3 de Leo). Por este motivo, aunque en los casos de $\mathrm{TN}$ incluidos en la etapa final también hemos localizado traducciones procedentes de los datos espontáneos, la mayor parte de ellas se corresponden con los producidos a raíz de las pruebas experimentales, de ahí que, de nuevo, en esta etapa se observe un aumento de traducciones producidas por ambos niños. Sin embargo, en este caso los niños producen un número de casos de TN más dispar (Simon realiza el doble de traducciones que Leo, concretamente, 62 casos frente a 31), un dato que se refleja también en las proporciones (un $60,2 \%$ frente a un $45 \%$, respectivamente) que hace que existan diferencias significativas $(p=0,02)$ entre ambos niños a la hora de producir TTNN a lo largo de esta etapa.

Si atendemos de forma más específica al comportamiento de los niños a lo largo del estudio según los tipos de actividad de TN a los que hemos aludido al principio de este apartado, así como en el apartado 2 dedicado a las variables de análisis, obtenemos los resultados mostrados en las tablas 16 y 17. 


\begin{tabular}{|c|ccc|c|}
\hline \multicolumn{6}{|l|}{ TABLA 16. LA PRODUCCIÓN DE TTNN DE SIMON SEGÚN LA VARIABLE 1 POR ETAPAS } \\
\hline & Completa & Incompleta & Reformulación & Total por tipo de actividad \\
\hline Inicial (2,00-3;00) & $28(30,8 \%)$ & $1(16,6 \%)$ & $2(33,3 \%)$ & $31(30,1 \%)$ \\
Intermedia (3;05-4;05) & $7(7,7 \%)$ & $1(16,6 \%)$ & $2(33,3 \%)$ & $10(9,7 \%)$ \\
Final (4;09-6;03) & $56(61,5 \%)$ & $4(66,8 \%)$ & $2(33,4 \%)$ & $62(60,2 \%)$ \\
\hline Total por etapas & $91(100 \%)$ & $6(100 \%)$ & $6(100 \%)$ & $103(100 \%)$ \\
\hline
\end{tabular}

\begin{tabular}{|c|ccc|c|}
\hline \multicolumn{7}{|l|}{ TABLA 17. LA PRODUCCIÓN DE TTNN DE LEO SEGÚN LA VARIABLE 1 POR ETAPAS } \\
\hline & Completa & Incompleta & Reformulación & Total por tipo de actividad \\
\hline Inicial (2,00-3;00) & $31(49,2 \%)$ & $3(100 \%)$ & $1(33,3 \%)$ & $35(50,7 \%)$ \\
Intermedia (3;05-4;05) & $2(3,2 \%)$ & 0 & $1(33,3 \%)$ & $3(4,3 \%)$ \\
Final (4;09-6;03) & $30(47,6 \%)$ & 0 & $1(33,4 \%)$ & $31(45 \%)$ \\
\hline Total por etapas & $63(100 \%)$ & $3(100 \%)$ & $3(100 \%)$ & $69(100 \%)$ \\
\hline
\end{tabular}

En los datos que aparecen en estas dos tablas, se puede observar que, a lo largo de la etapa inicial, la traducción completa es la más numerosa en los resultados de ambos niños (siendo $\mathrm{p}=0$ en todos los contrastes de porcentajes realizados). Simon y Leo producen prácticamente el mismo número de casos tanto de este tipo de actividad (31 frente a 28) como del resto (1 traducción incompleta frente a 3; y 2 reformulaciones frente a 1). Sin embargo, si bien no existen diferencias significativas con respecto a las reformulaciones, sí que existen diferencias significativas tanto en las traducciones completas $(\mathrm{p}=0,01)$ como en las incompletas $(\mathrm{p}=0,008)$ debidas a que Leo realiza más traducciones de estos dos tipos que Simon en esta primera etapa. En la etapa intermedia, en cambio, no se dan diferencias significativas entre ambos pero sí en la etapa final, donde encontramos que Leo y Simon se comportan de manera inversa a como lo hacen en la etapa inicial. Es decir, ambos siguen produciendo un mayor número de casos de traducción completa, pero la disparidad en el número de casos (56 casos de Simon frente a 30 de Leo) y la correspondiente diferencia de porcentajes en este tipo de traducción entre un sujeto y otro nos indica que Simon produce significativamente $(\mathrm{p}=0,04)$ más casos de traducción completa que Leo. También se produce una diferencia significativa en lo que respecta a las traducciones incompletas, pues, al realizar el contraste de porcentajes de este tipo de traducción en ambos niños, el p-valor se sitúa en 0,02. Esta diferencia se debe a que Simon produce 4 traducciones incompletas en la etapa final, mientras que Leo no produce ninguna 
traducción de este tipo. Finalmente, y frente a lo que sucede con los dos tipos de traducción anteriores, no existe una diferencia significativa en la producción de reformulaciones $(\mathrm{p}=0,5)$, pues en esta etapa, sigue manteniéndose en un 33\% aproximadamente en cada uno de los niños.

\subsubsection{Conclusiones sobre la producción de TTNN de Simon y Leo según la variable 1}

Retomando las tres cuestiones de análisis expuestas al principio de este apartado y aludiendo a los resultados principales de dicho análisis, destacaremos las siguientes conclusiones.

En primer lugar, podemos afirmar que los niños realizan TTNN y además completan la actividad o el proceso de traducción de forma significativa. Es más, desde un punto de vista global, no existen diferencias significativas en la actuación de nuestros sujetos en lo que respecta a la actividad de traducción, siendo la más numerosa en ambos niños la traducción completa, tanto a nivel global como en cada una de las etapas.

En segundo lugar, en cuanto a las diferencias de comportamiento entre ambos niños que han surgido, hemos procedido a observar el desarrollo de dicho comportamiento a lo largo de las tres etapas en las que está divido el presente estudio. De esta manera, el comportamiento de Simon y Leo es similar sólo en la etapa intermedia, ya que las diferencias entre ambos se manifiestan en las etapas inicial y final. Concretamente, en la etapa inicial es Leo el que produce más casos de traducción completa e incompleta que Simon, mientras que en la etapa final la situación es la inversa, pues es Simon el que produce más casos de estos dos tipos de traducción que Leo. En esta última etapa, además, aumenta la producción de traducciones de uno y otro tipo con respecto a la de etapas anteriores, y esto sucede sobre todo en el caso de Simon, ya que Leo produce menos traducciones completas y deja de producir las incompletas ya en la segunda etapa.

Así pues, y a modo de conclusión general, podemos afirmar que el análisis estadístico de estos datos viene a avalar que, en el comportamiento traductor de los niños bilingües objeto de nuestro estudio, existe claramente una mayor proporción de casos en los que traducen el enunciado de forma completa, un hecho que vendría a constatar, por un lado, que la puesta en práctica de su capacidad traductora no es rudimentaria, una afirmación contraria a la definición de Lörscher (1992) que veíamos en el apartado 2.2.4. 
del capítulo 2. Por otro lado, este hecho también deja patente que las traducciones que realizan nuestros sujetos no constituyen casos anecdóticos sino que son muy numerosos y, por tanto, merecerían ser estudiadas como un fenómeno lingüístico con características propias y no como un tipo de AC, tal y como plantean en su terminología investigadores como Meisel (1989), Köppe y Meisel (1995), Lanza (1992, 1997) y McClure (1981), entre otros, siendo los únicos que establecen esta distinción Lindholm y Padilla (1978b), Srivastava y Gupta (1989) y Fernández Fuertes et al. (en prensa) [ver los apartados 5.1.1. del capítulo 1 y 2.1. del capítulo 3]. Al mismo tiempo, también consideramos que los niños de nuestro estudio no traducen de forma arbitraria, sino que llevan a cabo esta actividad de traducción en diversas ocasiones en las que la situación así lo requiere, tal y como plantean Lörscher $(1988,1992)$ y Srivastava y Gupta (1989), y que hemos visto reflejado tanto en nuestros propios ejemplos como en ejemplos que hemos ido mostrando a lo largo de este trabajo de investigación y que proceden de niños bilingües de otros estudios (Ronjat 1913; Leopold 1939-1949; Fantini 1985; Köppe y Meisel 1995; Lanza 1997; Genesee et al. 1995; Nicoladis y Genesee 1996, 1998; Van der Linden 2000; etc.) [ver los ejemplos de los apartados 5.2.2.2. del capítulo 1, 2.1 del capítulo 2, y 1.2. y 1.3. del capítulo 3].

\subsection{Variable 2: la tipología semántico-conceptual}

La segunda variable principal que vamos a analizar en la TN es la que se basa en la relación que se establece entre el TO y el TM en el nivel de la FL, de tal forma que, tal y como ya explicamos en el apartado 2 del presente capítulo, encontramos dos tipos de TN según la relación semántico-conceptual de este binomio TO/TM. El primer tipo es la TN basada en una FL equivalente, como el ejemplo que incluimos en (99a), en el que, ante el hecho de que Leo no produzca un cambio de códigos en su intento de traducción, Simon traduce la unidad léxica en español ("otro") por otra unidad léxica en inglés ("another"), estableciendo una relación tanto formal como semántico-conceptual entre estas dos unidades [ver casos semejantes en ejemplos anteriores como (76a), (78), (80) y (81b)].

(99a)*LEO: ot(r)o@sp otro@sp .

*MEL:uh@fp what [///] how do you say otro@sp in English?

*LEO: ot(ro) +//.

*SIM: (a)nothe(r) . 
El segundo tipo se corresponde con aquella TN basada en una FL no equivalente en el binomio TO/TM, como el caso de (99b), donde Leo, ante la reacción de incomprensión por parte de Melanie, traduce la parte del enunciado original que había expresado en español ("quiero") pero añadiendo una información que, aunque está en el contexto conversacional, no está presente en dicho enunciado ("Petit Suisse"). De esta manera, consigue transmitir un mensaje que conlleva más información que el anterior [ver casos semejantes de este tipo de de traducciones en ejemplos anteriores como los de (79) y (81a)].

(99b) *MEL:but you do eat Petit Suisse though don't you ?

*LEO: quiero@sp please .

*MEL:huh@i?

*LEO: I want Petit Suisse please .

En el caso del ejemplo (99b), dado que una parte del TM ("I want") se corresponde con el TO, pero la otra ("Petit Suisse”) no, el componente semántico del enunciado origen se ve ampliado en el TM y, por tanto, hemos considerado que en este ejemplo la TN se basa en una FL no equivalente desde el punto de vista semántico-conceptual.

En cuanto a las subcategorías de cada una de esas variables, dentro de las TTNN en las que la FL del binomio TO/TM es equivalente, podemos distinguir dos tipos de traducciones: aquellas en las que se produce un emparejamiento léxico y formal que no responde a una necesidad comunicativa, y aquellas en las que también se produce un emparejamiento léxico pero que responden a una necesidad comunicativa. Un posible caso del primer tipo lo mostramos anteriormente en (99a) y también a continuación en (100a), donde Melanie, la madre, que es bilingüe, le pide a Simon que traduzca "toma" al inglés pero no para impedir la ruptura en la comunicación sino para mantener la fórmula de una persona-una lengua [ver el apartado 1.2. del capítulo 4].

(100a) *MEL:yes, you want to play, ok .

*SIM: toma@sp .

*MEL:how do you say toma@sp?

*SIM: he(re) . 
El segundo tipo de emparejamiento léxico aparece ejemplificado en (100b), donde Leo le traduce a Esther, la investigadora monolingüe de español, lo que su hermano Simon acaba de decir en inglés. En este caso, la necesidad comunicativa viene dada por el hecho de que Esther no entiende inglés y, por tanto, necesita de la traducción de Leo para poder tener la información necesaria y así poder seguir jugando y formando parte de la interacción.

(100c) *SIM: we don't have payus [: pairs]!

*LEO: [\% to Esther] que no tienen $+/$.

*RAQ: son tontos .

*LEO: <ya ha di:cho> [?] que no tienen parejas . [5;05.29] / 61B(TR)_01

[FL EQ / EMP (NC)]

En lo que respecta a las subcategorías incluidas en las TTNN con una FL no equivalente, y tal y como explicamos en el apartado 2.1.3. de este capítulo [ver los ejemplos (90) y (91) de dicho apartado], podemos tener casos como el de (101a) y el de (101b), que se corresponden con los subtipos que hemos caracterizado como traducción de carácter económico y de carácter expansivo, respectivamente.

(101) (a) *SUS: [\% se dirige a Simon para que le dé un pañuelo de papel para poder borrar las manecillas dibujadas] and can I have one please?

*SUS: $\quad$ okey the whole lot .

*SUS: we want these because it's not very nice it's not a very nice game if you use it just once right?

*SUS: $\quad$ so when we're practicing and we're learning we'll mark different times right?

*EST: qué es eso ?

*SUS: this is why you can use this pen but not the others you've got, right?

*SUS: this one cause we can erase things okey?

*EST: qué ha dicho qué ha dicho?

*SIM: $\quad$ que...+

*EST: qué ha dicho que hay que hacer?

*SIM: mascar [: marcar] la hora. 
(b) *EST: ahora sí que lo he entendido y Susana sabrá leer los [///] $\underline{\text { el }}$ reloj sin números?

*SIM: sí .

*EST: $\quad$ se lo puedes preguntar por favor?

*SUS: what what?

*SIM: do you know how to [///] do you know the time without the numbers on the clock?

En el caso del ejemplo (101a), o traducción económica, el TM aporta menos información que el TO, ya que en el TM (“marcar la hora”) se recoge el mensaje más importante de todos los enunciados anteriores que conforman el TO. En cambio, en el ejemplo (101b), o traducción expansiva, la información que se ofrece en la traducción es más amplia que la que se da en el TO, en este caso porque se añade el concepto de "time" que no estaba en dicho TO.

A partir de los casos de TN recopilados en nuestra selección de datos y que han sido clasificados de forma semejante a los de (99)-(101), la variable de análisis relacionada con la tipología de las TTNN que hemos propuesto nos sirve para mostrar el comportamiento traductor de nuestros sujetos desde el punto de vista del componente semántico-conceptual de sus traducciones. De esta manera, las principales cuestiones que se nos plantean a partir de esta variable y que vamos a tratar a continuación son las relacionadas con el número de casos de TN de un tipo semántico-conceptual u otro, así como las diferencias o similitudes que se puedan establecer en cuanto al uso de determinadas estrategias traductoras en uno $\mathrm{u}$ otro niño. Una vez planteadas estas cuestiones y las reflexiones derivadas de su análisis, ofreceremos los resultados desde una perspectiva longitudinal con el fin de observar si existe algún tipo de patrón evolutivo en estos mecanismos de traducción a lo largo del desarrollo lingüístico de nuestros sujetos. 


\subsubsection{La producción de casos de TN según la variable 2}

En cuanto a la primera cuestión de análisis, si realizamos un recuento de los casos de TTNN recogidos en nuestra base de datos atendiendo a la variable de la tipología semántico-conceptual, obtenemos los resultados recogidos en la tabla 18 .

\begin{tabular}{|cc|c|}
\hline TABLA 18. LA PRODUCCIÓN TOTAL DE LAS TTNN DE SIMON Y LEO SEGÚN LA VARIABLE 2 \\
\hline FL equivalente & FL no equivalente & Total \\
\hline $97(56,4 \%)$ & $75(43,6 \%)$ & $172(100 \%)$ \\
\hline
\end{tabular}

Según la tabla 18, las 172 TTNN realizadas por nuestros sujetos responden a una FL común a dos outputs (uno por cada lengua) y es la que establece una relación semántico-conceptual equivalente o no equivalente en el binomio TO/TM, siendo el primer tipo de relación más numeroso que el segundo (97 casos frente a 75 , o un 56,4\% frente a un $43,6 \%$, respectivamente). Esta diferencia resulta significativa si realizamos un contraste de porcentajes, ya que el p-valor resultante es 0,008 , lo cual indica que el número de traducciones con una FL equivalente es significativamente más elevado que el de las traducciones con una FL no equivalente.

Ante este resultado y con el fin de profundizar en el análisis de esta variable, creemos conveniente plantear que aunque la finalidad fundamental de la TN es la de comunicar un mensaje [ver el apartado 1.3.1.1. de este capítulo] y, por tanto, es el componente semántico-conceptual el que prima en este tipo de producciones, esto no quiere decir que el componente formal carezca de importancia. Para defender este argumento, los subtipos de las categorías "FL equivalente" y "FL no equivalente" incluidos en nuestra propuesta de clasificación de TTNN nos ayudarán a demostrar que nuestros sujetos ponen en juego distintos mecanismos lingüísticos para comunicar un mensaje a través de la traducción y que no son traducciones rudimentarias (como hemos visto que plantea Lörscher (1992) en el apartado 2.2.4. del capítulo 2) ni meras transcodificaciones (como califica Harris (1980a) a algunas de estas producciones).

La distribución de los resultados de cada uno de estos subtipos de TN la mostramos en la tabla 19, de tal forma que, partiendo de la información reflejada en esta tabla, nos centraremos en el análisis de los subtipos semántico-conceptuales incluidos en ambos tipos 
de TN para después atender en dos subapartados a los aspectos contextuales que pueden tener una determinada influencia en los resultados aquí mostrados.

\begin{tabular}{|c|c|c|c|c|}
\hline \multicolumn{2}{|c|}{ FL equivalente } & \multicolumn{2}{|c|}{ FL no equivalente } & \multirow[t]{2}{*}{ Total } \\
\hline Emparejamiento (no NC) & Emparejamiento (NC) & Económica & Expansiva & \\
\hline $71(41,3 \%)$ & $26(15,1 \%)$ & $48(27,9 \%)$ & $27(15,7 \%)$ & $172(100 \%)$ \\
\hline
\end{tabular}

En la tabla 19 observamos que las TTNN equivalentes, tanto las 26 que se deben a una necesidad comunicativa (NC) como las 71 que no (no NC), se corresponden con emparejamientos léxicos, de tal forma que en la mayor parte de las traducciones de nuestros sujetos no sólo prestan atención al sentido del enunciado sino también a la forma, tal y como seguiremos argumentando a continuación.

En primer lugar, tal y como ya demostramos al principio de este apartado a partir de la información reflejada en la tabla 18 , estos resultados indican que son significativamente más numerosos $(\mathrm{p}=0,008)$ los casos de emparejamiento (independientemente de si hay o no una necesidad comunicativa que los provoque) en los que respetan la equivalencia formal (97 en total) que aquellos en los que el componente formal pasa a un segundo plano porque se da más importancia al componente semántico, como sucede en las traducciones económicas y expansivas ( 75 casos en total). En este sentido, habría que admitir que en las TTNN de nuestro estudio los niños han respetado el componente semántico y en la mayoría de ellas también la equivalencia formal, lo cual viene a poner en duda los planteamientos de algunos estudios (Harris 1980a; Malakoff y Hakuta 1991; Lörscher 1992) en los que se hace referencia a que los traductores naturales tienen problemas a la hora de traducir por la influencia de una lengua sobre la otra y que, por este motivo, las TTNN se caracterizan por incluir estructuras oracionales erróneas (como calcos estructurales, por ejemplo) o poco adecuadas.

En segundo lugar, también los resultados de la tabla 19 vendrían a demostrar que nuestros sujetos utilizan otras estrategias de traducción diferentes al emparejamiento de ítems con el fin de expresar el mensaje de un determinado enunciado. En este sentido, los 48 casos de traducción económica y los 27 de traducción expansiva indican que los mecanismos lingüísticos que han utilizado a la hora de traducir no se reducen solamente al 308 
hecho de que, como bilingües, poseen dos lexicones separados o una competencia bilingüe (como planteaba Toury (1986) [ver el apartado 2.2. del capítulo 2]), sino que dichos mecanismos forman parte de la competencia traductora típica de niños bilingües.

De esta manera, y si seguimos con la idea de que uno de los postulados básicos de la TN es la captación y transmisión del sentido del TO, es lógico que, tal y como aparece en la tabla 19, el número de casos de TN económica sea significativamente mayor $(\mathrm{p}=0,003)$ que el de casos de TN expansiva (48 frente a 27, respectivamente). Sin embargo, este resultado tampoco ha de implicar que la traducción expansiva haya de ser relegada a un segundo plano, ya que existen prácticamente los mimos casos de este tipo de traducción que de traducciones con una FL equivalente producidas por una necesidad comunicativa (en ambos casos el porcentaje representa alrededor del 15\%), de tal forma que no existe una diferencia significativa entre estos dos tipos de $\mathrm{TN}(\mathrm{p}=0,44)$.

Sin embargo, consideramos que el dato que más llama la atención dentro de los resultados de la tabla 19 es que las TTNN que reflejan un emparejamiento que no responde a una necesidad comunicativa son significativamente las más numerosas (71 casos que representan el 41,3\% del total de las traducciones). Es más, los emparejamientos léxicos y formales que no se deben a una necesidad comunicativa son los que representan una proporción significativamente más alta en la producción de traducciones, ya que, en un contraste de porcentajes, el p-valor obtenido en la comparación con el resto de tipos de traducciones es siempre menor que $0,05 \quad(\mathrm{p}=0$ con respecto a la proporción de emparejamientos con necesidad comunicativa y de traducciones expansivas, $y=0,004$ con respecto a la proporción de traducciones económicas).

Llegados a este punto, hemos creído conveniente valernos de las variables relacionadas con el contexto comunicativo para ver si podemos explicar el hecho de que los emparejamientos que no se deben a una necesidad comunicativa sean los más numerosos, cuando hemos afirmado que la TN es un fenómeno esencialmente comunicativo, y, al mismo tiempo, justificar que dichos emparejamientos no responden simplemente a una forma de practicar dos lexicones (como plantea Harris 1980b) sino a otros motivos relacionados con el contexto lingüístico en el que se desarrollan nuestros sujetos. Para ello, comenzaremos cruzando la variable de la tipología semántico-conceptual con el factor ausencia/presencia de estímulo para, posteriormente, tener en cuenta en qué medida influye otra variable como la relacionada con la procedencia del TO en los resultados reflejados en la tabla 19. 


\subsubsection{Las variables contextuales y la variable 2: la ausencia/presencia de estímulo}

El primer factor contextual que vamos a tener en cuenta para explicar los resultados incluidos en la tabla 19 es el relacionado con el hecho de que esas traducciones sean o bien inducidas por un interlocutor (uno de los padres o un investigador) o bien realizadas por iniciativa propia, una influencia que hemos pretendido reflejar en la tabla 20.

\begin{tabular}{|c|c|c|c|c|c|}
\hline \multicolumn{6}{|l|}{$\begin{array}{l}\text { TABLA 20. LA } \\
\text { VARIABLE } 2\end{array}$} \\
\hline & \multicolumn{2}{|c|}{ FL equivalente } & \multicolumn{2}{|c|}{ FL no equivalente } & \multirow{2}{*}{$\begin{array}{l}\text { Total por } \\
\text { inductor }\end{array}$} \\
\hline & $\begin{array}{c}\text { Emparejamiento } \\
\text { (no NC) }\end{array}$ & $\begin{array}{c}\text { Emparejamiento } \\
\text { (NC) }\end{array}$ & Económica & Expansiva & \\
\hline Iniciativa propia & $28(39,5 \%)$ & $11(42,3 \%)$ & $7(14,6 \%)$ & $5(18,5 \%)$ & $51(29,7 \%)$ \\
\hline Inducida & $43(60,5 \%)$ & $15(57,7 \%)$ & $41(85,4 \%)$ & $22(81,5 \%)$ & $121(70,3 \%)$ \\
\hline Total por tipo & $71(100 \%)$ & $26(100 \%)$ & $48(100 \%)$ & $27(100 \%)$ & $172(100 \%)$ \\
\hline
\end{tabular}

Ante los resultados expuestos en la tabla 20, lo que podemos resaltar es que los niños de nuestro estudio producen emparejamientos sin necesidad comunicativa tanto si los realizan por iniciativa propia como si los realizan inducidos por otro interlocutor (28 y 43 casos, respectivamente). Lo que nos dicen estos datos es que existe una tendencia a que los niños produzcan más casos de estos emparejamientos cuando son traducciones inducidas, de tal forma que el resultado del análisis del contraste de porcentajes indica que el p-valor se sitúa en 0,005 y que, por tanto, esa diferencia es significativa. Es decir, la proporción de emparejamientos (no NC) es significativamente mayor cuando son inducidos por otro interlocutor. Como consecuencia, podemos afirmar que el número tan elevado de emparejamientos (no NC) se debe, concretamente, a la influencia de la presencia de estímulos para que traduzcan por parte de otros interlocutores.

En cambio, en cuanto a los otros tipos de $\mathrm{TN}$, se constata que no existe una influencia de este factor presencia/ausencia de estímulo en los emparejamientos debidos a una necesidad comunicativa, ya que no obtenemos una diferencia significativa $(p=0,13)$ al comparar el porcentaje de este tipo de casos que han sido inducidos con el porcentaje de casos que han realizado por iniciativa propia. 
Sin embargo, en lo que respecta a las traducciones económicas y las expansivas, sí existen diferencias significativas cuando los niños reciben o no reciben un estímulo (siendo $\mathrm{p}=0$ tanto en uno como en otro subtipo). De esta manera, al igual que lo que sucedía con los emparejamientos (no NC), los niños producen un porcentaje significativamente alto de traducciones con una FL no equivalente (económicas o expansivas) cuando un interlocutor les induce a realizarlas y no tanto cuando las realizan por iniciativa propia.

Para poder profundizar aún más en esta influencia de la presencia/ausencia de estímulo, procederemos a desgranar la tabla 20 anterior para poder observar quiénes son los interlocutores responsables de que los niños realicen traducciones inducidas, una información que reflejamos en la tabla 21.

\begin{tabular}{|c|c|c|c|c|c|}
\hline & \multicolumn{2}{|c|}{ FL equivalente } & \multicolumn{2}{|c|}{ FL no equivalente } & \multirow[b]{2}{*}{ Total por inductor } \\
\hline & $\begin{array}{c}\text { Emparejamiento } \\
\text { (no NC) }\end{array}$ & $\begin{array}{c}\text { Emparejamiento } \\
\text { (NC) }\end{array}$ & Económica & Expansiva & \\
\hline Padres & $40(93 \%)$ & $1(6,7 \%)$ & $3(7,3 \%)$ & $2(9,1 \%)$ & $46(38 \%)$ \\
\hline Investigadores & $3(7 \%)$ & $14(93,3 \%)$ & $38(92,7 \%)$ & $20(90,9 \%)$ & $75(62 \%)$ \\
\hline Total por tipo & $43(100 \%)$ & $15(100 \%)$ & $41(100 \%)$ & $22(100 \%)$ & $121(100 \%)$ \\
\hline
\end{tabular}

Si comenzamos el análisis con los emparejamientos (no NC), es evidente que existe una diferencia significativa $(\mathrm{p}=0)$ entre el porcentaje de aquellos inducidos por los padres y aquellos inducidos por los investigadores (un 93\% frente a un 7\%, respectivamente), lo cual vendría a explicar por qué este tipo de traducción es el más numeroso con respecto a los otros tipos semántico-conceptuales, en general, y con respecto a las TTNN con FL equivalente, en particular. Es decir, el hecho de que sean los padres, los cuales siguen la estrategia de una persona-una lengua, los que inducen a los niños para que traduzcan tiene, por tanto, una gran influencia en el tipo de traducción que realizan, una cuestión en la profundizaremos más adelante en el apartado dedicado a las diferencias de producción entre los dos sujetos del estudio.

En cuanto al resto de tipos de TN (emparejamiento (NC), traducción económica y traducción expansiva), observamos también en la tabla 21 que, a diferencia del primer tipo de traducción (el emparejamiento (no NC)), son los investigadores los que instan a traducir a los niños en una proporción significativamente más elevada que los padres ( $p=0,03$ en los 
emparejamientos ( $\mathrm{NC}) ; \mathrm{p}=0$ en las económicas; $\mathrm{p}=0,01$ en las expansivas), algo que, de nuevo, puede constituir un factor contextual que influye en la tipología de TTNN a las que hemos aludido.

A continuación, vamos a plantear si el segundo de los factores contextuales que hemos tenido en cuenta, la procedencia del TO, tiene influencia o no en los resultados obtenidos en la producción total de TTNN según la variable 2, al igual que hemos hecho con la variable relativa a la presencia/ausencia de un estímulo para traducir.

\subsubsection{Las variables contextuales y la variable 2: la procedencia del TO}

El segundo de los factores contextuales que hemos considerado que puede tener influencia en la variable 2 es el relacionado con el origen del enunciado a traducir, de ahí que hayamos cruzado la variable lingüística 2 con la variable contextual que hemos denominado procedencia del TO, tal y como mostramos en la tabla 22.

\begin{tabular}{|c|cc||c|c|c|}
\hline \multicolumn{7}{|c|}{ TABLA 22. LA PROCEDENCIA DEL TO EN LA PRODUCCIÓN TOTAL DE TTNN SEGÚN LA VARIABLE 2} \\
\hline
\end{tabular}

Según los resultados de la tabla 22, la mayoría de las TTNN que hemos recopilado en el presente estudio son autotraducciones $(51,7 \%)(\mathrm{p}=0,02$ en comparación con las traducciones de los enunciados de otros interlocutores y $\mathrm{p}=0$ en comparación con las traducciones situacionales). A las autotraducciones les siguen muy de cerca, con un 41,3\%, las traducciones en las que el enunciado origen procede de otros interlocutores (normalmente de los adultos), las cuales también pueden ser de diverso tipo desde el punto de vista semántico-conceptual. En el caso de las traducciones situacionales (7\%), son las 
que representan una menor proporción y, por definición, se corresponden exclusivamente con traducciones de carácter económico.

Curiosamente, si nos centramos en la subtipología semántico-conceptual con respecto a esta variable contextual, la mayor parte de los casos de emparejamiento léxico (no NC) se corresponden con autotraducciones (77,5\%), una correlación significativa ya que el p-valor equivale a 0 tanto si comparamos este número de casos con los de las traducciones en las que el TO procede de otros interlocutores, como con los de las traducciones situacionales. Esta relación directa entre los emparejamientos (no NC) y las autotraducciones que se observa en nuestros datos tiene una implicación interesante, pues nos lleva a profundizar en las estrategias utilizadas en la TN constatando lo que apuntó Harris (1980a) al definir la autotraducción: es más probable que los niños produzcan emparejamientos léxicos y formales en sus traducciones, es decir, TTNN con una FL equivalente, cuando no necesitan descodificar lo que tienen que traducir (como en el caso de que los enunciados procedan de otros interlocutores o de una situación), sino que ya han tenido un acceso previo a la expresión verbal del mensaje que ellos mismos han producido.

Sin embargo, si seguimos partiendo de los datos recogidos en la tabla 22, la probabilidad de la que habla Harris (1980a) queda un tanto reducida desde el momento en el que la traducción con una FL equivalente no se relaciona exclusivamente con la autotraducción, tal y como podemos observar en los resultados de las traducciones de enunciados de otros interlocutores que aparecen en la mencionada tabla. En este caso, es decir, cuando traducen a otros interlocutores, los sujetos siguen utilizando como estrategia traductora los emparejamientos (no NC) (16 casos) aunque en una menor proporción ( $p=0)$ que los emparejamientos (NC) (18 casos en los que actúan de intérpretes entre dos investigadores monolingües que necesitan comunicarse entre sí) y que las traducciones económicas $(25$ casos $)(\mathrm{p}=0,0004)$.

Ante este cruce de resultados, podemos afirmar que, independientemente de la variable contextual relativa a la procedencia del TO, vamos a poder encontrar tanto traducciones con una FL equivalente (sobre todo autotraducciones que constituyen emparejamientos (no NC) y emparejamientos (NC) cuando traducen lo que han dicho otros interlocutores), como traducciones con una FL no equivalente (sobre todo traducciones económicas de enunciados de otros interlocutores). Evidentemente, y a diferencia del resto de subtipos semántico-conceptuales, las traducciones situacionales, por definición y por lógica, estarán asociadas exclusivamente a las traducciones económicas. 
La siguiente cuestión de análisis que vamos a abordar a continuación en nuestro análisis es la relacionada con las posibles diferencias significativas que hayan podido surgir en lo que respecta al comportamiento traductor de uno y otro niño.

\subsubsection{Las diferencias de producción entre Simon y Leo según la variable 2}

Atendiendo a la tipología semántico-conceptual de las TTNN realizadas por nuestros sujetos y tal y como aparece en la tabla 23, los datos nos indican que Simon produce prácticamente el mismo número de traducciones con una FL equivalente (51 casos) y traducciones con una FL no equivalente (52 casos), mientras que en Leo la producción es inferior (46 y 23 casos, respectivamente), lo cual hace que las diferencias entre ambos niños no sean significativas en el primer tipo de traducción $(p=0,98)$ pero sí en el segundo tipo $(\mathrm{p}=0,01)$.

\begin{tabular}{|c|cc|c|}
\hline \multicolumn{4}{|c|}{ TABLA 23. LA PRODUCCIÓN TOTAL DE TTNN DE SIMON Y LEO SEGÚN LA VARIABLE 2 } \\
\hline & Simon & Leo & Total por tipo semántico-conceptual \\
\hline FL equivalente & $51(49,5 \%)$ & $46(66,6 \%)$ & $97(56,4 \%)$ \\
FL no equivalente & $52(50,5 \%)$ & $23(33,4 \%)$ & $75(43,6 \%)$ \\
\hline Total por niño & $103(100 \%)$ & $69(100 \%)$ & $172(100 \%)$ \\
\hline
\end{tabular}

De esta manera, si tenemos en cuenta los índices de significación a los que hemos aludido para establecer las posibles diferencias entre Simon y Leo, podemos afirmar que Simon no sólo produce más casos de TN (103 frente a los 69 de Leo), sino que, concretamente, el porcentaje que produce de traducciones con una FL no equivalente es significativamente mayor que el que produce Leo.

Para poder profundizar más en esta diferencia del comportamiento traductor entre ambos niños, creemos conveniente recurrir a un análisis más refinado que nos puede proporcionar la tabla 24, en la que hemos especificado la relación estadística que se establece entre los cuatro subtipos de TN atendiendo al aspecto semántico-conceptual. 


\begin{tabular}{|c|c|c|c|c|}
\hline \multicolumn{5}{|c|}{ LAS SUBCATEGORÍAS } \\
\hline Tipos & Subtipos & Simon & Leo & $\begin{array}{l}\text { Total por subcategorias } \\
\text { semántico-conceptuales }\end{array}$ \\
\hline FL equivalente & $\begin{array}{c}\text { Emparejamiento (no NC) } \\
\text { Emparejamiento (NC) }\end{array}$ & $\begin{array}{c}37(36 \%) \\
14(13,6 \%)\end{array}$ & $\begin{array}{l}34(49,3 \%) \\
12(17,4 \%)\end{array}$ & $\begin{array}{l}71(41,3 \%) \\
26(15,1 \%)\end{array}$ \\
\hline FL no equivalente & $\begin{array}{l}\text { Económica } \\
\text { Expansiva }\end{array}$ & $\begin{array}{l}33(32 \%) \\
19(18,4 \%)\end{array}$ & $\begin{array}{l}15(21,7 \%) \\
8(11,6 \%)\end{array}$ & $\begin{array}{l}48(27,9 \%) \\
27(15,7 \%)\end{array}$ \\
\hline \multicolumn{2}{|c|}{ Total por niño } & $103(100 \%)$ & $69(100 \%)$ & $172(100 \%)$ \\
\hline
\end{tabular}

En la tabla 24 observamos que no existen diferencias significativas entre Simon y Leo en lo que respecta a subtipos correspondientes a la TN con FL equivalente: 37 casos de emparejamiento (no NC) en Simon y 34 en Leo $(p=0,95) ; 14$ emparejamientos (NC) en Simon y y 12 en Leo $(p=0,75)$. Tampoco existen diferencias significativas entre ambos niños en lo que respecta a las traducciones con FL no equivalente, concretamente en los porcentajes relativos a la traducción económica $(\mathrm{p}=0,06)$ y a la traducción expansiva $(\mathrm{p}=0,11)$. Es decir, lo que podemos apuntar es que no hay diferencias entre Simon y Leo en lo que respecta al uso de cada uno de estos subtipos de TTNN desde el punto de vista semántico-conceptual, algo que tendremos que poner en perspectiva con los resultados que obtengamos de las variables contextuales, que son los que vamos a mostrar a continuación.

\subsubsection{Las variables contextuales y la variable 2: las diferencias de producción entre} Simon y Leo según la presencia/ausencia de estímulo

En cuanto a la posible influencia que puedan tener los factores contextuales en los resultados de cada uno de los sujetos, podemos tener en cuenta la tabla 25 , en la que destacamos el papel del factor relacionado con la presencia/ausencia de estímulo en la producción de TTNN (con el fin de que la terminología que aparece en la tabla 25 resulte lo más clara posible, hemos incluido, además, una leyenda de las abreviaturas utilizadas). 


\begin{tabular}{|c|c|c|c|c|c|c|c|c|c|}
\hline \multicolumn{10}{|c|}{ TABLA 25. LA PRESENCIA/AUSENCIA DE ESTÍMULO EN LAS TTNN DE SIMON Y LEO SEGÚN LA VARIABLE 2} \\
\hline & \multicolumn{4}{|c|}{ Simon } & \multicolumn{4}{|c|}{ Leo } & \multirow{3}{*}{$\begin{array}{l}\text { Total por } \\
\text { inductor }\end{array}$} \\
\hline & \multicolumn{2}{|c|}{ FL equivalente } & \multicolumn{2}{|c|}{ FL no equivalente } & \multicolumn{2}{|c|}{ FL equivalente } & \multicolumn{2}{|c|}{ FL no equivalente } & \\
\hline & $\begin{array}{c}\text { EMP } \\
\text { (no NC) }\end{array}$ & $\begin{array}{l}\text { EMP } \\
\text { (NC) }\end{array}$ & ECO & EXP & $\begin{array}{c}\text { EMP } \\
\text { (no NC) }\end{array}$ & $\begin{array}{l}\text { EMP } \\
\text { (NC) }\end{array}$ & ECO & EXP & \\
\hline IP & $18(48,6 \%)$ & $7(50 \%)$ & $5(15,2 \%)$ & $2(10,5 \%)$ & $10(29,4 \%)$ & $4(33,3 \%)$ & $2(13,3 \%)$ & $3(37,5 \%)$ & $51(29,7 \%)$ \\
\hline IND & $19(51,4 \%)$ & $7(50 \%)$ & $28(84,8 \%)$ & $17(89,5 \%)$ & $24(70,6 \%)$ & $8(66,7 \%)$ & $13(86,7 \%)$ & $5(62,5 \%)$ & $121(70,3 \%)$ \\
\hline $\begin{array}{c}\text { Total por } \\
\text { tipo }\end{array}$ & $37(100 \%)$ & $14(100 \%)$ & $33(100 \%)$ & $19(100 \%)$ & $34(100 \%)$ & $12(100 \%)$ & $15(100 \%)$ & $8(100 \%)$ & $172(100 \%)$ \\
\hline
\end{tabular}

\begin{tabular}{|l|}
\hline LEYENDA DE ABREVIATURAS \\
\hline IP Iniciativa propia \\
IND Inducida \\
EMP (no NC) Emparejamiento (sin necesidad comunicativa) \\
EMP (NC) Emparejamiento (necesidad comunicativa) \\
ECO Traducción económica \\
EXP Traducción expansiva
\end{tabular}

Teniendo en cuenta la tabla 25 , en cuanto a los resultados individuales de cada niño, podemos afirmar que, en el caso de Leo, existen diferencias significativas en los resultados de casi todos los tipos de traducciones dependiendo de si recibe estímulo o no para que traduzca. Así, tanto en el caso de los emparejamientos (siendo p=0,0003 en los emparejamientos (no NC) y $\mathrm{p}=0,05$ en los emparejamientos (NC)), como en las traducciones económicas $(\mathrm{p}=0)$, las diferencias entre las traducciones producidas por iniciativa propia y las inducidas son significativas, siendo estas últimas las que representan el porcentaje más alto. Sólo en el caso de las traducciones expansivas que produce Leo no podemos realizar esta afirmación, pues la diferencia no resulta significativa $(p=0,15)$.

En el caso de Simon, en cambio, sólo existen diferencias significativas entre las TTNN producidas por iniciativa propia y las TTNN inducidas en lo que respecta a las traducciones con FL no equivalente: es significativamente más alto el porcentaje de traducciones económicas y traducciones expansivas (siendo $\mathrm{p}=0$ en ambos casos) cuando estas son inducidas por otros interlocutores.

Así pues, en ambos niños el hecho de que se les induzca a traducir provoca una mayor cantidad de producción de TTNN, sobre todo de emparejamientos (no NC) en el caso de Leo, y de traducciones económicas y expansivas en el caso de Simon. 
En cuanto a las comparaciones que se pueden establecer entre los resultados de ambos niños y si seguimos atendiendo a la tabla 25 , los resultados más destacables son los siguientes: en los casos de TN que realizan los niños por iniciativa propia, se observa que se establecen diferencias significativas entre ambos niños, ya que Simon produce una mayor proporción de emparejamientos (no NC) que Leo $(p=0,03) y$, en cambio, Leo produce una mayor proporción de traducciones expansivas que Simon $(p=0,04)$, aunque estas diferencias no sean altamente significativas. En lo que respecta a las traducciones inducidas también encontramos diferencias significativas entre ambos sujetos, aunque el índice no sea muy alto, ya que Leo produce más emparejamientos (no NC) que Simon $(p=0,04)$, aunque Simon produce más traducciones expansivas que Leo $(p=0,04)$.

Lo que se observa, pues, con respecto a las traducciones inducidas es que existe una relación entre la producción de traducciones desde el punto de vista semántico-conceptual y el factor externo que es la presencia de un estímulo: cuando reciben estímulos por parte de otros interlocutores, Leo produce más traducciones con FL equivalente que Simon, mientras que este realiza con más frecuencia que su hermano traducciones con una FL no equivalente.

Para ir un poco más allá de los argumentos expuestos hasta ahora, tendremos en cuenta la tabla 26, en la que mostramos el tipo de inductor que insta a traducir a los niños con el fin de estudiar no sólo porqué parece que a Leo le afecta más el factor externo del estímulo en casi todos los tipos de traducción (sobre todo en los emparejamientos léxicos), excepto en la traducción expansiva, y por qué a Simon sólo parece afectarle cuando se trata de realizar traducciones con una FL no equivalente.

\begin{tabular}{|c|c|c|c|c|c|c|c|c|c|}
\hline & \multicolumn{4}{|c|}{ Simon } & \multicolumn{4}{|c|}{ Leo } & \multirow{3}{*}{$\begin{array}{l}\text { Total por } \\
\text { inductor }\end{array}$} \\
\hline & \multicolumn{2}{|c|}{ FL equivalente } & \multicolumn{2}{|c|}{ FL no equivalente } & \multicolumn{2}{|c|}{ FL equivalente } & \multicolumn{2}{|c|}{ FL no equivalente } & \\
\hline & $\begin{array}{c}\text { EMP } \\
\text { (no NC) }\end{array}$ & $\begin{array}{l}\text { EMP } \\
\text { (NC) }\end{array}$ & ECO & EXP & $\begin{array}{c}\text { EMP } \\
\text { (no NC) }\end{array}$ & $\begin{array}{l}\text { EMP } \\
\text { (NC) }\end{array}$ & ECO & EXP & \\
\hline PAD & $16(84,2 \%)$ & $1(14,3 \%)$ & $1(3,6 \%)$ & $1(5,9 \%)$ & $24(100 \%)$ & 0 & $2(15,4 \%)$ & $1(20 \%)$ & $46(38 \%)$ \\
\hline INV & $3(15,8 \%)$ & $6(85,7 \%)$ & $27(96,4 \%)$ & $16(94,1 \%)$ & 0 & $8(100 \%)$ & $11(84,6 \%)$ & $4(80 \%)$ & $75(62 \%)$ \\
\hline $\begin{array}{c}\text { Total por } \\
\text { niño }\end{array}$ & $19(100 \%)$ & $7(100 \%)$ & $28(100 \%)$ & $17(100 \%)$ & $24(100 \%)$ & $8(100 \%)$ & $13(100 \%)$ & $5(100 \%)$ & $121(100 \%)$ \\
\hline
\end{tabular}




\begin{tabular}{|l|}
\hline LEYENDA DE ABREVIATURAS \\
\hline IP Iniciativa propia \\
IND Inducida \\
EMP (no NC) Emparejamiento (sin necesidad comunicativa) \\
EMP (NC) Emparejamiento (necesidad comunicativa) \\
ECO Traducción económica \\
EXP Traducción expansiva \\
\hline
\end{tabular}

$\mathrm{Si}$, en el caso de las traducciones inducidas, tenemos en cuenta el inductor de la traducción, observamos en la tabla 26 que, ambos niños producen un mayor número de emparejamientos (no NC) cuando es uno de los progenitores quien les incita a traducir ( $p=0$ tanto en Simon como en Leo), mientras que producen un mayor número del resto de tipos de TTNN cuando es uno de los investigadores el que les incita a traducir.

En cuanto a las diferencias significativas entre ambos niños basándonos en el caso de que los inductores sean los progenitores, se observa que, en lo que respecta al primer tipo de traducción (el emparejamiento (no NC)), Leo produce significativamente más traducciones de este tipo ( 24 casos) que Simon ( 16 casos), siendo p=0,02. En este sentido, consideramos un dato interesante a tener en cuenta que del total de estos 40 casos de emparejamiento sin necesidad comunicativa inducidos por los padres, 38 son inducidos por Melanie, la madre, que se dirige a los niños exclusivamente en inglés a pesar de ser bilingüe (de ahí que los emparejamientos que estamos considerando carezcan de una necesidad comunicativa). Este tipo de casos los hemos visto en los ejemplos (76a) y (99a), y en el ejemplo (102) que mostramos a continuación, en el que ambos niños traducen al inglés la parte del TO que está en español, a pesar de que Melanie ha entendido lo que Leo ha dicho.

(102)*LEO: cae@sp nose .

*MEL: the nose fell?

*MEL: yeah?

*MEL: L how do you say cae@sp in English ?

*LEO: fall .

*SIM: fall. 
En cuanto a los casos inducidos por los investigadores, sólo existe una diferencia significativa entre Simon y Leo: a diferencia de lo que ocurre con Leo, los emparejamientos (no NC) producidos por Simon vienen inducidos por los investigadores en la mayor parte de los casos ( $\mathrm{p}=0,02)$. En lo que respecta a los emparejamientos (NC), no existen diferencias significativas $(\mathrm{p}=0,13)$, una tónica general que se repite en las traducciones económicas y expansivas ( $p=0,08$, en ambos tipos). Esta ausencia de diferencias significativas entre ambos niños, nos lleva a apuntar que, en general, ambos niños se comportan de manera similar en este caso, aunque es evidente que, desde el punto de vista numérico, Simon produce más casos de TTNN con FL no equivalente que Leo cuando quien le induce a traducir es, concretamente, un investigador. Sin embargo, con el tipo de análisis que hemos planteado no podemos establecer cuáles son las causas concretas de esta mayor producción y, por tanto, lo único que podemos apuntar es la posible influencia de una situación experimental en el hecho de que uno de los sujetos siga un patrón de comportamiento distinto al del otro sujeto o a la posible diferencia de personalidad de los individuos, y no tanto a su capacidad lingüística o traductológica. De hecho, Simon es siempre más comunicativo y extrovertido que Leo. Esta circunstancia podemos justificarla a partir de los datos obtenidos en los apéndices III y IV sobre la LMEp y el número de enunciados que produce uno y otro niño sobre todo en las sesiones de traducción (TR), donde se localiza la mayor parte de las TTNN con FL no equivalente y donde se demuestra que, excepto en la sesión 74(TR), Simon produce un mayor número de enunciados que Leo y, por tanto, suele interactuar más con sus interlocutores.

En el siguiente apartado, podremos observar si otro factor externo al proceso de traducción como puede ser la procedencia del TO afecta en la misma medida a las diferencias significativas entre ambos niños. 
3.2.2.2. Las variables contextuales y la variable 2: las diferencias de producción entre Simon y Leo según la procedencia del TO

Podemos aludir a la variable relacionada con el enunciado origen que aparece en la tabla 27 para observar si dicha variable tiene influencia también en las diferencias de comportamiento traductor que se han observado entre Simon y Leo.

\begin{tabular}{|c|c|c|c|c|c|c|c|c|c|}
\hline & & & & & & $\mathrm{L}$ & & & \\
\hline & FL equ & alente & FL no e & ivalente & FL equ & alente & FL no eq & ivalente & Total por \\
\hline & $\begin{array}{c}\text { EMP } \\
\text { (no NC) }\end{array}$ & $\begin{array}{l}\text { EMP } \\
\text { (NC) }\end{array}$ & ECO & EXP & $\begin{array}{c}\text { EMP } \\
\text { (no NC) }\end{array}$ & $\begin{array}{l}\text { EMP } \\
\text { (NC) }\end{array}$ & ECO & EXP & inductor \\
\hline AUTOTRAD & $28(75,7 \%)$ & $5(35,7 \%)$ & $8(24,2 \%)$ & $12(63,2 \%)$ & $27(79,4 \%)$ & $3(25 \%)$ & $3(20 \%)$ & $3(37,5 \%)$ & $89(51,7 \%)$ \\
\hline OTROS & $9(24,3 \%)$ & $9(64,3 \%)$ & $16(48,5 \%)$ & $7(36,8 \%)$ & $7(20,6 \%)$ & $9(75 \%)$ & $9(60 \%)$ & $5(62,5 \%)$ & $71(41,3 \%)$ \\
\hline SITUACIÓN & 0 & 0 & $9(27,3 \%)$ & 0 & 0 & 0 & $3(20 \%)$ & 0 & $12(7 \%)$ \\
\hline $\begin{array}{c}\text { Total por } \\
\text { niño }\end{array}$ & $37(100 \%)$ & $14(100 \%)$ & $33(100 \%)$ & $19(100 \%)$ & $34(100 \%)$ & $12(100 \%)$ & $15(100 \%)$ & $8(100 \%)$ & $172(100 \%)$ \\
\hline
\end{tabular}

\begin{tabular}{|l|}
\hline LEYENDA DE ABREVIATURAS \\
AUTOTRAD Autotraducción (el TO procede del propio hablante) \\
OTROS el TO procede de otros interlcoutores \\
SITUACIÓN el TO procede de un conjunto de enunciados previos \\
EMP (no NC) Emparejamiento (sin necesidad comunicativa) \\
EMP (NC) Emparejamiento (necesidad comunicativa) \\
ECO Traducción económica \\
EXP Traducción expansiva
\end{tabular}

En la tabla 27 podemos observar que el comportamiento traductor en ambos niños, según esta variable contextual, es muy semejante en general, pues ambos producen de forma significativa más autotraducciones que se corresponden con un emparejamiento (no NC) que traducciones relacionadas con otros subtipos semántico-conceptuales (siendo $\mathrm{p}=0$ o cercano a 0 en todos los contrastes de porcentajes realizados). Este resultado vendría a incidir de nuevo en la correlación que se establece entre la autotraducción y el emparejamiento (no NC) que comentamos en el apartado 3.2.1.2. Sin embargo, al mismo 
tiempo, se aprecia que el emparejamiento (no NC) no está asociado exclusivamente a la autotraducción, ya que los niños también utilizan esta estrategia cuando tienen que traducir los enunciados procedentes de otros interlocutores.

En cuanto a las diferencias en el comportamiento traductor entre Simon y Leo, no existen diferencias significativas entre ambos en ninguno de los tipos planteados en la tabla 27, aunque, de nuevo, Simon incluya en los datos un cantidad de producción más elevada que Leo, sobre todo de traducciones con FL no equivalente, lo cual puede incidir en el hecho de que exista una proporción significativamente mayor de traducciones con una FL no equivalente en la producción de Simon frente a la de Leo, sobre todo en la última etapa, como veremos en el apartado siguiente.

\subsubsection{Las diferencias de producción entre Simon y Leo según la variable 2 por etapas}

Una vez presentados los principales resultados relativos a las diferencias significativas entre ambos niños en el recuento de casos de $\mathrm{TN}$ de uno u otro tipo y aprovechando los resultados obtenidos hasta ahora, mostraremos los datos que nos ayuden a resolver la tercera cuestión de análisis: ¿existen diferencias en el uso de las estrategias de traducción a lo largo del desarrollo lingüístico de nuestros sujetos?

Para responder a esta pregunta, presentaremos la información necesaria en los gráficos 4 y 5, donde aparece la variable de partida de este apartado (la tipología semántico-conceptual o variable 2) cruzada con la variable longitudinal de las etapas en cada uno de los niños.

Gráfico 4. La producción de TTNN de Simon según la variable 2 por etapas

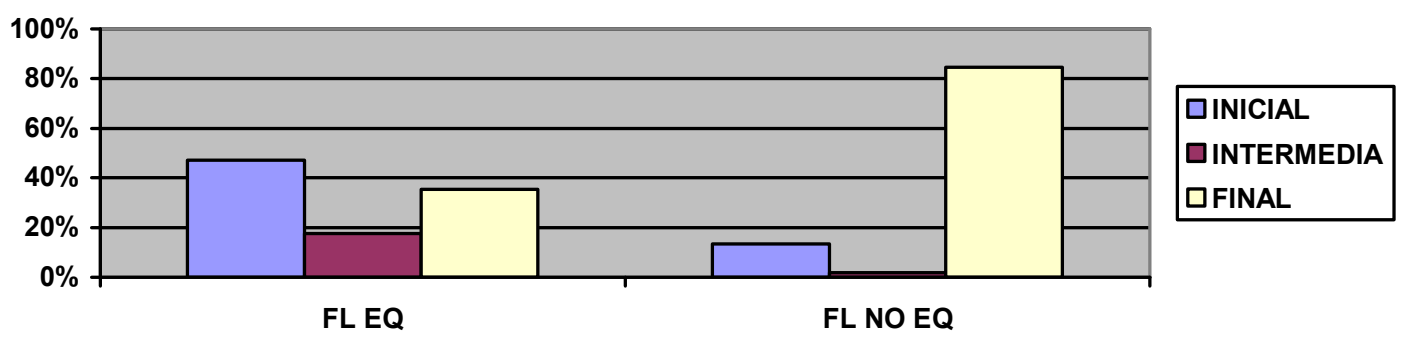


Gráfico 5. La producción de TTNN de Leo según la variable 2 por etapas

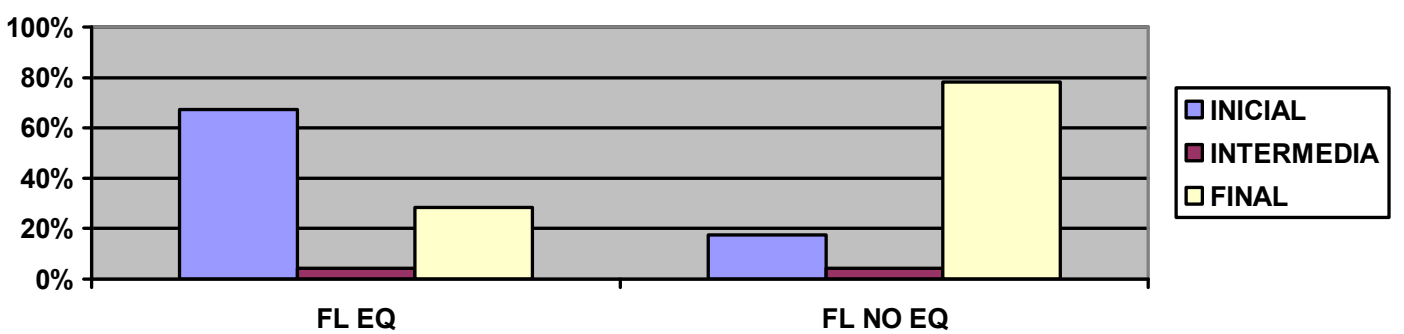

Por la información que obtenemos de $\operatorname{los}$ gráficos 4 y 5 , está claro que la proporción de los dos tipos de traducción (con una FL equivalente y no equivalente) sufre una serie de altibajos a lo largo de las tres etapas, siendo la línea general y común de ambos tipos de traducción el que, en un primer momento, en la etapa inicial, es donde se produce el número más alto de traducciones con una FL equivalente, mientras que en la final es la no equivalente la más numerosa.

A partir de esta apreciación general, recurriremos a las tablas 28 y 29 para averiguar si existen diferencias significativas en el comportamiento traductor de Simon y Leo a lo largo del período estudiado y atendiendo a la variable 2.

\begin{tabular}{|c|cc|c|}
\hline \multicolumn{4}{|l|}{ TABLA 28. LA PRODUCCIÓN DE TTNN DE SIMON SEGÚN LA VARIABLE 2 POR ETAPAS } \\
\hline & FL equivalente & FL no equivalente & Total por etapas \\
\hline Inicial (2,00-3;00) & $24(47 \%)$ & $7(13,5 \%)$ & $31(30 \%)$ \\
Intermedia (3;05-4;05) & $9(17,7 \%)$ & $1(1,9 \%)$ & $10(9,7 \%)$ \\
Final (4;09-6;03) & $18(35,3 \%)$ & $44(84,6 \%)$ & $62(60,3 \%)$ \\
\hline Total por tipología & $51(100 \%)$ & $52(100 \%)$ & $103(100 \%)$ \\
\hline
\end{tabular}

\begin{tabular}{|c|cc|c|}
\hline \multicolumn{1}{|l|}{ TABLA 29. LA PRODUCCIÓN DE TTNN DE LEO SEGÚN LA VARIABLE 2 POR ETAPAS } \\
\hline & FL equivalente & FL no equivalente & Total por etapas \\
\hline Inicial (2,00-3;00) & $31(67,4 \%)$ & $4(17,4 \%)$ & $35(50,7 \%)$ \\
Intermedia (3;05-4;05) & $2(4,4 \%)$ & $1(4,4 \%)$ & $3(4,3 \%)$ \\
Final (4;09-6;03) & $13(28,2 \%)$ & $18(78,2 \%)$ & $31(45 \%)$ \\
\hline Total por tipología & $46(100 \%)$ & $23(100 \%)$ & $69(100 \%)$ \\
\hline
\end{tabular}


De esta manera, retomaremos lo que habíamos planteado anteriormente acerca de que la mayor parte de la traducción con FL equivalente (sobre todo la que constituye un emparejamiento de ítems (no NC)) se asocia con el hecho de que los padres (concretamente, la madre), en el intento por mantener desde el principio la fórmula una persona-una lengua, son los que inducen a los niños a cambiar de código a través de traducciones sobre todo en la primera etapa de su desarrollo lingüístico. Así, este tipo de emparejamiento, junto con el emparejamiento (NC), hace que obtengamos 24 casos producidos por Simon y 31 por Leo, existiendo una diferencia significativa entre ambos $(p=0,02)$ a favor de la mayor proporción de Leo, y que representen un porcentaje significativamente más alto que las traducciones con FL no equivalente durante esta etapa $(p=0)$ en ambos niños.

Posteriormente, en la etapa intermedia, este empeño por parte de los padres parece que ya no es tan necesario, puesto que la producción de TTNN en dicha etapa disminuye drásticamente en ambos niños (9 casos de Simon y 2 de Leo), aunque en este caso, a diferencia de la etapa inicial en la que es Leo el que produce más casos de traducción con FL equivalente, es Simon el que produce significativamente más casos de este tipo de traducción que Leo $(p=0,01)$. Este resultado puede contribuir, al menos en el caso de Simon, a que en esta etapa intermedia siga habiendo más casos de traducciones con FL equivalente que de traducciones con FL no equivalente.

En la etapa final, la producción de TTNN en general vuelve a subir debido a que recurrimos a pruebas experimentales que nos permiten seguir observando el uso de estas estrategias traductoras por parte de nuestros sujetos. Al igual que sucede en la etapa inicial, en esta etapa final no se observan diferencias significativas en el comportamiento traductor de Simon y Leo, pero sí que existen diferencias en cuanto a su comportamiento individual que contrastan con lo que sucede en la etapa inicial: Simon en la etapa final produce un número significativamente mayor de traducciones con $\mathrm{FL}$ no equivalente que de traducciones con FL equivalente $(\mathrm{p}=0)$, mientras que en Leo la diferencia de porcentajes entre uno y otro tipo de traducción en esta etapa no es significativa $(\mathrm{p}=0,10)$.

Este último comportamiento de Simon vendría, de nuevo, a reafirmar lo dicho anteriormente sobre la superioridad en porcentaje de las traducciones con FL no equivalente en este sujeto y durante la esta última etapa, lo cual podríamos justificar atendiendo a la información más precisa mostrada en las tablas 30 y 31 , donde aparecen los 
resultados de las distintas subcategorías semántico-conceptuales encontrados en nuestro corpus de datos.

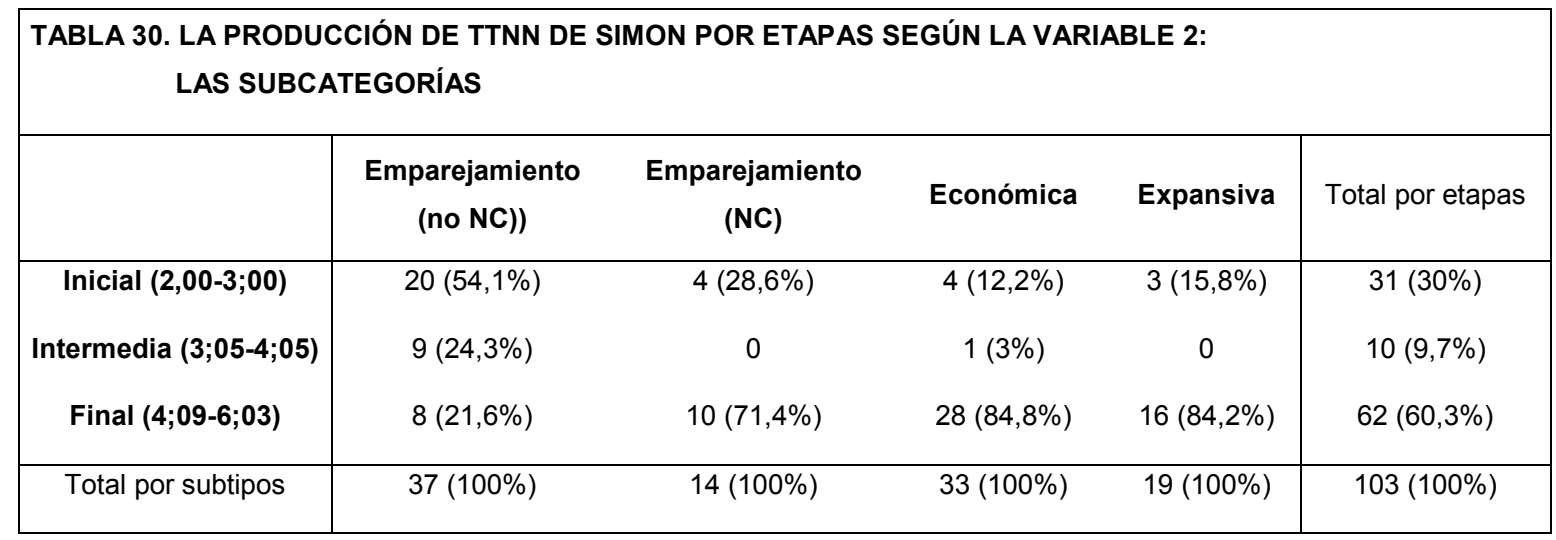

\begin{tabular}{|c|c|c|c|c|c|}
\hline \multicolumn{6}{|c|}{$\begin{array}{l}\text {. LA PRODUCCIÓN D } \\
\text { SUBCATEGORÍAS }\end{array}$} \\
\hline & $\begin{array}{c}\text { Emparejamiento } \\
\text { (no NC)) }\end{array}$ & Emparejamiento (NC) & Económica & Expansiva & Total por etapas \\
\hline Inicial $(2,00-3 ; 00)$ & $30(88,2 \%)$ & $1(8,3 \%)$ & $2(13,3 \%)$ & $2(25 \%)$ & $35(50,7 \%)$ \\
\hline Intermedia $(3 ; 05-4 ; 05)$ & $2(5,9 \%)$ & 0 & 0 & $1(12,5 \%)$ & $3(4,3 \%)$ \\
\hline Final $(4 ; 09-6 ; 03)$ & $2(5,9 \%)$ & $11(91,7 \%)$ & $13(86,7 \%)$ & $5(62,5 \%)$ & $31(45 \%)$ \\
\hline Total por subtipos & $34(100 \%)$ & $12(100 \%)$ & $15(100 \%)$ & $8(100 \%)$ & $69(100 \%)$ \\
\hline
\end{tabular}

A partir de estas dos tablas, podemos destacar los siguientes datos que se producen en la última etapa: en primer lugar, tal y como hemos apuntado anteriormente, Simon produce significativamente más traducciones con FL no equivalente que con FL equivalente; en segundo lugar, en ambos niños se produce un aumento del emparejamiento (NC) en la etapa final (10 casos en Simon y 11 en Leo), lo cual puede venir dado, tal y como se puede observar en las tablas 32 y 33, no tanto por la necesidad comunicativa que tengan los sujetos sino por la de los investigadores monolingües de las pruebas experimentales de traducción que necesitan de su labor como traductores para poder entenderse. Este resultado indica, pues, que los niños responden con sus traducciones a una necesidad social que se encuadra en un contexto familiar. 


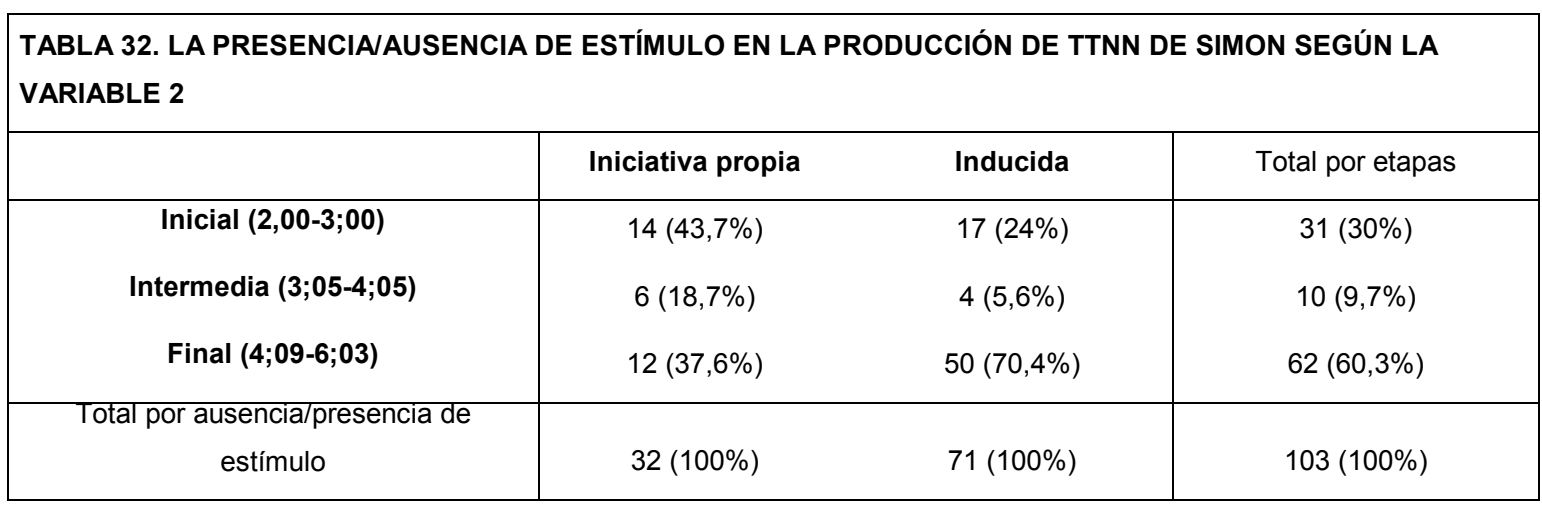

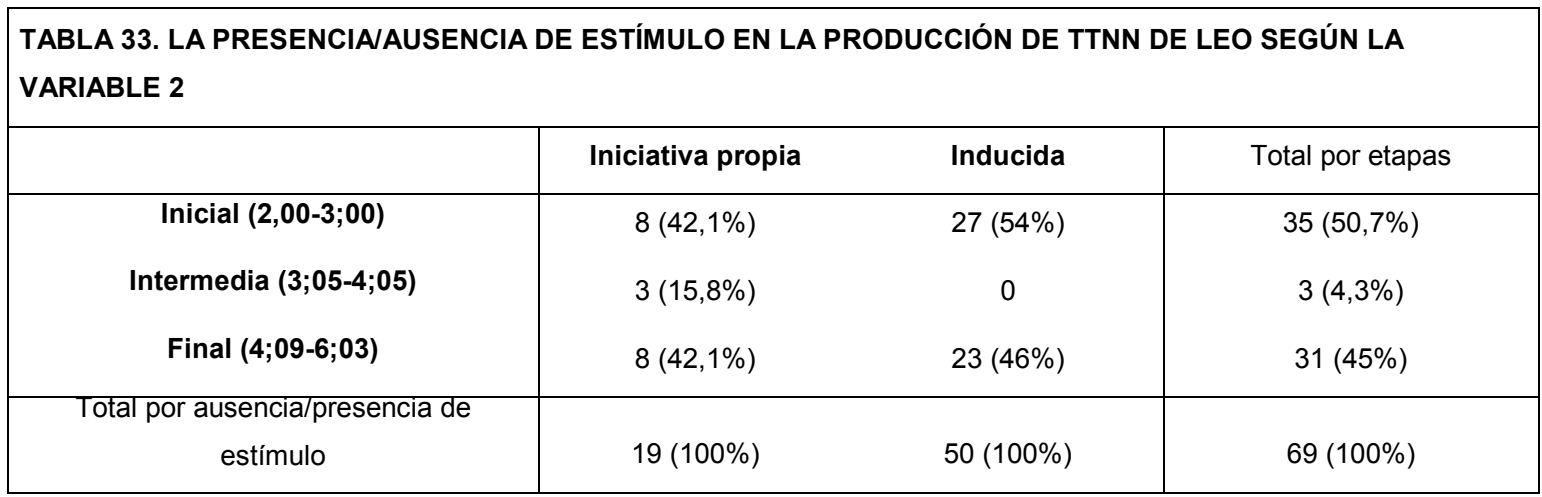

Así pues, por lo que se observa también en la tabla 32, el tipo de datos (en este caso, los experimentales concentrados en la etapa final) y, por tanto, el factor presencia/ausencia de estímulo también tendrán su influencia la mayor proporción de traducciones con FL no equivalente en la etapa final. De hecho, este aumento es más importante en Simon, cuya producción de traducciones inducidas es significativamente mayor ( $\mathrm{p}=0,003$ ) que la de Leo en la última etapa $\mathrm{y}$, por tanto, produce un mayor número de traducciones que su hermano.

\subsubsection{Conclusiones sobre la producción de TTNN de Simon y Leo según la variable 2}

Una vez mostrados los diversos resultados relacionados con la variable de la tipología semántico-conceptual y las posibles influencias de las correspondientes variables de carácter contextual, procederemos a presentar las conclusiones en tres partes que las mismas en las que hemos dividido el análisis. Así, comenzaremos con las conclusiones relacionadas con la producción total de TTNN en ambos sujetos según la variable 2, para después presentar las conclusiones relativas a las diferencias significativas entre ambos niños $\mathrm{y}$, finalmente, haremos referencia a las conclusiones generales a las que hemos 
llegado tras el análisis longitudinal de las TTNN recopiladas para nuestro estudio atendiendo a dicha variable.

En cuanto a la primera conclusión general, lo que hemos observado a partir de nuestros datos es que existe una diferencia significativa entre la proporción de traducciones con una FL equivalente y las que tienen una FL no equivalente, siendo las primeras las más numerosas y, dentro de estas, el tipo de TTNN que producen con más frecuencia el emparejamiento de ítems que no se produce por una necesidad comunicativa. En este sentido, la mayoría de las traducciones responden a una equivalencia tanto léxica como semántica, lo cual hace que nos planteemos dos cuestiones: la primera, que en la TN también el componente formal tiene más importancia de lo que pudiera pensarse en un primer acercamiento al tema; y la segunda, que a pesar de que este tipo de TN más numeroso no parta de una necesidad comunicativa, esto no quiere decir que esta traducción carezca de uno de sus objetivos fundamentales, sino que responde a otras finalidades contextuales diferentes a la de superar una ruptura en la comunicación, como puede ser el que se mantenga de forma estricta la fórmula de una persona-una lengua, que es la que los padres siguen en la interacción con sus hijos. Este tipo de estrategia comunicativa por parte de los padres, por tanto, puede tener una gran influencia en la tipología de casos de TN que pueden producir los niños bilingües.

En lo que respecta a las TTNN con FL no equivalente, hemos observado que, a pesar de que no existen diferencias significativas entre los niños desde el punto de vista de las proporciones, sí se observa que, por ejemplo, Simon realiza un mayor número de traducciones económicas que expansivas, lo cual incide de nuevo en una de las características fundamentales de la TN a la que han aludido otros autores (Lörscher 1988, 1992; Harris 1977, 1980a/b; Harris y Sherwood 1978; entre otros) y que consiste en transmitir el sentido o el mensaje principal del TO, tal y como vimos en los apartados 2.2.1. y 2.2.4. del capítulo 2. Al mismo tiempo, la cantidad de producción de este tipo de traducción parece venir determinada por el factor estímulo, ya que los niños producen más traducciones económicas (y con FL no equivalente en general) cuando son los investigadores los que les instan a traducir y no tanto cuando las realizan por iniciativa propia, lo cual puede deberse a la inmediatez de la comunicación.

También hemos demostrado que la mayoría de las TTNN son autotraducciones que se corresponden con los casos de emparejamiento sin necesidad comunicativa y que, al mismo tiempo, gran parte de las traducciones en las que los niños traducen enunciados 
procedentes de otros interlocutores se corresponde con traducciones económicas. Consideramos que tanto uno como otro resultado son interesantes desde el punto de vista del proceso de traducción en un hablante bilingüe ya que, si tenemos en cuenta el modelo propuesto por MacSwan $(2000,2005)$ acerca de la representación de la facultad del lenguaje bilingüe [ver el diagrama 6 en el apartado 2.2. y los diagramas 7(a)-7(c) en el apartado 3.1. del capítulo 1] y, al mismo tiempo, los diagramas (15a)-(15c) sobre el desarrollo lingüístico bilingüe que hemos propuesto a partir de dicho modelo [ver el apartado 1.3.1. del capítulo 3], podemos plantear la siguiente cuestión sobre estos resultados obtenidos.

Por un lado, estos resultados vendrían a apoyar la propuesta de que, durante el proceso de traducción, los niños bilingües, que parten de dos lexicones y de una única FL, una vez que ellos mismos u otro interlocutor han producido el TO (que se corresponde con la FF de la lengua origen pero con una sola FL), a continuación han de generar un TM que se corresponda con la otra FF (diferente de la del TO) pero que se interprete en el nivel semántico-conceptual de la misma manera que el TO. Es decir, para que los niños bilingües puedan traducir han de manejar una FL común en ambos textos para poder plantear la relación semántico-conceptual del binomio TO/TM. Sólo de esta manera, ambas derivaciones, la del TO y la del TM (a partir de la FL del TO), podrán funcionar en el contexto comunicativo en el que los niños las produzcan y, por tanto, sólo de esta manera, podremos hablar de que han realizado una $\mathrm{TN}$.

Por otro lado, el que exista una sola FL no implica que sólo pueda darse un emparejamiento absoluto entre el TO y el TM, sino que la relación semántico-conceptual en este binomio puede ser de diverso tipo: según nuestros resultados, podemos apuntar que el hecho de que en las autotraducciones sea el propio niño el que haya producido el TO puede influir en que la mayoría de las veces se correspondan con emparejamientos absolutos, concretamente con emparejamientos (no NC), los cuales suelen ser enunciados de una sola palabra $\mathrm{u}$ oraciones simples $\mathrm{y}$, por tanto, casos en los que se establece de manera más directa una equivalencia semántica total en la FL común. Al mismo tiempo, también observamos que la mayoría de las veces nuestros sujetos prefieren la traducción económica cuando tienen que traducir un TO procedente de otros interlocutores y no de ellos mismos. Este tipo de TO suele ser bastante más complejo que el TO correspondiente a las autotraducciones, lo cual puede influir a la hora de realizar este tipo de traducción. Sin embargo, como hemos dicho, se trata de tendencias o preferencias que a veces ni 
siquiera resultan significativas, de ahí que también podamos encontrar casos en los que los niños deciden utilizar una $\mathrm{u}$ otra estrategia de traducción tanto en las autotraducciones como en los casos que los que tengan que traducir lo que han dicho los demás, lo cual pone de manifiesto que nuestros sujetos, tanto en un caso como en otro, mantienen una FL común (bien equivalente o no equivalente) que les permite utilizar diversos mecanismos lingüísticos para poder llegar al final (y a la finalidad) del proceso de traducción.

La segunda conclusión general que podemos establecer se relaciona con la existencia de diferencias significativas en el uso de determinadas estrategias traductoras por parte de los niños bilingües de nuestro estudio. A este respecto podemos afirmar, por un lado, que Leo produce significativamente más casos de emparejamientos (no NC) que Simon y, por otro, que Simon produce significativamente más traducciones con FL no equivalente que Leo. Si atendemos a factores contextuales para explicar tanto uno como otro comportamiento, podemos afirmar que, debido a la insistencia por parte de la madre anglófona por mantener la fórmula una persona-una lengua, ambos niños, pero sobre todo Leo, reciben muchos estímulos por parte de Melanie para que se dirijan a ella en inglés y no en español, lo cual hace que sea responsable de muchas de las traducciones de este tipo producidas sobre todo por Leo. En cuanto al segundo comportamiento y la influencia de los factores contextuales, concretamente el relacionado con la diferencia significativa entre las traducciones económicas y expansivas de Simon y las de Leo, apuntaremos que no se puede determinar hasta qué punto y en qué medida este tipo de factores puede influir para que el comportamiento traductor de uno y otro niño sea diferente.

La tercera y última conclusión general se basa en que, si tenemos en cuenta el factor longitudinal, los resultados más significativos se resumen en la lógica que subyace al hecho de que en la etapa inicial, por lo que planteábamos anteriormente acerca de las estrategias comunicativas que siguen los padres con sus hijos, lo que más predomine sean las traducciones basadas en los emparejamientos léxicos sin necesidad comunicativa, aunque también destaca la producción de los emparejamientos debidos a una necesidad comunicativa (en los que los niños recurren a la traducción para poder hacerse entender ante los padres, que son hablantes bilingües). En esta primera etapa, de hecho, existen diferencias significativas entre ambos niños, pues Leo produce significativamente más traducciones con FL equivalente que Simon. En cambio, en la etapa intermedia, que se caracteriza por la circunstancia de que los padres ya no necesitan esforzarse tanto en mantener la fórmula una persona-una lengua a estas alturas del desarrollo bilingüe de los 
niños $(3 ; 05-4 ; 05)$, se produce una disminución drástica en la producción de TTNN por parte de ambos sujetos, los cuales se diferencian significativamente en que Simon produce en esta etapa más traducciones con FL equivalente. Las diferencias significativas también las encontramos en la etapa final, que incluye fundamentalmente las producciones resultantes de las pruebas experimentales de traducción. Así, la producción de TTNN aumenta de forma importante en esta última etapa, siendo la diferencia significativa más importante entre Simon y Leo el que el primero produce un mayor número de traducciones con una FL no equivalente que Leo. Esta diferencia, como ya apuntamos anteriormente, puede deberse al carácter experimental de los datos de la etapa final, en los que son los investigadores los que incitan directamente a los niños, sobre todo a Simon, para que traduzcan. Sin embargo, también podemos apuntar otras posibles causas que pueden influir en este resultado como, por ejemplo, el que Leo, en este caso, intervenga menos en las interacciones lingüísticas que Simon, siendo esta una circunstancia cuyo análisis se escapa del ámbito de investigación del presente estudio ${ }^{60}$.

Sí que forma parte de nuestro ámbito de estudio, en cambio, el analizar si, ante estos datos, podemos concluir que la organización mental del lexicón de nuestros sujetos ha ido variando a lo largo de las etapas de este estudio, tal y como vimos que proponían Volterra y Taeschner (1978) en el apartado 3.1. del capítulo 1. Así, desde el punto de vista del desarrollo bilingüe, nuestros sujetos se comportan a lo largo de las etapas que hemos establecido como hablantes bilingües compuestos [ver el diagrama 2 en el apartado 1.2. del capítulo 1], es decir, como hablantes que disponen de dos lexicones separados (uno por cada lengua) y una única FL y no dos (una por cada lengua), como tendrían los coordinados [ver el diagrama 2 en el apartado 1.2. del capítulo 1]. Por este motivo, consideramos que el planteamiento de autores como Volterra y Taeschner (1978), que consideran que los niños bilingües parten de un lexicón único y gradualmente los van separando, no se ve reflejado en nuestros datos, ya que desde el principio de nuestro estudio (cuando los niños tienen 2;00 años) y no a partir de lo que estas autoras consideran la segunda etapa (de los 2;05 a los 3;01 años), son capaces de mantener las lenguas separadas, lo cual les permite traducir [ver el apartado 5 del presente capítulo para profundizar en este tema $]^{61}$.

\footnotetext{
${ }^{60}$ Ver los apéndices III y IV en los que se observa que en las dos primeras pruebas de traducción (56(TR) y 61B(TR)) Leo tiene una LMEp inferior y produce muchos menos enunciados que su hermano.

${ }^{61}$ Aunque, como ya dijimos en el apartado 4 del capítulo anterior [ver el ejemplo (64)], existe un caso de TN que no está incluido en nuestro corpus, pero que hay que tener en cuenta, pues Leo es capaz de realizar este tipo de producción bilingüe a la
} 
Al hilo de esta última propuesta y retomando el debate que ya describimos en el apartado 4.1. del capítulo 1 sobre si los niños bilingües parten de dos lexicones diferenciados (uno por cada lengua) o si comienzan manejando un único lexicón, la postura que mantenemos a partir de nuestros datos se identifica con la primera, ya que si la hipótesis del sistema lingüístico unitario fuese cierta, los niños bilingües no podrían derivar en una sola FL dos textos que se corresponden con FF diferentes y, por tanto, no se podría hablar de traducción sino de una mezcla de lenguas marcada por casos de AC pero sin traducción, siguiendo la propuesta de clasificación del diagrama 14 que describimos en el capítulo 3 [ver el apartado 1.1. del mencionado capítulo].

Por tanto, para finalizar este apartado podemos decir que los niños bilingües de nuestro estudio son capaces de realizar traducciones tanto con una FL equivalente como traducciones con una FL no equivalente, lo cual indica, por un lado, que existe un desarrollo paralelo de la competencia traductora y la competencia bilingüe, ya que, mientras que en la primera etapa predominan las traducciones con FL equivalente, en la última predominan las que tienen una FL no equivalente. Por otro lado, este resultado también indica que Simon y Leo son capaces de recurrir a estrategias lingüísticas diferentes para realizar la actividad de traducción y en cuyo uso pueden influir circunstancias tales como las fórmulas comunicativas que sigan los padres con ellos desde el primer momento y que hacen que produzcan más emparejamientos sin necesidad comunicativa (como los padres son bilingües, entienden a los niños independientemente de la lengua que estos utilicen) o el contexto espontáneo o experimental (donde los investigadores suelen ser los inductores) en el que se produzca la recogida de los datos. Así, en el primer contexto las traducciones van disminuyendo con el tiempo porque las circunstancias así lo requieren y esto hace que tengamos que recurrir al segundo contexto con las pruebas experimentales de traducción con el fin de seguir observando la evolución del comportamiento traductor de los dos niños.

A continuación, y como aspecto fundamental en dicho comportamiento traductor, estudiaremos los resultados obtenidos según la variable 3 que es la que se relaciona con la direccionalidad de las TTNN que hemos recopilado en el presente estudio.

edad de 1;02 años y, por tanto, es un comportamiento que no se correspondería con la división en etapas que plantean Volterra y Taeschner (1978). 


\subsection{Variable 3: la direccionalidad}

También como parte de la competencia traductora de los niños bilingües y de las características intrínsecas a la $\mathrm{TN}$, podemos destacar la tercera variable que vamos a analizar en el presente trabajo de investigación y que se relaciona con la dirección de códigos que se establece en la traducción. Es decir, vamos a estudiar la variable de la direccionalidad de las traducciones que, en el caso de los sujetos de nuestro estudio, puede ser de dos tipos: de español a inglés, como veíamos en el ejemplo previo de (80a) o a continuación en (103a), o de inglés a español, como en el ejemplo previo de (80b) y el siguiente de (103b).

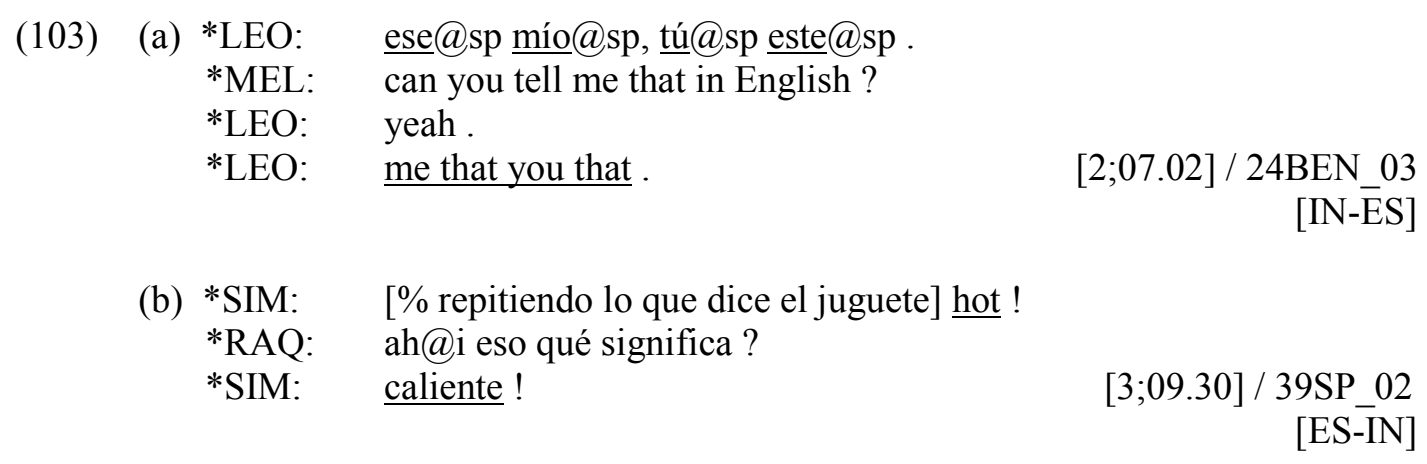

La compilación de casos clasificados desde este punto de vista puede ofrecernos resultados interesantes con respecto a los recursos lingüísticos y comunicativos que se encuentran a disposición de los niños bilingües, de tal forma que procederemos en esta parte del análisis de la misma forma que con las otras variables. Así, plantearemos diversas cuestiones de análisis que pueden surgir, partiendo del cómputo total de casos de TN obtenidos en cada una de las direcciones, las posibles diferencias porcentuales entre los dos niños a la hora de realizar traducciones de un código a otro, así como la cuestión asociada al tipo de direccionalidad en las TTNN de los dos niños a lo largo del período estudiado en este trabajo. 


\subsubsection{La producción de casos de TN según la variable 3}

Teniendo en cuenta los resultados mostrados en la tabla 34, de los 172 casos de TN recopilados, 95 se corresponden con traducciones realizadas de español a inglés y 77 con traducciones realizadas de inglés a español, un resultado que nos va a dar pie a plantear una diferencia significativa entre una direccionalidad y otra en las TTNN que realizan nuestros sujetos, tal y como mostraremos a continuación.

\begin{tabular}{|c|c|c|}
\hline Español-Inglés & Inglés-Español & Total \\
\hline $95(55,7 \%)$ & $77(44,8 \%)$ & $172(100 \%)$ \\
\hline
\end{tabular}

Los resultados de la tabla 34 demuestran que los niños bilingües simultáneos de nuestro estudio son capaces de traducir en una doble dirección. A esta capacidad ya se había aludido en estudios anteriores (Harris 1978) y nuestros datos apuntan también en esa dirección. Sin embargo, aunque por los porcentajes que aparecen en la tabla 34 parece que no existe una diferencia muy amplia entre una direccionalidad y otra (un 55,7\% de traducciones español-inglés, frente a un 44,8\% de traducciones inglés-español), sí existe una diferencia significativa entre estos dos tipos de traducciones, ya que las que los niños realizan de español a inglés (los 95 casos) son significativamente más numerosas que las que realizan de inglés a español (los 77 casos $)(p=0,02)$.

De las posibles influencias que otras variables hayan podido tener en estos resultados trataremos en posteriores apartados, cuando profundicemos más en el análisis de la variable de direccionalidad en la TN. 


\subsubsection{Las diferencias de producción entre Simon y Leo según la variable 3}

Una vez presentados los resultados relacionados con el cómputo total de casos de TTNN procedentes de nuestro corpus de datos, procederemos a mostrar los resultados obtenidos en cada uno de los sujetos según la variable de la direccionalidad de la traducción, tal y como aparecen en la tabla 35.

\begin{tabular}{|c|cc|c|}
\hline \multicolumn{4}{|c|}{ TABLA 35. LA PRODUCCIÓN DE TTNN DE SIMON Y LEO SEGÚN LA VARIABLE 3 } \\
\hline & Simon & Leo & Total por direccionalidad \\
\hline Español-Inglés & $51(49,5 \%)$ & $44(63,8 \%)$ & $95(55,2 \%)$ \\
Inglés-Español & $52(50,5 \%)$ & $25(36,2 \%)$ & $77(44,8 \%)$ \\
\hline Total por niño & $103(100 \%)$ & $69(100 \%)$ & $172(100 \%)$ \\
\hline
\end{tabular}

Tal y como vimos en el apartado anterior y seguimos observando en la tabla 35, el número de traducciones español-inglés que realizan los sujetos es significativamente más alto $(p=0,02)$ que el correspondiente a las traducciones inglés-español, algo en lo que puede incidir las diferencias entre Simon y Leo. Así, por un lado, tal y como podemos apreciar en esa misma tabla, Simon produce prácticamente la misma cantidad de un tipo de traducción que de otro (51 español-inglés y 52 inglés-español), mientras que Leo produce una cantidad de traducciones significativamente mayor de español a inglés (44 casos) que de inglés a español ( 25 casos $)(p=0,0006)$, una diferencia que es la responsable de que existan más traducciones en esta segunda dirección que en la primera.

Por otro lado, los resultados mostrados en la tabla 35, concretamente los relacionados con las traducciones español-inglés (51 casos de Simon frente a 44 de Leo), nos indican que no existe una diferencia significativa entre ambos sujetos en lo que respecta a este tipo de producciones $(\mathrm{p}=0,96)$. Sin embargo, sí existe una diferencia en cuanto a las traducciones inglés-español, pues la desproporción de casos de este tipo entre ambos niños hace que en el contraste de porcentajes obtengamos un índice de significación del p-valor que equivale a 0,03 que nos indica que Simon produce una mayor cantidad de traducciones de inglés a español que Leo (52 casos frente a 25).

Para intentar explicar esta diferencia entre ambos niños, tal y como ya hemos planteado en otros apartados de este capítulo, recurriremos a los factores contextuales 
relacionados con las variables asociadas a la presencia o la ausencia de estímulo que provoca (o no) la realización de TTNN y a la procedencia del TO en dichas traducciones.

\subsubsection{Las variables contextuales y la variable 3: la ausencia/presencia de estímulo}

Con el fin de explicar la diferencia observada en el comportamiento traductor de ambos niños en lo que a la direccionalidad de las traducciones se refiere, mostramos la tabla cruzada de 36 en la que aparecen los resultados relativos a esta variable en Simon y en Leo junto con la variable relacionada con el estímulo que reciben (traducciones inducidas o traducciones realizadas por iniciativa propia).

\begin{tabular}{|c|c|c|c|c|c|}
\hline & \multicolumn{2}{|c|}{ Simon } & \multicolumn{2}{|c|}{ Leo } & \multirow[b]{2}{*}{$\begin{array}{c}\text { Total por } \\
\text { presencia/ausencia de } \\
\text { estímulo }\end{array}$} \\
\hline & $\begin{array}{c}\text { Español- } \\
\text { Inglés }\end{array}$ & $\begin{array}{l}\text { Inglés- } \\
\text { Español }\end{array}$ & $\begin{array}{c}\text { Español- } \\
\text { Inglés }\end{array}$ & $\begin{array}{l}\text { Inglés- } \\
\text { Español }\end{array}$ & \\
\hline Iniciativa propia & $11(21,6 \%)$ & $21(40,4 \%)$ & $9(20,5 \%)$ & $10(40 \%)$ & $51(29,7 \%)$ \\
\hline Inducida & $40(78,4 \%)$ & $31(59,6 \%)$ & $35(79,5 \%)$ & $15(60 \%)$ & $121(70,3 \%)$ \\
\hline Total por niño & $51(100 \%)$ & $52(100 \%)$ & $44(100 \%)$ & $25(100 \%)$ & $172(100 \%)$ \\
\hline
\end{tabular}

Teniendo en cuenta la tabla 36, podemos afirmar que no existen diferencias significativas entre ambos niños en lo que respecta a la direccionalidad de las traducciones según el factor ausencia/presencia de estímulo. Sin embargo, sí podemos encontrar diferencias interesantes si nos centramos en cada uno de los tipos de estímulo (por iniciativa propia o inducidas) que hemos indicado en la tabla 36.

Si nos centramos únicamente en los 51 casos de traducciones que realizan por iniciativa propia, lo único a destacar es que los 21 casos de traducción inglés-español que produce Simon representan una proporción significativamente más alta $(\mathrm{p}=0,008)$ que la que representan los 10 casos de Leo. En lo que respecta a las traducciones inducidas (121 casos en total $\mathrm{y}$, por tanto, más del doble que del tipo anterior), Simon no produce significativamente una proporción más alta de traducciones en una dirección que en otra $(p=0,10)$, mientras que Leo produce un número de traducciones español-inglés significativamente mayor que de traducciones inglés-español $(p=0,0007)$, una diferencia 
que, de nuevo, constituye otra de las causas que inciden en que existan más casos de traducción español-inglés que a la inversa.

Esta similitud en el comportamiento traductor de ambos niños relacionado con la variable 3 (o falta de diferencias significativas entre ambos niños) hace que nos planteemos hasta qué punto esta variable contextual nos puede ayudar a explicar los hechos que hemos apuntado en este apartado y en otros anteriores: el que Leo produzca más traducciones español-inglés que en la dirección inversa y el que, en cambio, Simon produzca más traducciones inglés-español que Leo. Sin embargo, contamos con la subcategoría de esta variable que es la que hace referencia al tipo de inductor de las traducciones inducidas que realizan nuestros sujetos y que puede que sea lo que marque el comportamiento de uno y otro niño en la direccionalidad de sus traducciones. Para constatar este y otros comportamientos, podemos recurrir a la tabla 37.

\begin{tabular}{|c|c|c|c|c|c|}
\hline & \multicolumn{2}{|c|}{ Simon } & \multicolumn{2}{|c|}{ Leo } & \multirow{2}{*}{$\begin{array}{c}\text { Total por ausencia/presencia } \\
\text { de estímulo }\end{array}$} \\
\hline & $\begin{array}{l}\text { Español- } \\
\text { Inglés }\end{array}$ & $\begin{array}{l}\text { Inglés- } \\
\text { Español }\end{array}$ & $\begin{array}{l}\text { Español- } \\
\text { Inglés }\end{array}$ & $\begin{array}{l}\text { Inglés- } \\
\text { Español }\end{array}$ & \\
\hline Padres & $17(42,5 \%)$ & $2(6,5 \%)$ & $26(74,3 \%)$ & $1(6,7 \%)$ & $46(38 \%)$ \\
\hline Investigadores & $23(57,5 \%)$ & $29(93,5 \%)$ & $9(25,7 \%)$ & $14(93,3 \%)$ & $75(62 \%)$ \\
\hline Total por niño & $40(100 \%)$ & $31(100 \%)$ & $35(100 \%)$ & $15(100 \%)$ & $121(100 \%)$ \\
\hline
\end{tabular}

En cuanto las dos cuestiones planteadas, podemos obtener las respuestas a partir de los datos reflejados en la tabla 37 apuntando lo siguiente: en primer lugar, en el caso de Leo, este sujeto produce significativamente más casos de traducciones español-inglés $(\mathrm{p}=0)$ cuando los inductores son los padres (26 casos) y no tanto los investigadores (9 casos), lo cual puede deberse a la influencia de la fórmula comunicativa que siguen los padres (una persona-una lengua). Este resultado, al mismo tiempo, provoca que Leo produzca significativamente $(\mathrm{p}=0,002)$ más traducciones de este tipo (es decir, de español a inglés) que Simon cuando los inductores son los padres (sobre todo la madre, como ya hemos visto en apartados anteriores), mientras que Simon sigue el comportamiento contrario, ya que es precisamente cuando los inductores son los investigadores cuando produce significativamente más traducciones español-inglés que Leo $(p=0,002)$. 
En segundo lugar, en lo que respecta a las traducciones inglés-español, no existen diferencias significativas entre ambos niños $(p=0,48$ en las traducciones inducidas por los investigadores y $\mathrm{p}=0,51$ en las inducidas por los padres), a pesar de que Simon produce prácticamente el doble de estos casos que Leo (29 frente a 14). Sin embargo, estos últimos resultados que nos indican que no existen diferencias significativas entre ambos niños en la realización de traducciones inglés-español según la subcategoría del inductor, tampoco nos han ayudado a responder la segunda cuestión planteada, lo cual nos lleva a reiterar la afirmación de que Simon produce más traducciones de este tipo que Leo y simplemente a apuntar como posible interpretación la influencia de factores externos al proceso de traducción tales como que Simon interviene más en las pruebas de traducción que Leo o que la personalidad de ambos, en este sentido, es diferente (Simon es más comunicativo que Leo) [véanse los datos relativos a la LMEp de Simon y de Leo en las sesiones TR incluidos en los apéndices III y IV]. Sin embargo, el análisis de este tipo de factores y su posible influencia en los resultados se escapa de nuestro ámbito de estudio.

Así pues, podemos concluir este apartado apuntando que, en lo que respecta a las traducciones inducidas inglés-español, no existen diferencias significativas entre ambos niños, pero sí en lo que respecta a las traducciones español-inglés: en el caso de las traducciones inducidas por los padres (sobre todo por Melanie), Leo realiza más traducciones en esta direccionalidad que Simon, mientras que Simon realiza más traducciones de este tipo que Leo cuando el inductor es uno de los investigadores y no uno de los padres, por lo que podemos afirmar que el factor contextual relacionado con quién es el inductor de las traducciones influye en el tipo de direccionalidad de las TTNN que realizan nuestros sujetos.

Con el fin de poder agotar todas las posibilidades que pudieran explicar la diferencia entre Simon y Leo en lo que respecta a la direccionalidad de las traducciones, recurriremos a la otra variable contextual de la que disponemos y que se relaciona con la procedencia del TO. 


\subsubsection{Las variables contextuales según la variable 3: la procedencia del TO}

Otra variable que podría tenerse en cuenta para ver hasta qué punto otros factores externos pueden influir en los resultados de la direccionalidad de las traducciones es la relacionada con la procedencia del TO, tal y como vamos a exponer en este apartado, que es lo que mostramos en la tabla 38.

\begin{tabular}{|c|c|c|c|c|c|}
\hline \multirow{2}{*}{ TABLA 38. LA PROCEDENCIA DEL TO EN LAS TTNN DE SIMON Y LEO SEGÚN LA VARIABLE 3 } \\
\hline \multirow{2}{*}{} & \multicolumn{2}{|c|}{ Simon } & \multicolumn{2}{c|}{ Leo } & \\
\cline { 2 - 6 } & $\begin{array}{c}\text { Español- } \\
\text { Inglés }\end{array}$ & $\begin{array}{c}\text { Inglés- } \\
\text { Español }\end{array}$ & $\begin{array}{c}\text { Español- } \\
\text { Inglés }\end{array}$ & $\begin{array}{c}\text { Inglés- } \\
\text { Español }\end{array}$ & $\begin{array}{c}\text { Total por procedencia del } \\
\text { TO }\end{array}$ \\
\hline Autotraducción & $32(62,7 \%)$ & $21(40,4 \%)$ & $29(66 \%)$ & $7(28 \%)$ & $89(51,7 \%)$ \\
Otros interlocutores & $18(35,3 \%)$ & $23(44,2 \%)$ & $15(34 \%)$ & $15(60 \%)$ & $71(41,3 \%)$ \\
Situación & $1(2 \%)$ & $8(15,4 \%)$ & 0 & $3(12 \%)$ & $12(7 \%)$ \\
\hline Total por niño & $51(100 \%)$ & $52(100 \%)$ & $44(100 \%)$ & $25(100 \%)$ & $172(100 \%)$ \\
\hline
\end{tabular}

Los resultados de la tabla 38 nos indican que ambos niños realizan más autotraducciones de español a inglés que en la dirección inversa ( $p=0,01$ en el caso de Simon y $\mathrm{p}=0,001$ en el caso de Leo), y que Simon realiza significativamente más traducciones situacionales $(\mathrm{p}=0,007)$ de inglés a español que a la inversa ( 8 casos frente a 1), una diferencia que también es significativa en Leo $(p=0,009)$ ( 3 casos de traducción situacional de inglés a español y ninguno de español a inglés). Sin embargo, desde el punto de vista de las diferencias entre ambos niños en lo que respecta a esta variable contextual, al igual que sucedía con la presencia/ausencia de estímulo, no existe significatividad entre los resultados de uno y otro sujeto, lo cual hace que, de nuevo, sólo podamos justificar el hecho de que Simon produzca más traducciones inglés-español desde el punto de vista numérico y no desde el punto de vista del contexto. 


\subsubsection{Las diferencias de producción entre Simon y Leo según la variable 3 por etapas}

Si prestamos atención a la variable de la direccionalidad con respecto al desarrollo bilingüe y traductor de Simon y Leo a lo largo del período estudiado, recurriremos a los resultados que aparecen en los gráficos 6 y 7 .

Gráfico 6. La producción de TTNN de Simon según la variable 3 por etapas

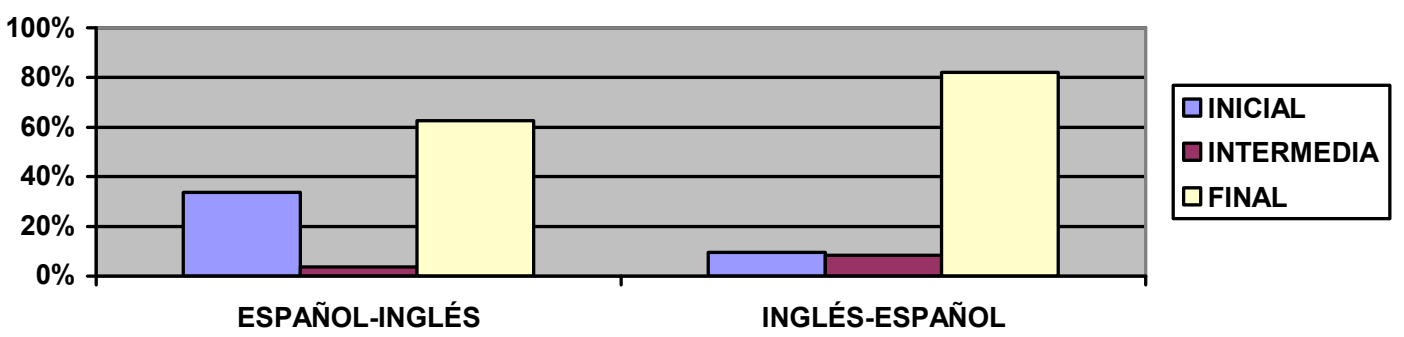

Gráfico 7. La producción de TTNN de Leo según la variable 3 por etapas

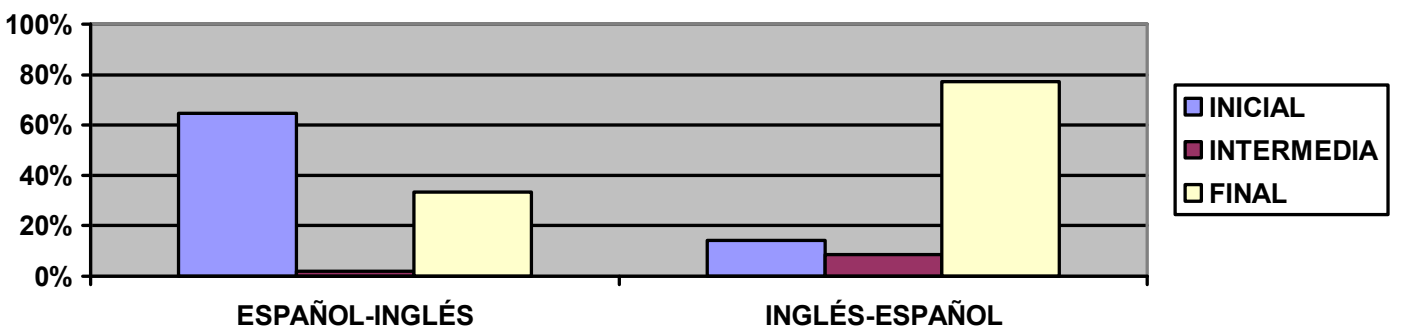

Atendiendo a los resultados mostrados en los gráficos 6 y 7, podemos afirmar que, en lo que respecta a la dirección inglés-español, el comportamiento aparentemente es bastante similar en ambos niños, a pesar de que Leo produce un número menor de traducciones que Simon en todas las etapas excepto en la inicial (31 de Simon frente a 35 de Leo). Al mismo tiempo, también parece que las diferencias más significativas entre ambos niños las vamos a encontrar en las traducciones español-inglés, algo que intentaremos constatar con los datos que mostramos en las tablas 39 y 40. 


\begin{tabular}{|c|cc|c|}
\hline \multicolumn{4}{|c|}{ TABLA 39. LA PRODUCCIÓN DE TTNN DE SIMON SEGÚN LA VARIABLE 3 POR ETAPAS } \\
\hline & Español-Inglés & Inglés-Español & Total por etapas \\
\hline Inicial (2,00-3;00) & $23(33,7 \%)$ & $8(9,5 \%)$ & $31(30,1 \%)$ \\
Intermedia (3;05-4;05) & $3(3,6 \%)$ & $7(8,3 \%)$ & $10(9,7 \%)$ \\
Final (4;09-6;03) & $25(62,7 \%)$ & $37(82,2 \%)$ & $62(60,2 \%)$ \\
\hline Total por direccionalidad & $51(100 \%)$ & $52(100 \%)$ & $103(100 \%)$ \\
\hline
\end{tabular}

\begin{tabular}{|c|cc|c|}
\hline \multicolumn{4}{|c|}{ TABLA 40. LA PRODUCCIÓN DE TTNN DE LEO SEGÚN LA VARIABLE 3 POR ETAPAS } \\
\hline & Español-Inglés & Inglés-Español & Total por etapas \\
\hline Inicial (2,00-3;00) & $30(64,8 \%)$ & $5(14,3 \%)$ & $35(50,7 \%)$ \\
Intermedia (3;05-4;05) & $1(1,9 \%)$ & $2(8,6 \%)$ & $3(4,3 \%)$ \\
Final (4;09-6;03) & $13(33,3 \%)$ & $18(77,1 \%)$ & $31(45 \%)$ \\
\hline Total por direccionalidad & $44(100 \%)$ & $25(100 \%)$ & $69(100 \%)$ \\
\hline
\end{tabular}

Así, a lo largo de la etapa inicial, si bien no existen diferencias significativas entre ambos niños en lo que respecta a la traducción inglés-español, sí existe una diferencia significativa entre Simon y Leo en lo que a las traducciones español-inglés se refiere $(\mathrm{p}=0,01)$, por lo que podemos afirmar que la preferencia de Leo por este tipo de traducción es significativamente mayor que la de Simon en esta etapa. Al mismo tiempo, la diferencia numérica de casos en uno y otro niño podría venir justificada por el hecho que ya expusimos en el apartado 3.2.2.1. y es que Leo realiza más traducciones inducidas por su madre, Melanie, que por los investigadores, cuando esta intenta mantener la fórmula de una persona-una lengua [ver los ejemplos (99a) (100a) y (102) en el apartado 3.2. y (104a) en el apartado 3.3.].

Precisamente, es posible que la influencia de este tipo de factores contextuales sea la responsable de una disminución de casos de traducción en la etapa intermedia con respecto a la etapa inicial. De esta manera, tanto Simon como Leo producen menos traducciones en la etapa intermedia (10 casos y 3, respectivamente), aunque esta disminución en la producción no provoca diferencias significativas entre ambos niños en ninguna de las dos direcciones, ya que producen ambos tipos de traducciones en una proporción similar (3 traducciones español-inglés de Simon y 1 de Leo; 7 traducciones inglés-español de Simon y 2 de Leo). 
En cuanto a la etapa final, sólo hemos constatado la existencia de una diferencia significativa entre ambos niños con respecto a las otras etapas: Simon produce más traducciones de español a inglés que Leo $(p=0,02)$, un patrón contrario al que se da en la primera etapa y que incide, a su vez, en que las traducciones con esta direccionalidad sean más numerosas que las traducciones inglés-español.

Por lo tanto, en lo que respecta a la direccionalidad hemos encontrado dos diferencias significativas entre ambos niños a lo largo del período estudiado pero sólo en las proporciones relacionadas con la traducción español-inglés: si bien en la primera etapa es Leo el que produce un mayor número de traducciones de este tipo (como ya sabemos, incitado por la madre la mayoría de las veces), es Simon quien produce más traducciones de este tipo en la tercera etapa, en la que se incluyen sobre todo las traducciones realizadas durante las pruebas experimentales y, por tanto, a diferencia de Leo, en estos casos es inducido por los investigadores. La justificación, por tanto, de estas diferencias vendría dada, de nuevo, por factores externos al proceso de traducción como el relacionado con el tipo de inductor que provoque que los niños traduzcan, tal y como hemos visto también en el apartado anterior. Estos factores, en cambio, no parecen tener una influencia decisiva en las traducciones inglés-español pues, en estos casos, no se han encontrado diferencias significativas entre los porcentajes de producción de este tipo de traducciones en ambos niños a lo largo de las etapas planteadas.

\subsubsection{Conclusiones sobre la producción de TTNN de Simon y Leo según la variable 3}

Como conclusión al análisis de la variable de la direccionalidad en las TTNN realizadas por Simon y Leo, podemos realizar las siguientes afirmaciones generales: en primer lugar, que ambos niños pueden traducir tanto de español a inglés como de inglés a español, aunque la diferencia de producción entre una dirección y otra es significativa, predominando la primera sobre la segunda. En este sentido, es importante apuntar que no se puede ignorar que los niños viven en Salamanca y, por tanto, no viven en un ambiente bilingüe fuera del entorno familiar, lo cual contribuye a explicar dicha diferencia de producción.

Afinando más en el análisis, y desde el punto de vista del número de casos, hemos encontrado que existen diferencias entre ambos niños en lo que respecta a las traducciones 
español-inglés, lo cual puede venir motivado por la influencia de factores contextuales como los relacionados con los interlocutores que les inducen a traducir, de ahí que resulte evidente que los factores externos al proceso de la traducción tienen un papel importante a la hora de realizar TTNN en una dirección o en otra.

En segundo lugar, a pesar de haber tenido en cuenta la posible influencia de determinados factores contextuales como la presencia o la ausencia de un estímulo o la procedencia del $\mathrm{TO}$, hemos llegado a la conclusión de que este tipo de factores no justifican esta última diferencia, lo cual nos lleva a apuntar que, efectivamente, Simon produce más casos de traducción inglés-español que Leo (aunque el contraste de proporciones no resulte significativo) y que este hecho, tal y como hemos apuntado anteriormente, quizás pueda interpretarse recurriendo a otro tipo de factores externos al proceso de traducción como la LMEp y el número de enunciados de uno y otro niño en cada una de dichas sesiones [ver apéndices III y IV].

En tercer y último lugar, en lo que respecta a la direccionalidad de las traducciones a lo largo de las tres etapas establecidas, no sólo Leo produce en total un número inferior de traducciones sino que, además, produce significativamente más TTNN español-inglés que Simon en la primera etapa. Sin embargo, en la última etapa Simon es el que produce más TTNN que Leo, aunque en la dirección contraria, de inglés a español, en lo cual incide la influencia de determinados factores externos al proceso de traducción.

De esta manera, a lo largo de este apartado, hemos constatado que los niños bilingües de nuestro estudio pueden actuar como canales de comunicación de dos lenguas y son capaces de traducir en una doble dirección, aunque en la producción de traducciones en una u otra dirección tendrá gran influencia sobre todo la presencia o la ausencia de un estímulo para que traduzcan. Concretamente, habrá que tener en cuenta el interlocutor que induzca a los niños a traducir en el caso de que se trate de traducciones inducidas. De hecho, tal y como hemos constatado en nuestros datos, en el análisis de los resultados ha tenido un gran papel la influencia de factores contextuales relacionados, de nuevo, con la estrategia comunicativa que siguen los padres y con las características lingüísticas de los interlocutores (concretamente, si los investigadores son bilingües o monolingües).

Finalizado el análisis de los casos de $\mathrm{TN}$ que han realizado los dos sujetos de nuestro estudio, a continuación realizaremos un análisis similar pero de aquellos casos en 
los que el proceso de traducción ha comenzado pero que, en un momento dado y por determinadas causas, se ve interrumpido y no llega hasta el final, es decir, se produce una actividad de traducción que ha resultado nula.

\section{LA ACTIVIDAD NULA DE TRADUCCIÓN: LA AUSENCIA DE TN}

Tal y como ya planteamos en el apartado 2 del presente capítulo, la TN constituye un proceso que, como tal, puede llegar a completarse o puede resultar nulo. Una vez realizado el análisis de las TTNN que hemos considerado que han seguido el proceso de traducción per se, procederemos a continuación a realizar un análisis semejante de la actividad nula de traducción para casos como los de (104), donde el resultado del proceso de traducción no se ha llevado a cabo a pesar de que las circunstancias requieren lo contrario.

(104) *MEL:[\% pointing to the elephant] look look show me that animal .

*MEL: what's it called?

*LEO: elefante@sp .

*MEL: can you say that in English?

*LEO: [\% with a trace of tears in his voice] no, elefante@sp .

[2;07.02] / 24BEN_01

[NUL̄A]

Para ello, tendremos en cuenta aquellas variables que son de aplicación a este tipo de actividad relacionadas tanto con los aspectos lingüísticos de ese proceso traductor fallido como con los aspectos contextuales que lo rodean, siguiendo, en la medida de lo posible, el mismo patrón de análisis que hemos planteado para las TTNN. 


\subsection{Las implicaciones de las variables de análisis en el estudio de la ausencia de TN}

En el presente estudio también hemos tenido en cuenta una serie de variables formales y contextuales para poder analizar aquellos casos en los que el proceso de traducción ha resultado nulo. Como se puede apreciar en la tabla 41, algunas de esas variables coinciden con las planteadas para el análisis de la TN per se (direccionalidad, estímulo, procedencia del TO y tipo de datos), pero hemos añadido otras (la longitud y la complejidad del TO) con el fin de observar si este tipo de variables pueden influir a la hora de que la traducción no se produzca.

\begin{tabular}{|c|c|c|}
\hline VARIABLES & CATEGORÍAS & SUBCATEGORÍAS \\
\hline \multirow{2}{*}{ ACTIVIDAD NULA } & $\begin{array}{l}\text { Longitud del TO en } \mathrm{n}^{\circ} \text { de palabras } \\
\text { (LONG) }\end{array}$ & $\begin{array}{c}1-4 \\
7-14 \\
+14\end{array}$ \\
\hline & Complejidad del TO (COMPLEJ) & $\begin{array}{c}\text { Sintagma simple (SS) } \\
\text { Sintagma complejo (SC) } \\
\text { Oración simple (OS) } \\
\text { Oración compleja (OC) }\end{array}$ \\
\hline $\begin{array}{l}\text { DIRECCIONALIDAD } \\
\text { (potencial) }\end{array}$ & $\begin{array}{l}\text { Español(-inglés) (ES(-IN)) } \\
\text { Inglés(-español) (IN(-ES)) }\end{array}$ & \\
\hline \multirow[t]{2}{*}{ ESTÍMULO } & Inducida (INDUC) & $\begin{array}{c}\text { Investigador (INV) } \\
\text { Padres (PAD) }\end{array}$ \\
\hline & Por iniciativa propia (IP) & \\
\hline \multirow{3}{*}{ PROCEDENCIA DEL TO } & Autotraducción (AUTOTRAD) & \\
\hline & Otros interlocutores (OTROS) & $\begin{array}{l}\text { Adulto (ADULT) } \\
\text { Hermano (HERM) }\end{array}$ \\
\hline & Situación (SITUA) & \\
\hline DATOS & $\begin{array}{c}\text { Espontáneos (ESPONT) } \\
\text { Experimentales (EXPERIM) }\end{array}$ & \\
\hline
\end{tabular}

Al mismo tiempo, y como se puede observar en esta misma tabla, hemos omitido una de las variables de aplicación a la TN, la relacionada con la tipología semánticoconceptual, ya que, una de las características intrínsecas de los casos de ausencia de TN es la falta de TM o, como sucede en el ejemplo anterior de (104), la falta de un CC, lo cual 
provoca que no podamos analizar la relación que de este tipo se puede dar en el binomio TO/TM.

Los resultados obtenidos tras la recopilación de la totalidad de casos recogidos para el presente estudio lo mostramos en la tabla 42.

\begin{tabular}{|c|cc|c|}
\hline \multicolumn{2}{|l|}{ TABLA 42. LA PRODUCCIÓN DE TTNN FRENTE A LA ACTIVIDAD NULA } & Total general \\
\hline & TN & Actividad nula & 227 \\
\hline Total por tipo de actividad & 172 & $\mathbf{5 5}$ & \\
\hline
\end{tabular}

De acuerdo con la tabla 42, el número total de casos en los que la actividad de traducción ha resultado nula es de 55 , los cuales marcan una diferencia significativa $(\mathrm{p}=0)$ con respecto a los casos de TTNN. Al mismo tiempo, tal y como apuntamos en el apartado 2 de este capítulo, estos 55 casos en los que la actividad de traducción ha sido nula pueden haber sucedido por diversos motivos tanto de carácter lingüístico (no realizan un CC, tienen un vacío léxico, tienen dificultad para traducir determinados términos, no recuerdan el TO, etc.), como de carácter situacional o subjetivo (están cansados y no quieren traducir, por ejemplo).

Realizando un análisis de este tipo según los resultados de la actividad nula en cada niño, tal y como indicamos en la tabla 43, obtenemos que no existen diferencias significativas $(p=0,28)$ entre Simon y Leo en lo que a esta variable respecta, de tal forma que podemos afirmar que ambos niños no realizan traducciones en una proporción semejante (26 casos frente a 29).

TABLA 43. LA PRODUCCIÓN DE TTNN FRENTE A LA ACTIVIDAD NULA DE TRADUCCIÓN EN SIMON Y LEO

\begin{tabular}{|c|cc|c|}
\hline & Simon & Leo & Total general \\
\hline Total por niño & 26 & 29 & 55 \\
\hline
\end{tabular}

En lo que respecta al cómputo de casos de actividad nula de traducción por cada niño a lo largo de las etapas establecidas en el presente estudio, observamos los siguientes resultados a partir de los datos mostrados en la tabla 44. 


\begin{tabular}{|c|c|c|c|}
\hline \multicolumn{1}{|c|}{ TABLA 44. LA ACTIVIDAD NULA DE TRADUCCIÓN DE SIMON Y LEO POR ETAPAS } \\
\hline & Simon & Leo & Total por etapas \\
\hline Inicial (2,00-3;00) & $4(15,4 \%)$ & $14(48,3 \%)$ & $18(32,7 \%)$ \\
Intermedia (3;05-4;05) & $4(15,4 \%)$ & 0 & $4(7,3 \%)$ \\
Final (4;09-6;03) & $18(69,2 \%)$ & $15(51,7 \%)$ & $29(60 \%)$ \\
\hline Total por niño & $26(100 \%)$ & $29(100 \%)$ & $55(100 \%)$ \\
\hline
\end{tabular}

Lo que se deriva de esta tabla es que, en cuanto al comportamiento individual de cada niño, Simon sigue el mismo patrón a lo largo de las etapas inicial e intermedia (con 4 casos de actividad nula en cada una), pero en la etapa final se produce un aumento de este tipo de casos, siendo significativa la diferencia $(\mathrm{p}=0)$ con respecto al número de casos de las etapas anteriores. En el caso de Leo, el patrón común se localiza en las etapas inicial y final, ya que en la etapa intermedia no hemos localizado ningún caso de actividad nula. De forma más concreta, los 14 casos de Leo en la etapa inicial suponen una mayor proporción $(\mathrm{p}=0,004)$ que los 4 casos de Simon y se corresponderían con casos como el de (105), en el que, a pesar de la petición expresa de Melanie para que traduzca al inglés (siguiendo la la fórmula de “una persona-una lengua”), Leo no cambia de código y, por tanto, el proceso de traducción queda anulado.

(105)*MEL:how do you say no@sp puedo@sp in English?

*LEO:no@sp puedo@sp.

En la etapa intermedia, en cambio, la situación se invierte, pues Simon no traduce en 4 ocasiones y Leo en ninguna, lo cual supone una diferencia significativa entre ambos $(p=0,01)$. Sin embargo esta diferencia ya no se da en la etapa final $(p=0,09)$, en la que ambos niños no traducen en un número similar de situaciones (18 casos frente a 15).

Si tenemos en cuenta lo que ya apuntamos en el apartado 2 acerca de las variables de análisis relacionadas con la actividad nula de traducción, con el fin de estudiar con mayor detalle las líneas de comportamiento traductor comunes o diferentes entre las TTNN y los casos de la actividad nula recogidos en nuestros datos, procederemos a continuación a analizar esta actividad nula en Simon y Leo teniendo en cuenta aquellas variables 
relacionadas con las características lingüísticas propuestas para el proceso de traducción (la direccionalidad, y la longitud y la complejidad sintáctica del TO), así como las variables relacionadas con las características contextuales de las circunstancias que rodean a este proceso nulo (la ausencia o presencia de un estímulo verbal y explícito, así como la procedencia del enunciado origen).

\subsubsection{Las variables lingüísticas en la actividad nula de traducción}

A continuación, analizaremos la actividad nula de traducción en Simon y Leo a lo largo del período longitudinal propuesto desde el punto de vista lingüístico e inherente al proceso de traducción, teniendo en cuenta una variable de análisis común con la TN (la direccionalidad de la traducción) y otras variables no comunes con la TN que también se relacionan con aspectos inherentes al proceso de traducción (la longitud y la complejidad sintáctica del TO) que nos puedan ayudar a profundizar en la interpretación del proceso de traducción que ha resultado nulo.

\subsubsection{La direccionalidad}

Una de las variables comunes al análisis que hemos realizado de las TTNN es la relacionada con la direccionalidad. Obviamente, dado que en el caso de la actividad nula el proceso traductor no ha llegado a su fin, no podemos hablar de TM, pero sí podemos decir en qué código debería haber sido expresado para haberlo considerado una traducción. Así, hemos tenido en cuenta que esta variable de la direccionalidad también es aplicable a la actividad nula de traducción y, de acuerdo a ella, hemos obtenido los resultados recogidos en la tabla 45 .

TABLA 45. LA PRODUCCIÓN TOTAL DE ACTIVIDAD NULA DE TRADUCCIÓN SEGÚN LA VARIABLE 3

\begin{tabular}{|c|c|c|}
\hline Español(-Inglés) & Inglés(-Español) & Total por direccionalidad \\
\hline $23(41,8 \%)$ & $32(58,2 \%)$ & $55(100 \%)$ \\
\hline
\end{tabular}


Tal y como se puede apreciar en la tabla 45, de los 55 casos de actividad nula recogidos, 23 casos se corresponden con traducciones cuya direccionalidad debería haber sido de español a inglés y 32 casos con traducciones potenciales inglés-español, lo cual indica que se da una situación inversa a la que se daba en las TTNN, donde las traducciones español-inglés eran más numerosas. Al mismo tiempo, tal y como sucedía también con las TTNN, la diferencia entre ambos tipos es significativa $(p=0,04)$, por lo que la direccionalidad puede afectar al hecho de que el proceso traductor resulte nulo.

En cuanto a las diferencias entre Simon y Leo en lo que respecta a este tipo de actividad, recurriremos al análisis de los resultados mostrados en la tabla 46.

\begin{tabular}{|c|cc|c|}
\hline \multicolumn{4}{|c|}{ TABLA 46. LA DIRECCIONALIDAD DE LA ACTIVIDAD NULA DE TRADUCCIÓN DE SIMON Y LEO } \\
\hline & Simon & Leo & Total por direccionalidad \\
\hline Español(-Inglés) & $8(30,8 \%)$ & $15(51,7 \%)$ & $23(41,8 \%)$ \\
Inglés(-Español) & $18(69,2 \%)$ & $14(48,3 \%)$ & $32(58,2 \%)$ \\
\hline Total por niño & $26(100 \%)$ & $29(100 \%)$ & $55(100 \%)$ \\
\hline
\end{tabular}

En el caso de Leo, el número de casos son muy similares tanto en una dirección como en otra (15 de español a inglés y 14 de inglés a español), mientras que en el caso de Simon es claro que no llega a completar el proceso de traducción sobre todo en el caso de las traducciones inglés-español (18 casos) que son significativamente más numerosas $(p=0,002)$ que las traducciones español-inglés ( 8 casos).

Un análisis de contraste de porcentajes en ambos niños refleja que existen diferencias significativas entre Simon y Leo, aunque estas diferencias habría que establecerlas con cierta cautela, pues el valor de significatividad calculado equivale exactamente a 0,05. Las diferencias que de esta manera hemos obtenido son que Leo produce más casos abortados de traducción español-inglés que Simon, quien, a su vez, produce más casos abortados de traducción inglés-español que Leo.

Si realizamos este mismo análisis teniendo en cuenta el desarrollo longitudinal del comportamiento traductor de ambos niños, obtenemos los resultados recogidos en los gráficos 8 y 9 . 
Gráfico 8. La actividad nula de traducción de Simon según la variable 3 por etapas

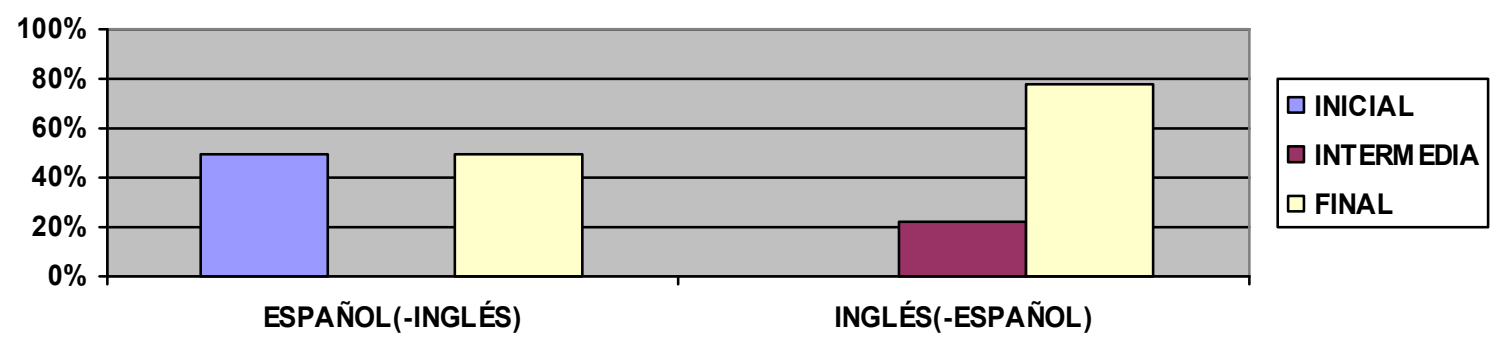

Gráfico 9. La actividad nula de traducción de Leo según la variable 3 por etapas

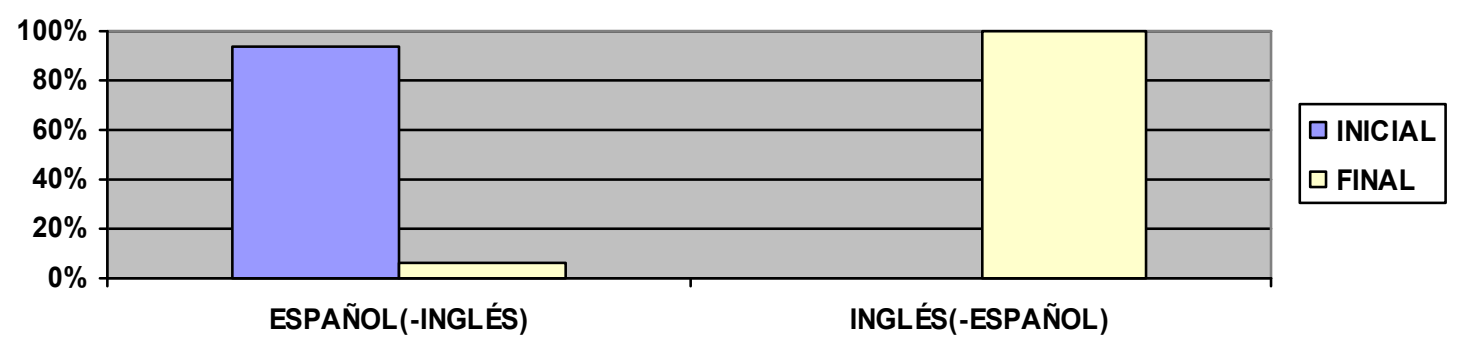

Según lo mostrado en los gráficos 8 y 9, el comportamiento de los dos sujetos de nuestro estudio en lo que a la actividad nula de traducción se refiere es bastante dispar y para poder examinar más detenidamente estas diferencias, procederemos a mostrar los resultados de forma más detallada en las tablas 47 y 48.

\begin{tabular}{|c|c|c|c|}
\hline \multicolumn{4}{|c|}{ TABLA 47. LA ACTIVIDAD NULA DE TRADUCCIÓN DE SIMON SEGÚN LA VARIABLE 3 POR ETAPAS } \\
\hline & Español(-Inglés) & Inglés(-Español) & Total por etapas \\
\hline Inicial (2,00-3;00) & $4(50 \%)$ & 0 & $4(15,4 \%)$ \\
Intermedia (3;05-4;05) & 0 & $4(22,2 \%)$ & $4(15,4 \%)$ \\
Final (4;09-6;03) & $4(50 \%)$ & $14(77,8 \%)$ & $18(69,2 \%)$ \\
\hline Total por direccionalidad & $8(100 \%)$ & $18(100 \%)$ & $26(100 \%)$ \\
\hline
\end{tabular}

\begin{tabular}{|c|c|c|c|}
\hline \multicolumn{4}{|c|}{ TABLA 48. LA ACTIVIDAD NULA DE TRADUCCIÓN DE LEO SEGÚN LA VARIABLE 3 POR ETAPAS } \\
\hline & Español(-Inglés) & Inglés(-Español) & Total por etapas \\
\hline Inicial (2,00-3;00) & $14(93,3 \%)$ & 0 & $14(48,3 \%)$ \\
Intermedia (3;05-4;05) & 0 & 0 & 0 \\
Final (4;09-6;03) & $1(6,7 \%)$ & $14(100 \%)$ & $29(100 \%)$ \\
\hline Total por direccionalidad & $15(100 \%)$ & $14(100 \%)$ & $29)$ \\
\hline
\end{tabular}


Atendiendo tanto a los gráficos 8 y 9 como a las tablas 47 y 48 , se observa que no existe ningún patrón común en ambos niños en lo que a la direccionalidad de la actividad nula se refiere. Así, en el caso de Simon, en la etapa inicial sólo hay 4 casos de actividad nula de español a inglés y ninguna de inglés a español. Este comportamiento se invierte en la etapa intermedia, mientras que en la etapa final, si bien existen 4 casos de actividad nula español-inglés, el número de casos de actividad nula inglés-español sigue siendo la más alta, aunque en ninguna de estas etapas la diferencia entre una dirección y otra sea significativa. En el caso de Leo, durante la etapa inicial no realiza traducciones en 14 ocasiones cuando se trata de traducir del español al inglés y no se encuentra ante ninguna situación en la que no traduzca de inglés a español, lo cual hace que exista una diferencia significativa $(p=0)$ entre un tipo de traducción y otro. En cambio, durante la etapa intermedia no se ha localizado ningún caso de actividad nula por parte de este sujeto, ni en una dirección ni en la otra. En la etapa final el comportamiento de Leo se invierte con respecto a la etapa inicial y la mayor parte de los casos de actividad nula se corresponden con la dirección inglés-español, al igual que sucedía con Simon, pero en el caso de Leo la diferencia entre un tipo de traducción y otro resulta significativa $(\mathrm{p}=0)$.

En cuanto a si hay diferencias significativas entre ambos niños, Leo produce una mayor cantidad de actividad nula español-inglés en la primera etapa ( $\mathrm{p}=0,008)$, lo cual puede venir motivado porque se encuentra en situaciones de este tipo mucho más a menudo que Simon, como hemos visto anteriormente en este capítulo [ver el apartado 3.2.3.].

También es significativa la diferencia entre ambos niños en la etapa intermedia, ya que Simon produce 4 casos de traducción inglés-español mientras que Leo no produce ninguno, volviéndose a equiparar el número de casos en la etapa final con 14 casos de actividad nula cada uno. Para este último resultado hay que tener en cuenta, como veremos en el apartado siguiente, que se trata de pruebas experimentales de traducción en las que se les exige continuamente traducir y esta circunstancia externa y contextual puede hacer que aumente el número de casos en los que deciden voluntariamente no traducir.

Finalmente, la última diferencia significativa $(p=0,008)$ entre ambos niños que se localiza en la etapa final se corresponde con el número de casos de actividad nula de traducción en la dirección español-inglés, pues Simon produce significativamente más casos de este tipo (4 concretamente) que Leo (que produce sólo 1). 
Tras los resultados expuestos, no podemos concluir que la causa de que los niños no traduzcan se deba a la direccionalidad de las traducciones, puesto que existen casos de actividad nula tanto en una dirección como en otra que hacen que a veces las diferencias entre uno y otro niño sean estadísticamente significativas y otras veces no.

\subsubsection{La longitud y la complejidad del TO}

En cuanto a las otras variables de carácter lingüístico y de aplicación exclusiva a la actividad nula, hemos propuesto dos: la que se relaciona con la longitud del enunciado (o el número de palabras de que consta el TO a traducir) (LONG) y la que se relaciona con la complejidad sintáctica de dicho enunciado (si se trata de un sintagma o de una oración de carácter simple o complejo) (COMPLEJ). De esta manera, podemos encontrarnos casos como los de (106a) en los que el TO consta de una sola palabra y, por tanto, es un sintagma simple, hasta casos como el de (106b), en el que TO consta de diez palabras que, a su vez, forman una oración simple.

(106) (a) *MEL: you wanna book?

*MEL: or a puzzle?

*LEO: $\quad$ ese@sp.

*MEL: I don't know what ese@sp means .

*LEO: 0 . [2;01.28] / 17EN_01

[NULA / LONG (1-4) / COMPLEJ ( $\overline{\mathrm{SS}})]$

(b) *SUS: it says Monday Tuesday Wednesday Thursday Friday

*EST: $\quad$ qué ha dicho qué ha dicho qué ha dicho ?

*SIM: $\quad$ eh@fp no sé cómo se llaman esos días en español .

$[4 ; 10.19] / 56 \mathrm{~B}(\mathrm{TR})[01$

[NULA / LONG (7-14) / COMPLEJ (OS)]

Para comprobar si existe algún tipo de relación entre la longitud o la complejidad del TO y la frecuencia de la actividad nula de traducción, hemos clasificado los 55 casos como aparecen en las tablas 49 y 50. 


\begin{tabular}{|c|c|c|c|}
\hline \multicolumn{2}{|c|}{ TABLA 49. LA LONGITUD DEL TO EN LA ACTIVIDAD NULA DE TRADUCCIÓN DE SIMON Y LEO } \\
\hline & Simon & Leo & Total por longitud \\
\hline 1-4 palabras & $19(73,1 \%)$ & $22(75,9 \%)$ & $41(74,5 \%)$ \\
7-14 palabras & $3(11,5 \%)$ & $5(17,2 \%)$ & $8(14,5 \%)$ \\
$\mathbf{+ 1 4}$ palabras & $4(15,4 \%)$ & $2(6,9 \%)$ & $6(11 \%)$ \\
\hline Total por niño & $26(100 \%)$ & $29(100 \%)$ & $55(100 \%)$ \\
\hline
\end{tabular}

\begin{tabular}{|c|c|c|c|}
\hline \multicolumn{4}{|c|}{ TABLA 50. LA COMPLEJIDAD DEL TO EN LA ACTIVIDAD NULA DE TRADUCCIÓN DE SIMON Y LEO } \\
\hline & Simon & Leo & Total por complejidad \\
\hline Sintagma simple & $15(57,7 \%)$ & $13(44,8 \%)$ & $28(50,9 \%)$ \\
Sintagma complejo & $2(7,7 \%)$ & 0 & $15(27,3 \%)$ \\
Oración simple & $4(15,4 \%)$ & $11(37,9 \%)$ & $10(18,2 \%)$ \\
Oración compleja & $5(19,2 \%)$ & $5(17,2 \%)$ & $55(100 \%)$ \\
\hline Total por niño & $26(100 \%)$ & $29(100 \%)$ & $2 \%)$ \\
\hline
\end{tabular}

En lo que respecta a la longitud del TO, observamos en la tabla 49 que la mayor parte de la actividad nula se produce cuando el TO consta de una estructura sintáctica del tipo " $1-4$ palabras", siendo $\mathrm{p}=0$ con respecto a los otros dos grupos en ambos niños.

En el caso de la complejidad del TO, tal y como aparece en la tabla 50, de los 55 casos de actividad nula, la mayor parte se produce cuando los niños se enfrentan a la traducción de sintagmas simples (siendo el p-valor cercano a 0 en todas las comparaciones) y la menor proporción de este tipo de actividad se corresponde con aquellos casos en los que tienen que traducir un sintagma complejo. Este resultado parece indicar que no es precisamente la complejidad sintáctica del TO lo que les impide llevar a cabo el proceso de traducción, algo que ya ha quedado patente desde el momento en el que, en el análisis de TTNN que hemos realizado en anteriores apartados y ante los ejemplos que hemos mostrado, tanto la longitud como la complejidad del TO de dichas traducciones se caracteriza por su gran variedad tipológica.

Por tanto, no podemos decir que estos aspectos lingüísticos relacionados con el TO nos ayuden a encontrar motivos por los cuales los niños no traducen. Al mismo tiempo, si seguimos partiendo de los resultados mostrados en las tablas 49 y 50, tampoco existen diferencias significativas entre Simon y Leo en lo que respecta a la proporción de casos en función de la longitud del TO, siendo la única diferencia significativa $(p=0,03)$ entre 
ambos la que se localiza en la complejidad del TO: Leo realiza más casos de actividad nula cuando se enfrenta a la traducción de una oración simple (11 casos) que Simon (4 casos).

La cuestión final que nos faltaría por plantear en estas dos variables sería la relacionada con el componente longitudinal del estudio, para lo cual recurriremos, en primer lugar, a los resultados reflejados en las tablas 51 y 52 para la variable de la longitud del TO, y, posteriormente en las tablas 53 y 54, para los resultados de la variable de la complejidad del TO, con objeto de que podamos interpretar mejor lo que sucede con la actividad nula de traducción.

\begin{tabular}{|c|ccc|c|}
\hline \multicolumn{2}{|c|}{ TABLA 51. LA LONGITUD DEL TO EN LA ACTIVIDAD NULA DE TRADUCCIÓN DE SIMON POR ETAPAS } \\
\hline & $\mathbf{1 - 4}$ palabras & $\mathbf{7 - 1 4}$ palabras & $\mathbf{+ 1 4}$ palabras & Total por etapas \\
\hline Inicial (2,00-3;00) & $4(21 \%)$ & 0 & 0 & $4(15,4 \%)$ \\
Intermedia (3;05-4;05) & $4(21 \%)$ & 0 & 0 & $4(15,4 \%)$ \\
Final (4;09-6;03) & $11(58 \%)$ & $3(100 \%)$ & $4(100 \%)$ & $18(69,2 \%)$ \\
\hline Total por longitud & $19(100 \%)$ & $3(100 \%)$ & $4(100 \%)$ & $26(100 \%)$ \\
\hline
\end{tabular}

\begin{tabular}{|c|ccc|c|}
\hline \multicolumn{6}{|c|}{ TABLA 52. LA LONGITUD DEL TO EN LA ACTIVIDAD NULA DE TRADUCCIÓN DE LEO POR ETAPAS } \\
\hline & $\mathbf{1 - 4}$ palabras & $\mathbf{7 - 1 4}$ palabras & $\mathbf{+ 1 4}$ palabras & Total por etapas \\
\hline Inicial (2,00-3;00) & $14(63,6 \%)$ & 0 & 0 & $14(48,3 \%)$ \\
Intermedia (3;05-4;05) & 0 & 0 & 0 & 0 \\
Final (4;09-6;03) & $8(36,4 \%)$ & $5(100 \%)$ & $2(100 \%)$ & $15(51,7 \%)$ \\
\hline Total por longitud & $22(100 \%)$ & $5(100 \%)$ & $2(100 \%)$ & $29(100 \%)$ \\
\hline
\end{tabular}

En las tablas 51 y 52 se refleja que la actividad nula de ambos niños se produce en las etapas inicial e intermedia solamente cuando se enfrentan a un TO que está constituido por una sola palabra o un grupo de dos a cuatro palabras, mientras que en la etapa final se da una mayor variedad de longitud, también en ambos niños, aunque sigue siendo la actividad nula más numerosa cuando el enunciado que van a traducir es más corto (de una a cuatro palabras). Esto nos indica que, tanto en la etapa inicial, cuando su desarrollo lingüístico aún es limitado, como en la etapa final, cuando su conocimiento lingüístico ha evolucionado, pueden tener vacíos léxicos a la hora de traducir, que no tienen por qué corresponderse ni con la carencia de EET (que es lo que defienden autores como Volterra y 
Taeschner 1978, entre otros) ni con la posible preferencia de una lengua sobre la otra (como plantea Pearson et al. 1995, entre otros) [ver el apartado 3.2. del capítulo 1]. Es más, tal y como plantearemos más adelante cuando tratemos los factores contextuales, habrá otros motivos por los cuales los niños no traduzcan que pueden venir determinados tanto por cuestiones lingüísticas como por cuestiones pragmáticas, tal y como proponen otros autores (Poplack 1981; Grosjean 1982; Romaine 1989; entre otros) cuando analizan la AC y como hemos propuesto también nosotros para analizar específicamente los casos de TN [ver el apartado 5.2.2. del capítulo 1 para la propuesta de otros autores y el 1.3. del capítulo 4 para la nuestra]. Además, otro de los posibles factores que pueden propiciar la existencia de casos de actividad nula es la falta de interés por parte de los niños, ya que puede resultar mucho más atractivo ayudar a los investigadores para que sigan jugando (de ahí la mayor cantidad de casos de actividad nula en la última etapa) que satisfacer las demandas lingüísticas de la madre (sobre todo en la primera etapa), que sigue la fórmula de una persona-una lengua, pero que es bilingüe, una circunstancia que no pasa desapercibida a los niños.

En cuanto a las diferencias que surgen entre ambos niños a lo largo del período observado, aludiremos concretamente a dos: en la etapa inicial existe una diferencia significativa entre ambos $(p=0,003)$, pues Leo deja de traducir en 14 ocasiones frente a las 4 de Simon cuando el TO está compuesto por una palabra o una estructura que abarca de una a cuatro palabras, mientras que en la etapa intermedia la situación se invierte, pues es Simon el que deja de traducir en 4 ocasiones frente a la ausencia de casos de este tipo en Leo, siendo esta diferencia significativa $(p=0,01)$.

En segundo lugar, hemos de recurrir al componente longitudinal de la actividad nula de traducción desde el punto de vista de la complejidad sintáctica del TO, para lo cual, tendremos en cuenta las tablas 53 y 54.

\begin{tabular}{|c|cccc|c|}
\hline \multicolumn{7}{|c|}{ TABLA 53. LA COMPLEJIDAD DEL TO EN LA ACTIVIDAD NULA DE TRADUCCIÓN DE SIMON POR ETAPAS } \\
\hline & $\begin{array}{c}\text { Sintagma } \\
\text { simple }\end{array}$ & $\begin{array}{c}\text { Sintagma } \\
\text { complejo }\end{array}$ & $\begin{array}{c}\text { Oración } \\
\text { simple }\end{array}$ & $\begin{array}{c}\text { Oración } \\
\text { compleja }\end{array}$ & $\begin{array}{c}\text { Total por } \\
\text { etapa }\end{array}$ \\
\hline Inicial (2,00-3;00) & $4(26,7 \%)$ & 0 & 0 & 0 & $4(15,4 \%)$ \\
Intermedia (3;05-4;05) & $2(13,3 \%)$ & $1(50 \%)$ & $1(25 \%)$ & 0 & $4(15,4 \%)$ \\
Final (4;09-6;03) & $9(60 \%)$ & $1(50 \%)$ & $3(75 \%)$ & $5(100 \%)$ & $18(69,2 \%)$ \\
\hline Total por complejidad & $15(100 \%)$ & $2(100 \%)$ & $4(100 \%)$ & $5(100 \%)$ & $26(100 \%)$ \\
\hline
\end{tabular}




\begin{tabular}{|c|cccc|c|}
\hline \multicolumn{7}{|c|}{ TABLA 54. LA COMPLEJIDAD DEL TO EN LA ACTIVIDAD NULA DE TRADUCCIÓN DE LEO POR ETAPAS } \\
\hline & $\begin{array}{c}\text { Sintagma } \\
\text { simple }\end{array}$ & $\begin{array}{c}\text { Sintagma } \\
\text { complejo }\end{array}$ & $\begin{array}{c}\text { Oración } \\
\text { simple }\end{array}$ & $\begin{array}{c}\text { Oración } \\
\text { compleja }\end{array}$ & $\begin{array}{c}\text { Total por } \\
\text { etapa }\end{array}$ \\
\hline Inicial (2,00-3;00) & $8(61,5 \%)$ & 0 & $6(54,5 \%)$ & 0 & $14(48,3 \%)$ \\
Intermedia (3;05-4;05) & 0 & 0 & 0 & 0 & 0 \\
Final (4;09-6;03) & $5(38,5 \%)$ & 0 & $5(45,5 \%)$ & $5(100 \%)$ & $15(51,7 \%)$ \\
\hline Total por complejidad & $13(100 \%)$ & 0 & $11(100 \%)$ & $5(100 \%)$ & $29(100 \%)$ \\
\hline
\end{tabular}

Según estas tablas, la actividad nula de traducción se produce sobre todo cuando el TO es un sintagma simple, siendo las diferencias significativas más importantes entre ambos niños las que transcurren fundamentalmente en la etapa inicial: la primera de dichas diferencias $(p=0,03)$ ocurre cuando Leo tiene que traducir sintagmas simples (en 8 ocasiones frente a las 4 de Simon) y la segunda $(\mathrm{p}=0,02)$ cuando tiene que traducir oraciones simples (en 6 ocasiones frente a la ausencia de este tipo de actividad nula en Simon).

A partir de estos resultados podemos plantear que es en la etapa inicial donde Leo encuentra más dificultades que Simon para traducir sintagmas y oraciones simples, lo cual se corresponde con la situación que veíamos en los resultados relacionados con la longitud del TO, ya que este mismo sujeto también refleja una diferencia significativa con Simon cuando tiene que traducir un TO compuesto por una palabra o una estructura que abarca de dos a cuatro palabras.

Como conclusión general a este apartado, podemos decir que los sujetos de nuestro estudio abortan el proceso de traducción en la etapa inicial y en la intermedia, cuando tienen que traducir sintagmas u oraciones simples que están formados por una palabra o por un grupo de palabras (hasta cuatro), un resultado, pues, que nos indica que no es la complejidad sintáctica del TO lo que explica la ausencia de TN.

Una vez examinadas las variables lingüísticas que pueden determinar la actividad nula de traducción, procederemos, a continuación, a considerar si los factores más externos a la producción lingüística pueden tener una mayor o menor influencia a la hora de que los sujetos de nuestro estudio no produzcan traducciones en situaciones en las que se requerirían este tipo de producciones. 


\subsubsection{Las variables contextuales en la actividad nula de traducción}

Como factores externos a la actividad de traducción o, en este caso, a la falta de ella, tendremos en cuenta las mismas variables que para el análisis de las TTNN en los anteriores apartados: la presencia o ausencia de un estímulo verbal por parte de otros interlocutores y la procedencia del enunciado origen.

\subsubsection{La presencia/ausencia de estímulo}

De esta manera, consideramos importante tener en cuenta el papel que haya podido tener en la actividad nula de traducción la variable relacionada con el estímulo verbal para que los niños traduzcan (por iniciativa propia o inducida), así como el interlocutor que haya actuado de inductor (padres o investigadores), con el fin de poder encontrar algún tipo de patrón relacionado con la actividad nula. Para ello, mostraremos en las tablas $55 \mathrm{y}$ 56 los resultados obtenidos por cada niño acerca de la actividad nula en relación al papel del estímulo y del inductor, respectivamente.

\begin{tabular}{|c|cc|c|}
\hline \multicolumn{4}{|c|}{ TABLA 55. LA PRESENCIA/AUSENCIA DE ESTÍMULO EN LA ACTIVIDAD NULA DE TRADUCCIÓN DE SIMON Y } \\
\hline & Simon & Leo & Total por ausencia/presencia de estímulo \\
\hline Iniciativa propia & $5(19,2 \%)$ & $3(10,3 \%)$ & $8(14,5 \%)$ \\
Inducida & $21(80,8 \%)$ & $26(89,7 \%)$ & $47(85,5 \%)$ \\
\hline Total por niño & $26(100 \%)$ & $29(100 \%)$ & $55(100 \%)$ \\
\hline
\end{tabular}

\begin{tabular}{|c|cc|c|}
\hline \multicolumn{4}{|c|}{ TABLA 56. EL INDUCTOR EN LA ACTIVIDAD NULA DE TRADUCCIÓN DE SIMON Y LEO } \\
\hline & Simon & Leo & Total por inductor \\
\hline Padres & $3(14,3 \%)$ & $10(38,5 \%)$ & $13(27,7 \%)$ \\
Investigadores & $18(85,7 \%)$ & $16(61,5 \%)$ & $34(72,3 \%)$ \\
\hline Total por niño & $21(100 \%)$ & $26(100 \%)$ & $47(100 \%)$ \\
\hline
\end{tabular}

Es posible que resulte extraña la mezcla de una traducción realizada por "iniciativa propia" pero que resulte nula en el proceso traductor. Esto es lo que sucede cuando al niño se le pone en la situación en la que existe la posibilidad de que traduzca por iniciativa 
propia, sin que la reacción del interlocutor suponga necesariamente un estímulo verbal y expreso para que traduzca. Como ejemplo, podemos mostrar el de (107), donde Melanie les insiste a ambos niños para que le digan exactamente a qué libro se refieren con "ese” y no necesariamente a que traduzcan y digan "that book" en inglés. De hecho, por iniciativa propia ninguno de los niños traduce en este ejemplo, sino que utilizan la función deíctica del determinante demostrativo ("ese”), acompañándola con la acción extralingüística de traer en las manos el libro al que se refieren.

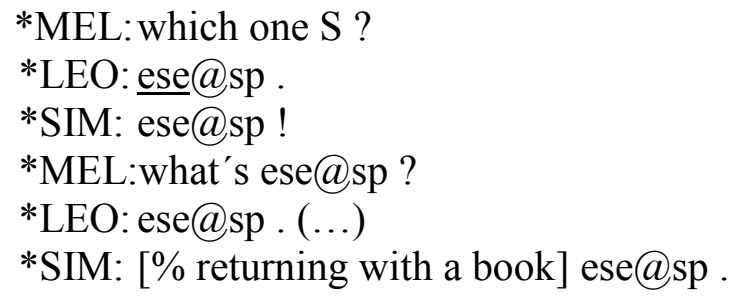

En todo caso, por los resultados mostrados en la tabla 55 está claro que este tipo de circunstancias no son las más frecuentes, sino que la mayor parte de la actividad nula de traducción $(\mathrm{p}=0)$ se da en ambos niños cuando las traducciones vienen inducidas. Para profundizar más en esta conclusión, los datos incluidos en la tabla 56 nos indican que existen diferencias entre Simon y Leo, pues Leo deja de traducir en una proporción mayor que Simon cuando quien le induce a traducir es uno de sus progenitores (la madre, la mayoría de las veces) y, en cambio, Simon deja de traducir en una proporción más alta que Leo cuando el inductor es un investigador, siendo ambas diferencias significativas con un p-valor equivalente a 0,03 . Este resultado, por tanto, coincide con el obtenido en el caso de las TTNN per se, es decir, existe una relación directamente proporcional entre ambos tipos de producciones: a mayor proporción de TTNN, mayor proporción de actividad nula.

Por tanto, también en la actividad nula de traducción podemos encontrar que el tipo de estímulo, pero sobre todo el inductor, da lugar a que existan diferencias en el comportamiento de nuestros sujetos en relación a dicha actividad, de tal forma que, dependiendo de quién les pida que traduzcan, lo hacen o no. Es más, al igual que sucedía con las TTNN, dicho comportamiento guarda una relación estrecha con el análisis longitudinal, tal y como se observa en la tablas 57. 


\begin{tabular}{|c|cc|c|}
\hline \multicolumn{4}{|c|}{ TABLA 57. EL INDUCTOR EN LA ACTIVIDAD NULA DE TRADUCCIÓN DE SIMON Y DE LEO POR ETAPAS } \\
\hline & Investigadores & Padres & Total por etapas \\
\hline Inicial (2,00-3;00) & $1(3 \%)$ & $12(92,3 \%)$ & $13(27,6 \%)$ \\
Intermedia (3;05-4;05) & $2(5,9 \%)$ & $1(7,7 \%)$ & $3(6,4 \%)$ \\
Final (4;09-6;03) & $31(91,1 \%)$ & 0 & $31(66 \%)$ \\
\hline Total por inductor & $34(100 \%)$ & $13(100 \%)$ & $47(100 \%)$ \\
\hline
\end{tabular}

Según la tabla 57, en la etapa inicial la actividad nula que aparece se da casi exclusivamente es uno de los progenitores quien les incita a traducir (12 casos frente a 1); en la etapa intermedia el porcentaje del tipo de inductores se equilibra, mientras que en la etapa final los niños no traducen únicamente cuando los investigadores les solicitan traducciones, ya que en dicha etapa son los únicos que les incitan a traducir.

En el siguiente apartado, observaremos si otro factor externo como la procedencia del TO puede tener una influencia semejante en la ausencia de traducción.

\subsubsection{La procedencia del TO}

Partiendo de la tabla 58, tendremos en cuenta la variable relacionada con la procedencia del enunciado origen con el fin de observar si existe alguna influencia de este factor en la frecuencia de la actividad nula de traducción.

\begin{tabular}{|c|cc|c|}
\hline \multicolumn{4}{|l|}{ TABLA 58. LA PROCEDENCIA DEL TO EN LA ACTIVIDAD NULA DE TRADUCCIÓN DE SIMON Y LEO } \\
\hline & Simon & Leo & Total por procedencia del \\
\hline Autotraducción & $12(46,2 \%)$ & $12(41,4 \%)$ & $24(43,6 \%)$ \\
Otros interlocutores & $11(42,3 \%)$ & $16(55,2 \%)$ & $27(49 \%)$ \\
Situación & $3(11,5 \%)$ & $1(3,4 \%)$ & $4(7,4 \%)$ \\
\hline Total por niño & $26(100 \%)$ & $29(100 \%)$ & $55(100 \%)$ \\
\hline
\end{tabular}

Los resultados observados en esta tabla nos indican que no existen diferencias significativas $(\mathrm{p}=0,28)$ entre aquella actividad nula que exigiría una autotraducción y la 
que exigiría la traducción de lo que han dicho otros interlocutores (en la mayoría de las ocasiones, adultos). En cuanto a la circunstancia en la que tendrían que traducir toda una situación, es la que representa el porcentaje más bajo con respecto a los otros dos tipos $(\mathrm{p}=0)$, una circunstancia que, tal y como vimos en los apartados 3.2.2. y 2.2.3. de este capítulo, no es diferente a lo que sucede cuando el proceso traductor sí se lleva a cabo. Así, pues, en vista de estos resultados, tampoco podemos afirmar que la procedencia del enunciado origen suponga un factor de influencia a la hora de no producir traducciones. Es más, tampoco parecen existir diferencias significativas entre ambos niños en lo que respecta a esta variable, lo cual, de nuevo, indica que existe un patrón común de comportamiento en ambos niños y que, por tanto, es posible que no traduzcan independientemente de quién sea quien produzca el enunciado origen.

\subsection{Conclusiones generales acerca de la actividad nula de traducción}

A partir de los resultados obtenidos de la actividad nula de traducción en ambos niños y a lo largo del período de tiempo observado en el presente estudio, podemos establecer una serie de conclusiones generales que recogen lo que hemos venido apuntando hasta ahora acerca de dicha actividad.

En primer lugar, y desde un punto de vista global, los casos en los que la actividad de traducción ha resultado nula son muy inferiores a los casos en los que el proceso de traducción se ha llevado a cabo, lo cual indica que los niños bilingües de nuestro estudio traducen cuanto la situación lo requiere en la gran mayoría de las ocasiones.

Desde un punto de vista individual, si bien en el cómputo total de casos de actividad nula no existen diferencias significativas entre uno y otro niño, sí las hay si tenemos en cuenta las etapas en las que hemos dividido este estudio. Así, Leo no traduce en más ocasiones que Simon en la etapa inicial, mientras que en la etapa intermedia nos encontramos con la situación inversa (es Simon el que no traduce en más ocasiones que Leo). En el caso de la etapa final, a pesar de que el número de casos de este tipo se incrementa en ambos niños, no existen diferencias significativas en este tipo de producción.

En segundo lugar, en cuanto a las variables de carácter lingüístico, observamos que, en el caso de la direccionalidad, existen diferencias significativas en lo que respecta a las 
traducciones potenciales español-inglés y las traducciones potenciales inglés-español, siendo las primeras las más numerosas dentro de los casos de actividad nula recopilados en nuestro corpus de datos, tal y como sucedía con las TTNN. Si bien podríamos decir que en este resultado puede incidir el hecho de que Leo produzca más casos de actividad nula en los que tenía que haber traducido del español al inglés, también se da la circunstancia de que Simon produce significativamente más casos de actividad nula inglés-español que Leo, lo cual nos lleva a considerar que no existe un parámetro común en el comportamiento de ambos niños en lo que respecta a esta variable en la actividad nula de traducción. Un análisis desde un punto de vista longitudinal, nos indica que el comportamiento de Leo al que hemos hecho referencia tiene lugar en la primera etapa del estudio, mientras que el de Simon tiene lugar en la etapa intermedia. En cuanto a la etapa final, en la que se producen las pruebas experimentales de traducción, observamos que las diferencias significativas entre ambos sujetos se invierten, ya que es en esta ocasión Simon el que produce más casos de actividad nula español-inglés que Leo.

En tercer lugar, en cuanto a las otras variables de carácter lingüístico, hemos recurrido a la longitud del TO y a la complejidad del mismo. Atendiendo a los resultados de ambas variables y como conclusión general, consideramos que la mayor parte de la actividad nula se produce cuando el TO consta de estructuras cortas (formadas por una o varias palabras) o de sintagmas u oraciones simples y se localiza en la etapa inicial (siendo Leo el que no traduce en más ocasiones que Simon) y en la etapa intermedia (en la que destaca Simon, a diferencia de la etapa inicial). Este resultado podría llevarnos a plantear que el grado de conocimiento lingüístico que tienen los niños influye a la hora de no traducir. Sin embargo, hay que tener en cuenta que las situaciones que implican la traducción de este tipo de estructuras sintácticas no sólo se dan en las etapas inicial e intermedia, sino también en etapa final, cuando el desarrollo lingüístico de los sujetos se encuentra en un estadio más avanzado y, por tanto, sería menos esperable el encontrar una actividad nula para dichas estructuras. Por este motivo, consideramos que la longitud del TO y la complejidad sintáctica de dicho enunciado no suponen factores que influyan de forma determinante en nuestros sujetos a la hora de no traducir.

En cuarto lugar, si tenemos en cuenta las variables contextuales, podemos indicar dos conclusiones principales: por un lado, en cuanto a la procedencia del TO, podemos afirmar que no existen diferencias significativas entre ambos sujetos, ya se trate de una autotraducción, de una traducción de lo que dicen otros interlocutores o de una traducción 
situacional (la cual representa el tipo de traducción con el porcentaje más bajo, al igual que sucedía con las TTNN). Por otro lado, en cambio, si atendemos a la variable del factor ausencia/presencia de estímulo, la mayor parte de la actividad nula de traducción se produce sobre todo en aquellas ocasiones en las que la traducción resultante, en el caso de que el proceso se hubiese llevado a cabo, sería de carácter inducido. De hecho, existen diferencias significativas entre los niños en este sentido, ya que Leo no traduce en más ocasiones que Simon cuando quien le induce a traducir es uno de sus progenitores (la madre, normalmente), mientras que Simon no traduce en más ocasiones que Leo cuando el inductor de la traducción potencial es uno de los investigadores, lo cual se relaciona con los patrones de comportamiento traductor de ambos niños que hemos ido viendo a lo largo del análisis de las TTNN que han llegado a realizar.

Hasta aquí hemos realizado el análisis del corpus de casos de TN que hemos recopilado para el presente estudio y que han producido los dos sujetos de dicho estudio, un análisis en el que no sólo hemos tenido en cuenta los resultados correspondientes a la TN per se, sino también aquellos casos en los que la actividad de traducción ha resultado nula. En el último apartado correspondiente a este capítulo de análisis, aludiremos a las implicaciones de estos resultados en las diversas teorías, hipótesis y planteamientos que hemos presentado a lo largo de los capítulos anteriores de este trabajo de investigación.

\section{CONSECUENCIAS DE NUETROS RESULTADOS EN EL ACERCAMIENTO TEÓRICO A LA TN: UNIFICANDO TEORÍA Y DATOS}

El análisis que hemos presentado en el presente capítulo ha tenido como punto de partida un estudio descriptivo y explicativo de las TTNN que han realizado dos niños bilingües simultáneos, lo cual nos ha permitido observar los mecanismos lingüísticos y las estrategias comunicativas que han utilizado dichos niños en el proceso de traducción a lo largo de un período de poco más de 5 años. De esta manera, los resultados más destacables que hemos obtenido del análisis estadístico de las variables que hemos ido presentando a lo largo de este capítulo nos servirán para poder aludir a las implicaciones que pueden tener dichos resultados en los planteamientos teóricos que ya expusimos en capítulos anteriores. 
De esta manera, a continuación intentaremos reflejar en los apartados siguientes cómo los resultados obtenidos en nuestro análisis nos pueden ayudar a diferenciar la TN de otros fenómenos característicos de la adquisición bilingüe como la $\mathrm{AC}$, así como cuestiones más relacionadas con la facultad del lenguaje del hablante bilingüe y la organización léxica de este. Seguidamente, procederemos a destacar las implicaciones de nuestros resultados en algunas cuestiones incluidas en la literatura sobre la adquisición bilingüe que hacen referencia al desarrollo lingüístico del niño bilingüe y la influencia de determinados factores contextuales. A su vez, estas implicaciones se tendrán en cuenta a la hora de retomar algunas de las características fundamentales de la TN que hemos apuntado a lo largo del presente trabajo de investigación y, finalmente, dedicaremos un apartado a la comparación de los resultados obtenidos en el análisis de las TN realizadas por nuestros sujetos y los obtenidos con respecto a la actividad nula de traducción, presente también en nuestro corpus.

\subsection{La distinción tipológica entre la $\mathrm{TN}$ y la AC}

Los niños bilingües de nuestro estudio producen muchos más casos de TTNN per se que de actividad nula de traducción, lo cual supone un resultado importante para poder afirmar que estos dos niños bilingües son capaces de poner en juego una serie de mecanismos y estrategias lingüísticos y comunicativos que les permite llevar a término el proceso de traducción la mayor parte de las veces que lo demanda la situación comunicativa.

De esta manera, en una gran parte de las TTNN recopiladas nuestros sujetos llegan a completar el proceso de traducción, pues las traducciones incompletas (o con AC) que realizan son muy inferiores en número (y en proporción) a las traducciones completas ( 9 casos frente a 154). Este resultado nos lleva a plantear que estos niños bilingües pueden utilizar las dos lenguas mezclándolas en los casos de AC o separándolas en la labor de traducción cuando la situación así lo requiere, tal y como habían planteado anteriormente estudios como los de Srivastava y Gupta (1989) y Fernández Fuertes et al. (en prensa) [ver los apartados 4.5. y 2.1. de los capítulos 1 y 3 , respectivamente].

Esta última afirmación trae consigo que, a su vez, consideremos importante la cuestión que hace referencia a la distinción tipológica que hemos establecido entre los 
casos de AC y los casos de TN. Estos dos fenómenos son característicos de la adquisición bilingüe y pueden tener propiedades similares en cuanto que, según nuestra propuesta terminológica [ver el apartado 1.1. del capítulo 3], ambos constituyen tipos de mezclas de lenguas que puede producir un hablante bilingüe. Sin embargo, tal y como hemos visto en los casos recopilados en el presente estudio, un tipo de mezcla no implica necesariamente la otra, ya que la TN constituye un cambio de códigos (con un trasvase de significado de una lengua a otra) y no una alternancia (sin un trasvase de significado). Es más, este tipo de distinción nos ha permitido estudiar los casos de TN como casos diferentes a los de la $\mathrm{AC}$ y, por tanto, diferenciar formal y conceptualmente las traducciones completas ( $\sin \mathrm{AC}$ en el TM) de las traducciones incompletas (con AC). La conclusión a la que hemos llegado a este respecto tras el análisis estadístico es que los niños producen significativamente más traducciones completas que incompletas, de ahí que, a la hora de estudiar la TN, se hayan tenido en cuenta los casos de traducción incompleta aunque no sean tan numerosos como los de traducción completa.

Por tanto, consideramos que el número de casos de $\mathrm{TN}$ que hemos recopilado supone una cantidad suficiente para tenerla en cuenta en el estudio de fenómenos característicos de la adquisición bilingüe y, al mismo tiempo, para analizarla como un fenómeno con entidad propia que puede estar relacionado con la AC pero no necesariamente.

\subsection{La organización léxica del individuo bilingüe}

El hecho de que afirmemos que los niños bilingües de nuestro estudio son capaces de separar las dos lenguas en la labor de traducción tiene, a su vez, una serie de implicaciones desde el punto de vista de las propuestas de la organización del lexicón en la mente de un bilingüe.

Así, a diferencia de lo que propone Romaine (1989), consideramos que, a la vista de los resultados globales de nuestro análisis, los niños de nuestro estudio no serían capaces realizar ni un solo caso de TTNN si partieran de una mezcla de lexicones y una sola FL. De hecho, tal y como expusimos en el capítulo 3 [ver el diagrama 15 del apartado 1.3.1.], consideramos que precisamente el hecho de que dispongan de dos lexicones separados (uno por cada lengua) y una FL común que les permite establecer una relación 
semántica entre el TO y el TM es lo que hace que estos niños no sólo lleguen al final del proceso de traducción incluso en edades muy tempranas sino que, además, recurran a una variedad tipológica de TTNN desde el punto de vista semántico-conceptual (emparejamientos, así como traducciones económicas y expansivas). En este sentido, si retomamos lo planteado por autores como Kroll et al. (1998), Hell y De Groot (1998) o Kroll y Tokowic (2001), entre otros [ver el apartado 1.1. del capítulo 2] acerca de la traducción en adultos bilingües secuenciales, consideramos que los niños bilingües simultáneos de nuestro estudio, a diferencia de este tipo de hablantes, no comienzan accediendo a los conceptos de una de las lenguas a través de la traducción de las palabras de la otra lengua, sino que acceden al componente semántico-conceptual (o FL) directamente seleccionando los rasgos incluidos en dicha FL que consideren más óptimos para cada situación de traducción. Es más, en el proceso de traducción, han de partir de la FL del TO para poder expresar un TM, por lo que podríamos apuntar que el proceso de traducción en el caso de nuestros sujetos se correspondería con una mediación conceptual directa y, por tanto, a diferencia de los bilingües secuenciales adultos, se comportarían como hablantes bilingües compuestos desde las primeras etapas de su desarrollo bilingüe, es decir, con dos lexicones separados y una sola representación conceptual [ver los diagramas 2 y 6 de los apartados 1 y 2.2., respectivamente, del capítulo 1].

Al mismo tiempo, y al hilo de lo que acabamos de concluir, el hecho de que nuestros sujetos sean capaces de separar las lenguas (es decir, en el caso de este estudio, de traducir de una lengua a otra) para responder a determinadas demandas comunicativas, nos lleva a abordar la cuestión de en qué medida nuestros datos nos ayudan a apoyar la hipótesis de la separación de los sistemas lingüísticos desde el comienzo del desarrollo lingüístico bilingüe en nuestros sujetos o, por el contrario, a rechazarla, una cuestión que trataremos en el siguiente apartado. 


\subsection{Las etapas del desarrollo lingüístico en el niño bilingüe y la influencia de los factores contextuales}

Tal y como hemos observado a partir de los resultados obtenidos en el análisis longitudinal de los casos de TN en los dos niños bilingües de nuestro estudio, desde la primera etapa que hemos establecido en el presente estudio $(2 ; 00-3 ; 00)$ estos niños utilizan ya EET en proporciones elevadas (66 casos del total de 172) y en contextos apropiados, es decir, realizan TTNN tempranas (o lo que autores como Vihman (1985) denominan “yuxtaposición de EET”, como veíamos en el apartado 3.3. del capítulo 1). Este resultado vendría a apoyar la hipótesis de que los niños ya en esa etapa tienen una conciencia bilingüe que les permite controlar el manejo de las dos lenguas a través de las TTNN que realizan en las que, además, existe una correspondencia semántico-conceptual entre el TO y el TM. Es decir, a igual que autores como Swain (1972a/b), Swain y Wesche (1975) y Lindholm y Padilla (1978b) [ver el apartado 2.2.1. del capítulo 2], consideramos que precisamente porque son conscientes de la diferenciación de lenguas, los niños de nuestro estudio pueden realizar TTNN.

Al mismo tiempo, el que estos niños utilicen medios lingüísticos diferentes para expresar las mismas funciones semántico-conceptuales en ambas lenguas (por iniciativa propia o inducidos por otro interlocutor) evidencia que los niños ya tienen los dos sistemas lingüísticos separados a los 2;00 años y que no hay que esperar a los 3;00 años para hablar de esta diferenciación, tal y como proponían Volterra y Taeschner (1978) o los partidarios de la hipótesis del sistema lingüístico unitario [ver el apartado 3 del capítulo 1].

Así pues, consideramos que nuestros resultados apoyan la hipótesis de la diferenciación (Meisel 1989, 2001; De Houwer 1990, 1995; Lanza 1992, 1997; Quay 1995; Wapole 2000, entre otros), la cual, además, considera que para explicar la presencia de determinados fenómenos lingüísticos en el desarrollo bilingüe (como la $\mathrm{AC}$ ), hay que tener en cuenta el entorno comunicativo en el que se desarrollan los niños (Genesee 1989, 2001; Paradis y Genesee 1996; Nicoladis y Paradis 1996). En esta misma línea, se observa que la producción de TTNN en ambos niños en la segunda etapa que hemos planteado (3;05-4;05 años) disminuye hasta 13 casos debido a la influencia de los factores contextuales que hemos reflejado en algunas de las variables de nuestro análisis. Concretamente, y tal y como plantea Genesee (2001), [ver el apartado del capítulo] las estrategias comunicativas seguidas por los padres con sus hijos pueden influir en la 
diferenciación inicial de las dos lenguas. De esta manera, esta influencia es evidente en nuestro estudio, puesto que los padres (sobre todo la madre), al insistir en mantener la fórmula de "una persona-una lengua" [ver el apartado 1.2. del capítulo 4], son los responsables de la mayor parte de las TTNN que realizan sus hijos en la primera etapa. Una vez que los padres consideran que esta fórmula ya no es necesaria mantenerla, los casos de TN disminuyen, pues los niños ya la han internalizado y no les demandan que traduzcan con tanta frecuencia, de ahí la disminución de casos de TN en la segunda etapa.

Finalmente, en la última etapa se observa un aumento en la producción de TTNN en ambos niños, la mayoría de las cuales se incluyen en las pruebas experimentales de traducción. Sin embargo, tal y como hemos demostrado en nuestro análisis de datos, en esta etapa, a diferencia de la inicial o la intermedia, los inductores ya no son los padres sino los investigadores, que son los que inducen constantemente a los niños para que traduzcan como objetivo fundamental de dichas pruebas. De esta manera, hemos constatado que determinados contextos comunicativos influyen de manera clara en el tipo de producción traductora de los niños a lo largo de las tres etapas, pues si bien en las dos primeras etapas la mayoría de las traducciones se corresponden fundamentalmente con emparejamientos léxicos que no responden a una necesidad comunicativa (sobre todo las autotraducciones que realiza Leo de español a inglés), en el caso de las pruebas experimentales, la mayor parte de las traducciones son expansivas $\mathrm{y}$, sobre todo, económicas (de enunciados procedentes de otros interlocutores que son traducidos sobre todo por Simon y la mayoría de las veces de inglés a español).

Como conclusión general de este apartado, podemos afirmar que los factores contextuales pueden llegar a determinar algunos de los comportamientos de los niños bilingües de nuestro estudio a lo largo de su desarrollo como traductores. Sin embargo, no siempre hemos podido recurrir a estos factores para explicar, por ejemplo, por qué uno de los sujetos, Simon, concretamente, produce una mayor cantidad de traducciones que su hermano Leo. Por este motivo, hemos apuntado otros posibles factores que se relacionan con la mayor capacidad comunicativa del primer niño frente al segundo pero que pertenecen a ámbitos de estudio diferentes al planteado en el presente trabajo de investigación.

Centrándonos en el análisis que hemos realizado, mostraremos a continuación los resultados más destacables en relación al tipo de TTNN que hemos encontrado desde el 
punto de vista semántico-conceptual en el que también han tenido una gran influencia los factores contextuales que acabamos de mencionar.

\subsection{Las TTNN del presente estudio y el concepto de TN}

El análisis estadístico de las TTNN recopiladas a partir de la variable 2 o aquella relacionada con el componente semántico-conceptual de dichas traducciones, nos ofrece resultados interesantes en cuanto al proceso de traducción que siguen los niños bilingües de nuestro estudio, así como al concepto de TN que hemos venido manejando a lo largo del presente trabajo de investigación [ver los apartados 3.3. y 1.3. de los capítulo 2 y 3 , respectivamente]. En este sentido, el primer resultado que hemos obtenido es que los niños pueden realizar tanto traducciones en las que la FL es equivalente como traducciones con una FL no equivalente, de tal forma que un análisis más profundo de esta variable revela que es el primer tipo de traducciones el que los niños realizan con mayor frecuencia, siendo, a su vez, el emparejamiento de ítems que no responde a una necesidad comunicativa el más numeroso.

A pesar de que este resultado pudiera parecer contradictorio con la afirmación de que la TN tiene la finalidad fundamental de comunicar un mensaje, hay que tener en cuenta que este tipo de traducciones no se dan de forma indiscriminada sino controlada, pues responden a necesidades comunicativas personales (las que realizan por iniciativa propia) o a determinadas demandas del contexto comunicativo (procedentes de sus interlocutores), tal y como hemos visto en el apartado anterior. Así, la mayor parte de las TTNN se corresponden con emparejamientos léxicos que no responden a una necesidad comunicativa puesto que suelen ser inducidos por Melanie, la madre, para que expresen en inglés lo que acaban de decir en español o, dicho de otro modo, para que se autotraduzcan. Las autotraducciones de este tipo (concretamente de español a inglés) son las que más predominan en la primera etapa del desarrollo lingüístico por la razón que esgrimíamos anteriormente y que está relacionada con la fórmula "una persona-una lengua" que mantienen los padres con estos niños bilingües, sobre todo durante la primera etapa. Si atendemos a la clasificación de TTNN que proponen Harris (1980b) y Harris y Sherwood (1978) [ver el apartado 2.2.1. del capítulo 2], estas autotraducciones son de carácter interpersonal puesto que el niño traduce a otro interlocutor lo que acaba decir aunque, a diferencia de lo que plantean estos autores, no sólo con el fin de que su interlocutor 
monolingüe les entienda sino, y sobre todo, para atender la petición de traducción que suele dirigirles su madre (hablante bilingüe inglés/español). Desde este punto de vista, este segundo tipo de emparejamiento tendría una función redundante, puesto que la madre les entiende igualmente si se comunican con ella en español. Sin embargo, sigue respondiendo a una finalidad contextual: la de respetar la separación pragmática de las lenguas maternas de cada uno de sus progenitores.

Finalmente, y siguiendo con el planteamiento de Harris (1980a/b) que, en definitiva, es el que incluye el único intento de clasificación de TTNN del que disponemos hasta el momento, nos gustaría señalar que si bien este autor alude a que la interpretación (o captación del mensaje o del sentido) encaja de forma más precisa en el concepto de TN que lo que denomina transcodificación (o traducción de estructuras lingüísticas), nuestros resultados demuestran que es esta última estrategia o modalidad de traducción (representadas en los casos de emparejamientos léxicos) la que más utilizan los niños bilingües de nuestro estudio. Sin embargo, esto no significa que estos emparejamientos sean meras transcodificaciones o transposiciones literales y elementales, como afirmaban algunos teóricos de la traducción como Lörscher (1988, 1992), por ejemplo [ver el apartado 2.2.4. del capítulo 2]. De hecho, son traducciones en las que los niños demuestran que son capaces de evaluar equivalencias de significado al mismo tiempo que prestan atención a la equivalencia formal, de ahí que consideremos que, a diferencia de lo que hemos venido planteando a lo largo de los capítulos anteriores, podamos afirmar que en la mayor parte de las TTNN que realizan nuestros sujetos, el componente formal tiene tanta importancia como el componente semántico.

Esta última afirmación no implica, sin embargo, que los niños bilingües de este estudio sólo realicen emparejamientos léxicos pues, si este fuese el caso, la competencia de traducción se limitaría exclusivamente a una competencia bilingüe (como planteaba Toury 1986 en el apartado 2.2.3. del capítulo 2). De hecho, como hemos comprobado en los diversos apartados de análisis (sobre todo en lo referente a la variable 2), la competencia traductora en desarrollo de estos niños les permite utilizar otras técnicas de traducción en las que la equivalencia semántica no es total, como es el caso de las traducciones expansivas y las económicas. Suelen utilizar este tipo de traducciones especialmente en las pruebas de traducción correspondientes a la etapa final donde traducen estructuras lingüísticas mucho más complejas que pueden llegar a constituir desde uno o dos enunciados hasta toda una conversación. 
Precisamente en relación a la dificultad sintáctica de las estructuras lingüísticas que han de traducir, algunos autores (Harris 1978; Malakoff y Hakuta 1991; Malakoff 1991) [ver apartado 2.2. del capítulo 2] han aludido a los errores o la baja calidad de las traducciones realizadas por niños bilingües. Por este motivo, a continuación realizaremos desde un punto de vista general una comparación entre los resultados obtenidos para la TN per se y los obtenidos para la actividad nula de traducción con el fin de observar si existen diferencias o semejanzas en el comportamiento traductor de nuestros sujetos que nos indiquen la causa o las causas por las cuales en la mayoría de los casos se completó el proceso traductor y por qué en otros este proceso quedó anulado.

\subsection{La comparación de la TN con la actividad nula de traducción}

Con el fin de comparar la TN con la actividad nula de traducción, tendremos en cuenta las conclusiones generales obtenidas a partir del análisis estadístico de cada una de estas producciones, intentando apuntar las diferencias y semejanzas que se pueden establecer entre ambas.

En primer lugar, podemos afirmar que la cantidad de casos en los que la actividad de traducción ha resultado nula es muy inferior a la de TTNN recopiladas para el presente estudio (55 casos frente a 172), por lo que es evidente que los niños consiguen completar el proceso de traducción en la mayoría de los contextos que así lo requieren.

Desde el punto de vista longitudinal, en cambio, sí existen semejanzas entre ambos tipos de producción ya que también la actividad nula se produce a lo largo de las tres etapas que hemos establecido, disminuyendo en la etapa intermedia y volviendo a aumentar en la etapa final.

Sin embargo, a diferencia de lo que sucedía con la producción de TTNN y tal y como hemos visto en el apartado dedicado al análisis de la actividad nula, el número de ocasiones en las que ambos niños no traducen es bastante parejo (26 en el caso de Simon y 29 en el caso de Leo), por lo que podemos afirmar que el que Simon produzca más TTNN que su hermano Leo no implica necesariamente que se encuentre también con más casos en los que la actividad de traducción ha resultado nula.

En segundo lugar, y al igual que sucedía con las TTNN, la mayoría de las traducciones que han resultado nulas se corresponden con la dirección español-inglés en la 
primera y segunda etapas (sobre todo por parte de Leo), mientras que en la etapa final, las traducciones nulas se corresponden sobre todo con traducciones potenciales de inglés a español, al igual que sucedía con las TTNN, siendo el responsable de esta mayor proporción en este caso Simon.

En tercer lugar, como ya comentamos en el apartado 4.2., si bien parece que la actividad nula ocurre la mayor parte de las veces cuando tienen que traducir enunciados cortos o sintagmas u oraciones simples (sobre todo en la etapa inicial e intermedia), hay que tener en cuenta que también en la producción de TTNN se incluyen este tipo de estructuras sintácticas y, además, en todas las etapas. Por este motivo, consideramos que el desarrollo lingüístico de los sujetos no tiene por qué influir a la hora de no traducir y que pueden existir otras causas que incidan en la frecuencia de la actividad nula de traducción como pueden ser los vacíos léxicos o causas más subjetivas (están cansados, no quieren, se aburren, etc.), que no entran dentro del ámbito de estudio del presente trabajo de investigación.

En cuarto y último lugar, en cuanto a las variables contextuales, ya hemos visto cómo el tipo de estímulo y la procedencia del TO afectan a la producción de TTNN. En el caso de la actividad nula de traducción, la procedencia del TO no parece afectar a la frecuencia de casos en los que los niños no traducen. Sin embargo, al igual que sucede con los casos de TN, sí existen diferencias entre ambos niños dependiendo de quién sea el inductor. De hecho, el patrón de comportamiento que se observa en los casos de actividad nula de traducción es paralelo al observado en los casos de TN: Leo suele no traducir en más ocasiones cuando quien le induce a traducir es su madre (normalmente), mientras que Simon no traduce en más ocasiones cuando el inductor es uno de los investigadores.

Así pues, en el caso de la actividad nula de traducción pueden existir patrones de comportamiento semejantes a los que aparecen en la producción de TTNN, lo cual implica que, si bien existen diferencias en cuanto a estos dos tipos de producciones, también existen semejanzas que justifican el análisis que hemos hecho de este tipo de producción en el que, a pesar de que no se han seguido todos los pasos del proceso de traducción hasta el final, se obtienen resultados interesantes que nos ayudan a profundizar en el estudio de los factores (lingüísticos y contextuales) que caracterizan la TN. 


\section{CONCLUSIONES}

En este apartado recogeremos, en primer lugar, las aportaciones del presente estudio de investigación relacionadas con (1) la terminología que distingue la traducción natural $(\mathrm{TN})$ de otros fenómenos característicos de la adquisición bilingüe como la alternancia de códigos (AC), (2) con las variables propuestas para el análisis de la TN y (3) con el análisis lingüístico de la TN. En segundo lugar, y en concreto sobre este tercer punto, aludiremos a las distintas hipótesis que hemos propuesto y las correspondientes conclusiones a las que hemos llegado a raíz de los resultados de dicho análisis. En tercer lugar, presentaremos las implicaciones que trae consigo este estudio para distintos campos de investigación, como el de la adquisición bilingüe y el de la teoría de la traducción y, finalmente, haremos referencia a una serie de aspectos que han surgido a partir del presente estudio y que pueden abrir posibles líneas de investigación para trabajos futuros.

En cuanto a las aportaciones de este estudio, por un lado, dentro de los distintos fenómenos asociados al contacto de lenguas, hemos establecido una distinción, así como diversas semejanzas, entre la AC y el cambio de códigos, una distinción que, a su vez, nos permite incluir la TN como un tipo de cambio de códigos característico de la adquisición bilingüe. De esta manera, hemos partido de que, mientras que en la TN se produce un trasvase de información de una lengua a otra, en la $\mathrm{AC}$, aunque también aparecen dos lenguas dentro del mismo contexto conversacional, no existe dicho trasvase de información. Esta diferencia, sin embargo, no implica que ambos fenómenos lingüísticos no puedan darse de forma simultánea en una misma situación comunicativa, ya que en el texto meta resultante de una TN puede incluirse una AC. A partir de este planteamiento en el que se enlazan estos dos tipos de producciones bilingües, hemos resaltado que, 
normalmente, estos casos en los que confluyen de manera simultánea la TN y la AC, y que nosotros hemos denominado traducciones incompletas, se deben a la introducción de elementos de una lengua en un enunciado expresado en la otra, lo cual puede responder a un vacío léxico o a la intención por parte del hablante de dar una mayor información con el elemento mezclado, una posible causa que respondería igualmente a la función comunicativa de la TN. Al mismo tiempo, y a diferencia de otros casos de TN que aparecen, a veces de forma anecdótica, en algunos estudios de bilingüismo infantil, el estudio que hemos realizado nos ha permitido disponer del suficiente contexto previo a la producción de una traducción por parte de nuestros sujetos, como para constatar que, efectivamente, son casos de TTNN y no solamente de AC.

Por otro lado, otra de las aportaciones que ha supuesto este estudio se refiere a las variables de análisis que hemos propuesto, en las que hemos conjugado tanto aquellas que son de carácter lingüístico e inherentes a toda actividad de traducción como aquellas asociadas a los factores contextuales que rodean la producción de TTNN. En cuanto a las primeras, hemos distinguido tres y son las siguientes: el tipo de actividad (completa, incompleta, reformulación y nula), el tipo de relación semántico-conceptual que se plantea en el binomio texto origen (TO)/texto meta (TM) (emparejamientos que responden o no a una necesidad comunicativa; traducciones económicas y traducciones expansivas) y la direccionalidad de las traducciones (de inglés a español o de español a inglés, en nuestro caso). El segundo tipo de variables, de carácter pragmático y, por tanto, más externas a la actividad de traducción, nos ha ayudado a demostrar que los niños bilingües utilizan la TN como estrategia comunicativa de una forma deliberada con la intención de adaptarse al interlocutor o a la situación y mejorar así la comunicación. Por ello, hemos considerado que el contexto en el que tiene lugar la TN también ha de formar parte del análisis de la $\mathrm{TN}$, pues dicho contexto tiene una gran influencia en las características gramaticales de las traducciones que realizan nuestros sujetos. Estas variables externas son, concretamente, la ausencia o la presencia de estímulo que provoque la producción de TTNN (por iniciativa propia o inducidas), la procedencia del enunciado origen (que puede venir producido por uno de los sujetos, por los padres o por uno de los investigadores) y la tipología de los datos (espontáneos y experimentales). 
Los resultados obtenidos a partir de este tipo de análisis doble (el gramatical y el pragmático) nos han permitido comprobar si se cumplen las principales hipótesis que hemos ido planteando a lo largo de este trabajo de investigación y que giran en torno a los patrones de comportamiento de nuestros dos sujetos bilingües en lo que respecta a la producción de casos de TN, así como a los posibles factores (lingüísticos y contextuales) que hayan podido influir en el hecho de que traduzcan (o no) en determinadas ocasiones.

La primera hipótesis de la que partíamos es que la TN juega un papel importante dentro de los fenómenos de mezcla de lenguas típicos de la adquisición bilingüe que hay que distinguir de otras producciones lingüísticas como la AC. En este sentido, podemos afirmar que los 172 casos de TTNN per se recogidos en nuestro corpus de datos vienen a constatar, no sólo la presencia numerosa de este fenómeno en la producción bilingüe de nuestros sujetos, sino también que dichos sujetos han conseguido completar la actividad de traducción en la gran mayoría de los casos. Más concretamente, la proporción de casos de $\mathrm{TN}$ en los que han llegado a completar el proceso es significativamente superior desde el punto de vista estadístico tanto a los casos en los que han realizado traducciones parciales (o con $\mathrm{AC}$, en las que han dejado de producir determinados términos del texto origen) como a los casos en los que la actividad de traducción ha resultado completamente nula.

Así pues, los niños bilingües de nuestro estudio son capaces de utilizar una serie de mecanismos y estrategias lingüísticos y comunicativos que les permiten a llevar a término el proceso de traducción la mayor parte de las veces que lo requiere la situación comunicativa.

Con respecto a estas estrategias lingüísticas y comunicativas, hemos planteado la segunda y la tercera hipótesis en este trabajo. Según la segunda hipótesis, la competencia bilingüe y la traductora se desarrollan de forma paralela, de tal forma que, a medida que avanzamos en el estudio longitudinal, el tipo de TTNN que realizan los niños ha de variar a lo largo de las etapas en las que hemos dividido el estudio. Así, en este trabajo nos hemos centrado en el análisis gramatical de las TTNN en el nivel semántico-conceptual con el fin de demostrar que los niños también van evolucionando en el uso de las estrategias traductoras a lo largo del desarrollo de su competencia (de emparejamientos léxicos a mecanismos lingüísticos más complejos como la traducción económica y la expansiva) y que en esta evolución los factores contextuales tienen una gran influencia. 
Esta evolución paralela nos lleva a plantear una tercera hipótesis muy relacionada con la anterior: el que los niños bilingües dispongan de dos lexicones separados (uno por cada lengua) y una Forma Lógica común les permite no sólo traducir en una dirección o en otra, sino también establecer adecuadamente ( $\mathrm{y}$ no de forma imperfecta) una relación semántico-conceptual común en el binomio TO/TM, la cual puede reflejar una equivalencia semántica total, como en los emparejamientos léxicos, o parcial, como el caso de las traducciones económicas (la información del TM es más reducida que la del TO) y expansivas (la información del TM es más amplia), en las que se comparte sólo parte de la equivalencia semántica. El hecho de que los niños no traduzcan en determinadas ocasiones no ha de verse como una incapacidad para mantener dicha relación semántica, sino que, al igual que en la TN per se, habrá de tenerse en cuenta las propiedades gramaticales y contextuales que rodean a la ausencia de $\mathrm{TN}$, siendo este un tema que hemos abordado en este trabajo pero que no ha sido tratado por otros estudios hasta el momento.

Como cuarta y última hipótesis, el hecho de que los niños sean capaces de realizar TTNN desde etapas muy tempranas de su desarrollo lingüístico evidenciaría que diferencian las dos lenguas desde el principio, lo cual viene a apoyar, a su vez, la hipótesis de la diferenciación que han defendido otros autores (Lindholm y Padilla 1978a; Genesee 1989; De Houwer 1995; Lanza 1997; Paradis y Genesee 1996; Döpke 2000; Meisel 2001, etc.).

Ante los resultados obtenidos en nuestro estudio en relación a cada una de estas hipótesis, podemos mantener, en lo que respecta a la primera, que la cantidad de TTNN que hemos recopilado para el presente estudio (tanto las procedentes de los datos espontáneos como las de los datos experimentales) suponen una cantidad considerable que nos ha conducido a tratar la TN como un fenómeno con entidad propia que constituye, además, una estrategia lingüística que forma parte del desarrollo bilingüe y que, como tal, ha de incluirse en los estudios de adquisición bilingüe como un posible caso de mezcla de lenguas (o, concretamente, de cambio de códigos), de la misma manera que la AC.

En cuanto a la segunda y la tercera hipótesis, los resultados concernientes a la evolución de la competencia traductora y la tipología semántico-conceptual de los casos de TN revelan que si bien la mayor parte de las TTNN realizadas por nuestros sujetos, sobre todo durante la etapa inicial, se corresponden con emparejamientos léxicos que responden 
tanto a una necesidad comunicativa en un contexto familiar como a peticiones expresas de los padres para que cambien de lengua cuando hablan con ellos, también existen varios casos en los que utilizan los otros tipos de estrategias traductoras (traducciones económicas y expansivas), que se localizan fundamentalmente en la etapa final.

De esta manera, la producción de TTNN requiere que los niños pongan en juego no sólo su competencia gramatical sino también su competencia pragmática, tanto en inglés como en español, las cuales conforman una habilidad traductora que puede alcanzar en su desarrollo un alto grado de sofisticación. Es decir, tal y como hemos propuesto en la segunda hipótesis, existe una relación paralela entre la TN y la competencia bilingüe, pero esto no implica que la competencia bilingüe se reduzca simplemente a la disponibilidad de dos lexicones, sino que también supone una competencia innata que responde a una necesidad comunicativa, en este caso, en un contexto familiar y no profesional. En este sentido, el desarrollo de esta competencia en los niños bilingües no viene dado por una instrucción formal en la materia (como en los traductores profesionales), sino que, al igual que sucede con la competencia bilingüe, se desarrolla a partir del input que reciben de los padres, lo cuales, además, suelen incitarles a traducir. Además, hay que tener en cuenta que en ese desarrollo de la competencia traductora también han de incluirse aquellos casos de TN que los niños realizan por iniciativa propia cuando la situación contextual así lo requiere, con el fin de que no se rompa la comunicación entre ellos y sus interlocutores.

Por este motivo, también hemos atendido en nuestro análisis a los factores contextuales, cuyos resultados más importantes se resumen en que la insistencia por parte de la madre anglófona por mantener la fórmula de una persona - una lengua hace que esta sea la que incita muchas de las traducciones que constituyen emparejamientos léxicos (sobre todo en el caso de Leo). Este tipo de estrategia comunicativa es utilizada por los padres en las primeras etapas del desarrollo bilingüe de los niños (sobre todo en la inicial (2;00-3;00 años)) pero no en la etapa final (4;09-6;03 años), que es la que se corresponde fundamentalmente con los datos experimentales. De este modo, consideramos que en esta última etapa, si bien ambos niños siguen produciendo emparejamientos léxicos, el hecho de que los investigadores, y no los padres, sean los que estimulan a los niños para que traduzcan, influye en el resultado de que la mayor parte de las traducciones que realizan en dicha etapa se corresponda con traducciones económicas y no tanto con emparejamientos léxicos. Al mismo tiempo, hay que tener en cuenta el carácter oral de estas producciones, en las que la traducción como producto no es la finalidad, sino que es el medio para que los 
niños puedan seguir jugando durante las pruebas experimentales $\mathrm{y}$, por tanto, es una actividad que exige una inmediatez en la interacción verbal. Aún así, independientemente de estas circunstancias, las TTNN clasificadas según nuestra propuesta no se identifican con traducciones elementales, rudimentarias, imperfectas o poco adecuadas, como las califican otros autores (Toury 1986; Lörscher 1992, entre otros), sino con producciones propias de niños bilingües simultáneos que las realizan a lo largo de su desarrollo lingüístico.

Por tanto, y como otra de las conclusiones generales que podemos extraer del presente estudio, hemos demostrado que, en lo que respecta tanto a las TTNN per se como a la actividad nula de traducción, determinados contextos comunicativos (la estrategia comunicativa de una persona - una lengua que siguen los padres o el contexto experimental en el que se producen las últimas TTNN recopiladas) influyen de manera clara en el comportamiento de los niños a lo largo de su desarrollo como traductores.

Finalmente, relacionando la tercera hipótesis con la cuarta, podemos establecer dos últimas conclusiones. Por un lado, tanto en los casos de emparejamiento como en los de traducción económica y expansiva, los niños han sido capaces de seleccionar un output apropiado, así como también los rasgos incluidos en la FL que han considerado más óptimos para cada situación de traducción. En este sentido, hemos demostrado que los niños de nuestro estudio pueden traducir en una doble dirección, es decir, en nuestro caso, de inglés a español y de español a inglés, aunque la cantidad de TTNN en una y otra dirección también puede venir determinada por algunos factores contextuales. Así, Leo, concretamente, y sobre todo en la primera etapa, produce más traducciones español-inglés que Simon cuando es uno de sus progenitores el que le induce a traducir lo que él mismo ha dicho (es decir, la mayor parte de las traducciones español-inglés son autotraducciones). En cambio, Simon traduce en una mayor proporción de inglés a español cuando es inducido por investigadores y especialmente en la última etapa del estudio, lo cual nos lleva a concluir, al igual que con el resto de las variables intrínsecas de la actividad de traducción, que los factores externos influyen a la hora de realizar TTNN en una dirección o en otra.

Por otro lado, y tal y como se puede desprender de los resultados y conclusiones de las hipótesis anteriores, hemos constatado en las TTNN recogidas en nuestro corpus que los niños bilingües no sólo disponen de distintos mecanismos lingüísticos para poder transmitir la misma información en una u otra lengua y que van evolucionando en el uso de 
dichos mecanismos a lo largo del estudio, sino que también pueden elegir la lengua adecuada al contexto lingüístico en el que se desarrollan dependiendo del interlocutor con el que interactúen (si es bilingüe o monolingüe), lo cual viene de nuevo a evidenciar que pueden diferenciar las dos lenguas desde el comienzo de su desarrollo.

Como conclusión general, podemos afirmar que con este tipo de estudio de datos de producción lingüística, hemos podido perfilar y precisar muchas de las cuestiones que hemos ido exponiendo sobre la TN y así poderlas demostrar empíricamente. En este sentido, nuestro centro de interés no ha sido saber cómo deberían traducir los niños bilingües sino cómo traducen. Además, los datos de que disponemos, con el contexto previo y posterior a los casos de $\mathrm{TN}$, nos han permitido observar cuándo surgen los primeros casos de TN y de qué tipo son, cómo evoluciona su competencia traductora, qué factores influyen en este desarrollo, y todo ello desde un enfoque lingüístico. Es decir, con este tipo de estudio hemos podido establecer los patrones que marcan las TTNN en niños bilingües simultáneos, lo cual hace que dispongamos de una fuente idónea de datos (tanto espontáneos como experimentales) para profundizar en cuestiones como la representación léxica en la mente del niño bilingüe, o el contacto de lenguas a lo largo del desarrollo lingüístico de este tipo de hablantes. En este sentido, el trabajo que aquí hemos presentado nos ha servido para aunar dos disciplinas de estudio desde el punto de vista del análisis empírico, la adquisición bilingüe y la teoría de la traducción.

Para finalizar este apartado dedicado a las conclusiones del presente trabajo, aludiremos a cómo las implicaciones derivadas de este hacen que se puedan plantear aspectos sobre los que encaminar futuras líneas de investigación dentro de los dos campos de estudio a los que acabamos de hacer referencia.

En primer lugar, dado que las grabaciones y las transcripciones procedentes del estudio longitudinal de Fernández Fuertes et al. (2002-2005) aún no están concluidas, la selección de datos que aquí presentamos representa sólo una parte del corpus de dicho estudio longitudinal, de ahí que consideremos que nuestro análisis ha de ampliarse para incluir la totalidad de las TTNN encontradas en el corpus de datos que conforma el mencionado estudio, para, de esa manera, poder comprobar si podemos seguir manteniendo las mismas hipótesis y obteniendo los mismos resultados que con nuestra selección de datos. 
En esta línea, consideramos que este tipo de estudios longitudinales y descriptivos, así como el análisis propuesto, son imprescindibles para poder observar y examinar el desarrollo de la TN no sólo como fenómeno característico de la adquisición bilingüe, sino también como un tipo de traducción que se encuentra en la base de la competencia traductora. Un análisis de este tipo de individuos traductores podría servir para profundizar no sólo en el análisis de la TN, sino también para establecer diferencias y similitudes entre los diferentes papeles que dichos individuos pueden desempeñar en una interacción lingüística en la que entre en juego la traducción.

En segundo lugar, según los resultados que acabamos de exponer de forma resumida, se puede deducir que los niños traducen principalmente porque hay estímulos externos concretos y ligados a un tipo de estrategia de adquisición bilingüe por parte de los padres. Es decir, ¿hasta qué punto esta estrategia de adquisición bilingüe marca la producción de TTNN? La comparación de estos datos con otros de TTNN realizadas por niños con los que no se ha seguido esta fórmula comunicativa profundizaría en la influencia de los factores contextuales en la producción de TTNN de niños bilingües a lo largo del proceso de adquisición o incluso en la producción de paráfrasis u otros recursos comunicativos similares y característicos tanto de los niños monolingües como de los niños bilingües, como defienden otros autores como Swain (1972).

Siguiendo este planteamiento basado en distintas comparaciones, también se podrían comparar las TTNN que realizan los niños bilingües (cuya competencia lingüística está en desarrollo) con las que realizan adultos bilingües (con o sin entrenamiento formal) o, incluso, con las realizadas por traductores profesionales. Es más, un estudio de este tipo plantearía nuevos retos para el estudio de la traducción en general y de la traducción profesional en particular, pues se partiría de la base del estudio científico de toda traducción (no sólo la profesional) y se analizaría la competencia traductora desde el punto de vista de distintos tipos de hablantes bilingües (niños/adultos y simultáneos/secuenciales) y distintos contextos (natural/profesional y adquisición/aprendizaje).

Al mismo tiempo, tal y como hemos ido apuntado a lo largo del presente trabajo de investigación, hemos utilizado casos de TN producidos por niños bilingües con pares de lenguas diferentes procedentes de otros estudios de adquisición bilingüe. Dado que en la mayoría de dichos estudios se ofrecen muchos datos anecdóticos de $\mathrm{TN}$ en los que carecemos de contexto situacional o conversacional, una comparación entre estos casos y los que aquí hemos presentado no resultaría muy objetiva al no poder analizarlos de la 
misma manera. Sin embargo, en la actualidad existe un gran interés por este tipo de datos grabados periódicamente y en contextos naturales, lo cual sería interesante desde el punto de vista de nuestro estudio, pues se podrían tener en cuenta otros corpora bilingües con distintos pares de lenguas con los que realizar el mismo tipo de análisis que aquí hemos propuesto y poder tener otros datos con los que comparar nuestros resultados, llevando a cabo, de esta manera, una comparación que nos permitiría plantear si existe algún comportamiento sistemático en la TN realizada por los niños bilingües.

En tercer y último lugar, otro de los temas de interés que se han podido suscitar a raíz de este trabajo es el posible análisis conjunto que se podría realizar de la $\mathrm{TN}$ y la $\mathrm{AC}$ que realizan los niños bilingües, investigando de forma rigurosa la relación que hay entre ambos fenómenos dentro de ese contexto lingüístico, lo cual aportaría una autonomía de la TN como un tipo de producción lingüística propia del desarrollo bilingüe diferente a la $\mathrm{AC}$, aunque puedan darse en el discurso de manera simultánea.

Lo que se ha puesto de manifiesto con el presente estudio, tanto desde el punto de vista de los planteamientos teóricos de los trabajos de adquisición como de los de TN a los que hemos hecho referencia en los capítulos anteriores, es que estos casos de TN constituyen un tema de investigación muy interesante para estos ámbitos de estudio porque reflejan parte del proceso de adquisición bilingüe, así como el desarrollo de la competencia traductora en estado natural. Sólo analizando este tipo de producciones bilingües, podremos descubrir, tal y como afirma Harris (comunicación personal) y como hemos demostrado en nuestro estudio empíricamente, que

"children are surprisingly effective translators for the communication that is needed within their own world'. 


\section{BIBLIOGRAFÍA}

Aguado, G. 1988. "Appraisal of the morphosyntactic competence in a 2.5 year old child". Infancia y aprendizaje 43: 75-95.

Albrecht, E. 2004. "I can speak German - und Deutsch". The Development and Use of Code-Switching among Simultaneous and Successive English-German Bilingual Children. Tesis doctoral, Albert-Ludwigs-Universität.

$<$ http://www.freidok.uni-freiburg.de/volltexte/1783/pdf/Acquisition_of_codeswitching.pdf.pdf $>$ (20-03-2007)

Arnberg, L. 1987. Raising children bilingually: the pre-school years. Clevedon: Multingual Matters.

Arnberg, L. y P. Arnberg. 1992. "Language awareness and language separation in the young bilingual child". Harris, R.J. (ed.) Cognitive processing in bilinguals. Amsterdam: Elsevier. 475-500.

As-Safi, A-B. e I.S. Ash-Sharifi. 1997. "Naturalness in Literary Translation". Babel 43.1: $60-75$.

Aubin, P. 1994. "Youth tackle novel project. Students translate holocaust diary into English". Ottawa citizen, Ottawa, Canadá. 22 de junio. B4.

Azuma, S. 1993. "The frame-content hypothesis in speech production: evidence from intrasentential code-switching". Linguistics 31: 1071-1093.

Babbe, M. 1995. From language mixing to codeswitching: the development of language contact in child bilingual acquisition. Tesis doctoral, Universidad de Santa Barbara, California, EE.UU.

Baetens Beardsmore, H. 1982. Bilingualism: basic principles. Clevedon: Multilingual Matters.

Baetens Beardsmore, H. 2003. "Who's afraid of bilingualism?" Dewaele, J.-M., A. Housen y L. Wei (eds.) Bilingualism: beyond basic principles. Festschrift in honour of Hugo Baetens Beardsmore. Clevedon: Multilingual Matters. 10-27.

Baker, C. 1993. Foundations of bilingual education and bilingualism. Clevedon: Multilingual Matters. 
Baker, C. 2000. A parent and teacher's guide to bilingualism. Clevedon: Multilingual Matters.

Barron-Hauwaert, S. 2004. Language strategies for bilingual families: the one-parent-onelanguage approach. Clevedon: Multilingual Matters.

Belazi, H.M., E.J. Rubin y A.J. Toribio. 1994. "Code-switching and X-bar theory: the functional head constraint". Linguistic inquiry 25: 221-237.

Bell, A. 2001. Teoria lingüistica $i$ adquisició del llenguatge. Anàlisi comparada dels trets morfològics en català $i$ en castellà. Barcelona: Institut d'estudis catalans.

Bergman, C.R. 1976. "Interference vs. independent development in infant bilingualism". Keller, G.D., R.V. Taeschner y S. Viera (eds) Bilingualism in the bicentennial and beyond. Nueva York: The Bilingual Review Press. 86-96.

Bernardini, P. y S. Schlyter. 2004. "Growing syntactic structure and code-mixing in the weaker language". Bilingualism: language and cognition 7: 49-69.

Bhatia, T.K. y W.C. Ritchie (eds.). 2004. The handbook of bilingualism. Malden, MA: Blackwell.

Bhatia, T.K. y W.C. Ritchie. 1996a. "Light verbs in code-switched utterances: derivational economy in I-Language or incongruence in production?" Stringfellow, A., D. Cahana-Amitay, E. Hughes y A. Zukowski (eds.) Proceedings of the Boston University conference on language development 20. Somerville, Mass.: Cascadilla Press. 52-62.

Bhatia, T.K. y W.C. Ritchie. 1996b. "Bilingual language mixing, universal grammar, and second language acquisition." Bhatia, T.K. y W. Ritchie (eds.) Handbook of second language acquisition. San Diego, CA: Academic Press Inc. 627-88.

Bialystok, E. (ed.) 1991. Language processing in bilingual children. Cambridge: Cambridge University Press.

Bialystok, E. 1987. "Influences of bilingualism on metalinguistic development”. Second language research 3.2: 154-166.

Bialystok, E. 2001. Bilingualism in development. Language, literacy, and cognition. Cambridge: Cambridge University Press.

Borer, H. y K. Wexler. 1987 . "The maturation of syntax". Roeper, T. y E. Williams (eds.) Parameter-setting and language acquisition. Dordrecht: Reidel. 123-172.

Bosch, L. y N. Sebastián-Gallés. 2001. "Early language differentiation in bilingual infants". Cenoz, J. y F. Genesee (eds.) Trends in bilingual acquisition. Amsterdam: John Benjamins. 71-94.

Brown, R. 1973. A first language. The early stages. Cambridge, MA: Harvard University Press.

Buchanan, C. 1993. "Leslie Park's ambassador's club". Ottawa Citizen. Ottawa, Canadá. 2 de abril: B3.

Bullock, C. y B. Harris. 1997. "Schoolchildren as community interpreters". Carr, S.E. y R. Roberts (eds.) The critical link: interpreters in the community. Amsterdam: John Benjamins. 227-235. 
Burling, R. 1978. "Language development of a Garo- and English-speaking child. Hatch, E.M. (ed.) Second language acquisition: a book of readings. Rowley, Mass.: Newbury House. 54-75.

Butler, Y.G. y Hakuta, K. 2004. "Bilingualism and second language acquisition". Bhatia, T.K. y W.C. Ritchie (eds.) The handbook of bilingualism. Malden, MA: Blackwell. 114-144.

Celce-Murcia, M. 1978. "The simultaneous acquisition of English and French in a twoyear-old child”. Hatch, E.M. (ed.) Second language acquisition: a book of readings. Rowley, Mass.: Newbury House. 39-53.

Chomsky, N. 1957. Syntactic structures. La Haya: Mouton.

Chomsky, N. 1965. Aspects of the theory of syntax. Cambridge, Mass.: The MIT Press.

Chomsky, N. 1968. Language and mind. Nueva York: Harcourt Brace Jovanovich.

Chomsky, N. 1981. Lectures on government and binding. Dordrecht: Foris Publications.

Chomsky, N. 1986. Knowledge of language: its nature, origin, and use. Nueva York: Praeger.

Chomsky, N. 1991. "Some notes on economy of derivation and representation". Freidin, R. (ed.) Principles and parameters in comparative grammar. Cambridge, Mass.: MIT Press. 417-454.

Chomsky, N. 1993. "A minimalist program for linguistic theory”. Hale, K. y S.J. Keyser (eds.) The view from building 20. Cambridge, Mass.: MIT Press. 1-52.

Chomsky, N. 1995. The minimalist program. Cambridge, Mass.: MIT Press.

Chomsky, N. 1998 "Minimalist inquiries: the framework". MIT working papers in linguistics 15: 1-56.

Chomsky, N. 2001. "Derivation by phase". Kenstowicz, M. (ed.) Ken Hale. A life in language. Cambridge, Mass.: MIT Press.

Christoffels, I. A.M.B. De Groot y L. Waldorp. 2003. "Basic skills in a complex task: a graphical model relating memory and lexical retrieval to simultaneous interpreting". Bilingualism: language and cognition 6.3: 201-211.

Clark, E. 1987 "The principle of contrast: a constraint on language acquisition". MacWhinney, B. (ed.) Mechanisms of language acquisition. Hillsdale, NJ: Lawrence Erlbaum Assoc.. 1-33.

Clyne, M. 1987 “Constraints on code-switching: how universal are they?" Linguistics 25: 739-764. Reimpresión: Wei, L. (ed.) 2000. The bilingualism reader. Nueva York: Routledge. 257-280.

Comeau, L. y F. Genesee. 2001. "Bilingual children's repair strategies during dyadic communication". Cenoz, J. y F. Genesee (eds.) Trends in bilingual acquisition. Amsterdam: John Benjamins. 231-256.

Crain, S. y R. Thornton. 1998. Investigations in Universal Grammar. A guide to experiments on the acquisition of syntax and semantics. Cambridge, Mass.: MIT Press.

Crystal, D. 2003. A dictionary of linguistics and phonetics. Oxford: Basil Blackwell. 
Cummins, J. 1979. "Linguistic interdependence and the educational development of bilingual children”. Review of educational research 49: 222-251.

Dale, P.S., E. Simonoff, D.V.M. Bishop, T.C. Eley, B. Oliver, T.S. Price, S. Purcell, J. Stevenson y R. Plomin. 1998. "Genetic influence on language delay in two-year-old children". Nature neuroscience 1.4: 324-328.

Darwish, A. 2000. "Is translation natural?"

$<$ http://www.translocutions.com/translation/index.html> (última actualización 303-2007)

Davidson, D., D. Jergovic, Z. Imami y V. Theodos. 1997. "Monolingual and bilingual children's use of the mutual exclusivity constraint". Journal of child language 24.1: 3-24.

De Bot, K. 1992. "A bilingual production model: Levelt's 'speaking' model adapted". Applied linguistics 13: 1-24.

De Bot, K., A. Cox, S. Ralston, A. Schaufeli y B. Weltens. 1995. "Lexical processing in bilinguals'. Second language research 11: 1-19.

De Groot, A.M.B. 1993. "Word-type effects in bilingual processing tasks". Schreuder, R. y B. Weltens (eds.) The bilingual lexicon. Amsterdam: John Benjamins. 27-51.

De Groot, A.M.B., L. Dannenburg y J.G. van Hell. 1994. "Forward and backward word translation by bilinguals". Journal of memory and language 33: 600-629.

De Houwer, A. 1990. The acquisition of two languages from birth. Cambridge: MIT Press.

De Houwer, A. 1995. "Bilingual language acquisition". Fletcher, P. y B. MacWhinney (eds.) The handbook of child language. Cambridge, Mass.: Blackwell. 219-250.

De Houwer, A. 1998. "By way of introduction: methods in studies of bilingual first language acquisition”. International journal of bilingualism 2.3. 249-263.

De Houwer, A. 2007. Base de datos CHILDES.

$<$ http://childes.psy.cmu.edu/data/Biling/> (última actualización 4-02-2007)

Delisle, J. 1984. "L'analyse du discours comme méthode de traduction. Théorie et practique". Cahiers de traductologie 2: 24-46.

Deuchar, M. 2007. Base de datos CHILDES.

$<$ http://childes.psy.cmu.edu/data/Biling/> (última actualización 4-02-2007)

Deuchar, M. y S. Quay 2000. Bilingual acquisition: theoretical implications of a case study. Oxford: Oxford University Press.

Di Sciullo, A.M., P. Muysken y R. Singh. 1986. "Government and code-switching". Journal of linguistics 22: 1-24.

Döpke, S. (ed.) 2000. Cross-linguistic structures in simultaneous bilingualism. Amsterdam: John Benjamins.

Döpke, S. 1992. One parent, one language. An interactional approach. Amsterdam: John Benjamins.

Döpke, S. 1998. "Competing language structures: the acquisition of verb placement by bilingual German-English children”. Journal of child language 25.3: 555-584. 
Dufour, R. y J.F. Kroll. 1995. "Matching words to concepts in two languages: a test of the concept mediation model of bilingual representation". Memory and cognition 23: 166-180.

Elman, J.L., E.A. Bates, M.H. Johnson, A. Karmiloff-Smith, D. Parisi y K. Plunkett. 1996. Rethinking innateness. A connectionist perspective on development. Cambridge, Mass.: The MIT Press.

Erreich, A., V. Vallian y J. Winzemer. 1980. "Aspects of a theory of language acquisition". Journal of child language 7: 157-179.

Ervin, S. y C. Osgood. 1954. "Second language learning and bilingualism". Osgood, C. y T. Sebeok (eds.) Psycholinguistics. Indiana University Press: Bloomington. 139146.

Ezeizabarrena, M.J. 1994. "Primeras formas verbales de concordancia en euskera". Meisel, J.M. (ed.) La adquisición del vasco y del castellano en niños bilingües. Madrid: Iberoamericana. 181-230.

Ezeizabarrena, M.J. 1996. Adquisición de la morfología verbal en euskera y castellano por niños bilingües. Bilbao: Servicio Editorial de la Universidad del País Vasco.

Fantini, A.E. 1985. Language acquisition of a bilingual child: a sociolinguistic perspective (to age ten). Clevedon, U.K.: Multilingual Matters.

Fernández Fuertes, R., E. Álvarez de la Fuente, S. Muñiz Fernández, M. Bermúdez Bausela, J.M. Liceras y K.T. Spradlin. 2002-2005. La teoría lingüistica y el análisis de los sistemas bilingües: estudio longitudinal de la adquisición simultánea del inglés y del español. Proyecto de investigación co-financiado por el Ministerio de Ciencia y Tecnología y por Fondos FEDER [BFF2002-00442]. Universidad de Valladolid y Universidad de Ottawa (Canadá).

Fernández Fuertes, R., E. Álvarez de la Fuente, y J.M. Liceras (en prensa) "Los datos de adquisición bilingüe inglés/español: separación y mezcla de códigos". XXIV Congreso Internacional de AESLA (Asociación Española de Lingüistica Aplicada). Madrid.

Forlemu, E. 1985. Glossary of terms and concepts used by Brian Harris in his work on translation, especially natural translation. Tesis de maestría, Universidad de Ottawa, Canadá.

Forster, K.I. y N. Jiang. 2001. "The nature of the bilingual lexicon: experiments with the masked priming paradigm". Nicol, J.L. (ed.) One mind, two languages: bilingual language processing. Oxford: Blackwell. 72-83.

Gardner-Chloros, P. 1995. "Code-switching in community, regional and national repertoires: the myth of the discreteness of linguistic systems". Milroy, L. y P. Muysken (eds.) One speaker, two languages: cross-disciplinary perspectives on code-switching. Cambridge: Cambridge University Press. 68-89.

Gavarró, A. 1998. "Word order alternations and feature assignment in bilingual Catalan acquisition". Probus 10: 1-12.

Gavarró, A. 2003. "Economy and word order patterns in bilingual English-Dutch acquisition". Bilingualism: language and cognition 6.1: 69-79. 
Gawlitzek-Maiwald, I. 2000. "II want a chimney builden': the acquisition of infinitival constructions in bilingual children”. Döpke, S. (ed.) Cross-linguistic structures in simultaneous bilingualism. Amsterdam: John Benjamins. 123-148.

Gawlitzek-Maiwald, I. y R. Tracy. 1996. "Bilingual Bootstrapping”. Linguistics 34.5: 901926.

Genesee, F. 1989. "Early bilingual development: one language or two?" Journal of child language 16.1: 161-179.

Genesee, F. 2001. "Bilingual first language acquisition: exploring the limits of the language faculty". McGroarty (ed.), M. 21st annual review of applied linguistics. Cambridge: Cambridge University Press. 153-168.

Genesee, F. 2003. "Rethinking bilingual acquisition”. Dewaele, J-M, A. Housen y L. Wei (eds.) Bilingualism: beyond basic principles. Festschrift in honour of Hugo Baetens Beardsmore. Clevedon: Multilingual Matters. 204-228.

Genesee, F. y J. Cenoz. 2001. "First words". Cenoz, J. y F. Genesee (eds.) Trends in bilingual acquisition. Amsterdam: John Benjamins. 1-9.

Genesee, F., E. Nicoladis y J. Paradis. 1995. "Language differentiation in early bilingual development". Journal of child language 22.3: 611-631.

Genesee, F., J. Paradis y M. Crago. 2004. Dual language development and disorders. Baltimore: Brookes.

Gollan, T.H. y J.F. Kroll. 2001. "Bilingual lexical access". Rapp, B. (ed.) The handbook of cognitive neuropsychology: what deficits reveal about the human mind/brain. Philadelphia: Psychology Press. 321-345.

Goodenough, F. 1926. "Racial differences in the intelligence of school children". Journal of experimental psychology 9: 388-397.

Goodz, N.S. 1994. "Interactions between parents and children in bilingual families". Genesee, F. (ed.) Educating second language children. Cambridge: Cambridge University Press. 61-81.

Grammont, M. 1902. Observation sur le langage des enfants. París: Mélanges Meillet.

Green, D.W. 1993. "Towards a model of L2 comprehension and production". Schreuder, R. y B. Weltens (eds.) The bilingual lexicon. Amsterdam: John Benjamins. 249277.

Grosjean, F. 1982. Life with two languages: an introduction to bilingualism. Cambridge, Mass.: Harvard University Press.

Grosjean, F. 1995. "A psycholinguistic approach to codeswitching: the recognition of guest words by bilinguals". Milroy, L. y P. Muysken (eds.) One speaker, two languages: cross-disciplinary perspectives on code-switching. Cambridge: Cambridge University Press. 259-275.

Grosjean, F. 1997. "Processing mixed languages: issues, findings and models". De Groot, A.M. y J.F. Kroll (eds.) Tutorials in bilingualism. Mahweh, NJ: Lawrence Erlbaum. 225-54.

Grosjean, F. 2001. "The bilingual's language modes". Nicol, J. (ed.) One mind, two languages: bilingual language processing. Oxford: Blackwell. 1-22. 
Gut, U. 2000. "Cross-linguistic structures in the acquisition of intonational phonology by German-English bilingual children". Döpke, S. (ed.) Cross-linguistic structures in simultaneous bilingualism. Amsterdam: John Benjamins. 201-226.

Hakuta, K. 1990. "Language and cognition in bilingual children". Padilla, A., H.H. Fairchild y C.M. Valadez (eds.) Bilingual education. Issues and strategies. Newbury Park: Sage. 60-74.

Hall, N. 2003-2005. Children and adolescents as language brokers. Proyecto de investigación financiado por el Economic and Social Research Council. Manchester Metropolitan University (Reino Unido).

$<$ http://www.esri.mmu.ac.uk/resprojects/brokering/seminars.php> (20-03-2007)

Hall, N. 2004. 'The child in the middle: agency and diplomacy in language brokering events.' Hansen, G., K. Malmkjaer y D. Gile (eds.) Claims, changes and challenges in translation studies. Amsterdam: John Benjamins. 285-297.

Hall, N. y S. Sham. 1998. "Language brokering by children”. Comunicación presentada en Annual conference of the British educational research association. Belfast, 27 - 30 agosto.

Halverson, S. 1998 "Translation studies and representative corpora: establishing links between translation corpora, theoretical/descriptive categories and a conception of the object of study". META XLIII 4: 1-4.

$<\mathrm{http} /$ www.erudit.org/revue/meta/1998/v43/n4/003000ar.html> (20-03-2007)

Hamers, J.F. y H.A.M. Blanc. 2000. Bilinguality and Bilingualism. Cambridge: Cambridge University Press.

Harris, B. 1973. "La traductologie, la traduction naturelle, la traduction automatique et la sémantique“. McA'Nulty, J. et al. (eds.) Problèmes de sémantique (Cahier de linguistique 2). Montreal: Presses de 1'Université du Québec. 133-146.

Harris, B. 1977. "The importance of natural translation". Working papers in bilingualism 12: $96-114$.

Harris, B. 1978 "The difference between natural and professional translation". Canadian modern language review/Revue canadienne des langues vivantes 34: 417-427.

Harris, B. 1980a. "How a three-year-old translates". Afrendas, E.A. (ed.) Patterns of bilingualism. Singapore: National University of Singapore Press. 370-393.

Harris, B. 1980b. "Elicited translation by a three-year old English/French bilingual". Ingram, D., F.C.C. Peng y P. Dale (eds.) Proceedings of the first international congress for the study of child language. Association for the study of child language: University Press of America. 610-631.

Harris, B. 1992 "Natural translation: a reply to Hans P. Krings". Target 4.1: 97-103.

Harris, B. 2003. “Aspects of interpretation”. Curso superior de traducción. Valladolid: Universidad de Valladolid.

Harris, B. y B. Sherwood. 1978. "Translating as an innate skill". Gerver, D. y W.H. Sinaiko (eds.) Language interpretation and communication. Nueva York: Plenum. 155-170.

Haugen, E. 1969. The Norwegian language in America. Bloomington: Indiana University Press. 
Heredia, R.R. y J.M. Brown. 2004. "Bilingual memory". Ritchie, W.C. y T.K. Bhatia (eds.) Handbook of bilingualism. Oxford: Blackwell. 225-249.

Hoffmann, C. 1991. An introduction to bilingualism. London: Longman.

Hornstein, N., J. Nunes y K.K. Grohmann. 2005. Understanding minimalism. Cambridge: Cambridge University Press.

Hurtado Albir, A. 2001. Traducción y traductología. Madrid: Cátedra.

Hymes, D. 1971. "Competence and performance in linguistic theory". Huxley, R. y E. Ingram (ed.) Acquisition of languages: models and methods. Nueva York: Academic Press. 3-23.

Idiazabal, I. 1994. "Elementos de cohesión y conexión en las primeras fases de la adquisición del lenguaje: análisis de la producción verbal de un niño bilingüe vasco-hispanófono". Meisel, J.M. (ed.) La adquisición del vasco y del castellano en niños bilingües. Madrid: Iberoamericana. 35-68.

Imedadze, N. 1960. "On the psychological nature of early bilingualism". Voprosy Psikhologii 6: 60-68.

Jakubowicz, C. 1992. "Mecanismos de cambio cognitivo y lingüístico. Principios y parámetros de la gramática universal". Substratum 1: 45-78.

Johnson, C.E. y P. Lancaster. 1998. "The development of more than one phonology: a case study of a Norwegian-English bilingual child. International journal of bilingualism 2: $265-300$.

Joshi, A. 1985. "Processing of sentences with intrasentential code-switching". Dowty, D., L Karttunen y A. Zwicky (eds.) Natural language parsing: psychological, computational and theoretical perspectives. Cambridge: Cambridge University Press. 190-205.

Juan-Garau, M. y C. Pérez-Vidal. 2001. "Mixing and pragmatic parental strategies in early bilingual acquisition". Journal of child language 28: 9-86.

Kasuya, H. 1998. "Determinants of language choice in bilingual children: the role of input". The international journal of bilingualism 2.3: 327-346.

Keith, H. 1989. "Training of translators". Picken, C. (ed.) The translator's handbook. Londres: Aslib. 163-173.

Kirstein, B.H. 1972. "Reducing negative transfer: two suggestions for the use of translation". Modern language journal 56.2: 73-78.

Klausen, T. y M. Hayashi. 1990. "A cross-linguistic study of the development of bilingualism - reorganisation in early lexical development". The European journal of intercultural studies 1.1: 31-39.

Klee, T., M. Schaffer, S. May, I. Membrino, I. y K. Mougey. 1989. "A comparison of the age-MLU relation in normal and specifically language impaired preschool children". Journal of speech and hearing disorders 54: 226-233.

Knapp-Potthoff, A. y K. Knapp. 1986. "Interweaving two discourses. The difficult task of the non-professional interpreter". House, J. y S. Blum-Kulka (eds.) Interlingual and intercultural communication. Discourse and cognition in translation and second language acquisition studies. Tübingen: Narr. 151-168. 
Knapp-Potthoff, A. y K. Knapp. 1987. "The man (or woman) in the middle: discoursal aspects of non-professional interpreting”. Karlfried, K., W. Enninger y A. KnappPotthoff (eds.) Analyzing intercultural communication. Berlín: Mouton. 181-211.

Köppe, R. 1997. Sprachentrennung im frühen bilingualen Erstspracherwerb Französisch/Deutsch. Tübingen: Gunter Narr Verlag.

Köppe, R. y J. Meisel. 1995. "Code-switching in bilingual first language acquisition". Milroy, L. y P. Muysken (eds.) One speaker, two languages: cross-disciplinary perspectives on code-switching. Cambridge: Cambridge University Press. 276-301.

Krings, H.P. 1986. "Was in den köpfen von übersetzern vorgeht/Eine empirische untersuchung zur struktur des übersetzungsprozesses an fortgeschrittenen Franzöischlernern”. Tübinger Beiträge zur Linguistik 291. Tübingen: Narr.

Kroll, J.F. 1993. "Accessing conceptual representations for words in a second language". Schreuder, R. y B. Weltens (eds.) The bilingual lexicon. Amsterdam: John Benjamins. 53-81.

Kroll, J.F. y A. Sholl. 1992. "Lexical and conceptual memory in fluent and non-fluent bilinguals". Harris, R. (ed.) Cognitive processing in bilinguals. Amsterdam: Elsevier. 191-204.

Kroll, J.F. y E. Stewart. 1994. "Category interference in translation and picture naming: evidence for asymmetric connections between bilingual memory representations". Journal of memory and language 33: 149-174.

Kroll, J.F. y N. Tokowicz. 2001. "The development of conceptual representation for words in a second language". Nicol, J. (ed.) One mind, two languages: bilingual language processing. Oxford: Blackwell. 49-71.

Kroll, J.F., E. Michael y A. Sankaranarayanan. 1998. "A model of bilingual representation and its implications for second language acquisition". Healy, A.F. y L.E. Bourne (eds.) Foreign language learning: psycholinguistic experiments on training and retention. Mahwah, NJ: Lawrence Erlbaum Publishers. 365-395.

Lambert, W.E. 1979. "Language as a factor in intergroup relations". Giles, H. y R. St. Clair (eds.) Language and social psychology. Oxford: Basil Blackwell. 186-192.

Lanza, E. 1988. "Language strategies in the home: linguistic input and infant bilingualism". Holmen, A., E. Hansen, J. Gimbel y J.N. Jørgensen (eds.) Bilingualism and the individual. Clevedon, U.K.: Multingual Matters. 69-84.

Lanza, E. 1992. “Can bilingual two-year-olds code-switch?” Journal of child language 19: 633-658.

Lanza, E. 1993. "Language mixing and language dominance in bilingual first language acquisition". Clark, E.V. (ed.) The proceedings of the twenty-fourth annual child language research forum. Stanford, Cal.: Center for the Study of Language and Information. 197-208.

Lanza, E. 1997. Language mixing in infant bilingualism: a sociolinguistic perspective. Oxford: Oxford University Press.

Lanza, E. 2000. "Concluding remarks: language context - a dilemma for the bilingual child or for the linguist?" Döpke, S. (ed.) Cross-linguistic structures in simultaneous bilingualism. Amsterdam: John Benjamins. 227-246. 
Lanza, E. 2001. "Bilingual first language acquisition. A discourse perspective on language contact in parent-child interaction". Cenoz, J. y F. Genesee (eds.) Trends in bilingual acquisition. Amsterdam: John Benjamins. 201-229.

Larrañaga, M.P. 1994. "La evolución del caso en euskera y castellano”. Meisel, J.M. (ed.) La adquisición del vasco y del castellano en niños bilingües. Madrid: Iberoamericana. 113-150.

Leopold, W.F. 1939-1949. Speech development of a bilingual child. A linguist's record. Evanston, IL: Nortwestern University Press.

Liceras, J.M. y R. Fernández Fuertes. 2005. "Formal features in child and adult codemixing”. Cuadernos de lingüística XII. Madrid: Instituto Universitario Ortega y Gasset.

Liceras, J.M., K.T. Spradlin y R. Fernández Fuertes. 2005. "Bilingual early functionallexical mixing and the activation of formal features". International journal of bilingualism 9-2: 227-251.

Liceras, J.M., K.T. Spradlin y R. Fernández Fuertes. 2005. "Bilingual early functionallexical mixing and the activation of formal features". International journal of bilingualism 9.2: 227-252.

Liceras, J.M., K.T. Spradlin, C. Senn, M. Sikorska, R. Fernández Fuertes y E. Alvárez de la Fuente. 2003. "Second language acquisition and bilingual competence: The Grammatical Features Spell-out Hypothesis". Comunicación presentada en European Association of Second Language Acquisition (EUROSLA-13). Edimburgo, Reino Unido, 19 - 21 septiembre.

Lindholm, K.J. y A.M. Padilla. 1978a. "Language mixing in bilingual children”. Journal of child language 5: 327-335.

Lindholm, K.J. y A.M. Padilla. 1978b. "Child bilingualism: report on language mixing, switching and translations". Linguistics 211: 23-44.

Lipski, J. 1985. Linguistic aspects of Spanish-English language shifting. Tempe: Latin American Studies Center, Universidad de Arizona State.

Ljudskanov, A. 1969. Traduction humaine et traduction mécanique. París: Dunod.

Llácer Llorca, E.V. 1997. "Introducción a los estudios sobre traducción. Historia, teoría y análisis descriptivos". Cuadernos de filología (anejo $\mathrm{n}^{\mathrm{o}} \mathrm{XX}$ ). Universitat de València. 94-97.

Llácer Llorca, E.V. 2004. Sobre traducción: ideas tradicionales y teorías contemporáneas. Valencia: Servei de Publicacions de la Universitat de València.

López Ornat, S. 1994. La adquisición de la lengua española. Madrid: Siglo XXI.

Lörscher, W. 1988. "On the construct of a rudimentary ability of mediate". Texto original mecanografiado.

Lörscher, W. 1992. "Process-oriented research into translation and implications for translation teaching". Interface 6.2: 105-117.

Lozés-Lawani, C. 1994 La traduction naturelle chez les enfants fon de la République de Bénin. Tesis doctoral, Universidad de Ottawa.

Mackey, W.F. 1962. "The description of bilingualism". Canadian journal of linguistics 7: 51-85. 
MacSwan, J. 2000. "The architecture of the bilingual language faculty: evidence from intrasentential code-switching". Bilingualism. Language and cognition 3.1: 37-54.

MacSwan, J. 2005. "Codeswitching and generative grammar: a critique of the MLF model and some remarks on "modified minimalism". Bilingualism: language and cognition 8.1: 1-22.

MacWhinney, B. 2000. The CHILDES project: tools for analyzing talk. Mahwah, NJ: Lawrence Erlbaum Associates.

Mahlau, A. 1994. "El proyecto BUSDE: corpus y metodología". Meisel, J.M. (ed.) La adquisición del vasco y del castellano en niños bilingües. Madrid: Iberoamericana. 21-34.

Mahlau, A. 1994a. "El proyecto BUSDE: corpus y metodología". Meisel, J.M. (ed.) La adquisición del vasco y del castellano en niños bilingües. Madrid: Iberoamericana. 21-34.

Mahlau, A. 1994b. "Orden de palabras y estructura oracional en los niños bilingües". Meisel, J.M. (ed.) La adquisición del vasco y del castellano en niños bilingües. Madrid: Iberoamericana. 69-112.

Malakoff, M. y K. Hakuta. 1991. "Translation skills and metalinguistic awareness in bilinguals". Bialystok, E. (ed.) Language processing in bilingual children. Cambridge: Cambridge University Press. 141-166.

Malakoff, M.E., L.C. Mayes, R. Schottenfeld y S. Howell. 1999. "Language production in 24-month-old inner-city children of cocaine-and-other-drug-using mothers". Journal of applied developmental psychology 20: 159-180.

Malakoff, M.E. 1991. Natural translation ability in French-English bilingual school-age children: a study of source language errors in naive child-translators. Tesis doctoral, Universidad de Yale.

Malakoff, M.E. 1992. "Translation ability: a natural bilingual and metalinguistic skill". Harris, R.J (ed.) Cognitive processing in bilinguals. Amsterdam: North-Holland. 515-529.

McClure, E. 1981. "Formal and functional aspects of the codeswitched discourse of bilingual children." Duran, R.P. (ed.) Latino language and communicative behavior. Norwood, NJ: Ablex Publishing Company. 69-94.

McDaniel, D., C.M. Ckee y H. Smith (eds.). 1996. Methods for assessing children's syntax. Cambridge, Mass.: MIT Press.

McLaughlin, B. 1978. "The monitor model: some methodological considerations". Language learning 28: 309-332.

McLaughlin, B. 1984. Second-language acquisition in childhood. Preschool children (vol. 1). Hillsdale: Lawrence Earlbaum Associates.

Meisel, J.M. 1989. "Early differentiation of languages in bilingual children". Hyltenstam, K. y L.K. Obler (eds.) Bilingualism across the lifespan: aspects of acquisition, maturity and loss. Cambridge, Mass.: C. U. P. 13-40.

Meisel, J.M. (ed.) 1990. Two first languages. Early grammatical development in bilingual children. Dordrecht: Foris. 
Meisel, J.M. (ed.) 1994a. Bilingual first language acquisition: French and German grammatical development. Philadelphia: John Benjamins.

Meisel, J.M. 1994b. La adquisición de la negación en euskera y castellano. Meisel, J.M. (ed.) La adquisición del vasco y del castellano en niños bilingües. Madrid: Iberoamericana. 151-180.

Meisel, J.M. 1994c. "Getting fat. Finiteness, agreement and tense in early grammars". Meisel, J.M. (ed.) Bilingual first language acquisition. French and German grammatical development. Amsterdam: John Benjamins. 89-129.

Meisel, J.M. (ed.) 1994d. La adquisición del vasco y del castellano en niños bilingües. Madrid: Iberoamericana.

Meisel, J.M. 1994e. "Code-switching in young bilingual children. The acquisition of grammatical constraints". Studies in second language acquisition 16.4. 413-439.

Meisel, J.M. 2001. "The simultaneous acquisition of two first languages. Early differentiation and subsequent development of grammars". Cenoz, J. y F. Genesee (eds.) Trends in bilingual acquisition. Amsterdam: John Benjamins. 11-41.

Meisel, J.M. 2004. "The bilingual child”. Ritchie, W.C. y T.K. Bhatia (eds.) Handbook of bilingualism. Oxford: Blackwell. 91-113.

Milroy, L. y P. Muysken (eds.) 1995. One speaker, two languages: cross-disciplinary perspectives on code-switching. Cambridge: Cambridge University Press.

Müller, F. 1989. "Translation in bilingual conversation: pragmatic aspects of translatory interaction". Journal of pragmatics 13: 713-739.

Müller, N. y A. Hulk. 2001. "Crosslinguistic influence in bilingual language acquisition: Italian and French as recipient languages". Bilingualism: language and cognition 4.1: $1-21$.

Muysken, P. 1995. "Code-switching and grammatical theory". Milroy, L. y P. Muysken (eds.) One speaker, two languages. Cross-disciplinary perspectives on codeswitching. Cambridge: Cambridge University Press. 177-198.

Myers-Scotton, C. 1995. "A lexically based model of code-switching”. Milroy, L. y P. Muysken (eds.) One speaker, two languages: cross-disciplinary perspectives on code-switching. Cambridge: Cambridge University Press. 233-256.

Myers-Scotton, C. 1997. "Code switching". Coulmas, F. (ed.) The handbook of sociolinguistics. Oxford: Blackwell. 217-237.

Myers-Scotton, C. y J.L. Jake. 1995. "Matching lemmas in a bilingual competence and production model”. Linguistics 33: 981-1024.

Neubert, A. y G.M. Shreve. 1992. Translation as text. Kent, Ohio: The Kent State University Press.

Newmark, P. 1988. Approaches to translation. Londres: Prentice Hall.

Newmark, P. 1991. About translation. Clevedon: Multilingual Matters.

Nicoladis, E. 1998. "First clues to the existence of two input languages: pragmatic and lexical differentiation in a bilingual child". Bilingualism: language and cognition 1: 105-116. 
Nicoladis, E. 2001. "Finding first words in the input. Evidence from a bilingual child". Cenoz, J. y F. Genesee (eds.) Trends in bilingual acquisition. Amsterdam: John Benjamins. 131-147.

Nicoladis, E. 2002. "What's the difference between 'toilet paper' and 'paper toilet'? French-English bilingual children's crosslinguistic transfer in compound nouns". Journal of child language 29.4: 843-863.

Nicoladis, E. y F. Genesee. 1996. "A longitudinal study of pragmatic differentiation in young bilingual children". Language learning 46.3: 439-464.

Nicoladis, E. y F. Genesee. 1997. "The role of parental input and language dominance in bilingual children's code-mixing". Hughes, E., M. Hughes y A. Greeenhill (eds.) Proceedings of the Boston University conference on language development 21. Somerville, Mass.: Cascadilla Press. 442-432.

Nicoladis, E. y F. Genesee. 1998. "Parental discourse and codemixing in bilingual children”. International journal of bilingualism 2.1: 85-99.

Nicoladis, E. y G. Secco. 1998. "The role of translation equivalents in a bilingual family's code-mixing”. Greenhill, A., M. Hughes, H. Littlefield y H. Walsh (eds.) Proceedings of the Boston University conference on language development 22. Somerville, Mass.: Cascadilla Press. 576-585.

Nida, E.A. 1964. Toward a science of translating. Leiden: E.J. Brill.

Nida, E.A. 1976. "A framework for the analysis and evaluation of theories of translation". Brislin, R.W. (ed.) Translation. Applications and research. Nueva York: Gardner Press. 47-91.

Oksaar, E. 1983. Language acquisition in the early years. Nueva York: St. Martins Press.

Oller, D.K., R.E. Eilers, R. Urbano y A.B. Cobo-Lewis. 1997. "Development of precursors to speech in infants exposed to two languages". Journal of child language 24.2: 407-425.

Olmedo, I.M. 2003. "Language mediation among emergent bilingual children". Linguistics and education 14.2: 143-162.

Orellana, M.F. 2003. "In other words: learning from bilingual kids' translating and interpreting experiences". Evanston, Il: School of Education and Social Policy, Northwestern University.

$<$ http://www.gseis.ucla.edu/faculty/orellana/samples/IOW61003.pdf $>$ (20-03-2007)

Orellana, M.F., J. Reynolds, L. Corner y M. Meza. 2003a. "In other words: translating or "para-phrasing" as a family literacy practice in immigrant households". Reading research quarterly 38.1: 12-34.

Orellana, M.F., L. Dorner, y L. Pulido. 2003b. "Accessing assets: immigrant youth as family interpreters. Social problems 50.5: 505-524.

Paradis, J. 1996. "Prosodic development and differentiation in bilingual first language acquisition". Stringfellow, A., D. Cahana-Amitay, E. Hughes, y A. Zukowski (eds.) Proceedings of the 20th annual Boston University conference on language development. Somerville, MA: Cascadilla Press. 528-539.

Paradis, J. 2001. "Do bilingual two-year-olds have separate phonological systems?" International journal of bilingualism 5.1: 19-38. 
Paradis, J y F. Genesee. 1996. "Syntactic acquisition in bilingual children: autonomous or interdependent?" Studies in second language acquisition 18: 1-25.

Paradis, J. y Genesee, F. 1997. "On continuity and the emergence of functional categories in bilingual first language acquisition". Language acquisition 6.2: 91-124.

Paradis, J. y S. Navarro. 2003. "Subject realization and crosslinguistic interference in the bilingual acquisition of Spanish and English: what is the role of the input?". Journal of child language 30: 371-393.

Paradis, J., E. Nicoladis y F. Genesee. 2000. "Early emergence of structural constraints on code mixing: evidence from French-English bilingual children". Bilingualism: language and cognition 3: 245-261.

Paradis, M. 1980. "Bilingualism and aphasia". Whitaker, H. y H.A. Whitaker (eds.) Studies in neurolinguistics 3. Nueva York: Academic Press. 65-121.

Patterson, J.L. 1998. "Expressive vocabulary development and word combinations of Spanish-English bilingual toddlers". American journal of speech-language pathology 7.4: 46-56.

Pavlenko, A. 2000. "New approaches to concepts in bilingual memory". Bilingualism: language and cognition 3.1: 1-4.

Pearson, B.Z. 1998. "Assessing lexical development in bilingual babies and toddlers". International journal of bilingualism 2.3: 347-372.

Pearson, B.Z. y S. Fernández. 1994. "Patterns of interaction in the lexical development in two languages of bilingual infants". Language learning 44: 617-653.

Pearson, B.Z., S. Fernández y D.K. Oller. 1993. "Lexical development in bilingual infants and toddlers: comparison to monolingual norms". Language learning 43: 93-120.

Pearson, B.Z., S. Fernández y D.K. Oller. 1995. "Cross-language synonyms in the lexicons of bilingual infants: one language or two?" Journal of child language 22: 345-368.

Pearson, B.Z., S. Fernández, V. Lewedeg y D.K. Oller. 1997. "The relation of input factors to lexical learning by bilingual infants. Applied psycholinguistics 18: 41-58.

Pena Díaz, C. 2006. Bilingual speech: a case study of a bilingual community. Madrid: Servicio de publicaciones de la Universidad de Alcalá.

Petersen, J. 1988. "Word-internal code-switching constrains in a bilingual child's grammar". Linguistics 26: 479-493.

Petitto, L., M. Katerelos, B.G. Levy, K. Gauna, K. Tétreault y V. Ferraro. 2001. "Bilingual signed and spoken language acquisition from birth: implications for the mechanisms underlying early bilingual language acquisition". Journal of child language 28: 453-496.

Pfaff, C.W. 1979. "Constraints on language mixing: intrasentential code-switching and borrowing in Spanish/English". Language 55: 291-318.

Philips, B. 1993. "Bilingual students use skills to relay horror of death camp". Ottawa Citizen. Ottawa, Canadá. 26 de noviembre: B1-B2.

Pollock, J.Y. 1989. "Verb movement, universal grammar, and the structure of IP". Linguistic inquiry 20, 3: 365-424. 
Poplack, S. 1980. "Sometimes I'll start a sentence in Spanish y termino en español: toward a typology of code-switching". Linguistics 18: 581-618.

Poplack, S. 1981. "The syntactic structure and social function of code-switching". Durán, R. (ed.) Latino language and communicative behavior. Norwood, NJ: Ablex. 16984.

Potter, M.C., K. So, V. Eckardt y L. Feldman. 1984. "Lexical and conceptual representation in beginning and proficient bilinguals". Journal of verbal learning and verbal behavior 23: 23-38.

Poulin-Dubois, D. y N. Goodz. 2001. "Language differentiation in bilingual infants. Evidence from babbling". Cenoz, J. y F. Genesee (eds.) Trends in bilingual acquisition. Amsterdam: John Benjamins. 95-106.

Poulisse, N. 1993. "Theoretical account of lexical communication strategies". Schreuder, R. y B. Weltens (eds.) The bilingual lexicon. Amsterdam: John Benjamins. 157190.

Presas, M. 2000. "Bilingual competence and translation competence". Schäffner, C. y B. Adabs (eds.) Developing translation competence. Amsterdam: John Benjamins. 1931.

Price, C.J., D.W. Green y R. von Studnitz. 1999. "A functional imaging study of translation and language switching". Brain 122: 2221-2235.

Pym, A. 2002. "Redefining translation competence in an electronic age. In defence of a minimalist approach". Intercultural studies group, Universitat Rovira i Virgili. Tarragona.

$<$ http://www.tinet.org/ apym/on-line/competence.pdf> (20-03-2007)

Quay, S. 1993. Language choice in early bilingual development. Tesis doctoral, Universidad de Cambridge.

Quay, S. 1995. "The bilingual lexicon: implications for studies of language choice". Journal of child language 22: 369-387.

Quay, S. 2001. "Managing linguistic boundaries in early trilingual development". Cenoz, J. y F. Genesee (eds.) Trends in bilingual acquisition. Amsterdam: John Benjamins. 148-199.

Rabadán Álvarez, R. 1991. Equivalencia y traducción. Problemática de la equivalencia translémica inglés-español. León: Universidad de León.

Radford, A. 1990. Syntactic theory and the acquisition of English syntax. Cambridge: Blackwell.

Redlinger, W. y T. Park 1980. "Language mixing in young bilinguals". Journal of child language 7: 337-352.

Romaine, S. 1989. Bilingualism. Nueva York: Basil Blackwell Inc.

Romaine, S. 1999. "Bilingual language development". Barrett, M. (ed.) The development of language. East Sussex, U.K.: Pshychology Press. 251-275.

Rondal, J.A., M. Ghiotto, S. Bredart y J.F. Bachelet. 1987. "Age-relation, reliability, and grammatical validity of measures of utterance length". Journal of child language 14: 433-446. 
Ronjat, J. 1913. Le développement du langage observé chez an enfant bilingue. París: Librairie Ancienne H. Champion.

Ruan, J. 2003. "A study of bilingual Chinese/English children's code switching behaviour". Academic exchange quaterly 7.1: 142-147.

Sánchez-Casas, R.M. 1999. "Una aproximación psicolingüística al estudio del léxico en el hablante bilingüe". Vega, M. de y F. Cuetos (eds.) Psicolingüística del español. Madrid: Trotta. 597-650.

Sankoff, D. y S. Poplack. 1981. “A formal grammar of code-switching”. Papers in linguistics 14: 3-46.

Saunders, G. 1982. Bilingual children: guidance for the family. Clevedon: Multilingual Matters.

Saunders, G. 1988. Bilingual children: from birth to teens. Clevedon: Multilingual Matters.

Sayols Lara, J. 2002. "Adquisició de la competència traductora del xinés. El procès d'aprenentatge". Doctorat en teoria de la traducció. Processos cognitius i traducció. $<$ http://campus.uab.es/ 2069236/ACTX.PDF> (20-03-2007)

Schelletter, C. 2000. "Negation as a crosslinguistic structure in a German-English bilingual child". Döpke, S. (ed.) Cross-linguistic structures in simultaneous bilingualism. Amsterdam: John Benjamins. 105-121.

Schlyter, S. 1987. "Language mixing and linguistic level in three bilingual children". Scandinavian working papers on bilingualism 7: 29-48.

Schnitzer, M.L. y E. Krasinski. 1996. "The development of segmental phonological production in a bilingual child: a contrasting second case". Journal of child language 23.3: 547-571.

Schreuder, R. y B. Weltens. 1993. "The bilingual lexicon: an overview". Schreuder, R. y B. Weltens (eds.) The bilingual lexicon. Amsterdam: John Benjamins. 1-10.

Seleskovitch, D. 1976. "Interpretation, a psychological approach to translating". Brislin, R.W. (ed.) Translation. Applications and research. Nueva York: Gardner Press. 92116.

Serra, M. 2007. Base de datos CHILDES.

$<$ http://childes.psy.cmu.edu/data/Biling/> (última actualización 4-02-2007)

Shannon, S. 1990a. "Spanish for Spanish speakers: a translation skills curriculum". Padilla, A.M., H.H. Fairchild y C.M. Valadez (eds.) Foreign language education. Issues and strategies. Newbury Park: Sage. 223-237.

Shannon, S. 1990b "English in el barrio: the quality of contact". Hispanic journal of behavioral sciences 12.3: 256-276.

Shannon, S. 1996. "A reconsideration of natural translation for a theory of translation". Coulthard, M. y P.A. Odber de Baubeta (eds.) The knowledges of the translator: from literary interpretation to machine classification. Queenston: Edwin Mellen Press. 99-118.

Sherwood, B. 2000. "Features of NT in a language testing environment". Tesis de maestría, School of Translation and Interpretation, Universidad de Ottawa. 
Shlesinger, M. 1994. "Intonation in the production and perception of simultaneous interpretation", Lambert, S. y B. Moser-Mercer (eds.) Bridging the gap: empirical research in simultaneous interpretation. Amsterdam: John Benjamins. 225-236.

Sholl, A., A. Sankaranarayanan y J.F. Kroll. 1995. "Transfer between picture naming and translation: a test of asymmetries in bilingual memory". Psychological science 6: 45-49.

Shreve, G.M. 1997. "Cognition and evolution of translation competence". Danks, J.H., G.M. Shreve, S.B. Fountain y M.K. Macbeath (eds.) Cognitive processes in translation and interpreting. Thousand Oaks: Sage. 120-136.

Siguán, M. 2001. Bilingüismo y lenguas en contacto. Madrid: Alianza Editorial.

Sinka, I. 2000. "The search for cross-linguistic influences in the language of young Latvian-English bilinguals". Döpke, S. (ed.) Cross-linguistic structures in simultaneous bilingualism. Amsterdam: John Benjamins. 149-174.

Slobin, D. 1985. The cross-linguistic study of language acquisition: the data. Hillsdale, NJ: Lawrence Erlbaum Associates.

Slobin, D.I. 1973. "Cognitive prerequisites for the development of grammar". Ferguson, C.A. y D.I. Slobin (eds.) Studies of child language development. Nueva York: Holt, Rinehart y Winston. 175-208.

Snodgrass, J.G. 1993. “Translating versus picture naming”. Schreuder, R. y B. Weltens (eds.) The bilingual lexicon. Amsterdam: John Benjamins. 83-114.

Soares, C. y F. Grosjean. 1984. "Bilinguals in a monolingual and bilingual speech mode: the effect on lexical access". Memory and cognition 12: 380-386.

Spradlin, K.T., J.M. Liceras y R. Fernández Fuertes. 2003. "Functional-lexical codemixing patterns as evidence for language dominance in young bilingual children: a minimalist approach". Generative approaches to second language acquisition conference (GASLA-6 2002): L2 links. Liceras, J.M., H. Zobl y H. Goodluck (eds.). Somerville: Cascadilla Press. 298-307.

Sridhar, S.N. y K.K. Sridhar. 1980. "The syntax and psycholinguistics of bilingual codemixing". Canadian journal of psychology 34: 407-16.

Srivastava, R.N. y R.S. Gupta. 1989. "Natural translation and translation theory". International journal of translation 1.1: 17-24.

Steiner, G. 1975. After Babel. Aspects of language and translation. Oxford: Oxford University Press.

Swain, M.K. 1972a. Bilingualism as a first language. Tesis doctoral, Universidad de California, Irvine.

Swain, M.K. 1972b Bilingual first-language acquisition. Comentarios realizados en el International symposium on first-language acquisition. Florencia, Italia.

Swain, M.K. 1973. "Bilingual language acquisition and linguistic interdependence". Comunicación presentada en Bilingualism and its implications for Western Canada. Universidad de Alberta, Edmonton, Canadá.

Swain, M.K. y M.B. Wesche. 1975. "Linguistic interaction: case study of a bilingual child”. Language sciences 37: 17-22. 
Swain, M.K., G. Dumas y N. Naiman. 1974. "Alternatives to spontaneous speech: elicited translation and imitation as indicators of second language competence". Working papers in bilingualism 3: 68-79.

Taeschner, T. 1983. The sun is feminine: A study on language acquisition in bilingual children. Berlin: Springer-Verlag.

Thornton, R. 1996. "Elicited production". McDaniel, D., C. McKee y H. Smith Cairns (eds.) Methods for assessing children's syntax. Cambridge, Mass.: MIT Press. 77102.

Toribio, A.J. 2001. "On the emergence of bilingual code-switching competence". Bilingualism: language and cognition 4.3: 203-231.

Toribio, A.J. y B.L. Brown. 1995. "Language contact and differentiation in child bilingualism: a syntactic analysis. MacLaughlin, D. y S. McEwen (eds.) Proceedings of the Boston University conference on language development 19. Somerville, Mass.: Cascadilla Press. 629-642.

Toury, G. 1984. "The notion of native translation and the translation teaching". Wilss, W. y G. Thome (eds.) Die theorie des übersetzens und ihr aufschlußwert für die übersetzungs und dolmetschdidaktik. Tübingen: Gunter Narr Verlag. 186-195.

Toury, G. 1986. "Natural translation and the making of a native translator". Textcontext 1.1: 11-29.

Tse, L. 1996. "Language brokering in linguistic minority communities: the case of Chinese -and Vietnamese- American students". The bilingual research journal 20.3-4: 485498.

Tucker, R. 1998. "A global perspective on multilingualism and multilingual education". Cummins, J. y D. Corson (eds.) Bilingual education. Dordrecht, The Netherlands: Kluwer Academic Publishers. 3-15.

Valdés, G. 1981. "Codeswitching as deliberate verbal strategy: a microanalysis of direct and indirect requests among bilingual Chicano speakers". Duran, R. (ed.) Latino language and communicative behaviour. Norwood, NJ: Ablex. 95-107.

Valdés, G. 2003. Expanding the definition of giftedness: the case of young interpreters from immigrant communities. Londres: Lawrence Earlbaum.

Van der Linden, E. 2000. "Non-selective access and activation in child bilingualism: the lexicon”. Döpke, S. (ed.) Cross-linguistic structures in simultaneous bilingualism. Amsterdam: John Benjamins. 37-56.

Van Hell, J.G. y A.M.B. De Groot. 1998. "Disentangling context availability and concreteness in lexical decision and word translation". The quarterly journal of experimental psychology 51A: 41-63.

Verhallen, M. y R. Schoonen. 1993. "Lexical knowledge of monolingual and bilingual children". Applied linguistics 14: 344-363.

Verhoeven, L. 1994. "Transfer in bilingual development: the linguistic interdependence hypothesis revisited". Language learning 44.3: 381-415.

Viding, E., T.S. Price, F.M. Spinath, D.V.M. Bishop, P.S. Dale y R. Plomin. 2004. "Genetic and environmental mediation of the relationship between language and nonverbal impairment in 4-year-old twins". Journal of speech, language and hearing research 46.6: 1271-1282. 
Vihman, M. 1985. "Language differentiation by the bilingual infant". Journal of child language 12.2: 297-324.

Vihman, M. 1998. "A developmental perspective on codeswitching: conversations between a pair of bilingual siblings". International journal of bilingualism 2.1: 45-84.

Vinagre Laranjeira, M. 2005. El cambio de código en la conversación bilingüe: la alternancia de lenguas. Madrid: Arco/Libros.

Volterra, V. y T. Taeschner 1978. "The acquisition and development of language by bilingual children". Journal of child language 5: 311-326.

Von Raffler-Engel, W. 1970 "The concept of sets in a bilingual child”. Actes du X congrès international des linguistes. Rumanía: Éditions de l'Academie de la Rèpublique Socialiste de Roumanie.

Wadensjö, C. 1998. Interpreting as an interaction. Londres: Longman.

Walichowski, M. 2001. "Language brokering: laying the foundation for success and bilingualism". Research in bilingual education. Symposium conducted at the annual educational research exchange. College Station, Texas. $<\mathrm{http}$ ://dn.tamu.edu/awresearch/walichowski.htm> (20-03-2007)

Wapole, C. 2000. "The bilingual child: one system or two?" Clark E.V. (ed.) The proceedings of the thirtieth annual child language research forum. Stanford, California: Center for the study of language and information. 187-194.

Wei, L. (ed.). 2000. The bilingualism reader. Nueva York: Routledge.

Weinreich, U. 1968. Languages in contact. La Haya: Mouton.

Wilss, W. 1976. "Perspectives and limitations of a didactic framework for the teaching of translation". Brislin, R.W. (ed.) Translation. Applications and research. Nueva York: Gardner Press. 117-137.

Woolford, H. 1983. "Bilingual code-switching and syntactic theory". Linguistic Inquiry 14: 520-536.

Woutersen, M., A. Cox, B. Weltens y K. De Bot. 1998. "Lexical aspects of standard dialect bilingualism". Applied psycholinguistics 15.4: 447-473.

Zentella, A.C. 1997. Growing up bilingual. Boston, MA: Blackwell. 
APÉNDICES 
Apéndice I: transcripción 39SP_02

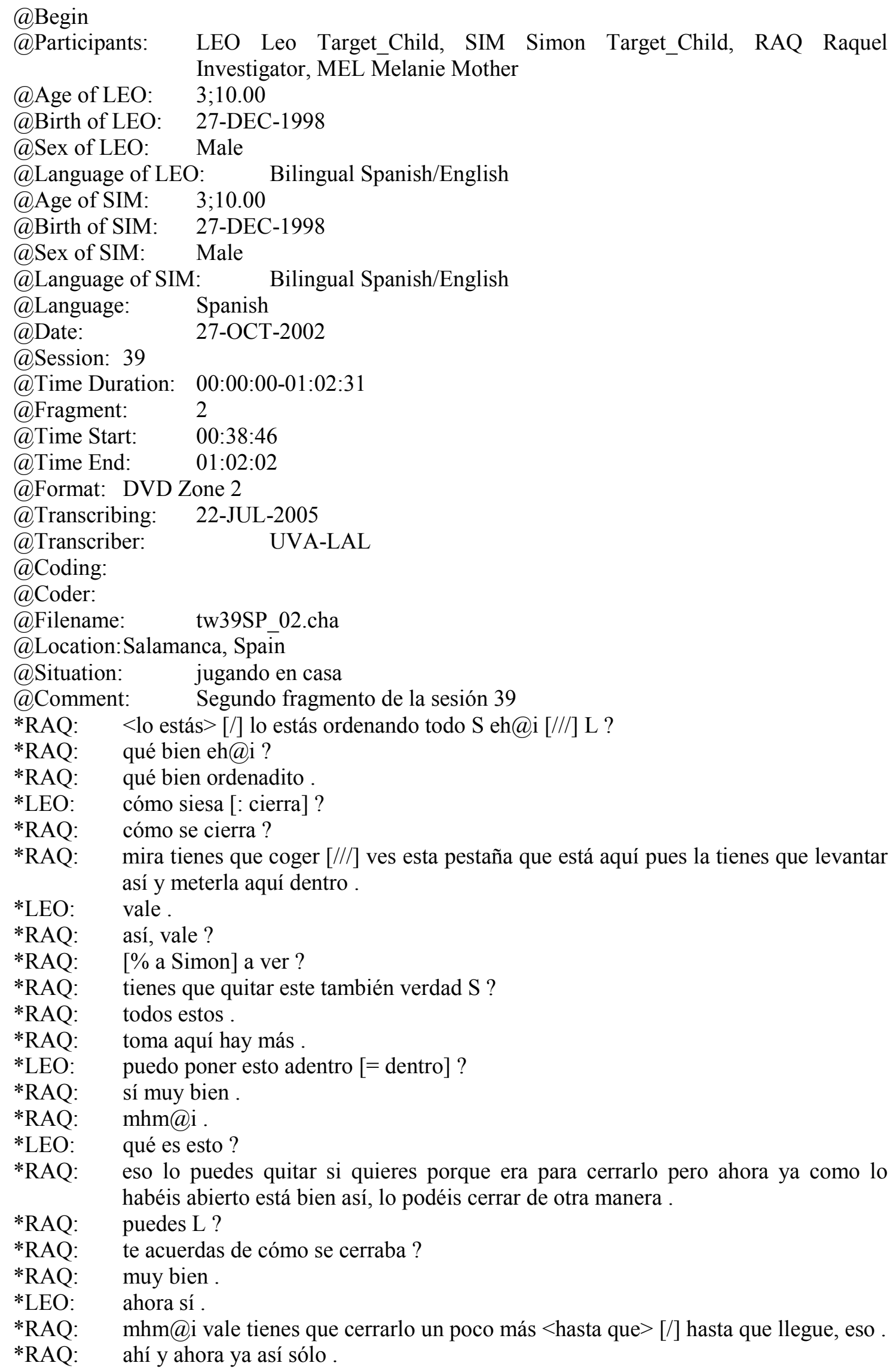


*RAQ: muy bien has visto ?

*RAQ: muy bien .

*RAQ: espera que voy a quitar esto de aquí vale ?

*RAQ: ya .

*RAQ: has visto que tie [///] pero tienes una maleta eh@i ?

*RAQ: porque mira la puedes coger de aquí .

*RAQ: ves?

*RAQ: como papá cuando va a trabajar .

*RAQ: has visto L eh@i [///] S ?

*RAQ: qué bonita es la maleta de L ?

*SIM: sí .

*RAQ: $\quad$ mira es que $\mathrm{S}+/$.

*LEO: mira qué he hecho!

*RAQ: qué has hecho?

*LEO: mira venga .

*RAQ: a dónde ?

*RAQ: arriba?

*LEO: sí .

*RAQ: vamos arriba $\mathrm{S}$ ?

*SIM: no cuando acabo [= acabe] esto .

*RAQ: $\quad$ sí vamos a esperar a $\mathrm{S}$ que va a acabar la [///] de..+

*RAQ: quieres que te ayudemos $\mathrm{S}$ ?

*SIM: no .

*RAQ: no ?

*RAQ: vale pues entonces nada sólo vamos a esperarle .

*RAQ: oye L esto es tuyo verdad ?

*RAQ: $\quad<$ es tu tesoro $>$ [//] son tus tesoros .

*RAQ: a ver?

*RAQ: me los enseñas ?

*RAQ: hala@i había una cosa de estas ahí en el suelo no ?

*RAQ: creo .

*LEO: aquí

*RAQ: que es igual que esta .

*LEO: $\quad$ sí porque son $+\ldots$

*RAQ: $\quad$ son del mismo...+

*RAQ: del mismo collar ?

*RAQ: mira aquí hay otra también ves ?

*LEO: $\quad$ sí aquí hay trositos [: trocitos] .

*RAQ: hay ositos .

*LEO: toma !

*LEO: esto no + /.

*SIM: hay ositos y estas qué son?

*LEO: ven arriba .

*LEO: eh@i de collares .

*RAQ: pero estas cómo se llaman ?

*LEO: $\quad$ eh@fp pelotitas .

*RAQ: pelotitas?

*RAQ: no las pelotitas son estas no ?

*LEO: flores .

*RAQ: flores exactamente por eso $+/$.

*LEO: $\quad$ y estas pe [/] pelotitas .

*RAQ: esas pelotitas

*RAQ: mira ves?

*RAQ: ya [/] ya casi ha terminado .

*RAQ: lo vas a cerrar ? 
*RAQ: a ver?

*RAQ: $\quad$ ya .

*LEO: qué es esto blanco ?

*RAQ: perdón?

*LEO: qué es esto blanco ?

*RAQ: $\quad$ eso son las instrucciones para [/] para que papá y mamá las lean y os expliquen qué es lo que tenéis que hacer y para que sepáis cómo tenéis que jugar con [/] con <las $>$ [//] los cordones y la ropa en las figuras .

*LEO: $\quad$ este es de $\mathrm{S}$ pero $+\ldots$

*RAQ: $\quad$ ese es el de $\mathrm{S}$ ?

*LEO: $\quad+$, pero si quitas esto se rompe porque $\mathrm{xxx}$ porque mira ves esto ?

*RAQ: esto tienes que ponerlo así $\mathrm{S}$ si no no te va a entrar

*LEO: $\quad$ esta raya qué es esta raya qué es ?

*RAQ: [\% a Simon] esto también es tuyo.

*LEO: mira esto es una raya que está roto [= rota] así .

*RAQ: que está roto [= rota] así .

*LEO: $\quad$ sí .

*RAQ: [\% refiriéndose al maletín de los juguetes] sabes cómo se cierra S ?

*SIM: no .

*RAQ: mira .

*LEO: mira yo te enseño mira .

*LEO: $\quad$ haces esto esto así $+\ldots$

*LEO: ya!

*LEO: (a)hora voy arriba .

*LEO: (a)hora vamos arriba

*RAQ: ahora vamos arriba?

*LEO: ya tenemos un maletín!

*RAQ: claro tenéis un maletín !

*RAQ: qué chicos más importantes con maletín y todo vamos !

*LEO: vamos

*SIM: [\% colocándose la daga en la cintura] a ver si puedo !

\%com: se van arriba a buscar los libros y hay un corte en la grabación

*LEO: mi [: me] lees estos cuentos?

*RAQ: venga pues $+/$.

*LEO: todos esos!

*RAQ: todos esos?

*RAQ: bueno pues yo me siento aquí y vosotros aquí venga aquí a este lado .

*SIM: $\quad$ sí $\mathrm{xxx}$.

*LEO: también este ?

*RAQ: y ese también ?

*LEO: $\quad$ sí ese leemos .

*RAQ: ese es el de Mexico no ?

*LEO: sí .

*SIM: sí .

*RAQ: mira has visto que pirámide más bonita ?

*SIM: a ver?

*LEO: [\% enseñándole a Raquel un peluche] yo tengo un osito !

*RAQ: tienes un osito ?

*RAQ: ah@i mira las máscaras !

*RAQ: usan máscaras \# dónde se ponen las mascaras ?

*SIM: en la cabesa [: cabeza] .

*RAQ: [\% hace como que se pone una máscara] así .

*SIM: me lo pones ?

*LEO: sí mira mi cara .

*RAQ: pero son preciosas eh@i ? 
*RAQ: no os gustan las máscaras ?

*RAQ: mira esta qué bonita !

*RAQ: has visto ?

*RAQ: para los ojos .

*LEO: $\quad$ que no te [///] ah@i mira esto qué pistola más grande !

*SIM: oh@i no s(e) ha rompido [= roto] !

*RAQ: oh@i no se ha rompido [= roto], se ha rompido no, se ha roto .

*LEO: $\quad[\%$ señalando la pistola $]$ mira..+

*RAQ: $\quad$ vamos a ver $+/ /$.

*LEO: +, eso no es rompido [= está roto] .

*SIM: $\quad$ vamos $+\ldots$

*LEO: una pistola!

*SIM: has visto ?

*RAQ: hola .

*LEO: a ver .

*RAQ: [\% a Simon] has visto cuál ?

*LEO: hola .

*SIM: ah@i mira esto !

*RAQ: mira esos son [/] son enormes eh@i ?

*SIM: mira esto mira mira !

*RAQ: hala@i !

*RAQ: y esos qué són?

*SIM: qué [/] qué diente tiene !

*RAQ: $\quad$ sí y qué boca más grande has vsito ?

*SIM: sí .

*LEO: $\quad$ yah@i .

*RAQ: estos son dragones no ?

*SIM: dragón .

*LEO: sí yo lo ví pero ya yo no quiero uno !

*RAQ: claro aquí [/] aquí sí te mentirían $\mathrm{xxx}$.

*SIM: $\quad$ mira esto pa(ra) abajo .

*RAQ: aquí ?

*SIM: aquí .

*LEO: [ [\% subido al sofá] me caigo wow@i .

*RAQ: así .

*LEO: que me caigo !

*RAQ: así estamos todos listos .

*SIM: todos listos .

*SIM: a ver cuántos libros tenemos ?

*SIM: $\quad$ uno $+\ldots$

*RAQ: tenemos un montón .

*SIM: $\quad+, \operatorname{dos}+\ldots$

*RAQ: $\quad \operatorname{dos}+\ldots$

*SIM: $\quad+$, tres cuatro cinco seis !

*RAQ: $\quad$ seis libros .

*LEO: $\quad$ seis libros .

*RAQ: un montón eh@i !

*SIM: $\quad$ y mi otro ?

*LEO: $\quad$ xxx dónde están ?

*RAQ: [\% a Simon] el tuyo este [//] este creo que es el $\mathrm{S}<\mathrm{el}$ de $>$ [/] el de L este es el tuyo el grande el que me decías $+/$.

*LEO: $\quad$ este es el miyo [= mío]

*LEO: [\% bajándose del sofá] que voy a coger algo (a)hora voy !

*LEO: que voy a coger mis cosas .

*RAQ: $\quad$ vas a coger $+/ /$. 
*LEO: [\% yéndose de la habitación ] xxx .

*RAQ: vas a coger tus cosas ?

*SIM: $\quad$ ah@i mira un cocodrilo!

*RAQ: un cocodrilo?

*RAQ: anda y esta?

*SIM: mhm@i el mhm@i es +...

*RAQ: esto qué es ?

*SIM: mira un cocodrilo s(e) ha comido una mansana [: manzana] !

*RAQ: ah@i este es un cocodrilo lo que pasa es que este es un cocodrilo verde no ?

*SIM: sí .

*RAQ: $\quad$ y este ?

*SIM: po(r)que los cocodrilos son verdes !

*RAQ: $\quad$ entonces este ?

*RAQ: qué le pasa a este ?

*SIM: a que esto no es un cocodrilo como esto .

*SIM: $\quad$ y esto es un pes [: pez]

*SIM: mira esto .

*RAQ: qué es eso ?

*SIM: ves?

*SIM: a que esto es un delfín .

*RAQ: $\quad$ eh@i yo creo que más bien es un pez espa [/] espada .

*SIM: espada .

*RAQ: $\quad$ es un pez espada porque ves cómo tiene la [/] la boca ?

*RAQ: parece una espada?

*SIM: $\quad$ y mira esto .

*RAQ: $\quad$ un alce qué bonito eh@i !

*SIM: ves con cosas diferentes ves ?

*RAQ: mhm@i .

*SIM: mira es::te elefante!

*RAQ: sí está en un triciclo verdad ?

*RAQ: pero es un triciclo un poco pequeño

\%com: vuelve Leo

*RAQ: uy@i qué de cosas trae L !

*RAQ: a ver vamos a + .

*LEO: $\quad$ se $+/$.

*SIM: mira mira mira mira esto !

*RAQ: te quieres sentar a este otro lado ?

*SIM: $\quad<\mathrm{e}$ e $>$ [/] está en la jungla !

*LEO: [\% llevándose el libro] ese ya lo vi .

*RAQ: te sientas aquí $L$ a este lado ?

*LEO: sí .

*RAQ: $\quad$ o adónde te quieres sentar ?

*LEO: [\% trayendo otro libro] ves ?

*RAQ: [\% a Simon] estos son de los dinosaurios no ?

*LEO: mis libros .

*SIM: $\quad$ los dinosaurios xxx .

*LEO: quién lo tenía?

*LEO: [\% poniéndose una máscara] te veyo [: veo] !

*RAQ: anda@i !

*RAQ: [\% a Leo] eso es una máscara no ?

*SIM: mira hay unos patos aquí xxx esto !

*LEO: $\quad$ pero quiero que $+\ldots$

*SIM: $\quad$ cómo se defende [ $=$ defiende $]$ este dinosaurio ?

*RAQ: cómo se defiende este dinosaurio ? 
*LEO: $\quad$ sí este se defende [ $=$ defiende $]$ con eso, ese se defende [= defiende] con la cola, este se defende $<$ con los $>$ [/] con los cuernos y este se defende [= defiende] con la cola y este $+/$.

*SIM: $\quad$ y este se defende $[=$ defiende $]<$ con con con con con $>[/]<$ con su $>[/]$ con su cola pecuda [: picuda] $\mathrm{y}+/$.

*LEO: $\quad$ y este se defende [= defiende $]$ con su cola también y ese se defende [= defiende] con su cabeza .

*RAQ: ah@i !

*SIM: mhm@i .

*LEO: $\quad$ es a que este dinosaurio se defende [= defiende] con su cola ?

*RAQ: $\quad$ si lo has visto ?

*RAQ: que tiene ahí en la cola como unos pinchos verdad ?

*SIM: no ves ?

*SIM: $\quad$ si tiene estos pinchos y no es para nada..+

*SIM: cómo nos puede pillar !

*LEO: ay@i .

*RAQ: [\% ayudando a Leo a subir al sofá] a:rriba arriba !

*SIM: dónde está el de México ?

*RAQ: el de México creo que está aquí abajo no ?

*RAQ: oh@i no dónde está el de México ?

*RAQ: dónde hemos puesto el de México ?

*RAQ: $\quad$ eh@fp +...

*SIM: aquí .

*RAQ: aquí dónde ?

*SIM: a ver a ver a ver .

*RAQ: $\quad$ no no está aquí .

*RAQ: si lo teníamos en la mano ahora!

*RAQ: dónde está el de México ?

*RAQ: $\quad$ ah@i está aquí está aquí !

*SIM: está aquí está aquí !

*LEO: me caigo !

*RAQ: a ver pues + .

*LEO: pones esto que xxx pone en los ojos?

*RAQ: ah@i eso es la máscara !

*LEO: Raquel me lo quiero poner .

*RAQ: te lo quieres poner?

*LEO: ves cómo parese [: parece] ?

*RAQ: [\% poniéndole la máscara] ves bien así ?

*RAQ: espera ahora [/] ahora lo ponemos bien eh@i ?

*RAQ: un momentito .

*SIM: $\quad$ yo quiero !

*LEO: los piratas llevan eso ?

*RAQ: sí los piratas llevan el antifaz sabes por qué ?

*LEO: por qué ?

*RAQ: $\quad$ para que nadie los reconozca .

*RAQ: para que nadie los reconozca así y entonces + .

*SIM: $\quad$ pues yo no quiero probar a mío .

*RAQ: $\quad$ y si [///] tú no tienes ?

*LEO: $\quad$ por qué no me pones [///] a que no sabes quién soy?

*RAQ: $\quad$ no sé quién eres porque como $<$ no tie $>[/ /]$ no te veo la cara no sé quién eres

*RAQ: así que ahora qué ?

*RAQ: quién serás ?

*RAQ: oye y tú quién eres?

*LEO: un pirata

*RAQ: ah@i un pirata de los buenos o de los malos? 
*LEO: de los malos .

*RAQ: no, no me digas eso !

*LEO: $\quad$ sí .

*RAQ: $\quad$ y tú no tienes < una ti $>[/ /]$ un $+/$.

*LEO: sí po(r)que mira .

*RAQ: oh@i oh@i es un pirata de los malos S .

*RAQ: qué vamos a hacer!

*SIM: $\quad$ no ese es L y yo soy $\mathrm{S}$ !

*RAQ: no él es un pirata él no es L !

*RAQ: ves como no es L ?

*RAQ: es un pirata!

*RAQ: ah@i oh@i oh@i oh@i oh@i !

*RAQ: y tú no tienes una máscara como esa ?

*SIM: no .

*RAQ: no ?

*RAQ: sólo tenéis una máscara ?

*SIM: no.

*SIM: pero tenemos espadas .

*RAQ: tenemos espadas para defendernos ?

*SIM: toma .

*LEO: $\quad<$ a que no sabes no> [//] a que no sabes quién soy?

*RAQ: quién serás ?

*RAQ: $\quad$ este niño quién es ?

*LEO: un pirata!

*RAQ: tú lo conoces a este pirata ?

*RAQ: es un pirata pero además +/.

*SIM: bu@i !

*RAQ: pi@i !

*RAQ: es un pirata de los malos eh@i !

*SIM: pi@i !

*LEO: $\quad$ ya yo [/] yo te lo digo <que que que $>[/]$ que soy $<$ que que que que $>$ [/] que tú no sabes quién eres y luego tú dices $<$ que que que $>$ [/] que soy un bueno pirata y yo [/] yo digo que soy un malo pirata de acuerdo ?

*RAQ: vale

*RAQ: $\quad$ o sea que este ya sé quién es $\mathrm{S} \#$ ya sé quién es este .

*RAQ: tú sabes quién es?

*SIM: un + .

*RAQ: es un pirata bueno .

*SIM: no, es un pirata malo .

*RAQ: $\quad$ no no no no, es de los buenos de verdad !

*SIM: $\quad$ no es de los buenos que no!

*RAQ: que sí sí sí !

*LEO: $\quad$ soy un pirata malo .

*RAQ: $\quad$ oh@i no es de los malos !

*RAQ: $\quad$ S corre corre defiende defiende !

*RAQ: ey@i que nos va a atacareh@i ?

*RAQ: $\quad$ porque es un pirata $+/$.

*RAQ: [\% Leo se quita la máscara] ah@i !

*RAQ: pero si es L no es un pirata malo es L !

*RAQ: entonces ya no hay problema verdad ?

*SIM: $\quad$ mira qué dos espadas $+\ldots$

*LEO: que me lo quiero quitar $+\ldots$

*SIM: $\quad+$, mira dos espadas !

*LEO: $\quad$ que me lo quiero quitar porque $\& a+\ldots$

*RAQ: tienes dos ! 
*LEO: +, me lo pongo cuando [/] cuando después de la historia porque así no puedo ver !

*RAQ: $\quad$ ah@i porque así no puedes ver bien verdad ?

*RAQ: $\quad$ bueno pues < vamos a $>$ [/] vamos a quitarle el nudo porque esto tiene un nudo aquí

*RAQ: vamos a quitárselo así eso es !

*LEO: así eso es !

*RAQ: toma!

*LEO: $\quad$ sin nudo!

*RAQ: $\quad$ sin nudos no ?

*LEO: lleva esto para [/] para que <sa $>$ [//] saben que no estoy loco y luego y los ascuestras [: encuentran] .

*RAQ: $\quad$ los encuentran, si ?

*LEO: $\quad<$ y luego los a> [//] y luego los llevan .

*RAQ: se los llevan?

*RAQ: y qué hacen con ellos ?

*LEO: los atan .

*RAQ: los atan ?

*RAQ: guau@i porque han sido malos no ?

*LEO: sí porque han sido malos .

*RAQ: porque han sido malos .

*LEO: que mi [: me] caigo uh@i !

*RAQ: cuidado que te caes !

*LEO: oye mira qué hace esto !

*LEO: $\quad$ mira < qué> [//] cómo funciona esto !

*LEO: que se cae!

*RAQ: a ver?

*LEO: mira qué hace !

*RAQ: a ver?

*SIM: oa@i !

*LEO: mira qué hace mira!

*RAQ: qué hace eso ?

*LEO: mira qué hace !

*SIM: $\quad$ este es este !

*SIM: $\quad[\%$ encendiendo un juguete que habla] mira !

*RAQ: ah@i !

*SIM: [\% repitiendo lo que dice el juguete] gua@i bye bye !

*LEO: mira qué hace ahora si escojo e [/] esto

*SIM: quita !

*SIM: $\quad[\%$ repitiendo lo que dice el juguete $]$ you !

*SIM: [\% repitiendo lo que dice el juguete] hot !

*RAQ: ah@i eso qué significa?

*SIM: caliente !

*RAQ: ah@i caliente !

*LEO: mira!

*RAQ: uy@i qué ha dicho !

*SIM: [\% repitiendo lo que dice el juguete] xxx .

*RAQ: y eso qué significa?

*LEO: [\% escogiendo otra melodía en el juguete] mira !

*RAQ: y esto qué es ?

*RAQ: uy@i !

*LEO: mira!

*RAQ: ay@i qué música más chula eh@i ?

*LEO: mira esto !

*LEO: mira qué hace esto !

*SIM: a ver! 
*RAQ: $\quad$ y qué dice ?

*RAQ: qué son esas?

*RAQ: lo que os gusta es que se ríen !

*RAQ: ay@i qué gracioso es el S !

*RAQ: www .

*MEL: $\quad$ www

\%exp: $\quad$ llega Melanie y mantiene una conversación aparte con Raquel

\%tim: $\quad$ 00:56:33

*RAQ: a ver y qué más !

\%tim: $\quad 00: 57: 23$

*RAQ: $\quad$ [\% repitiendo lo que dice el juguete] you !

*RAQ: $\quad$ estas qué son?

*LEO: uvas!

*SIM: uvas!

*RAQ: uvas?

*RAQ: no, son aceitunas .

*RAQ: [\% Simon está dando vuelta y se marea] ey@i cuidado S pirata que te vas a hacer daño!

*LEO: ahora esto

*RAQ: [\% abriendo un libro] a ver yo voy a ver esto .

*LEO: $\quad$ ya s(e) acabó .

*RAQ: $\quad$ ya se acabó ?

*RAQ: hala@i mira este qué grande guau@i jolín@i !

\%com: llega Melanie y se los lleva a comer y hay un corte en la grabación

*LEO: $\quad$ mira se ha rompido [= roto]

*RAQ: mira aquí hay otra ficha eh@i ?

*RAQ: sí .

*SIM: mira el coche va así .

*RAQ: ah@i pero <lo has> [/] lo has roto .

*SIM: pero son [///] sí están .

*RAQ: sí así sí .

*LEO: a:h@i !

*RAQ: a ver .

*RAQ: $\quad$ esto yo creo que no va ahí eh@i !

*RAQ: a ver vamos a ver si conseguimos...+

*SIM: $\quad$ es esto ?

*SIM: $\quad$ esto $+/$.

*RAQ: no pero lo tenías bien hecho antes $\mathrm{S}$.

*RAQ: $\quad$ es que <es muy> [/] es muy fino verdad ?

*SIM: $\quad$ es muy fino.

*RAQ: $\quad$ es muy fino entonces...+

*RAQ: quieres hacerlo mejor encima de la mesa $\mathrm{S}$.

*SIM: pues sí.

*RAQ: $\quad$ yo creo que es mejor mira $<$ te voy a poner $>$ [/] te voy a poner aquí la mesa $+\ldots$

*SIM: $\quad$ sí y pongo eso aquí .

*RAQ: +, y yo creo que igual es más fácil porque es que es tan fino que ah@fp en el suelo es muy difícil .

*RAQ: $\quad$ a ver las ponemos todas boca arriba .

*SIM: ah@i ha ponido [= puesto] uno así po(r)que no me daba cuenta !

*RAQ: no te dabas cuenta ?

*SIM: $\quad$ estos son así .

*RAQ: así está bien ya ?

*SIM: sí .

*RAQ: bueno pues venga a ver !

*SIM: $\quad$ (es)pera (es)pera que voy a haser [: hacer] esto . 
*RAQ: no jobar@i no lo p(u)edo abrir [\% tiene un huevo Kinder en la mano y quiere ver la sorpresa]!

*RAQ: quieres que te lo abra yo ?

*LEO: $\quad$ sí .

*LEO: que me caigo!

*RAQ: uh@i mira lo que tienes tú !

*RAQ: no es un puzle!

*LEO: oh@i qué es ?

*RAQ: no sé vamos a ver .

*LEO: no lo sé .

*LEO: qué es?

*RAQ: a ver qué es ?

*LEO: ah@i ya lo sé qué es !

*RAQ: qué es esto ?

*RAQ: a ver?

*SIM: qué es eso ?

*SIM: mira mira un gusano !

*RAQ: ay@i mira lo que es !

*LEO: a ver?

*RAQ: $\quad$ para ponerlo $<$ en el $>[/]<$ en el lapicero $>[/ /]$ en los lápices .

*RAQ: qué bonito!

*RAQ: $\quad$ mira tienes un [/] un lápiz ?

*RAQ: $\quad$ a ver vamos $<$ a co $>[/ /]$ a $[/ / /]$ no tienes un lápiz ?

*LEO: [\% a Melanie] look what I have look what I have !

*LEO: I got a xxx !

*RAQ: es como un gusanito no ?

\%com: Leo va a enseñarle el juguete a Melanie

@End 
Apéndice II: símbolos CHAT utilizados en los datos del presente estudio

\begin{tabular}{|c|c|}
\hline Símbolo & Función \\
\hline$@$ sp & Uso del español en un contexto inglés (o con un interlocutor que hable en inglés) \\
\hline @en & $\begin{array}{l}\text { Uso del inglés en un contexto español (o con un interlocutor que hable en } \\
\text { español) }\end{array}$ \\
\hline @fp & Pausa para indicar reflexión o titubeo \\
\hline$@ \mathrm{i}$ & Interjección \\
\hline @o & Onomatopeya \\
\hline$@ \mathrm{f}$ & Palabra utilizada sólo en el contexto familiar \\
\hline() & Material que falta en una palabra incompleta \\
\hline$[/]$ & Repetición \\
\hline$[/ /]$ & Repetición con corrección \\
\hline$[/ / /]$ & Reformulación \\
\hline$[:]$ & Sustitución por la forma ortográfica completa o correcta \\
\hline$[=]$ & Sustitución por la forma gramaticalmente correcta \\
\hline [?] & Palabra o enunciado supuestos \\
\hline$[\%]$ & Explicación o comentario \\
\hline$[>]$ & Solapamiento con la línea siguiente \\
\hline$[<]$ & Solapamiento con la línea precedente \\
\hline [? texto] & Ambigüedad \\
\hline$+\ldots$ & Puntos suspensivos \\
\hline$+/$. & Interrupción \\
\hline$+/ /$. & Interrupción propia \\
\hline $\begin{array}{l}+\ldots \\
++\end{array}$ & $\begin{array}{l}\text { Enunciado incompleto } \\
\text { Finalización del enunciado (por parte de otro participante) }\end{array}$ \\
\hline $\begin{array}{l}+\ldots \\
+\end{array}$ & $\begin{array}{l}\text { Enunciado incompleto } \\
\text { Finalización del enunciado (por parte del propio participante) }\end{array}$ \\
\hline $\begin{array}{l}+\% \\
+"\end{array}$ & Cita en la línea siguiente \\
\hline $\mathrm{xxx}$ & Material inteligible \\
\hline 0 & Ausencia de producción \\
\hline$\&$ & Fragmento fonológico \\
\hline \# & Pausa larga \\
\hline : & Alargamiento de vocal \\
\hline$\%$ com & Comentario (en línea dependiente) \\
\hline$(\ldots)$ & Material que aparece en la transcripción pero que se ha omitido \\
\hline
\end{tabular}


Apéndice III: las sesiones en español (SP) de la selección de datos

\begin{tabular}{|c|c|c|c|c|c|c|c|}
\hline \multirow[t]{2}{*}{ Sesión } & \multirow[t]{2}{*}{ Edad } & \multirow[t]{2}{*}{ Fecha } & \multirow[t]{2}{*}{ Duración } & \multicolumn{2}{|c|}{ LMEp } & \multicolumn{2}{|c|}{$\begin{array}{c}\mathrm{N}^{\circ} \mathrm{de} \\
\text { enunciados }\end{array}$} \\
\hline & & & & SIM & LEO & SIM & LEO \\
\hline $21 \mathrm{SP}$ & $2 ; 04.09$ & $06-05-2001$ & $00: 32: 29$ & 1,520 & 1,479 & 50 & 48 \\
\hline $22 \mathrm{SP}$ & $2 ; 04.30$ & $27-05-2001$ & $00: 29: 15$ & 1,288 & 1,462 & 163 & 145 \\
\hline $23 \mathrm{SP}$ & $2 ; 05.12$ & 09-06-2001 & $00: 42: 27$ & 1,653 & 1,745 & 72 & 157 \\
\hline 24ASP & $2 ; 05.27$ & $24-06-2001$ & $00: 48: 31$ & 1,926 & 2,191 & 232 & 178 \\
\hline $25 \mathrm{SP}$ & $2 ; 10.21$ & $18-11-2001$ & $00: 52: 42$ & 2,361 & 2,195 & 241 & 384 \\
\hline $26 \mathrm{SP}$ & $2 ; 11.05$ & $02-12-2001$ & 01:02:00 & 2,586 & 2,251 & 249 & 219 \\
\hline $27 \mathrm{SP}$ & $2 ; 11.19$ & $16-12-2001$ & $00: 40: 52$ & 3,449 & 3,102 & 216 & 315 \\
\hline $28 \mathrm{SP}$ & $3 ; 00.23$ & $20-01-2002$ & 01:02:40 & 3,821 & 3,879 & 308 & 390 \\
\hline 34ASP & $3 ; 05.12$ & 09-06-2002 & 01:07:28 & 3,641 & 3,052 & 256 & 288 \\
\hline 38ESP & $3 ; 09.26$ & $23-10-2002$ & $00: 16: 43$ & 3,900 & 3,077 & 321 & 239 \\
\hline $39 \mathrm{SP}$ & $3 ; 09.30$ & $27-10-2002$ & 01:02:31 & 3,212 & 3,577 & 321 & 239 \\
\hline $41 \mathrm{SP}$ & $3 ; 10.27$ & $24-11-2002$ & 01:02:32 & 3,756 & 3,540 & 291 & 367 \\
\hline 50BSP & $4 ; 03.30$ & $27-04-2003$ & $00: 58: 27$ & 3,640 & 3,664 & 333 & 430 \\
\hline $51 \mathrm{SP}$ & $4 ; 04.28$ & $25-05-2003$ & $00: 16: 58$ & 5,883 & 4,207 & 77 & 58 \\
\hline $53 \mathrm{SP}$ & $4 ; 05.25$ & $22-06-2003$ & 00:49:32 & 2,737 & 2,046 & 171 & 152 \\
\hline $54 \mathrm{SP}$ & $4 ; 09.08$ & $05-10-2003$ & 01:02:33 & 4,224 & 4,265 & 397 & 234 \\
\hline $56 \mathrm{~B}(\mathrm{TR})$ & $4 ; 10.19$ & $16-11-2003$ & $00: 33: 54$ & 4,354 & 2,382 & 189 & 55 \\
\hline $58 \mathrm{SP}$ & $5 ; 02.02$ & 29-02-2004 & $00: 29: 28$ & 3,430 & 3,463 & 200 & 231 \\
\hline $60 \mathrm{SP}$ & $5 ; 04.26$ & $23-05-2004$ & $00: 22: 54$ & 3,280 & 2,280 & 157 & 25 \\
\hline 61ASP & $5 ; 05.29$ & $26-06-2004$ & $00: 22: 34$ & 1,675 & 1,743 & 123 & 101 \\
\hline $61 \mathrm{~B}(\mathrm{TR})$ & $5 ; 05.29$ & $26-06-2004$ & $00: 27: 28$ & 4,490 & 3,914 & 157 & 116 \\
\hline $62 \mathrm{ASP}$ & $5 ; 06.23$ & $20-07-2004$ & $00: 13: 43$ & 3,767 & 4,077 & 60 & 65 \\
\hline 62BSP & $5 ; 06.24$ & 01-08-2004 & $00: 44: 13$ & 3,962 & 3,962 & 133 & 147 \\
\hline 63SP & $5 ; 09.20$ & $17-10-2004$ & $00: 32: 42$ & 4,548 & 4,668 & 161 & 241 \\
\hline
\end{tabular}


Apéndice IV: las sesiones en inglés (EN) de la selección de datos

\begin{tabular}{|c|c|c|c|c|c|c|c|}
\hline \multirow[t]{2}{*}{ Sesión } & \multirow[t]{2}{*}{ Edad } & \multirow[t]{2}{*}{ Fecha } & \multirow[t]{2}{*}{ Duración } & \multicolumn{2}{|c|}{ LMEp } & \multicolumn{2}{|c|}{$\begin{array}{c}\mathrm{N}^{\circ} \mathrm{de} \\
\text { enunciados }\end{array}$} \\
\hline & & & & SIM & LEO & SIM & LEO \\
\hline $15 \mathrm{EN}$ & $2 ; 00.16$ & $13-01-2001$ & $00: 17: 45$ & 1,391 & 1,117 & 46 & 83 \\
\hline $16 \mathrm{EN}$ & $2 ; 01.01$ & $28-01-2001$ & 00:14:02 & 1,228 & 1,159 & 57 & 44 \\
\hline $17 \mathrm{EN}$ & $2 ; 01.28$ & $25-02-2001$ & $00: 10: 33$ & 1,375 & 1,375 & 96 & 24 \\
\hline $18 \mathrm{EN}$ & $2 ; 02.07$ & 04-03-2001 & 00:16:02 & 1,089 & 1,158 & 45 & 101 \\
\hline $19 \mathrm{EN}$ & $2 ; 02.21$ & $18-03-2001$ & 00:22:03 & 1,193 & 1,229 & 88 & 166 \\
\hline $20 \mathrm{EN}$ & $2 ; 03.25$ & $22-04-2001$ & $00: 43: 58$ & 1,317 & 1,289 & 356 & 266 \\
\hline $21 \mathrm{EN}$ & $2 ; 04.09$ & 06-05-2001 & $00: 24: 27$ & 1,207 & 1,500 & 29 & 8 \\
\hline $22 \mathrm{EN}$ & $2 ; 04.30$ & $27-05-2001$ & 00:30:39 & 1,373 & 1,580 & 67 & 176 \\
\hline $23 \mathrm{EN}$ & $2 ; 05.12$ & 09-06-2001 & $00: 35: 13$ & 1,521 & 1,349 & 119 & 175 \\
\hline $24 \mathrm{AEN}$ & $2 ; 05.27$ & $24-06-2001$ & $00: 32: 18$ & 1,632 & 1,711 & 201 & 190 \\
\hline 24BEN & $2 ; 06.30$ & $27-07-2001$ & $00: 25: 13$ & 1,000 & 1,760 & 1 & 229 \\
\hline $24 \mathrm{CEN}$ & $2 ; 07.09$ & 06-08-2001 & 00:41:59 & 2,157 & 2,349 & 217 & 281 \\
\hline 24HEN & $2 ; 08.04$ & 01-09-2001 & $00: 23: 44$ & 1,912 & 2,310 & 68 & 174 \\
\hline $28 \mathrm{EN}$ & $3 ; 00.23$ & $20-01-2002$ & $00: 20: 48$ & 2,884 & 3,288 & 138 & 208 \\
\hline $34 \mathrm{AEN}$ & $3 ; 05.12$ & 09-06-2002 & $00: 30: 49$ & 2,874 & 1,912 & 119 & 102 \\
\hline $38 \mathrm{EEN}$ & $3 ; 09.14$ & $11-10-2002$ & 00:18:02 & 4,198 & 4,352 & 81 & 108 \\
\hline 39EN & $3 ; 09.30$ & $27-10-2002$ & $00: 32: 08$ & 3,908 & 3,879 & 153 & 116 \\
\hline 40AEN & $3 ; 10.05$ & $02-11-2002$ & 00.34:18 & 3,135 & 4,985 & 156 & 203 \\
\hline 40BEN & $3 ; 10.22$ & $19-11-2002$ & $00: 24: 52$ & 4,294 & 5,014 & 126 & 74 \\
\hline $41 \mathrm{EN}$ & $3 ; 10.27$ & $24-11-2002$ & $00: 52: 23$ & 2,932 & 3,454 & 266 & 227 \\
\hline 42AEN & $3 ; 11.08$ & $05-12-2002$ & $00: 16: 12$ & 4,255 & 4,016 & 51 & 62 \\
\hline $46 \mathrm{EN}$ & $4 ; 01.26$ & $23-02-2003$ & 00:22:02 & 5,000 & 4,901 & 105 & 121 \\
\hline $50 \mathrm{BEN}$ & $4 ; 03.30$ & $27-04-2003$ & 00:54:04 & 4,444 & 4,276 & 319 & 239 \\
\hline $51 \mathrm{EN}$ & $4 ; 04.28$ & $25-05-2003$ & $00: 31: 11$ & 5,379 & 5,886 & 116 & 140 \\
\hline $53 \mathrm{EN}$ & $4 ; 05.25$ & $22-06-2003$ & $00: 17: 34$ & 2,521 & 3,269 & 48 & 78 \\
\hline $54 \mathrm{EN}$ & $4 ; 09.08$ & $05-10-2003$ & 00.22:09 & 3,045 & 4,267 & 110 & 135 \\
\hline $57 \mathrm{BEN}$ & $4 ; 11.04$ & $01-12-2003$ & 00:02:35 & 5,538 & 5,000 & 26 & 1 \\
\hline $58 \mathrm{EN}$ & $5 ; 02.02$ & 29-02-2004 & $00: 21: 28$ & 6,572 & 3,500 & 138 & 66 \\
\hline $59 \mathrm{EN}$ & $5 ; 03.21$ & $18-04-2004$ & $00: 17: 54$ & 3,300 & 3,706 & 80 & 136 \\
\hline $60 \mathrm{EN}$ & $5 ; 04.26$ & $23-05-2004$ & $00: 14: 56$ & 4,209 & 3,020 & 91 & 49 \\
\hline 61AEN & $5 ; 05.29$ & $26-06-2004$ & $00: 10: 12$ & 1,788 & 1,743 & 52 & 35 \\
\hline $62 \mathrm{AEN}$ & $5 ; 06.23$ & $20-07-2004$ & $00: 24: 29$ & 5,081 & 5,393 & 149 & 135 \\
\hline $62 \mathrm{BEN}$ & $5 ; 06.24$ & Ju-Ag 2004 & 00:31:01 & 4,761 & 5,179 & 67 & 78 \\
\hline $63 \mathrm{EN}$ & $5 ; 09.20$ & $17-10-2004$ & 00:11:10 & 3,333 & 3,383 & 21 & 81 \\
\hline $64 \mathrm{EN}$ & $5 ; 11.23$ & $20-11-2004$ & $00: 29: 25$ & 4,856 & 5,516 & 188 & 182 \\
\hline $68 \mathrm{EN}$ & $6 ; 00.05$ & 02-01-2005 & $00: 12: 52$ & 3,132 & 3,577 & 121 & 149 \\
\hline $69 \mathrm{EN}$ & $6 ; 01.19$ & $16-01-2005$ & $00: 16: 21$ & 4,281 & 4,687 & 128 & 147 \\
\hline $70 \mathrm{EN}$ & $6 ; 02.30$ & $27-02-2005$ & $00.17: 31$ & 7,474 & 5,947 & 76 & 94 \\
\hline 74(TR) & $6 ; 03.22$ & $17-04-2005$ & $00: 41: 03$ & 3,859 & 4,634 & 184 & 224 \\
\hline
\end{tabular}


Apéndice V: etapas en el proceso de adquisición de Simon y Leo en nuestra selección de datos

\begin{tabular}{|c|c|}
\hline \multicolumn{2}{|c|}{ ETAPA INICIAL (2;00-3;00) } \\
\hline Sesiones & Edad \\
\hline $15 \mathrm{EN}$ & $2 ; 00.16$ \\
$16 \mathrm{EN}$ & $2 ; 01.01$ \\
$17 \mathrm{EN}$ & $2 ; 01.28$ \\
$18 \mathrm{EN}$ & $2 ; 02.07$ \\
$19 \mathrm{EN}$ & $2 ; 02.21$ \\
$20 \mathrm{EN}$ & $2 ; 03.25$ \\
$21 \mathrm{EN} ; 21 \mathrm{SP}$ & $2 ; 04.09$ \\
$22 \mathrm{EN} ; 22 \mathrm{SP}$ & $2 ; 04.30$ \\
$23 \mathrm{EN} ; 23 \mathrm{SP}$ & $2 ; 05.12$ \\
$24 \mathrm{AEN} ; 24 \mathrm{ASP}$ & $2 ; 05.27$ \\
$24 \mathrm{BEN}$ & $2 ; 06.30$ \\
$24 \mathrm{CEN}$ & $2 ; 07.09$ \\
$24 \mathrm{HEN}$ & $2 ; 08.04$ \\
$25 \mathrm{SP}$ & $2 ; 10.21$ \\
$26 \mathrm{SP}$ & $2 ; 11.05$ \\
$27 \mathrm{SP}$ & $2 ; 11.19$ \\
$28 \mathrm{EN} ; 28 \mathrm{SP}$ & $3 ; 00.23$ \\
\hline
\end{tabular}

\begin{tabular}{|c|c|}
\hline \multicolumn{2}{|c|}{ ETAPA INTERMEDIA (3;05-4;05) } \\
\hline Sesiones & Edad \\
\hline 34AEN; 34ASP & $3 ; 05.12$ \\
38EEN; 38ESP & $3 ; 09.14$ \\
39EN; 39SP & $3 ; 09.30$ \\
40AEN & $3 ; 10.05$ \\
40BEN & $3 ; 10.22$ \\
41EN; 41SP & $3 ; 10.27$ \\
42AEN & $3 ; 11.08$ \\
46EN & $4 ; 01.26$ \\
50BEN; 50BSP & $4 ; 03.30$ \\
51EN; 51SP & $4 ; 04.28$ \\
53EN; 53SP & $4 ; 05.25$ \\
\hline
\end{tabular}

\begin{tabular}{|c|c|}
\hline \multicolumn{2}{|c|}{ ETAPA FINAL (4;09-6;03) } \\
\hline Sesiones & Edad \\
\hline 54EN; 54SP & $4 ; 09.08$ \\
56B(TR) & $4 ; 10.19$ \\
57BEN & $4 ; 11.04$ \\
58EN; 58SP & $5 ; 02.02$ \\
$59 \mathrm{EN}$ & $5 ; 03.21$ \\
60EN; 60SP & $5 ; 04.26$ \\
$61 \mathrm{AEN}, 61 \mathrm{ASP}$ & $5 ; 05.29$ \\
$61 \mathrm{~B}(\mathrm{TR})$ & $5 ; 05.29$ \\
$62 \mathrm{AEN}, 62 \mathrm{ASP}$ & $5 ; 06.23$ \\
$62 \mathrm{BEN}, 62 \mathrm{BSP}$ & $5 ; 06.24$ \\
$63 \mathrm{EN}, 63 \mathrm{SP}$ & $5 ; 09.20$ \\
$64 \mathrm{EN}$ & $5 ; 11.23$ \\
$68 \mathrm{EN}$ & $6 ; 00.05$ \\
$69 \mathrm{EN}$ & $6 ; 01.19$ \\
$70 \mathrm{EN}$ & $6 ; 02.30$ \\
$74(\mathrm{TR})$ & $6 ; 03.22$ \\
\hline
\end{tabular}


1. *MEL:

go choose a book .

*SIM:

[\% going off camera] voy por esto sí .

$[2 ; 01.28] / 17 \mathrm{EN} 01$

[SIM / COMPL / FL NO EQ-ECO / IN-ES / IP / OTROS-ADULT/ ESPONT]

2. *MEL: which one $\mathrm{S}$ ?
*LEO:
(1)(3)ese@sp .
*SIM:
(2)(4)ese@sp !
*MEL:
what's ese@sp?
*LEO:
(1)ese@sp .
*MEL:
which one's ese@sp ?
*SIM:
(2)ese@sp .
*LEO:
(3)ese@sp .
*SIM:
(4)[\% returning with a book] ese@sp .
[2;01.28] / 17EN_01

(1) y (3) [LEO / NULA / LONG (1-4) / COMPLEJ-SS / ES(-IN) / IP / AUTOTRAD / ESPONT]

(2) y (4) [SIM / NULA / LONG (1-4) / COMPLEJ-SS / ES(-IN) / IP / AUTOTRAD / ESPONT]

3. *MEL:

*MEL:

*LEO:

*MEL:

*LEO:

*ELI:

*MEL:

you wanna book?

or a puzzle ?

ese@sp .

I don't know what ese@sp means .

0 .

(doe)s he wants a $[/]$ a $[/]$ a record ?

I don't know .

$[2 ; 01.28] / 17 \mathrm{EN} 01$

[LEO / NULA / LONG (1-4) / COMPLEJ-SS / ES(-IN) / IP / AUTOTRAD / ESPONT]

4. *MEL: $\quad$ you wanna make something with the blocks ?

*SIM: $\quad$ sí@sp.

*MEL: $\quad$ what would you like to make ?

*SIM: $\quad$ douse [: house]

*MEL: $\quad$ a house ?

*SIM: $\quad$ douse [: house]!

*MEL: $\quad$ two ?

*SIM: $\quad$ \# casa@sp !

*MEL: a house ?

*SIM: $\quad$ sí@sp . [2;01.28]/17EN_01

[SIM / COMPL / FL EQ-EMP (NC) / IN-ES / IP / AUTOTRAD / ESPONT]

5. *MEL: where ?

*MEL: $\quad$ where are you going?

*SIM: down.

*MEL: $\quad$ down ?

*SIM: $\quad$ ahí@sp. $\quad[2 ; 01.28] / 17 \mathrm{EN} 01$

[SIM / COMPL / FL NO EQ-ECO / IN-ES / IP / AUTOTRAD / ESPONT]
6. *MEL:
*MEL:
who's in the bed?
*MEL:
is that a mouse ?
*SIM:
*MEL:
*SIM:
no:, what is that?
wow@owow@o.
what's awow@owow@o?
*MEL:
piro@sp [: perro] .
a doggy?
[2;01.28 ] / 17EN 01
[SIM / COMPL / FL NO EQ-EXP / IN-ES / IP / AUTOTRAD / ESPONT] 
7. *MEL: $\quad[\%$ picking up the cow $]$ and what is this one ?

*LEO: $\quad$ vaca@sp

\%com: Melanie laughs

*SIM: $\quad$ cow . $\quad[2 ; 02.07] / 18 \mathrm{EN} 02$

[SIM / COMPL / FL EQ-EMP (no NC) / ES-IN / IP / OTROS-HERM / ESPONT]

8. \%com: Melanie starts spooning strawberries into their cups

*MEL: $\quad$ here one for $\mathrm{S}$.

*LEO: $\quad$ me yo@sp yo@sp . [2;02.21]/19EN_01

[LEO / COMPL / FL EQ- EMP (no NC) / IN-ES / IP / AUTOTRAD/ ESPONT]

9. *MEL: look, what's that ?

*LEO: $\quad$ (ov)eja@sp

*MEL: $\quad$ uhhuh@i how do you say that in English do you know ?

*MEL: $\quad$ how do you say oveja@sp in English ?

*MEL: $\quad$ how does mommy say oveja@sp ?

*MEL: $\quad$ do you know?

*LEO: $\quad$ s(h)eep $. \quad[2 ; 02.21] / 19 E N \_02$

[LEO / COMPL / FL EQ-EMP (no NC) / ES-IN / INDUC-PAD / AUTOTRAD / ESPONT]

10. *MEL: what's that ?

*SIM: $\quad$ pavo@sp.

*MEL: $\quad$ what's that honey ?

*LEO: $\quad$ tu(r)key . $\quad[2 ; 02.21] / 19 E N \_02$

[LEO / COMPL / FL EQ- EMP (no NC) / ES-IN / IP / OTROS-HERM / ESPONT]

11. *MEL: let's see maybe we could look at these pictures and we could $+/$.

*SIM: $\quad$ cai@sp [: cae] .

*MEL: $\quad$ they're gone ?

*MEL: $\quad$ S S how does mommy say cae@sp ?

*LEO: $\quad$ fall . $\quad[2 ; 02.21] / 19 E N \_02$

[LEO / COMPL / FL EQ-EMP (no NC) / ES-IN / INDUC-PAD / OTROS-HERM / ESPONT]

12.*LEO: $\quad(1)(2)$ ot(r)o@sp otro@sp .

*MEL: $\quad$ uh@fp what [///] how do you say otro@sp in English ?

*LEO: $\quad$ (1)

*SIM: $\quad$ (2) $(\mathrm{a})$ nothe(r) . [2;02.21] / 19EN_02

(1) [LEO / NULA / LONG (1-4) / COMPLEJ-SS / ES(-IN) / INDUC-PAD / AUTOTRAD / ESPONT]

(2) [SIM / COMPL /FL EQ-EMP (no NC) / ES-IN / INDUC-PAD / OTROS-HERM / ESPONT]

13. *SIM: $\quad(1)(2)$ otro@sp, otra@sp hat .

*MEL: $\quad$ S, how do you say otro@sp in English?

*MEL: $\quad$ how do you say otro@sp in English ?

*SIM: $\quad$ (1)no !

*MEL: $\quad$ maybe L knows, $\mathrm{L}+\ldots$

*MEL: $\quad$ L, how do you say otro@sp in English ?

*LEO: $\quad$ (2)do n(o)t know [\% quietly, and walking away] .

*MEL: $\quad$ you told me the other day . [2;03.25] / 20EN_01

(1) [SIM / NULA / LONG (1-4) / COMPLEJ-SS / ES(-IN) / INDUC-PAD / AUTOTRAD / ESPONT]

(2) [LEO / NULA / LONG(1-4) / COMPLEJ-SS / ES(-IN) / INDUC-PAD / OTROS-HERM / ESPONT] 
14. *LEO:

*MEL:

*MEL:

*MEL:

*LEO:

*SIM: (1)(2)cae@sp nose .

the nose fell ?

yeah?

L how do you say cae@sp in English?

(1) fall .

(2) fall.

[2;04.30] / 22EN_01

(1) [LEO / COMPL / FL EQ- EMP (no NC) / ES-IN / INDUC-PAD / AUTOTRAD / ESPONT]

(2) [SIM / COMPL / FL EQ- EMP (no NC) / ES-IN / INDUC-PAD / OTROS-HERM / ESPONT]

15. *MEL:

*SIM:

*MEL:

*SIM:

no, otro@sp naus [: nose] .

another nose ?

*MEL:

sí@sp.

*LEO:

S, how do you say otro@sp in English?

*SIM:

out .

nice ! $\quad[2 ; 04.30] / 22 \mathrm{EN} 01$

[SIM / NULA / LONG (1-4) / COMPLEJ-SS / ES(-IN) / INDUC-PAD / AUTOTRAD / ESPONT]

16. *MEL: this guy is red and he has a goldfish .

*SIM: $\quad$ [\% getting up] yo@sp .

*MEL: $\quad$ who has a goldfish ?

*SIM:

ma $[: \mathrm{me}]$.

[2;04.30] / 22EN 01

[SIM / COMPL / FL EQ- EMP (no NC) / ES-IN / IP / AUTOTRAD / ESPONT]

17. *LEO:

(1)(2)no peyo@sp [: puedo] .

*MEL:

you can't pick them out ?

*LEO:

no: .

*MEL:

let's [/] let's [/] let's see [///] how do you say no@sp puedo@sp in

English ?

*MEL:

Juana's gonna like this one .

*MEL:

how do you say no@sp puedo@sp in English?

*LEO:

*MEL:

(1)no@sppuedo@sp.

*MEL:

no@sp puedo@sp ?

*LEO:

(2)yo@sp can't .

$[2 ; 05.12] / 23 \mathrm{EN} \_01$

(1) [LEO / NULA / LONG (1-4) / COMPLEJ-OS / ES(-IN) / INDUC-PAD / AUTOTRAD/ ESPONT]

(2) [LEO / INCOMPL /FL EQ-EMP (no NC) / ES-IN / INDUC-PAD / AUTOTRAD / ESPONT]

18.*RAQ: es un monkey@en ?

*SIM: $\quad$ sí .

*LEO: $\quad$ monkey@en .

*SIM: $\quad$ mono . $[2 ; 05 ; 27] / 24 A S P \_02$

[SIM / COMPL / FL EQ- EMP (no NC) / IN-ES / IP / OTROS-HERM / ESPONT]

19. *RAQ: $\quad(1)(2)$ cómo se dice nariz en inglés ?

*LEO: $\quad$ (1)nariz !

*RAQ: $\quad$ en inglés ?

*SIM: $\quad$ (2)nose@en! $\quad[2 ; 05 ; 27] / 24 A S P \_02$

(1) [LEO / NULA / LONG (1-4) / COMPLEJ-SS / ES(-IN) / INDUC-INV / OTROS-ADULT / ESPONT]

(2) [SIM / COMPL / FL EQ-EMP (no NC) / ES-IN / INDUC-INV / OTROS-ADULT / ESPONT] 
20. *IVO:

cómo se dice the@en bunnie@en o el bunnie@en ?

*LEO:

nejo [: conejo].

$[2 ; 05 ; 27] / 24 \mathrm{ASP} 02$

[LEO / COMPL / FL EQ-EMP (no NC) / IN-ES / IP / OTROS-ADULT / ESPONT]

21. *MEL: the stem wasn't there when I bought it .

*MEL: $\quad$ it was all $[/ /]$ it $+/$.

*SIM: $\quad$ ese@sp tem [: stem] no@spestá@sp. [2;05;27] / 24AEN_01

[SIM / INCOMPL / FL NO EQ-ECO / IN-ES / IP / OTROS-ADULT / ESPONT]

22. *MEL: where do you put socks?

*SIM: $\quad[\%$ holding his foot $]$ aquí@sp .

*MEL: $\quad$ aquí@sp what's that?

*SIM: $\quad$ foot. $[2 ; 05 ; 27] / 24$ AEN_01

[SIM / COMPL / FL NO EQ-EXP / ES-IN / IP / AUTROTRAD / ESPONT]

23. *MEL: does the big bad wolf like cherries you think ?

*LEO: $\quad$ yeah sí@sp . [2;05;27]/24AEN_01

[LEO / COMPL / FL EQ- EMP (no NC) / IN-ES / IP / AUTOTRAD / ESPONT]

24.*SIM: no@sp puedo@spno@sp puedo@sp .

*MEL: how do you say no@sp puedo@sp in English ?

*SIM:

(h)elp .

$[2 ; 05 ; 27] / 24$ AEN_02

[SIM / COMPL / FL NO EQ-EXP / ES-IN / INDUC-PAD / AUTOTRAD / ESPONT]

25. \%com: Simon continues trying to make his toy make noise

*SIM: $\quad$ está@sp loto@sp [: roto] .

*MEL: mi@sp schoolbus .

*SIM: $\quad$ está@sploto@sp [: roto] .(...)

*SIM: b(r)eak b(r)eak.

*MEL: $\quad$ how about + /.

*SIM: $\quad$ b(r)eak mommy b(r)eak . $\quad[2 ; 05 ; 27] / 24$ AEN_02

[SIM / COMPL / FL EQ-EMP (NC) / ES-IN / IP / AUTOTRAD / ESPONT]

26. *MEL: what, sweet?

*LEO: $\quad$ qué@sp

*MEL: $\quad$ can you say that in English ?

*LEO: $\quad$ [\% camera pans over to him] qué@sp ca(11) ?

*MEL: $\quad$ who's calling ?

*LEO:

sí@sp.

$[2 ; 07.02] / 24 B E N \_01$

[LEO / INCOMPL / FL EQ-EMP (no NC) / ES-IN / INDUC-PAD / AUTOTRAD / ESPONT]

27. *MEL: $\quad[\%$ pointing to the elephant $]$ look look show me that animal, what's it called ?

*LEO: $\quad$ elefante@sp .

*MEL: $\quad$ can you say that in English?

*LEO: $\quad[\%$ with a trace of tears in his voice $]$ no, elefante@sp .

$[2 ; 07.02]$ / 24BEN 01

[LEO / NULA / LONG (1-4) / COMPLEJ-SS / ES(-IN) / INDUC-PAD / AUTOTRAD / ESPONT] 
28. *LEO:

[\% turning to reach Melanie, he drops his pen to the floor]

ma:má@sp !

*MEL: $\quad$ it fell.

*MEL: $\quad$ what's that ?

*LEO: $\quad$ ma:má@sp.

*MEL: $\quad$ can you say that in English ?

*LEO: no, mamá@sp . [2;07.02] / 24BEN_02

[LEO / NULA / LONG (1-4) / COMPLEJ-SS / ES(-IN) / INDUC-PAD / AUTOTRAD / ESPONT]

29. *MEL: $\quad$ maybe they're getting off the seesaw .

*MEL: $\quad$ where do you think they are ?

*LEO: $\quad$ there $[\%$ pointing at the book] .

*MEL: $\quad$ Tigger?

*LEO: $\quad$ no .

*MEL: $\quad$ tail ?

*LEO: $\quad$ aquí@sp, E(r)nie Be(r)t aquí@sp .

*MEL: $\quad$ they're there, uhhuh@i . [2;07.02]/24BEN_02

[LEO / COMPL / FL EQ-EMP (NC) / IN-ES / IP / AUTOTRAD / ESPONT]

30. *MEL: what are they riding?

*LEO: $\quad$ bici(cleta)@sp.

*MEL: $\quad$ how do you say bici(cleta)@sp in English, do you remember ?

*LEO: $\quad$ bai::hle [: bicycle] . [2;07.02]/24BEN_02

[LEO / COMPL / FL EQ-EMP (no NC) / ES-IN / INDUC-PAD / AUTOTRAD / ESPONT]

31.*MEL: how do you say ahora@spyo@sp in English [\% speaking from behind camera]?

*LEO: $\quad$ ahora@sp yo@sp+...

*LEO: my turn.

*MEL: $\quad$ your turn . [2;07.02]/24BEN_03

[LEO / COMPL / FL EQ-EMP (no NC) / ES-IN / INDUC-PAD / OTROS-ADULT / ESPONT]

32. *LEO: ok all the pieces, toma@sp estas@sp pieces, some othe(r) pieces

* toma@sp pieces todo@sp vaya@sp vaya@sp toma@sp .

MEL: how do you say toma@sp pieces in English ?

*LEO: $\quad[\%$ kicking the pieces towards Melanie] here here

*MEL: $\quad$ here are the pieces, here are the pieces .

*LEO: $\quad$ here here pieces . [2;07.02]/24BEN_03

[LEO / COMPL /FL NO EQ.-ECO / ES-IN / INDUC-PAD / AUTOTRAD / ESPONT]

33. *MEL: $\quad$ ay@i don't step on the camera no .

*LEO: $\quad$ (1)

*MEL: can you say that in English ?

*LEO: $\quad$ (1)(2) $\quad$ lo@sp quiero@sp hold it that .

*MEL: $\quad$ can you say that in English ?

*LEO: $\quad$ (2) $\quad$ I want hold it that .

*MEL: $\quad$ you want to hold that ? [2;07.02] / 24BEN_03

(1) [LEO / INCOMPL / FL NO EQ-EXP / ES-IN / INDUC-PAD / AUTOTRAD / ESPONT]

(2) [LEO / COMPL / FL EQ-EMP (no NC) / ES-IN / INDUC-PAD / AUTOTRAD / ESPONT] 
34. *MEL:

*LEO:

*MEL:

*MEL:

*LEO:

*MEL:

*LEO:

do you ever break things L ?

yo@spno@sp.

you no?

how do you say yo@sp no@sp in English ?

yo@spno@sp.

do you remember how we say it in English?

yo@spno@sp.

[2;07.02] / 24BEN_03

[LEO / NULA/ LONG (1-4) / COMPLEJ-OS / ES(-IN) /INDUC-PAD / AUTOTRAD / ESPONT]

35. *MEL:

*LEO:

*MEL:

*LEO:

*MEL:

*LEO:

*LEO:

here, you want to put this away hon?

yeah .

yeah, ok .

ese@sp mío@sp, tú@sp este@sp.

can you tell me that in English?

yeah .

me that you that.

[2;07.02] / 24BEN_03

[LEO / COMPL / FL EQ-EMP (no NC) / ES-IN / INDUC-PAD / AUTOTRAD / ESPONT]

36. *MEL:

*LEO:

*MEL:

*MEL:

who wants milk?

yo@spsí@sp.

how do you say yo@sp sí@sp in English?

*LEO:

how do you say yo@sp sí@sp in English?

$\underline{\text { I \# do . }}$.

$[2 ; 07.09] / 24 C E N \_01$

[LEO / COMPL /FL EQ-EMP (no NC) / ES-IN / INDUC-PAD / AUTOTRAD / ESPONT]

37. *SIM:

*MEL:

quiero@sp_más@sp.

can you tell that $[/ /]$ me that in English?

*SIM:

want more please.

$\left.[2 ; 07.09) / 24 C E N \_01\right]$

[SIM / COMPL / FL EQ-EMP (no NC) / ES-IN / INDUC-PAD / AUTOTRAD / ESPONT]

38. *LEO:

*MEL:

quiero@sp c(1)ose [?] .

*LEO:

can you say that in English?

I want close please.

[2;07.09] / 24CEN_01

[LEO / COMPL / FL EQ-EMP (no NC) / ES-IN / INDUC-PAD / AUTOTRAD / ESPONT]

39. *SIM:

*MEL:

quiero@sp see Muzzy .

can you say that in English?

*SIM:

can I see Muzzy please?

[2;07.09] / 24CEN_01

[SIM / COMPL / FL EQ-EMP (no NC) / ES-IN / INDUC-PAD / AUTOTRAD / ESPONT]

40.*LEO: $\quad$ quiero@sp that .

*MEL: $\quad$ English .

*LEO: $\quad$ I want that please .

$[2 ; 07.09] / 24 C E N \_02$

[LEO / COMPL / FL EQ-EMP (no NC) / ES-IN / INDUC-PAD / AUTOTRAD/ ESPONT]

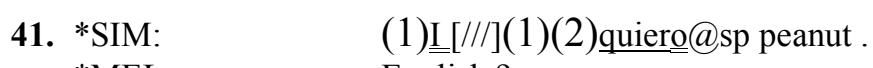

*MEL: $\quad$ English?

*SIM: (2)I want peanut please [\% drumming on the table in rhythm to this] .

[2;07.09] / 24CEN_02

(1) [SIM / REFORM / FL EQ-EMP (no NC) / IN-ES / IP / AUTOTRAD/ ESPONT]

(2) [SIM / COMPL / FL EQ-EMP (no NC) / ES-IN / INDUC-PAD / AUTOTRAD / ESPONT] 
42. *LEO:

[\% getting off his chair] $(1)(2)(3)(4)$ quiero@sp tha:t .

*MEL:

English ?

*LEO:

(1)quiero@sp that .

*MEL:

English ?

*LEO:

(2)dame@sp that?

*MEL:

what?

*LEO: $\quad$ (3) [\% sighing] quiero@sp that one .

*MEL: $\quad$ English ?

*LEO:

(4)I want that please .

$[2 ; 07.09] / 24 C E N \_02$

(1), (2) y (3) [LEO / NULA / LONG (1-4) / COMPLEJ-OS / ES-IN / INDUC-PAD / AUTOTRAD / ESPONT]

(4) [LEO / COMPL / FL EQ-EMP (no NC) / ES-IN / INDUC-PAD / AUTOTRAD / ESPONT]

43. *MEL:

*LEO:

what's that?

*MEL:

cabeza@sp!

*LEO:

cabeza@sp, how do you say that in English ?

head!

[2;07.09]/24CEN_02

[LEO / COMPL / FL EQ-EMP (no NC) / ES-IN / INDUC-PAD / AUTOTRAD / ESPONT]

44. *MEL:

*LEO:

*MEL:

*LEO:

*MEL:

*LEO:

and what happened?

why?

what?

cae no aquí [?] no noise .

[\% to Leo] can you say that in English ?

no, esto no ruido

[2;07.09]/24CEN 02

[LEO / COMPL / FL EQ-EMP (no NC) / IN-ES / INDUC-PAD / AUTOTRAD / ESPONT]

45. *SIM:

*MEL:

quiero@sp atrás@sp the(re) .

*SIM:

what sweetie?

back the(re).

[2;07.09] / 24CEN_02

[SIM / COMPL / FL NO EQ-ECO / ES-IN / IP / AUTOTRAD / ESPONT]

46. *LEO:

*MEL:

quiero@sp peanuts .

can you tell me in English?

*LEO:

I want peanuts please

[2;07.09] / 24CEN_02

[LEO / COMPL / FL EQ-EMP (no NC) / ES-IN / INDUC-PAD / AUTOTRAD / ESPONT]

47. *SIM:

quiero@sp [//] want the(re) .

[2;07.09] / 24CEN_02

[SIM / REFORM / FL EQ-EMP (no NC) / ES-IN / IP / AUTOTRAD / ESPONT]

48. *LEO:

quiero@sp peanuts .

*MEL:

can you tell me in English?

*LEO:

I want peanuts please .

[2;07.09] / 24CEN_02

[LEO / COMPL / FL EQ-EMP (no NC) / ES-IN / INDUC-PAD / AUTOTRAD / ESPONT]

49. *SIM:

no@sp,yo@sp_solo@sp.

*MEL:

how do you say yo@sp solo@sp in English?

*SIM:

by myself

[2;07.09] / 24CEN_02

[SIM / COMPL / FL EQ-EMP (no NC) / ES-IN / INDUC-PAD / AUTOTRAD / ESPONT] 
50. *MEL:

*SIM:

*MEL:

aha@i you're scared.

*SIM:

yo@spno@sp,yo@spno@sp.

how do you say yo@sp no@sp in English?

$\underline{\mathrm{I} \text { do } \mathrm{n}(\mathrm{o}) \mathrm{t}}$.

[2;07.09]/24CEN_02

[SIM / COMPL / FL EQ-EMP (no NC) / ES-IN / INDUC-PAD / AUTOTRAD / ESPONT]

51. *LEO: quiero@sp apple .

*MEL: $\quad$ English ?

*LEO: $\quad$ apple please . $\quad$ [2;07.09]/24CEN_02

[LEO / COMPL / FL NO EQ-ECO / ES-IN / INDUC-PAD / AUTOTRAD / ESPONT]

52. *LEO:

*MEL:

quiero@sp milk .

*LEO:

can you tell me in English?

I want milk please.

$[2 ; 07.09] / 24 C E N \_02$

[LEO / COMPL / FL EQ-EMP (no NC) / ES-IN / INDUC-PAD / AUTOTRAD / ESPONT]

53. *SAF: $\quad$ you were playing with the kitchen ?

*SIM: $\quad$ (1)(2)yo@sp_no@sp.

*MEL: $\quad$ how do you say yo@sp no@sp in English ?

*LEO: $\quad$ (1) do n(o)t

*SIM: $\quad$ (2)I do n(o)t . [2;07.09] / 24CEN_02

(1) [LEO / COMPL / FL EQ-EMP (no NC) / ES-IN / INDUC-PAD / OTROS-HERM / ESPONT]

(2) [SIM / COMPL / FL EQ-EMP (no NC) / ES-IN / INDUC-PAD / AUTOTRAD / ESPONT]

54. *LEO: $\quad$ quiero@sp see Sesame Stweet [: Street] .

*MEL: $\quad$ can you say that in English?

*LEO: $\quad$ I want see Sesame sweet [: Street] please . [2;07.09] / 24CEN_02

[LEO / COMPL / FL EQ-EMP (no NC) / ES-IN / INDUC-PAD / AUTOTRAD / ESPONT]

55. *MEL: $\quad$ yes, you want to play, ok .

*SIM: $\quad$ toma@sp.

*MEL: $\quad$ how do you say toma@sp ?

*SIM: $\quad \underline{\text { he(re) }}$. [2;07.09]/24CEN_02

[SIM / COMPL / FL EQ-EMP (no NC) / ES-IN / INDUC-PAD / AUTOTRAD / ESPONT]

56. *LEO: $\quad[\%$ getting off his chair $]$ quiero@sp see tetme tweet [: Sesame Street] .

*MEL: $\quad$ English .

*LEO: $\quad \quad$ I want see tetme [: Sesame] tweet [: Street] please .

$[2 ; 07.09] / 24 C E N \_02$

[LEO / COMPL / FL EQ-EMP (no NC) / ES-IN / INDUC-PAD / AUTOTRAD / ESPONT]

57. *MEL: $\quad$ what sweetie ?

*SIM: $\quad$ yo@sp no finish.

*MEL: $\quad$ how do you say yo@sp no finished in English ?

*SIM: $\quad \underline{\text { I }}$ (am) not finish .

*LEO: I want that .

*MEL: $\quad$ I'm not finished, very good $\quad[2 ; 07.09] / 24 C E N \_02$

[SIM / COMPL / FL EQ-EMP (no NC) / ES-IN / INDUC-PAD / AUTOTRAD / ESPONT] 
58. *LEO: $\quad$ quiero@sp tetme tweet [: Sesame Street] please .

*MEL: $\quad$ huh ?

*LEO: $\quad$ I want tetme tweet [: Sesame Street] please . [2;07.09] / 24CEN_02

[LEO / COMPL / FL EQ-EMP (no NC) / ES-IN / IP / AUTOTRAD / ESPONT]

59.*LEO: $\quad$ quiero papás@f

*MEL: $\quad$ English ?

*LEO: no .

*LEO: quiero papás@f. $\quad$ [2;07.09] / 24CEN_02

[LEO / NULA / LONG (1-4) / COMPLEJ-OS / ES(-IN) / INDUC-PAD / AUTOTRAD / ESPONT]

60. *MEL:

*LEO:

*MEL:

*LEO:

*MEL:

*LEO

we have to wait for $\mathrm{S}$.

yo@sp sí@sp finished.

how do you say yo@sp sísp finished in English?

$\underline{I \text { do }}$.

no, I am finished.

I am finished .

$[2 ; 07.09] / 24 C E N \_02$

[LEO / COMPL / FL EQ-EMP (no NC) / ES-IN / INDUC-PAD / AUTOTRAD / ESPONT]

61. *SIM:

*MEL:

quiero@sp see tetme [: Sesame] tweet [: Street] .

*SIM:

English?

I want tee [: see] tetme tweet [: Sesame Street] please .

[2;07.09] / 24CEN_02

[SIM / COMPL / FL EQ-EMP (no NC) / ES-IN / INDUC-PAD / AUTOTRAD / ESPONT]

62. *MEL:

*LEO:

*MEL:

*MEL:

*LEO:

*MEL:

*LEO:

*MEL:

*MEL:

*MEL:

*LEO:

[\% touching the glass next to the cup] what's this ?

azúcar@sp.

azúcar@sp?

do you know how to say that in English?

yeah.

what is the word for azúcar@sp in English?

mmm@i.

it's what mommy puts in your yoghourt .

do you know what that is?

what?

shua [: sugar].

[2;07.09] / 24CEN_03

[LEO / COMPL / FL EQ-EMP (no NC) / ES-IN / INDUC-PAD / AUTOTRAD / ESPONT]

63. *MEL:

*SIM:

*MEL:

*SIM:

L likes yoghourt with a little bit of sugar in it . yo@spno@spyo@spno@sp.

how do you say yo@spno@sp?

I don't .

$[2 ; 07.09] / 24 C E N \_03$

[SIM / COMPL / FL EQ-EMP (no NC) / ES-IN / INDUC-PAD / AUTOTRAD / ESPONT]

64. *MEL:

*LEO:

*MEL:

but you do eat Petit Suisse though don't you?

*LEO:

quiero@sp please .

huh@i?

I want Petit Suisse please.

[2;07.09] / 24CEN_03

[LEO / COMPL / FL NO EQ-EXP / ES-IN / IP / AUTOTRAD / ESPONT] 
65. *LEO:

*MEL:

quieronana@f [: teta].

*LEO:

$\mathrm{I}+\ldots$

I want nana@f $[$ : teta] please.

$[2 ; 07.09] / 24 C E N \_03$

[LEO / COMPL / FL EQ-EMP (no NC) / ES-IN / INDUC-PAD / AUTOTRAD / ESPONT]

66. *SIM:

*MEL:

*SIM:

*MEL:

*SIM:

*MEL:

*SIM:

quiero@sp_apple .

what?

apple .

huh ?

apple .

can you tell me in English ?

I want apple please .

[2;07.09] / 24CEN_03

[SIM / COMPL / FL EQ-EMP (no NC) / ES-IN / INDUC-PAD / AUTOTRAD / ESPONT]

67. *LEO:

*MEL:

taklit [: chocolate]

*LEO:

*MEL:

where?

*SIM:

taklit [: chocolate]

where's that?

*LEO:

taklit [: chocolate]

*SIM:

taklit [: chocolate]

*LEO:

takilit [: chocolate] .

*SIM:

I xxx takilit house .

*MEL: chocolate@sp . chocolate!

[2;08.04] / 24HEN_02

[SIM / COMPL / FL EQ-EMP (NC) / IN-ES / IP / OTROS-HERM / ESPONT]

68. *SAF: *SIM:

tell me what chocolate@sp is!

chocolate!

[2;08.04] / 24HEN_02

[SIM / COMPL / FL EQ (NC) / ES-IN / INDUC-PAD / OTROS-ADULT / ESPONT]

69. *SIM:

*RAQ:

*SIM:

*RAQ:

*IVO:

mira Paco Pico!

Paco Pico?

sí .

así se llama ese ?

*SIM:

y en inglés cómo se llama Paco Pico ?

Big@en Bird@en .

$[2 ; 10.21] / 25 \mathrm{SP} \_02$

[SIM / COMPL / FL EQ-EMP (no NC) / ES-IN / INDUC-PAD / AUTOTRAD / ESPONT]

70. *LEO:

hay@sp [///] there's a pea in too .

$[3 ; 00.23] / 28 E N \_01$

[LEO / REFORM / FL EQ- EMP (NO NC) / ES-IN / IP / AUTOTRAD / ESPONT]

71. *IVO:

*RAQ:

L, S, le habéis explicado a Raquel cómo se dice Peter Pan en español y en inglés?

*IVO:

ah@i .

*RAQ:

*RAQ:

*SIM:

es que yo creo que no lo sabe .

no, no, yo no lo sé, a ver cómo es?

cómo es en español ?

*RAQ:

Peter Pan .

*SIM:

y en inglés?

Peter@enPan@en.

$[3 ; 05.12] / 34 A S P \_02$

[SIM / COMPL / FL EQ-EMP (no NC) / ES-IN / INDUC-PAD / AUTOTRAD / ESPONT] 
72. *MEL:

no ?

*SIM:

yo@sp [///] I'll give you one .

[3;05.12] / 34AEN_02

[SIM / REFORM / FL EQ- EMP (no NC) / ES-IN / IP / AUTOTRAD / ESPONT]

73. *SIM:

*SIM:

*MEL:

(1)mommy I wan(t) my lollipop .

*LEO:

I want to suck my lollipop .

\%com: after breakfast .

(2) my lollipo(p) $+\ldots$

the boys go off camera with their father

nunca desayunan bien y los sábados no desayunan xxx porque desayunan muy tarde .

*LEO:

*MEL:

(2) [\% to Ivo] yo quiero mi chupa chuns [: chups] . (...)

*IVO: after breakfast you can eat it .

*SIM: qué memoria tienes!

(1)yo quiero mi chupa chuns [: chups] .

[3;09.26] / 38EEN_01

(1) [SIM / COMPL / FL EQ-EMP (no NC) / IN-ES / IP / AUTOTRAD / ESPONT]

(2) [LEO / COMPL / FL NO EQ-EXP / IN-ES / IP / AUTOTRAD / ESPONT]

74. *RAQ:

*SIM:

qué de estrellitas verdad?

*LEO:

mira hay $+/ /$.

*LEO:

there@en [\% señalando la página de un libro] .

aquí.

[3;09.30] / 39SP_01

[LEO / COMPL / FL EQ- EMP (no NC) / IN-ES / IP / AUTOTRAD / ESPONT]

75. *SIM:

*RAQ:

*SIM:

[\% repitiendo lo que dice el juguete] hot !

ah@i eso qué significa?

caliente !

$[3 ; 09.30] / 39 S P \_02$

[SIM / COMPL / FL EQ- EMP (no NC) / IN-ES / INDUC-INV / AUTOTRAD / ESPONT]

76. *SIM:

look how many I have left one two tree [: three] .

(...)

*SIM:

$[\%$ to Raquel] mira lo que me queda .

[3;09.30]/39EN_01

[SIM / COMPL / FL EQ- EMP (no NC) / IN-ES / IP / AUTOTRAD / ESPONT]

77. *MEL:

and now what are you going to say to Raquel when I give you the chocolate?

*LEO:

*MEL:

sank [: thank] \# you .

*MEL:

*LEO:

*MEL:

*MEL:

*SIM:

*MEL:

thank you .

[\% to Simon] now what are you going to say to Raquel ?

thank you.

[\% to Simon] you say thank you to Raquel?

what do you say to Raquel?

[\% puts out his hand towards the chocolate] thank you .

thank you gimme, right?

*MEL:

[\% whispering] no, you say gracias@sp . [ [3;09.30]/39EN_01

[SIM / NULA / LONG (1-4) / COMPLEJ-SS / IN(-ES) / INDUC-PAD / OTROS-HERM / ESPONT] 
78. *MEL:

[\% whispering to Simon and pointing to Raquel] ask her if she wants some chocolate let's go ask her if she wants some chocolate .

*MEL: $\quad$ very yummy

*SIM:

0 .

$[3 ; 09.30] / 39 E N 01$

[SIM / NULA / LONG (1-4) / COMPLEJ-OS / IN(-ES) / IP / ESPONT / OTROS-ADULT]

79. *LEO: yo@sp [///] I was chasin(g) the \# yo@sp+... [3;10.27] / 41EN_02

[LEO / REFORM / FL EQ- EMP (no NC) / ES-IN / IP / AUTOTRAD / ESPONT]

80. *MEL:

*SIM:

a $\underline{\& t}$ which is the letter..+

++ te@ $@ s p$ !

$[3 ; 10.27] / 41 \mathrm{EN} 02$

[SIM / COMPL / FL EQ-EMP (no NC) / IN-ES / IP / OTROS-ADULT / ESPONT]

81. *SIM:

* RAQ:

y luego hay <una bee@en $>$ [//] una abeja allí .

*SIM:

un mosquito ?

sí un mosquito .

$[3 ; 10.27] / 41 \mathrm{SP} 01$

[SIM / REFORM / FL EQ- EMP (no NC) / IN-ES / IP / AUTOTRAD / ESPONT]

82. *SIM:

*MEL:

I have to put something in the camera .

*MEL:

in the camera

*SIM:

the tape ?

*SIM:

umhm@i .

*LEO:

de [: the] tape .

*MEL:

[\% pronouncing it for Melanie] no the tape the tape .

*SIM:

I think it's in there though .

*MEL:

no .

*SIM:

ask Raquel .

*MEL:

what is a tape in Spanish ?

*MEL:

what?

*SIM:

cinta@sp.

[\% to Raquel off camera] has ponida [= puesto] [///] está la cinta adentro ?

[4;03.30] / 50BEN_01

[SIM / COMPL / FL NO EQ-ECO / IN-ES / INDUC-PAD / SITUA / ESPONT]

83. *MEL:

*MEL:

*MEL:

*SIM:

ok well I'll do it in English and then you say it in Spanish ok ?

three little mice sat $+/ .(\ldots)$

ok tres@sp that's the first word.

tres@sp \&raton [//] ratoncitos@sp+... (...)

*SIM:

[\% mumbling] tres@sp ratoncitos@sp sat down to spin . (...)

$[4 ; 03.30] / 50 B E N \_02$

[SIM / INCOMPL / FL EQ-EMP (no NC) / IN-ES / INDUC-PAD / OTROS-ADULT / ESPONT]

84. *SIM:

mirad que voy a contar una histo [\% se va hacia la cocina mientras se dirige a su madre] mummy I'm gonna tell you a story xxx [\% sale de la habitación].

[4;04.28]/51SP_01

[SIM / COMPL / FL EQ-EMP (no NC) / ES-IN / IP / AUTOTRAD / ESPONT] 
85. *RAQ

*RAQ:

*SIM:

*RAQ:

*RAQ:

*SIM:

*RAQ:

*SIM:

*RAQ:

*EST:

*RAQ:

*RAQ:

entonces qué puede ser?

un pez .

no .

no ?

y lo sabéis en inglés o tampoco lo sabéis en inglés ?

sí.

cómo es en inglés ?

eh@fp seal@en .

claro y cómo se dice seal@en en español ?

ah@i.

$<$ no os $>$ [/] no os acordáis de eso ?

se dice foca

$[4 ; 05.25] / 53 \mathrm{SP} 01$

[SIM / NULA / LONG (1-4) / COMPLEJ-SS / IN(-ES) / INDUC-INV / AUTOTRAD / ESPONT]

86. \%com:

*SIM:

*LEO:

*EST:

*RAQ:

*SIM:

*EST:

*RAQ:

*SIM: fuera de plano Raquel y los niños escogen un juego diferente al del fragmento anterior y regresan a la mesa no sé cómo se llama en español pero sí sé como se llama en inglés . voy a recoger .

ah@i!

y cómo se llama en inglés ?

Chutes@en and@en Ladders@en .

ah@i .

eh@i y eso [///] y cómo [/]< cómo se dicen $>[/ /]<$ cómo se dice $>[/ /]$ y cómo se dicen esas dos palabras en español ?

no sé .

$[4 ; 05.25] / 53 \mathrm{SP} 02$

[SIM / NULA / LONG (1-4) / COMPLEJ-SC / IN(-ES) / INDUC-INV / AUTOTRAD / ESPONT]

87. \%com:

Simon y Leo están enseñándole a Esther un rifle de juguete lleno de caramelos

*EST:

ah@i pero Susana no sabe lo que es .

*EST:

se lo decís lo que es ?

*SIM:

(1)(2) una pistola !

*EST:

pero no sabe + ..

*SUS:

what's that?

*SIM:

(1)una pistola .

*EST:

pero no sabe español .

*SIM:

(2)[\% a Susana] eh@fp es@sp un@sp riffle .

*SUS:

okey a riffle right.

$[4 ; 10.19] /$ 56B(TR)_01

(1) [SIM / NULA / LONG (1-4) / COMPLEJ-SS / ES(-IN) / INDUC-INV / AUTOTRAD / EXPERIM]

(2) [SIM / INCOMPL / FL NO EQ-EXP / ES-IN / INDUC-INV / AUTOTRAD / EXPERIM]

88. *SIM:

*SUS:

*EST:

*SUS:

*LEO:

*SUS:

$<$ it's not $>[/]$ it's not a real riffle it's for playing .

ah@i it's for playing okey .

[\% a Simon] qué ha dicho que no la he entendido?

candy, whose candies are these ?

$[\%$ a Esther $]$ es es...+

[\% Simon se señala a si mismo] yours okey . [4;10.19] / 56B(TR)_01

[LEO: NULA/ IN-ES /INDUCIDA; INVESTIGADOR/ EXPERIM / OTROS-ADULT//3//OS] 
89. *SUS:

*SIM:

*SUS:

*SIM:

*SUS:

*SIM:

*SUS:

*EST:

*SUS:

*SUS:

*EST:

*SUS:

*SIM:

*SUS:

*EST:

*SIM:

*EST:

*SIM:

*EST:

*EST:

*SIM: so do you know your numbers?

yeah .

[\% a Simon] but do you know how to write them ?

not yet.

not yet, but you're gonna learn right?

yeah .

yeah okey so .

$<$ qué qué> [/] qué está diciendo que no me entero ?

[\% a Esther] okey, you have to learn .

poor Esther right?

qué ha dicho ?

you have $<$ to to $>[/]$ to help her .

(1) [\% a Esther] that [/] that if you don't know the numbers yet but we know how to count them to me .

but you [/] you're helping her in English !

yeah@en [///] sí, no sé no sé .

(2)[\% a Esther] mhm@fp one two three four five six seven eight nine ten eleven twelve.

pero [/] pero no sé lo que ha dicho en español no lo sé .

mhm@fp.

qué ha dicho?

qué es eso ?

(3)no me acuerdo muy bien . $\quad$ [4;10.19]/56B(TR)_01

(1), (2) y (3) [SIM / NULA / LONG (+14) / COMPLEJ-OC / IN(-ES) / INDUC-INV / SITUA / EXPERIM]

90. *SIM:

*SUS:

and I'm gonna eat when I'm a $+/$.

*SIM:

are you gonna eat them all ?

*SUS:

when I'm a grown up .

*EST:

okey okey when he's a grown up .

qué has dicho $\mathrm{S}$ que no lo sé no lo entiendo.

*LEO: que va a comer cuando es [= sea] eh@fp mayor

$[4 ; 10.19] / 56 \mathrm{~B}(\mathrm{TR})[01$

[LEO / COMPL / FL EQ-EMP (NC) / IN-ES / INDUC-INV / OTROS-HERM / EXPERIM]

91. *SUS:

[\% enseñándoles un póster donde aparece un reloj en el que pueden dibujar las manecillas] when you learn how to write them, and mom is gonna help you, this is for you to learn how to say the time right?

*SUS: there's a big clock and you can use a pen I've got one somewhere, okey $?(\ldots)$

*EST: qué es?

*EST: para qué es?

*SUS: but we have to help Esther okey?

*EST: para qué es?

*SUS: you can $+\%$.

*SIM: $<$ para apren $>[/ /]$ para saber el tiempo $<\underline{\text { del }}>[/ /]$ de recloj [: reloj].

[SIM / COMPL / FL NO EQ-ECO / IN-ES / INDUC-INV / OTROS-ADULT / EXPERIM]

92. *SUS:

*SUS:

*SUS:

*EST:

*EST:

*LEO: okey same with this you're gonna learn .

we need, what do we need?

some cloth or a handkerchief a paper one or something .

qué dice?

es que no sé lo que dice . (...)

papel y pañuelos tenemos que coger .

[4;10.19] / 56B(TR)_01 
93. *SUS:

*SUS:

*EST:

*SUS:

*EST:

*EST:

*SUS:

*SUS:

*SUS:

*LEO:

that's the clock but it doesn't have any xxx right?

we're gonna mark the time here $+\ldots$

qué hay que hacer?

+ , and here .

qué hay que hacer?

qué hay que hacer chicos?

finish it because it's not finished .

we can't know the time with this clock right?

now we can

tenemos que mascarlo $[:$ marcarlo] . [4;10.19] / 56B(TR)_01

[LEO / COMPL / FL NO EQ-ECO / IN-ES / INDUC-INV / OTROS-ADULT / EXPERIM]

94. *SUS:

[\% se dirige a Simon para que le dé un pañuelo de papel para poder borrar las manecillas dibujadas] and can I have one please ?

*SUS: okey the whole lot

*SUS:

(1)we want these because it's not very nice it's not a very nice game if you use it just once right?

*SUS: $\quad$ so when we're practicing and we're learning we'll mark different times

right?

*EST:

*SUS:

qué es eso ?

*SUS:

*EST:

*SIM:

*EST:

this is why you can use this pen but not the others you've got, right?

(1)this one cause we can erase things okey?

qué ha dicho qué ha dicho?

que $+\ldots$

*SIM:

*EST:

*SIM:

*EST:

*EST:

*SIM:

qué ha dicho que hay que hacer?

(2) $\underline{\text { mascar }}[$ : marcar] la hora .

$<$ masc $>[/ /]$ marcar la hora?

sí .

ah@i y qué más?

$\mathrm{y}<$ por qué $>$ [/] por qué ha hecho eso con el pañuelo ?

po(r)que [/] po(r)que se mueve y tienes que saber qué hora es cuando se mueve .

*EST: $\quad$ ah@i vale, pero y por qué ha utilizado el pañuelo ?

*SIM: $\quad$ (1)para limpiaslo [: limpiarlo] cuando queremos haserla [: hacerla] cuando queremos. $\quad[4 ; 10.19] / 56 \mathrm{~B}(\mathrm{TR}) \_01$

(1) [SIM / COMPL / FL NO EQ-ECO / IN-ES / INDUC-INV / OTROS-ADULT / EXPERIM]

(2) [SIM / COMPL / FL NO EQ-ECO / IN-ES / INDUC-INV / SITUA / EXPERIM]

95. *EST:

*SIM:

pregúntale a Susana cómo se hace por favor

*EST:

[\% como si estuviese pensando]mhm@fp .

*SIM: pregúntale cómo se hace anda .

how do you do it?

$[4 ; 10.19] / 56 B(T R)+01$

[SIM / COMPL / FL EQ-EMP (NC) / ES-IN / INDUC-INV / OTROS-ADULT / EXPERIM]

96. *SUS:

*SUS:

*SIM:

*EST:

*SIM: (1)(2)just write one line, a small one and a longer one .

(2)one for the hour and the longer one for the minutes .

(1)tienes que haser [: hacer] uno pequeño y uno grande .

uno pequeño uno grande qué ?

(2) si < pa pa $>$ [/] para que se puede y luego cuando está en los números tienes que saber qué hora es y entonses [: entonces] tienes que haser [:

hacer] uno pequeño y uno grande . [4;10.19] / 56B(TR)_01

(1) [SIM / COMPL / FL NO EQ-ECO / IN-ES / INDUC-INV / OTROS-ADULT / EXPERIM]

(2) [SIM / COMPL / FL NO EQ-EXP / IN-ES / INDUC-INV / OTROS-ADULT / EXPERIM] 
97. *EST:

*EST:

dile que si lo he dicho bien .

*SIM:

lo he hecho bien?

did she do it well?

[4;10.19] / 56B(TR)_01

[SIM / COMPL / FL EQ-EMP (NC) / ES-IN / INDUC-INV / OTROS-ADULT / EXPERIM]

98. *SIM:

*SUS:

did she do it well?

*SIM:

*EST:

very well yeah of course she did !

*SIM:

(1)[\% a Esther] sí@sp you did do it well.

perdona?

(2)que sí lo has hecho bien ha dicho!

$[4 ; 10.19] /$ 56B(TR)_01

(1) [SIM / INCOMPL / FL EQ-EMP (NC) / IN-ES / IP / OTROS-ADULT / EXPERIM]

(2) [SIM / COMPL / FL EQ-EMP (NC) / IN-ES / IP / OTROS-ADULT / EXPERIM]

99. *EST:

*SIM:

*EST:

*SUS:

ahora sí que lo he entendido y Susana sabrá leer los $[/ / /]$ el reloj sin números?

sí .

se lo puedes preguntar por favor?

*SIM: what what?

do you know how to $[/ / /]$ do you know the time without the numbers on the clock?

$[4 ; 10.19] /$ 56B(TR)_01

[SIM / COMPL / FL NO EQ-EXP / ES-IN / INDUC-INV / OTROS-ADULT / EXPERIM]

100.*SUS:

*EST:

it's very difficult you've got to learn with number first okey?

*SIM:

L qué ha dicho Susana que yo no lo sé ?

que lo tienes que aprender primero con númberos [: números] .

$[4 ; 10.19] /$ 56B(TR)_01

[SIM / COMPL / FL NO EQ-ECO / IN-ES / INDUC-INV / OTROS-ADULT / EXPERIM]

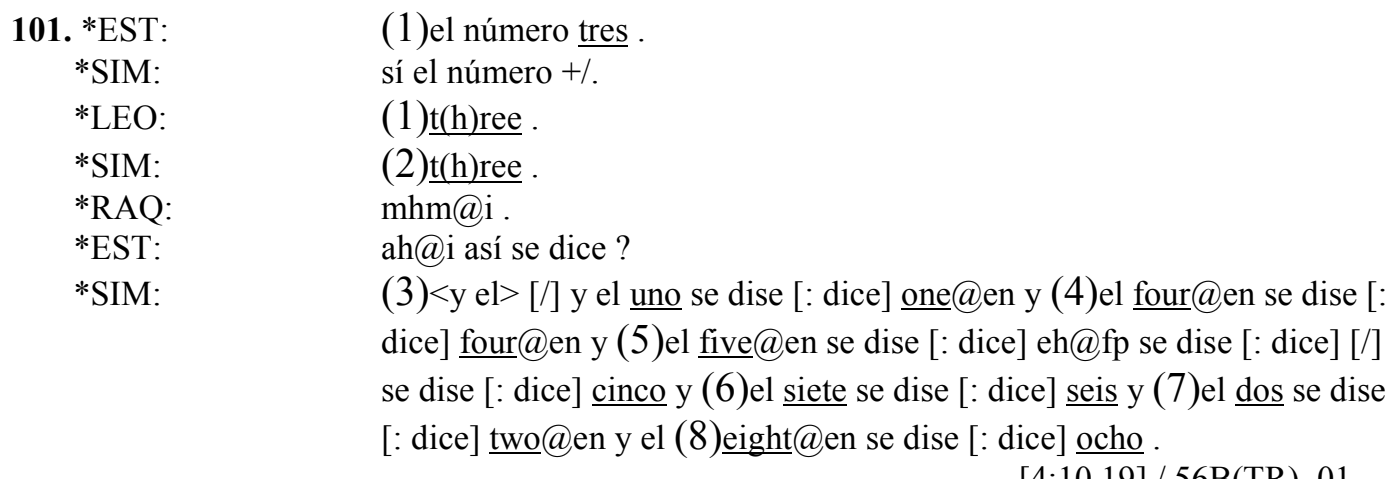

[4;10.19] / 56B(TR)_01

(1) [LEO / COMPL / FL EQ-EMP (no NC) / ES-IN / IP / OTROS-ADULT / EXPERIM]

(2) [SIM / COMPL / FL EQ-EMP (no NC) / ES-IN / IP / OTROS-ADULT / EXPERIM]

(3) [SIM / COMPL / FL EQ-EMP (no NC) / ES-IN / IP / AUTOTRAD / EXPERIM]

(4) [SIM / NULA / LONG (1-4) / COMPLEJ-SS / IN(-ES)/ IP / AUTOTRAD / EXPERIM]

(5) [SIM / COMPL / FL EQ-EMP (no NC) / IN-ES / IP / AUTOTRAD / EXPERIM]

(6) [SIM/ NULA / LONG (1-4) / COMPLEJ-SS / ES(-IN) / IP / AUTOTRAD / EXPERIM]

(7) [SIM / COMPL / FL EQ-EMP (no NC) / ES-IN / IP / AUTOTRAD / EXPERIM]

(8) [SIM / COMPL / FL EQ-EMP (no NC) / IN-ES / IP / AUTOTRAD / EXPERIM] 
102.*SUS

*RAQ:

it's more colourful it's a calendar !

*SUS:

*SUS:

mhm@i !

*SUS:

and it says the name [///] (1) the days of the week in $+/ /$.

again I unders [///] there're two words but I just understand one .

*EST:

(2)it says Monday Tuesday Wednesday Thursday Friday Saturday and Sunday right?

*SIM:

*EST:

*SIM:

*EST:

qué ha dicho qué ha dicho qué ha dicho ?

(2)eh@i no sé cómo se llaman esos días en español.

no sabes cómo se dicen esos días en español ?

no .

pero qué son días de qué ?

*SIM:

(1) días de la semana .

$[4 ; 10.19] / 56 B(T R) \_01$

(1) [SIM / COMPL / FL EQ-EMP (NC) / IN-ES / INDUC-INV / OTROS-ADULT / EXPERIM]

(2) [SIM / NULA / LONG (7-14) / COMPLEJ-SC / IN(-ES) / INDUC-INV / OTROS-ADULT/ / EXPERIM]

103.*EST:

*LEO:

eh@fp dile a Susana que qué es esto .

*SIM:

*EST:

[\% a Esther] a bear .

[\% a Esther] a bear .

*SIM:

se lo podéis preguntar por favor?

$[\%$ a Susana $]$ this is a bear right ? $\quad[4 ; 10.19] / 56 \mathrm{~B}(\mathrm{TR}) \_01$

[SIM / COMPL / FL NO EQ-EXP / ES-IN / INDUC-INV / OTROS-ADULT / EXPERIM]

104. *SUS:

*SIM:

*LEO

*SUS:

*EST:

*EST:

*SIM:

one $+\ldots$

$<$ two three four five six $>[>]$.

$<$ two three four five $\operatorname{six}>[<]$.

six one is a bit smaller but six .

$<\mathrm{y}$ en $>[/]$ y en español ?

qué es eso en español?

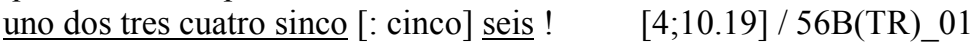

[SIM / COMPL / FL EQ-EMP (no NC) / IN-ES / INDUC-INV / AUTOTRAD / EXPERIM]

105. *SIM: $\quad(1)(2)(3)<\underline{\text { cloudy }}>[<]$.

*EST: $\quad[\%$ señalando una viñeta en la que aparecen dos árboles y una nube $]$

eh@fp cómo es en español esto ?

*SIM: $\quad$ (1)pues [/] pues eso son árboles .

*LEO: $\quad$ (2)pinos !

*SIM: $\quad$ pinos .

*EST: $\quad$ ah@i pinos !

*EST: $\quad$ pero [/] pero el tiempo ?

*EST: $\quad$ cómo es el tiempo aquí ?

*SIM: $\quad$ (3)el tiempo no hay ningún tiempo aquí !

\%com: $\quad$ mientras responde, Simon mira la parte superior del póster donde estaba

el reloj en el primer póster

$[4 ; 10.19] / 56 B(T R) \_01$

(1) [SIM / NULA / LONG (1-4) / COMPLEJ-SS / IN(-ES) / INDUC-INV / AUTOTRAD / EXPERIM]

(2) [LEO / NULA / LONG (1-4) / COMPLEJ-SS / IN(-ES) / INDUC-INV / OTROS-HERM / EXPERIM]

(3) [SIM / NULA / LONG (1-4) / COMPLEJ-SS / IN(-ES) / INDUC-INV / OTROS-HERM / EXPERIM] 
106. *SIM:

*EST:

*SUS:

pues eso es cuando sale eh@fp todo el sol.

*SIM:

el sol .

and in English?

sunny.

$[4 ; 10.19] / 56 B(T R) \_01$

[SIM / COMPL / FL NO EQ-ECO / ES-IN / INDUC-INV / AUTOTRAD / EXPERIM]

107. *SIM

*EST:

[\% a Esther y señalando una viñeta diferente] $(1)(2)$ esto es

*SIM:

cuando está lloviendo .

*EST:

cuando está lloviendo

*LEO:

(3)(4)y esto es cuando hay tormenta .

*SIM: y en inglés cómo es esto ?

*EST:

(1) $<$ rain $>[>]$.

*SIM:

(2) $<\underline{\text { rain }}>[<]$ rainny .

ah@i y esto?

*LEO:

pues + ...

*SIM:

(3) storm .

*EST:

(4) storm .

ah@i !

*SIM:

*EST:

snow cloudy $<$ and wind $>[/ /]$ and [/] and (5)windy .

*SIM:

*EST:

*EST:

*SIM:

*EST:

y qué es windy@en en [/] en español ?

(5)eh@i pues eh@fp es [/] es cuando hay frío.

cuando hay frío ?

windy@en $<$ cuando hac(e) $>[/ /]$ cuando hay frío .

sí .

*EST:

ah@i vale .

*SIM:

(6)y cuando hace calor ?

*EST:

(6) $<$ calor $>[/ /]$ cuando hace calor $<$ sale sa $>$ [/] sale el sol .

ah@i vale vale.

[4;10.19] / 56B(TR)_01

(1) y (3) [LEO / COMPL / FL NO EQ-ECO / ES-IN / INDUC-INV / OTROS-HERM / EXPERIM]

(2) y (4) [SIM / COMPL / FL NO EQ-ECO / ES-IN / INDUC-INV / AUTOTRAD / EXPERIM]

(5) [SIM / COMPL / FL NO EQ. EXP / IN-ES / INDUC-INV / AUTOTRAD / EXPERIM]

(6) [SIM / NULA / LONG (1-4) / COMPLEJ-OS / ES(-IN) / INDUC-INV / OTROS-ADULT / EXPERIM]

108.*SUS:

*SIM:

*SUS:

*SUS:

\%com:

*SIM:

*LEO:

*SUS:

*SIM:

*EST:

*SUS:

*SUS:

*SUS:

*LEO:

*SIM:

*SUS:

*SIM:

*EST:

*EST:

*SIM:

*EST: which one do we mark today?

eh@i .

how is $[/ / /]$ what's the weather today?

which one?

Simon y Leo miran por la ventana

eh@fp sunny .

cold .

looks very sunny?

mhm@i.

de qué estáis hablando ahora?

it's like this right?

you've got the sun but there's [/] there's some clouds as well right?

can we mark one then?

yeah .

yeah .

L which one ?

[\% señalando uno de los dibujos] this one !(..)

de qué estáis hablando ahora?

por favor me lo decís?

pues es:tamos hablando de mascarlo [: marcarlo] po(r)que [/] po(r)que no sabemos si es $[/ / /]$ si sale el sol $<_{0}$ si o si o si $>[/]$ o si no sabemos si hay sol o si es viento .

ah@i vale vale vale.

$[4 ; 10.19] /$ 56B(TR)_01

[SIM / COMPL / FL NO EQ-ECO / IN-ES / INDUC-INV / SITUA / EXPERIM] 


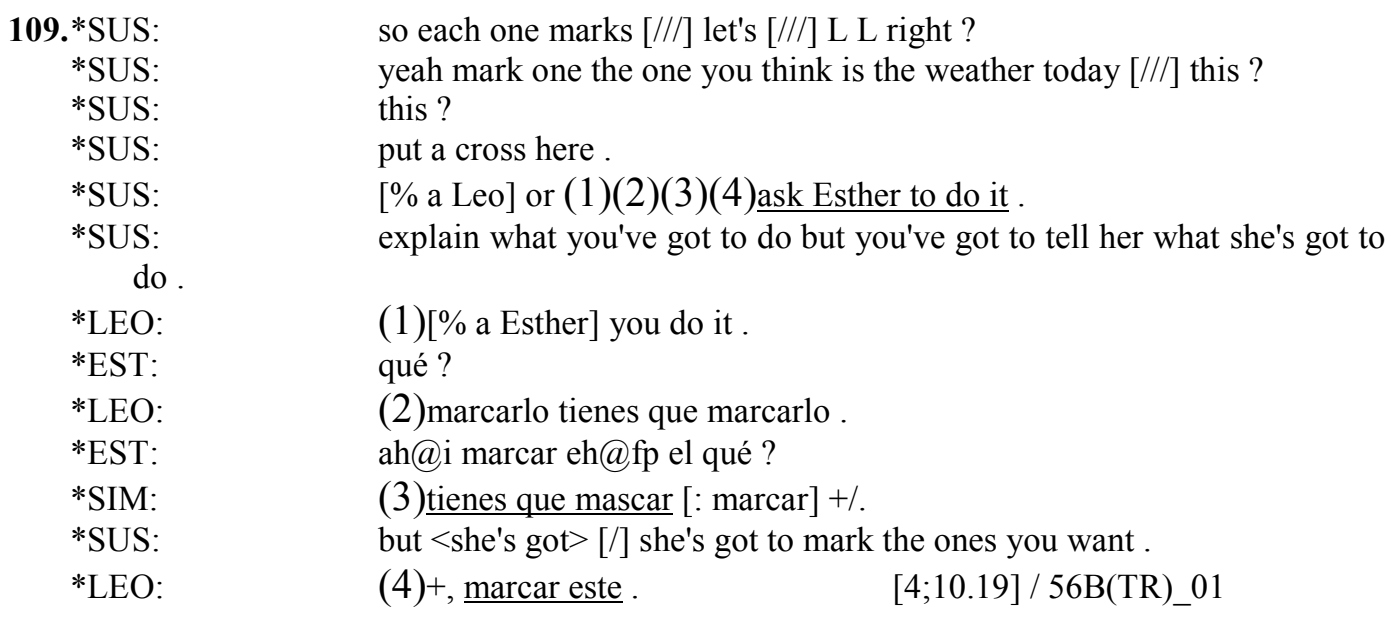

(1) [LEO/ NULA / LONG (1-4) / COMPLEJ-OS / IN(-ES) / INDUC-INV / OTROS-ADULT / EXPERIM]

(2) y (4) [LEO / COMPL / FL NO EQ-ECO / IN-ES / INDUC-INV / SITUA / EXPERIM]

(3) [SIM / COMPL / FL NO EQ-ECO / IN-ES / INDUC-INV / SITUA / EXPERIM]

(4) [LEO / COMPL / FL NO EQ-ECO / IN-ES / INDUC-INV / SITUA / EXPERIM]

110.*EST: $\quad[\%$ a Leo $]$ pregúntale a Susana qué más tengo que hacer por favor . *LEO: $\quad$ what do you need to do now ? $\quad[4 ; 10.19] / 56 \mathrm{~B}(\mathrm{TR}){ }^{0} 01$

[LEO / COMPL / FL NO EQ-EXP / ES-IN / INDUC-INV / OTROS-ADULT / EXPERIM]

111. *SUS: $\quad(1)(2)$ you can mark one two three four .

*EST: $\quad$ qué hago ?

*SUS: $\quad$ ask her don't look at me L .

*EST: qué hago L qué hago ?

*LEO: $\quad$ (1)mark this one . (..)

*EST: $\quad$ qué tengo que hacer a ver L qué tengo que hacer ?

*LEO: $\quad$ (2)eh@fp marcar uno que crees . [4;10.19] / 56B(TR)_01

(1) [LEO / NULA / LONG (7-14) / COMPLEJ-OS / IN(-ES) / INDUC-INV / OTROS-ADULT / EXPERIM]

(2) [LEO / COMPL / FL NO EQ-EXP / IN-ES / INDUC-INV / OTROS-ADULT / EXPERIM]

112.*EST:

*LEO:

+ , qué hace hoy?

*EST:

sí .

*EST:

[\% mirando por la ventana] ah@i eh@fp pues nublado .

*EST: nublado con muchas nubes mhm@i .

*SUS:

*EST: ah@i también nubes y sol.

*SIM: she's gonna mark them all ! qué qué ? que no tienes que mascar [: marcar] todos!

$[4 ; 10.19] / 56 B(T R) \_01$

[SIM / COMPL / FL NO EQ-EXP / IN-ES / INDUC-INV / OTROS-ADULT / EXPERIM]

113. *SIM: $\quad$ and this weather is hot this weather is eh@fp warm this weather is
*EST:
*SIM: pero qué es warm@en qué es cold@en ?
\%com:
(1)eh@fp pues aquí está al calor aquí eh@fp ah@fp es +//.
*SIM:
Simon deja de hablar porque Leo le está poniendo una pelota pequeña en el cuello e intentando metérsela por la camiseta
$\mathrm{y}+/ /$.
[\% a Leo] what are you doing ?

(1)(2)warm and this one is (3)cold. 
*EST: $\quad$ calor?

*EST: esto ?

*SIM: $\quad$ eh@fp es donde hay sol .

*EST: $\quad$ donde hay sol.

*SIM: $\quad$ (2) $\quad$ esto es cuando hay sol y (3)esto cuando hay frío . $[4 ; 10.19] / 56 B(T R) \_01$

(1), (2) y (3) [SIM / COMPL / FL NO EQ-EXP / IN-ES / INDUC-INV / AUTOTRAD / EXPERIM]

114.*EST: $\quad$ no sé qué ha dicho qué pena qué pena .

*EST: $\quad$ le puedes decir a Susana que lo siento que no entiendo inglés ?

*SIM: $\quad$ that she + .

\%com: durante unas décimas de segundo la grabación se interrumpe por fallo técnico

*SUS: $\quad$ all right okey what does she want to do ?

*SUS: what's she asking?

*SIM: $\quad$ she wants to learn . $\quad[4 ; 10.19] / 56 \mathrm{~B}(\mathrm{TR}) \_01$

[SIM / COMPL / FL NO EQ-EXP / ES-IN / INDUC-INV / OTROS-ADULT / EXPERIM]

115.*EST: qué tengo que hacer?

*SIM: $\quad$ you@en have@en [///] tienes que mascar [: marcar] este .

$[4 ; 10.19]$ / 56B(TR)_01

[SIM / REFORM / FL EQ-EMP (NC) / IN-ES / IP / AUTOTRAD / EXPERIM]

116.*SUS:

*LEO:

*EST:

*EST:

*SIM:

*SIM:

(1)(2)[\% a Simon] oh@i ask her tell her you wanted to mark this perhaps she wants to mark this as well .

(1) [\% a Esther] quieres marcar esto ? marcar esto ?

por qué ?

si quieres .

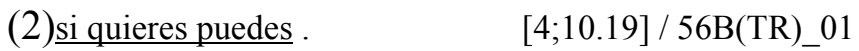

(1) [LEO / COMPL / FL NO EQ-ECO / IN-ES / INDUC-INV / OTROS-ADULT / EXPERIM]

(2) [SIM / COMPL / FL NO EQ-ECO / IN-ES / INDUC-INV / OTROS-ADULT / EXPERIM]

117.*SUS:

*SIM:

*SUS:

*SUS:

*SIM:

*SUS:

*SUS:

*SUS:

*EST:

*RAQ:

*SIM:

*LEO:

*SIM:

*EST:

*RAQ:

*LEO:

*EST:

*EST:

*SIM: what's the day today?

eh@fpmhm@fp summer.

summer?

no the day of the week as Monday Tuesday Wednesday $+\ldots$

Wednesday!

is it Wednesday today?

I should be working in Valladolid if it were Wednesday!

are you sure?

[\% a Leo] qué está diciendo ?

tendríais que ir al cole si es miércoles no ?

$[\%$ a Susana $]$ Tuesday..+

[\% mirando al suelo] sé muy bien .

,$+[\%$ a Susana $]$ Tuesday .

$<$ qué está> [/] qué está diciendo ?

tú qué crees $\mathrm{L}$ ?

(1) [\% mirando al suelo] sé muy bien .

no sabes muy bien lo que están diciendo ? (...)

qué está diciendo ?

(2)mhm@fp está disiendo [: diciendo] qué día es .

[4;10.19] / 56B(TR)_01

(1) [LEO / NULA / LONG (+14) / COMPLEJ-OC / IN(-ES) / INDUC-INV / SITUA / EXPERIM]

(2) [SIM / COMPL / FL NO EQ-ECO / IN-ES / INDUC-INV / SITUA / EXPERIM] 
118. *SIM:

*EST:

*EST:

*SIM:

*RAQ:

*SIM:

*RAQ:

*RAQ:

*EST:

*EST:

*SIM:

*SUS:

*SUS:

*RAQ:

*EST:

*SIM: mhm@fp está disiendo [: diciendo] qué día es .

qué día es ?

pues hoy es domingo no?

sí .

(1)(2)mhm@fp y cómo es domingo en inglés ?

(1)no sé .

no sabemos?

se lo preguntamos a Susana a ver si lo sabe ella?

[\% a Simon] pregúntaselo .

[\% a Leo] pregúntaselo .

(2)what day is it today?

today?

Sunday .

aha@i!

ah@i y en inglés entonces es ?

Sunday!

[4;10.19] / 56B(TR)_01

(1) [SIM / NULA / LONG (1-4) / COMPLEJ-SS / ES(-IN) / INDUC-INV / OTROS-ADULT / EXPERIM]

(2) [SIM / COMPL / FL NO EQ-ECO / ES-IN / INDUC-INV / OTROS-ADULT / EXPERIM]

119.*SUS:

you can ask Esther to write it in Spanish here cause I can't right?

*LEO:

[\% dándole el rotulador a Esther] lo hases [: haces] en español ?

$[4 ; 10.19] / 56 B(T R)+01$

\section{[LEO / COMPL / FL NO EQ-ECO / IN-ES / INDUC-INV / OTROS-ADULT / EXPERIM]}

120.*SUS:

*LEO:

*SIM:

*SUS:

*RAQ:

*LEO:

*SIM:

*SUS:

*RAQ:

*LEO:

*SIM:

*SUS:

*RAQ:

*LEO:

*SIM:

*SUS:

*LEO:

*SIM:

*SUS:

(...)

*SIM:

*LEO:

*RAQ:

*RAQ:

*SUS:

*SUS:

*RAQ:

*SUS:

*EST:

*SUS: you [/] you don't read now but when you learn how to read you've got [///] ah@i no the days of the

$\mathrm{k}$ are here but months are here all the months January and $+\ldots$

Feb $+\ldots$

+ , ruary .

February $+\ldots$

guau@i!

March .

(Mar)ch .

March +...

guau@i!

$<$ April $>[>]$.

$<$ April $>[<]$.

April +...

ah@i!

$<$ May $>[>]$.

$<$ May $>[<]$.

May + ...

$<$ June $>[>]$.

$<$ June $>[<]$.

June + ...

$<$ December $>[>]$.

$<$ December $>[<]$.

oh@iguau@i!

eso sí que no me lo sabía yo !

are you sure you don't know how to read and you're reading them ?

do you know them by heart?

[\% riéndose] qué chicos más listos !

great!

qué ha pasado qué ha pasado?

okey! 
*EST:

*SIM:

qué ha pasado ?

*EST:

estamos leyendo los días .

*EST:

*SIM:

los días?

*EST:

[\% señalando el póster] los días o [/] o los meses ?

los meses .

ah@i vale!

$[4 ; 10.19] / 56 \mathrm{~B}(\mathrm{TR}) \_01$

[SIM / COMPL / FL NO EQ-ECO / IN-ES / INDUC-INV / SITUA / EXPERIM]

121.*SUS:

*SIM:

*EST:

*EST:

*SIM:

*EST:

*RAQ:

*SIM:

*RAQ:

(1)(4)tell her to [/] to write the month $\mathrm{xxx}$ [\% susurrando a Simon] here .

(1)tienes que mascar [: marcar] el month@en . tengo que $<$ mas $>[/ /]$ marcar el month@en ?

y el qué ?

(2)(3)elmonth@en .

elmonth@en?

cómo se dice eso en español ?

(2)no sé .

L tú sabes cómo se dice month@en en español ?

*LEO:

(3)no

*RAQ:

*LEO:

[\% susurrándole a Leo] mes .

*EST:

mes!

ah@i mes !

vale!

*SIM:

$<$ tienes que mar $>[/ /](4)$ tienes que escribir el mes .

$$
\text { [4;10.19] / 56B(TR)_01 }
$$

(1) [SIM / INCOMPL / FL NO EQ-ECO / IN-ES / INDUC-INV / OTROS-ADULT / EXPERIM]

(2) [SIM / NULA / LONG (1-4) / COMPLEJ-SS / IN(-ES) / INDUC-INV / AUTOTRAD / EXPERIM]

(3) [LEO / NULA / LONG (1-4) / COMPLEJ-SS / IN(-ES) / INDUC-INV / OTROS-HERM / EXPERIM]

(4) [SIM / COMPL / FL NO EQ-ECO / IN-ES / INDUC-INV / AUTOTRAD / EXPERIM]

122.*EST:

(1)(2)[\% a Simon] dile a Susana que ahora le toca a ella escribir el [/] el mes en inglés .

*LEO

(1) now it's your $<\underline{\text { turn }}>[>]$.

*SIM:

$(2)<\underline{\text { turn }}>[<]$ to write the $+\ldots$

*SUS:

*SIM:

my turn?

to $[/]$ to do what ?

*SIM:

(2)to [/] to write a day . $\quad[4 ; 10.19] / 56 \mathrm{~B}(\mathrm{TR}) \_01$

(1) [LEO / COMPL / FL NO EQ-ECO / ES-IN / INDUC-INV / OTROS-ADULT / EXPERIM]

(2) [SIM / COMPL / FL NO EQ-ECO / ES-IN / INDUC-INV / OTROS-ADULT / EXPERIM]

123.*SUS:

*EST:

*EST:

no there's something wrong here !

*LEO:

qué pasa?

qué ha pasado?

que hamos $[=$ hemos $] \underline{\text { confundido }}$. [4;10.19] / 56B(TR)_01

[LEO / COMPL / FL NO EQ-EXP / IN-ES / INDUC-INV / OTROS-ADULT / EXPERIM]

124.*SUS:

*SIM:

*SUS:

so what do I write?

you have to write the month .

oh@i the month okey!

*SUS:

oh@i which is the month? 
*SUS:

*SIM:

*SUS:

*SUS:

*EST:

*SIM:

*EST:

*EST:

*EST:

*SIM:

*EST:

*EST:

*SIM:

*EST:

*SIM:

*EST:

if you $[/ / /]$ if $[/ / /]$ so this is the month in Spanish . you have to write the month in English ! and which is this month?

(1)what's the name of this month in English?

qué está diciendo?

eh@i+...

no sabe hacerlo?

o <qué está qué está> [/] qué está preguntando ?

qué está preguntando Susana a ver ?

(1)está preguntando + ...

sabes cuál $+\ldots$

qué ha dicho sabes cuál + ...

(2)sí tienes que decir el mes .

tengo que decir el mes ?

(2)tienes que escribir .

ah@i escribir el mes.

$[4 ; 10.19] / 56 B(T R) \_01$

(1) [SIM / NULA /LONG (7-14) / COMPLEJ-OS / IN(-ES) / INDUC-INV / OTROS-ADULT / EXPERIM]

(2) [SIM / COMPL / FL NO EQ-ECO / IN-ES / INDUC-INV / SITUA / EXPERIM]

125. *MEL:

Raquel watch out !

*MEL:

(1)there's a really fierce dragon behind you .

*MEL:

$\%$ com:

(2)it's gonna chop your head off .

*MEL:

everyone giggles

well I guess she doesn't .

*MEL:

otherwise she would've jumped a mile huh ?

*RAQ:

de qué os reís?

*MEL:

nada, nada, de nada .

*MEL:

[\% to the boys] you guys gonna tell her?

*MEL:

huh@i ?

*RAQ:

de qué os reís?

*RAQ:

*RAQ:

qué os ha contado mamá ?

os ha contado un chiste mamá ?

*SIM:

[\% laughing] (1)mamá te ha dicho que había un dragón eh@fp detrás de tu espalda .

*RAQ:

no me digas no $+/$.

*LEO:

(2)te iba a cortar tu [= la] cabeza ! [5;03.21] / 59EN_01

(1) [SIM / COMPL / FL NO EQ-ECO / IN-ES / IP / OTROS-ADULT / ESPONT]

(2) [LEO / COMPL / FL EQ-EMP (NC) / IN-ES / IP / OTROS-ADULT / ESPONT]

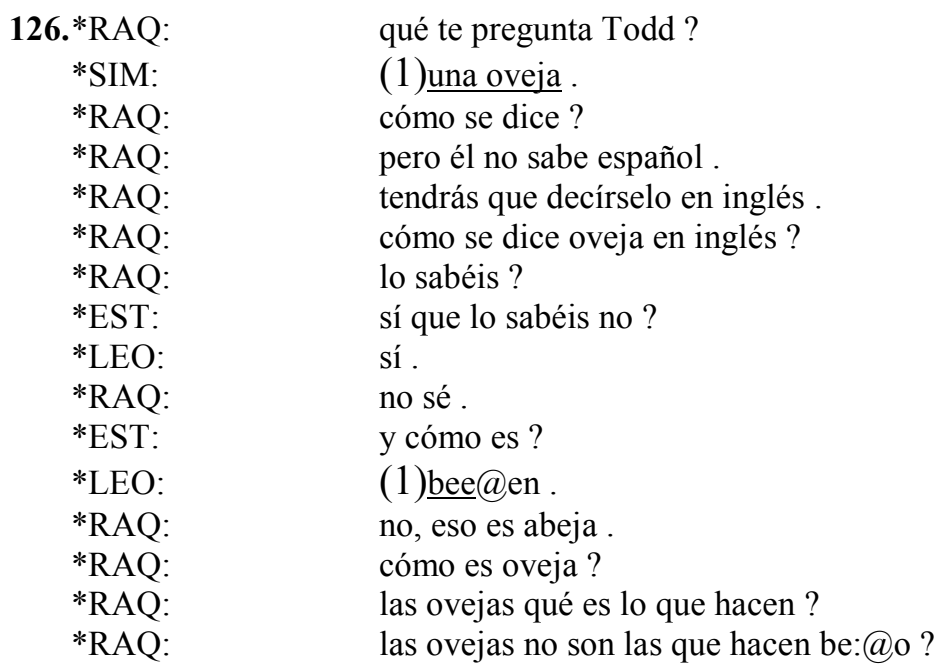


*RAQ: $\quad$ preguntadle a Todd cómo se dice

*RAQ: $\quad$ (2)decidle a Todd que es un animal .

*RAQ: $\quad$ pero tendréis que decírselo en inglés porque en español $+\ldots$

*SIM: $\quad$ (2) $\quad$ it's a(n) animal . [5;05.29] / 61 ASP_01

(1) [LEO / COMPL / FL EQ-EMP (NC) / INDUC-INV / OTROS-HERM / ESPONT / ES-IN]

(2) LEO / COMPL / FL EQ-EMP (NC) / ES-IN / INDUC-INV / OTROS-ADULT / ESPONT]

127. *SIM: $\quad(1)+$, tienes que rebis $[:$ recibir] \# $\underline{\text { sinco }}[:$ cinco] para ganar uno nuevo

*SIM: $\quad$ (2)+, pon estas otras aquí y di que si parejas .

*SIM: $\quad$ (3)si alguien dise [: dice] toro a alguien y lo tiene so@en tiene que dar eso [/] eso tú no lo sabes (4)o si no lo tiene y los otros no tienen y + /.

*RAQ: $\quad$ sí

*SIM: $\quad(5)+$, pues tiene que pescar

*SIM: $\quad$ y si + .

*RAQ: $\quad$ a pescar .

*SIM: $\quad \quad<\mathrm{y} \mathrm{si}>[/]$ y si $+/$.

*RAQ: $\quad$ vale vete a pescar me acuerdo de eso .

*SIM: $\quad<\mathrm{y} \mathrm{si}>[/]$ y si yo lo tengo pongo $<\mathrm{y}$ es $>[/ /]$ y cuando es mi turno se lo pido y luego ya me lo tiene que dar eh@i y es mi turno es otra vez .

*RAQ: ah@i vale o sea que es pareja es decir caballo con caballo +...

*SIM: $\quad$ sí

*RAQ: $\quad$ y vale

*TOD: $\quad$ what?

*RAQ: $\quad$ vale vamos a explicárselo a Susana $<\mathrm{y}$ a $>$ [/] y a Todd ?

*TOD: $\quad$ what do I have to do ?

*RAQ: $\quad$ vale \# S ?

*RAQ: $\quad$ ok so \# we have five cards yeah ?

*SIM: $\quad$ (1)you [/] you have to deal five howds [//] cowds [: cards] to everybody (2)and den [: then] you have to put other ones there $+\ldots$

*SIM: $\quad$ (3)i:f somebody in to sabe@sp to give him one animal one who that's a cat and then a fox and [/] and he have [= has] them she [///] the [///] then you get him and den [: then] you have to do again until you don't have any (4)but if you don't and another one haves [= has] them you can get (h)im and if you don't have him you don't and if da [: the] odder [: other] one doesn't have him dat [: that] (5)you're forced [?] to you have to pick from dere [: there] .

\%com: $\quad$ Simon points to the deck of cards $\quad[5 ; 05.29] / 61 B(T R) \_01$

(1) y (2) [SIM / COMPL / FL NO EQ-ECO / ES-IN / INDUC-INV / AUTOTRAD / EXPERIM]

(3) [SIM / INCOMPL / FL NO EQ-EXP / ES-IN / INDUC-INV / AUTOTRAD / EXPERIM]

(4) y (5) [SIM / COMPL / FL NO EQ-EXP / ES-IN / INDUC-INV / AUTOTRAD / EXPERIM]

128.*TOD:

[\% to Leo] I have to deal five cards ?

*LEO: yep .

*RAQ:

sí .

*EST:

Raquel qué ha dicho Todd?

*RAQ:

eh@fp qué es lo que ha dicho Todd?

*RAQ: que [///] cuántas cartas necesitamos?

*SIM: sinco $[$ : cinco] cada uno . [5;05.29] / 61B(TR)_01

[SIM / COMPL / FL NO EQ-EXP / IN-ES / INDUC-INV / OTROS-ADULT / EXPERIM] 


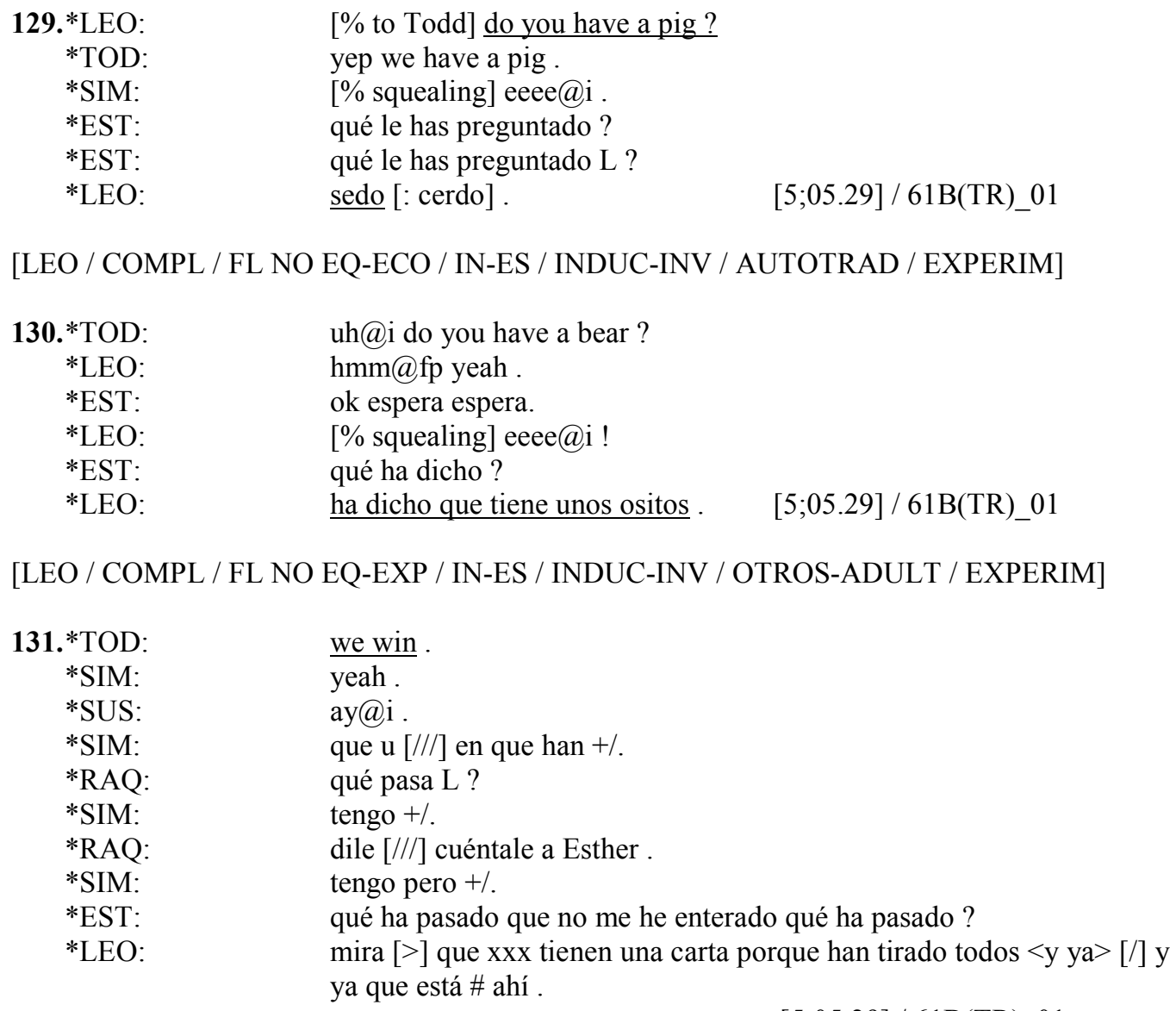

[SIM / COMPL / FL NO EQ-ECO / ES-IN / INDUC-INV / OTROS-ADULT / EXPERIM]

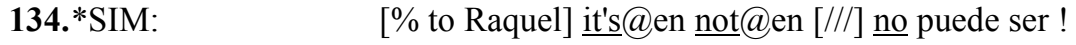
[5;05.29] / 61B(TR)_01

[SIM / REFORM / FL EQ-EMP (no NC) / IN-ES / IP / AUTOTRAD / EXPERIM] 

135. *SIM:
*LEO:
*RAQ:
we don't have payus [: pairs] !
*LEO:
[\% to Esther] que no tienen $+\%$.
son tontos.
$<$ ya ha di:cho $>$ [?] que no tienen parejas .

[5;05.29] / 61B(TR)_01

[LEO / COMPL / FL EQ-EMP (NC) / IN-ES / IP / OTROS-HERM / EXPERIM]

136. *SIM:

*TOD:

*TOD:

*SIM:

[\% to Todd] vamos a pedirte esto .

what?

what do you want?

alagayto [: alligator] .

$[5 ; 05.29] / 61 B(T R) \_01$

[SIM / COMPL / FL NO EQ-EXP / ES-IN / INDUC-INV / AUTOTRAD / EXPERIM]

137.*RAQ:

*RAQ:

$<$ que hemos cogido $>[/ /]$ (1)les dices que hemos cogido del montón esta y que como teníamos otra en la mano hemos hecho pareja .

*SIM:

[\% whispering] tienes que decírselo en inglés .

*SUS:

(1)we got a lion and $\sin (\mathrm{ce})$ we get a li:on and we don't want to $\mathrm{u}(\mathrm{se})$

*TOD

and we didn't have it and we had to go fis(h) and we get a beao [: bear] .

*LEO:

ok you fished a bear .

you fished a bear out of the pile oh@i ok alright.

*EST:

[\% to Esther] ha dicho una mentira .

*LEO:

*SIM:

por qué es una mentira?

que [/] que te han [//] dan petsidido [?] un leyón [: león] a ellos y luego lo han pescado otra vez y es una mentira .

*SIM:

no !

(2)hamos [: hemos] [/] hamos [: hemos] dicho que tú tenías un leyón [: león] y [/] y la [//] y [//] y lo hamos [: hemos] pedido a ellos y como un cocod(r)ilo y como no lo tenemos lo tenemos que pescar y nos hamos $[=$ ha] salido una pareja .

$$
\text { [5;05.29] / 61B(TR)_01 }
$$

(1) [SIM / COMPL / FL NO EQ-EXP / ES-IN / INDUC-INV / OTROS-ADULT / EXPERIM]

(2) [SIM / COMPL / FL NO EQ-ECO / IN-ES / INDUC-INV / SITUA / EXPERIM]

138.*TOD:

*SIM:

[\% to Simon] do you have an umbrella bird ?

*RAQ:

no .

*LEO:

a ver a ver.

*LEO:

let's see it let's see it .

ahá@i !

[5;05.29] / 61B(TR)_01

[LEO / COMPL / FL EQ-EMP (no NC) / ES-IN / IP / OTROS-ADULT / EXPERIM]

139.*SIM:

*TOD:

[\% to Todd] I knew you had it .

*TOD:

you did?

*SIM:

how did you know?

*TOD:

because I saw it .

*SUS:

you saw it?

*SUS:

$\mathrm{S}$ !

*RAQ:

[\% to Todd] careful with S .

*SUS:

[\% to Todd] no, it's your fault .

Susana $<$ we gotta be careful $>$ [/] we gotta be careful of him lookin(g) at our cards .

*RAQ:

[\% to Simon] it's their fault .

*LEO:

[\% to Esther] ha dicho que eran unos tramposos .

[5;05.29] / 61B(TR)_01

[LEO / COMPL / FL NO EQ-ECO / IN-ES / IP / SITUA / EXPERIM] 


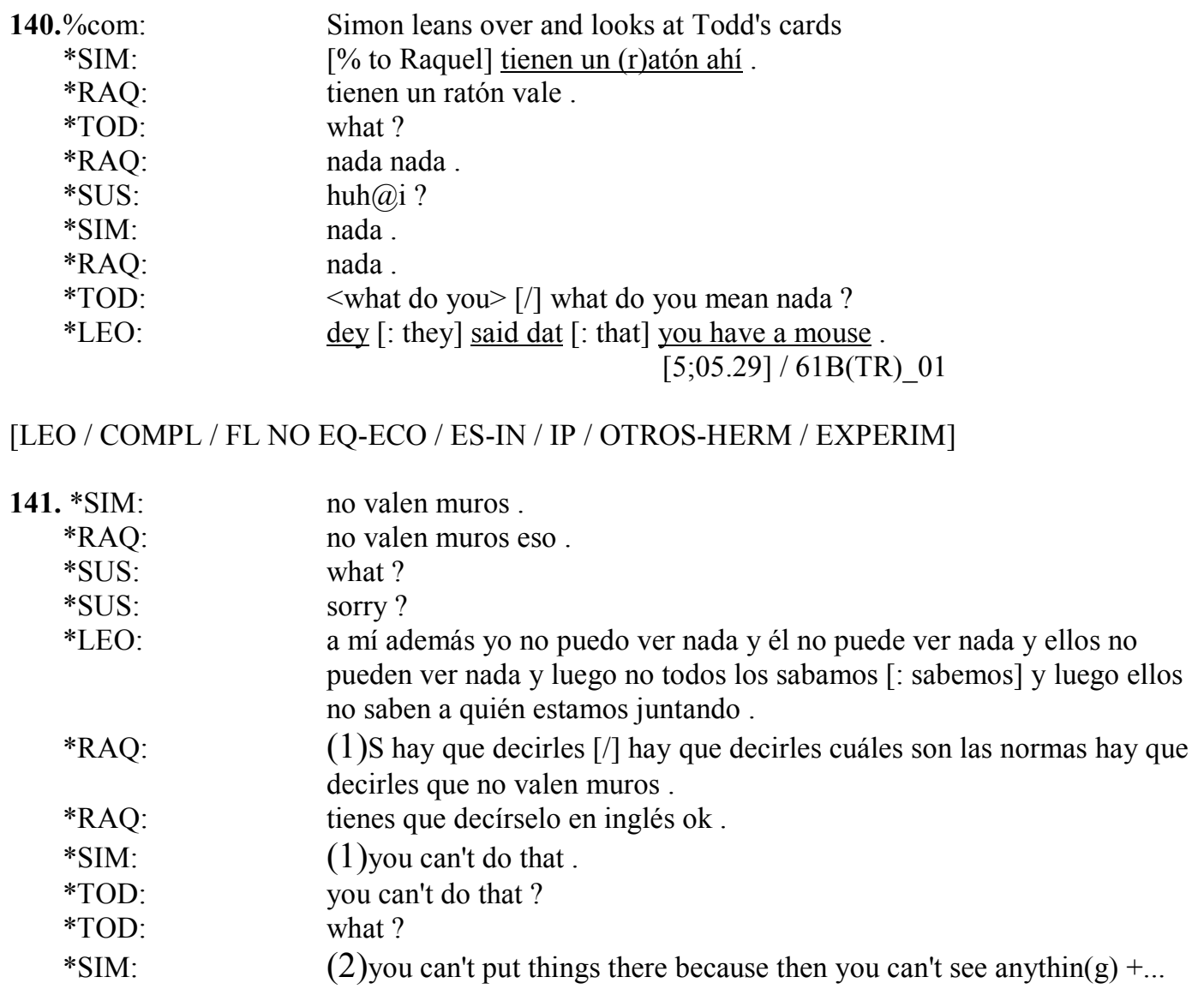
$[5 ; 05.29] / 61 B(T R) \_01$

(1) [SIM / COMPL / FL NO EQ-ECO / ES-IN / INDUC-INV / OTROS-ADULT / EXPERIM]

(2) [SIM / COMPL / FL NO EQ-ECO / ES-IN / INDUC-INV / SITUA / EXPERIM]

142.*SIM: $\quad[\%$ pointing at Leo and Esther $]$ theow $[:$ their $]$ turn .

*EST: $\quad$ qué ?

*EST: $\quad$ el qué ?

*SIM: $\quad$ it's still your turn . [5;05.29] $\quad$ 61B(TR)_01

[SIM / NULA / LONG (1-4) / COMPLEJ-SS / IN(-ES) / INDUC-INV / AUTOTRAD / EXPERIM]

143.*EST: $\quad$ sí pues \# decirles que vamos a ganar .

*EST: $\quad$ (1)díselo L, vamos a ganar .

*LEO: $\quad$ va + .

*EST: $\quad$ (1)vosotros vais a perder .

*LEO: $\quad+$, sí .

*EST: $\quad$ [\% pointing to Todd and Susana] díselo ha@i .

*LEO: $\quad$ (2) $\quad$ nosotros vamos a [///] (1) we (a)re going to win you (a)re going to lose . $\quad[5 ; 05.29] / 61 \mathrm{~B}(\mathrm{TR}) \_01$

(1) [LEO / COMPL / FL EQ-EMP (NC) / ES-IN / INDUC-INV / OTROS-ADULT / EXPERIM]

(2) [LEO / REFORM / FL EQ-EMP (NC) / ES-IN / IP / AUTOTRAD / EXPERIM]

144.*SIM: $\quad$ (1)you never know who: wins .

*TOD:

that's right .

*EST:

el qué ?

*TOD:

(2)that's because we're gonna win .

*EST: qué ? 
*TOD: $\quad$ mmmh@i I think so .

*EST: qué ha dicho L ?

*EST: $\quad$ qué le respondo?

*EST: $\quad$ qué ha dicho ?

\%com: $\quad$ Leo whispers to Esther

*EST: $\quad$ (2) [\% repitiendo lo que le ha susurrado Leo] que ellos van a ganar ?

*SIM: $\quad$ (1) $\quad$ no, hamos [: hemos] dicho que nunca sabes quién gana .

(1) [SIM / COMPL / FL EQ-EMP (NC) / IN-ES / IP / AUTOTRAD / EXPERIM]

(2) [LEO / COMPL / FL EQ-EMP (NC) / IN-ES / INDUC-INV / OTROS-ADULT / EXPERIM]

145.*TOD:

*SIM:

*TOD:

\%com:

*EST:

*LEO:

han + .

*EST:

*LEO:
$[\%$ to Leo $]$ do you have a mouse ?

no .

[\% picking a card from the pile] ah@i .

Leo starts whispering in Esther's ear

qué ?

[\% whispering] han dicho que nosotros tenemos un ratón y que ellos

han dicho que nosotros tenemos un ratón?

,$+ \mathrm{y}$ tenemos porque vamos pescando y ellos se alegra [?] que han dicho que tenemos un ratón y ahora ellos están diciendo que tenemos un ratón son unos tramposos.

\section{[LEO / COMPL / FL NO EQ-EXP / IN-ES / IP / OTROS-ADULT / EXPERIM]}

146.*SUS:

*EST:

what happens?

*SUS:

que sois unos tramposos .

*EST:

what?

*EST:

[\% to Leo] díselo .

*EST:

o no ?

es un poco fuerte decírselo eh@i ? [5;05.29] / 61B(TR)_01

[LEO / NULA / LONG (1-4) / COMPLEJ-OS / ES(-IN) / INDUC-INV / OTROS-ADULT / EXPERIM]

147.*EST:

*TOD:

(1)(2)[\% to Susana] ah@i \# tenéis un caballo ?

*SIM:

a what?

*LEO:

(1) [ $[>]$ hoasie [: horsie] .

(2) $\underline{\text { a }}[<]$ hoasie $[$ : horsie] .

[5;05.29] / 61B(TR)_01

(1) [SIM / COMPL / FL EQ-EMP (NC) / ES-IN / INDUC-INV / OTROS-ADULT / EXPERIM]

(2) [LEO / COMPL / FL EQ-EMP (NC) / ES-IN / INDUC-INV / OTROS-ADULT / EXPERIM]

148.*EST:

*EST:

qué significa eso + $\%$.

*SIM:

+" but that's awful?

es terrible.

[6;03.22] / 74(TR) 01

[SIM / COMPL / FL EQ-EMP (NC) / IN-ES / INDUC-INV / OTROS-ADULT / EXPERIM]

149.*EST: $\quad(1)+$ " you could help by asking your friends (2)if they have the sled,

*EST: suggested [/] suggested Sam .

*SIM: y qué ha dicho?

*EST: $\quad$ que le pregunte qué ?

*SIM: (2)que si lo ha visto. [6;03.22] / 74(TR)_01

(1) y (2) [SIM / COMPL / FL NO EQ-ECO / IN-ES / INDUC-INV / OTROS-ADULT / EXPERIM] 
150.*EST:

(1)(2)the@en icing@en qué es eso ?

*LEO:

(1)esto es icing@en.

*EST:

pero qué es ?

*SIM:

(2)se lo preguntas a M . [6;03.22]/74(TR)_01

(1) $[\mathrm{LEO} / \mathrm{NULA} / \mathrm{LONG}$ (1-4) / COMPLEJ-SS / IN(-ES) / INDUC-INV / OTROS-ADULT / EXPERIM]

(2) [SIM / NULA / LONG (1-4) / COMPLEJ-SS / IN(-ES) / INDUC-INV / OTROS-ADULT / EXPERIM]

151.*EST:

*EST:

es que no me [//] no lo entiendo eso .

*EST:

+" Helen jumped, and the icing jumped .

*LEO:

*EST:

(1)(2)y qué es eso de icing@en ?

*EST:

(1)pues esto, y se acaba!

*LEO:

pero esto qué es !

es que no sé qué es esto para hacer galletas .

(2)icing@en, eso es icing@en!

[6;03.22] / 74(TR)_01

(1) y (2) [LEO / NULA / LONG (1-4) / COMPLEJ-SS / IN(-ES) / INDUC-INV / OTROSADULT / EXPERIM]

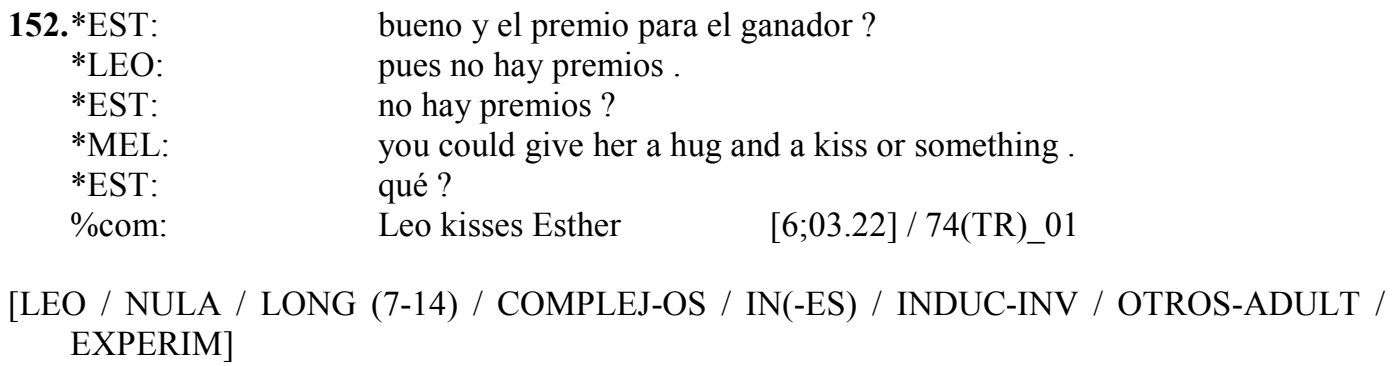

153. *MEL:

*MEL:

*EST:

*LEO:

*MEL:

*LEO:

*LEO:

*MEL:

*LEO:

*MEL:

*LEO:

*MEL:

*LEO:

*MEL:

*LEO:

*MEL:

*LEO:

*SIM:

*LEO:

*EST:

*SIM:

*EST:

*SIM:

*EST:

*EST: (1)when you hold a seashell to your ear, what are you hearing? the sea, the air blowing through it, or your blood? cómo es la pregunta a ver? pues + ... when you hold a seashell to your ear...+

(1)cuando: eh@fp cogemos...+

[\% to Melanie] what is it called ? una@spconcha@sp.

(1)una concha y lo pones a tu oído qué oyas [= oyes] el mhm@fp $+\ldots$ $[\%$ prompting Leo] the sea...+ and what (i)s el@sp sea in Spanish? ocean + ...

(1) $\mathrm{el} \mathrm{mar}+\ldots$

the air blowing through it + ..

(1) + , el aire $<$ en $>[/ /]$ por soplando por allí $+\ldots$

or your blood .

(1) + , o tu $+\ldots$

(2) [\% filling in for Leo] sangre .

(1) sangre .

buf@i pues el [/] el mar .

no!

no ?

la sangre .

mhm@i la sangre?

cómo vas a oír la sangre ? 
*MEL: $\quad$ (3)the shape of the shell sends the sound of your blood circulating back into your ear .

*LEO: $\quad$ (3)mira la sangra [: sangre] te lleva allí pero luego el aire lo empuja para allá y oyes tu sangre moviéndose .

[6;03.22] / 74(TR)_01

(1) [LEO / COMPL / FL EQ-EMP (NC) / IN-ES / INDUC-INV / OTROS-ADULT / EXPERIM]

(2) [SIM / COMPL / FL EQ-EMP (NC) / IN-ES / IP / OTROS-ADULT / EXPERIM]

(3) [LEO / COMPL / FL NO EQ-ECO / IN-ES / INDUC-INV / OTROS-ADULT / EXPERIM]

154.*SIM: $\quad$ how long does your large intestine@sp let food hang around before you [/] you poop it out ?

*SIM: $\quad$ two minutes, two hours, or two days ?

*LEO: [\% whispering to Esther] sabes qué pasa si comes mucho espárrago ?

*MEL: $\quad[\%$ to Leo] ok, you tell Esther, you tell Esther .

*EST: $\quad$ sabes qué pasa qué cuándo \&co ?

*LEO: $\quad$ si comes mucho espárrago ?

*EST: $\quad$ ah@i qué pasa?

*LEO: $\quad$ que, bueno tu caca se vuelve $<$ un ve> [//] un poco verde .

*EST: $\quad$ la $[/ / /]$ mi caca se vuelve un poco verde ?

*LEO: $\quad$ como el espárrago .

$[6 ; 03.22] / 74(\mathrm{TR})+01$

[LEO / NULA / LONG (+14) / COMPLEJ-OC / IN(-ES) / INDUC-INV / OTROS-HERM / EXPERIM]

155.*MEL: $\quad$ how long [//] if you [/] if you eat something, how long does it hang around in your large intestine, down here, before you poop it out?

*MEL: $\quad$ two minutes ?

*MEL: $\quad$ two hours or two days [\% asking Simon for confirmation] ?

*SIM: $\quad$ yeah .

*MEL: $\quad[\%$ back to Leo] are you going to tell her ?

*SIM: $\quad$ no .

*SIM: $\quad$ well yes .

*SIM: $\quad$ but you do it this time . [6;03.22] / 74(TR)_01

[SIM / NULA / LONG (+14) / COMPLEJ-OC / IN(-ES) / INDUC-INV / OTROS-ADULT / EXPERIM]

156. *SIM:

*EST:

*RAQ:

*LEO:

*EST:

*SIM:

$+"$ turn to the player to your left and look into his or her throat .

cómo cómo cómo a ver a ver a ver .

ah@i .

I already did that .

qué $[/]$ qué tienes que hacer a ver a ver a ver a ver .

$\underline{\text { mirar }}<$ en algún eh@fp $>[/]<$ en \&alg $>[/ /]$ en $[/]<$ en otra $>[/ /]$ en una

garganta . $\quad[6 ; 03.22] / 74(T R) \_01$

[SIM / COMPL / FL NO EQ-ECO / IN-ES / INDUC- INV / AUTOTRAD / EXPERIM]

157. *EST:

*MEL:

*MEL:

*LEO:

*MEL:

\%com:

*EST:
$<$ qué le ha pasado $>[/]<$ qué le ha pasado $>[/ /]$ qué pasa con ese pez ? just $[/ / /]$ if you do $[/ /]$ if you explain $<$ the \&pres $>[/ /]$ the question to her I'll explain the answer ok?

$(1)(2)(3)(4)+"$ what does the African longfish like to do in mucus, sleep bathe or vomit?

(1) [\% to Esther] dormir .

yeah but she doesn't know the question .

(2)Leo groans

dormir . 
*MEL: $\quad$ S can you help him with the question ?

*LEO: $\quad$ (3) [\% whining] you do it I do n(o)t want [///] leave me alone I (a)m not doing it .

*SIM: $\quad$ what was the question?

*MEL: $\quad$ well $\mathrm{S}$ can do it ok .

*MEL: $\quad+$ " what does the African longfish like to do in mucus, sleep bathe or vomit?

*SIM: $\quad$ (4)con esos no .

*EST: $\quad$ qué ?

*MEL: $\quad$ what?

*SIM: $\quad$ (4)que con esos no !

*MEL: $\quad$ yourself no ?

*MEL: $\quad$ ok African longfish we [///] I think we gonna just say African longfish .

*MEL: $\quad$ we don't have to translate that because we don't know the translation. $[6 ; 03.22] / 74(T R) \_01$

(1), (2) y (3) [LEO / NULA / LONG (+14) / COMPLEJ-OC / IN(-ES) / INDUC-INV / OTROSADULT / EXPERIM]

(4) [SIM / NULA / LONG (7-14) / COMPLEJ-OC / IN(-ES) / INDUC-INV / OTROS-ADULT / EXPERIM]

158.*SIM:

*RAQ:

*SIM:

+" see how many times you can blink in twenty seconds .

okey .

what (i)s blink?

*SIM:

qué tengo que hacer?

*MEL:

*SIM:

what (i)s blink ?

parpadear o pestañear, pestañear .

$<$ a ver> [/] a ver qué eh@i $+\ldots$

*SIM:

cuántas veces puedes pestañear en veinte segundos?

$[6 ; 03.22] / 74(\mathrm{TR}) \_01$

[SIM / COMPL / FL EQ-EMP (NC) / IN-ES / INDUC-INV / AUTOTRAD / EXPERIM] 


\section{ÍNDICE DE TABLAS, GRÁFICOS Y DIAGRAMAS}

TABLAS

TABLA 1. LA RELACIÓN DE LOS MODELOS DE DESARROLLO DE LA COMPETENCIA TRADUCTORA:

ALGUNAS PUNTUALIZACIONES

TABLA 2. ESTUDIOS DE BILINGÜISMO INFANTIL: EDADES DE LOS SUJETOS, LENGUAS Y

METODOLOGÍA

TABLA 3. PERIODICIDAD DE LAS GRABACIONES EN EL ESTUDIO LONGITUDINAL DE FERNÁNDEZ

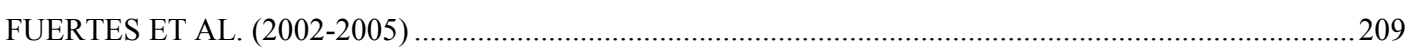

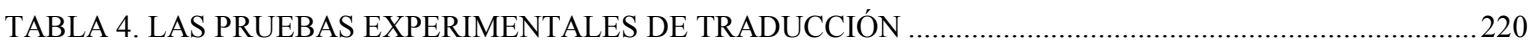

TABLA 5. LOS DATOS DISPONIBLES EN EL ESTUDIO LONGITUDINAL DE FERNÁNDEZ FUERTES ET

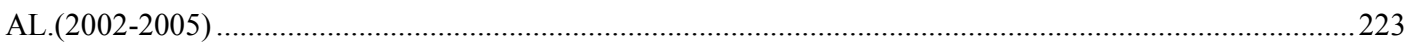

TABLA 6. LA SELECCIÓN DE DATOS DEL PRESENTE ESTUDIO ……………………………………….......22

TABLA 7. LA LMEp EN LAS SESIONES DE ESPAÑOL, DE INGLÉS Y DE TRADUCCIÓN EN CADA ETAPA. 232 TABLA 8. SELECCIÓN DE DATOS: SESIONES Y DURACIÓN DE LAS GRABACIONES EN CADA ETAPA ...234 TABLA 9. PROPUESTA DE VARIABLES PARA LA CODIFICACIÓN Y EL ANÁLISIS DE LOS DATOS DE TN

TABLA 10. EJEMPLO DE CLASIFICACIÓN DE UN CASO TN EN FUNCIÓN DE LAS VARIABLES

PROPUESTAS .290

TABLA 11. EJEMPLO DE ELABORACIÓN DE NUESTRA BASE DE DATOS EN FUNCIÓN DE LAS VARIABLES PROPUESTAS 291

TABLA 12. LA PRODUCCIÓN DE LA ACTIVIDAD DE TRADUCCIÓN DE SIMON Y LEO....................................292

TABLA 13. LA PRODUCCIÓN TOTAL DE TTNN SEGÚN LA VARIABLE 1 1.......................................................29

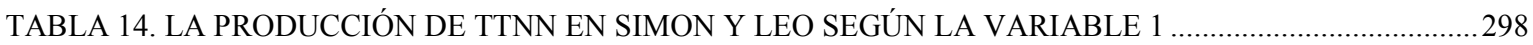

TABLA 15. LA PRODUCCIÓN TOTAL DE TTNN DE SIMON Y LEO POR ETAPAS ..............................................300

TABLA 16. LA PRODUCCIÓN DE TTNN DE SIMON SEGÚN LA VARIABLE 1 POR ETAPAS ……………….......301

TABLA 17. LA PRODUCCIÓN DE TTNN DE LEO SEGÚN LA VARIABLE 1 POR ETAPAS ..................................301

TABLA 18. LA PRODUCCIÓN TOTAL DE LAS TTNN DE SIMON Y LEO SEGÚN LA VARIABLE 2...................307

TABLA 19. LA PRODUCCIÓN TOTAL DE LAS TTNN SEGÚN LA VARIABLE 2: LAS SUBCATEGORÍAS .......308

TABLA 20. LA PRESENCIA/AUSENCIA DE ESTÍMULO EN LA PRODUCCIÓN TOTAL DE TTNN SEGÚN LA

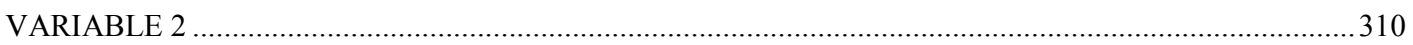

TABLA 21. EL INDUCTOR EN LA PRODUCCIÓN TOTAL DE TTNN SEGÚN LA VARIABLE 2 …......................311

TABLA 22. LA PROCEDENCIA DEL TO EN LA PRODUCCIÓN TOTAL DE TTNN SEGÚN LA VARIABLE $2 . .312$

TABLA 23. LA PRODUCCIÓN TOTAL DE TTNN DE SIMON Y LEO SEGÚN LA VARIABLE 2 …........................314

TABLA 24. LA PRODUCCIÓN TOTAL DE TTNN DE SIMON Y LEO SEGÚN LA VARIABLE 2: LAS

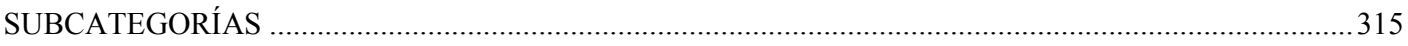

TABLA 25. LA PRESENCIA/AUSENCIA DE ESTÍMULO EN LAS TTNN DE SIMON Y LEO SEGÚN LA

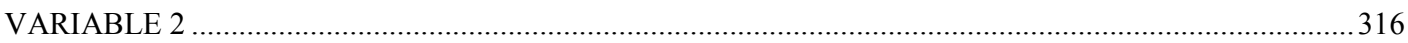

TABLA 26. EL INDUCTOR DE LAS TTNN DE SIMON Y LEO SEGÚN LA VARIABLE 2 ……………………......317

TABLA 27.LA PROCEDENCIA DEL TO DE LAS TTNN DE SIMON Y LEO SEGÚN LA VARIABLE 2................320

TABLA 28. LA PRODUCCIÓN DE TTNN DE SIMON SEGÚN LA VARIABLE 2 POR ETAPAS …………………..... 322

TABLA 29. LA PRODUCCIÓN DE TTNN DE LEO SEGÚN LA VARIABLE 2 POR ETAPAS ..................................322 
TABLA 30. LA PRODUCCIÓN DE TTNN DE SIMON POR ETAPAS SEGÚN LA VARIABLE 2: LAS

SUBCATEGORÍAS

TABLA 31. LA PRODUCCIÓN DE TTNN DE LEO POR ETAPAS SEGÚN LA VARIABLE 2: LAS

SUBCATEGORÍAS 324

TABLA 32. LA PRESENCIA/AUSENCIA DE ESTÍMULO EN LA PRODUCCIÓN DE TTNN DE SIMON SEGÚN

LA VARIABLE 2

TABLA 33. LA PRESENCIA/AUSENCIA DE ESTÍMULO EN LA PRODUCCIÓN DE TTNN DE LEO SEGÚN LA

VARIABLE 2 .325

TABLA 34. LA PRODUCCIÓN TOTAL DE LAS TTNN DE SIMON Y LEO SEGÚN LA VARIABLE 3 ...................332

TABLA 35. LA PRODUCCIÓN DE TTNN DE SIMON Y LEO SEGÚN LA VARIABLE 3 .....................................333

TABLA 36. LA PRESENCIA/AUSENCIA DE ESTÍMULO EN LAS TTNN DE SIMON Y LEO SEGÚN LA

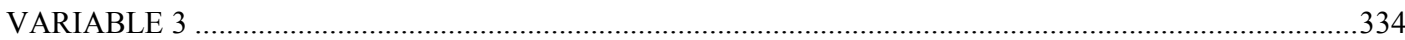

TABLA 37. EL INDUCTOR EN LAS TTNN INDUCIDAS DE SIMON Y LEO SEGÚN LA VARIABLE 3 ...............335

TABLA 38. LA PROCEDENCIA DEL TO EN LAS TTNN DE SIMON Y LEO SEGÚN LA VARIABLE 3 ...............337

TABLA 39. LA PRODUCCIÓN DE TTNN DE SIMON SEGÚN LA VARIABLE 3 POR ETAPAS ............................339

TABLA 40. LA PRODUCCIÓN DE TTNN DE LEO SEGÚN LA VARIABLE 3 POR ETAPAS ..................................339

TABLA 41. PROPUESTA DE VARIABLES PARA LA CODIFICACIÓN Y EL ANÁLISIS DE LA AUSENCIA DE TN

TABLA 42. LA PRODUCCIÓN DE TTNN FRENTE A LA ACTIVIDAD NULA .344

TABLA 43. LA PRODUCCIÓN DE TTNN FRENTE A LA ACTIVIDAD NULA DE TRADUCCIÓN EN SIMON Y

LEO.

TABLA 44. LA ACTIVIDAD NULA DE TRADUCCIÓN DE SIMON Y LEO POR ETAPAS ...................................345

TABLA 45. LA PRODUCCIÓN TOTAL DE ACTIVIDAD NULA DE TRADUCCIÓN SEGÚN LA VARIABLE 3.346 TABLA 46. LA DIRECCIONALIDAD DE LA ACTIVIDAD NULA DE TRADUCCIÓN DE SIMON Y LEO ...........347 TABLA 47. LA ACTIVIDAD NULA DE TRADUCCIÓN DE SIMON SEGÚN LA VARIABLE 3 POR ETAPAS....348 TABLA 48. LA ACTIVIDAD NULA DE TRADUCCIÓN DE LEO SEGÚN LA VARIABLE 3 POR ETAPAS..........348 TABLA 49. LA LONGITUD DEL TO EN LA ACTIVIDAD NULA DE TRADUCCIÓN DE SIMON Y LEO ............351 TABLA 50. LA COMPLEJIDAD DEL TO EN LA ACTIVIDAD NULA DE TRADUCCIÓN DE SIMON Y LEO ....351 TABLA 51. LA LONGITUD DEL TO EN LA ACTIVIDAD NULA DE TRADUCCIÓN DE SIMON POR

ETAPAS .352

TABLA 52. LA LONGITUD DEL TO EN LA ACTIVIDAD NULA DE TRADUCCIÓN DE LEO POR ETAPAS ....352 TABLA 53. LA COMPLEJIDAD DEL TO EN LA ACTIVIDAD NULA DE TRADUCCIÓN DE SIMON POR

ETAPAS .353

TABLA 54. LA COMPLEJIDAD DEL TO EN LA ACTIVIDAD NULA DE TRADUCCIÓN DE LEO POR

ETAPAS .354

TABLA 55. LA PRESENCIA/AUSENCIA DE ESTÍMULO EN LA ACTIVIDAD NULA DE TRADUCCIÓN DE

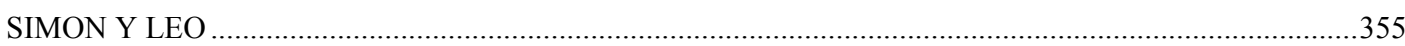
TABLA 56. EL INDUCTOR EN LA ACTIVIDAD NULA DE TRADUCCIÓN DE SIMON Y LEO...........................355 TABLA 57. EL INDUCTOR EN LA ACTIVIDAD NULA DE TRADUCCIÓN DE SIMON Y DE LEO POR ETAPAS

TABLA 58. LA PROCEDENCIA DEL TO EN LA ACTIVIDAD NULA DE TRADUCCIÓN DE SIMON Y LEO ....357 


\section{GRÁFICOS}

Gráfico 1. División en etapas según la LMEp

Gráfico 2. La producción de TTNN de Simon según la variable 1 por etapas..............................................................299

Gráfico 3. La producción de TTNN de Leo según la variable 1 por etapas.....................................................................299

Gráfico 4. La producción de TTNN de Simon según la variable 2 por etapas.............................................................321

Gráfico 5. La producción deTTNN de Leo según la variable 2 por etapas .........................................................................322

Gráfico 6. La producción deTTNN de Simon según la variable 3 por etapas...................................................................338

Gráfico 7. La producción deTTNN de Leo según la variable 3 por etapas ..................................................................338

Gráfico 8. La actividad nula de traducción de Simon según la variable 3 por etapas ....................................................348

Gráfico 9. La actividad nula de traducción de Leo según la variable 3 por etapas ..........................................................348

\section{DIAGRAMAS}

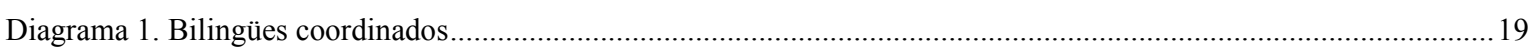

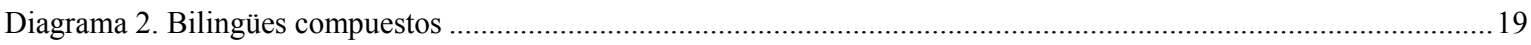

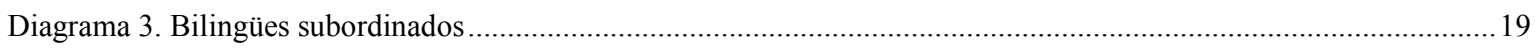

Diagrama 4. Los niveles de representación lingüística según el PM .........................................................................22

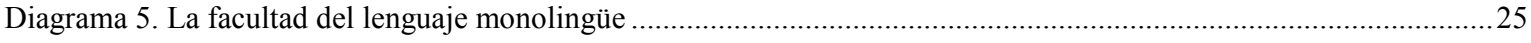

Diagrama 6. La facultad del lenguaje bilingüe (adaptado de MacSwan 2000 54) ......................................................25

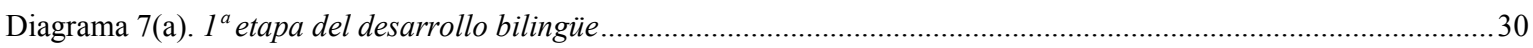

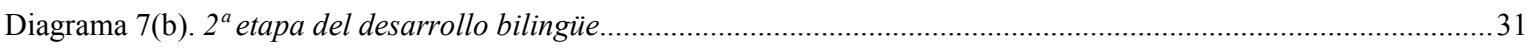

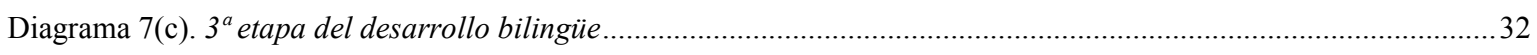

Diagrama 8. La tipología y terminología de la mezcla de lenguas (Lindholm y Padilla 1978b) ...................................53

Diagrama 9. La tipología y la terminología de la mezcla de lenguas (Lanza 1992, 1997).............................................55

Diagrama 10. La tipología y la terminología de la mezcla de lenguas (Meisel 1989, 1994a y Köppe y Meisel 1995).......56

Diagrama 11. La terminología y la tipología de la AC (McClure 1981) .....................................................................59

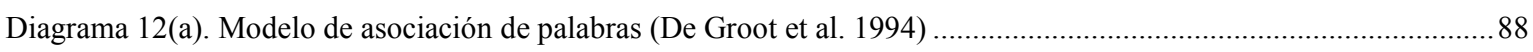

Diagrama 12(b). Modelo de mediación conceptual (De Groot et al. 1994) .........................................................................8 88

Diagrama 13. Modelo jerárquico revisado de la representación léxica y conceptual en la memoria bilingüe (Kroll y

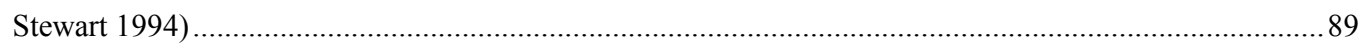

Diagrama 14. La mezcla de lenguas y la TN: propuesta de clasificación .....................................................................153

Diagrama 15. El PM y la facultad del lenguaje bilingüe: la TN (Fernández Fuertes, Álvarez de la Fuente y Liceras (en

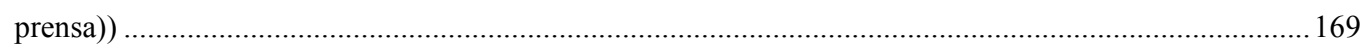

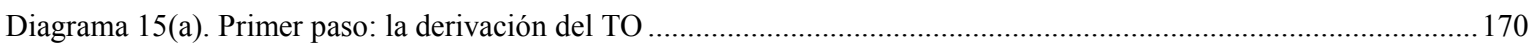

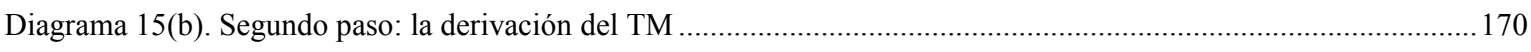

Diagrama 15(c). Tercer paso: la FL del binomio TO/TM........................................................................................... 171 


\section{ÍNDICE DE ABREVIATURAS}

$\mathrm{AC}$

ADULT

AUTOTRAD

$\mathrm{CC}$

COMPL

COMPLEJ

ECO

EET

EMP (NC)

EMP (no NC)

EN

ES-IN

ESPONT

ET

EXP

EXPERIM

FL EQ

FL NO EQ

GU

HERM

INCOML

INDUC

IN-ES

INV

IP

LM

LMEp

LO

LONG

$\mathrm{MC}$

$\mathrm{OC}$

$\mathrm{OS}$

PAD

PM

REFORMUL

$\mathrm{SC}$

$\mathrm{SP}$

SS

TM

$\mathrm{TN}$

TO

TP

TTNN alternancia de códigos

el texto origen procede de un adulto

autotraducción

cambio de códigos

traducción completa

complejidad del texto origen

traducción económica

equivalentes de traducción

emparejamiento por necesidad comunicativa

emparejamiento sin necesidad comunicativa

sesión grabada en contexto inglés

traducción español-inglés

datos espontáneos

equivalente de traducción

traducción expansiva

datos experimentales

Forma Lógica equivalente

Forma Lógica no equivalente

Gramática Universal

texto origen procede del hermano

traducción incompleta

traducción inducida

traducción inglés-español

traducción inducida por el investigador

traducción realizada por iniciativa propia

lengua meta

longitud media del enunciado por palabras

lengua origen

longitud del texto origen

mezcla de códigos

oración compuesta

oración simple

traducción inducida por los padres

Programa Minimalista

reformulación

sintagma compuesto

sesión grabada en contexto español

sintagma simple

texto meta

traducción natural

texto origen

traducción profesional

traducciones naturales 
